FAIÇAL MASSAD

Eng. ${ }^{\circ}$ Civil, Escola Politécnica da USP, 1965

Master of Science, Harvard University, 1969

\title{
EFEITO DA TEMPERATURA NOS EMPUXOS DE TERRA SOBRE ESCORAMENTOS DE VaLAS
}

Tese apresentada à Escola Politécnica da USP para a obtenção do Título de Doutor em Engenharia.

\footnotetext{
Orientador: Prof. Dr. Milton Vargas Professor Catedrático do Departamento de Es truturas e Fundações da EPUSP.
}

São Paulo 
Aов теив раis

A minha esposa 
0 autor manifesta seus mais sinceros agradecimentos ao Prof. Dr. Milton Vargas, orientador deste trabatho, pelo apoio $e$ incentivo dados na sua iniciação e desenvolvimento na Engenharia de Solos. Ao Prof. Dr. Carlos de Sousa Pinto, mestre e camigo, expressa os reconhecimentos pelo mito que deve na sua formacão camo pesquisador e tecnologista.

Sem o combiente de liberdade que sempre existiu no Instituto de Pesquisas Tecnológicas, tradicionalmente voltado ao desen-

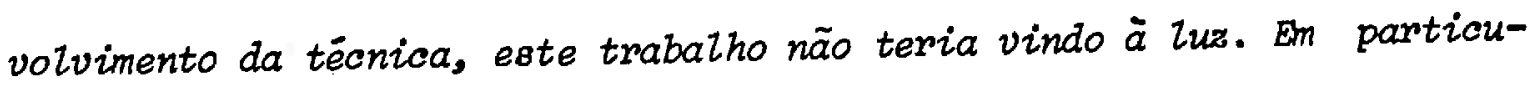
Iar o autor agradece ao seu Diretor Superintendente Dr. Alberto Pereira de Castro, espirito aberto e compreensivo, pelas oportunidades propiciadas para o desenvolvimento de sua carreira profissional.

Exprime também seu reconhecimento aos engenheiros e técnicos que, de uma forma ou de outra, tomaran parte das atividades ligadas às observações nos trechos experimentais da linha Norte-Sul do Metrô de São Paulo.

A Cia. do Metropolitano de São Paulo revela sua gratidão pelas condições favorâveis para a realização dos estudos geotéc nicos que tornaram possivel este trabalho.

o autor deseja tombém deixar expresso вeus agradecimentos ao Eng? Waldemar Bon Jr. pelas sugestões dadas, bem camo à Sra. Hilda Barbosa da Silva Lima pelos servicos de datilografia e à Srta. Lúcia Maria Dias pelo auxilio prestado na impressão do trabatho. 
As observações experimentais em trechos ao longo da Linha Norte-Sul do Metrô de São Paulo revelaram a Importâncla da temperatura nos empuxos sobre escoramentos de valas. A influêncla é tal que chega a duplicar a resultante das cargas provenientes da pressão de terra e do encunhamento.

A preocupação com o efel to da temperatura ē bastante recente, remontando a cerca de 15 anos, e introduz uma nova contingêncla no dimensionamento de escoramentos. Trata-se da variação dos incrementos de temperatura nas diversas estroncas, em profundidade, que depende do ângulo de incidência dos ralos solares, da presença de anteparos ou edificações nas proximidades da vala, das condições de ventllação, entre ou tros fatores.

Evidênclas empíricas quanto à linearidade da resposta carga-temperatura levaram à construção de um modelo matemático, que faz recorrência ao Método dos Elementos Finitos, e permitiu não só ídentificar. os fatores condicionantes dos gradientes de carga-temperatura, co mo tambēm superar a dificuldade colocada pela contingència supra-citada, inerente ao fenômeno em questão.

A fixação dos mōdulos de deformabilildade fol felta através de retroanālise do comportamento de valas instrumentadas, pois os resultados de ensalos de laboratōrio conduziram apenas a tendênclas de variações com a profundidade.

0 aspecto contingente do problema fol superado com a introdução do conceit to de envol tória dos gradientes mäximos, computados dentro de uma faixa experimental de varlação dos incrementos relati- 
vos de temperatura nas estroncas dos diversos niveis.

Embasadas nesta teorla foram estabelecidas förmulas práticas para o cálculo dos gradientes máximos, aferidos empiricamente, tanto para escoramentos com paredes flexiveis quanto rigidas. Mostra-se como estas förmulas possibilitam a inclusão do efel to da temperatura no dimensionamento de escoramentos de valas.

Ressalta-se que a obtenção experimental dos diagramas de pressōes aparentes precisa ser purificada das parcelas representa das pelo encunhamento e dil latação tērmica das estroncas.

Esta depuração foi párcialmente levada a cabo na interpretação das mediçōes em valas da Linha Norte-Sul, tendo-se concluído que, apōs separação do efeit to da temperatura, os diagramas de pressões aparentes para as Argilas Vermelhas e os Solos Variegados da Cidade de São Paulo possuem uma envoltöría de forma trapezoldal, com pressão mäxima da ordem de 0,1 YH a partir do primeiro nivel de estroncas. Este resultado é coerente com os máximos deslocamentos laterals medidos, da orden de $0,1 \% H$.

São tambēm tecidas consideraçōes quanto ao alívio das cargas de encunhamento ou de prë-compressão, mostrando-se a sua inte ração com o efelto da dilatação térmica das estroncas, principalmente pa ra paredes rigidas, onde existe, ademals, o problema da incorporação efe tiva das cargas nominals. 
The measurements in full-sized outs accomplished in the first line of the Subway in São Paulo have shown that, beoides the accidental factors such as the local variations in the soil, the constructive details and the extent and uniformity of prestressing, the temperature affects the loads carried by the individual struts. As a matter of fact, these loads were up to or more than three times greater than those originated from the earth pressure and preloading.

The first published work of the temperature effect on strut load seems to have been written fifteen years ago, but it was soon recognized that its contribution was difficult to evaluate.

The contingent aspect of the problem was brought about in this study and is related with sun rays incidence angle, the presence and/or absence of barriers like buildings" close to the excovations, the ventilation conditions inside the cuts, and so on. They were responsible for the accidental temperature increment distribution on the strut levels.

A linear response between load and temperature in the braces was found out. This led to the constmuction of a mathematical model, to simulate the field conditions formulated by means of the Finite Element Method. It allowed the identification of the most relevant parameters that affect the ratio of the increment of load to that of temperature (Zoad-temperature ratio).

The difficulties placed by the contingencies mentioned above were overcome by the introduction of the concept of the 
maximum load-temperature ratio, and their envelope, set up by applying the mathematical model to the instmmented cuts and by letting the temperature increments assume values in ranges effectively observed in the field.

Practical formulas were developed to figure up the maximom load-temperature ratio that seem to be well-founded to braced cuts using both flexible walls (piles, lagging and wales) or rigid walls (cast-in-place concrete). The analysis also showed how to make use of these findings to include the temperature effect in the design of braced cuts.

Another achievement of this study refers to the fact that apparent earth pressure diagrams will have to be drawn by correcting the measured loads of the temperature effects. A procedure is proposed to carry out the separation of loads in individual struts in their components, caused by the earth pressure, the preloading or wedging and the temperature effects.

This separation was partly done in the sites investigated in the Subway in São Paulo and induced to a trapezoidal envelope for the apparent earth pressure distribution. The maximum earth pressure value, starting at the first strut level, was figured on $0.1 Y H$, which was in agreement with the measured lateral displacements (smaller than $0.1 \% H$ ).

Some considerations were also made in relation to the wedging or the preloading influences on the loads in other brace levels and their interaction with the temperature effect. Warning measures have to be taken in order to achieve the designed preload in the braces whenever cast-in-place concrete walls are built. 
CAPITULO 1: INTRODUCAO

1. Generalidades

2. Interesse pelo Assunto 2

3. Concei tuação bäsica 3

4. Objetivos 4

5. Revisão Bibliogräfica 5

5.1. Metrō de São Paulo - Secção Experimental $1 \quad 8$

5.2. Metró de Washington - Corner of $16^{\text {th }}$ and L. Street 9

5.3. Metrō de Washington - Galery Place Station 12

5.4. Publicações Mais Recentes 14

CAPITULO 11 : CARACTERISTICAS GERAIS DAS SECCOES EXPERTMENTATS DO METRO DE SAOO PAULO

$\begin{array}{ll}\text { 1. Preliminares } & 17\end{array}$

2. Sequêncla de Construção 17

3. Instrumentação Utillizada 19

4. Caracteristicas Gerais das Diversas Secções Experimentais 19

CAPITULO III: LINEARIDADE DA RESPOSTA CARGA-TEMPERATURA EM ESTRONCAS

1. Preliminares

2. Evidencias Empiricas 22

3. Gradientes de Carga-Temperatura 27 


\subsection{Concel tuação}

3.2. Valores Observados dos Gradlentes nas Secçöes Experimentais do Metrô de São Paulo.

CAPITULO IV: CONSTRUCGAO DE UM MODELO MATEMATICO SIMPLES - IDENTIFICACAO DOS CONDICIONANTES MAIS SIGNIEICATIVOS DO EEETTO DA TEMPERATURA

1. Hipöteses Simplificadoras

2. Formulação Matemática do Problema Atravës do Método dos Elementos Finitos

3. Parâmetros Elāsticos mais Significativos do Modelo Matemätico

4. Avallação de Erros Inerentes à Aplicação do Método de C.älculo Escolhido

5. Resultados da Aplicação do Modelo a Valas Escoradas

5.1. Relações Hiperbölicas Entre a Matriz U e $n$

5.2. Heterogeneidade dos Solos

5.3. Fatores que mals Condiclonam os Valores dos Gradien tes

6. Envol törias dos Gradientes Mäximos

7. Nivel de Tensões no Solo Provocado pelas Varlações de Temperatura

8. Módulos de Deformabillidade dos Solos

CAPITULO V: CARACTERISTICAS DE DEFORMABILIDADE DOS SOLOS ESCORADOS 
2.1. Parâmetros Elästlcos 53

2.2. Fatores Condicionantes da Deformabillidade dos Solos 54

3. Il ustração de Como Obter Uma Relação Entre Mödulos de Deformabillidade, o NTvel das Tensões Aplicadas a Relação de Sobre-Adensamento

4. Mödulos de Deformabillidade dos Solos da Cldade de Săo Paulo 64

4.1. Argilas Vermelhas (Porosas e RIJas) 65

4.2. Solos Variegados

5. Alguns Resultados Sobre a Influêncla do Tipo de Solicl tação Imps to ao Solo

6. Súmula: Tendênclas de Varlação dos Mödulos E com a Pro fundi dade

CAPTTULO VI: FORMULAS PRATICAS PARA O CALCULO DOS GRADIENTES DE CARGA-TEMPERATURA

1. Fixação dos Módulos de Deformabilidade dos Solos Escorados Atravēs de Retroanälise

1.1. Mödulos de Deformabilidade Adotados 76

1.2. Avaliação dos Mōdulos Es por Retroanālise 77

2. Redefinição do Parâmetro $n$ para Solos Heterogēneos 80

3. Förmulas simples para o Cálculo de $\bar{n} \quad 81$

4. Förmulas Präticas para o Cálculo dos Gradientes em final de escavação. Comprovação Empírica 
5. Influêncla da Rigldez da Parede de Escoramento, da Geometria da Vala e do Tipo de Solo nos Gradientes Mäximos de Carga-Temperatura

6. Fases de Reaterro

7. Outras Aplicações do Modelo Matemätico Elaborado An teriormente

CAPITULO VII: REPARTICAOO DAS CARGAS MEDIDAS NAS SECÇOES EXPERIMENTAIS COM PAREDES FLEXIVEIS EM TRES PARCELAS: $A \quad D E$ ENCUNHAMENTO; A DE EMPUXO DE TERRA E A DE DILATAÇO TERMICA DAS ESTRONCAS.

1. Preâmbulo

2. Estimativa dos Alivios de Carga Devidos ao Encunhamento

2.1. Fundamentos Teöricos

2.2. Comprovação Experimentai

2.3. Limites Superiores das Parcelas de Encunhamento

3. Repartição das Cargas Totals Observadas 96

4. Repartição das Cargas Distrlbuídas nas Estroncas de uma Mesma Vala

5. Diagramas de Pressōes Aparentes

CAPITULO VIII: INCLUSAO DO EFEITO DA TEMPERATURA NO CALCULO DAS CARGAS NAS ESTRONCAS EM ESCORAMENTOS COM PAREDES FLEXIVEIS

1. Preliminares

1.1. Colocação do Problema e Proposição 
2. Cálculo das Cargas Provenientes do Empuxo de Terra

2.1. Envoltōrias das Pressões Aparentes para as Argi las Vermelhas e os Solos Variegados

2.2. Comparação Entre o Empuxo Ativo de Rankine e o $\Sigma C_{0}$

2.3. Resumo das Alternativas para o Cálculo das Cargas Resultantes do Empuxo de Terra

3. Rotelro de Cālculo das Cargas Provenientes da Dila tação Tērmica das Estroncas

3.1. 1: Al ternativa

3.2. 2. Alternativa

4. Comparações Entre Cargas Calculadas e Observadas

4.1. Cargas Totais

4.2. Cargas Distribuídas nas Estroncas

CAPTTULO IX: A PRE-COMPRESSAO DE ESTRONCAS - SUA INFLUENCIA NOS RECALQUES DO TERRENO E SUA INTERRELACAO COM OEFEITO DA DILATACAO TERMICA DAS ESTRONCAS

1. Consideraçōes Iniclais

2. A Prë-Compressão de Escoras no Caso de Paredes Fle xíveis

2.1. A sua Função Real

2.2. O Efelto da Temperatura

2.3. Fontes de Recalques nas Imediações das Valas

3. A Incorporação das Cargas nas Estroncas Prë-Comprimidas - Paredes de Escoramento Rigldas 
3.2. Alivio de Cargas em Estroncas Vizinhas, Durante a Pré-Compressão

3.3. O Efel to da Temperatura na Carga Instalada

124

\section{CAPITULO $X:$ CONCLUSOES}

1. Evidênclas Empiricas do Efel to da Temperatura

2. Resultados Da Apllcação do Modelo Matemático-Envoltórias dos Gradientes Máximos

3. Förmulas Práticas para o Cálculo dos Gradientes

4. Recomendações Quanto à Consideração do Efelto da Temperatura Nas Manipulaçōes dos Dados Experimentais e no Dimenslonamento de Escoramentos

4.1. Paredes de Escoramento Flexiveis

4.2. Paredes de Escoramento Rígidas

5. Sugestões Para Futuras Observações no Contexto desta Inves t I gação

REFERENCIAS BIBLIOGRAFICAS

134

APENDICE A: CONSIDERAÇŌES QUANTO A PRECISAO DAS CELULAS DE CARGA E DOS PARES TERMOELETRICOS

1. Introdução

2. Precisão de Medida das Células de Carga de Corda Vibrante

2.1. Precisão do Aparelho em Si

2.2. Influêncla da Temperatura no Aparelho de Medida

2.3. Influêncla da Rigldez das Cēlulas de Carga 
3. Precisão nas Medidas da Temperatura

3.1. Erros Inerentes à Pröprla Técnica de Medida

3.2. O Que $\ddot{a}$ a Temperatura de Uma Estronca?

150

APENDICE B: DESCRICAO UETALHADA DAS CARACTERISTICAS DE SECCOES EXPERTMENTAIS DO METRO DE SAO PAULO

1. Secção Experimental 1

153

2. Secção Experimental 6

154

3. Secção Experimental 8

156

4. Seç̧ão Experimental 2

158

5. Secçăo Experimental 5

160

6. Secção Experimental do Bloco 17

163

7. Secção Experimental 7

164

8. Seç̧ão Experimental 3

166

APENDICE C: FUNDAMENTOS MATEMATICOS DAS REGRESSOES DE QUE TRATA O CAPITULO III

1. Bases Teöricas

2. "Sensibllidade Inerente"do Sistema de Equaçōes Obtido

APENDICE D: PROPRIEDADES DA MATRIZ DOS GRADIENTES BASICOS

1. Propriedades da Matriz U

174

2. Demonstração da Propriedade 3

2.1. Matriz U de Ordem 2

175

2.2. Matriz U de Ordem 3

176

2.3. Matriz $\cup$ Qualquer

176 
APENDICE E: DISCUSSAO DE ALGUMAS HIPOTESES INCORPORADAS AO MODELO MATEMATICO DO CAPITULO IV

1. Vigas de Distribuição Com Rigidez Infinita

2. Efeito da Temperatura em Paredes de Sistemas de Escoramentos

2.1. Medições de Temperatura em Lajes de Concreto e em Solos

2.2. Hipōteses Concernentes à Variação da Temperatura nas Paredes Diafragma

2.3. Aplicação do Método dos Elementos Finl tos

2.4. Resultados Obtidos

3. Simulação das Paredes Flexiveis Por Paredes Contínuas

APENDICE F: APANHADO GERAL SOBRE AS PROPRIEDADES GEOTECNICAS DE SOLOS DA CTDADE DE SAO PAULO DE INTERESSE A ESTE ES rnIIDO

1. Preliminares

2. Caracteristicas Gerais de Alguns Solos da Bacla de São Paulo

2.1. Argilas Porosas Vermelhas

2.2. Argllas RIjas Vermelhas 194

2.3. Solos Varlegados

3. O Problema do Coeficiente de Empuxo Em Repouso dos Solos Terclārlos Da Cidade de São Paulo 
B - Matriz que relaciona o vetor Deformaçăc de um elemento finitó com o Vetor dos Deslocamentos Nodais.

$B^{2}$ - Matriz Transposta de $B$.

$C$ - Vetor de Cargas nas estroncas ou, simplesmente, Cargas. As vezes apa recem os símbolos $C_{A}, C_{B^{3}}$, etc., onde os indices $A, B$, etc. denotam os niveis das estroncas. Outras vezes designa o vetor dos $\Delta C_{i}$.

c - Intercepto de coesão.

$c^{\prime}$ - Coesão efetiva.

$C_{j}$ - Carga atuante na j-ēsima estronca, na temperatura mäxima; $\Sigma C_{j} \dot{e}$ a carga total associada a uma vala.

$c_{E}^{\mathcal{J}}$ - Parcela de carga devida ao encunhamento, na j-ésima estronca; $\Sigma c_{E}^{j} \dot{e}$ a carga total de encunhamento, associada a uma vala.

$C_{o}, \bar{C}_{o}$ - Cargas observadas nas estroncas das Secções Experimentais, descontados os efeitos da temperatura; $\Sigma \bar{C}_{O}$ è o somatōrio das cargas médias observadas, descontados os efeitos da temperatura, assoclado a uma vala.

$\bar{C}_{m a \tilde{x}}$ - Cargas mëdias observadas nas temperaturas mäximas; $\Sigma \bar{C}_{\operatorname{mäx}} \bar{e}$ o seu somatório, assoclado a uma vala.

D - Matriz de Elasticidade; ou altura das paredes contínuas de escoramen to; ou comprimento das estacas metälicas.

$D^{\prime}, D_{1}$ - Espessuras de camadas de solos.

$E, E_{8}$ - Mödulos de Deformabilidade dos solos.

$\bar{E}_{B}$ - Mëdla ponderada dos mōdulos $E_{B}$ de diversas camadas de solo escorado, atē a profundidade $D$.

$E_{1}$ - Mödulos de Deformabilidade dos Solos para 1 de deformação especifica axial. 
$E_{50}$ - Idem para $50 \%$ de resistência mobilizada.

$E_{i}$ - Idem tangente inicial.

$E_{0,1}$ - Idem para $0,1 \%$ de deformação especifica axlal.

$E_{r}$ - Módulo de Recarga, após repetlção cícllca de carga-descarga (Reload Modulus).

$E_{a}$ - Mödulo de Elastíclidade do Aço.

$E_{c}$ - Idem do concreto.

$E_{p}$ - Mödulo de Elasticidade da parede contínua equivalente, no sentido Indicado no item 3 do Apêndice E.

$E_{T}$ - Cargas nas estroncas, oriundas do efel to da temperatura. As vezes aparecem os simbolos $E_{T}^{A} E_{T}^{B}$, etc., onde $A, B$, etc. denotam os niveis das estroncas.

$E_{T}^{i}$ - Somatório das cargas calculadas como efeito da temperatura, pela 1 . Alternativa, item 3.1. do Capitulo VIII.

$E_{T}^{m a \dot{x}}$ - I dem, pela 2. Alternativa, item 3.2. do Capitulo VIII.

$E_{T}^{*}$ - Somatörio das cargas observadas, oriundas do efeit to da temperatura.

$E_{R}$ e $E_{R}^{\prime}$ - Empuxos Ativos Totais de Rankine ou simplesmente Empuxos de Rankine, calculados atë as profundidades $H$ e $H^{\prime}$, respectivamente.

$E_{j}$ - Carga atuante na j-ēsima estronca proveniente da pressāo ou empuxo de terra; $\Sigma E_{j}$ ë o Empuxo de Terra.

$e_{p}, e_{1}, e_{2}$ - Espessuras da parede contínua equivalente, no sentido Indicado no item 3 do Apêndice E.

B - Indice de vazios de um solo.

F - Força linearmente distriburda.

$G, G_{j}$ - Gradientes de Carga-Temperatura, isto $\dot{e}$, cargas que surgem numa dada estronca, para um incremento unl tärio de sua temperatura. As vezes aparecem como $G_{A}, G_{B^{B}}$ etc., ou como $G_{1}, G_{Z}$ etc., onde os indices denotam o nivel das estroncas. 
$\bar{G}$ - Gradientes de Carga-Temperatura adimensionalizados, Isto è, fração de carga numa dada estronca em relação à carga $\left(E_{a} S_{a}^{\alpha} . \Delta T\right)$ que ocorreria estivessem suas extremidades impedidas de se movimentar, por efeito de incrementos de temperatura $\Delta T$.

$G_{m a ́ x}$ - Māximo valor dos Gradientes assoclado a uma vala, para todas as possivels comblnações do vetor $T$ variando dentro de uma faixa exper $\underline{I}$ mental de valores.

$G_{i}^{m a ́ x}$ - Idem na i-ésima estronca.

$g_{i j}$ - Coeficientes da Matriz $G$ dos gradientes de carga-temperatura, defi nida de tal forma que $g_{i j}=0$ para $i \neq j$ e $g_{i i}=G_{i}$.

$h$ - Espessura de Paredes Continuas de concreto.

$H, H^{\prime}$ - Profundidade da vala $(H)$ e distância da superfície do terreno até o ponto mēdio entre a ültima estronca e o fundo da vala (H').

IP - Indice de Plasticidade de um solo.

$J$ - Momento de Inërcla.

$J_{a}$ - Momento de Inērcla da secção transversal das estacas metälicas, em relação ao elxo que passa pelo seu centro de gravidade e é paralelo às linhas das paredes de escoramento.

$J_{p}$ - Idem da secção da parede continua equivalente, no sentido indicado no it tem 3 do Apèndice $E$.

$K$ - Coeficlente de Mola ou Matriz de Rigidez.

$\bar{K}_{s}, \bar{K}_{p}, \bar{K}_{b}$ - Matrizes de Rigidez a menos de um escalar, onde os índices s, $p$ e b denotam, respectivamente, solo, parede contínua e barras. $K_{0}$ - Coeficlente de Empuxo em Repouso.

$\ell, \ell^{\prime}$ - Comprimentos de estroncas e de Vigas de Distribulção, respectiva mente.

$L_{\text {, }} L_{0}$ - Frequências de ressonância de cordas vlbrantes.

LL - Limite de Liquidez de un solo. 
$M$ - Fator de Rigidez Relativa Parede Rigida-Solo.

$n$ - Nümero de nivels de estroncas numa vala escorada.

p - Pressão.

$p_{o}$ - Tensão efetiva média inicial ou de adensamento.

$p_{m a ̄ x}$ - Māxima tensāo efetiva mëdia a que uma amostra de solo esteve submetida anteriormente. Ou mäxima pressäo aparente de diagramas trapezoidals.

$P, \bar{P}, P_{i}$ - Cargas. As vezes $P$ denota um vetor de forças $P_{i}=E_{a} S_{a}^{\alpha} \cdot \Delta T$.

$\boldsymbol{r}$ - Relação entre os incrementos relativos de temperatura das estroncas superiores para as inferiores, em valas com 2 niveis de escoras. As vezes designa o coeficiente de regressōes estatisticas.

RSA - Relação de Sobre Adensamento.

$S_{a}$ - Área da secção transversal de estroncas.

$T$ - Vetor dos incrementos relativos de temperatura $\Delta T_{i}$.

$T_{i}$ - Temperatura na $i$-ësima estronca. As vezes aparecem os símbolos $T_{A^{2}}$ $T_{B^{\prime}}$ etc., onde $A, B$, etc., denotam os nivels das estroncas.

$T_{m}$ - Autovetor de $U$ associado a $\lambda_{m}$.

$T_{m}^{j}$ e $T_{0}^{j}$ - Temperaturas mäxima e minima, respectivamente, na j-ësima estronca.

$T_{m}^{8}$ e $T_{0}^{\beta}$ - Idem, na estronca superior.

$T^{\prime}$ - Vetor transpos to de $T$. Ou temperatura média de uma estronca.

$t$ - Espaçamento em planta entre estroncas.

$t_{i}$ - Tem, no Apêndice 0 , o mesmo sentido que os $\Delta T_{i}$

$U$ - Matriz dos Gradientes Básicos.

$u_{i j}$ - Gradientes básicos de carga-temperatura, is to é, força exercida pe la i-èsima estronca contra a parede de escoramento, quando apenas a j-ësima estronca sofre um incremento de temperatura de $1^{\circ} \mathrm{C}$. As vezes aparecem os simbolos $u_{\theta}^{8}, u_{i}^{8}=u_{s}^{i}$ e $u_{i}^{i}$ para deslgnar estes gradientes, onde as letras $\underline{B} e \underline{i}$ denotam superior e inferlor, respectivamente. 
$V$ - Volume de un elemento finito.

$X$ - Vetor das forças $X_{i}$.

a, $z_{i}$ - Profundidades medidas a partir da superficle do terreno.

๔ - Coeficlente de dilatação tërmica do aço.

B - Escalar ou Rigldez relativa Solo-Viga de Distribulção.

$Y_{n} Y_{n}$ - Densidades naturais dos solos.

$\delta$ - Deslocamento.

$\delta_{i j}$ - Deslocamento horizontal do ponto onde a i-ésima estronca toca a pa rede, se à j-ésima estronca for dado um acréscimo de temperatura de $\mathrm{P}^{\mathrm{C}} \mathrm{C}$.

$\delta^{e}$ - Vetor dos deslocamentos nodais de um elemento finito.

$\delta_{m a ́ x}$ - Máximo deslocamento horizontal observado nas Seç̧ões Experimentaiș, em final de escavação.

$\Delta \sigma_{h}$ - Incremento de tensão axial em corpos de prova talhados horlzontalmente.

$\Delta C_{i}$ - Incremento de carga.

$\Delta T_{i}$ - Incremento Relativo de Temperatura, is to $\dot{e}$, incrementos de tempera tura nas estroncas dos niveis inferiores $(i>1)$ quando a do nivel su perior $(i=1)$ sofre um aquecimento de $1^{\circ} \mathrm{C}$

$\Delta T$ - Incremento de temperatura.

$\Delta T_{m}$ - Máxima variação de temperatura observada nas Secções Experimentais.

$n$ - Designa o Adimensional $E_{a} S_{a} / E_{8} t l$, isto ë, a relação entre a rigidez das estroncas e a do solo.

$\bar{n}$ - Idem, quando o mödulo do solo $\overline{\mathrm{e}} \bar{E}_{g}$, média ponderada dos módulos das diversas camadas do solo escorado até a profundidade $D$.

$\varepsilon$ - Vetor Deformação de um elemento finito.

$\varepsilon_{1}$ - Deformação especifica axíal.

$\emptyset$. Angulos de atrito em termos de pressōes totais e efetivas, respectivamente, acima dos efeitos do pré-adensamento.

$\emptyset_{a},{ }_{a}^{\prime}$ - Idem, abaixo dos efeltos do prē-adensamento. 
$\lambda$ - Autovalor da Matriz $U$. Ou coeficiente angular da linha do estado crítico.

$\lambda_{m}$ - Minimo dos Autovalores de $U$.

$v$ - Coeficiente de Poisson.

$\xi$ - Relação entre $E_{p}$ e $E_{a}$

$\rho$ - Relação entre $E_{p}$ e $E_{s}$

$\sigma$ - Vetor Tensão de um elemento finito.

$\bar{\sigma}_{c}$ - Pressão de câmara em ensaio triaxial $\bar{R}$.

$\bar{\sigma}_{\alpha}$ - Pressão de prë-adensamento.

$\bar{\sigma}_{c m}$ - Māxima pressão a que um elemento de solo foi anteriormente adensado, isotropicamente.

$\sigma_{1}, \sigma_{2}, \sigma_{3}$ - Tensões principais maior, intermediäria e menor, respectivamente.

$\bar{\sigma}_{v} e \bar{\sigma}_{h}$ - Tensões efetivas vertical e horizontal, respectivamente.

$\left(\sigma_{1}-\sigma_{3}\right)_{m a ̈ x}$ - Māximo acréscimo de tensão axial.

$\bar{\sigma}_{v c} e \bar{\sigma}_{h c}$ - Pressão de câmara e tensão axial de adensamento anisotröpico, em corpos de prova talhados horizontalmente (Ensaio Triaxial $\bar{R}$ ). 
11-1: Localização Esquemātlca das Secçōes Experimentals. LInha NorteSul do Metrô de São Paulo.

|11-1: Carga em Função da Temperatura - Secção Experimental 1 - Estägio 5.

111-2: Temperaturas dos Niveis A e B Em Função do Tempo - Secção Exper 1mental I - Estāgio 8. Secção Transversal 1.

111-3: Cargas dos Níveis A e B Em Função do Tempo - Seç̧ão Experimental 1 - Estāgio 8. Secção Transversal 1.

111-4: Comparação Entre Valores Observados e Calculados das Cargas nas Estroncas - Secção Experimental 1 - Estägio 8, Secção Transver sal I.

111-5: Comparação Entre Valores Observados e Calculados das Cargas. nas Estroncas - Secção Experimental 1 - Estăgio 8, Mëdia das Secções Transversais 1 , 11 e 111 .

111-6: Ilustração Gräfica da Afinidade Existente entre as Curvas que Correlacionam $T_{B} \operatorname{com} T_{A}$ e $C_{B} \operatorname{com} C_{A}$. - Secção Experimental 1, Estāgio 8. Secção Transversal 1.

111-7: Carga em Função da Temperatura - Secção Experimental 1 - Estägio 9. Secção Transversal 1.

IV 1: Secção Experimental do Bloco 17 - Paredes Rigidas.

IV-2: Discretlzação da Secção da Vala em Elementos Finitos Planos e de Barras - Secção Experimental do Bloco 17 - Paredes Rígidas.

IV-3: Curvas de Iguais Erros Percentuais nos Valores dos Gradientes aásicos Devidos à Delimi tação Geométrica - Secção Experimental do Bloco 17. Paredes Rigidas - $\xi=1 / 10$ e $\eta=2,6$. 
IV-4: Erros Percentuais nos Valores dos Gradientes Bāsicos $u_{s}^{5}, u_{s}^{i}=$ $u_{i}^{s}$ e $u_{i}^{i}$, Devidos à Delimitação Geomētrica - Seç̧ão Experimental do Bloco 17 - Paredes Rígidas. $\xi=1 / 10$ e $n=2,6$.

IV-5: Influência da Relaçāo dos Mödulos de Deformabilidade nos Valores dos Incrementos Relativos de Temperatura, que Geram Iguais Gradientes em Todas as Estroncas. Secção Experimental 8.

IV-6: Comparação entre Valores Calculados e Observados dos Incrementos Relativos de Temperatura, que Geram Iguais Gradientes. Seç̧ão Experimental 2 .

IV-7: Gradientes de Carga-Temperatura ein Funçäo de $\eta$, $\varepsilon$, e $r$.

IV-8: Faixa de Valores Extremos Adotada para os Incrementos Relativos de Temperaturà, em Função da Profundidade.

IV-9: Correlação entre o Máximo Gradiente de Carga-Temperatura na Oltima Estronca $\left(G_{\text {mäx }}\right)$ e o Parâmetro $\eta$.

IV-10: Variação dos Gradientes Máximos $\left(G_{i}^{m a ̄ x}\right)$, em Cada Nível de Estroncas, com a Profundidade - Secção Experimental 8.

IV-11: Limite Superior para o Máximo Gradiente na i-ésima Estronca.

IV-12: Acréscimos de Tensões nos Pontos do Plano A-A, Provocados pelo Aquecimento da Estronca Inferior de $1^{\circ} \mathrm{C}$ - Secção Experimental do Bloco 17 - Paredes Rígidas.

IV-13: Acrēscimos de Tensöes nos Pontos do Plano A-A, Provocados pelo Aquecimento da Estronca Superior de $1^{\circ} \mathrm{C}$ - Secção Experimental do Bloco 17 - Paredes Rigidas.

IV-14: Linha Elästica do Contato Solo-Concreto (Linha A-B) - Seç̧ão Experimental do Bloco 17 - Paredes Rígidas.

V-1: Curvas Tensão-Deformação de Ensaios Triaxiais Räpidos Prē-Adensa$\operatorname{dos}(\bar{R})$ I sotropicamente.

V-2: Desenvolvimento de Pressōes Neutras - Ensaios Triaxiais Räpidos Pré-Adensados $(\bar{R})$ I sotropicamente. 
V-3: Trajetörlas de Tensões Efetivas - Ensaios Trlaxials Rápidos PrēAdensados (R) Isotropicamente.

V-4: Circulos de Mohr na Ruptura, em Termos de Pressões Efetivas - Ensaios Trlaxiais Rápidos Prë-Adensados $(\bar{R})$ Isotropicamente.

V-5: Variaçāo do Módulo de Deformabilidade Secante com o Nivel de Tensōes, Acima dos Efeitos do Prë-Adensamento.

V-6: Varlação dos Mödulos de Deformabililidade com a Pressão $\bar{\sigma}_{c}$ e com a Relação $\bar{\sigma}_{a} / \bar{\sigma}_{c}$ - Ensalos Triaxials Rápldos Pré-Adensados (R) Isotroplcamente.

V-7: Faixa de Valores do Mödulo de Deformabilidade $\left(E_{1}\right)$ - Ensaios Trla xiais Rāpidos Prë-Adensados $(\bar{R})$ I sotropicamente. Argllas VermeIhas.

V-8: Faixa de Valores do Mödulo de Deformabillidade (E, ) Ensaios Tría xiais Rápidos Prē-Adensados $(\bar{R})$ Isotropicamente. Argilas VermeIhas.

V-9: Faixa de Valores do Mödulo de Deformabilidade $\left(E_{50}\right)$ - Ensaios Tria xiais Räpidos Prē-Adensados $(\bar{R})$ I sotropicamente. Argilas VermeIhas.

V-10: Correlação Linear entre o Mödulo de Deformabilidade Tangente Inicial e a Relação $\bar{\sigma}_{a} / \bar{\sigma}_{c}$.

V-11: Faixa de Valores do Mödulo de Deformabilidade (E, ) Ensalos Tría xiais Räpidos Prë-Adensados (R) Isotropicamente - Solos Variegados.

V-12: Faixa de Valores do Módulo de Deformabilidade $\left(E_{1}\right)$ - Ensaios Tría xiais Rāpldos Prē-Adensados (R) I sotroplcamente - Solos Varlegados.

V-13: Faixa de Valores do Mödulo de Deformabllidade $\left(E_{50}\right)$-Ensalos Tría xials Rápidos Pré-Adensados (R) Isotropicamente - Solos Variegados. 
V-14: Tendências de Varlação, com a Profundidade, dos Mōdulos de Deformabilidade Iniclais Médios dos Solos Variegados, Calculados Através da Expressäo $E_{1} /\left(\bar{\sigma}_{1}-\bar{\sigma}_{3}\right)_{\text {maxx }}=200$.

V-15: Ensalos Trlaxials Rápidos de Compressão e Extensão Axials, em Cor pos de Prova Talhados Horizontalmente e Adensados Anisotropicamen te.

V-16: Ilustração de Ensalo Trlaxial Rãpldo, de Extensão Axlal, com Repe tição de Carga - Corpos de Prova Talhados Horlzontalmente.

VI-1: Fixação da Rigldez dos Solos Atravēs de Retroanālise - Secçōes Experimentais 1 e 6 .

VI-2: Fixação da Rigidez dos Solos Atravēs de Retroanälise - Secção Experimental 8.

VI-3: Fixação da Rigidez dos Solos Atravēs de Retroanālise - Secçōes Experimentais 6 e 8 .

V1-4: Mödulos de Deformabllidade Adotados - Secçäo Experimental 2.

VI-5: Ábacos para o Cālculo do Gradlente Máximo.

VI-6: Influêncla da Área da Secção Transversal das Estroncas ( ${ }_{a}$ ) e do seu Comprimento ( $l$ ) nos Valores dos Gradientes Mäximos - Paredes Flexivels e Rigidas.

VII-1: Seç̧ão Experlmental n: 1. Tempo Decorrldo apōs a Instalação da 1: Es tronca.

VII-2: Secção Experimental n: 6. Tempo Decorrido apös a Instalação da I: Estronca.

VII-3: Secção Experimental no 8. Tempo Decorrido apōs a Instalação da 1? Estronca.

VII-4: Secçāo Experimental n: 2. Tempo Decorrido apös a Instalação da 1: Estronca.

VII-5: Dlagramas de Pressões Aparentes - Secção Experimental 8, com IncI dêncla dos Raios Solares, Ventillação, etc. da Secção Experímen- 


\section{XXIII}

tal 2 .

VII-6: Dlagramas de Pressöes Aparentes - Secção Experimental 2, Com Incidência dos Ralos Solares, Ventilaçāo, etc. da Secção Experimental 8 .

VIII-I: Diagramas de Pressōes Aparentes Mäximas, Descontado o Efel to da Dillatação Tërmica das Estroncas.

VIII-2: Deslocamentos Horizontais Medidos Com o Inclinömetro.

A-1: Esquema da Cèlula de Carga de Corda Vibrante.

A-2: Detalhes da Instalação de Termopar.

A-3: Detalhes da Instalação de Termopar.

A-4: Inéxistência de Fenômenos de Histerese na Resposta de Cēlulas de Carga Maihak, Devido a Variações de Temperatura.

A-5: Variaçōes da Temperatura em Função do Tempo - Muro de Arrimo, Mos teiro São Bento.

A-6: Variações da Carga com o Tempo - Muro de Arrimo, Mosteiro São Ben to.

A-7: Medidas de Temperaturas Feitas Num Perfil Duplo $112^{\prime \prime}$.

A-8: Medidas de Temperaturas Feitas no Interior de um Perfil Duplo " 1 12", ao Longo de seu Comprimento.

A-9: Correlação entre a Média das Temperaturas, Medidas em Quatro Pontos no Interior de uma Estronca $\left(212^{\prime \prime}\right)$, ao Longo de seu Compr I mento, e as Temperaturas em Cada um Destes Pontos.

B-1: Secção Experimental | - Localização, Planta e Corte.

B-2: Secção Experimental 1 - Perfil de Sondagem.

B-3: Estágios da Escavação - Secção Experimental 1.

B-4: Secção Experimental 6 - Localização, Planta e Corte.

B-5: Secção Experimental 6 - Perfis de Sondagens.

B-6: Estāgios da Escavação - Secção Experimental 6.

B-7: Secção Experimental 8 - Localização, Planta e Corte. 
B-8: Estāgios da Escavação - Secção Experimental 8.

B-9: Secção Experimental 2 - Localização, Planta e Corte.

B-10: Secção Experimental 2 - Perfil de Sondagem.

B-11: Estāgios da Escavação - Secção Experimental 2.

B-12: Secção Experimental 5 - Localização, Planta e Corte.

B-13: Sondagem de Reconhecimento do Subsolo na Área da Seç̧ão Experimental 5 .

B-14: Estāgios de Escavação - Secção Experimental 5.

B-15: Secção Experimental do Bloco 17 (Trecho 43) - Planta e Corte.

B-16: Secção Experimental 7 - Localização, Planta e Corte.

B-17: Seç̧ão Experimental 7 - Perfis de Sondagem.

B-18: Estãgios da Escavação - Secção Experimental 7.

B-19: Secção Experimental 3 - Localização, Planta e Corte.

B-20: Seç̧ão Experimental 3 - Perfil de Sondagem.

B-21: Secção Experimental 3 - Datas de Instalação e Retirada das Estroncas.

E-1: Forças de Reação, no Contato Viga-Base Elāstica.

E-2: Linha Elästica da Parede Diafragma (Ao Longo de $\overline{\mathrm{CDE}}$ ), Supondo que Somente Ela se Encontra Sob o Efeito da Temperatura - Secção Exper 1 mental do Bloco 17, Paredes Rígidas.

E-3: Incremento de Carga na Estronca Inferior em Função do Fator de RIg dez Relativa Parede-Solo, Quando sō a Parede Contínua de Escoramento Está Sob.o Efei to da Temperatura.

F-1: Curvas Granulométricas das Amostras Estudadas - Argilas Porosas Ver melhas.

F-2: Posição das Amostras Estudadas na Carta de Plasticidade - Argilas Porosas Vermelhas.

F-3: Características de Deformabilidade das Argilas Porosas Vermelhas da Cidade de São Paulo, Acima dos Efeitos do Pré-Adensamento. 
F-4: Curvas Granulométricas - Argilas Vermelhas Rijas.

F-5: Posição das Amostras na Carta de Plasticidade - Argllas Vermelhas Rijas.

F-6: Curvas Granulométricas das Amostras Estudadas - Solos Variegados.

F-7: Distribuição dos Solos na Carta de Plasticidade - Solos Varlegados.

F-8: Ensaio Oedométrlco em Anel cintado, do Aparelho "Direct Simples Shear Test". (Corpo de Prova Cilindrico com $32 \mathrm{~cm}^{2} \times 1,7 \mathrm{~cm}$ ) - Argi la Porosa Vermelha.

F-9: Ensaio no Aparelho de Deformação Plana, com Confinamento Lateral no Plano Horizontal (Adensamento) - (Corpo de Prova Prismático com DImensões de 8,89 (Altura) $\times 8,89 \times 3,56 \mathrm{~cm}^{3}$ ) - Argil la Porosa VermeIha.

F-10: Valores do Coeficiente de Empuxo em Repouso $\left(k_{0}\right)$ em Função da Relação de Sobre-Adensamento (RSA), em Prë-Carregamentos Induzidos em Laboratörio - Argila Porosa Vermelha. 


\section{LISTA DE TABELAS}

1-1: Dados Referentes ao Metrō de Washington D.C.

1-2: Dados Referentes ao Metrô do Rio.

|1-1: Informações Gerais Sobre as Secções Experimentais.

111-1: Secções Experimentais do Metrô de São Paulo.

1/1-2a: Seç̧ão Experimental 1 - Correlações.

1|1-2b: Seç̧ão Experimental 6 - Correlações.

|11-2c: Secção Experimental 2 - Correlações.

111-3: Secção Experimental I - Dados Relativos às Fases de Final de Escavação e Reaterro.

111-4: Secção Experimental 6 - Dados Relativos às Fases de Final de Escavação e Reaterro.

III-5: Secção Experimental 8 - Dados Relativos às Fases de Final de Escavação e Reaterro.

111-6: Secção Experimental 2 - Dados Relativos às Fases de Final de Escavação e Reaterro.

IV-1: Resultados para a Secção Experimental 1.

IV-2: Resultados para a Seç̧ão do Bloco 17, Parede Flexível.

IV-3: Resultados para a Seç̧äo Experimental 8.

IV-4: Resultados para a Seç̧ão do Bloco 17, Paredes Rígidas.

IV-5: Secção do Bloco 17, Paredes Rígidas.

V-1: Características das Amostras Estudadas.

V-2: Mōdulos de Deformabilidade - Argilas Vermelhas da Cidade de São Paulo.

V-3: Argilas Vermelhas da Cidade de São Paulo - Valores da RSA em Função da Profundidade, para Vãrios Perfis de Subsolo. 
V-4: Mödulos de Deformabilidade - Solos Variegados da Cidade de São Pạ lo.

V-5: Solos Variegados da Cidade de São Paulo - Valores da RSA em Função da Profundidade para Vários Perfís de Subsolo.

V-b: Relação entre Mödulos de Deformabilidade e a Resistêncla não Drenada - Solos da Cidade de São Paulo.

VI-1: Resultados Obtidos com a Aplicação do Modelo Matemätico.

VI-2: Resultados Obtidos com a Aplicação do Modelo Matemātico (continua ção)

VI-3: Metrô de São Paulo. Valores dos Gradientes (G) Adimensionalizados, Observados e Calculados pela Förmula de Chapman (V. Capítulo 1).

VI-4: Transferência de Carga para a Oitima Estronca Remanescente, nas Fa ses de Reaterro.

VI-5: Acrēscimos de Carga em Todas as Estroncas, Exceto as 01 timas, nas Fases de Reaterro.

VII-1: Secção Experimental 3. Alivios de Carga nas Estroncas dos Niveis A, B, C, D e E Quando da Prē-Compressāo das Estroncas do Nivel F (Em $27 / 10 / 72)$.

VII-2: Secção Experimental n: 7. Alívio de Carga nas Estroncas do Nivel B, Quando as do Nivel C Foram Pré-Comprimidas.

VII-3: Secçōes Experimentais com Paredes Flexiveis - Cargas de Encunhamen to.

VI1-4: Repartição das Cargas Totais Observadas nas Secções Experimentais (SE), em Final de Escavação.

VII-5: Repartição das Cargas Observadas nas Estroncas das Secções Experimentais.

VII-6: Progresso da Escavação por Ocasião da Instalação das Estroncas, nas Secções Experimentais. 
XXVIII

VIII-I: Parâmetros dos Solos Relacionados com as Secçōes Experimentals.

VIII-2: Cargas, Pressōes Aparentes e Deslocamentos Máximos.

VIII-3: DIstribulção das Cargas nas Estroncas - Secçōes Experimentais Com Paredes Flexiveis.

|X-1: Cargas Realmente Instaladas em Estroncas Prë-Comprimidas. Secçōes Experimentais.

F-1: Valores Médios e Intervalos de Varlação de Algumas CaracterístiCas das Argilas Porosas (Retiradas Entre as Cotas 800 e 820 ).

F-2: Valores Mëdios e Intervalos de Variação de Algumas Características das Argilas Porosas (Dados Publlcados Por Pichler, 1948).

F-3: Características Médias das Argillas Rijas Vermelhas. 


\section{CAPITULO 1}

$$
\text { I NTRODUÇÃO }
$$

\section{GENERALI DADES}

Desde a introdução dos conceltos de pressões de terra aparentes e de suas envoltörias, consubstanciados em teorias semi-empiricas, as preocupaçōes com medições das cargas em estroncas, de sistemas de escoramentos de valas profundas escavadas a céu aberto, multiplicaram-se no espaço e no tempo.

A procura de receitas regionais para o cálculo dos empuxos de terra tornou-se antes uma necessidade em virtude das razöes tão bem sintetizadas pelos, se não mentores, propagadores dos citados conceitos: contingēncia dos processos construtivos de escavação e escoramento; variaçōes locais dos solos escorados; velocidade de escavação e tempo de espera para a instalação das estroncas; e intensidade e uniformidade de prē-carregamentos ou de simples encunhamentos. In view of these facts, no procedure for designing the bracing should be trusted until its reliability has been demonstrated by the results of measurements in fullijialed cuts, afirmaram Terzaghi e Pecḱ (1967), pägina 397.

$$
\text { E assim aconteceu nas areias de New York, Berlin e }
$$
Munique; nas argilas de Chicago e Oslo; e mais recentemente em Washington, São Paulo e Rio de Janeiro, entre tantas outras cidades, durante a construção dos seus metropolitanos.

E bastante nova a preocupação quanto à influência da dilatação térmica das estroncas ou, como tambēm é conhecido, o efeito da temperatura nas cargas nelas instaladas. Anteriormente, as referèncias 
a este efelto restringiam-se à sua interferência nos aparelhos de medida das cargas.

Se esta influência puder ser equacionada e seus condicionantes explicltados, então serã possivel:

a) separar as cargas observadas nas estroncas em parcelas devidas só ao empuxo de terra, ao encunhamento e, ainda, so pröprlo efel to da temperatura; e

b) levā-la em consideraçāo nos cālculos para o dimensionamento de sistemas de escoramentos de valas a cèu aberto.

2. INTERESSE PELO ASSUNTO

A primeira referência de que se tem noticla sobre 0 assunto fol apresentada nos relatos das medições feitas entre 1955 e 1962 no Metrô de Oszo, onde è di to, textualmente, que as lelturas das cëlulas de carga eram feitas de manhā, bem cedo, antes que os raios solares atingissem as estroncas. Procurava-se, assim, eliminar a variāvel dilatação tērmica das es troncas das observações experimentais.

Recentemente, no início desta década, por ocasião da construção de uma linha do Metrô de Washington D.C. e, paralelamente, da linha Norte-Sul do Metrô de são Paulo, o problema fol focallizado sob novo prisma. Constatou-se que as cargas nas estroncas poderiam até duplicar de valor quando se passava das temperaturas mais balxas para as mais altas, fazendo com que as envoltörlas de pressões aparentes fossem referldas a estas ültimas; ou às temperaturas mals balxas, desde que se adicionasse o efeit to da dilataçāo térmica das estroncas, calculado de alguma forma.

Dal a razāo de terem surgido tentativas de construção 
de modelos matemäticos, alguns deles fazendo recorrēncia ao Método ảos EZementos Finitos; não sö para este cảiculo, como tambëm para explicar o fenōmeno e os seus condicionantes.

Como o efeito da temperatura depende de fatores como incidência direta dos raios solares, ventilação, diferença entre as tempe raturas mäximas e mínimas, presença de anteparos, tais como edifícios altos, que projetem sombras nas imediações, uma mesma formação de solo pode induzir empuxos totalmente diferentes em duas valas de caracteristicas idênticas quanto à geometria (mesma profundidade,largura, niveis de estroncas, espaçamentos entre elas, etc.) e aos processos construtivos, mas situadas em locais diferentes, ou escavadas em ëpocas distintas ao longo do ano.

\section{CONCEITUAÇÃO BÃSICA}

0 efeito da temperatura è entendido nesta Investigação como a influência da dilatação tërmica das estroncas metālicas no valor das cargas nelas atuantes, em valas escavadas a cēu aberto, sujeitas por tanto à ação solar.

Essas valas tanto podem estar escoradas com paredes flexiveis, formadas, por exemplo, por estacas metálicas, pranchöes de madeira e vigas de rigidez; ou com paredes rígidas, isto $\vec{e}$, paredes diafragmas ou estacas justapostas, de concreto.

As cargas nas estroncas flutuam em função de variaçōes de suas temperaturas. Assim, os inorementos relativos de temperatura nas diversas estroncas, isto é, os incrementos de temperatura nas estroncas inferiores quando a estronca superior sofre um aquecimento unitärio, são fatores decisivos nesta Investigação. Eles afetam sensivelmente 
os valores dos gradientes de carga-temperatura, is to $\dot{e}$, as cargas que sur gen numa dada estronca, para um incremento unitärio de sua temperatura.

Por outro lado, as cargas nas estroncas jā instaladas varlam também quando do encunhamento de estroncas adjacentes ou siltuadas em niveis inferiores. Este fenômeno pode ser simulado, de forma aproximada, como efel to de varlações ficticias de temperaturas.

\section{OBJETIVOS}

Os objetivos da presente Investigação são:

a) identificar os parâmetros que mais influem nos valores dos gradientes de carga-temperatura;

b) propor fórmulas präticas para o seu cālculo; e

c) tentar obter uma repartição percentual dos três tipos de carga em estroncas, oriundas do encunhamento, pressão de terra e de sua dilatação térmica, para algumas formações de solos da cidade de São Paulo e para a tẻenica de escavação usada na construção do seu Metrō.

As metas a que se propôs atinglr foram:

a) revisão dos estudos feltos anteriormente sobre o assunto;

b) apresentação dos resultados de campo pertinentes, obtidos através das Secções Experimentais do Metropolltano de São Paulo, instrumentadas e observadas pelo Instituto de Pesquisas Tecnolögicas;

c) construçāo de um modelo matemático simples e aproximado, que permita en tender o fenōmeno do efeito da temperatura em suas diversas facetas, tanto na identificação dos parâmetros de influência mais significativa, tais como a rigidez do solo e do sistema de escoramento, dos incre mentos relativos de temperatura, etc.; quanto na superação das dificul dades referentes à aleatorledade da variação dos incrementos relativos 
de temperatura e à geometría das valas;

d) comportamento e parāmetros dos solos em função da solicitaçãn cíclica de carga repetida; retroanálise dos resultados relativos às Secçōes Ex perimentals do Metrō de São Paulo para definir módulos de deformabllidade e sua comparação com os mödulos obtidos atravës de ensalos trlaxials;

e) fórmuizas práticas para o cālculo dos gradientes de carga-temperatura , tanto em final de escavação quanto nas fases de reaterro;

f) tentativa de repartição das cargas nas estroncas das Secções Experimen tais em cargas de encunhamento, de empuxo de terra e do efeito da sua dilatação tërmica;

g) inciusão do efeito da temperatura nos processos usuais de cälculo das cargas nas estroncas; aplicação às Secçōes Experimentais; e

h) interrelação da carga de prē-compressão de estroncas com o efel to da sua di latação tērmica.

\section{REVISAOO BIBLIOGRAFICA}

A Influēncla da dilatação tërmica das estroncas em es coramentos de valas não costuma ser cltada em trabalhos tēcnicos publicados e multo menos ë levada em conta em projetos.

Nos trabalhos anteriores a 1970 quase não se encontra nenhuma referência sobre o assunto. Tanto is to è verdade que Flaate (1966), em sua tese de doutoramento, e Morgenstern e Eisenstein (1970), no seu re lato geral sobre métodos de cālculo de cargas e deformaçōes em estruturas de arrimo, citam um dos poucos trabalhos que fazem mençāo ao efei to da temperatura, de autoria de Endo (1963), que observou variaçōes de 10 a $20 \%$ da carga mäxima nas estroncas, para incrementos de 6 a $9^{\circ} \mathrm{C}$ na temperatura do ar amblente. A escavação, em frente ao Edifício $M$, possula $80 \mathrm{~m}$ de 
comprimento por $60 \mathrm{~m}$ de largura e $13,7 \mathrm{~m}$ de profundidade, escorada com $6 \underline{n}$ veis de estroncas (perfis $H$ ). No subsolo predominava uma argila siltosa, sobreposta a camada de pedregulho. Este autor nipônico chegou a indicar que a obtenção da distribuição da pressão de terra deve ser felta atravēs de mediçöes nas temperaturas mais baixas do dia.

Nos Technical Reports nis 1 a 9 da Norwegian

Geotechnical Institute (1962), que tratam das jā cltadas medições feitas durante a construção do Metrô de 0 slo, encontram-se referênclas ao efei to da temperatura, principalmente nos de nümeros 4,7 e 8 .

Nestes dois ültimos a preocupação está voltada quase que exclus ivamente para a sua influência nos aparelhos de medida de carga nas estroncas (web strain gauges e load cells), cujos elementos sensores eram constituídos de cordas vibrantes. E dito, na pägina 16 do Report n? 7. que In all load calculations the mean squares of the measured frequencies were corrected ... to bring all measurements to a $0^{\circ} \mathrm{C}$ temperature datum. Ademais, com o objetivo de minimizar os efeitos de variações bruscas de temperatura nos aparelhos de medida, foram tomadas as seguintes precauções:

a) as observaçōes eram feitas de manhã, antes que os raios solares atingissem as estroncas; e

b) a parte instrumentada da escavação fol protegida da ação do vento.

- Technical Report $n \& \&$ relata as observações feitas numa escavação de $8,7 \mathrm{~m}$ de profundidade, $5 \mathrm{~m}$ de largura, com três níveis de estroncas, em frente ao Edifício do Telëgrafo de 0slo. 0 subsolo apresentava-se com uma argi la ressecada sobreposta a camada de quick clay. A resistêncla ao cisalhamento não drenada decrescia de $6 \mathrm{t} / \mathrm{m}^{2}$ para cerca de $2 \mathrm{t} / \mathrm{m}^{2}$, o que leva a crer que a rigidez do subsolo decrescia da camada su perior para a inferior na proporção de 3:1. Alēm do efel to do congelamen 
to do solo, foram observadas variações das cargas mäximas de até 14\%, média de 7\%, por influência de aumentos da temperatura do ar dentro da esca vação, em torno de $17^{\circ} \mathrm{C}$.

Medições da temperatura do ar eram feltas rotineiramente, como lembram Bjerrum et al (1965), a propósito de um relato sobre a Instrumentação utllizada nas observações de Oslo. No entanto, atribula-se malor Importâncla à Instalação de termopares no perimetro do mac I ço escorado, com o objetivo de detectar a profundidade de penetração do congelamento, que pode ter influêncla decislva na dlstribulção das cargas em estroncas, conforme também relato de Dibiagio e Bjermom (1957), em regiões de clima temperado.

\section{J.L. Wilton, cltado na resenha fel ta por Rémy et al} (1974), ponderou em trabalho publicado em 1970 que as extremidades das es troncas devem ser consideradas quase fixas e asseverou sobre a necessidade das cargas de prë-compressão serem pequenas quando Incorporadas em ba! xas temperaturas. Ao acerto desta ültima asserção se contrapõe a vulnerabillidade da primeira, pois, como se verā, os Incrementos de carga nas estroncas por éfeito da sua dilatação térmica têm sido da ordem de 10 a $40 \%$ do valor que ocorreria, fossem as suas extremidades fixas. Finalmente, Wilton teria sugerido regular a temperatura das estroncas, em reglöes de clima muito quente, protegendo-as de alguma forma contra a incidêncla direta dos raios solares.

Ainda segundo Rémy et al (1974), Y. Lacroix e W. T. Jackson, em seminärio realizado em Ohio em 1972, chegaram a um valor da ordem de $0,8 \mathrm{t} /{ }^{\circ} \mathrm{C}$ para o gradiente de carga-temperatura numa estronca com primida de um sistema de escoramento de paredes rígidas. E teriam afirmado que o efeito da temperatura em paredes flexiveis è pequeno porque o so lo se desloca plasticamente, o que è duplamente falso, pois no Metró de 
São Paulo encontraram-se valores dos gradientes de atē 0,6 a $0,7 \mathrm{t} /{ }^{\circ} \mathrm{C}$, alēm do que a pulsação das estroncas, ao imprimirem acrēscimos de tensões baixíssimos nos maclços escorados, de uma forma cíclica, fazem com que o solo se comporte como melo elāstlco, a exemplo do que ocorre em certos problemas de dinâmica dos solos.

Foi em 1972 que apareceram as duas primeiras publicações, uma nacional outra alienigena, que consideravam mais a fundo o efel to da temperatura; esta era de autoria de Chapman, Cording e Schnabel (1972) e aquela de Sousa Pinto, Massad e Martins (1972).

De lä para cā värios outros trabalhos surgiram, alguns deles trazendo novas informações sobre o problema, outros tentando calcular este efeito, atravès de modelos simplificados, e outros ainda apontando simplesmente a dificuldade do problema de separar as cargas orlundas somente da dilatação térmica das estroncas.

\subsection{Metrô de São Paulo - Seção Experimental 1}

Nas medidas realizadas na Secção Experimental 1 do Me trō de São Paulo, objeto do trabalho de Sousa Pinto et al (1972), observou-se que as cargas nas estroncas praticamente duplicavam de valor quando a temperatura passava de $13^{\circ} \mathrm{C}$ para $41^{\circ} \mathrm{C}$, mäxima observada.

Alēm disso, constatou-se que:

a) em períodos em que não havia progressos na escavação, a flutuação da carga com a dilatação térmica das estroncas era tal que ela retornava a valores imperantes anteriormente, na mesma temperatura; por exemplo, no dia $04 / 02 / 71$, quando sö a estronca do nível A estava instalada e sua temperatura era de $20^{\circ} \mathrm{C}$, a carga por ela suportada era de $4,8 \mathrm{t}$; às 13 horas estes valores eram de $40^{\circ} \mathrm{C}$ e $8,6 \mathrm{t}$; no dia seguinte, pela manhä, $23^{\circ} \mathrm{C}$ e $4,7 \mathrm{t}$; 
b) os acréscimos de carga devidos à temperatura nāo ultrapassaram cerca de $10 \%$ dos acréscimos que ocorreriam, fossem as estroncas impedidas em suas extremidades; e

c) como năo foram separados os efeitos da temperatura do empuxo de terra proprlamente dito, os diagramas de pressão aparente foram traçados para as cargas na temperatura de $41^{\circ} \mathrm{C}$, is to é, para as mäximas cargas ob servadas.

Um outro resultado desse estudo refere-se à maneira como se mediu a temperatura nas estroncas. A tëcnica utillizada consistiu na instalação de pares termo-elētricos, também conhecidos por termopares, colocados nas mesas superior e inferior dos perfis metälicos, adotando-se a média dos valores como representativa da temperatura da estronca. Verificou-se que este procedimento poderia conduzir a erros grosseiros quanto à temperatura média da estronca, caso houvesse, por exemplo, um resfriamento brusco de temperatura na mesa superior, causado por um chuvisco ou mesmo pela passagem de uma nuvem, que encobrisse temporariamente o sol. Postericrmente, numa outra Secção Experimental do Metrō de São Paulo, ficou comprovado que o melhor processo consistia em medir-se a temperatura no interior da estronca, em pelo menos três pontos ao longo do seu compr! mento, tomando-se a média destes valores como a sua temperatura. Este tema serā examinado a fundo no Capïtulo II, ou, mais especificamente, no Apêndice $A$.

5.2. Metrô de Washington - Comer of $16^{\text {th }}$ and L Street

0 trabalho de Chapman et al (1972) apresenta observaçōes feitas por ocasião da construção de um trecho do Metrô de Washington o.C., num local em que a escavação atingira $25 \mathrm{~m}$ de largura, $40 \mathrm{~m}$ de compr! mento e profundidade variando de 12,5 a $15 \mathrm{~m}$. 


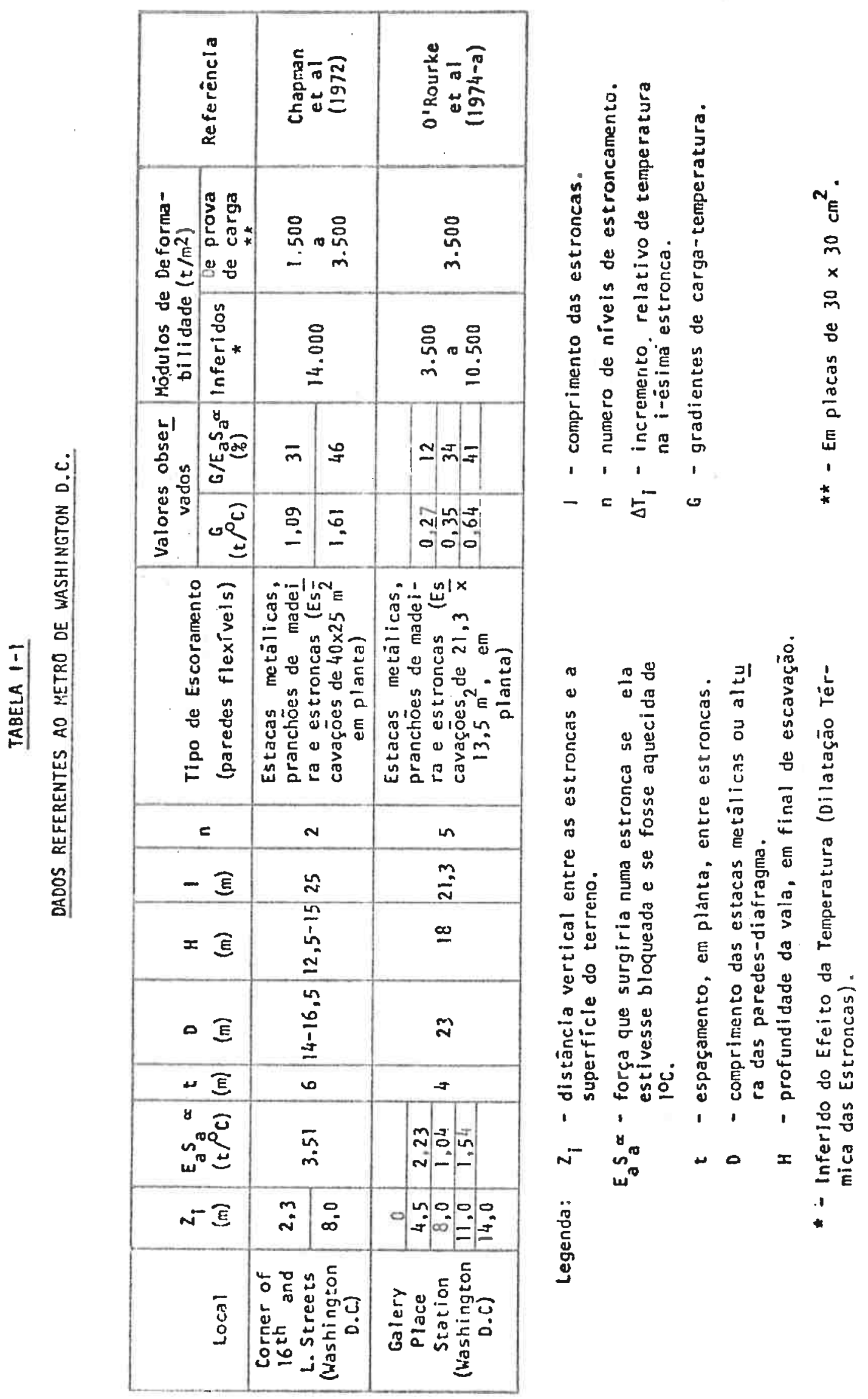


O escoramento usado era flexível e compunha-se de estacas metālicas, pranchões de madeira, vigas de distribuição, estroncas e escoras. O subsolo local consistia de camadas de areias e pedregulhos, medianamente compactas a compactas, areias siltosas e argllas siltosas rijas. Outros dados de interesse foram incluidos na tabela I-I.

Os dlagramas de pressões aparentes refletlram e absorveram o efel to da temperatura nas estroncas.

Alèm disso, durante o periodo compreendido entre os dias 82 e 118, a contar do inicio das obras, estando a escavação na cota final, em que a única varlävel era a temperatura, que flutuou de 10 a $50^{\circ} \mathrm{F}$, notou-se uma resposta quase elástica da parede de escoramento; convẻm fri sar que a temperatura referida acima era a ambiente.

Ficou comprovado também que, para uma variaçäo de $40^{\circ} \mathrm{F}$ na temperatura do ar, as cargas nas estroncas superior e inferior so freram acréscimos de 24 t e $36 \mathrm{t}$, respectivamente, o que significa, em mé dia, aumentos de $38 \%$ em relação à carga que surgiria se elas estivessem com as extremidades bloqueadas. Isto representou incrementos de 20 a $30 \%$ nas cargas das estroncas superior e inferlor, respectivamente, quando com paradas com as cargas nelas instaladas nas temperaturas mais baixas, em final de escavação.

Com base nos valores mëdios do Incremento de carga $(30 t)$ e de deslocamento $(1,14 \mathrm{~mm})$, medidos para variação de temperatura de $40^{\circ} \mathrm{F}$, e recorrendo a uma förmula simples do tipo da de Boussinesq, supondo ser o maciço escorado um espaço semi-infinito, isto $\vec{e}$, usando a expres são:

$$
E_{s}=\frac{1,5 H\left(1-v^{2}\right) p}{\delta}
$$


onde $\underline{p}$ è a pressão média atuante contra a parede, por efeito da dilatação térmica de todas as estroncas; $v$ o Coeficiente de Poisson; $\underline{H}$ a profundidade da vala e $\delta$ o deslocamento da parede, esses autores chegaram a um módulo de deformabilidade $\left(E_{8}\right)$ do solo da ordem de $14.000 \mathrm{t} / \mathrm{m}^{2}$. Provas de carga em placas revelaram valores iniciais deste módulo da ordem de 1500 a $3500 \mathrm{t} / \mathrm{m}^{2}$. Este fato se reveste de grande importância, apesar da anälise ser muito simplista, pois mostra que o tipo de solicitação imposta ao solo faz com que este responda com uma rigidez värias vezes maior do que era de se esperar, com os conhecimentos baseados em sollcitação de carga estätica e vertical.

Finalmente, Chapman e colaboradores idealizaram um mo delo matemätico bastante simples para o cälculo do efeito da temperatura, supondo que em cada extremidade das estroncas o solo atua como uma mola, cuja rigidez pode ser calculada atravēs da expressão (I.1). Assim, sendo $\Delta T$ a variação da temperatura nas estroncas, supostamente iguais para todas elas; $E_{a} S_{a} e$ l omödulo de deformabilidade, a ārea da secção transver sal e o comprimento da estronca, respectivamente; e $\Delta C$ o incremento de carga induzido, pode-se escrever:

$$
\frac{\Delta C}{\Delta T}=\frac{E_{a} S_{a} \propto}{1+2 \frac{E_{a} S_{a}}{l K}}
$$

onde $\mathrm{K}$ è a rigidez das molas, dada por

$$
K=\frac{\bar{P}}{\delta}, \quad \text { com } \bar{P}=\frac{P \cdot H \cdot t}{n}
$$

Note-se que $\underline{\bar{P}} \bar{e}$ a média das cargas nas estroncas, $\underline{n}$ o nümero de níveis de estroncamento e $t$ o espaçamento entre elas, em planta. Extraindo-se $p$ da Pxpressão $(I-1)$ vem que: 


$$
K=\frac{1,5 n E_{a} S_{a}}{t l E_{s}}
$$

donde:

$$
\frac{\Delta C}{\Delta T}=\frac{E_{a} S_{a}{ }^{\alpha}}{1+\frac{3 n E_{a} S_{a}}{t l E_{s}}}
$$

A aplicação desta förmula por Chapman ao seu problema

conduziu a:

$$
\frac{\Delta C}{E_{a} S_{a} \propto \Delta T}=50 \%
$$

e não $38 \%$, valor médio observado. Tal discrepâncla se deve, a nosso ver:

a) à simplicidade do modelo, que supôs vālida a fórmula de Boussinesq na transmissão de carga da estronca para o solo escorado;

b) ao fato de se ter desprezado a rigidez da parede que, como se verá no desenvolvimento desta Investigação, desempenha um papel multo importan te; e

c) à hipätese de que os incrementos de temperatura nas diversas estroncas fossem constantes e iguais ao do ar ambiente.

5.3. Metrô de Washington - Galery Place Station

Em 1974 apareceram dois trabalhos de O'Rourke e Cording (1974 a e b), divulgando outros resultados experimentais de observação em escavação do Metrô de Washington D.C.

O primeiro deles, mais rico em informações sobre o efel to da temperatura, refere-se a uma escavação de $18 \mathrm{~m}$ de profundidade, 
feita na Galery Place Station. 0 subsolo apresentava diversas alternânclas de areias com pedregulhos compactos e argilas duras. 0 escoramento flexível era constituído de estacas metälicas espaçadas de 2 em $2 \mathrm{~m}$, pranchões de madeira e estroncas, colocadas em planta de 4 em 4 metros, em 5 niveis. As estroncas dos 4 niveis inferlores foram prē-comprimidas com cerca de 56 toneladas. A tabela I-1 apresenta estas e outras informações, extraídas do trabalho em anälise.

Pela primeira vez, pelo menos até onde chegam os nossos conhecimentos, estes autores corrigiram as cargas medidas dos efeitos da temperatura, apresentando diagramas de pressões aparentes resultantes da carga de prë-compressão mais empuxo de terra.

No entanto, não ficou claro como foi feita a separação das cargas oriundas da di latação tērmica das estroncas. Neste sentido, Chopmon et al (1972) sugerem que os incrementos de carga devidos a grandes variações de temperatura sejam somados aos valores dos empuxos, extraidos de diagramas de pressōes aparentes, desde que estes sejam obtidos em situaçōes de temperatura constante, ou pequenas variações de tempe ratura.

Dos dados apresentados por O'Rourke et al (1974-a) infere-se que os aumentos das cargas instaladas nas estroncas do $2 \%, 3 \%$, e $4 \%$ niveis foram, respectivamente, de cerca de $12 \%, 34 \%$ e $41 \%$ do valor que existiria, se eias estivessem impedidas em suas extremidades.

Usando o mesmo modelo de cálculo elaborado por Chapman et al (1972), chegaram a valores do mödulo de deformabilidade da ordem de 3500 a $10500 \mathrm{t} / \mathrm{m}^{2}$, contra $3500 \mathrm{t} / \mathrm{m}^{2}$ obtido através de provas de carga em placas.

Finalmente, no segundo trabalho de O'Rourke e Cording (1974-b) referente a uma outra escavação com cerca de $25 \mathrm{~m}$ de profundida- 


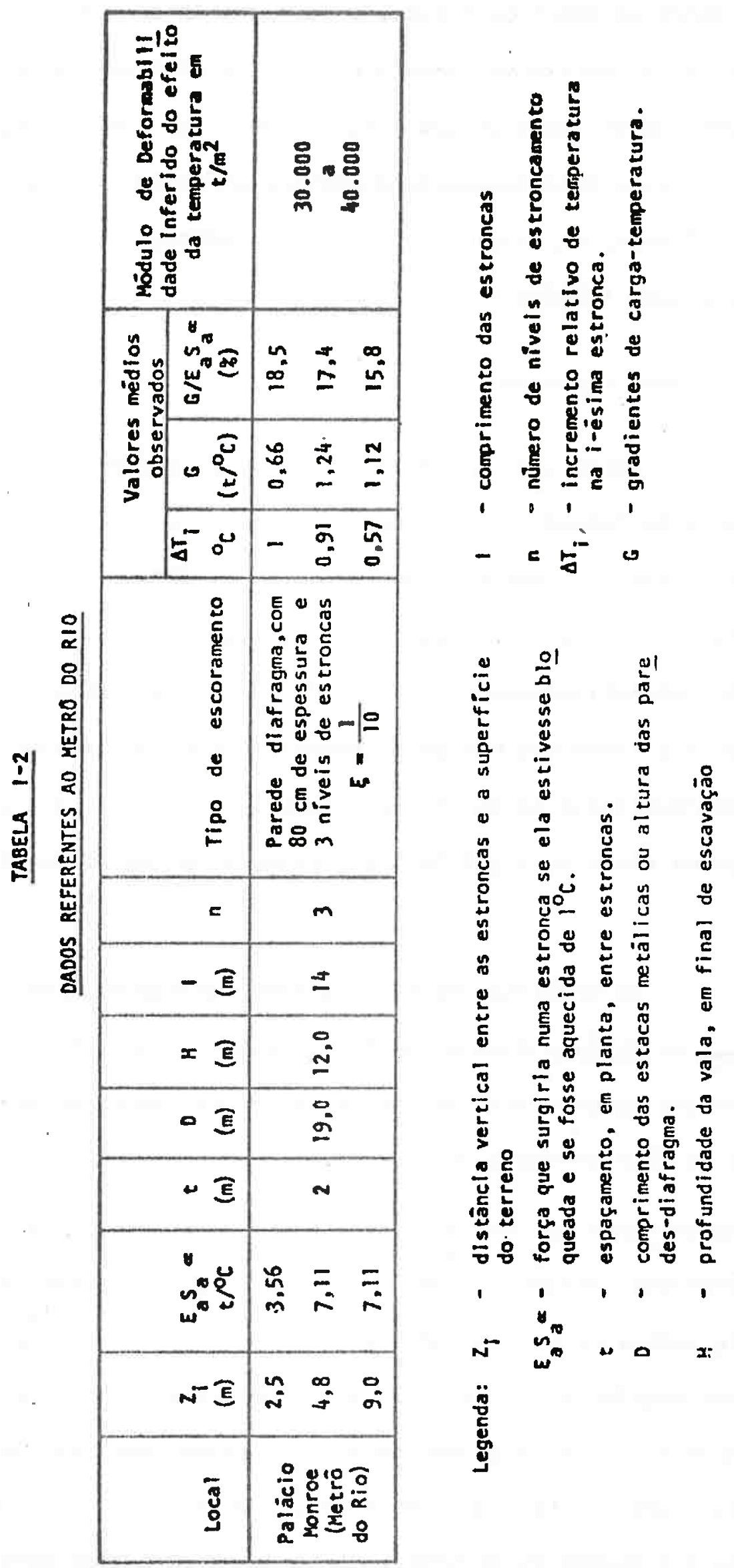


de, também no Metrô de Washington D.C., ē apresentado um gráfico que mostra nitidamente a influência da temperatura nos valores das cargas das es troncas, num periodo de tempo em que a escavação tinha sido completada. E comentam: It appears that temperature changes affected the development of loads in all levels, but its contribution in terms of load increase is difficult to evaluate (pägina 11).

\subsection{Publicações mais recentes}

Entre nōs, em 1974, surgi ram concomi tantemente os tra balhos de autoria de Massad et al (1974-a, $b$ e c) e Fujii et al (1974), que procuravam entender o fenômeno com o recurso do Método dos Elementos Finitos, aplicado a secções instrumentadas dos Metrôs de Sāo Paulo e do Rio de Janeiro, respectivamente; e outros, de Sousa Pinto et al (1974), que apresentava a sintese das medições levadas a cabo em 3 secções experimentais do Metropolitano de São Paulo e Rémy et al (1974), que anallsava, de um ponto de vista mais prätico, as medições feltas no Metrô do Rlo de Janeiro.

Os trabalhos de Fujli e Rëmy referem-se à Seção Experimental junto ao Paläcio Monroe, no Rio de Janeiro, em que o solo, que era constituido basicamente por camadas de areia, foi escorado por paredes diafragmas de $80 \mathrm{~cm}$ de espessura e 3 niveis de estroncas.

a) As temperaturas foram medidas no interior das estroncas dos 3 nivels, tendo-se observado incrementos de $23^{\circ} \mathrm{C}, 21^{\circ} \mathrm{C}$ e $13^{\circ} \mathrm{C}$, respectivamente, de cima para balxo; os correspondentes incrementos médios de carga foram, na mesma sequêncla, de 19\%, $17 \%$ e 16\%, em relação aos incrementos de carga que existiriam se as estroncas estivessem impedidas em suas extremidades; numa das estroncas do 19 nivel este percentual chegou a 37. A tabela I-2 resume os valores encontrados e dä outras caracterís- 
ticas do sistema de escoramento e da escavação.

b) Através da apllaçãa do Mëtodo dos Elementos Finitos, esses autores chegaram à conclusão de que o módulo de deformabilidade médio dos solos escorados è da ordem de 25.000 a $45.000 \mathrm{t} / \mathrm{m}^{2}$, valores considerados bastante elevados quando comparados com aqueles obtidos de ensalos tría xlals $\bar{R}$. Estes, para pressões de câmara de 1 a $2 \mathrm{~kg} / \mathrm{cm}^{2}$, revelaram mö dulos de deförmabilidade da ordem de $5.000 \mathrm{t} / \mathrm{m}^{2}$ para descarga total, e $15.000 \mathrm{t} / \mathrm{m}^{2}$ para o inicio do descarregamento, jā que as varlações mä ximas das tensões impostas ao solo pelas flutuações de temperatura foram da ordem de $4 \mathrm{t} / \mathrm{m}^{2}$. Os autores procuram explicar esta discrepância afirmando que o carregamento é cíclico e tenderia a aumentar a rigidez do solo com o aumento do nümero de repetições de carga.

c) Experiências do revestimento de uma estronca com isopor mostraram que as suas temperaturas praticamente coincidiram com a do ar ambiente; a proteção com tinta branca revelou-se ineficiente, apōs alguns dias. Assim, vê-se que o efeito da temperatura, embora atenuado, deve ser considerado, mesmo que se pense em isolar as estroncas da ação direta dos raios solares.

d) Por ültimo, um outro aspecto interessante refere-se à influência da temperatura nas paredes. rígidas que, por estarem, de um lado, em contato com o solo, portanto numa temperatura que varla muito pouco, de outro, em contato com a atmosfera, devem sofrer um processo equivalente a uma flexão composta com compressão ou tração. Rémy et al (1974) sugerem que este efelto, que não fol incluido nas anālises com o Método dos Elementos Finitos, deve ser acrescentado àquele proveniente da dilataçāo tërmlca das estroncas, princlpalmente para as dos niveis intermediārios.

Nos trabalhos de Massad et al (1974-a, $b$ e c), fol vi sado, em essêncla, Identificar os diversos parâmetros do solo, do slstema 
de escoramento e da geometrla da vala, que pudessem interferir no fenômeno do efeito da temperatura. Fol, antes de mais nada, wn estudo analitico, è bem verdade com respaldo nas observaçöes experimentais do comportamento de algumas das Seçõea Experimentais do Metrô de São Paulo. Como as idēlas-chave deste estudo foram incorporadas à presente Investigação, extensivamente apresentadas no Capitulo IV, delxar-se-ä de menclonä-las nesta revisão bibliogrāfica.

Finalmente, ao analisarem o comportamento de escavação escorada em argila de sensitividade elevada da cidade de 0s lo, Karstmud e Myrvoll (1976) fazem uma breve menção a flutuações na carga das estroncas dos dols niveis superiores, por efeito de variações de temperatura, sem, no entanto, apresentarem dados quantitativos. 


\section{CAP ITULO II \\ CARACTERTSTICAS GERAIS DAS SECÇOES EXPERIMENTAIS \\ DO METRO DE SÃO PAIILO}

\section{PRELIMINARES}

Durante a construção da Linha Norte-Sul do Metrô de São Paulo, o Instituto de Pesquisas Tecnológicas esteve engajado em Inves tigaçōes de campo e de laboratōrio relacionadas com o comportamento de es cavações escoradas.

Nas partes da linha em que as escavações foram a cëu aberto e o escoramento constituído de paredes flexíveis (estacas metālicas, pranchōes de madeira e vigas de rigidez) ou paredes rigidas (paredes diafragmas ou estacas justapostas) mais estroncas, foram Instrumentados 9 trechos, que foram designados por Seccões Experimentais. Deste total, 6 referem-se a escoramentos com paredes flexiveis.

Além da rigidez da parede de escoramento, as Secções Experimentals diferiam entre si em diversas outras caracteristicas:

a) tipo de solo escorado; e

b) geometria da vala, quer dizer, a profundidade e largura da escavação; espaçamentos vertical e horizontal entre estroncas; ficha; nümero de niveis de estroncamento e tipos de perfis metälicos.

2. SEQUENCIA DE CONSTRUÇÃO

Basicamente, as sequênclas de construção foram as mes 
mas para as diversas Secções Experimentals, diferindo em alguns detalhes, tais como velocidade de escavação e māxima distâncla permitida, durante as escavações, entre as estroncas e o fundo da vala, em virtude da presen ça de diferentes emprel teiras.

Em geral, eram desenvolvidas as seguintes operações para o caso de paredes flexiveis:

a) cravação das estacas metālicas com fichas de 2 a 2,5m, medidas abaixo da cota final de escavação; em alguns locais fol necessārlo fazer prēfuros para a colocação destas estacas;

b) à medida em que o solo entre as duas linhas de estacas la sendo escava do, eram colocados os pranchões de madeira, as vigas de rigidez e as estroncas encunhadas com cunhas metälicas;

c) a seguir, construla-se a base de concreto do tūnel, colocavam-se cunhas entre ela e as estacas metälicas e retirava-se o ültimo nivel de estroncas;

d) apōs a construção do tünel o espaço vazio entre as suas paredes laterais e as do escoramento era preenchido com pedrisco ou solo compactado; retirava-se mais um nivel de estroncas; e

e) procedia-se ao reaterro da vala e à retirada das estroncas superiores, atē atingir o nivel original do terreno. As estacas metälicas eram pos teriormente recuperadas.

Para as paredes rigidas o procedimento era anälogo, exceto no que se refere ao item (a), que consistla, obviamente, na escava ção de painēis com lama bentonítica, no caso de paredes dlafragmas, ou na execução de estacas Justapostas.

Em algumas Seções Experimentais fol possivel observar o comportamento da vala em estāglos intermediärlos da escavação. Mas, em geral, as medịdas referem-se mais a perfodos correspondentes às fases 
de final de escavação e de reaterro.

\section{INSTRUMENTAÇÃO UTILIZADA}

Invariavelmente, foram utilizados os seguintes instrumentos de medida:

a) células de carga Maihak (transmitter MDS 63-b), de cordas vibrantes, com carcaça à prova de choques mecânicos, de pingos de ägua e com coeficiente de dilatação térmica idêntica à da corda vibrante, para medir a carga das estroncas; as cēlulas eram colocadas em berços especiais entre as estroncas, envolvidas por caixas para proteção contra a Incidēncla direta dos ralos solares; e

b) pares termoelétricos nas mesas inferiores e superiores, algumas vezes na alma dos perfis metāilicos que serviam de estroncas; ou no seu interior, pois eram, em geral, soldados, formando perfis duplos.

Em algumas Secções Experimentais, com paredes de esco ramentos flexiveis, foram instalados tambëm tubos de inclinômetros, para a medida dos deslocamentos laterais da parede; e também marcos superficlais de recalques.

No Apêndice $A$ são feitas consideraçōes relativas ao problema de precisão de alguns dos aparelhos de medida utilizados, bem co mo è desenvolvida uma discussão sobre o conceito de temperatura de roma eg tronca.

4. CARACTERISTICAS GERAIS DAS DIVERSAS SECÇOES EXPERIMENTAIS

Uma descrição detalhada das características das diversas Secções Experimentais, Inclusive quanto à instrumentação instala- 


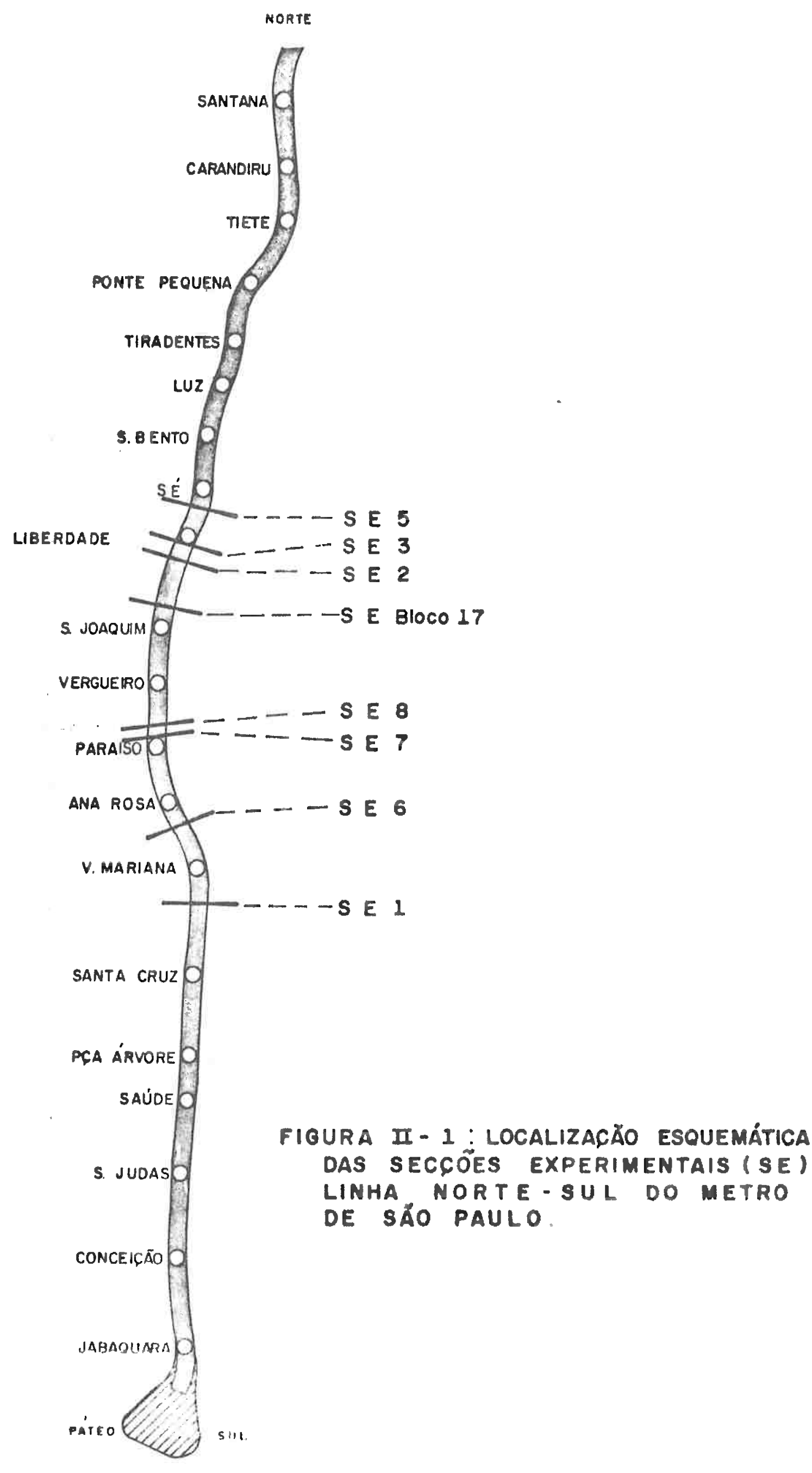


TAOELA $\mid 1-1$

IMFORMACOES GEMAIS SOBRE AS SECGOES EXPERIMEMTALIS

(PAM MAIORES DETALHES, VIOE APENDICE B)

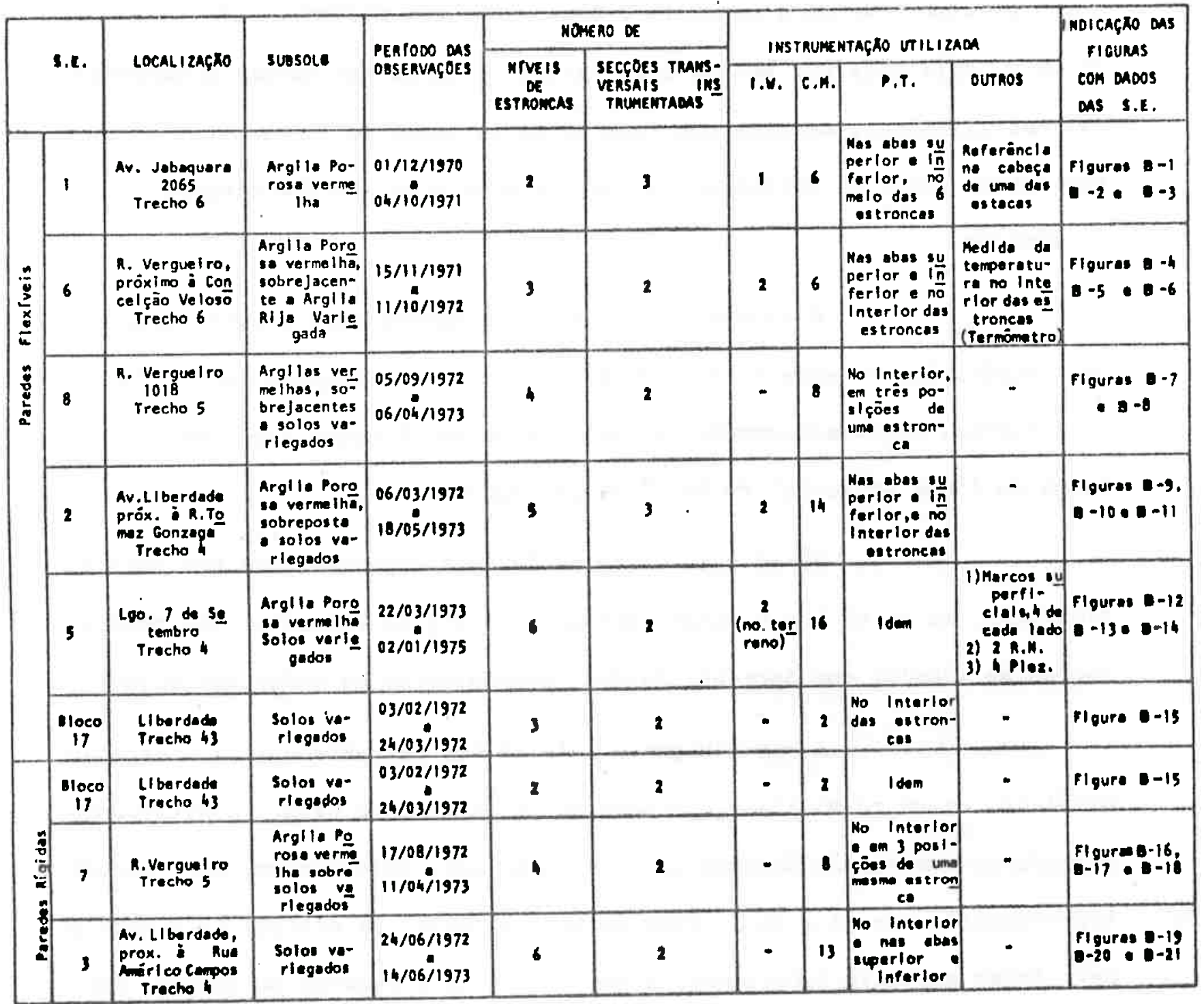

LeEvos: 1,W. - Inelinömetros WI Ison.

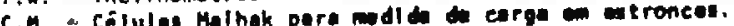

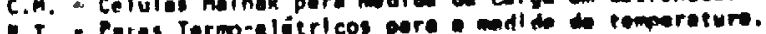

3.E. - Seccio Exparlmentel.

R.i., - Meferancio de MPrul.

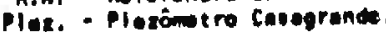


da, encontra-se no Apêndice $B$.

De um modo geral, as observações eram iniciadas com as primeiras leituras dos inclinónetros, quando estes existiam, antes do inicio das escavaçōes. Os demais Instrumentos eram Instalados à medida em que o andamento da obra permitía e observados com periodicidade variävel. Em un ou dois dlas por semana eram feitas lelturas das cargas a temperatu ras nas estroncas, em diversos intervalos de tempo no transcorrer do dia. Nas mesmas datas os deslocamentos das estacas eram medidos através do inclinômetro.

A tabela II-I reune informações gerais sobre cada uma das Seç̧ões Experimentais, de interesse a esta Investlgação. A figura II-1 indica, esquematicamente, a localização das Secções Experimentais ao longo da linha Norte-Sul do Metrō de São Paulo.

Vê-se que, entre as Secções Experimentais com paredes flexiveis, as de n: 1 e 6 foram escavadas em Argila Vermelha; nas demais, inclusive aquelas com paredes rigidas, predominaram os solos variegados.

A aparelhagem era Instalada nas estroncas e estacas metálicas de um mesmo plano, perpendicular ao eixo da vala, constituindo - conjunto uma Seçãa Transversal instrumentada, cujo nümero, por Secção Experimental, era de 2 ou 3. Como se verá adiante, os efeltos tridimensía nais foram bastante acentuados, o que justifica o aumento do nümero destas secções transversais em observaçōes futuras; via de regra, a sua IIm! tação se prende aos custos envolvidos em instrumentos e nos trabalhos de campo. Cabe lembrar que nas observações dos Metrōs de Oslo e Washington foram instrumentadas três destas secções transversals, em cada local ou Seç̧āo Experimental.

Em geral, o tempo de observação foi de 8 a 12 meses, constituindo-se em exceções as Secçōes Experimentais 5 e do Bloco 17, em 
que as medições duraram 22 e 2 meses, respectivamente.

Na ültima coluna da tabela II-I estão Indicadas as

figuras, enumeradas de B-1 a B-21, que contëm dados complementares sobre as diversas Secções Experimentais. 


\section{CAPITULO III}

\section{LINEARI DADE DA RESPOSTA CARGA-TEMPERATURA EM ESTRONCAS}

\section{PRELIMINARES}

Desde o Iniclo do programa de observação das Secções Experimentais constatou-se a Inexistêncla de fenômenos de histerese, is to ē, num mesmo estäglo de escavação, em clclos sucessivos de varlaçōes, para as mesmas temperaturas mediam-se as mesmas cargas. Ademals, os incrementos de tensões impostos ao solo escorado pela dilatação térmica das es troncas eram balxos e adicionavam-se às tensões que, num dado estägio da escavação, geravam o empuxo de terra contra a parede de escoramento. Em outras palavras, as cargas incorporadas às estroncas pelos empuxos de ter ra ou pela pré-compressão podiam ser tomadas como cargas iniciais.

0 que foi dito sugere a possibilidade de se admitir o solo como um meio linearmente elästico, em que o módulo de deformabilidade deve corresponder a um carregamento ciclico repetido, face à pröpría natureza do fenômeno em estudo.

\section{EVIDENCIAS EMPIRICAS}

Para comprovação apresentam-se nas figuras III-1, III-4 e III-7 variaçōes das cargas nas estroncas da Secção Experimental 1, respectivamente, nos estägios 5 (um sö nível de estroncas instaladas); 8 (dois niveis) e 9 (um nivel, mais o encunhamento na caixa de concreto), em função da temperatura medida no nivel A (superior). Ver também figura $I I I-3$. 


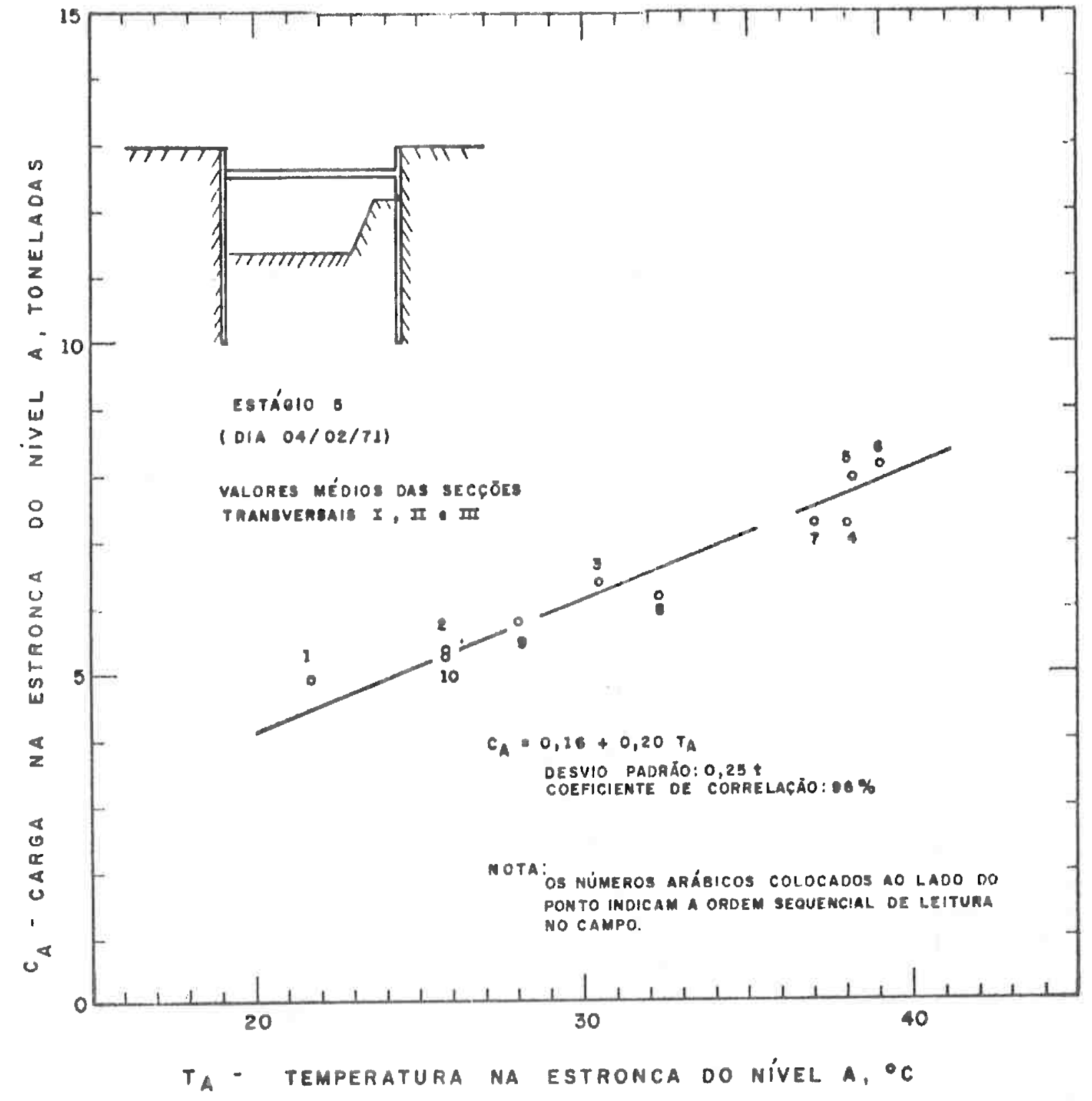

FIGURA III - I: CARGA EM FUNÇĀO DA TEMPERATURA SECCAAOO EXPERIMENTAL 1 


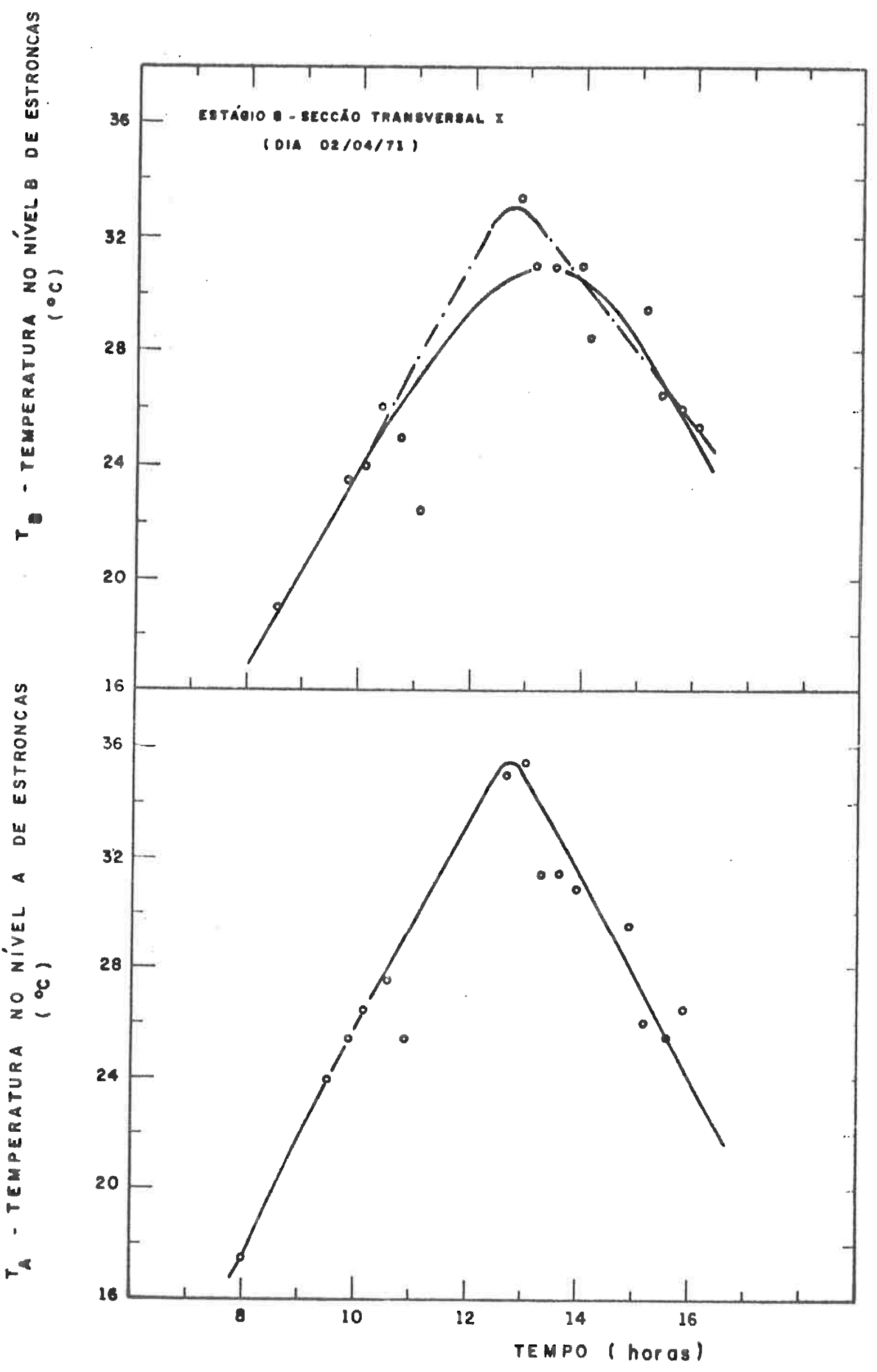

FIGURA III-2: TEMPERATURAS DOS NIVEIS A E B EM FUNCĀO DO TEMPO - SECCĀO EXPERIMENTAL 1 
Havendo uma sö estronca, a curva de resposta cargatemperatura é linear, com pequena dispersão. Aparentemente, esta linearidade não existe no caso de dols niveis de estroncas, ou de un só nivel, mas com encunhamento na caixa de concreto. No entanto, ë possível provar que o tipo de curva indicado nas figuras III-4 e III-7 ocorre mesmo se for admitido que o conjunto solo-sistema de escoramento é 1 inearmente elästico, para valas com dols ou mais nivels de estroncas.

De fato, considere-se uma vala escorada por paredes contínuas e $\underline{n}$ niveis de estroncas. Seja $\Delta C_{1}$ a força que a i-ësima estronca exerce contra a parede em consequência de acrëscimos de temperatura $\Delta T_{j}$ na j-ésima estronca, com $j=1,2, \ldots n$. A hipötese de sistema $1 i$ nearmente elästico permi te escrever:

$$
C=U \cdot T
$$

em que $C$ e $T$ são os vetores dos $\Delta C{ }_{i} \in \Delta T_{i}$, com $\underline{n}$ termos cada um; $U=\left\|u_{i j}\right\|$, onde $u_{i j}$ è o gradiente bäsico de carga-temperatura, is to è, a força exer cida pela i-ésima estronca contra a parede, quando apenas a j-ésima estronca sofre um incremento de temperatura de $1^{\circ} \mathrm{C}$.

$$
\text { Note-se que } u_{i j} \text {, para } i \neq j \text {, pode ser negativo, sign } i
$$

ficando um alívio das forças iniclais na i-ésima estronca que, por hipóte se, estā sujeita a esforços de pré-compressão ou de empuxos de terra, de vidos às escavaçōes.

Os gradientes bāsicos podem ser calculados se se conhecer os valores dos $\delta_{i j}$ (deslocamento do ponto onde a i-ésima estronca toca a parede, se à $\mathrm{j}$-ësima for dado um acréscimo de temperatura de $1^{\circ} \mathrm{C}$ ) e $\delta_{j i}$ (deslocamento do ponto onde a j-ésima estronca toca a parede, se à 1 -ésima estronca for dado um acréscimo de temperatura de $1^{\circ} \mathrm{C}$ ), através das seguintes expressões: 


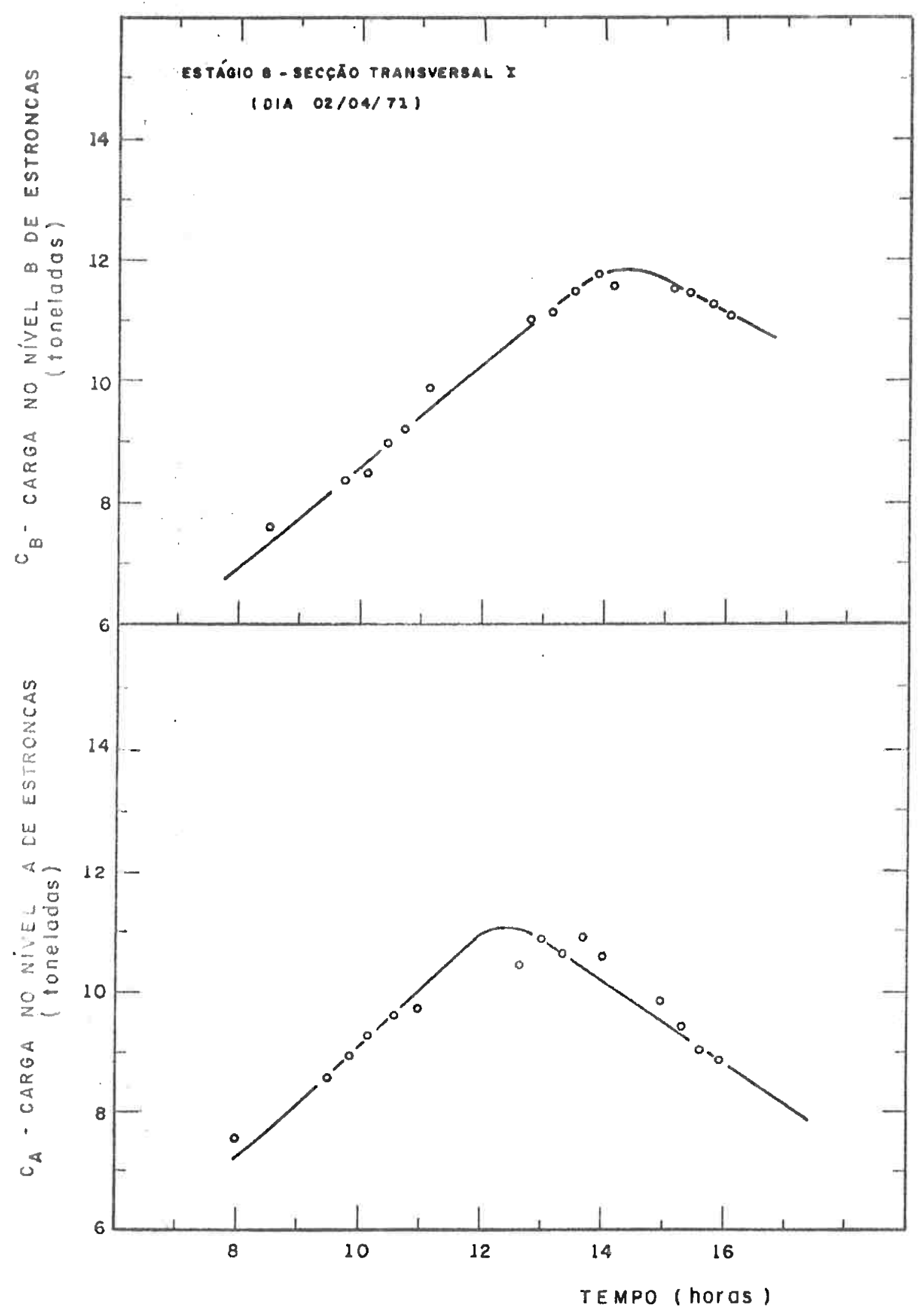

FIGURA III-3: CARGAS DOS NIVEIS A E B EM FUNÇĀO DO TEMPO - SECÇĀO EXPERIMENTAL $I$ 


$$
\begin{aligned}
& u_{i j}=-\frac{2 E_{a}^{S_{a}}}{\ell} \cdot \delta_{i j}(i+j) \\
& u_{i i}=\frac{2^{E_{a} s_{a}}}{l} \cdot\left(\frac{\alpha \ell}{2}-\delta_{i l}\right)
\end{aligned}
$$

onde $\ell, S_{a}, E_{a} e \propto$ são o comprimento, a ärea da secção transversal das estroncas, o mödulo de deformabilidade e o coeficiente de dilatação tērmí ca do aço, respectivamente. $0 s \delta_{i j}$ são deslocamentos horizontais.

A aplicação do Teorema de Betti ou da Reciprocidade (vide Langendonck, 1959, pägina 109 do Vol. 1), permite escrever:

$$
P_{i} \delta_{1 j}=P_{j} \delta_{j l}
$$

onde $P_{i}=P_{j}=E_{a} S_{a} \propto$ (Vide expressão $(I V-4)$ e seu enfoque, pāg. 35). Dar conclul-se que:

$$
\delta_{1 j}=\delta_{j 1}
$$

e, portanto,

$$
u_{i j}=u_{j i}
$$

is to $\dot{e}$, a matriz U é simétrica.

E interessante observar que da segunda das expressões (III-2) pode-se déduzir:

$$
\frac{u_{11}}{E_{a} s_{a}^{\alpha}}=1-\frac{2 \cdot \delta_{11}}{\alpha \cdot l}
$$

Isto $\dot{e}$, a carga que surge na l-ésima estronca quando ela é aqueclda de 


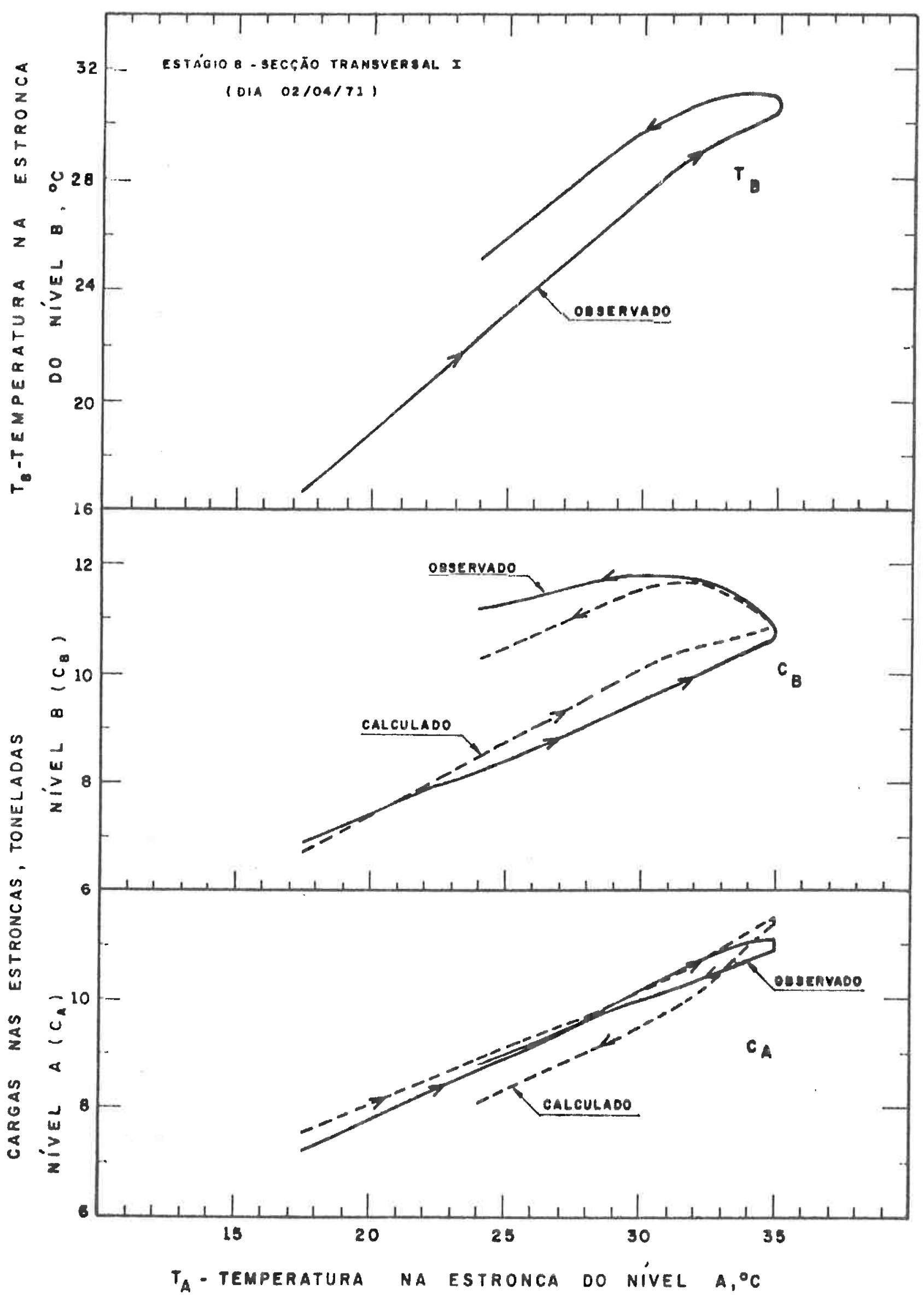

FIGURA III - 4: COMPARACĀO ENTRE VALORES OBSERVADOS E CALCULADOS DAS CARGAS NAS ESTRONCAS SECCÃO EXPERIMENTAL 1 
$1^{\circ} \mathrm{C}$ è o complemento de 1 do encurtamento da estronca, se a carga e o deslocamento forem referidos aos seus correspondentes valores mäximos, Isto $\vec{e}$, estronca impedida e livre em suas extremidades, respectivamente. Dito de outra forma, se o gradiente for da ordem de $10 \%$ da carga que surgiria na estronca se ela estivesse impedida nas extremidades, então os deslocamen tos serão de $90 \%$ do valor que existiria, se ela fosse livre nas extremida des.

Vol tando-se à figura III-4 ou mais precisamente às figuras III-2 e III-3, è possível correlacionar, pelo método dos mínimos quadrados (ver Apêndice $C$ ), as cargas $C_{A}$ e $C_{B}$ das estroncas dos níveis $A$ e $B$ com as correspondentes temperaturas $T_{A}$ e $T_{B}$, permitindo a determinação dos coeficientes da Matriz U.

Encontrou-se o seguinte resultado:

$$
\left\{\begin{array}{l}
C_{A} \\
C_{B}
\end{array}\right\}=\left\{\begin{array}{l}
4,42 \\
0,77
\end{array}\right\}+\left[\begin{array}{cc}
0,441 & -0,273 \\
-0,273 & 0,639
\end{array}\right]\left(\begin{array}{l}
T_{A} \\
T_{B}
\end{array}\right\}
$$

que tem a forma da expressão (III-1) e estã representado graficamente na figura III-4, pelas linhas tracejadas (valores calculados), o que è uma prova de que o sistema solo-escoramento é linearmente elästico.

Note-se que a simetria da matriz do segundo membro da expressão acima fol imposta, segundo desenvolvimento apresentado no Apêndice C. Ademais, o desvio padrão e o coeficlente de correlação obtidos foram, para as estroncas do nivel A, 0,44 te $95 \%$, e, para as do nivel $8,0,47$ t e $97 \%$, respectivamente.

A expreseão (III-4) pode ser reescrita do segulnte mo do:

$$
\left\{\begin{array}{l}
C_{A}+0,273 T_{B}=4,42+0,441 T_{A} \\
0,639 T_{B}-C_{B}=-0,77+0,273 T_{A}
\end{array}\right.
$$




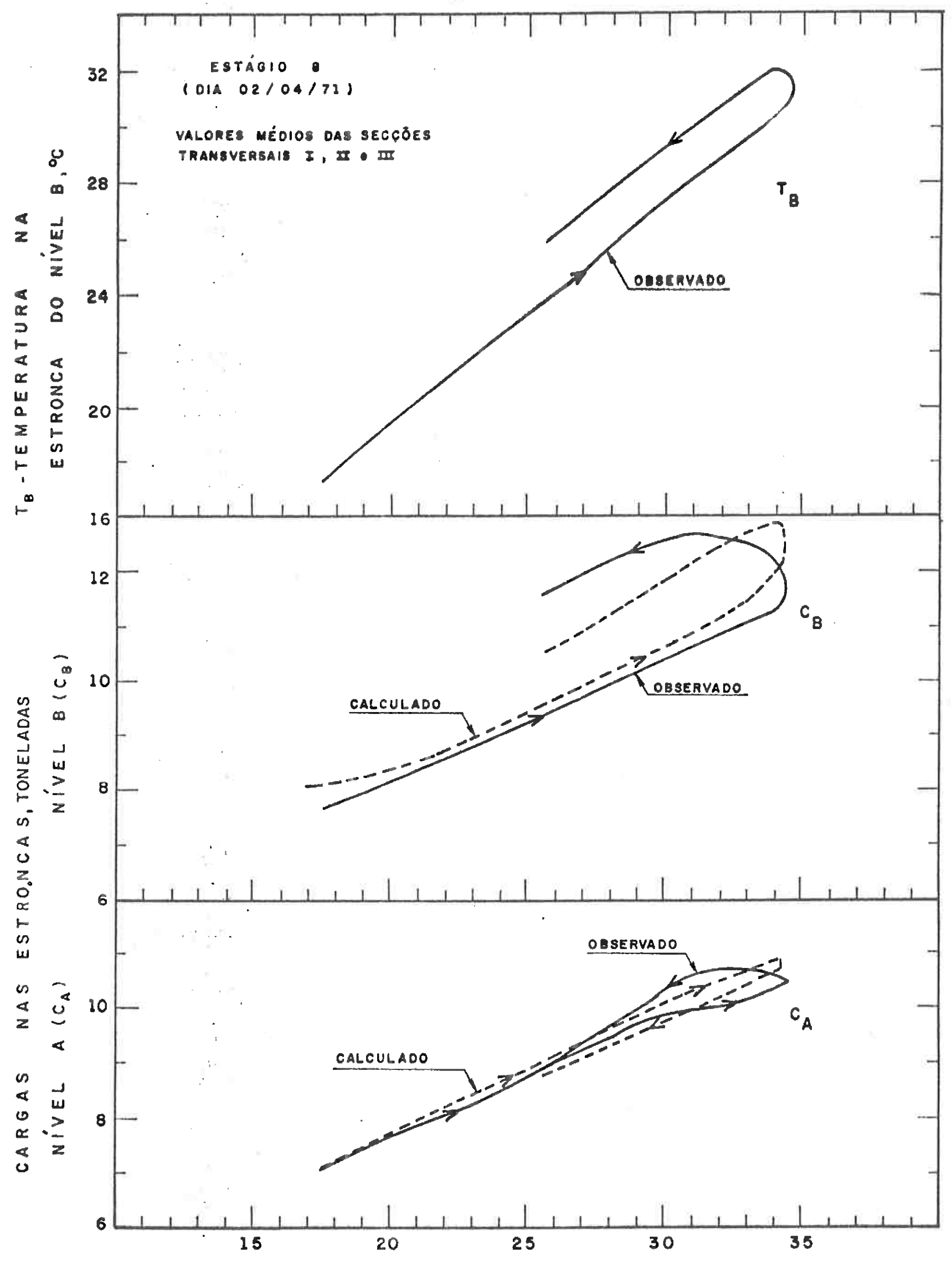

$T_{A}$ - temperatura na estronca do nível $A,{ }^{\circ} \mathrm{C}$ E CALCULADOS DAS CARGAS NAS ESTRONCAS SECGĀO EXPERIMENTAL I 


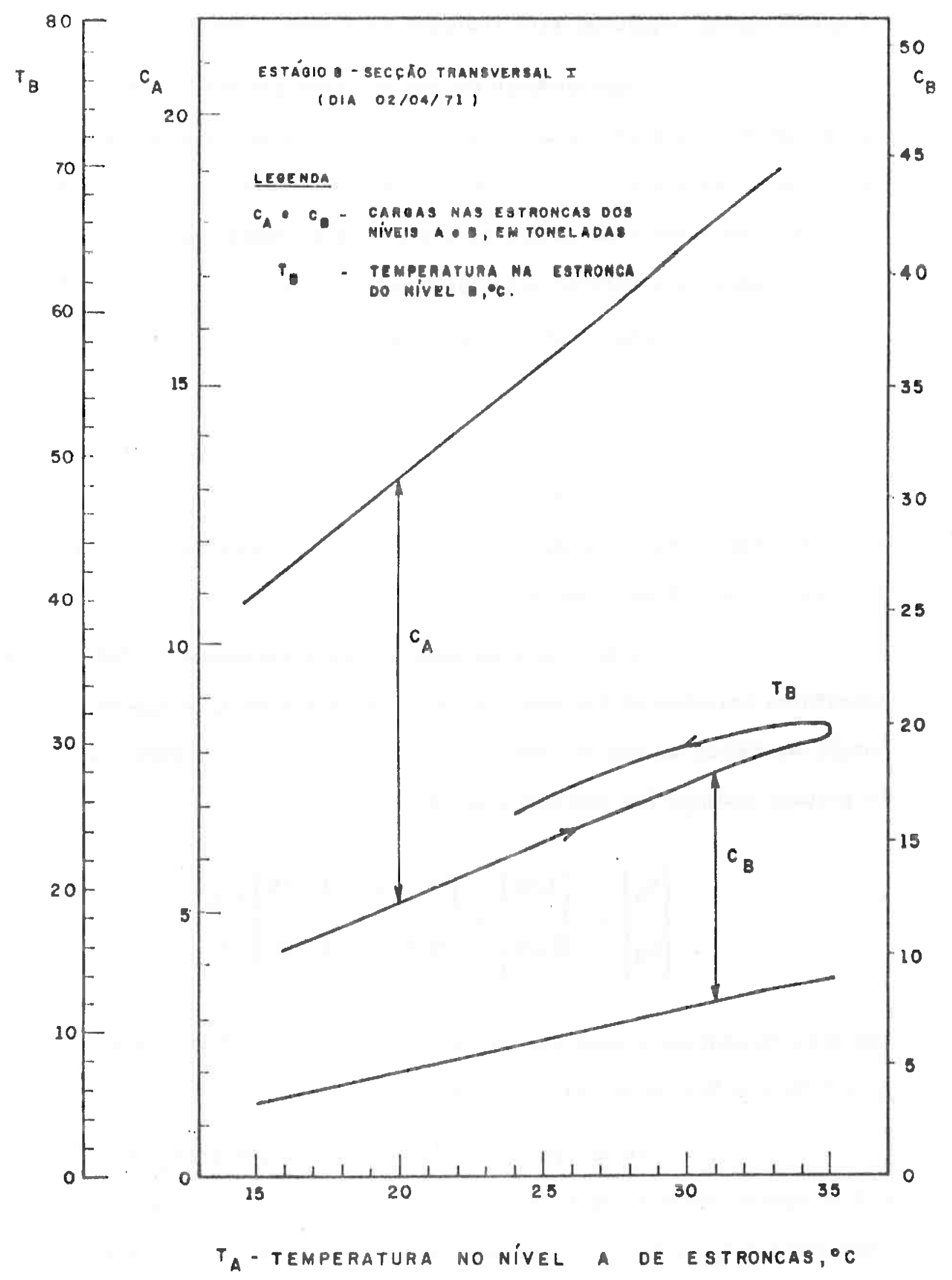

FIGURA III -6: ILUSTRAÇAO GRÁFICA DA AFINIDADE EXISTENTE ENTRE AS CURVAS QUE CORRELACIONAM $T_{B}$ COM TA E $C_{B}$ COM $C_{A}$ - SECCÃO EXPERIMENTAL 1 
ou graficamente, conforme estä indicado na figura III-6.

Depreende-se do que fol di to que a forma das curvas carga-temperatura é afim à da curva que relaclona as temperaturas dos dois niveis. Esta ültima não ë necessariamente linear, Isto $\ddot{e}$, os seus pI cos podem não serem simultâneos e, ademals, a estronca superior pode aque cer mals depressa e esfrlar mals lentamente do que a inferlor, o que imprime um carāter apenas aparente de histerese nas relaçōes de carga-temperatura.

Com relação ao estăgio 9 da Seç̧ão Experimental I, os resultados indicados na figura III-7 se justificam porque a laje de concreto da base do túnel também sofre os efeitos da temperatura, dilatandose e contraindo-se ao longo do tempo.

E de interesse mostrar que a expressão (III-4) se transforma bastante se for admitida a curva interrompida mista de $\mathrm{T}_{A}$ em função do tempo, em vez da curva contínua, indicadas na figura III-2. Esta pequena mudança faz com que a correlação seja:

$$
\left\{\begin{array}{l}
C_{A} \\
C_{B}
\end{array}\right\}=\left\{\begin{array}{l}
3,95 \\
2,22
\end{array}\right\}+\left[\begin{array}{cc}
0,599 & -0,415 \\
-0,415 & 0,772
\end{array}\right]\left(\begin{array}{c}
T_{A} \\
T_{B}
\end{array}\right\}
$$

com desvios padrões e coeficientes de correlação de 0,52 t e $93 \%$ (nível A) e 0,59 t e $96 \%$ (nivel B), respectivamente.

Se se tomar para as cargas e temperaturas dos niveis $A$ e B as mëdias dos correspondentes valores observados nas três secções tronsversals 1, II e 111 da Secção Experimental 1, aquela correlação passa a ser:

$$
\left(\begin{array}{l}
C_{A} \\
C_{B}
\end{array}\right)=\left(\begin{array}{l}
3,55 \\
2,07
\end{array}\right)+\left[\begin{array}{cc}
0,318 & -0,114 \\
-0,114 & 0,446
\end{array}\right]\left(\begin{array}{c}
T_{A} \\
T_{B}
\end{array}\right)
$$




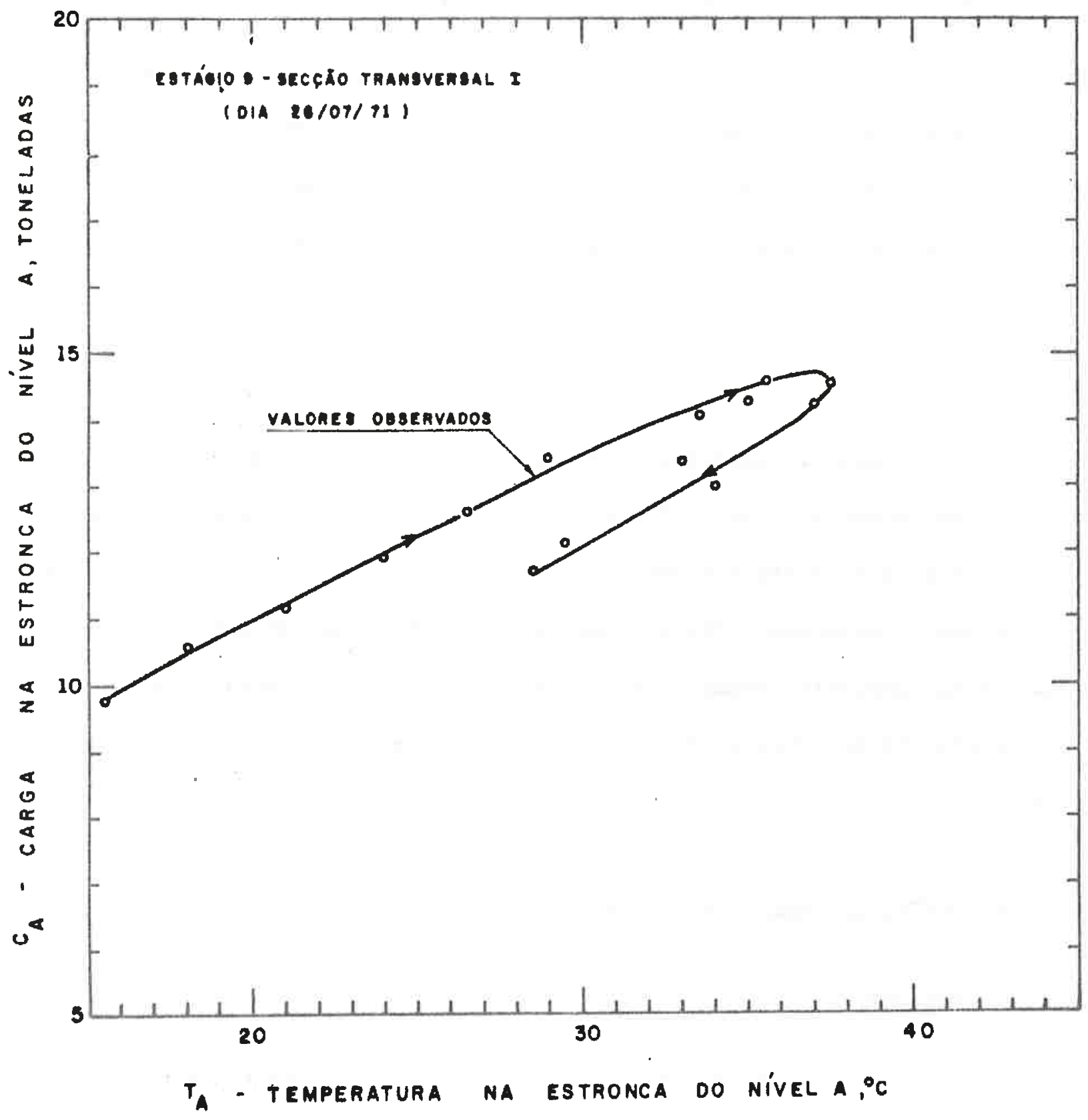

FIGURA III -7: CARGA EM FUNÇĀO DA TEMPERATURA SECCÃO EXPERIMENTAL 1 
com desvios padrões e coeficientes de correlação de 0,52 t e 92 \% (nível A) e 0,68 t e $94 \%$ (nivel B). A figura III-5 permite confrontar os resul tados assim calculados com aqueles observados.

A grande variação que se constata nos coeficientes da matriz dos gradientes bāsicos, segundos membros das expressões (III-4) e (III-5), não é acidental. E isto porque $T_{A}$ e $T_{B}$ não são variäveis indepen dentes, is to è, atravēs de uma regressão pode-se estabelecer a equação:

$$
T_{B}=3,63+0,82 T_{A}
$$

onde $T_{A}$ e $T_{B}$ são as temperaturas mëdias nos niveis $A$ e $B$ de estroncamento; o desvio padrão é de $1,19^{\circ} \mathrm{C}$ e o coeficiente de correlação da ordem de $97 \%$. Este valor è próximo dos $100 \%$, dependência total, o que faz com que - sistema de equações lineares, que permite determinar os coeficientes da Matriz U, apresente instabilidade numérica ou, numa palavra, seja mal con dicionado. No Apêndice $C$ encontra-se uma anālise mais profunda desta ques tão.

\section{GRADIENTES DE CARGA-TEMPERATURA}

\subsection{Conceituação}

Na sequēncia das investigações, pretendeu-se estabele cer, atravēs das regressões fundamentadas no Apêndice $C$, os coeficientes da matriz U da expressão (III-1), para as värias secções instrumentadas. Cedo verificou-se a impossibilidade deste projeto, pelas razões expostas acima.

Em trabalho jä citado, Sousa Pinto, Massad e Martins (1972) havlam introduzido o concel to de gradiente de carga-temperatura, ou simplesmente gradiente, cuja determinação é simples e precisa, e permite 
atingir os objetivos fixados na Introdução desta Investigação.

Retomando a vala com $\underline{n}$ níveis de escoramento, o acrës cimo de força $\Delta \varepsilon_{i}$ que a l-ëslma estronca exerce contra a parede, dividido pelo correspondente acrëscimo de temperatura $\Delta T_{1} \dot{e}$, por definição, o gradiente de carga-temperatura ou gradiente; is to é,

$$
G_{1}=\frac{\Delta C_{i}}{\Delta T_{i}} \quad(i=1,2, \ldots n)
$$

Se for introduzida a matriz quadrada G com todos os termos nulos, menos os da diagonal principal, que são tomados iguais aos gradientes $G_{i}$, is to $\vec{e}$ :

$$
\begin{aligned}
G=\left\|g_{i j}\right\| \text { com } g_{i j} & =G_{i} \\
\text { e } g_{i j} & =0, \text { para } \neq j
\end{aligned}
$$

éntão, pode-se escrever,

$$
C=\mathbf{G} \cdot \mathbf{T}
$$

Substi tuindo-se esta expressão em $(111-1)$ vem:

ou,

$$
\begin{aligned}
& G \cdot T=U \cdot T \\
& (U-G) \cdot T=0
\end{aligned}
$$

o que implica, obrigatorlamente, na anulação do determinante da matriz (U - G). Para dols niveis de estroncas tem-se:

$$
\left|\begin{array}{ll}
u_{11}-G_{1} & u_{12} \\
u_{21} & u_{22}-G_{2}
\end{array}\right|=0
$$


ou,

$$
\left(G_{1}-u_{11}\right) \cdot\left(G_{2}-u_{22}\right)=\left(u_{21}\right)^{2}=\left(u_{12}\right)^{2}
$$

relação hiperbōlica entre os gradientes, que tinha sido obtida anteriormente em trabalho jä cltado (Massad et ar, 1974-a).

Se os gradientes fossem todos iguais entre si,.

$$
G_{i}=\lambda
$$

para qualquer $i_{i}$, então a expressão (III-9a) se transformaria em:

$$
(U-\lambda I) T=0
$$

onde 1 è a matriz identidade. Matematicamente, como se sabe, $\lambda$ è denomina do autovalor da matriz $U$, e os correspondentes vetores $T$ dos incrementos de temperatura, seus autovetores.

No Apêndice $D$ são enunciadas algumas propriedades da Matriz $U$ dos Gradientes Bāsicos, que interessam ao desenvolvimento desta Investigação. A mais importante delas è que o menor dos autovalores de U é o único a estar associado a um autovetor com todos os termos positivos. A qualquer outro autovalor corresponde um autovetor com pelo menos um dos $\Delta T_{i}$ negativos, o que é incomum, pela pröpria definição destes incrementos relativos de temperatura.

3.2. Valores Obsemados 'dos Gradientes nas Seccões Experimentais do Metrö de são PauZo.

A tabela III-1 mostra valores médios e māximos dos gradientes observados, relativos às diversas Secções Experimentais, que diferem entre si pelo menos num dos seguintes itens:

a) rigidez da parede de escoramento; 


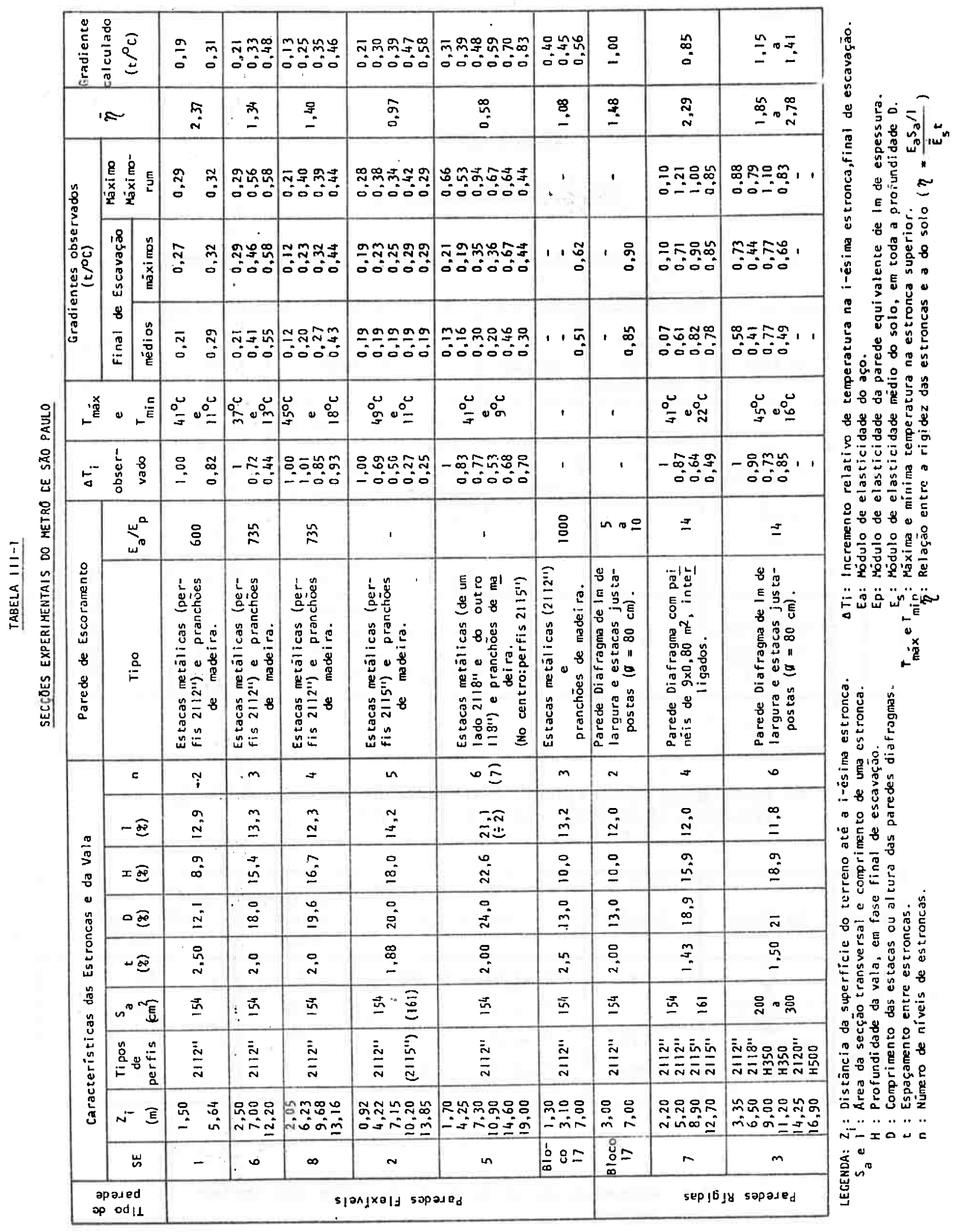




\section{TABELA $|1|-2 a$}

SECCAO EXPERIMENTAL NO I

a) Correlaçōes entre valores observados de Carga - Temperatura.

\begin{tabular}{|c|c|c|c|c|c|c|}
\hline Fase & Estägio & $\begin{array}{c}\text { Nivel } \\
\text { da } \\
\text { es tronca }\end{array}$ & Secção & Correlação & $\begin{array}{l}\text { Desvio } \\
\text { Padräo } \\
\text { (t). }\end{array}$ & $\begin{array}{c}\text { Correl ação do } \\
\text { correlaçāo } \\
\text { (屯) }\end{array}$ \\
\hline \multirow{2}{*}{ 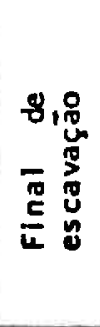 } & \multirow{2}{*}{$\begin{array}{c}8 \\
11 / 03 / 71 \\
a \\
20 / 05 / 7.1 \\
(45)^{\star}\end{array}$} & A & $\begin{array}{c}1 \\
11 \\
111 \\
\text { Média }\end{array}$ & $\begin{array}{l}C=3,73+0,206 T \\
C=4,08+0,163 T \\
C=2,23+0,271 T \\
C=3,42+0,210 T\end{array}$ & $\begin{array}{l}0,45 \\
0,48 \\
0,76 \\
0,51\end{array}$ & $\begin{array}{l}90 \\
91 \\
82 \\
90\end{array}$ \\
\hline & & B & $\begin{array}{c}1 \\
11 \\
111 \\
\text { Média } \\
\end{array}$ & $\begin{array}{l}C=3,33+0,267 T \\
C=4,40+0,320 T \\
C=2,25+0,298 T \\
C=3,35+0,294 T\end{array}$ & $\begin{array}{l}0,95 \\
0,98 \\
0,72 \\
0,79 \\
\end{array}$ & $\begin{array}{l}77 \\
82 \\
89 \\
86 \\
\end{array}$ \\
\hline 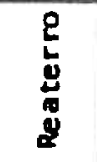 & $\begin{array}{c}99 \\
17 / 06 / 71 \mathrm{a} \\
18 / 10 / 71 \\
(152)^{\star}\end{array}$ & A & $\begin{array}{c}1 \\
11 \\
111 \\
\text { Média }\end{array}$ & $\begin{array}{l}C=5,14+0,264 T \\
C=5,15+0,268 T \\
C=5,16+0,291 T \\
C=5,15+0,269 T\end{array}$ & $\begin{array}{l}0,94 \\
1,13 \\
1,35 \\
1,05\end{array}$ & $\begin{array}{l}86 \\
85 \\
82 \\
84\end{array}$ \\
\hline
\end{tabular}

b) Correl eçōes entre valores observados da temperatura da es tronca do nivel $B\left(T_{B}\right)$ com a do nivel $A\left(T_{A}\right)$.

\begin{tabular}{|c|c|c|c|c|c|}
\hline Fase & Estägio & Seç̧äo & Correl açāo & $\begin{array}{l}\text { Des vio } \\
\text { Padrão } \\
\text { (OC) }\end{array}$ & $\begin{array}{l}\text { Coeficiente de } \\
\infty \mathrm{rrel} \text { açio } \\
(\xi)\end{array}$ \\
\hline 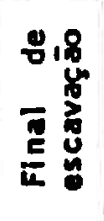 & $\begin{array}{c}8 \\
11 / 03 / 71 \\
8 \\
20 / 05 / 71 \\
(45)^{*}\end{array}$ & $\begin{array}{c}1 \\
11 \\
111 \\
\text { Média }\end{array}$ & $\begin{array}{l}T_{B}=2,44+0,888 T_{A} \\
T_{B}=5,34+0,745 T_{A} \\
T_{B}-4,81+0,768 T_{A} \\
T_{B}=3,72+0,820 T_{A}\end{array}$ & $\begin{array}{l}2,43 \\
1,49 \\
1,83 \\
0,47\end{array}$ & $\begin{array}{l}89 \\
94 \\
92 \\
95\end{array}$ \\
\hline
\end{tabular}

* Mümero de pares de valores usados nas correIeçōes. 
TABELA $111-26$

SECCAO EXPERIMENTAL N: 6

a) Correlaçōes entre valores observados de Carga (C) e Temperatura ( $T$ )

\begin{tabular}{|c|c|c|c|c|c|c|}
\hline Fase & Estägio & $\begin{array}{c}\text { Nivel } \\
\text { da } \\
\text { estronca }\end{array}$ & $\begin{array}{l}\text { Secçāo } \\
\text { Trans- } \\
\text { versal }\end{array}$ & Correlação & $\begin{array}{l}\text { Desvio } \\
\text { padräo } \\
(t)\end{array}$ & $\begin{array}{l}\text { Coeficiente } \\
\text { de correlaçăo } \\
(\xi)\end{array}$ \\
\hline \multirow{3}{*}{ 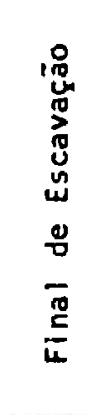 } & \multirow{3}{*}{$\frac{8}{(104)}$} & A & $\begin{array}{c}1 \\
\text { Média }\end{array}$ & $\begin{array}{l}c=4,18+0,121 \mathrm{~T} \\
\mathrm{C}=3,33+0,283 \mathrm{~T} \\
\mathrm{C}=3,77+0,201 \mathrm{~T}\end{array}$ & $\begin{array}{l}0,28 \\
0,25 \\
0,22\end{array}$ & $\begin{array}{l}89 \\
98 \\
97\end{array}$ \\
\hline & & $B$ & $\begin{array}{c}1 \\
\text { Média }\end{array}$ & $\begin{array}{l}c=0,44+0,467 \mathrm{~T} \\
c=6,36+0,363 \mathrm{~T} \\
c=3,40+0,415 \mathrm{~T}\end{array}$ & $\begin{array}{l}0,47 \\
0,63 \\
0,51\end{array}$ & $\begin{array}{l}95 \\
86 \\
92\end{array}$ \\
\hline & & C & $\begin{array}{c}\text { I } \\
\text { Média }\end{array}$ & $\begin{array}{l}c=-8,17+0,511 \mathrm{~T} \\
c=-6,78+0,575 \mathrm{~T} \\
c=-7,49+0,543 \mathrm{~T}\end{array}$ & $\begin{array}{l}0,60 \\
0,45 \\
0,42\end{array}$ & $\begin{array}{l}87 \\
94 \\
94\end{array}$ \\
\hline \multirow{2}{*}{ 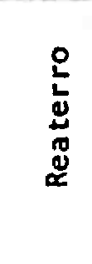 } & \multirow{2}{*}{$\stackrel{9}{(71) *}$} & A & $\begin{array}{c}1 \\
\text { Média }\end{array}$ & $\begin{array}{l}c=2,48+0,211 T \\
C=4,48+0,255 T \\
C=3,47+0,233 T\end{array}$ & $\begin{array}{l}0,61 \\
0,52 \\
0,47\end{array}$ & $\begin{array}{l}82 \\
90 \\
90\end{array}$ \\
\hline & & 8 & $\begin{array}{c}\text { I } \\
\text { Média }\end{array}$ & $\begin{array}{l}C=0,50+0,511 T \\
C=3,55+0,564 T \\
C=2,01+0,538 T\end{array}$ & $\begin{array}{l}1,04 \\
0,93 \\
0,87\end{array}$ & $\begin{array}{l}87 \\
91 \\
91\end{array}$ \\
\hline
\end{tabular}

b) Correlaçōes entre valores observados da Temperatura das estroncas dos niveis $B\left(T_{B}\right)=C\left(T_{C}\right)$ com a do nivel $A\left(T_{A}\right)$.

\begin{tabular}{|c|c|c|c|c|c|}
\hline Fase & Estäglo & $\begin{array}{l}\text { Seç̧äo } \\
\text { Trans- } \\
\text { versal }\end{array}$ & Correlaçāo & $\begin{array}{l}\text { Desvio } \\
\text { Padrão } \\
\text { (OC) }\end{array}$ & $\begin{array}{c}\text { Coeficiente } \\
\text { de correlação } \\
(\xi)\end{array}$ \\
\hline \multirow{2}{*}{ 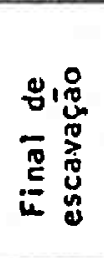 } & \multirow{2}{*}{$\begin{array}{c}8 \\
(104) *\end{array}$} & $\begin{array}{c}1 \\
\text { II } \\
\text { Média }\end{array}$ & $\begin{array}{l}T_{B}=4,64+0,712 T_{A} \\
T_{B}=4,42+0,720 T_{A} \\
T_{B}=4,51+0,717 T_{A}^{A}\end{array}$ & $\begin{array}{l}1.19 \\
1,19 \\
1,19\end{array}$ & $\begin{array}{l}91 \\
91 \\
91\end{array}$ \\
\hline & & $\begin{array}{c}1 \\
11 \\
\text { Média }\end{array}$ & $\begin{array}{l}T_{C}=11,39+0,434 T_{A}^{A} \\
T_{C}=11,07+0,444 T_{A}^{A} \\
T_{C}=11,20+0,440 T_{A}^{A}\end{array}$ & $\begin{array}{l}0,92 \\
0,91 \\
0,90\end{array}$ & $\begin{array}{l}90 \\
90 \\
90\end{array}$ \\
\hline 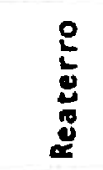 & $(71)^{*}$ & $\begin{array}{c}1 \\
\text { II } \\
\text { Média }\end{array}$ & $\begin{array}{l}T_{B}=2,97+0,786 T_{A} \\
T_{B}^{B}=2,95+0,786 T_{A}^{A} \\
T_{B}^{A}=2,96+0,786 T_{A}\end{array}$ & $\begin{array}{l}1,47 \\
1,49 \\
1,48\end{array}$ & $\begin{array}{l}91 \\
91 \\
91\end{array}$ \\
\hline
\end{tabular}

* N: de pares de valores usados nas correlaçōes. 
TABELA $\quad 111-2 C$

SECCAO EXPERIMENTAL 2

a) Correlaçōes entre valores observados de Carga e Temperatura

\begin{tabular}{|c|c|c|c|c|c|c|}
\hline Fase & Estäglo & $\begin{array}{c}\text { Nrvel } \\
\text { da } \\
\text { est ronca }\end{array}$ & Secção & Correl açāo & $\begin{array}{l}\text { Desulo } \\
\text { Padrāo } \\
\text { (t) }\end{array}$ & $\begin{array}{l}\text { Coeficlente } \\
\text { de correlação } \\
(\xi)\end{array}$ \\
\hline \multirow{5}{*}{ 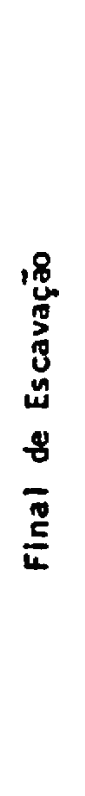 } & \multirow{5}{*}{$\begin{array}{c}6 \\
\mathrm{De} \\
27 / 07 / 72 \\
\mathrm{a} \\
03 / 08 / 72 \\
(25) *\end{array}$} & A & $\begin{array}{c}1 \\
11 \\
111 \\
\text { Mëdia }\end{array}$ & $\begin{array}{r}C=2,01+0,116 T \\
C=0,20+0,188 T \\
C=1,10+0,152 T\end{array}$ & $\begin{array}{l}0.61 \\
0,49 \\
0.60 \\
0.60\end{array}$ & $\begin{array}{l}81 \\
94 \\
- \\
87\end{array}$ \\
\hline & & 8 & $\begin{array}{c}1 \\
11 \\
111 \\
\text { Mèdia }\end{array}$ & $\begin{array}{l}C=3,76+0,216 T \\
C=5,44+0,106 T \\
C=1,09+0,231 T \\
C=3,44+0,185 T\end{array}$ & $\begin{array}{l}0,91 \\
0,90 \\
1,16 \\
1,45\end{array}$ & $\begin{array}{l}73 \\
51 \\
67 \\
53\end{array}$ \\
\hline & & C & $\begin{array}{c}1 \\
11 \\
111 \\
\text { Média }\end{array}$ & $\begin{array}{l}C=9,10+0,159 T \\
C=10,48+0,075 T \\
C=7,78+0,254 T \\
C=9,12+0,163 T\end{array}$ & $\begin{array}{l}0,78 \\
0,80 \\
0,93 \\
0,85\end{array}$ & $\begin{array}{l}59 \\
45 \\
70 \\
60\end{array}$ \\
\hline & & D & $\begin{array}{c}1 \\
11 \\
111 \\
\text { Média }\end{array}$ & $\begin{array}{l}c=7,06+0,191 T \\
C=7,25+0,096 T \\
c=3,53+0,293 T \\
C=5,95+0,193 T\end{array}$ & $\begin{array}{l}0,77 \\
0,80 \\
0,92 \\
1,17\end{array}$ & $\begin{array}{l}64 \\
45 \\
72 \\
53 \\
\end{array}$ \\
\hline & & $\varepsilon$ & $\begin{array}{c}1 \\
11 \\
111 \\
\text { Mëdia }\end{array}$ & $\begin{array}{l}C=9,59+0,288 T \\
C=9,83+0,241 \mathrm{~T} \\
C=11,81+0,160 \mathrm{~T} \\
C=10,41+0,230 \mathrm{~T}\end{array}$ & $\begin{array}{l}0,79 \\
0,93 \\
0,85 \\
0,89\end{array}$ & $\begin{array}{l}77 \\
65 \\
62 \\
71\end{array}$ \\
\hline
\end{tabular}

b) Corfelações entre valores observados da temperatura das es troncas dos niveis $B\left(T_{B}\right), C\left(T_{C}\right), D\left(T_{D}\right)$ e $E\left(T_{E}\right)$ com a do nível $A\left(T_{A}\right)$.

\begin{tabular}{|c|c|c|c|c|}
\hline Fase & Estägio & Correl açāo & $\begin{array}{l}\text { Des vioo } \\
\text { Padrāo } \\
\text { (oc) }\end{array}$ & $\begin{array}{c}\text { Coeficlente } \\
\text { de } \\
\text { Correlaçäo ( })\end{array}$ \\
\hline 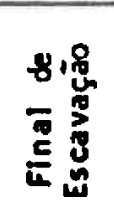 & $\begin{array}{c}6 \\
\text { De } \\
27 / 07 / 72 \\
a \\
03 / 08 / 72\end{array}$ & $\begin{array}{l}T_{B}=1,82+0,691 T_{A} \\
T_{C}=5,12+0,502 T_{A} \\
T_{D}=9,53+0,270 T_{A} \\
T_{E}=9,41+0,249 T_{A}\end{array}$ & $\begin{array}{l}2,31 \\
2,56 \\
2,30 \\
1,96\end{array}$ & $\begin{array}{l}92 \\
83 \\
72 \\
74\end{array}$ \\
\hline
\end{tabular}

* - Nümero de pares de valores usados nas correl eçöes. 
b) nümero de níveis de estroncas;

c) espaçamentos vertical e horizontal entre estroncas;

d) profundidade e largura da vala; e

e) tipo de solo escorado.

Antes de tecer alguns comentärios sobre o seu conteüdo, convēm que se detenha na sua gênese. A título de lilustração, as tabeZas III-2a, III-2b e III-2c, mostram correlações obtidas para algumas das Secções Experimentais, em värios estāgios de escavação, tanto entre cargas e temperaturas observadas na mesma estronca, quanto entre as temperaturas dos outros níveis e a do nível A. São dadas tambëm indicaçōes quanto ao desvio-padrão, coeficiente de correlação e tamanho do universo. As tabelas III-3 a III-6 reunem informações mais completas sobre as Secções Experimentais 1, 6, 8 e 2, respectivamente, que serão utilizadas no decorrer desta Investigação. Da anālise destes resultados pode-se concluir que:

a) existe um efeito tridimensional numa mesma Secção Experimental, que se reflete em diferentes valores dos gradientes num mesmo nivel de estron camento, em secções transversais diferentes; e

b) os desvios-padrão são relativamente baixos, situando-se em geral na faixa de 0,2 a 1 tonelada, para as correlações carga-temperatura, e 1 a $2^{\circ} \mathrm{C}$ para as correlaçōes entre as temperaturas dos diversos níveís com a do 19 nivel de estroncas.

Possiveis explicações para as dispersões encontradas são a não simultaneidade das medições das cargas e temperaturas, relativas às diversas estroncas; e o aquecimento desuniforme das mesmas, em fun ção do ângulo de incidêncía dos raios solares, o que torna problemática a definição das suas temperaturas mëdias. 0 Apêndice $A$ apresenta uma discussão desta queștão, com base em dados experimentais. 

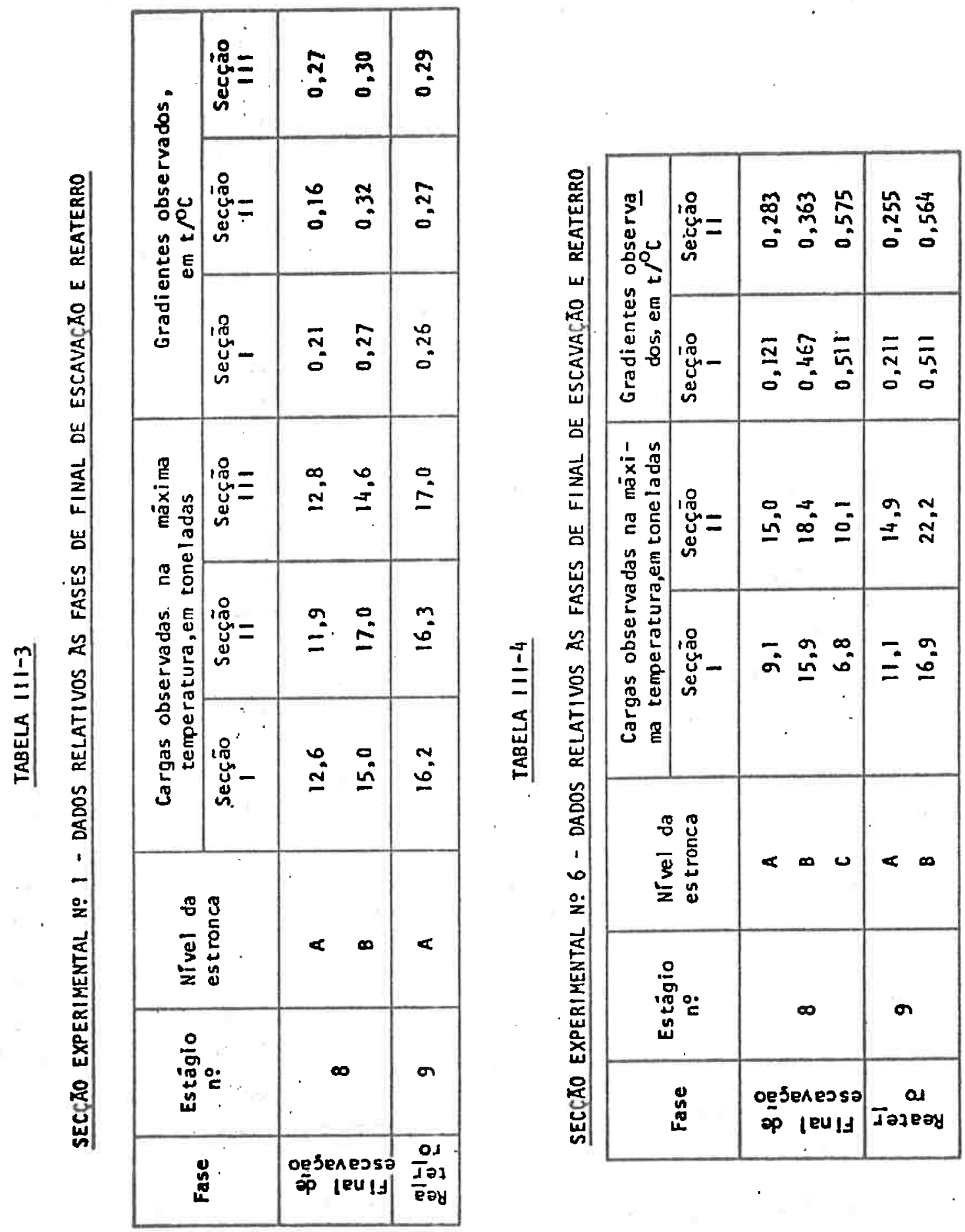


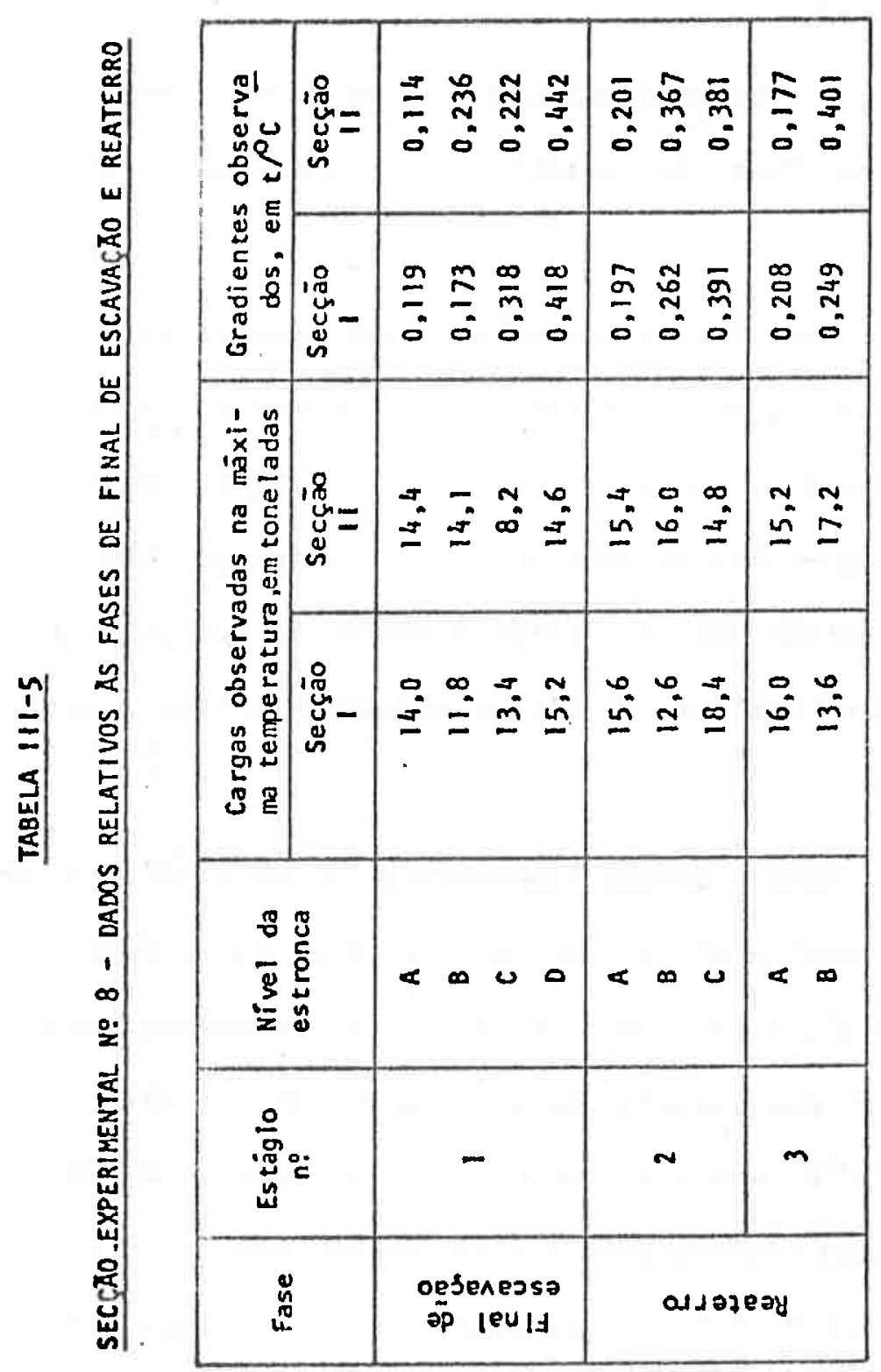


0 exame dos resultados apresentados na tabela III-1

mostra que:

a) para todas as Secções Experimentais, com exceção da de $n$ ? 2, os gradientes médios observados crescem com a profundidade em que as estroncas estão instaladas; e

b) para uma mesma vala, os gradientes mëdlos observados numa mesma estron ca são maiores nas fases de reaterro, comparados com a fase de final de escavação.

Esta ültima constatação è consequência, qualitativamente, do aumento da rigidez do sistema de escoramento, com o avançar do reaterro. E interessante mencionar que os resultados das medições em fren te ao Paläcio Monroe no Rio de Janeiro, apresentados por Rémy et al (1974), mostraram uma diminuição dos gradientes à medida em que as escavações prọ grediam. Quanto maior a altura da parede engastada (ficha), maior a rigidez do escoramento.

Para a Seç̧ão Experimental 2, os gradientes de cargatemperatura, observados nas trēs seç̧ões transversals em final de escavação, diferem entre sí, para o mesmo nivel de estroncamento, como se pode ver na tabela III-6; por exemplo, para o nivel B de estroncas obteve-se 0,$22 ; 0,11$ e $0,23 \mathrm{t} /{ }^{\circ} \mathrm{C}$. Ademais, como os espaçamentos em planta entre as estroncas das secções transversais I e II, de um lado, e II e 111 , de outro, eram de $1,74 \mathrm{~m}$ e $2,16 \mathrm{~m}$, respectivamente (vide figura $B-9$ ), resolveu-se trabalhar com os gradientes mëdios por nível de estroncamento. Assim, obteve-se 0,$15 ; 0,19 ; 0,16 ; 0,19$ e $0,23 \mathrm{t} /{ }^{\circ} \mathrm{C}$, respectivamente, para os niveis $A, B, C, D$ e $E$, valores estes mul to pröximos de $0,19 t /{ }^{\circ} \mathrm{C}$, que fol adotado para todas as estroncas, conforme tabeza III- 1 .

0 que importa frisar è que os gradientes são função não somente da rigidez, tanto do solo, da parede de escoramento, quanto 


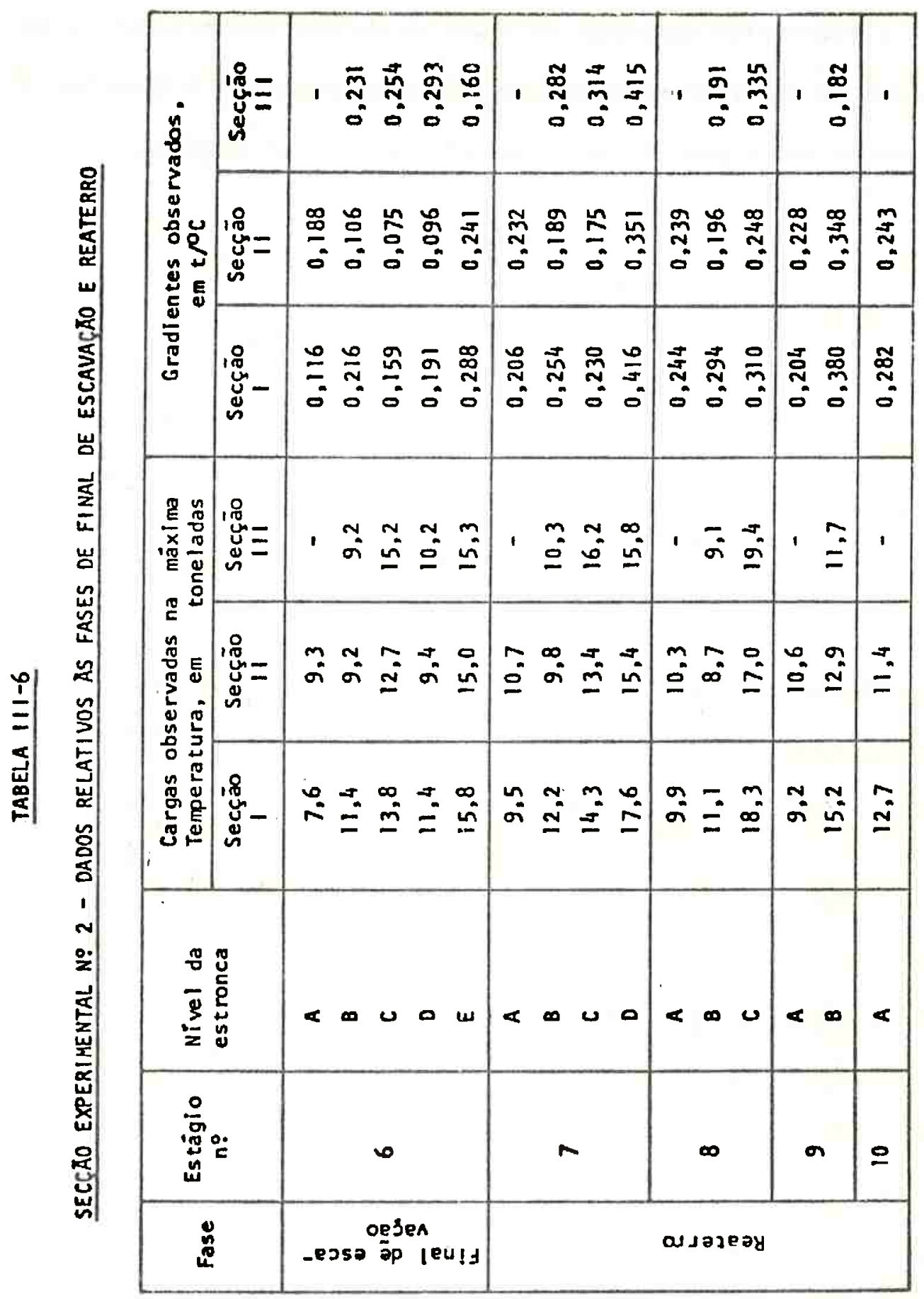


das estroncas, como também dos incrementos de temperatura, como mostra a expressão (III-9). Assim, pode-se afirmar que se a vala da Seç̧ão Experimental 2 tivesse sido escavada no local da Seção Experimental 8, por exem plo, as cargas nas es troncas teriam sido completamente diferentes. E oque se val provar com o auxilio de um modelo matemätico simples. 
CONSTRUÇÃO DE UM MODELO MATEMATICO SIMPLES-I DENTIFICAÇAOO DOS CON DICIONANTES MAIS SIGNIFICATIVOS DO EFEITO DA TEMPERATURA

\begin{abstract}
A fim de compreender melhor a influência dos diversos fatores na problemātica da resposta carga-temperatura, um modelo matemático relativamente simples, que faz recorrêncla ao Método dos Elemen tos Finitos, foi construido e publicado em três artigos, de autoria de Massad, Bon, Muller e Benvenuto, citados anteriormente.
\end{abstract}

1. HIPOTESES SIMPLIFICADORAS

As hipōteses adotadas e incorporadas ao modelo foram:

a) meios isotrópicos e linearmente elásticos, como foi justificado no Capitulo III, sem movimentos relativos no contato entre a parede de escoramento e o solo, pois as estruturas de arrimo já suportavam o empu xo de terra;

b) paredes de escoramento, tanto as flexiveis quanto as rigldas, simuladas atravēs de paredes continuas equivalentes, isto é, com mesma rigl dez à flexão; uma discussão sobre o assunto encontra-se no ítem 3 do Apêndice $E_{;}$

c) estroncas assimiladas a elementos de barra, articuladas nas extremida des e solicitadas apenas por forças axiais de compressão ou tração;

d) vigas de distribuição, dispostas horlzontalmente entre as estroncas e as paredes de escoramento, com rigidez Infinita; e

e) problema bidimensional, Isto è, estado plano de deformação, sendo nu- 
las as deformaçöes na direção do eixo da vala.

0 pressuposto das estroncas trabalharem como barras articuladas e solicitadas por forças axiais basela-se no fato das car gas realmente instaladas serem uma fração da carga admissivel, mesmo para os perfis de $2112^{\prime \prime}$, os mais esbel tos dos que foram empregados, graças à existêncla de barras de travejamento ao longo do eixo da vala, artículando os centros das estroncas, como está ilustrado na planta de escavação da figura B-1. Assim, por exemplo, pequenas excentrlclidades de cēlulas de carga poderiam provocar flexão, composta com a compreensão das escoras, mas de somenos importâncla à presente Investigação.

A questão da rigidea das vigas de distribuição encontrou subsídios em problema anālogo referente ao comportamento de triIhos submetidos a carregamentos estáticos. Conforme se mostra no item 1 do Apêndice $E$; quando o espaçamento em planta entre estroncas não supera a 2,5 m, a carga linearmente distribuida pelas vigas desvia-se do seu va lor médio de $\pm 10 \%$. Em outras palavras, as vigas de distribulção nestas condiçōes podem ser consideradas como infinitamente rígidas. Nesta Inves tigação elas são às vezes designadas por vigas de rigidez.

Finalmente, não se levou em conta o efeito da tem peratura na parede de escoramento que, se for rigida, pode introduzir acrēscimos de carga nas estroncas de até $16 \%$ dos valores que surgiriam sō por efeit to da sua dilatação tërmica. 0 Apêndice $E$ (ïtem 2) mostra este fato e mais, que os incrementos desta origem, para paredes continuas flexiveis, são despreziveis. Assim, em primeira aproximação e por simpli cidade, ignorou-se este efeito no modelo matemätico; no Copituzo VI mostrar-se-à como incorporä-lo, de uma forma simples e indireta, para as pa redes rigidas. 
2. FORMULAÇAOO MATEMATICA DO PROBLEMA ATRAVES DO METODO DOS ELEMENTOS FINITOS

A formulação matemática do problema assim colocado foi feita atravēs do Mētodo dos Elementos Finitos, para uma vala escorada com n niveis de estroncas.

O efeito da variação da temperatura $\left(\Delta T_{i}\right)$ na $i$-ésima estronca pode ser levado em conta imaginando-se inicialmente que as suas extremidades estão impedidas, implicando na sua sollicitação atravēs da força norma l:

$$
P_{i}=E_{a} S_{a}^{\alpha} \cdot \Delta T_{i}
$$

onde $E_{a}, S_{a} e x$ são, respectivamente, o mödulo de elasticidade, a ārea da secção transversal, e o coeficiente de dilatação térmica das estroncas metälicas. A segulir, llbera-se as extremidades da estronca, do que resulta a aplicação da força $P_{i}$ nos pontos em que ela toca as paredes de escoramento. Parte desta força $x_{i}$ é absorvida pela estronca; e o restante $\left(p_{i}-X_{i}\right) / t \dot{e}$ aplicado ao conjunto solo-paredes de escoramento, sendo $t$ - espaçamento entre estroncas, em planta; lembra-se aqui que as vigas de distribuição têm, por hipótese, rigidez infinita.

A aplicação do principio dos trabalhos virtuais ao conjunto solo-paredes de escoramento, jä discretizado em elementos fínitos, permite escrever:

$$
S^{\prime} \cdot \sigma \cdot d V=\frac{P-X}{t}
$$

onde $B$ è a matriz que relaciona o vetor deformação $\varepsilon$ de um elemento com - vetor dos deslocamentos nodais $\delta^{\mathrm{e}}$; isto é: 


$$
\varepsilon=B \cdot \delta^{\mathbf{e}} .
$$

$\sigma$ è o vetor tensão de un elemento; e $\frac{P-X}{t}$ è o vetor das forças aplica das.

A matriz B è função do tipo de elemento finito usado e sua obtenção, para o quadrilātero e o triângulo, pode ser encontrada, entre outros, no livro de Zienkiewicz (1972).

A Lei de Hooke generallizada permite que se escreva:

$$
\sigma=D \cdot \varepsilon
$$

onde $D$ é a matriz de elasticidade correspondente ao estado plano de deformação.

Substituindo-se a expressão $(I V-3)$ em $(I V-4)$ e a expressão resultante en $(I V-2)$, tem-se:

$$
\Sigma\left(B^{\prime} \cdot D \cdot B \cdot V \cdot \delta^{e}\right)=\frac{P-X}{t}
$$

onde o somatório se estende a todos os elementos finitos do conjunto solo-paredes continuas; $V$ è o volume de um elemento.

Reconhece-se no produto (B'.D.B.V) a matriz de rigidez do conjunto solo-parede de escoramento que, convenientemente expandida, permite substiltuir a ül tima expressão por esta outra:

$$
K \cdot \delta=\frac{p-x}{t}
$$

onde $\delta$ contém os deslocamentos de todos os pontos nodais, inclusive os das barras (estroncas). Alēm disso, esta matria de rigides pode ser 
decomposta em:

$$
K=E_{s} \cdot \bar{K}_{s}+E_{p} \cdot \bar{K}_{p}
$$

onde E designa o Mödulo de Young, os indices $\leq$ e $\mathrm{p}$, o solo e a parede continua, respectivamente.

Tem-se finalmente:

$$
\left(E_{s} \cdot t \cdot \bar{K}_{s}+E_{p} \cdot t \cdot \bar{K}_{p}\right) \cdot \delta=p-x
$$

Por outro lado, pode-se escrever para as barras:

$$
\frac{E_{a} S_{a}}{l} \cdot \bar{K}_{b} \cdot \delta=x
$$

onde $\delta$ refere-se aos deslocamentos de todos os pontos nodais, inclusive os do conjunto solo-paredes contínuas, e $\bar{K}_{b}$ è a matriz de rigidez das bar ras, a menos de um escalar, convenientemente expandida.

Eliminando $\mathrm{X}$ das expresoões $(I V-5)$ e $(I V-6)$ e, tendo-se em conta a expressão $(I V-1)$, chega-se, apōs algumas transformações, a:

$$
\left(\bar{K}_{s}+p \bar{K}_{p}+n \bar{K}_{b}\right) \cdot \delta=n \cdot \propto \cdot \ell \cdot T
$$

onde $\rho=E_{p} / E_{s} \vec{e}$ a relação entre os mödulos de elasticidade da parede con tínua e do solo; e $\eta=\left(E_{a} S_{a} / \ell E_{s} t\right) e \overline{~ a ~ r e l a c ̧ a ̃ o ~ e n t r e ~ a ~ r i g i d e z ~ d a s ~ e s-~}$ troncas e a rigidez do solo escorado, tomada como sendo $E_{s} t$.

Por conveniência, foi introduzido um terceiro parâmetro adimensional, definido por $\xi=E_{p} / E_{a}$, relação entre os módulos de elasticidade da parede contínua e das estroncas. 
o rotelro para o cálculo dos gradientes de cargatemperatura pode ser resumido da seguinte forma:

a) determina-se, atravēs do Método dos Elementos FInltos, os valores dos des locomentos $\delta_{\text {; }}$

b) atravès das expressöes (III-2) forma-se a matriz U dos gradientes bäaicos;

c) as forças $C$ que as estroncas exercem contra a parede de escoramento são calculadas através da expressão (III-1); e

d) por meio da expressão (III-7) tem-se os valores dos gradientes de car ga-temperatura procurados.

3. PARAMETROS ELASTICOS MAIS SIGNIFICATIVOS DO MODELO MATEMÁTICO

A importância do módulo de deformabilidade dos solos se destaca pela simples anālise da expressão $(I V-7)$, através do adi mensional $n$.

A influêncla do Coeficiente de Poisson não pode ser avaliada de uma forma direta, poís ele estä implíclto nas matrizes $\bar{K}_{\mathbf{s}}$ e $\bar{K}_{p}$. Para o concreto adotou-se um valor de 0,2 para este parâmetro. Quanto ao solo, a fim de verificar o grau de sua importância no cálculo dos gradientes, tomou-se o caso simples de vala escorada por parede diafragma (figura $[V-1)$, em que os adimensionais $p$ e $n$ valiam, respectivamente, 210 e 1,5 e o Coeficlente de Poisson $v$ foi tomado igual a 0,30 e 0,45 . Os resultados obtidos para os gradientes básicos foram:

$$
\begin{aligned}
\text { para } v=0,30 \quad U=\left[\begin{array}{rr}
812 & -699 \\
-699 & 1331
\end{array}\right] \\
\text { para } v=0,45 \quad U=\left[\begin{array}{rr}
880 & -701 \\
-701 & 1308
\end{array}\right]
\end{aligned}
$$




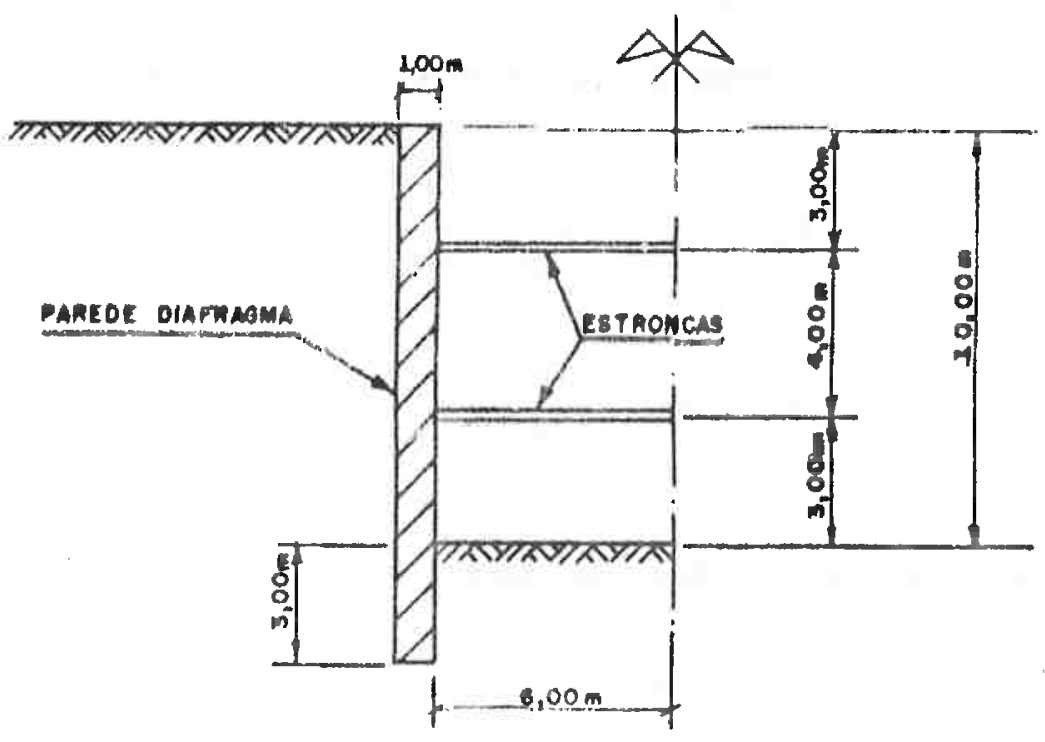

FIGURA IV-1: SECGĀO EXPERIMENTAL DO BLOCO 17 - PAREDES RIGIDAS.

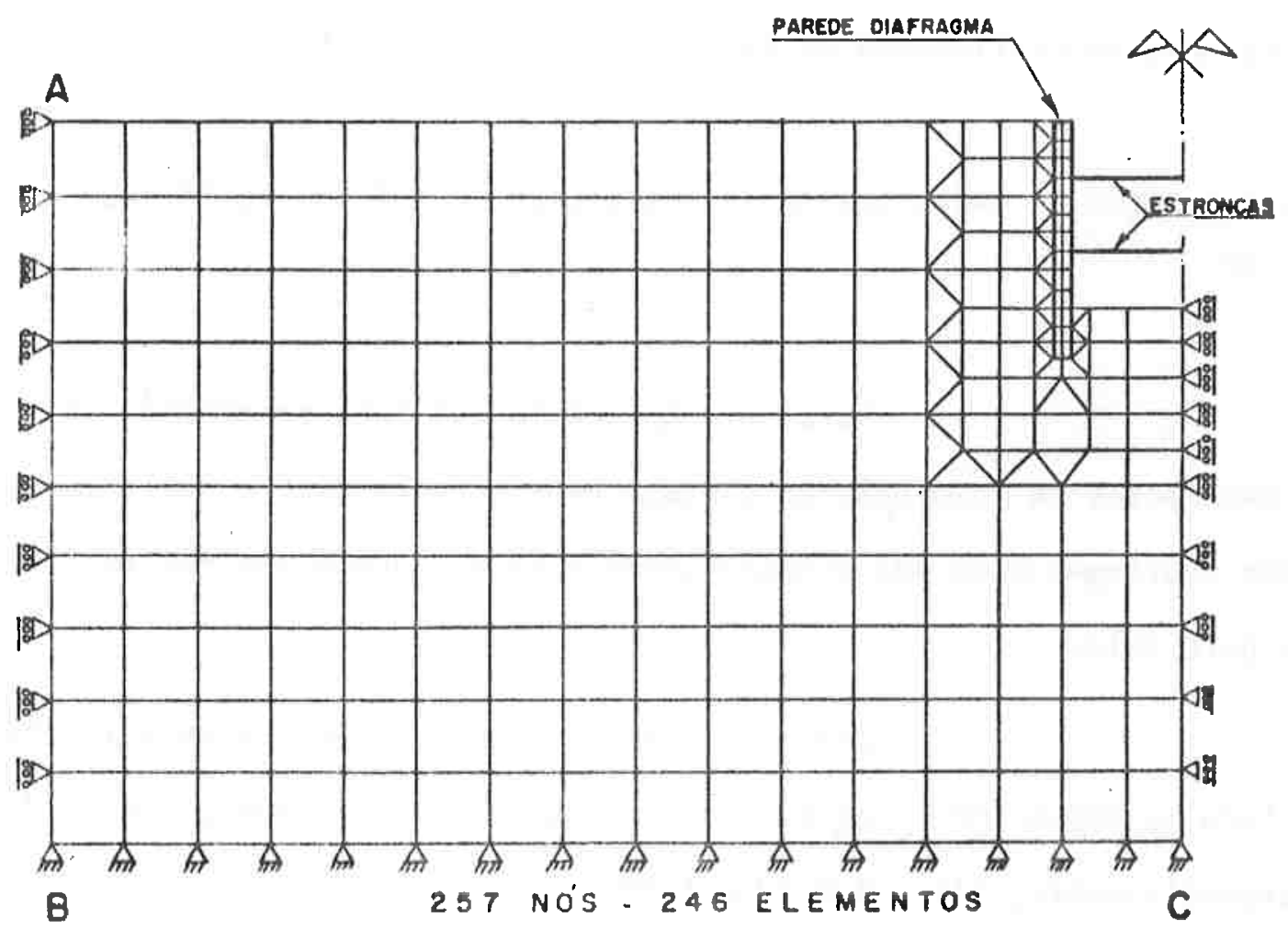

FIGUAA IY-2: DISCRETIZAGÄO DA SECGĀO DA VALAEM ELEMENTOS FINITOS PLANOS E DE BARRASSECGĀO EXPERIMENTAL DO BLOCO 17. PAREDES RIOIDAS. 
Usando-se a expressão (III-9), pode-se calcular os gradientes de carga-temperatura através das fórmulas:

$$
\begin{aligned}
& \tilde{u}_{1}=u_{11}+\frac{\Delta T_{2}}{\Delta T_{1}} \cdot u_{12} \\
& G_{2}=u_{22}+\frac{\Delta T_{1}}{\Delta T_{2}} \cdot u_{21}
\end{aligned}
$$

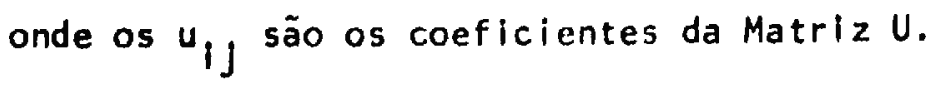

Como os coeficientes $u_{12}=u_{21}$ são pouco afetados pelo Coeficiente de Poisson, as variações nos gradlentes são consequêncla das que ocorrem em $u_{11}$ e $u_{22}$ que, para a estronca superior, são da or dem de $0,07 \mathrm{t} /{ }^{\circ} \mathrm{C}$ e para a inferior de $0,02 \mathrm{t} /{ }^{\circ} \mathrm{C}$. Em primeira aproximaçāo, estes valores são de pequena monta, razão pela qual não se deu muita importância ao Coeficlente de Poisson, no desenvolvimento deste estudo.

4. AVALIAÇAOO DE ERROS INERENTES A APLICAÇÃO DO METODO DE CALCULO ESCOLHIDO

Foram envidados esforços para se avaliar os erros provenientes da resolução do sistema de equaçōes, da discretização da parede dlafragma e da delimitação geomētrica do espaço semi-infinito, ocupa do pelo solo.

Conduziram-se estes estudos ainda para a vala indicada na figura $I V-1$, para o caso em que os adimensionais $\rho$ e $\eta$ valiam, respectivamente, 210 e $2,6(\xi=1 / 10)$.

a) Constatou-se o bon condicionamento dos sistemas de equaçōes lineares tomando-se o de malor nümero de equaçōes (456) e resolvendo-o tanto en simples precisão (7 algarismos significativos) quanto em dupla preclsão (15 algarismos significativos). O erro percentual relativo mäxi- 


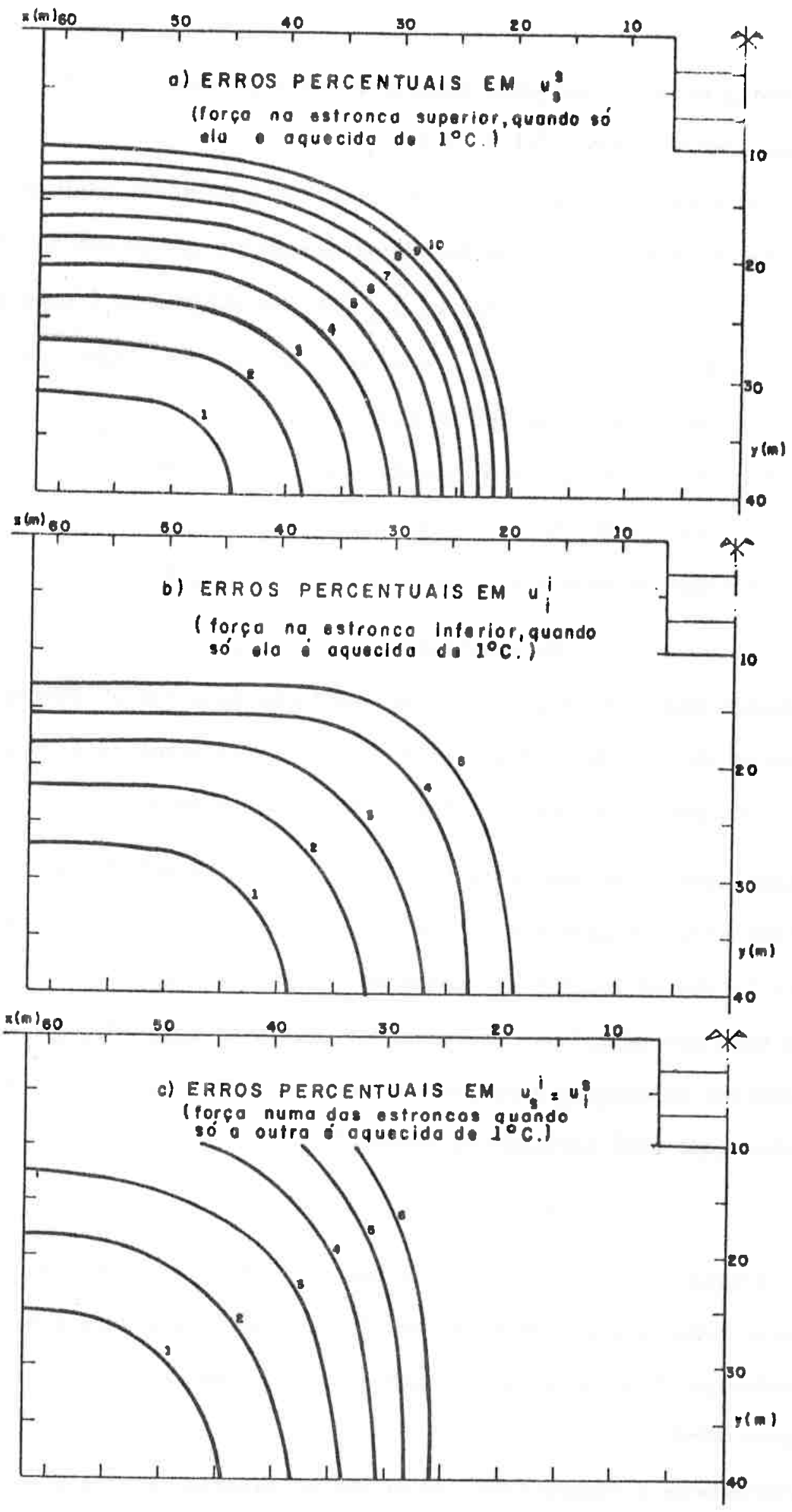

FIGURA II-3: CURVAS DE IGUAIS ERROS PERCENTUAIS NOS VALORES DOS GRADIENTES BÁSICOS DEVIDOSA DELIMITACÃO GEOMÉTRICA - SECCÃO EXPERIMENTAL DO BLOCO 17 PAREDES RIGIDAS $-\phi=1 / 10 \cdot \eta=2.6$. 
mo nos gradientes bäsicos, considerando-se os resultados de dupla precisão como corretos, foi de $0,3 \%$.

b) 0 erro percentual relativo nos valores dos gradientes bäslcos, proveniente da discretização da parede-diafragma em apenas uma filleira de elementos finitos, fol Inferior a $\pm 1 \%$, relativamente à subdivisão malor, com duas flleiras de elementos, Indicada na figura IV-2. Esta discretização foi a adotada em todo o estudo.

c) A influência da delimitaçāo geométrica exigiu um malor número de processamentos. Foram abordadas sels deliml tações, que diferiam entre si pela posição da base rigida $\overline{\mathrm{BC}}$ e da linha limi te $\overline{\mathrm{AB}}$, da figura $I V-2$.

Os resultados relativos ao caso de maior ärea foram tomados como referência para uma avaliação de erros percentuais nos gradientes bäsicos das outras delimitações. Estes'erros relativos foram manipulados por Massad et al (1972-a) da seguinte 'forma:

a) a cada ponto B de uma certa delimi tação foram associados os correspondentes erros percentuais e, com isto, foram traçadas, por Interpolação, curvas de igual erro, conforme a figura IV-3; e

b) com base nestas curvas, foi possível aquilatar separadamente as influências da largura e da profundidade da delimitação nos erros percen tuais, comio está indicado na figura IV-4.

A Inspeção destas figuras revela que:

a) os valores de $u_{s}^{s}$, isto é, das forças que surgem na estronca superior, quando somente ela é aquecida de $1^{\circ} \mathrm{C}$, são mais sensivels à delimitação geométrica. 0 erro percentual pode ser da ordem de $10 \%$, como se vê na figura $T V-3 ;$

b) referindo-se à figura IV-4 vê-se que os valores de $u_{5}^{i}$ e $u_{i}^{5}$, is to $\vec{e}$, das forças que surgem numa das estroncas quando só a outra é aquecida de $1^{\circ} \mathrm{C}$, são mals afetados pelas variações da largura do que da profun- 

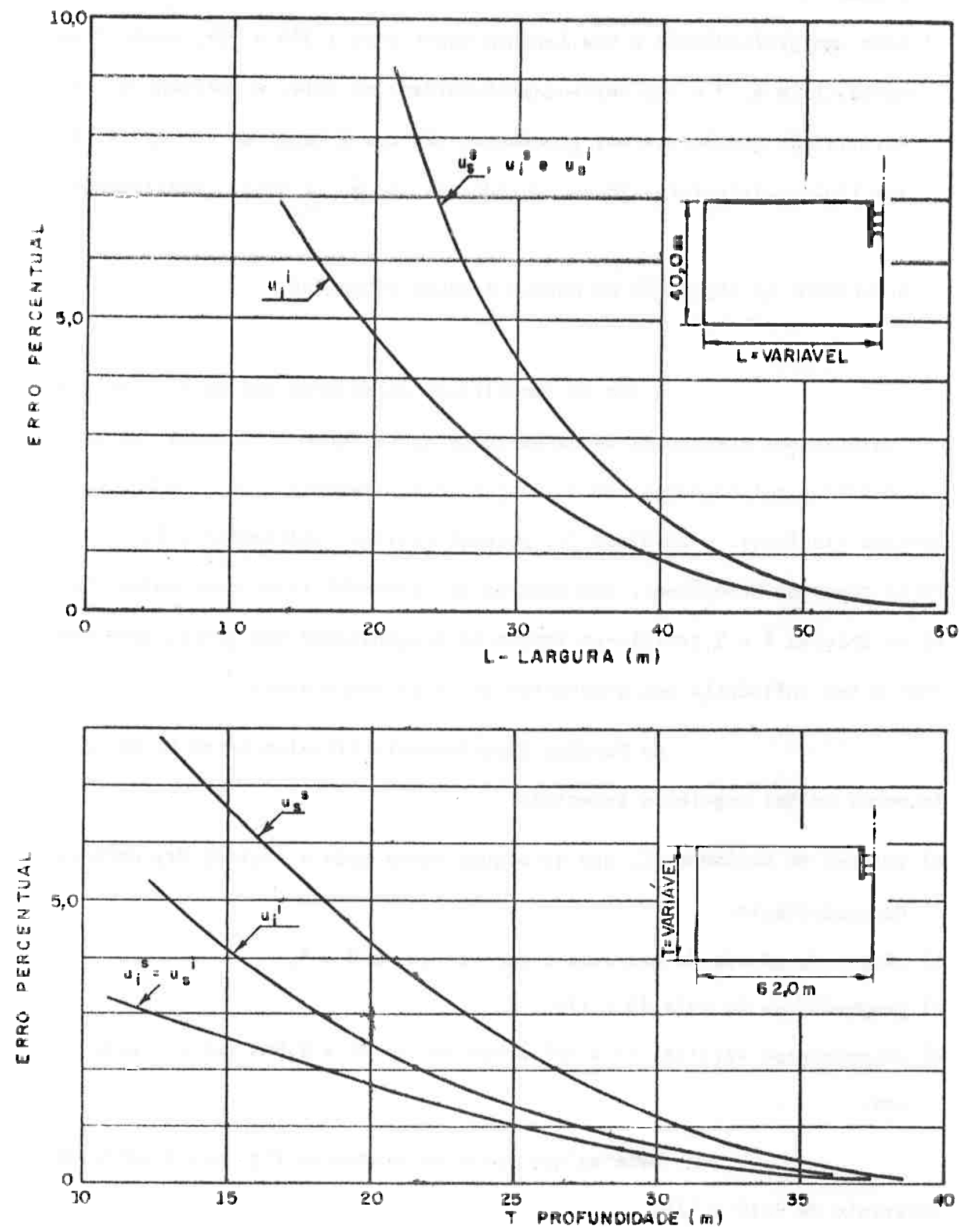

FIOURA IY- 4: ERROS PERCENTUAIS NOS VALORES DOS GRADIENTES BÁsicos $u_{s}^{3}, u_{s}^{\prime}=u_{i}^{*}$. $u_{i}^{i}$. DeVIDOS A DELIMITACÁO GEOMÉTRICA - SECGĀO EXPERIMENTAL DO BLOCO 17-PAREDES RIGIOAS. $\zeta=1 / 10, \eta=2,6$ 
didade; e

c) para uma profundidade e uma largura superiores a $32 \mathrm{~m}$ e $45 \mathrm{~m}$, respectiva mente, isto $\bar{e}, 3$ e 4,5 vezes a profundidade da vala, a influência da delimitação geométrica nos gradientes bäsicos è menor do que 1,0\%. Es tes limites inferiores foram adotados na sequência desta Investigação.

5. RESULTADOS DA APLICAÇAO DO MODELO A VALAS ESCORADAS

A fim de identificar os fatores que mals influem nos valores dos gradientes de carga-temperatura foram conduzidos estudos paramétricos relacionados com as Secções Experimentais 1, 8, 2 e Bloco 17, paredes flexiveis, e do Bloco 17, paredes rígidas. Inicialmente os solos foram supostos homogêneos, com Mödulos de Deformabillidade constantes. Para as Secções 8 e 2 admitiu-se tambēm heterogeneidade dos solos, para ava liar a sua influência nos gradientes de carga-temperatura.

As Secções Experimentais diferiam entre si em pelo menos um dos seguintes aspectos:

a) valores do parämetro $\xi$, que de alguma forma mede a rigidez das paredes de escoramento;

b) nimero de nïveis de estroncas, que variou de 2 a 4;

c) profundidade da vala (9 a $17 \mathrm{~m})$; e

d) espacamentos vertical ( 2 a $4 \mathrm{~m})$ e horizontal (2 a $2,5 \mathrm{~m})$ entre estroncas.

Note-se que, para escoramentos rigldos, $\xi$ varia no intervalo de $1 / 10$ a $1 / 5$.

Por outro lado, para paredes flexiveis pode-se escrever, tendo em vista a expressão $(E-9)$ do Apêndice $E$, resul tante do con celto de equivalência implicito na hipötese simplificadora do item $1 . b$ 
TABELA IV-1

RESULTADOS PARA A SECCAO EXPERIMENTAL 1

\begin{tabular}{|c|c|c|c|c|c|c|}
\hline E & $n$ & & $\begin{array}{l}\mathrm{R} I \mathrm{Z} \mathrm{U} \\
\left.{ }^{\circ} \mathrm{C}\right)\end{array}$ & $\lambda_{m}\left(k g /{ }^{\circ} \mathrm{C}\right)$ & $T_{m}$ & $\frac{G_{1}^{m a x}}{E_{a a^{\alpha}}}$ \\
\hline \multirow{3}{*}{$\frac{1}{400}$} & 0,5 & $\begin{array}{r}898 \\
-407 \\
\end{array}$ & $\begin{array}{l}-407 \\
1297\end{array}$ & 644 & $\begin{array}{c}1 \\
0,63\end{array}$ & $\begin{array}{l}0,179 \\
0,257\end{array}$ \\
\hline & 1,0 & $\begin{array}{r}575 \\
-328\end{array}$ & $\begin{array}{r}-328 \\
888\end{array}$ & 368 & $\begin{array}{c}1 \\
0,63\end{array}$ & $\begin{array}{l}0,102 \\
0,162\end{array}$ \\
\hline & 2,5 & $\begin{array}{r}297 \\
-212\end{array}$ & $\begin{array}{r}-212 \\
498\end{array}$ & 163 & $\begin{array}{c}1 \\
0,63\end{array}$ & $\begin{array}{l}0.044 \\
0.083\end{array}$ \\
\hline \multirow{3}{*}{$\frac{1}{600}$} & 0,5 & $\begin{array}{r}867 \\
-382 \\
\end{array}$ & $\begin{array}{l}-382 \\
1249\end{array}$ & 631 & $\begin{array}{c}1 \\
0,62\end{array}$ & $\begin{array}{l}0,175 \\
0,250\end{array}$ \\
\hline & 1,0 & $\begin{array}{r}552 \\
-305 \\
\end{array}$ & $\begin{array}{r}-305 \\
847\end{array}$ & 361 & $\begin{array}{c}1 \\
0,63\end{array}$ & $\begin{array}{l}0,099 \\
0,155\end{array}$ \\
\hline & 2,5 & $\begin{array}{r}283 \\
-193\end{array}$ & $\begin{array}{r}-193 \\
466\end{array}$ & 161 & $\begin{array}{c}1 \\
0,63\end{array}$ & $\begin{array}{l}0,044 \\
0,078\end{array}$ \\
\hline \multirow{3}{*}{$\frac{1}{1200}$} & 0,5 & $\begin{array}{r}812 \\
-340\end{array}$ & $\begin{array}{l}-340 \\
1161\end{array}$ & 604 & $\begin{array}{c}1 \\
0.61\end{array}$ & $\begin{array}{l}0,168 \\
0,237\end{array}$ \\
\hline & 1,0 & $\begin{array}{r}513 \\
-268\end{array}$ & $\begin{array}{r}-268 \\
779\end{array}$ & 347 & $\begin{array}{c}1 \\
0,62\end{array}$ & $\begin{array}{l}0,095 \\
0,147\end{array}$ \\
\hline & 2,5 & $\begin{array}{r}260 \\
-166\end{array}$ & $\begin{array}{r}-166 \\
420\end{array}$ & 156 & $\begin{array}{c}1 \\
0,63\end{array}$ & $\begin{array}{l}0,042 \\
0,073\end{array}$ \\
\hline
\end{tabular}

LEGENDA: $\xi$ - Relaçāo entre o Mödulo de Elasticidade do material da parede Continua Equivalente e a do aço.

$n$ - Relação entre a Rigidez das Estroncas e a do Solo.

U - Matriz dos Gradientes Bäsicos.

$\lambda_{m}$ e $T_{m}$ - Minimo Autovalor e Correspondente Autovetor da Matriz $U$.

$G_{j}$ max - Máximo Gradiente de Carga-Temperatura, para todas as com binaçōes possiveis de Incrementos Relativos de Temperatura ( $T$ ) dentro de faixas de valores observados no campo,em diversas Seç̧ōes Experimentais.

$E_{a} S_{a} \approx$ - Força que se instalaria numa estronca se ela estivesse bloqueada e após aquecimento de $1^{\circ} \mathrm{C}$. 
TABELA IV-2

RESULTADOS PARA A SECCÃO DO BLOCO 17, PAREDE FLEXIVEL

\begin{tabular}{|c|c|c|c|c|c|c|c|}
\hline$\xi$ & $n$ & & $\begin{array}{r}\text { MATRIZ } \\
(\mathrm{kg})^{\circ}\end{array}$ & & ${ }_{\left(\mathrm{kg} /{ }^{\circ} \mathrm{C}\right)}$ & $T_{m}$ & $\frac{G_{j}^{m a x}}{E_{a} S_{a} \alpha}$ \\
\hline \multirow{3}{*}{$1 / 1000$} & $0: 5$ & $\begin{array}{r}866 \\
-456 \\
-124\end{array}$ & $\begin{array}{l}-456 \\
1056 \\
-218\end{array}$ & $\begin{array}{r}-124 \\
-218 \\
1038\end{array}$ & 407 & $\begin{array}{c}1 \\
0,87 \\
0,50\end{array}$ & $\begin{array}{l}0,133 \\
0,142 \\
0,217\end{array}$ \\
\hline & 1 & $\begin{array}{r}661 \\
-441 \\
-81\end{array}$ & $\begin{array}{r}-441 \\
859 \\
-209\end{array}$ & $\begin{array}{r}-81 \\
-209 \\
761\end{array}$ & 235 & $\begin{array}{c}1 \\
0,87 \\
0,50\end{array}$ & $\begin{array}{l}0,084 \\
0,090 \\
0,151\end{array}$ \\
\hline & 2,5 & $\begin{array}{r}436 \\
-362 \\
-24\end{array}$ & $\begin{array}{r}-362 \\
615 \\
-172\end{array}$ & $\begin{array}{r}-24 \\
-172 \\
451\end{array}$ & 105 & $\begin{array}{c}1 \\
0,88 \\
0,51\end{array}$ & $\begin{array}{l}0,044 \\
0,048 \\
0,086\end{array}$ \\
\hline
\end{tabular}

LEGENDA: $\quad \xi$ - Relação entre o Mödulo de Elasticldade do material da Parede Contínua Equivalente a do aço.

n-Relação entre a Rigidez das Estroncas e do Solo.

U- Matriz dos Gradientes Básicos.

$\lambda_{m}$ e $T_{m}$ Minimo Autovalor e Correspondente Autovetor da Matriz $U$.

$G_{i}^{m a x}$ - Mäximo Gradiente de Carga-Temperatura, para todas as combinaçōes possiveis de Incrementos Relativos de Temperatura (T) dentro de faixas de valores observados no campo, em diversas Seç̧óes Experimentals.

$E_{a} S_{a}=$ - Forga que se instalaria numa estronca se ela estivesse bloqueada e após aquecimento de $1^{\circ} \mathrm{C}$. 
TABELA IV-3

RESULTADOS PARA A SECCAOO EXPERIMENTAL 8

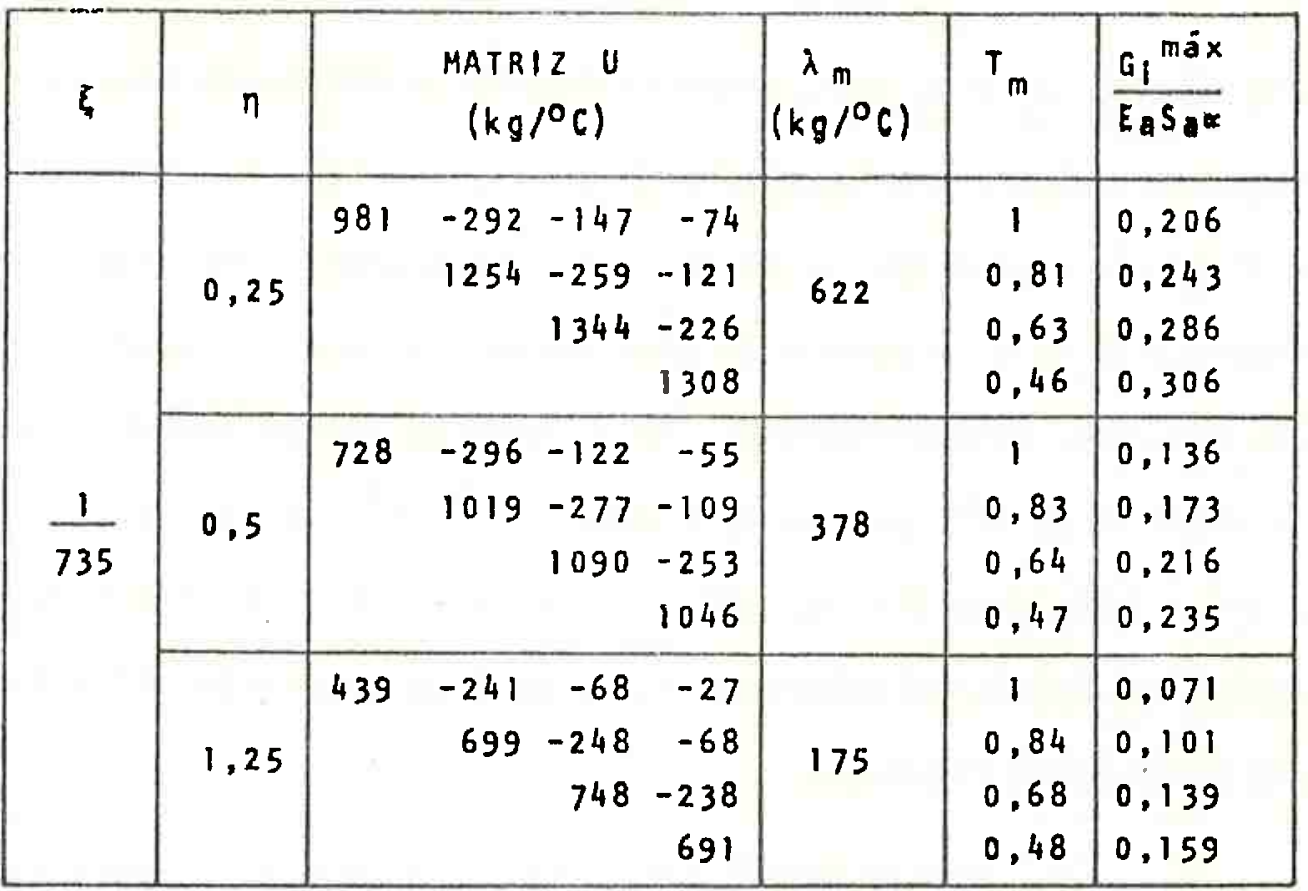

LEGENDA: $\xi$ - Relação entre o Mödulo de Elasticidade do material da pa rede contínua equivalente e a do aço.

$\eta$ - Relaçăo entre a Rigidez das Estroncas e a do Solo.

$U$ - Matriz dos Gradientes Básicos.

$\lambda_{m}$ e $T_{m}$ - Minimo Autovalor e Correspondente Autovetor da Matrlz $U$.

G, maxx - Mäximo Gradiente de Carga-Temperatura, para todas as com binaçöes possíveis de lncrementos Relativos de Temperatü ra $(T)$ dentro de faixas de valores observados no campo. em diversas Secçöes Experlmentais.

E Sa* - Força que se instalarla numa estronca se ela estivesse bloqueada e após aquecimento de $1^{\circ} \mathrm{C}$. 
des te Capitulo:

$$
\xi=\frac{E p}{E_{a}}=\frac{J_{a}}{J_{p}}=\frac{J_{a}}{\frac{t \cdot e_{p}^{3}}{12}}
$$

Nesta expressão $E_{p}, J_{p}$ e c são, respectivamento, o mödulo do olasticidade, o momento de Inērcla e a espessura da parede contínua equivalente, es ta ültima fixada arbitrariamente em Im; t è o espaçamento, em planta, entre estroncas; e $E_{a}$ e $J_{a}$ o módulo de elasticidade do aço e o momento de inērcia das estacas, respectivamente. Se as estacas fossem todas formadas por perfis duplo I de $12^{\prime \prime}$, em que $J_{a}=22600 \times 10^{-8} \mathrm{~m}^{4}$, ter-se-ia, para $t=1,5 \mathrm{~m}, 1 / \xi=550$; para $\mathrm{t}=2 \mathrm{~m}, 1 / \xi=735$ e para $\mathrm{t}=2,5 \mathrm{~m}, 1 / \xi=919$, ra zão pela qual, no estudo paramētrico, fixou-se $\xi$ no intervalo $1 / 1200$ e $1 / 400$, para as paredes flexiveis.

Para a Secção Experimental do Bloco 17, paredes ri gidas, variou-se verticalmente a posição da estronca Inferior, o que permitirä tirar algumas conclusōes importantes, como se verā adiante.

\subsection{Re Lações hiperbölicas entre a Matriz U e $n$.}

0 vetor dos incrementos relativos de temperatura $\left(T_{m}\right)$ que gera iguais valores $\left(\lambda_{m}\right)$ dos gradientes de carga-temperatura $a \tilde{a} o$ invariantes em relação aos parâmetros $\xi$ e $n$, conforme se depreende da anā lise de qualquer uma das tabelas IV-1 a IV-4, referentes aos casos de solos homogêneos. No entanto, ele depende fortemente da geometria da Seç̧ão Experimental, fato este que resulta da comparação dos dados contidos nestas tabelas e na tabela IV-5.

A invariâniaque se acaba de citar sugere a existênćla de uma funçāo racional, para cada Secção Experimental, ligando U e $\eta$, conséquêncla da Propriedade $\&$ da Matriz $U$, enunclada no Apêndice $D$. Em 
TABELA $1 V-4$

RESULTADOS PARA A SECCAOO DO BLOCO 17, PAREDES RTGIDAS

\begin{tabular}{|c|c|c|c|c|c|c|}
\hline$\xi$ & $n$ & $\begin{array}{r}M A T \\
(k\end{array}$ & $\begin{array}{l}2 \mathrm{O} \\
\left.10^{\circ} \mathrm{C}\right)\end{array}$ & $\lambda_{m}\left(\mathrm{~kg} /^{\circ} \mathrm{C}\right)$ & $T_{m}$ & $\frac{G_{i}^{\operatorname{maj} x}}{E_{a^{S} a^{\alpha}}}$ \\
\hline \multirow{3}{*}{$\frac{1}{10}$} & 1,0 & 1022 & $\begin{array}{r}-794 \\
1611 \\
\end{array}$ & 497 & $\begin{array}{c}1 \\
0,69 \\
\end{array}$ & $\begin{array}{l}0,148 \\
0,236 \\
\end{array}$ \\
\hline & 1,5 & 812 & $\begin{array}{r}-699 \\
1331 \\
\end{array}$ & 326 & $\begin{array}{c}1 \\
0,69\end{array}$ & $\begin{array}{l}0,105 \\
0,182 \\
\end{array}$ \\
\hline & 2,5 & 588 & $\begin{array}{r}-533 \\
999 \\
\end{array}$ & 204 & $\begin{array}{c}1 \\
0,69\end{array}$ & $\begin{array}{l}0,071 \\
0,134 \\
\end{array}$ \\
\hline \multirow{4}{*}{$\frac{1}{7}$} & $0 ; 5$ & 1428 & $\begin{array}{r}-906 \\
2127 \\
\end{array}$ & 806 & $\begin{array}{c}1 \\
0,68 \\
\end{array}$ & $\begin{array}{l}0,245 \\
0,352 \\
\end{array}$ \\
\hline & 1,0 & 1049 & $\begin{array}{r}-846 \\
1700 \\
\end{array}$ & 468 & $\begin{array}{c}1 \\
0,68\end{array}$ & $\begin{array}{l}0,146 \\
0,246\end{array}$ \\
\hline & 1,5 & 852 & $\begin{array}{r}-756 \\
1426\end{array}$ & 330 & $\begin{array}{c}1 \\
0,70\end{array}$ & $\begin{array}{l}0,106 \\
0,193\end{array}$ \\
\hline & 2,5 & 627 & $\begin{array}{r}-610 \\
1089 \\
\end{array}$ & 206 & $\begin{array}{c}1 \\
0,70 \\
\end{array}$ & $\begin{array}{l}0,068 \\
0,138 \\
\end{array}$ \\
\hline \multirow{3}{*}{$\frac{1}{5}$} & 1,0 & 1055 & $\begin{array}{r}-912 \\
1754 \\
\end{array}$ & 428 & $\begin{array}{c}1 \\
0,68\end{array}$ & $\begin{array}{l}0,136 \\
0,243\end{array}$ \\
\hline & 1,5 & 885 & $\begin{array}{r}-811 \\
1513 \\
\end{array}$ & 329 & $\begin{array}{c}1 \\
0,68 \\
\end{array}$ & $\begin{array}{l}0,106 \\
0,203 \\
\end{array}$ \\
\hline & 2,5 & 660 & $\begin{array}{l}-667 \\
1175\end{array}$ & 203 & $\begin{array}{c}1 \\
0,68\end{array}$ & $\begin{array}{l}0.067 \\
0.147\end{array}$ \\
\hline
\end{tabular}

LEGENDA: E-Relação entre o Mödulo de Elasticidade do concreto (parede diafragmal e o do aço.

n-Relaçäo entre a Rigidez das Estroncas e a do solo.

U- Matriz dos Gradientes Bäsicos.

$\lambda_{m}$ e T - Minimo Autovalor e Correspondente Autovetor da Matriz $U$.

$G_{i}{ }^{m a ́ x}$ - Máximo Gradiente de Carga-Temperatura, para todas as combinaçöes possíveis de Incrementos Relativos de Temperatura $(T)$ dentro de faixas de valores observados no campo, em diversas Seç̧öes Experimentais.

$E_{a} S_{a} \propto-$ Força que se instalaria numa estronca se ela estivesse bloqueada e apös aquecimento de $1^{\circ} \mathrm{C}$. 
TABELA IV-5

SECCAO DO BLOCO 17, PAREDES RIGIOAS

\begin{tabular}{|c|c|c|c|c|c|c|c|}
\hline$\xi$ & $n$ & $d / H$ & & $\begin{array}{ll}2 & U \\
{ }^{\circ} \mathrm{Cl}\end{array}$ & $\frac{\lambda_{\mathrm{m}}}{\left(\mathrm{kg} /{ }^{\circ} \mathrm{C}\right)}$ & $T_{m}$ & $\frac{G_{i}{ }^{\operatorname{ma} x}}{E_{a^{S}} S_{a}}$ \\
\hline \multirow{3}{*}{$1 / 10$} & \multirow{3}{*}{1.5} & 0,6 & $\begin{array}{r}991 \\
-889\end{array}$ & $\begin{array}{r}-889 \\
1445\end{array}$ & 300 & $\begin{array}{c}1 \\
0,78\end{array}$ & $\begin{array}{l}0,122 \\
0.160\end{array}$ \\
\hline & & 0.7 & $\begin{array}{r}812 \\
-699\end{array}$ & $\begin{array}{r}-699 \\
1331\end{array}$ & 326 & $\begin{array}{c}1 \\
0,70\end{array}$ & $\begin{array}{l}0,105 \\
0,182\end{array}$ \\
\hline & & 0.8 & $\begin{array}{r}688 \\
-558\end{array}$ & $\begin{array}{l}-558 \\
1273\end{array}$ & 350 & $\begin{array}{c}1 \\
0,61\end{array}$ & $\begin{array}{l}0,095 \\
0.206\end{array}$ \\
\hline
\end{tabular}

\footnotetext{
LEGENDA: d- Distancia da estronca do 20 nível até a superficie do terreno.

H - Profundidade da vala.

$\xi$ - Relação entre o Módulo de Elasticidade do concreto (parede diafragma) e o do aço.

$n$ - Relação entre a Rigidez das Estroncas e a do solo.

$U$ - Matriz dos Gradientes Básicos.

$\lambda_{m}$ e $T_{m}$ - Minimo Autovalor e Correspondente Autovetor da Matriz $U$.
Gímäx - Máximo Gradiente de Carga-Temperatura, para todas as combinaçös possiveis de Incrementos Relativos de Tem peratura (T) dentro de faixas de valores observados no campo, em diversas Seç̧ōes Experimentais.
$E_{a} S_{a}=$ - Força que se Instalaria numa estronca se ela estivesse bloqueada e após aquecimento de $1^{\circ} \mathrm{C}$.
} 
trabalho apresentado por Massad et al (1974-c) foi mostrado como construir tal função atravēs da ajustagem de Polinômios de Chebyshev.

Como se verificou mais tarde, este tipo de função é de pouca valla para fins präticos. Multo mais interessantes são relagões hiperbölicas, como a que segue a título de llustração, vällda para a Seção Experimental le para $0,5 \leq n \leq 2,5$ e $400 \leq 1 / \xi \leq 1200$, com erro inferior à $\pm 5 \%$ :

$$
\begin{gathered}
\frac{E_{a} S_{a}^{\alpha}}{u_{11}}=2+4,1 n \\
\frac{E_{a} S_{a}^{\alpha}}{u_{22}}=1,8+2,2 n \\
\frac{E_{a} s_{a}^{\alpha}}{u_{12}}=7,0+(5,4+3,5 \log \xi) n
\end{gathered}
$$

Estas correlações foram obtidas com os dados conti dos na tabela $I V-1$, onde se vê que o vetor $T_{m}$ tem coeficientes valendo 1 e 0,62 , em mëdia, independentemente de $\xi$ e $n$.

Este tipo de correlação não é, de certa forma, for tui to. De fato, considere-se uma barra de comprimento $\ell$, mödulo de elasticidade $E_{a}$ e área da secção transversal $S_{a}$, tendo em suas duas extremida des molas de rigidez $K$. A um acréscimo unitärio de temperatura da barra, a porcentagem de força (G) absorvida por qualquer uma das molas serä:

$$
\frac{E_{a} S_{a}^{\alpha}}{G}=1+2 \cdot\left(\frac{E_{a} S_{a}}{l K}\right)
$$

onde $\propto$ é o coeficiente de dilatação térmica do aço. Vê-se que, nesta análise, K, G e o termo entre parênteses fazem as vezes da rigidez do solo 
SECGÃO EXPERIMENTAL

at incremento relativo de temperatura, ${ }^{\circ} \mathrm{C}$
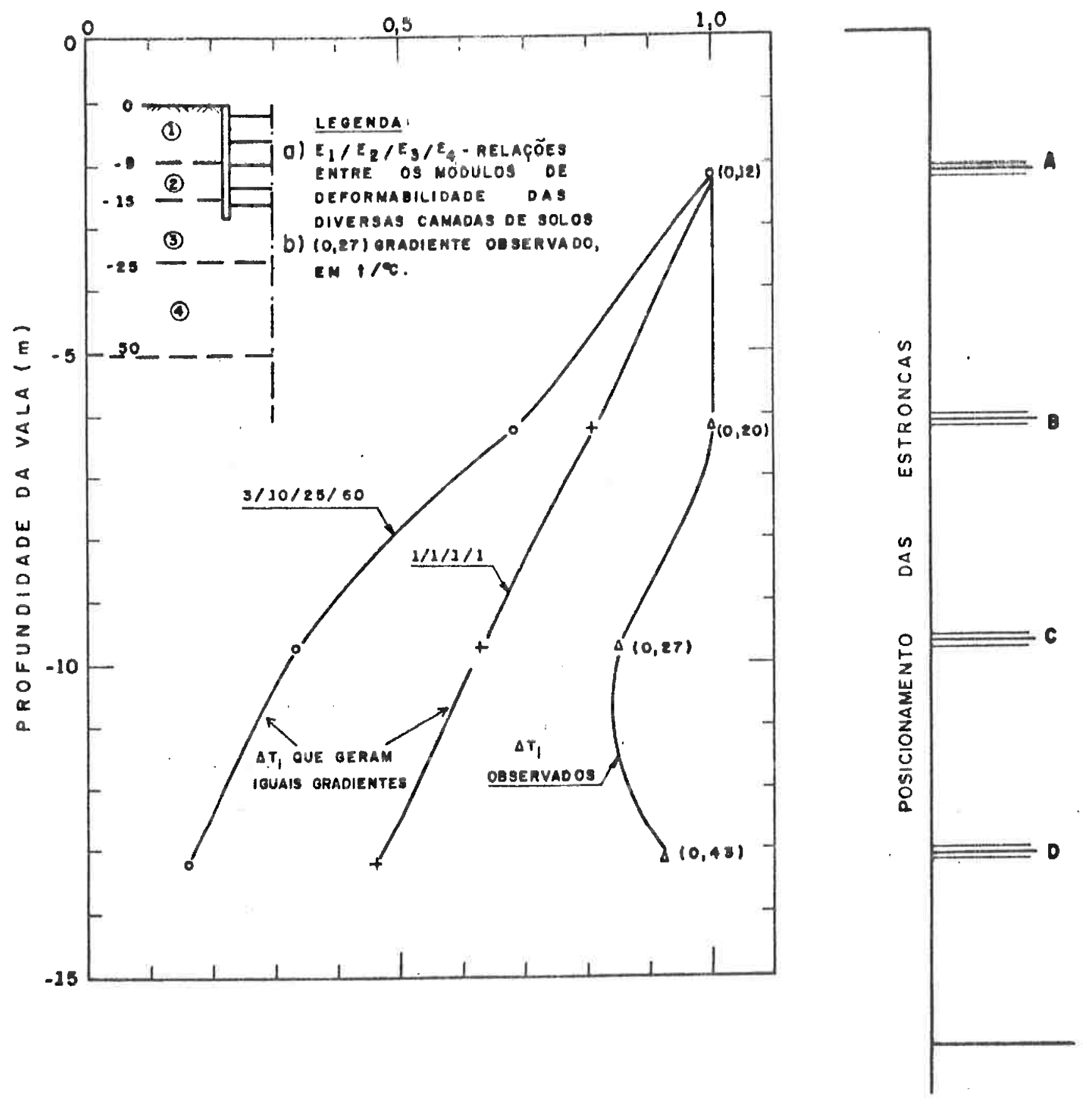

FIOURA IN - 5: INFLUÊNCIA DA RELACĀO dOS MÓDULOS DE DEFORMABILIDADE NOS VALORES DOS INCREMENTOS RELATIVOS DE TEMPERATURA, QUE GERAM IGUAIS GRADIENTES EM TODAS AS ESTRONCAS. 
$\left(E_{s} t\right)$, do gradiente e de $\eta$, respectivamente.

5.2. Heterogeneidade dos Solos

Além da geometría do conjunto vala-sistema de esco ramento, a heterogeneidade dos solos afeta significativamente o vetor dos incrementos relativos de temperatura $\left(T_{m}\right)$ que geram iguais gradientes $\left(\lambda_{m}\right)$.

A figura IV -5 mostra variações dos $T_{m}$ em função das relações entre os Módulos de Deformabilidade dos solos envolvidos, corroborando a asserção fei ta. 0 nümero entre parênteses è o gradiente de carga-temperatura realmente observado; nota-se que ele cresce com a profundidade de instalação das estroncas.

No mesmo sentido, a figura IV-6 apresenta resultados relativos à Secção Experimental 2, onde, como jä foi enfatizado, observou-se um gradiente praticamente constante e igual a $0,19 \mathrm{t} /{ }^{\circ} \mathrm{C}$ para to dos os niveis de estroncas. A proximidade da curva observada com a calculada é digna de nota, deixando-se por enquanto entre parēnteses as razões da escolha das relações entre mödulos, indicadas na mesma figura.

Conclui-se também que, mesmo que a rigidez dos solos aumente com a profundidade, o que é razoāvel supor para a Cidade de São Paulo, os gradientes podem não seguir esta tendência; ou, di to de outra forma, tivesse a Secção Experimental 2 sido escavada em outro local, por exemplo, o da Seç̧ão Experimental 8, as cargas nas estroncas teriom sido completamente diferentes, afirmação feita anteriormente, no final do Capituto III, que agora è comprovada atravēs do modelo matemātico.

5.3. Fatores que mais condicionam os valores dos gradientes

0 modelo matemätico proposto permite identificar os fatores que mais influem nos valores dos gradientes de carga-temperatu 


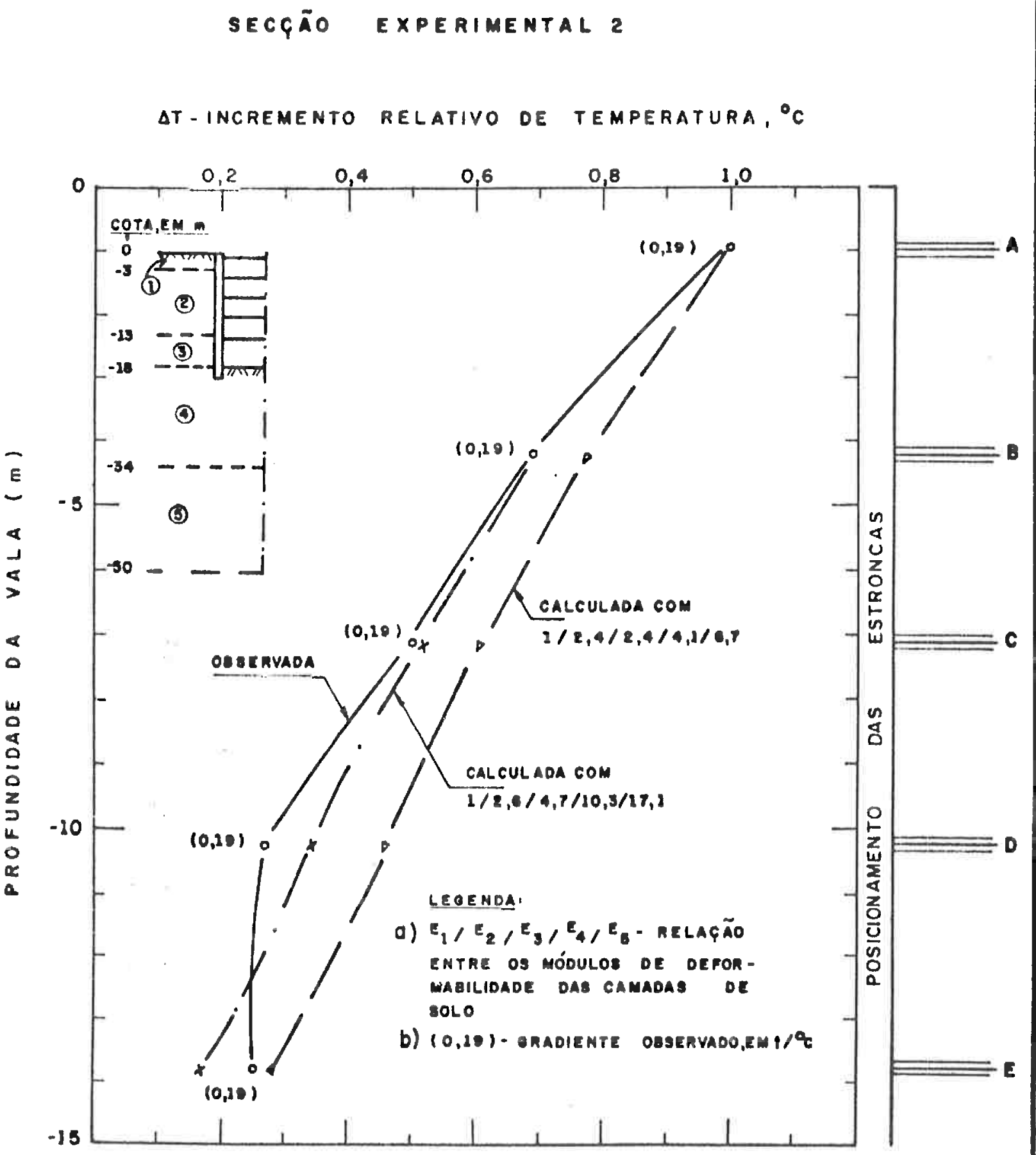

FIGURA II - 6 : COMPARAÇÃo ENTRE VALORES CALCULAdOS E OBSERVADOS DOS INCREMENTOS RELATIVOS dE TEMPERATURA, QUE gERAM IGUAIS GRADIENTES. 
a) SECGÃO EXPERIMENTAL DO BLOCO 17 "PAREDES RIGIDAS

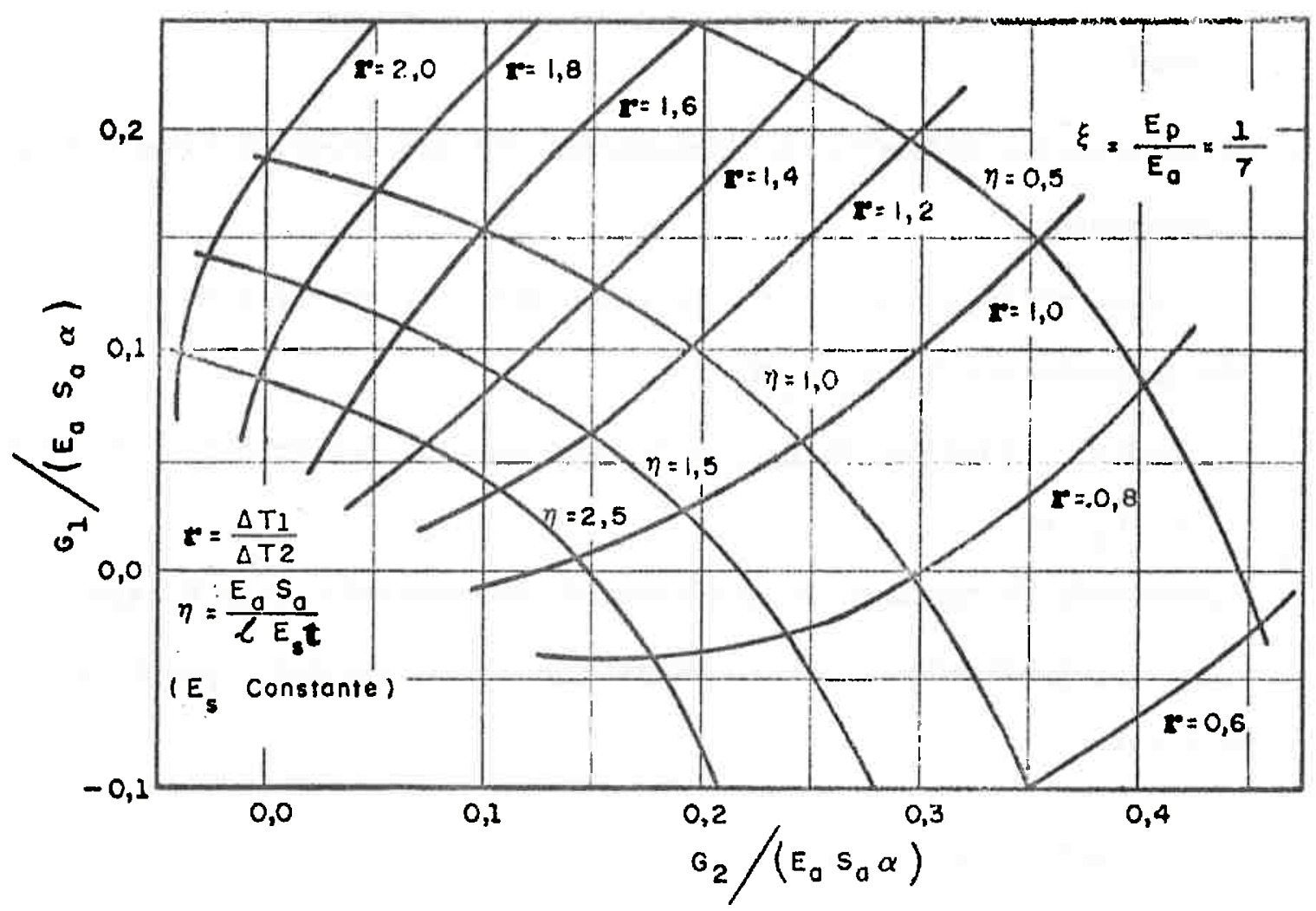

b) SECGÃo EXPERIMENTAL 2

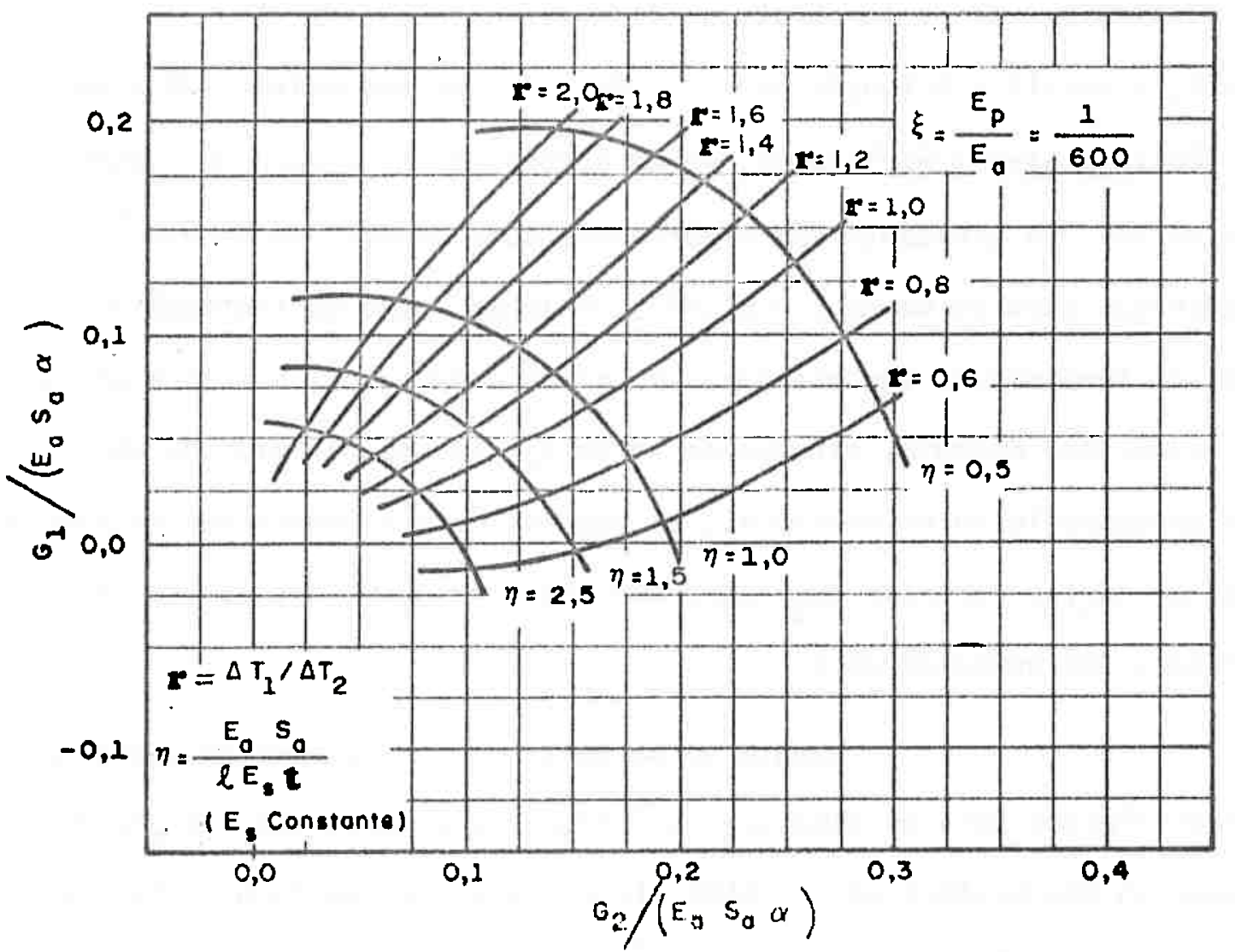

FIGURA IV - 7: GRADIENTES DE CARGA-TEMPERATURA EM FUNÇĀO DE $\eta, \xi \in r\left(G_{1} \bullet G_{2} S A ̈ O\right.$ OS GRADIENTES NAS ESTRONCAS SUPERIOR E INFERIOR, RESPECTIVAMENTE) 
ra, a saber:

a) os incrementos relativos de temperatura (T) nos diversos niveis de estroncamento;

b) a relação entre a rigidez a compressão das estroncas e a do solo, atra vẻs do parâmetro $\eta=E_{a} S_{a} / E_{s} t \ell$;

c) a rigidez relativa da parede de escoramento, por meio do parâmetro $\xi=E_{p} / E_{a} ; e$

d) a geometria do conjunto vala-sistema de escoramento, is to è, sua largura e profundidade, o nümero de estroncas e o seu posiclonamento na vertical.

5.3.1. Influência de T, $\eta$ e $\xi$

A dependência dos gradientes em relação aos incrementos relativos de temperatura (T) è evidente na expressão (III-9); ademais, a matriz $U$ é função de ne $\xi$. Para se ter uma melhor idēia da influência destes três fatores, foram preparados os ábacos da figura IV-?. As curvas $\eta$ = constante são hipérboles, consequência da expressão (III-9b). Vê-se que para um mesmo $r=\Delta T_{1} / \Delta T_{2}$, relação entre os incrementos relativos de temperatura das estroncas superior e inferior, à medida em que $n$ diminui, por exemplo, atravēs de um enrijecimento do solo, ou um aumento no espaçamento entre estroncas, em planta, os gradientes nas estroncas su perior $\left(G_{1}\right)$ e inferior $\left(G_{2}\right)$ aumentam. Para um mesmo $n, G_{1}$ cresce e $G_{2}$ de cresce, com aumentos de $r$.

Quanto ao parāmetro $\xi$, quando se passa das paredes rígidas para as flexiveis a influência è relativamente grande, mas menor do que as de $T$ ou $n$. Além disto, para $\xi$ variando no intervalo $1 / 10$ a $1 / 5$, os gradientes diferem mul to pouco entre $s i$, o mesmo sucedendo no intervalo 1/1200 a 1/400. Estes achados justificam a dicotomia paredes 
flexiveis - paredes rígidas, a ser mantida de ora em diante nesta Investígação, com a consequente el iminação da variāvel $\xi$.

No caso de paredes rigidas, a invarlância dos gradientes em relação a $\xi$ pode ter uma interpretação interessante.

Considere-se duas paredes de concreto com espessuras $\underline{e}_{1} e \underline{e}_{2}$ e mödulos de elasticldade $E_{c l}$ e $E_{c 2}$, respectivamente. Fazendo abstração do Coeficiente de Poisson, elas terão o mesmo comportamento na flexão se $E_{c l} J_{1}-E_{c 2} J_{2}$, onde $J_{1}$ e $J_{2}$ são os correspondentes momentos de inërcla. Esta igualdade pode ser escrita:

$$
E_{c 1} \frac{t e_{1}^{3}}{12}=E_{c 2} \frac{t e_{2}^{3}}{12}
$$

onde $t$ é o espaçamento entre estroncas, em planta.

$$
\begin{aligned}
& \text { Dai, se deduz que: } \\
& E_{c 2}=E_{c 1}\left(\frac{e_{1}}{e_{2}}\right)^{3}
\end{aligned}
$$

isto è, a variação da espessura da parede-diafragma, de e, para $e_{2}$, pode ser simulada alterando-se o mödulo de elasticidade de $E_{c l}$ para $E_{c 2}$, conve nientemente.

Dividindo-se ambos os membros da expressão $(I V-10)$ por $E_{a}$, módulo de elasticidade do aço, tem-se:

$$
\frac{E_{c 2}}{E_{a}}-\frac{E_{c 1}}{E_{a}}\left(\frac{e_{1}}{e_{2}}\right)^{3}
$$

ou

$$
\xi_{2}=\xi_{1}\left(\frac{e_{1}}{e_{2}}\right)^{3}
$$


ou

$$
\frac{\mathbf{e}_{2}}{\mathbf{e}_{1}}=\sqrt[3]{\frac{\xi_{1}}{\xi_{2}}}
$$

Na presente Investigação, todos os resultados são välidos para $e_{1}=1 m$. Portanto, a expressão acima pode ser escrita:

$$
e_{2}=\sqrt[3]{\frac{\xi_{1}}{\xi_{2}}}
$$

Ademais, foi visto que os gradientes de carga-temperatura independem de $\xi$, dentro do intervalo $1 / 10$ a $1 / 5$. Isto $\bar{e}, \xi$ e $\xi_{2}$ podem assumir valores de 0,1 a 0,2 .

Is to significa, retomando-se a expressão (IV-11), que, se a parede de concreto tiver espessuras variando de $\sqrt[3]{0,1 / 0,2}=$ $0,80 \mathrm{~m}$ até $\sqrt[3]{0,2 / 0,1}=1,25 \mathrm{~m}$, os resultados jä obtidos continuam välidos.

Voltando-se à figura IV-7, constata-se ainda que para incrementos de temperatura superiores aos correspondentes coeficientes do autovetor $T_{m}$, o que signlfica ter, para a Secção Experimental $1, r \leq 1 / 0,62-1,61$, e para o Bloco 17 , paredes $r i g i d a s$, a $r \leq 1 / 0,69=1,45$, mantidos $\xi$ e $n$ constantes, os gradientes mäximos ocorrem no nivel inferlor de estroncas.

5.3.2. Influência da geometria da Seção - Dificuldades analíticas encontradas e cálculo dos Gradientes Mäximos

A importâncla da geometria do sistema vala-escoramento $\ddot{e}$ patente nos elementos apresentados na tabela IV-5, que mostra a influência do posicionamento da estronca inferlor nos valores dos gradien tes. Ela tambèm está implícita nos outros resultados, ci tados anteriormente. 
at $T_{i}$ - incrementos relativos de temperatura, ${ }^{\circ} \mathrm{C}$

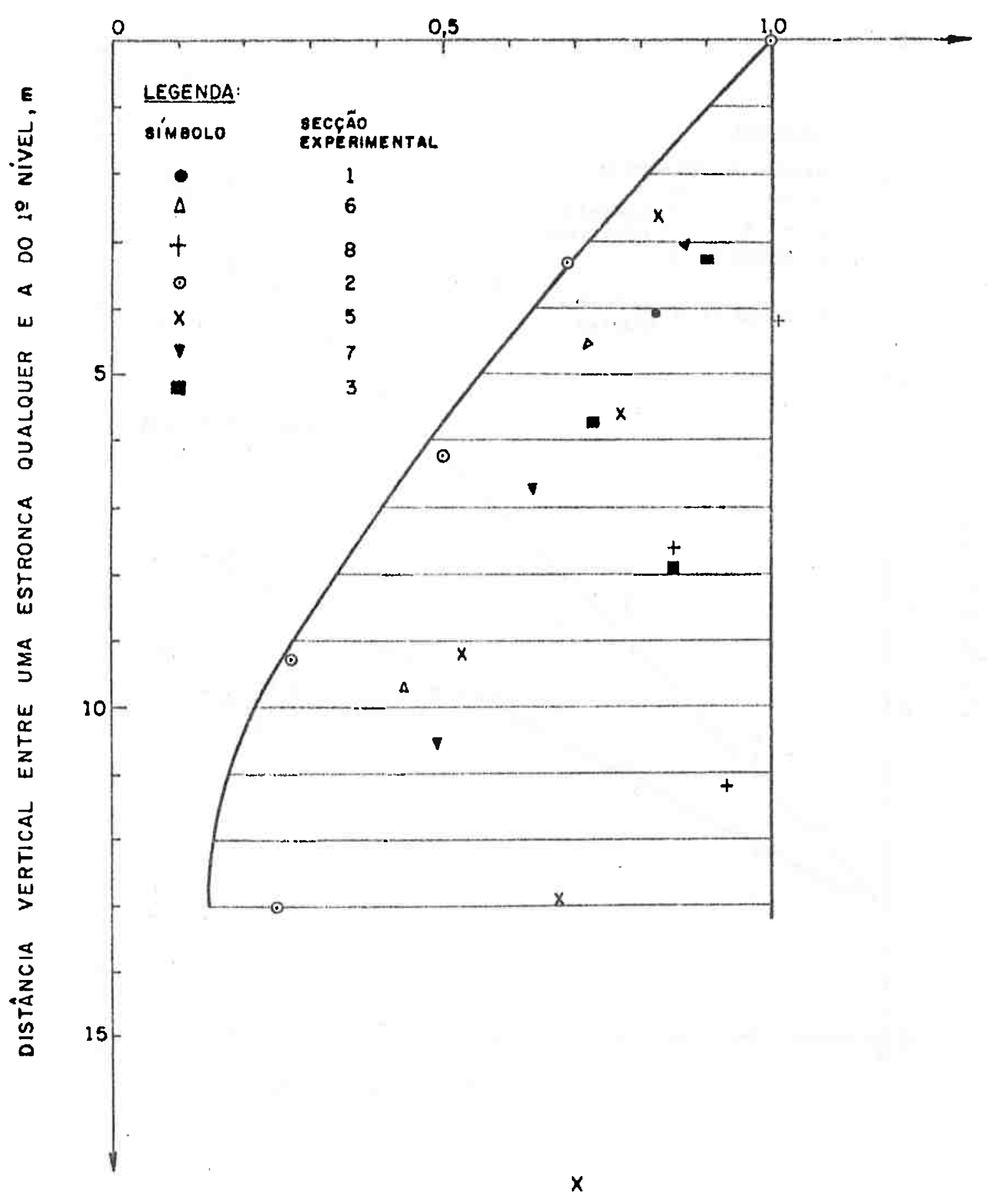

FIGURA IV - B: FAIXA DE VALORES EXTREMOS ADOTADA PARA OS INCREMENTOS RELATIVOS DE TEMPERATURA, EM FUNÇÃO DA PROFUNDIDADE 


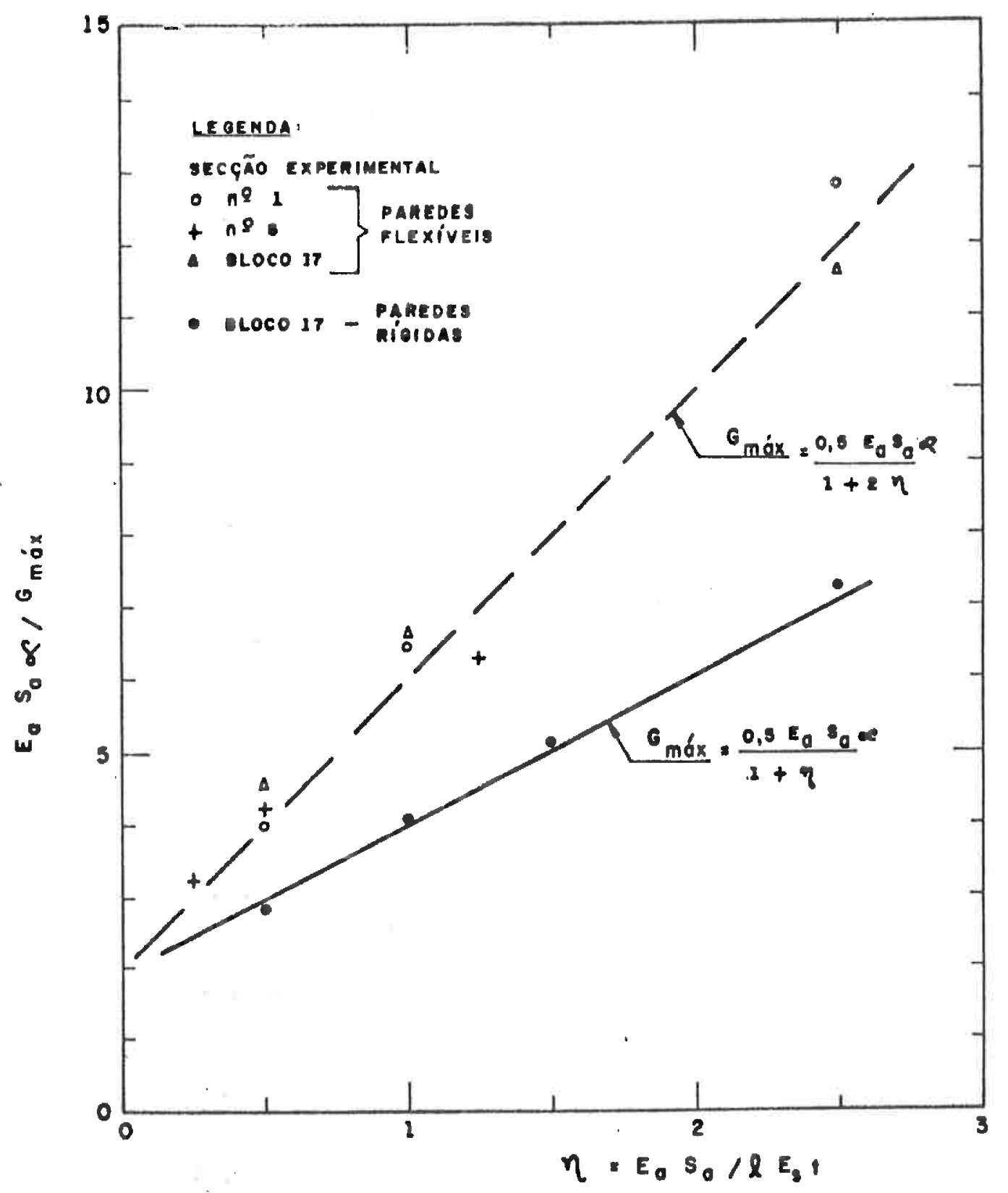

FIGURA II - 9: CORRELACÃo ENTRE O MÁXIMO GRADIENTE DE CARGA-TEMPERATURA NA ÚLTIMA ESTRONCA $\left(G_{\text {máx }}\right)$ E O PARÂMETRO $\eta$. 


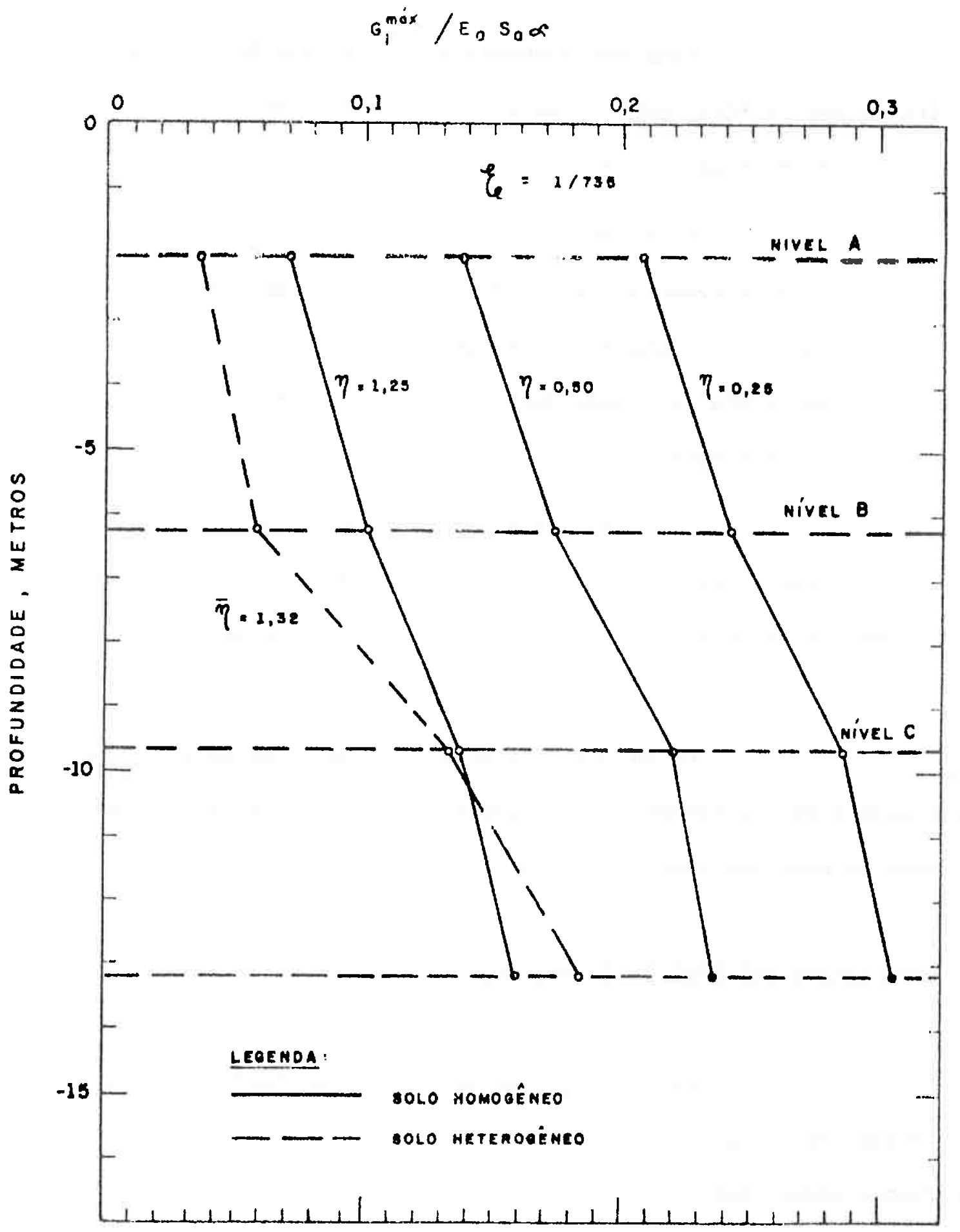

FIGURA II - 10: VARIAÇĀO DOS GRADIENTES MÁXIMOS ( $g_{i}^{m o ́ x}$ ), EM CADA NIVEL DE ESTRONCAS, COM A PROFUNDIDADE - SECGẢO EXPERI MENTAL 8 . 
Cedo verificou-se a dificuldade de interpretação analitica destes resultados, superada, para fins prāticos, com a iritrodu ção do conceito de gradientes máximos de uma vala escorada.

Estes vêm a ser os mäximos valores dos gradientes, em cada nivel de estroncas, calculados atravēs da expressão (III-9), para todas as possiveis combinações do vetor $T$ (vetor dos incrementos rela tivos de temperatura) variando dentro da ärea hachurada da figura IV-8, obtida experimentaimente.

Como se verā adiante, estes gradientes e as suas envoltörias são a base para o desenvolvimento de förmulas präticas para a inclusão da parcela do efeito da temperatura nas cargas de projeto das estroncas.

Os valores assim obtidos dos gradientes mäximos, para cada nívęl de estroncas e Seç̧ão Experimental, estão indicados nas ül timas colunas das tabelas IV-1 a IV-5 e nas figuras IV-9 a IV-11.

\section{ENVOLTORIAS DOS GRADIENTES MÁXIMOS}

Para atingir os objetivos manifestados no item 5.3.2, foi preparada a figura $I V-9$, correlacionando os gradientes máximos adimensionalizados, que ocorrem nas estroncas do ültimo nîvel, com o parâmetro $n$, para as Seç̧ões Experimentais 1, 8 e do Bloco 17, paredes flexí veis, e para a do 81 oco 17, paredes rigidas. A forma hiperbölica adveio do resultado apresentado no item 5.1 .

Vê-se que se pode tomar, com uma certa margem de segurança, a seguinte expressão para paredes flexîveis:

$$
G_{\max }=\frac{0,5 E_{a} S_{a}^{\alpha}}{1+2 n}
$$




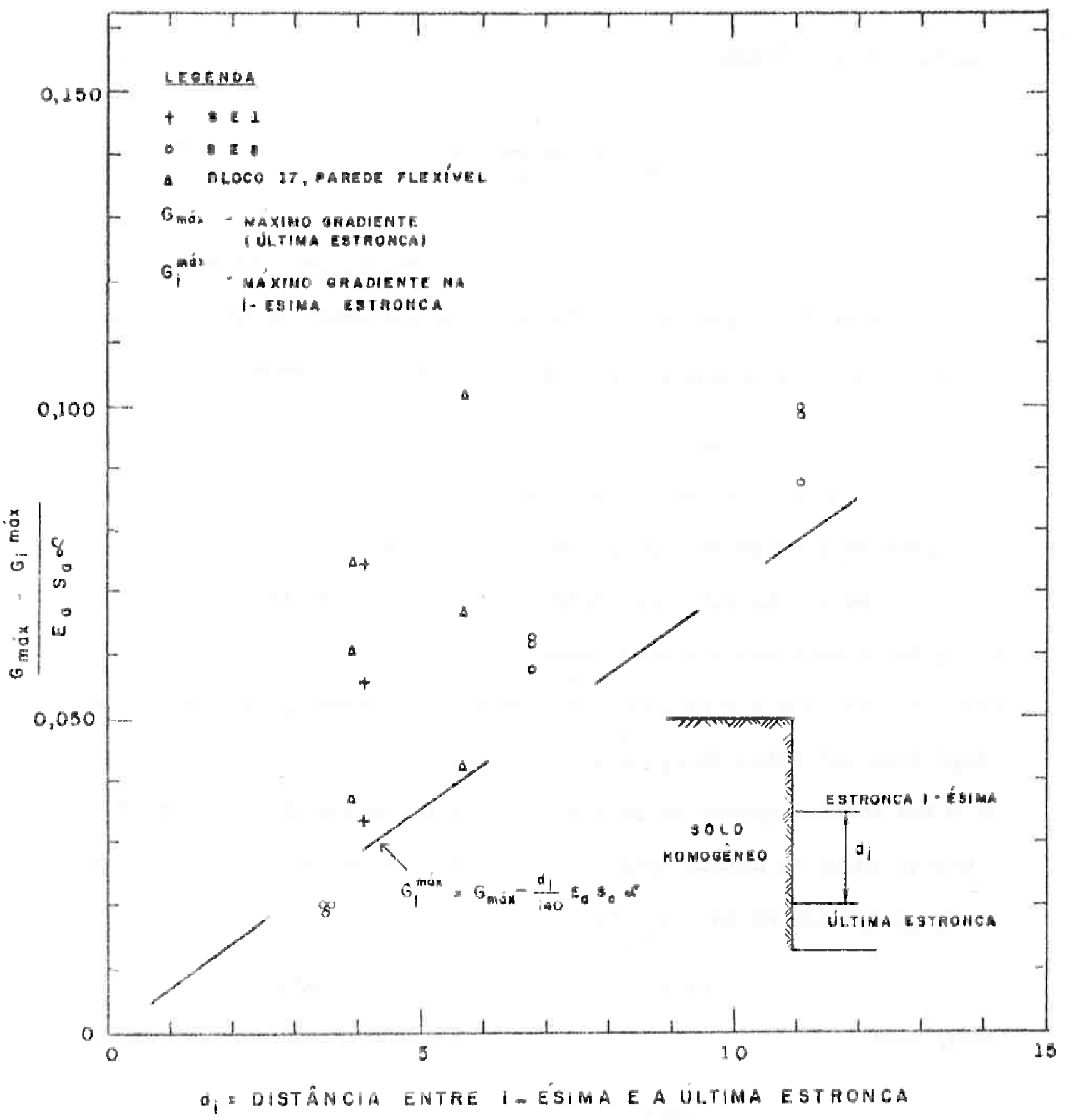

FIGURA IV 11: LIMITE SUPERIOR PARA O MÁXIMO GRADIENTE NA I-ÉSIMA ESTRONCA. 
e para paredes rigidas:

$$
G_{\max }=\frac{0,5 \mathrm{E}_{a_{a} \mathrm{~S}^{\alpha}}}{1+\eta}
$$

A figura IV-10 mostra como os gradientes máximos va riam com a profundidade, para cada nível de estroncas da Seç̧ão Experimental 8. Observa-se que o crescimento com a profundidade $\vec{e}$ quase linear.

Este fato sugeriu a construção do gräfico da figura IV-11, onde a reta que passa pela origem representa um limite superior para os gradientes mäximos na i-ésima estronca, si tuada a uma distância $d_{i}$ da ültima estronca. Para o caso de solos heterogêneos, em que a rigidez cresce com a profundidade, è de se esperar que os gradientes nas estroncas dos niveis superiores sejam relativamente menores, quando comparados com solos homogêneos, como está ilustrado na figura IV-10, on de $\bar{\eta}$ foi obtido tomando-se para $E_{s}$ a média ponderada dos módulos em toda a profundidade da estaca metālica. Esta maneira de definir o parâmetro $\eta$ serä discutida no Capituzo VI.

$$
\text { Deste modo, pode-se escrever, para paredes flexi- }
$$

veis, que:

$$
G_{i}^{\max }=G_{\text {mäx }}-\frac{d_{i}}{140} E_{a} S_{a} \propto
$$

onde $G_{i}^{\text {máx }}$ è o gradiente mäximo na i-ésima estronca, distante $d_{j}$ da ültima delas, que apresenta um gradiente mäximo igual a $G_{\text {mäx }}$

7. NTVEL DE TENSOES NO SOLO PROVOCADO PELAS VARIAÇOES DE TEMPERATURA

Foi di to anteriormente que o nivel de tensões no so 10, provocado pelas dilataçōes das estroncas, é muito baixo. Pretende- 

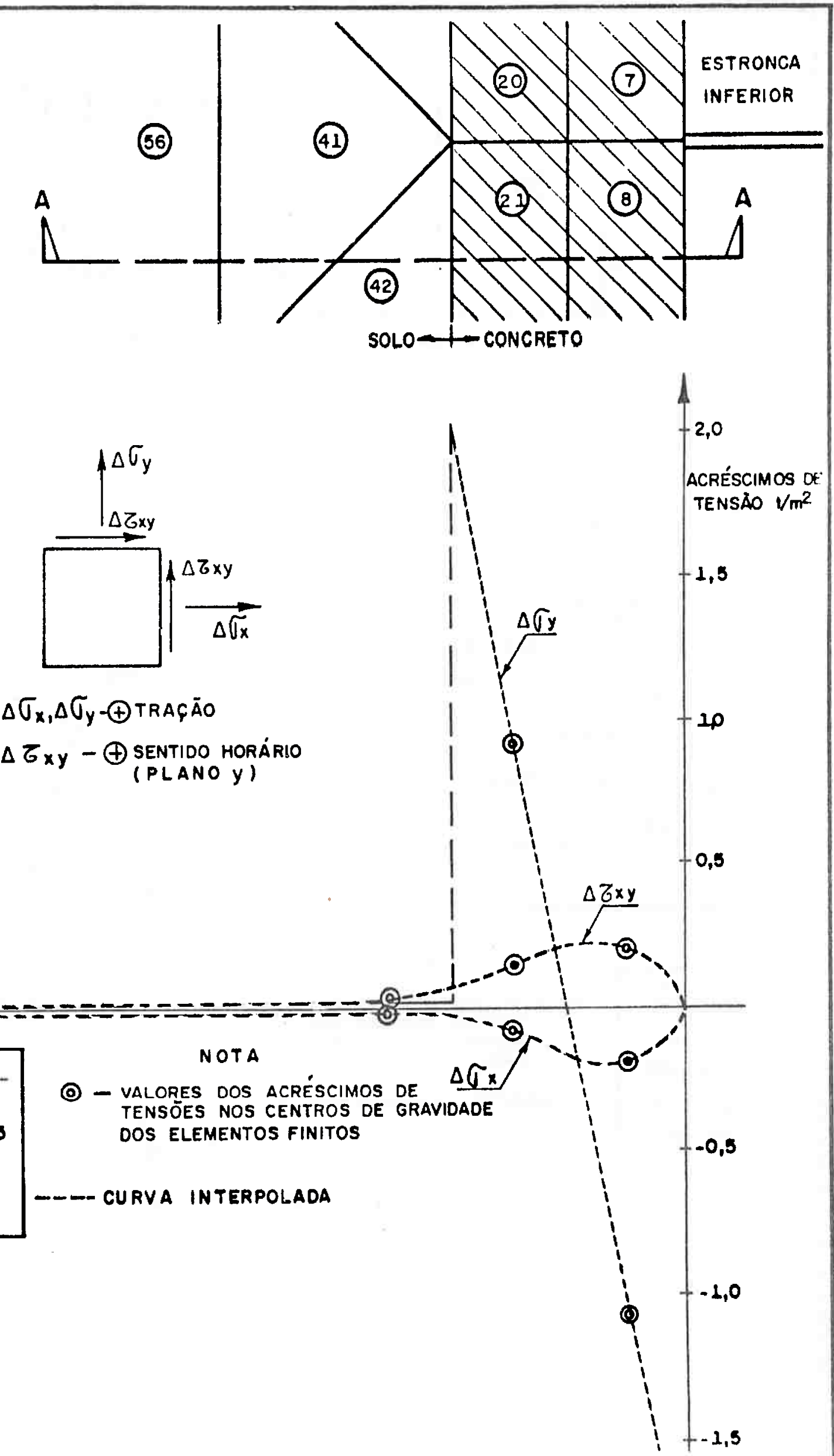

FIGURA LY-12: ACRÉSCIMOS DE TENSŌES NOS PONTOS DO PLANO A-A, PROVOCADOS PELO AQUECIMENTO DA ESTRONCA INFERIOR DE 1 •C - SECGĀO EXPERIMENTAL DO BLOCO 17-PAREDES RIGIDAS 


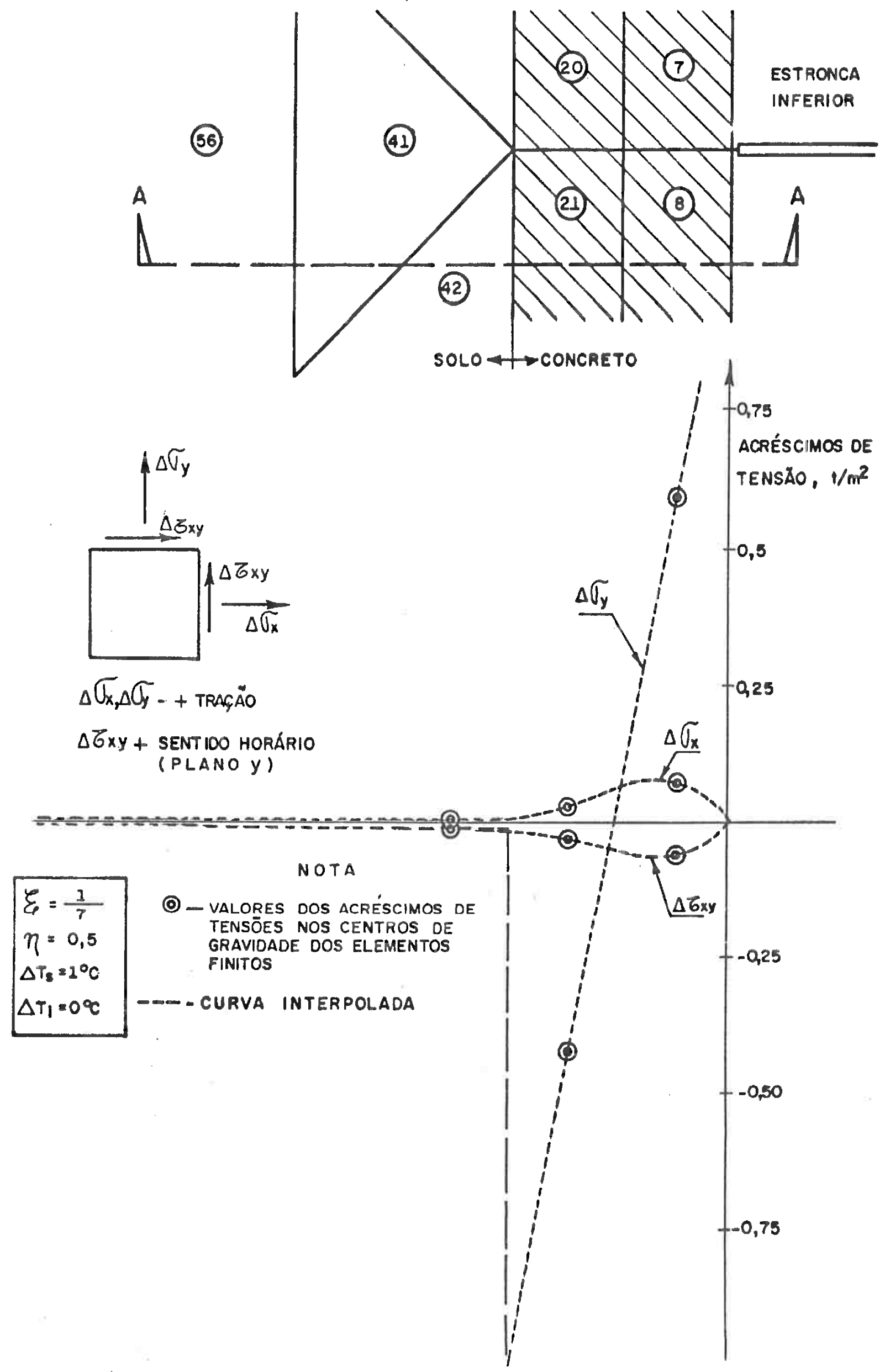

FIGURA IF-13: ACRÉSCIMOS DETENSÖES NOS PONTOS DO PLANO A-A, PROVOCADOS PELO AOUECIMENTO DA ES *TRONCA SUPERIOR DE I C - SECGÃO EXPERIMENTAL DO BLOCO I7-PAREDES RIGIDAS. 
se demonstrar esta asserção atravēs da anälise de resultados obtildos para o caso da Secção Experimental do Bloco 17, paredes rígldas.

As figuras IV-12 e IV-13 apresentam variações dos acréscimos (ou decréscimos) de tensöes, en planos horizontais e verticals, que passam por pontos situados ao longo do corte $\overline{A A}$, imediatamente abalxo do nivel inferlor de estroncas. Os resultados Indlcados na figura IV-12 referem-se ao aquecimento de $1^{\circ} \mathrm{C}$ da estronca superior; a figura IV-13 corresponde ao aquecimento da estronca inferlor, do mesmo valor de $1^{\circ} \mathrm{C}$

Como não podia deixar de ser, os acréscimos da tensão normal horlzontal e da tensão de cisalhamento são contínuos ao longo do contato solo-concreto; o mesmo não ocorre com relação aos acréscimos da tensão normal vertical. Esta si tuação ë anāloga àquela encontrada na distribulção de tensões em pavimentos flexíveis apolados em camada de so 10, em que os módulos de elastlcidade decrescem com a profundidade.

Os acrēscimos de tensōes transmitidos ao solo tendem assintoticamente a zero, à medida em que o ponto se afas ta da parede diafragma, ao longo da linha $\overline{A A}$, que praticamente coincide com a linha dos niveis inferlores de estroncas e aonde ocorrem os acréscimos de ten sōes māximas.

Quando a estronca inferior é aquecida de $1^{\circ} \mathrm{C}$, os acréscimos de tensão normal horizontal nunca ultrapassam o valor $8 \times 10^{-2}$ $\mathrm{t} / \mathrm{m}^{2}$ (compressão); quando is to se passa só com a superior, tem-se $2 \times 10^{-2}$ $t / m^{2}$ (tração). Assim, supondo um aquecimento de $40^{\circ} \mathrm{C}$ das duas es troncas, simuitaneamente, os acrëscimos de tensão no solo serão inferiores ou iguais a $40 \times(8-2) \times 10^{-2} \mathrm{t} / \mathrm{m}^{2}=2,4 \mathrm{t} / \mathrm{m}^{2}$.

A figura IV-14 apresenta as IInhas elästicas na interface solo-concreto, ora aquecendo-se somente a estronca superior, ora 


$$
\begin{array}{ll}
n & m \\
0 & 11 \\
5 & m
\end{array}
$$

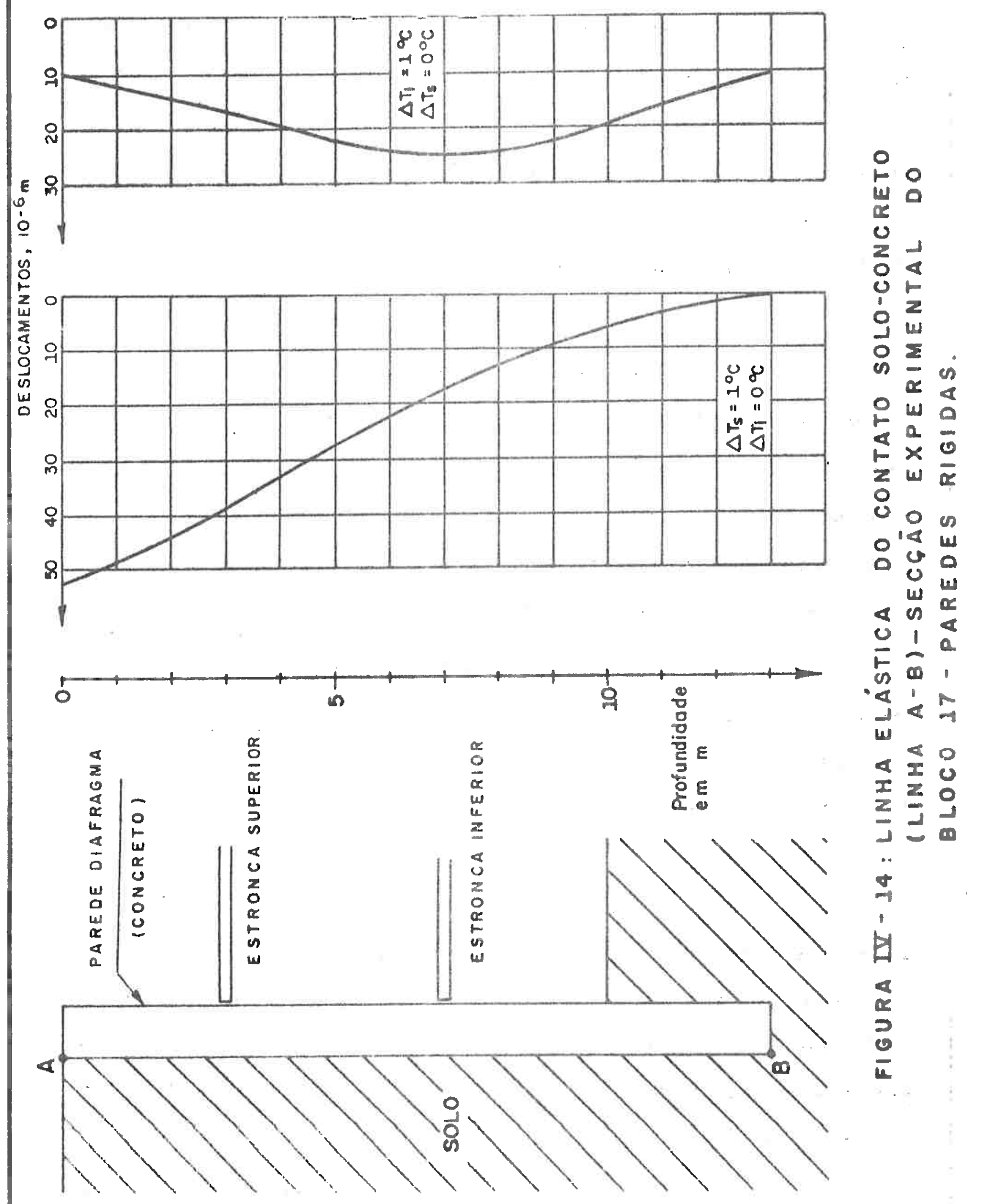


somente a inferior. Para a situação em que as duas estroncas são aquecidas ao mesmo tempo de $40^{\circ} \mathrm{C}$, os deslocamentos na altura das estroncas supe rior e inferior são, respectivamente, $2,2 \mathrm{~mm}$ e $1,7 \mathrm{~mm}$, calculados por superposição.

8. MODULOS DE DEFORMABILIDADE DOS SOLOS

Atẻ agora foram apresentados resultados de caräter teórico da aplicação do modelo matemático, com parâmetros adimensionalizą dos. A consideração das características reais de deformabilidade dos solos escorados exigirá uma incursão no domínio das propriedades dos solos de interesse a esta Investigação, valendo-se inicialmente dos dados dispo níveis de ensaios de laboratörio.

Como se supôs que a vala jā es tā escavada quando intervém o efeito da temperatura, um elemento de solo escorado é solicita do através de esforços repetitivos, apōs eventual alívio da tensão lateral de repouso. Assim, estā-se trabalhando numa faixa de recompressão do solo e mais, com incrementos de tensões baixíssimos.

E interessante notar o paralelismo existente entre - problema da influência da temperatura, aqui em foco, e aquele abordado pela Dinâmica dos Solos, em que o nível das tensões aplicadas é balxo e o solo é tratado como material elästico. 


\section{CARACTERTSTICAS DE DEFORMABILIDADE DOS SOLOS ESCORADOS}

1. PRELIMINARES

Os solos escorados, de interesse ao estudo das Sec ções Experimentais do Metró de São Paulo, consistiam de Argilas Porosas Vermelhas, sobrepostas às Argizas Rijas Vermelhas ou aos Solos Variegados. Às vezes, como na Secção Experimental 1, predominava um único tipo de solo em toda a profundidade da vala, no caso as Argilas Porosas Verme Ihas; outras vezes, havia a ocorrência das três formaçōes, como estā indicado na tabela II-1.

A caracterização destes solos típicos da cidade de São Paulo, com ênfase na sua origem geolögica e proprledades geotécnicas em geral, estā apresentada no Apêndice $F$.

Na sequência desta Investigação, enveredou-se por um estudo de suas características de deformabilidade, procurando-se trazer à luz subsídios para a aplicação do modelo matemātico, apresentado no Capitulo IV, aos casos de solos heterogèneos.

\section{CONCEITUAÇAOO BASIICA}

Os solos, materiais não-elásticos, em geral anisotróplcos, são considerados como elásticos em algumas si tuações, como por exemplo quando existem solicitações dināmicas, ou quando se trata de argilas al tamente prē-adensadas, como as de Londres, que, segundo Henkel 
(797\%), apresentám tracho inicial da curva tensão-deformação essencial mente linear e reversivel.

Normalmente, no entanto, quando se impōe uma carga a um solo, ocorrc uma defornaçāo instantàrea, elästica, seguida de uma deformação lenta, irreversivel, que depende da interısidade da carga e do tempo de sua aplicação. Se ela é aplicada e retirada varias vezes, chega se a estabelecer uma reversibilidade linear entre tensão e deformação, podendo-se pois falar em Mödulo de Young ou de Elasticidade do Solo, mas que, diferentemente de alguns outros materiais usados na Engenharia $\mathrm{Cl}$ vil, não è uma de suas propriedades intrínsecas. E pelo fato de as defor mações não serem necessariamente reversiveis que serā usado o nome Möduto de Deformabilidade.

Antes de abordar o comportamento desses solos típi cos da Cidade de São Paulo serã fei ta uma revisão bibliogrāfica sucinta, pondo em relevo conceitos básicos e fatores condicionantes da sua defor mabilidade, e a complexibilidade do problema em foco.

\subsection{Parâmetros elästicos}

Se for suposto que um certo solo tem comportamento elástico e isotrōpico, bastam dois parâmetros para definí-1o, a saber, o Módulo de Deformabilidade e o Coeficiente de Poisson. Nos ensaios conven cionais de laboratōrio as deformações são medidas depois da apllcação da pressão confinante e são o resultado exclusivo do acrëscimo das tensōes axiais. Assim sendo, a relação

$$
E=\frac{\Delta\left(\sigma_{1}-\sigma_{3}\right)}{\varepsilon_{1}}
$$

obtida com os dados do ensaio, fornece o Módulo de Deformabilidade Secan 
te $(E)$ do solo sob o aumento da tensão principal maior para uma pressão confinante constante. Esta constância torna-o independente do Coeficiente de Poisson; cuja determinação só pode ser feita através da medida da varlação volumétrica do corpo de prova, durante o ensaio.

Via de regra, em função da sua origem geolögica, os solos apresentam-se estratificados, com anisotropia transversal, isto $\bar{e}$, as suas propriedades são idênticas em qualquer direção de planos horị zontais. Como exemplo citam-se os casos de solos sedimentares, com ocorrência de microestratificações, ou de solos simplesmente sobre-adensados.

Nestas condiçöes, existem cinco parâmetros elästicos independentes que caracterizam o seu comportamento em termos de ten são-deformação; veja-se, por exemplo, Pieckering (1970) ou Henkel (1972), onde tambëm se encontram as Leis de Hooke generalizadas, aplicāveis ao caso.

E interessante realçar a influência da anisotropla nos Módulos de Deformabilidade, tal como foi apresentada por Henkel (1972), em trabalho publicado recentemente, sobre Argila de Londres.

Resultados de ensaios triaxiais rāpidos prë-adensados $(\vec{R})$, em corpos de prova talhados verticalmente, mostraram que esta arglla $\cdot \vec{e}$ mais rija horizontalmente, pois exige um maior valor do incremento da pressão de câmara efetiva para provocar uma certa distorção. 0 enrijecimento tende a aumentar para ensaios em corpos de prova talhados horizontalmente, tendo sido constatado que a relação entre os Mōdulos Efetivos Horizontal e Vertical é de 1,6. Em termos de tensōes totals, es ta relação variou no intervalo de 1,2 a 2,4, com média de 1,6.

\subsection{Fatores Condicionantes da Deformabitidade dos Solos}


Värios são os fatores que influem nas característi cas de deformabilidade dos solos, entre os quais incluem-se:

a) "o estado de tensōes a que esteve submetido anteriormente;

b) a trajetória das tensões, is to è, o tipo de solicitação imposta e as condigões de drenagem; e

c) o nivel de tensöes ou deformaçöroc aplicadas.

Mesmo que um solo normalmente adensado seja considerado isotrópico nos seus parâmetros de resistência e de pressão neutra, se houver uma rotação de $90^{\circ}$ na direção das tensões principais, o que implica em trajetōrias de tensões diferentes, a curva tensão-deforma ção, adimensionalizada em relação à tensão total vertical, será diferente daquela em que tal mudança não ocorra (Duncane Seed, 1966). Esta dife rença se acentua quando se trata de solos anisotröpicos (Lambe e Whitman, 1969 e Duncan e Seed, 1966).

Ademais, adensando-se anisotropicamente diversos solos com as tensões $\bar{\sigma}_{1 c}$ e $\bar{\sigma}_{3 c}$, Ladd (1964-b) mostrou que $E / \bar{\sigma}_{1 c}$ è função do tipo de carregamento (compressão ou extensão axial) em ensaios triaxiais do tipo $\bar{R}$. De novo a direção da tensão principal maior aplicada ao corpo de prova é relevante; o mesmo ocorre com o valor da tensão intermediāria imposta ao solo. Ademais, quando se passa de compressão axial $\left(\sigma_{2}=\sigma_{3}\right)$ para extensão axial $\left(\sigma_{1}=\sigma_{2}\right)$ os Mödulos $\mathrm{E}$ crescem. Daí ter concluido que os Módulos $E$ de ensaios de compressão triaxial devem ser menores do que os de deformação plana.

Esta conclusão foi confirmada experimentalmente por Henkel (1972) para Argila de Londres. Comparando os Mödulos de Deforma bilidade não drenados de ensaios de deformação plana e ensaios triaxiais $\bar{R}$, em corpos de prova talhados verticalmente, este autor chegou a uma relação de 1,3 a 1,5 , contra 1,4 obtido teoricamente com a aplicação 
da Lei de Hooke generalizada, supondo anisotropia transversal.

Uma vez fixada certa trajetōria de tensões, como por exemplo a de ensaios triaxiais com pressäo de câmara constante, è fato conhecido que o Mödulo de Deformabilidade E aumenta com o nível das tensões efetivas aplicadas e com a relação de sobre-adensamento (RSA). Foi - que mostraram Ladd (1964-b), experimentalmente, e, mais recentemente, Wroth (1972-b), com base teörico-experimental.

Partindo do Conceito de Estado Crítico, vālido para so̊los preparados em laboratörio, e de uma função exponencial ajustada pelo pröprio Wroth e Basset (1065) a curvas experimentais tensão-deforma ção, aquele autor provou que existe uma relação linear entre $E / P_{0}$ e o lo garítmo da RSA, sendo E o Módulo de Deformabilidade Iniclal ou para pequenas deformações, a tē mesmo $1 \%$. Note-se que:

$$
P_{0}=\frac{\bar{\sigma}_{1+2}^{0} \bar{\sigma}_{3}^{0}}{3}
$$

é a tensão efetiva média de adensamento; e

$$
\text { RSA }=\frac{P_{\text {mäx }}}{P_{0}}
$$

è a relação de sobre-adensamento, onde $p_{\operatorname{mäx}} \ddot{e}$ a māxima tensão efetiva mé dia a que o solo esteve submetido anteriormente. A validade desta relação linear foi verificada por Wroth ao reinterpretar resultados de ensaios feitos em Argila de Londres por outros pesquisadores ingleses.

$$
\text { Argumentando que a determinação de } P_{\text {māx }} \text { está sujei- }
$$
ta a erros, Wroth introduziu um novo parāmetro dado por

$$
e_{\lambda_{0}}=e_{0}+\lambda \log _{e} p_{0}
$$


(onde $e_{0} \dot{e}$ o indice de vazios associado a $p_{0}$ e $\lambda$ é o coeficiente ancular $d a$ Zinha do estado critico), que se correlaciona linearmente com $E / P_{0}$. Em outras palavras, no gräfico e- $\log p_{0}$ a relação $E / p_{0} \bar{e}$ constante ao longo de retas com coeficiente angular $(-\lambda)$. Finalmente Wroth pode estabelecer que $E$ varia linearmente com a profundidade $z$, para um perfil de subsolo da cidade de Londres.

Num outro contexto, para contornar esta dificuldade, o mesmo Wroth (1972-b) valeu-se da relação de sobre-adensamento comumente usada:

$$
R S A=\frac{\bar{\sigma}_{v m a ̈ x}}{\bar{\sigma}_{v}}
$$

onde $\underline{v}$ subentende vertical. Nas suas palavras, cada amostra extraída de uma certa profundidade $z$ sofreu uma diferente e desconhecida sobrecarga $p_{0}$ durante o seu adensamento, fenômeno que pode ter sldo complicado com cargas e descargas repetidas ciclicamente, por exemplo.

Trabalhando num campo puramente experimental e antecedendo as conclusões de Wroth, Ladd (1964-b) mostrou que para diversos tipos de solos saturados, alguns indeformados e outros amolgados, existe uma relação univoca não linear entre $E / \bar{\sigma}_{c}$ e a RSA, sendo $\bar{\sigma}_{c}$ a pres são de câmara em que o solo foi ensaiado em compressão triaxial $\bar{R}$; $E$, 0 Mödulo de Deformabilidade Secante; e RSA, a relação de sobre-adensamento, definida por:

$$
\mathrm{RSA}=\frac{\bar{\sigma}_{c \mathrm{~m}}}{\bar{\sigma}_{c}}
$$

Nesta expressão $\bar{\sigma}_{c m}$ é a máxima pressão a que o solo foi anteriormente adensado isotropicamente. A tendência é de $E / \sigma_{c}$ crescer com a RSA até um 
certo ponto, a partír do qual a variação não é bem definida. Mostrou tam bém que $E / \bar{\sigma}_{c}$ decresce com aumentos da resistência mobilizada, isto $\bar{e}$, com a relação entre o acrëscimo de tensão axial, no ponto em que se está defínindo $E$, e o mesmo acrēscimo no pico da curva tensão-deformação.

Um outro aspecto digno de nota refere-se à razăo entre $E_{1}$, Mödulo de Deformabilidade Secante para $1 \%$ de deformação, e a resistencia não drenada do solo. Wroth (1972-b) chegou a deduzir, para Argila de Londres, o valor de 150 para a relação:

$$
\frac{E_{1}}{\pi / 2 \cdot\left(\sigma_{1}-\sigma_{3}\right)_{\text {mäx }}}
$$

contra 140, obtido experimentalmente por Skempton e Henkez.

Relações deste tipo jā tinham sido sugeridas por outros autores. Assim è que Bjermum,citado por Ladd (1964b),chegou a valo res no intervalo 250 a 500 , para as argilas normalmente adensadas da Noruega; no mesmo sentido, Hanna e Adams (1968) obtiveram relações de 100 a 400 para uma argila de Ontärio. Obviamente ela depende do tipo de solo e nível de tensão ou deformação em que è definido o Mōdulo de Deformabilidade.

Há quem prefira trabalhar com Mödulos de Deformabi lidade obtidos em ensaios triaxiais após repetição estātica de ciclos de carga-descarga, a té estabilização, definindo o Móduzo de Recarga (Reload Modulus): terminado o adensamento, è aplicada uma tensão axial inicial (carga morta)que depois è aumentada e diminuida de um certo valor (carga viva).A sua adoção depende do tipo de problema a enfrentar, mas hā evidências de que ē a melhor maneira de se obter um Mödulo E para a estimativa de recalques de sapatas (Veja-se Perloff 1975 e Sodermanetal 1968d Assim, para Argilias de Londres, os dados de Ward et at (1959) conduzem a 
relação dada pela expressão $(V-7)$ a valores de 200 para o mödulo inicial e 300 para o módulo após segunda recarga, que, portanto, ē 1,5 vezes maior do que o inicial. Ainda segundo Ward, a relação entre os mödulos de carga e os de descarga, após dois ciclos de repetição, è da ordem de $70 \%$, para corpos de prova talhados de blocos indeformados. Finalmente, Witson e Dietrich (1960), entre outros, mostraram que os Módulos de Deformabili dade dinâmicos podem ser obtidos atravēs de ensaios estäticos, com repetição rāpida de ciclos de carga-descarga, e que estes módulos correlacio nam-se muito bem com a resistēncia não drenada, de uma forma não li near. Os seus dados levam à conclusão de que para as argilas ensaiadas, a expressão (V-7) varia no intervalo $350-700$.

Outros fatores condicionantes dos Mödulos de Deforma bilidade são decorrentes das técnicas de amostragem e de ensaio.

E fato muito conhecido que as perturbações em amostras tidas como indeformadas influem enormemente no Mödulo $E$, em ensaios não drenados, tendendo a diminuí-10, consequência de um aumento de pressão neutra desenvolvida durante o ensaio. Este efeito ē compreensivelmen te maior em ensaios triaxiais räpidos (Q) do que em ensaios rápidos préadensados (R) (Veja-se Ladd, 1964-b, e Bjermum, 1973). Ademais, o mesmo Ladd (1964-b) e Ward et al (1959) mostraram que este efeito prejudicial é mui to mais acentuado quando se usa amostradores ao invés de se talhar blocos indeformados nas paredes de poços. Para as argilas fissuradas de Londres, trabalhando-se com corpos de prova talhados de blocos e de tubos, foi verificada uma relação entre mödulos de 4 (mödulo inicial) ou 2 (mödulo de recarga). O fato deste último valor ser menor não é surpreendente, pois deve ter ocorrido um fechamento das fissuras, apōs a aplicação da carga morta, enrijecendo o solo; aliäs, a minimização dos efeitos nocivos da perturbação de amostras é um dos argumentos usados por aqueles 
que defendem o uso do Módulo de Recarga (Pertoff, 1975).

Värios autores mostraram a importância que a velocidade de deformação tem nos valores do Módulo E, em particular, e nas relações tensāo-deformação, em geral, obtidos atravēs de ensaios não dre nados, entre os quais citam-se: Canagrande e Shannon (1918); Casagrande -Wilron (1941); Bjerrnum et al (1958); Richardoon e Whitman (1964) e Ladd (1964-b). Richart et al (1970) assinalam que a relação dos módulos obtidos de ensaios mais rápidos (por exemplo, $1 \%$ de deformação por minuto) para aqueles mais lentos ( $1 \%$ em 500 minutos) varia de 1,1 a 3 , mas aler ta para o fato de que estes aumentos foram medidos para grandes deformações, acima de $1 / 3$ da resistência não drenada. Lambe e Whitman (1969) sugerem uma relação variando entre 1,5 e 2, entre o $E$ dinâmico e o $E$ estätico. O grande problema nos ensaios mais lentos reside no fato do aumento da pressão neutra no corpo de prova ser, pelo menos em parte, consequência da percolação de ägua atravēs da membrana (Bjermm et al, 1958 e Poulos, 1964), ou da migração de àgua nos vazios do solo, mercê da dís tribuição não uniforme das tensões e deformaçōes no corpo de prova (Richardson e Whitman, 1964).

As condiçōes de drenagem tambëm afetam significativamente os Módulos de Deformabilidade. Por exemplo, Wroth (1972-b) con cluiu que em ensaios triaxiais convencionais, em corpos de prova talhados verticalmente em Argila de Londres, a relação teōrica entre os Módulos E não drenados e drenados vale 1,34 ou 1,62 , se for suposto isotropia ou anisotropia, respectivamente.

Sobre este ültimo aspecto, Lambe e Whitman (1969) chegaram a uma relação tambëm teörica de 1,15 , supondo solo saturado e isotrópico. Mas afirmam que para as argilas normalmente adensadas podese atingir valores da ordem de 3 a 4 . 


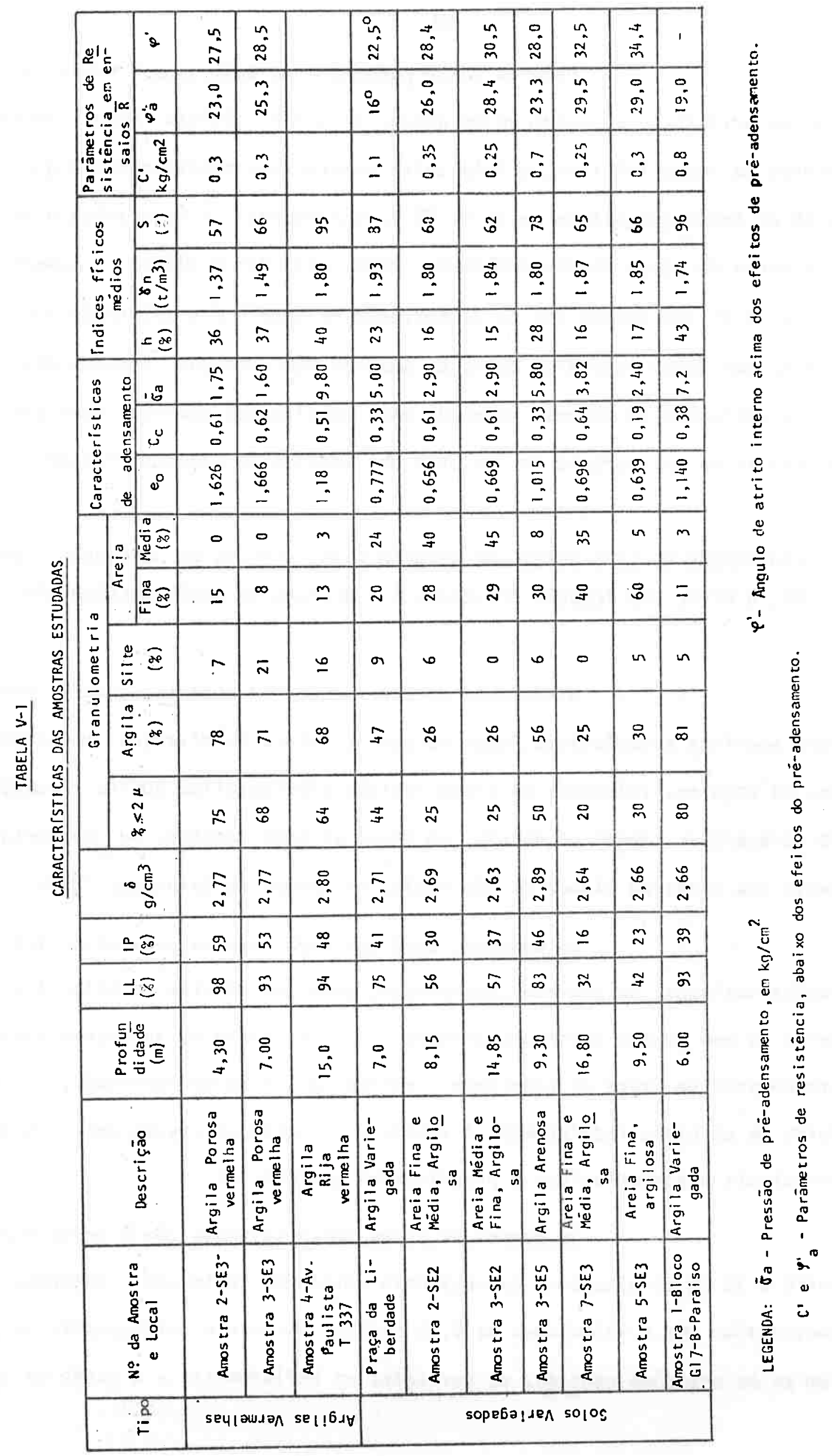


Para os solos parcialmente saturados, acredita-se que os princípios expostos acima sejam, em geral, välidos. Para incrementos de carga iniciais, o solo sofre compressōes acentuadas até que o grau de saturação atinja cerca de $85 \%$, quando então a ägua passa a rece ber parte da carga (Lambe e Whitman, 1969, pág. 435 e 8). Com aumentos desta, o ar dos vazlos val se dissolvendo na ăgua atë a saturação total. Assim, nas fases inlciais, mesmo em ensaios não drenados, ocorrem obviamente variações de volume, tornando mais complicadas anālises teöricas do efeito da anisotropla nos valores dos Módulos de Deformabilidade.

3. ILUSTRAÇÃO DE COMO OBTER UMA RELAÇĀO ENTRE MODULOS DE DEFORMABILIIDADE, O NIVEL DAS TENSOES APLICADAS E A RELAÇAO DE SOBRE-ADENSAMENTO

A carência de dados, quer em quantidade suficiente para anälises estatísticas, quer no que se refere ăt"diversas modalidades de ensaios, relatados na breve revisão bibliogräfica que se acabou de apresentar, impede um estudo, em todas as suas facetas, do comportamento dos solos da Cidade de São Paulo, em termos de deformabilidade.

No entanto, serä mostrado como se pode obter infor mações valiosas, se bem que incompletas, para uma amostra de solo. Trata-se de uma argila variegada arenosa, de cores amarela, laranja e rosa, proveniente da Praça da Liberdade, retirada a $7 \mathrm{~m}$ de profundidade, na forma de um bloco indeformado. A tabela $V-1$ contém um resumo das suas principais características e propriedades geotẻcnicas.

Os corpos de prova foram talhados com $5 \mathrm{~cm}$ de diâmetro e $12 \mathrm{~cm}$ de altura. O carregamento axial foi feito com deformação controlada, com a velocidade de $0,15 \mathrm{~mm} / \mathrm{min}$. Durante o carregamento medi ram-se as pressões neutras, as variaçōes no defletōmetro e a carga no di 


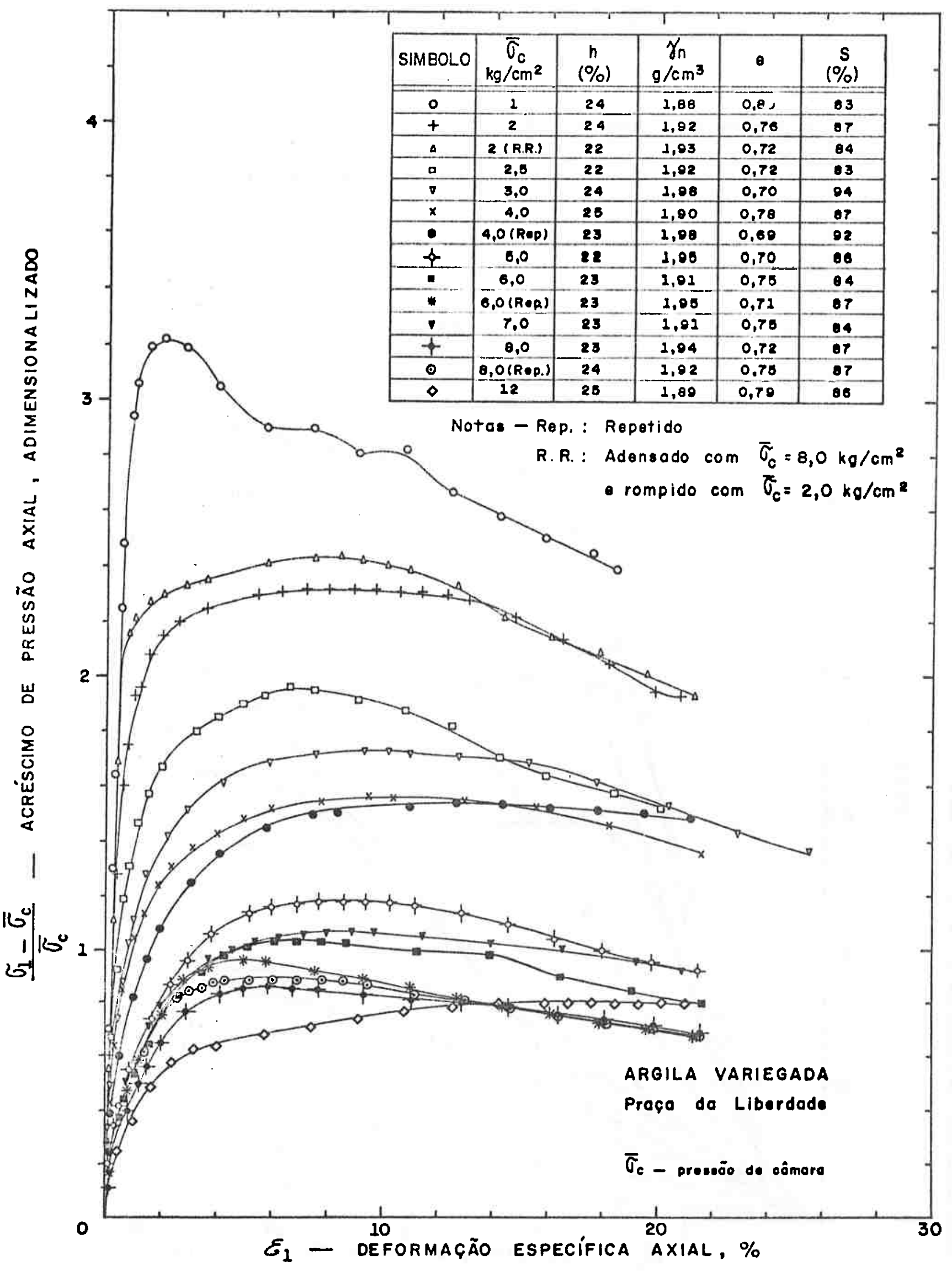

FIGURA Y-1: CURVAS TENSÃO - DEFORMAÇÃO DE ENSAIOS TRIAXIAIS RÁPIDOS PRÉ-ADENSADOS (I) ISOTROPICAMENTE. 


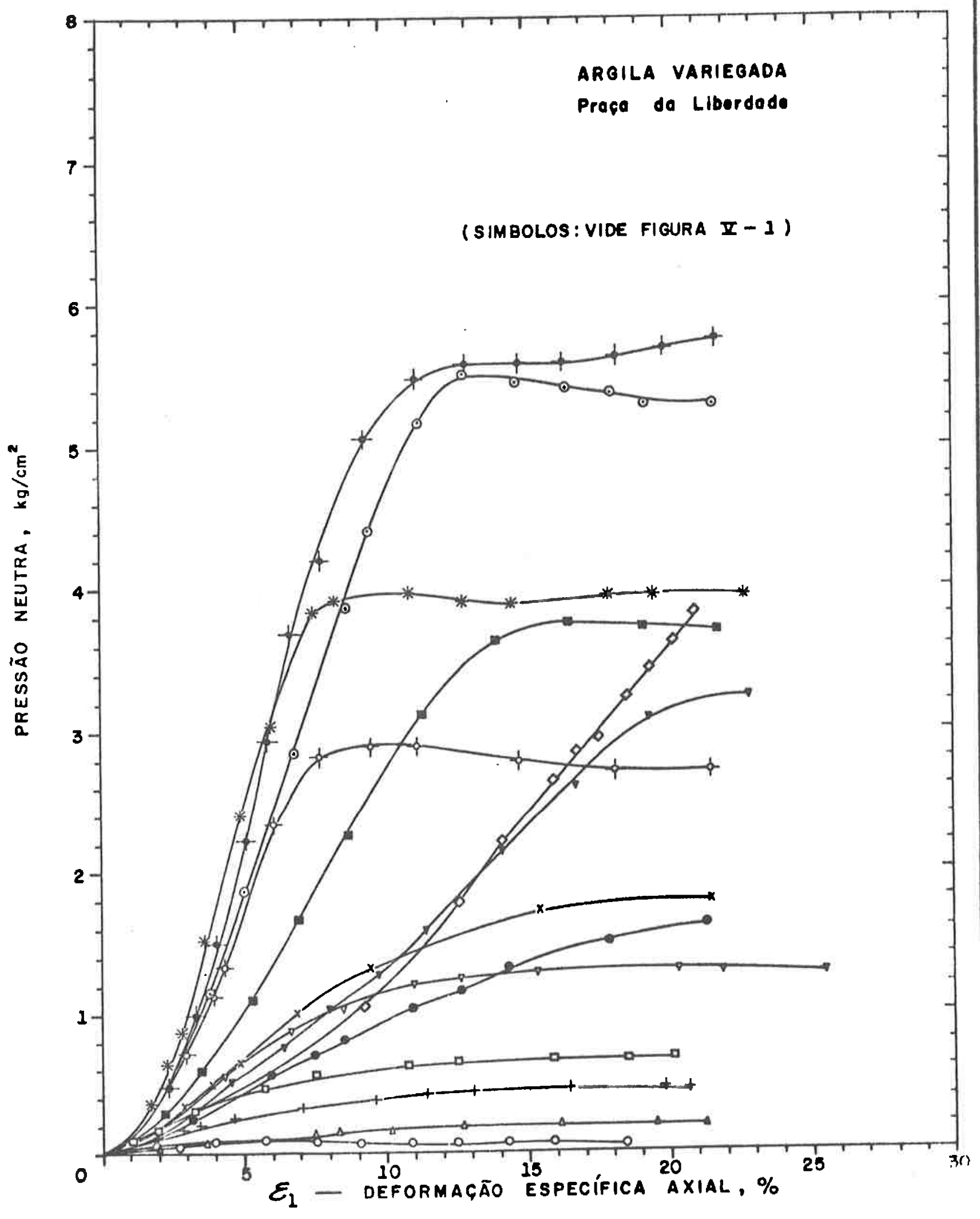

FIGURA $\square-2$ : DESENVOLVIMENTO DE PRESSÕES NEUTRAS ENSAIOS TRIAXIAIS RÁPIDOS PRÉ - ADENSADOS $(\bar{R})$ ISOTROPICAMENTE. 


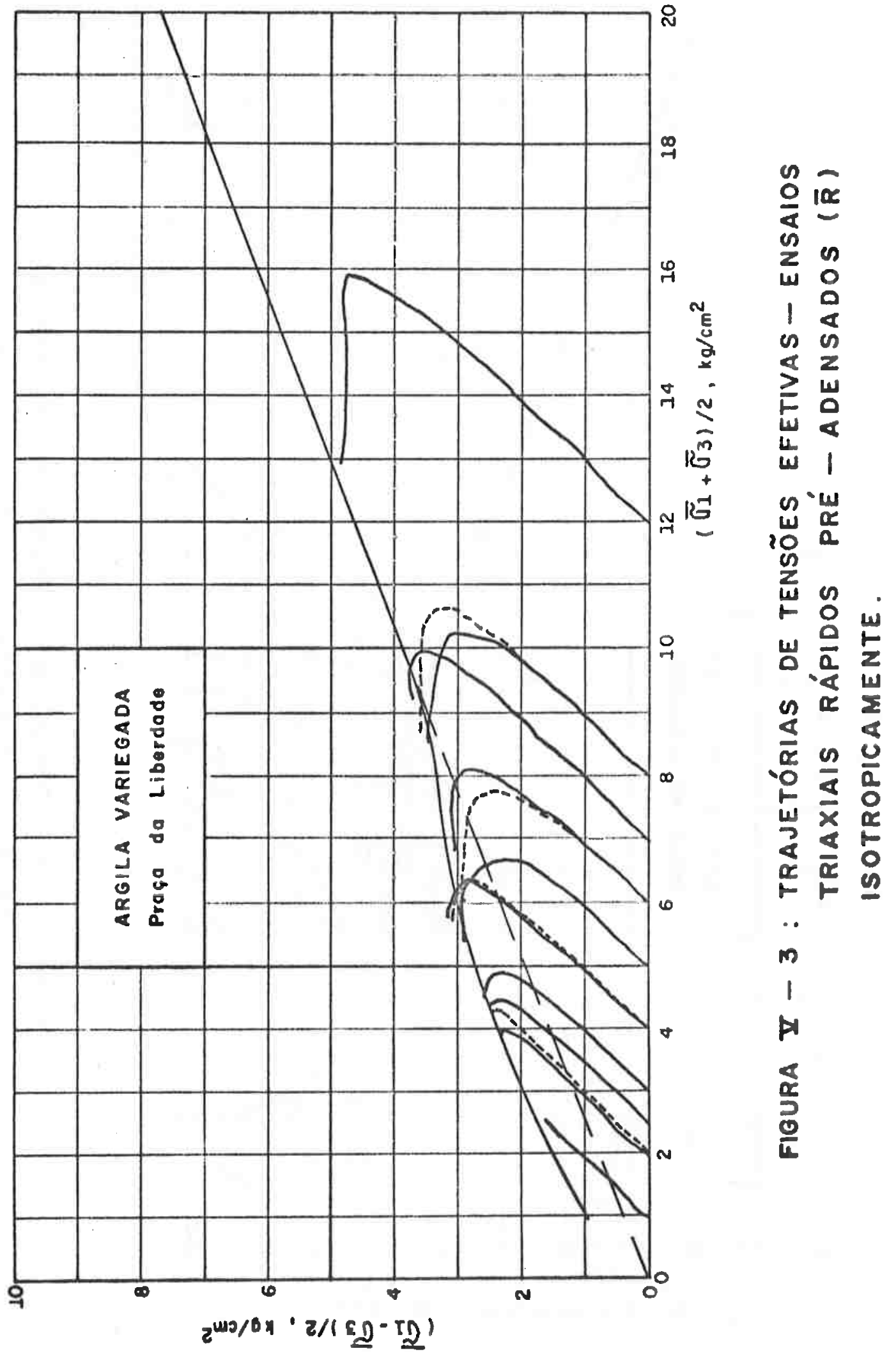




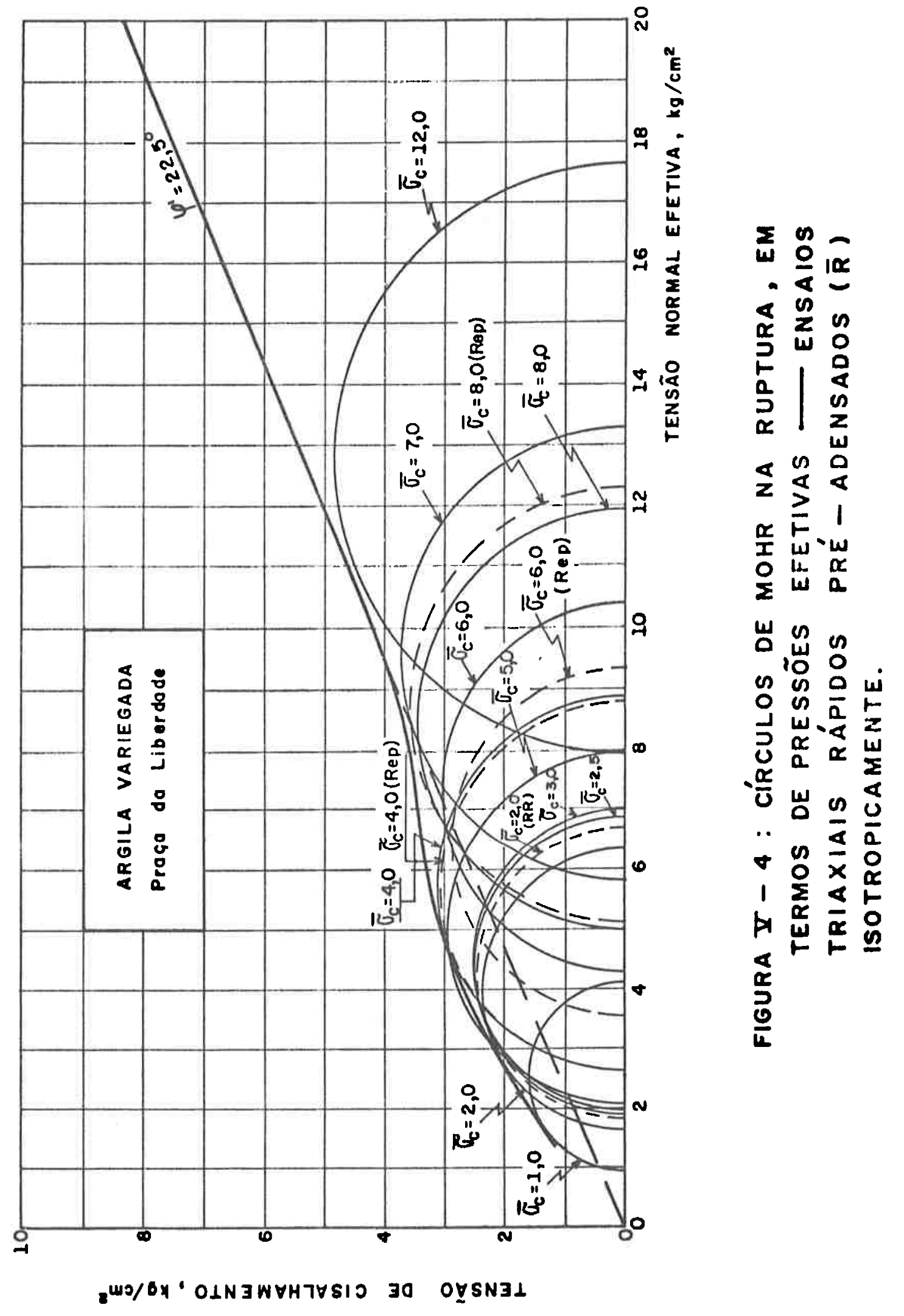


namōmetro, podendo-se, pois, traçar as curvas tensão-deformação axial; pressāo neutra-deformação axial e trajetörias de tensões efetivas, mostradas nas figuras $V-1$ a $V-4$.

0 grande nümero de ensaios se justificou pela heterogeneidade do bloco (vide indices físicos iniciais dos corpos de prova apresentados na figura $V-1$ ) e pela necessidade de se cobrir um intervalo de pressões confinantes de grande amplitude, tanto acima quanto aba xo dos efeitos do pré-adensamento. 0 ensaio com a pressão de câmara $\left(\bar{\sigma}_{c}\right)$ de $12 \mathrm{~kg} / \mathrm{cm}^{2}$ foi feito para definir com mais exatidão a envoltória de Mohr-Coulomb. Jā o ensaio indicado por $\bar{\sigma}_{c}=2(R R)$ foi executado adensando-se o corpo de prova com $\bar{\sigma}_{c}=8 \mathrm{~kg} / \mathrm{cm}^{2}$, portanto acima da pressão de prë-adensamento de $5 \mathrm{~kg} / \mathrm{cm}^{2}$; a seguir, a pressão de cāmara foi reduzida para $2 \mathrm{~kg} / \mathrm{cm}^{2} \mathrm{e}$, apōs a estabilização de deformações, inlciou-se o ensaio de cisalhamento propriamente dito; note-se que, neste caso, a relação de sobre-adensamento era igual a 4.

Um aspecto interessante refere-se à envoltómia de Mohr-Coulomb em termos de tensões efetivas, figura $V-3$, onde se nota que os efeitos do prë-adensamento são muito acentuados. Pensou-se na possibl lidade de uma cimentação entre as partículas do solo que, uma vez rompida, tenderia a apresentar, comparativamente, valores mais baixos de resistência. Essa hipótese, no entanto, foi descartada face ao resultado obtido para o ensaio indicado por $\bar{\sigma}_{c}=2(R R)$, mencionado acima, pois, a ser välida a hipötese, o adensamento prévio com $8 \mathrm{~kg} / \mathrm{cm}^{2}$ de pressão de câmara tería provocado a quebra nos pontos de cimentação, o que não se verificou.

Foram determinados três mōdulos de deformabillidade, a saber:

$E_{1}$ - Módulo de Deformabilidade Secante para 1 \% de deformação; 
$\mathrm{E}_{50}$ - Mödulo de Deformabilidade Secante para $50 \%$ da resistência mobili$z a d a ;$

$E_{\mathbf{i}}$ - Mödulo de Deformabilidade Inicial, definido como sendo o coeficien te angular da reta ajustada zos três primeiros pontos da curva ten são-deformação; invariavelmerte, o tercelro ponto correspondia a uma deformação de cerca de $0,1 \%$.

E razoävel supor que $E_{i}$ representa melhor o Mödulo de Deformabilidade dos solos escorados das Secções Experimentais com paredes flexíveis, em final de escavação, face à grandeza, de pequena monta, dos deslocamentos horizontais medidos nas paredes de escoramentos, co mo será mostrado no Capítulo IX. Esta é a razão pela qual se deu mais ên fase a es te Mödulo, na sequência desta Investigação.

Acima dos efeitos do prë-adensamento, o mödulo $E_{50}$ apresentou os seguintes valores:

$\begin{array}{llc}\bar{\sigma}_{c}\left(\mathrm{~kg} / \mathrm{cm}^{2}\right) & E_{50}\left(\mathrm{t} / \mathrm{m}^{2}\right) & E_{50} / \sigma_{c} \\ 5 & 2.700 & 54 \\ 6 & 3.100 & 52 \\ 6 \text { (Repetido) } & 3.300 & 55 \\ 7 & 4.000 & 57 \\ 8 & 3.850 & 48 \\ 8 \text { (Repetido) } & 5.200 & 65 \\ 12 \text { (2) } & 4.800 & 40\end{array}$

Aos mōdulos adimensionalizados, indicados na ültima coluna, estão associados um valor mëdio de 53 e um desvio padrão de 8; as dispersões podem ser atribuidas à heterogeneldade do solo. Tal fato se estende a outros valores da resistência mobilizada, o que permitiu traçar a curva indica- 


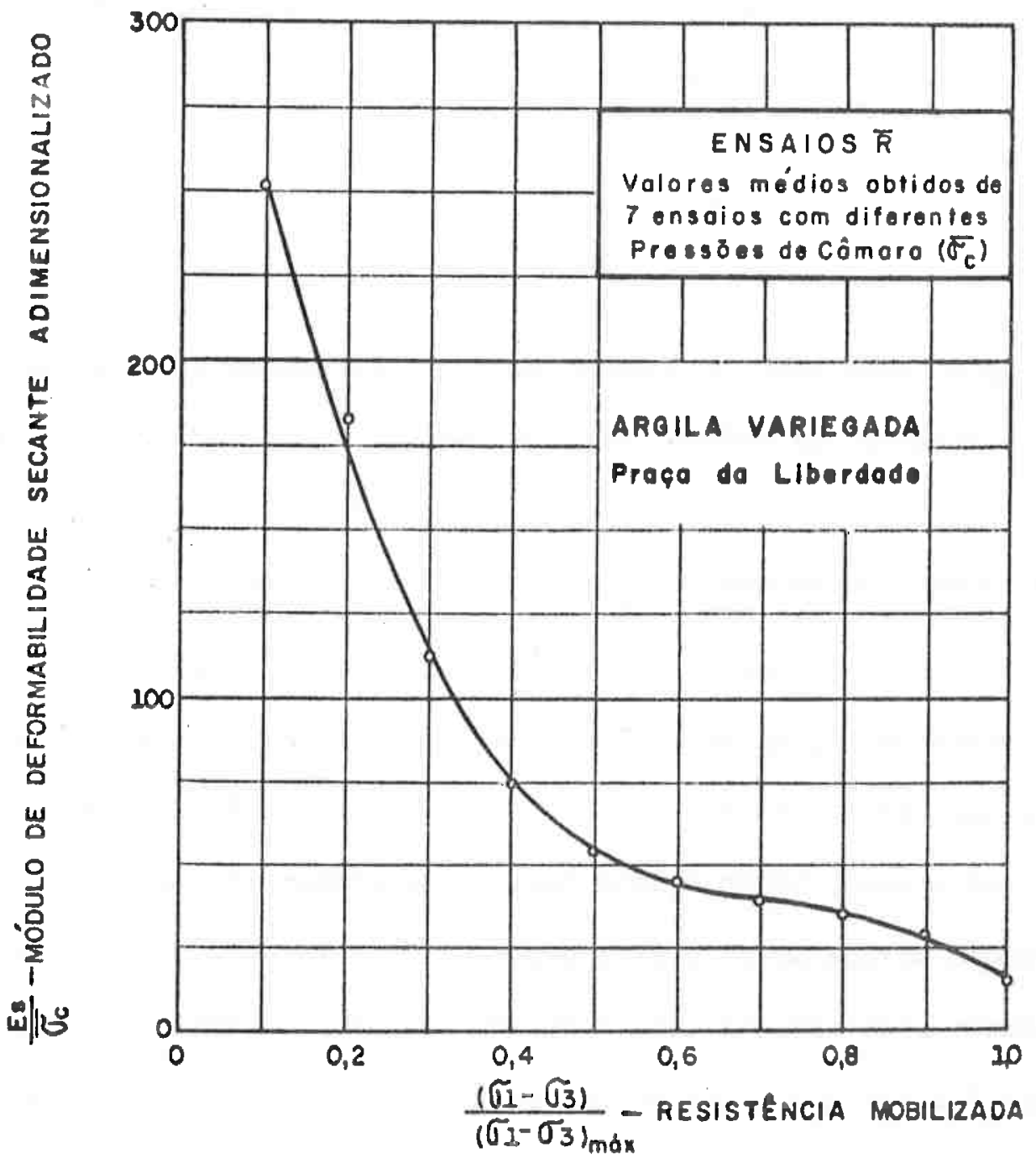

FIGURA $\Psi$ - 5 : VARIAÇÃO DO MÓDULO DE DEFORMABILIDADE SECANTE COM O NIVEL DE TENSÕEs, ACIMA DOS EFEITOS DO PRÉ-ADENSAMENTO. 
da na figura $V-5$, que realça a sua grande influência nos valores dos Módulos de Deformabilidade.

Na figura $V-6$ os três Mödulos de Deformabilidade

estão correlacionados linearmente con o logarítmo da relação de sobreadensamento, tomada como sendo:

$$
R S A=\frac{\bar{\sigma}_{a}}{\bar{\sigma}_{c}}
$$

is to é, como a razão entre a pressão de prē-adensamento e a pressão de câmara. Verifica-se, de inicio, uma confirmação das conclusões de Wroth $(1972-b)$, relatadas anteriormente. No entanto, näo se obteve tal lineari dade para o conjunto de amostras de solos analisadas mais adiante.

E curioso observar, reportando-se ainda à figura $V-6$, que o fato do $E_{50}$ aproximar-se do $E_{i}$ para valores elevados da RSA e, para baixos valores desta relação, coincidir com $\circ E_{1}$, não é fortuito. No primeiro caso, sendo o solo bastante prë-adensado, a curva tensão-deformação atinge um pico para pequenas deformações, sendo o seu tre cho ascendente praticamente retilíneo. No segundo, o carāter normalmente adensado faz com que a tensão mäxima ocorra para deformações mais altas, alēm do que o trecho inicial da relação tensão-deformação é curvo.

4. MODULOS DE DEFORMABILIDADE DE SOLOS DA CIDADE DE SAO PAULO

Is to posto, procurou-se definir as características de deformabilidade das Argilas Vermelhas (tanto as porosas quanto as rijas) e dos Solos Variegados, através de ensaios triaxiais $\bar{R}$, executados, em geral, em corpos de prova de $9 \mathrm{~cm}$ de altura e $10 \mathrm{~cm}^{2}$ de ärea da base, talhados invariavelmente de blocos de solos indeformados. 


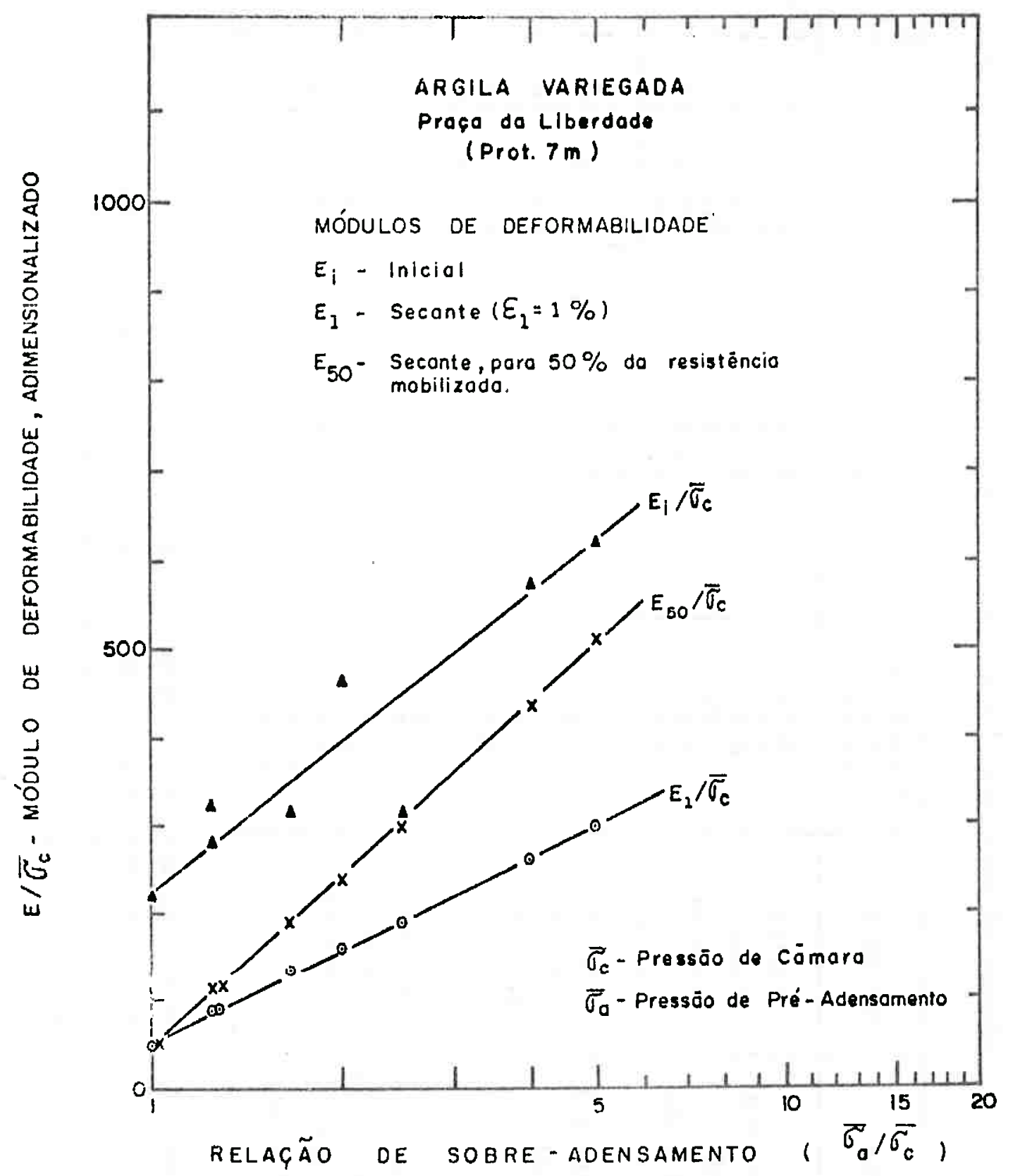

FIGURA $\Psi-6$ : VARIAÇĀO DOS MÓDULOS DE DEFORMABILIDADE COM A PRESSĀO $\bar{\sigma}_{c}$ E COM A RELAÇĀO $\bar{\sigma}_{a} / \bar{\sigma}_{c}-$ ENSAIOS TRIAXIAIS RÁPIDOS PRÉ-ADENSADOS( $\bar{R})$ IS OTROPICAMENTE. 


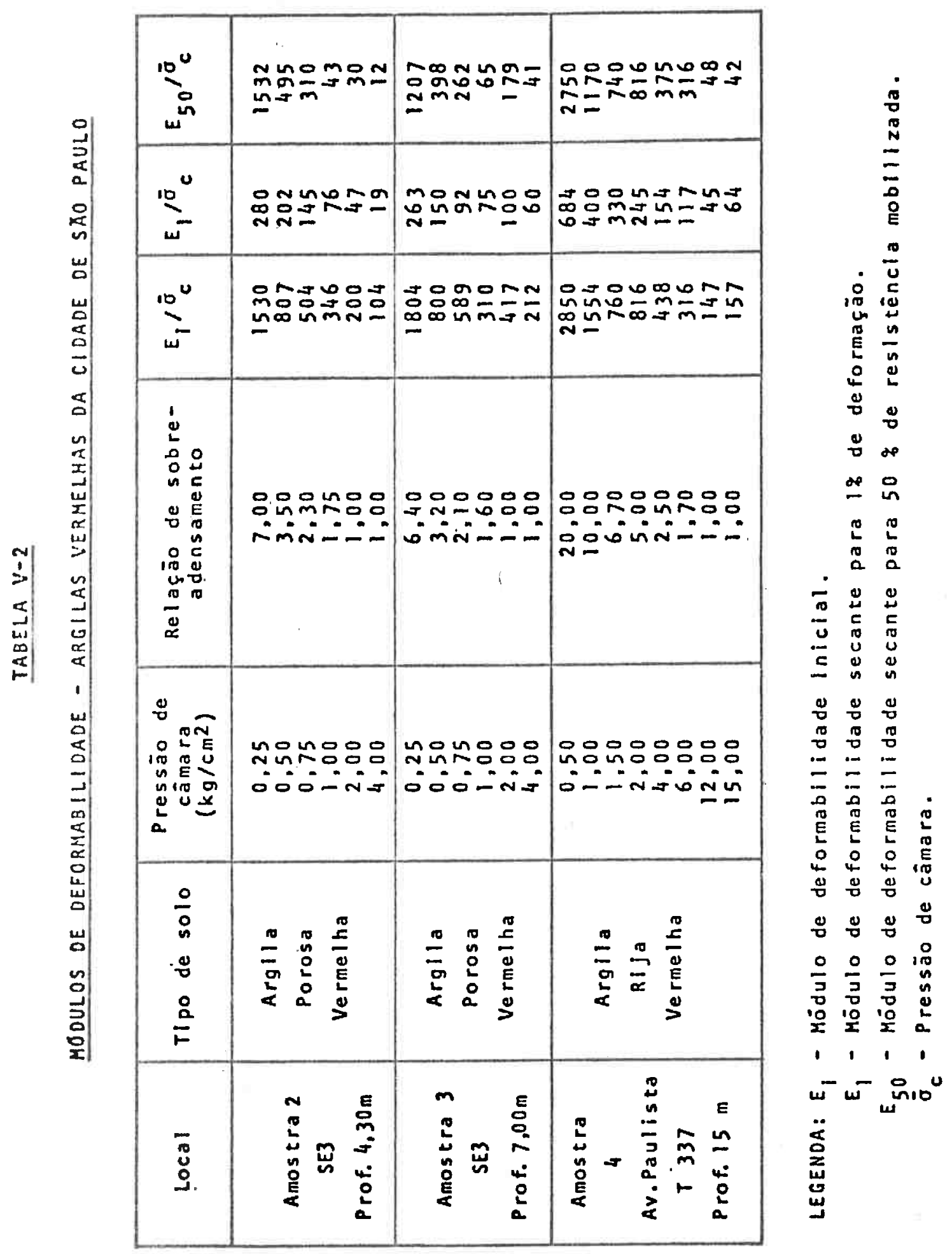




\subsection{Argilas Vermelhas (Porosas e Rijas)}

A tabela V-2 mostra os valores obtidos para os Mödulos, para duas amostras de Argila Porosa Vermelha e uma de Argija Rija Vermelha, cujas caracteristicas estão indicadas na tabela V-1.

Nas figuras $V-7, V-8$ e $V-9$ mostram-se faixas de variação dos tres Mödulos adimensionalizados, em função do logarítmo da re lação de sobre-adensamento, definida pela expressão $(V-8)$. Vê-se que, pa ra os Módulos $E_{1}$ e $E_{50}$, esta faixa è relativamente estrelta, o mesmo não ocorrendo para o $E_{i}$, razão pela qual separou-se as Argilas Porosas das Argilas Rijas Vermelhas, na figura V-7. Em todos os casos as relações são não lineares, coincidindo neste sentido com os resultados experimentais obtidos por Ladd $(1964-b)$, em trabalho comentado no item 2.2. acima.

$$
\text { Diante deste fato, e na tentativa de simplificar o }
$$
problema, obteve-se para as Argi las Porosas Vermelhas uma boa correlação Zinear entre $\mathrm{E}_{\mathrm{i}} / \bar{\sigma}_{\mathrm{c}}$ e a RSA, ambas em escalas aritméticas, conforme estā ilustrado na figura $\mathrm{V}-10$.

Correlaçöes do tipo:

$$
\frac{E_{1}}{\bar{\sigma}_{v}}=K \cdot \operatorname{RSA}
$$

onde $K$ è uma constante e $\bar{\sigma}_{v}$ a tensão vertical efetiva a que o solo esteve submetido,. implicam nas seguintes conclusöes, supondo tratar-se de um solo homogêneo, com pressão de pré-adensamento $\left(\sigma_{a}\right)$ constante em toda a profundidade $(z)$ :

a) abaixo dos efeitos do pré-adensamento

$$
\text { RSA }=\frac{\bar{\sigma}_{a}}{\bar{\sigma}_{v}} \operatorname{com} \bar{\sigma}_{v}=\gamma . z
$$




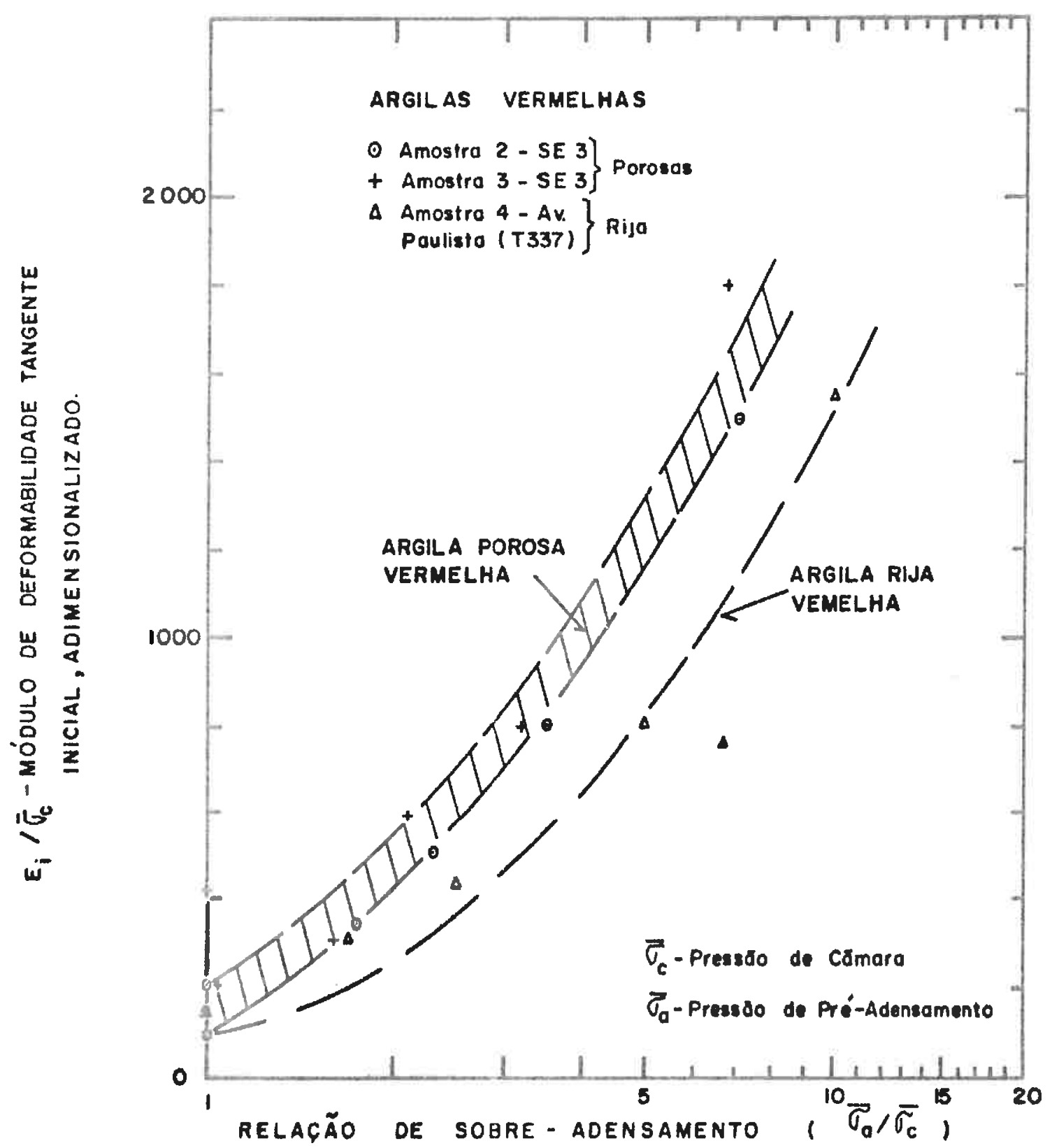

figura I - 7 I faIXa de VAlores do módulo de DEFORMABILIDADE - ENSAIOS TRIAXIAIS

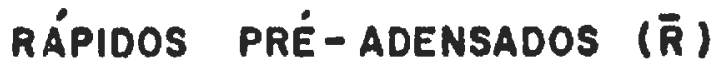
ISOTROPICAMENTE. 


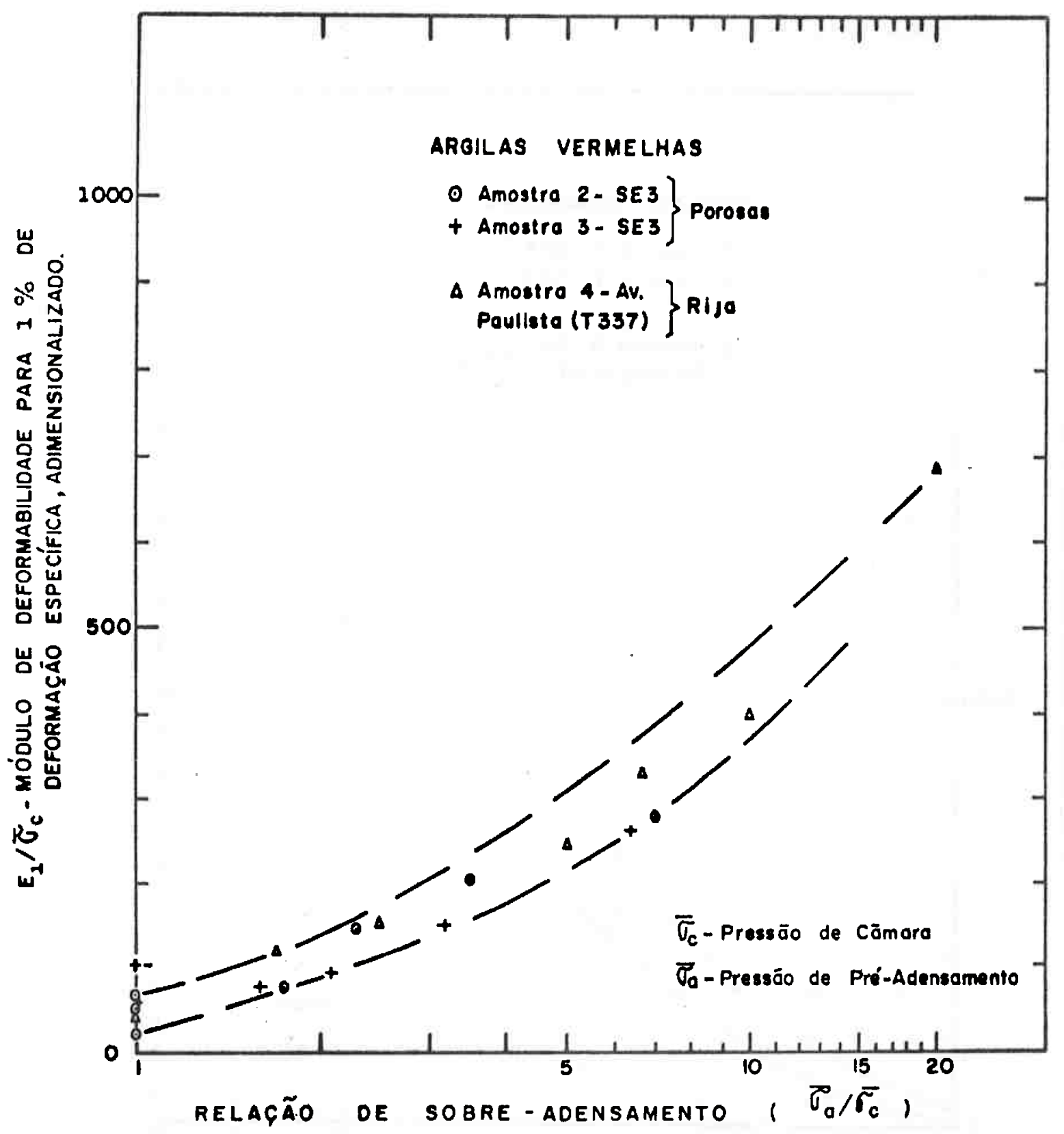

FIOURA Y - 8 : FAIXA DE VALORES DO MÓdULO DE DEFORMABILIOADE - ENSAIOS TRIAXIAIS RÁPIDOS PRÉ - ADENSADOS ( $\bar{R})$ ISOTROPICAMENTE. 


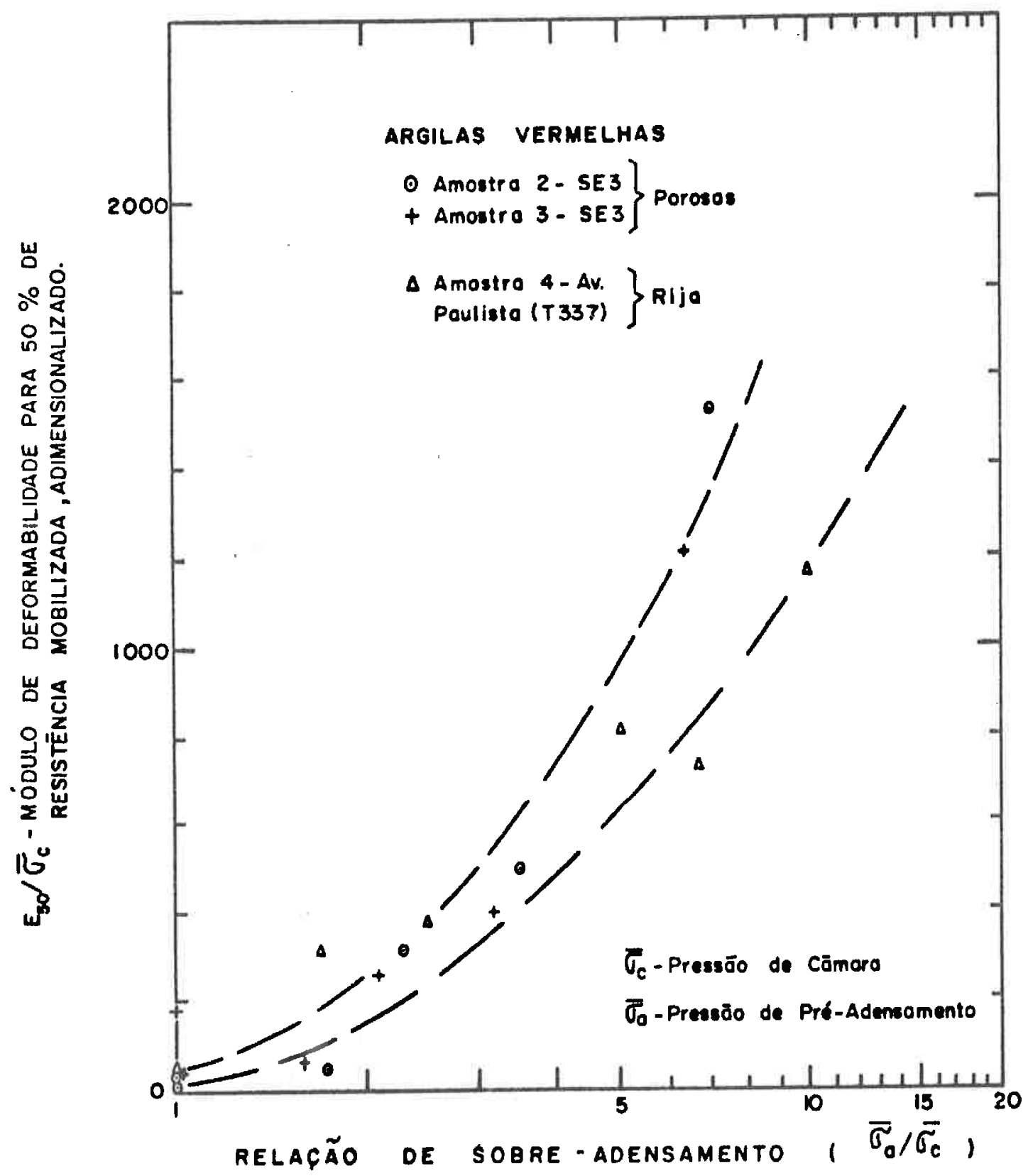

FIGURA $\mathbf{Y}$ - 9 : FAIXA DE VALORES DO MÓdULO DE OEFORMABILIDADE - ENSAIOS TRIAXIAIS RÁPIDOS PRÉ-ADENSADOS $(\bar{R})$ ISOTROPICAMENTE. 


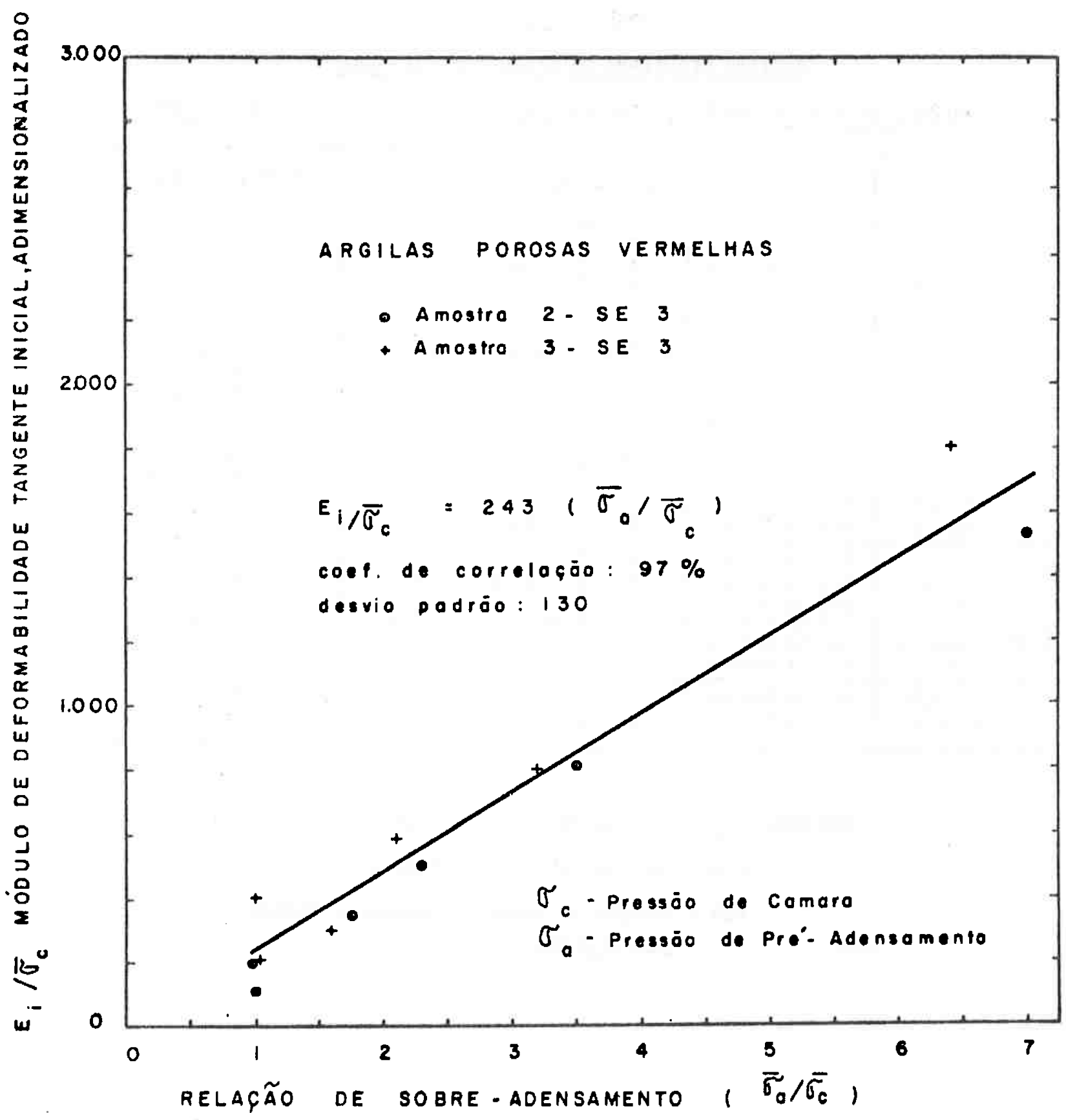

FIGURA V-10: CORRELAGĀO LINEAR ENTRE O MÓDULO DE DEFORMABILIDADE TANGENTE INICIAL E A RELAÇÁO $\bar{\sigma}_{0} / \bar{\sigma}_{c}$ 
TABELA V-3

ARGILAS VERMELHAS OA CIDADE DF SRO PAULO

VALORES DA RSA EM FUNCAO DA PROFUNDIDAOE PARA VARIOS PERFTS DE SUBSOLO

\begin{tabular}{|c|c|c|c|c|c|c|}
\hline Local & Tipo de Solo & $\begin{array}{c}\text { Amos tro } \\
n ?\end{array}$ & $\begin{array}{l}\text { Profundi dade } \\
\text { (m) }\end{array}$ & $\begin{array}{c}\bar{\sigma}_{a} 2 \\
\left(\mathrm{~kg} / \mathrm{cm}^{2}\right)\end{array}$ & $\begin{array}{l}\sum \gamma_{z_{2}} \\
\left(t / m^{2}\right)\end{array}$ & RSA \\
\hline $\begin{array}{c}\text { Center } \\
3\end{array}$ & $\begin{array}{l}\text { Argila Porosa } \\
\text { Argila Porosa } \\
\text { Argila Porosa } \\
\text { Argila Rija } \\
\text { Argila Rija }\end{array}$ & $\begin{array}{l}1 \\
2 \\
3 \\
4 \\
5\end{array}$ & $\begin{array}{r}3,5 \\
6,5 \\
10,8 \\
13,8 \\
16,0\end{array}$ & $\begin{array}{l}2,2 \\
1,4 \\
1,7 \\
5,2 \\
6,6\end{array}$ & $\begin{array}{l}5,6 \\
10,4 \\
17,3 \\
22,1 \\
25,6\end{array}$ & $\begin{array}{l}3,9 \\
1,4 \\
1,0 \\
2,4 \\
2,6\end{array}$ \\
\hline $\begin{array}{l}\text { Poço } 106 \\
\text { Pamplona }\end{array}$ & $\begin{array}{l}\text { Argila Porosa } \\
\text { Argila Porosa } \\
\text { Argila Porosa } \\
\text { Argila Rija }\end{array}$ & $\begin{array}{l}1 \\
2 \\
3 \\
4\end{array}$ & $\begin{array}{r}5,0 \\
8,0 \\
11,0 \\
14,0\end{array}$ & $\begin{array}{l}1,3 \\
3,8 \\
2,6 \\
5,6\end{array}$ & $\begin{array}{r}8,0 \\
12,8 \\
17,6 \\
23,0 \\
\end{array}$ & $\begin{array}{l}1,6 \\
3,0 \\
1,5 \\
2,4\end{array}$ \\
\hline $\begin{array}{c}\text { T } 337 \\
\text { Briga- } \\
\text { deiro }\end{array}$ & $\begin{array}{l}\text { Argila Rija } \\
\text { Argila Rija } \\
\text { Argila Rija }\end{array}$ & $\begin{array}{l}2 \\
3 \\
4\end{array}$ & $\begin{array}{l}10,0 \\
12,5 \\
15,0 \\
\end{array}$ & $\begin{array}{l}4,5 \\
5,1 \\
9,8 \\
\end{array}$ & $\begin{array}{l}16,0 \\
20,5 \\
25,0 \\
\end{array}$ & $\begin{array}{l}2,8 \\
2,5 \\
3,9 \\
\end{array}$ \\
\hline $\begin{array}{r}35-T 3 \\
333-T 3 \\
119-T 2\end{array}$ & $\begin{array}{l}\text { Argila Rija } \\
\text { Argil la Rija } \\
\text { Argila Rija }\end{array}$ & $\begin{array}{l}1 \\
1 \\
1\end{array}$ & $\begin{array}{l}16,1 \\
17,6 \\
14,4 \\
\end{array}$ & $\begin{array}{l}9,0 \\
7,4 \\
7,2 \\
\end{array}$ & $\begin{array}{l}27,0 \\
30,0 \\
24,0 \\
\end{array}$ & $\begin{array}{l}3,3 \\
2,5 \\
3,0 \\
\end{array}$ \\
\hline $\begin{array}{c}\text { R. Vergue i ro } \\
\text { (SE6) }\end{array}$ & $\begin{array}{l}\text { Argila Porosa } \\
\text { Argila Porosa }\end{array}$ & $\begin{array}{l}91 \\
92 \\
\end{array}$ & $\begin{array}{l}6,7 \\
9,0 \\
\end{array}$ & $\begin{array}{l}1,1 \\
2,1 \\
\end{array}$ & $\begin{array}{l}10,5 \\
14,0 \\
\end{array}$ & $\begin{array}{l}1.1 \\
1.5 \\
\end{array}$ \\
\hline $\begin{array}{l}\text { Estaçāo } \\
\text { Paraíso }\end{array}$ & $\begin{array}{l}\text { Argi la Porosa } \\
\text { Argila Porosa }\end{array}$ & $\begin{array}{l}101 \\
102\end{array}$ & $\begin{array}{l}6,7 \\
8,7\end{array}$ & $\begin{array}{l}2,1 \\
2,1\end{array}$ & $\begin{array}{l}10,5 \\
15,0\end{array}$ & $\begin{array}{l}2,0 \\
1,4\end{array}$ \\
\hline
\end{tabular}

LEGENDA: $\quad \bar{\sigma}_{a}$ - Pressão de prë-adensamento

¿Yz - Peso de terra na profundidade $\underline{z}$.

RSA - Relaçăo de sobre-adensamento, tomada como $\dot{\sigma}_{a} / \Sigma_{Y z}$. 


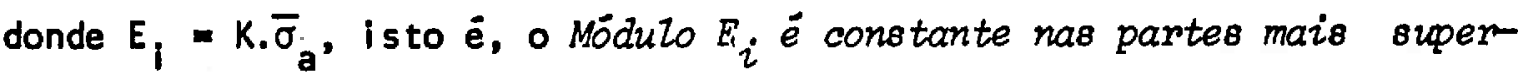
ficiais da camada; e

b) acima dos efeitos do prë-adensamento tem-se:

$$
\text { RSA }=1
$$

donde :

$$
E_{i}=K \cdot \gamma z
$$

is to $\overline{\mathrm{e}}$, O Módulo $E_{i}$ cresce linearmente com a profundidade para as partes mais profundas da camada.

E bom lembrar aliảs que Terzaghi (1955) propôs uma expressão semelhante para o Mödulo E de arelas, em condições de solicitação horizontal, onde a constante que multiplica o peso efetivo de terra assumia valores médios de 200,600 e 1500, conforme a sua compacidade fosse fofa, medianamente compacta ou densa, respectivamente. Para as Areias Basais da Cidade de São Paulo, Vargas (1961) calculou, atravēs de uma anälise retroativa a partir de recalques medidos em prëdios de mals de 20 andares, um valor de 1.000 para esta constante.

Na verdade, os solos da Cidade de São Paulo em geral, e as Argilas Porosas Vermelhas em partịcular, não são homogêneos, pelos motivos expostos no Apêndice $F$, razão pela qual foram tomados perfis de subsolo de värios locais, como estä indicado na tabeza V-3. As amostras indeformadas foram retiradas na forma de blocos, de poços abertos para es te fim. Na mesma tabela mostra-se também os valores da pressão de prē-adensamento e da RSA, que apresenta uma médla de 1,8 (desvio padrão de 0,9$)$.

Entrando-se com este valor mëdio no gräfico da figura V-10 tira-se, para as Argilas Porosas Vermelhas: 


$$
E_{i} / \bar{\sigma}_{c}=440
$$

Serã adotado para $\bar{\sigma}_{c}$ o valor do peso de terra efetivo, pois os esforços impostos ao solo escorado, pela dilataçăo tẻrmica das estroncas, è horizontal. Tacitamente, estão sendo admitidas duas simplificações. Em primeiro lugar, os ensaios de que se está tratando foram feitos en corpos de prova talhados verticalmente dos blocos indeformados, ignorando-se assim efeitos de anisotropia, isto $\bar{e}$, fol admiti da isotropia. Segundo, não se considerou o efeito da tensão principal intermediäria, que como se viu no item 2.2. deste capituzo, influi nos valores dos Módulos de Deformabilidade.

Estas simplificações se justificam, nesta etapa da presente Investigação, para tornar possivel, pelo menos, a determinação das tendências de variação do Módulo $E_{i}$ com a profundidade.

$$
\text { Voltando-se às Argilas Porosas Vermelhas e tendo }
$$

em mente as conclusões acima sobre camadas superficiais de solos préadensados, serả admitido que o mödulo $\mathrm{E}_{\mathrm{f}}$ è constante em toda a sua es" pessura $D$; valendo:

$$
E_{1}=440 \times \gamma \times \frac{D}{2}
$$

Assim, para uma camada de $10 \mathrm{~m}$ de profundidade tem-se um valor da ordem de $3500 \mathrm{t} / \mathrm{m}^{2}$ para este Mödulo.

Seguindo um raclocinio anālogo para as Argizas Rijas Vermelhas, chega-se à expressão:

$$
\frac{E_{i}}{\bar{\sigma}_{c}}=150 \mathrm{RSA}
$$


com um coeficiente de correlação de $99 \%$ e desvio padrão de 120 . Com os dados da tabela V-3, obtëm-se para RSA um valor mëdlo de 2,8 idesvlo padrão de 0,50$)$, o que tem como consequēncia:

$$
\frac{E_{1}}{\sigma_{c}}=420
$$

Novamente, supondo que a camada de Argi la Rija Vermelha esteja entre as profundidades 10 e $15 \mathrm{~m}$, tem-se como média o valor constante em toda a sua espessura:

$$
E_{i}=420 \times 1,72 \times 12,5 \cong 9000 \mathrm{t} / \mathrm{m}^{2}
$$

As dispersões em torno dos valores médios da RSA devem-se em primeiro lugar, à heterogeneidade dos solos de um mesmo blo co indeformado, que ocorria com certa frequência; também às imprecisões na determinação da pressão de prē-adensamento que, a rigor, deveria ser obtida através de pelo menos dois ensaios numa mesma amostra. Em geral, isto não è possível, por motivos ligados à disponibilidade de equipamentos e ao tempo necessärlo para a execução dos ensaios de adensamento.

A tabela V-6 mostra valores da relação entre os Mọ dulos de Deformabilidade e a resistência não drenada. Para as amostras de Argila Rija Vermelha a dispersão è menor quando comparada com as de Argilla Porosa Vermelha, no que se refere ao $E_{i}$; jă os valores médios são bastante pröximos entre sl, para os três tipos de mödulos definidos no item 3 deste Copitulo. Alēm disso, ainda em termos de valores médlos, os $E_{1}$ são ligeiramente superiores aos $E_{50}$ e ambos bem maiores do que o $E_{1}$; a relação $E_{i} / E_{1} \dot{e}$ da ordem de 5 para as Argilas Porosas Verme lhas, indi- 
TABELA $V-4$

MODULOS OE DEFORMABILIDADE

SOLOS VARIEGADOS DA CIDADE DE SÃO PAULO

\begin{tabular}{|c|c|c|c|c|c|c|}
\hline Local & TIpo de Solo & $\begin{array}{l}\text { Pressão de } \\
\text { cāma ra } \\
\mathrm{kg} / \mathrm{cm}^{2}\end{array}$ & $\begin{array}{c}\text { Relaçāo de sobre- } \\
\text { adensamento }\end{array}$ & $E_{i} / \bar{\sigma}_{c}$ & $\mathrm{E}_{1} / \bar{\sigma}_{\mathrm{c}}$ & $\bar{E}_{50} / \bar{\sigma}_{c}$ \\
\hline $\begin{array}{l}\text { Amostra } 3 \\
\text { SES } \\
\text { METRO } \\
\text { Prof. } 9,30 \mathrm{~m}\end{array}$ & $\begin{array}{l}\text { Argila } \\
\text { Sil tosa } \\
\text { Arenosa }\end{array}$ & $\begin{array}{l}0,25 \\
0,50 \\
1,00 \\
4,00 \\
6,00\end{array}$ & $\begin{array}{l}23,2 \\
11,6 \\
5,8 \\
1,45 \\
1,00\end{array}$ & $\begin{array}{r}2142 \\
1400 \\
670 \\
200 \\
90 \\
\end{array}$ & $\begin{array}{r}670 \\
316 \\
386 \\
90 \\
61 \\
\end{array}$ & $\begin{array}{r}1800 \\
1270 \\
532 \\
100 \\
50 \\
\end{array}$ \\
\hline $\begin{array}{l}\text { Pça. da } \\
\text { Liberdade } \\
\text { Prof. } 7 \mathrm{~m}\end{array}$ & $\begin{array}{l}\text { Arglla } \\
\text { Arenosa }\end{array}$ & $\begin{array}{c}1,0 \\
2,0 \\
2,0(R R) \\
2,5 \\
3,0 \\
4,0 \\
4,0(R E P) \\
5,6,6(R E P), 7,8 \\
8(R E P) \text { e } 12 \\
\end{array}$ & $\begin{array}{l}5,00 \\
2,50 \\
4,00 \\
2,00 \\
1,67 \\
1,25 \\
1,25 \\
1\end{array}$ & \begin{tabular}{|c|}
621 \\
321 \\
574 \\
469 \\
314 \\
321 \\
281 \\
$213(45) \star$
\end{tabular} & $\begin{array}{l}300 \\
192 \\
262 \\
161 \\
134 \\
89 \\
89 \\
50\end{array}$ & $\begin{array}{l}510 \\
300 \\
433 \\
240 \\
190 \\
115 \\
115 \\
50\end{array}$ \\
\hline $\begin{array}{l}\text { Amostra } 3 \\
\text { SE2 } \\
\text { METRO } \\
\text { Prof. } 14,85 \mathrm{~m}\end{array}$ & $\begin{array}{l}\text { Areia } \\
\text { média } \\
\text { e fina } \\
\text { Argilosa }\end{array}$ & $\begin{array}{l}0,25 \\
0,50 \\
0,75 \\
1,00 \\
2,00 \\
4,00\end{array}$ & $\begin{array}{r}11,60 \\
5,80 \\
3,87 \\
2,90 \\
1,45 \\
1,00 \\
\end{array}$ & $\begin{array}{l}803 \\
491 \\
400 \\
405 \\
370 \\
233 \\
\end{array}$ & $\begin{array}{l}392 \\
333 \\
281 \\
190 \\
166 \\
107 \\
\end{array}$ & $\begin{array}{l}333 \\
470 \\
413 \\
271 \\
274 \\
110 \\
\end{array}$ \\
\hline $\begin{array}{l}\text { Amostra } 2 \\
\text { SE2 } \\
\text { METRO } \\
\text { Prof. } 8,15 \mathrm{~m}\end{array}$ & $\begin{array}{l}\text { Areia } \\
\text { fina } \\
\text { e média } \\
\text { Argilosa }\end{array}$ & $\begin{array}{l}0,25 \\
0,50 \\
0,75 \\
1,00 \\
2,00 \\
4,00\end{array}$ & $\begin{array}{r}11,60 \\
5,80 \\
3,87 \\
2,90 \\
1,45 \\
1,00\end{array}$ & $\begin{array}{r}1080 \\
690 \\
726 \\
620 \\
320 \\
150\end{array}$ & $\begin{array}{r}316 \\
233 \\
257 \\
154 \\
112 \\
47 \\
\end{array}$ & $\begin{array}{r}958 \\
395 \\
479 \\
365 \\
185 \\
31 \\
\end{array}$ \\
\hline $\begin{array}{l}\text { Amostra } 5 \\
\text { SE3 } \\
\text { METRO } \\
\text { Prof. } 9.5 \mathrm{~m}\end{array}$ & $\begin{array}{l}\text { Arela } \\
\text { fina e } \\
\text { mëdla } \\
\text { Argilosa }\end{array}$ & $\begin{array}{l}0,25 \\
0,50 \\
0,75 \\
1,00 \\
2,00 \\
4,00\end{array}$ & $\begin{array}{l}9,60 \\
4,80 \\
3,20 \\
2,40 \\
1,20 \\
1,00 \\
\end{array}$ & $\begin{array}{r}1015 \\
683 \\
505 \\
517 \\
279 \\
100 \\
\end{array}$ & $\begin{array}{l}308 \\
138 \\
126 \\
137 \\
70 \\
40\end{array}$ & $\begin{array}{r}607 \\
287 \\
41 \\
215 \\
43 \\
23 \\
\end{array}$ \\
\hline $\begin{array}{l}\text { Amostra } 7 \\
\text { SE3 } \\
\text { METRO } \\
\text { Prof. } 16,8 \mathrm{~m}\end{array}$ & $\begin{array}{l}\text { Areia } \\
\text { fina } \\
\text { média } \\
\text { Argilosa }\end{array}$ & $\begin{array}{l}0,25 \\
0,50 \\
0,75 \\
1,00 \\
2,00 \\
4,00\end{array}$ & $\begin{array}{r}15,28 \\
7,64 \\
5,09 \\
3,82 \\
1,91 \\
1,00 \\
\end{array}$ & $\begin{array}{l}1160 \\
704 \\
777 \\
565 \\
353 \\
402 \\
\end{array}$ & $\begin{array}{l}442 \\
340 \\
270 \\
190 \\
165 \\
120 \\
\end{array}$ & $\begin{array}{l}947 \\
510 \\
702 \\
330 \\
245 \\
193 \\
\end{array}$ \\
\hline $\begin{array}{l}\text { Amostra } 1 \\
\text { 8loco } 17-\mathrm{B} \\
6 \mathrm{~m} \text { de prof. } \\
\text { Estação } \\
\text { Paralso } \\
\text { METRo }\end{array}$ & $\begin{array}{l}\text { Argila } \\
\text { varle- } \\
\text { gada }\end{array}$ & $\begin{array}{l}0,25 \\
0,50 \\
0,75 \\
1,00 \\
2,00 \\
4,00\end{array}$ & $\begin{array}{r}28,8 \\
14.4 \\
9.6 \\
7.2 \\
3.6 \\
1.8\end{array}$ & $\begin{array}{r}2100 \\
1460 \\
800 \\
1050 \\
405 \\
290\end{array}$ & $\begin{array}{l}720 \\
580 \\
550 \\
370 \\
205 \\
130\end{array}$ & $\begin{array}{l}1920 \\
1460 \\
800 \\
910 \\
400 \\
290\end{array}$ \\
\hline
\end{tabular}

- Nümero entre parêntesls é o desvio padrăo.

LEGENDA: I dêntica à da Tabela V-2 


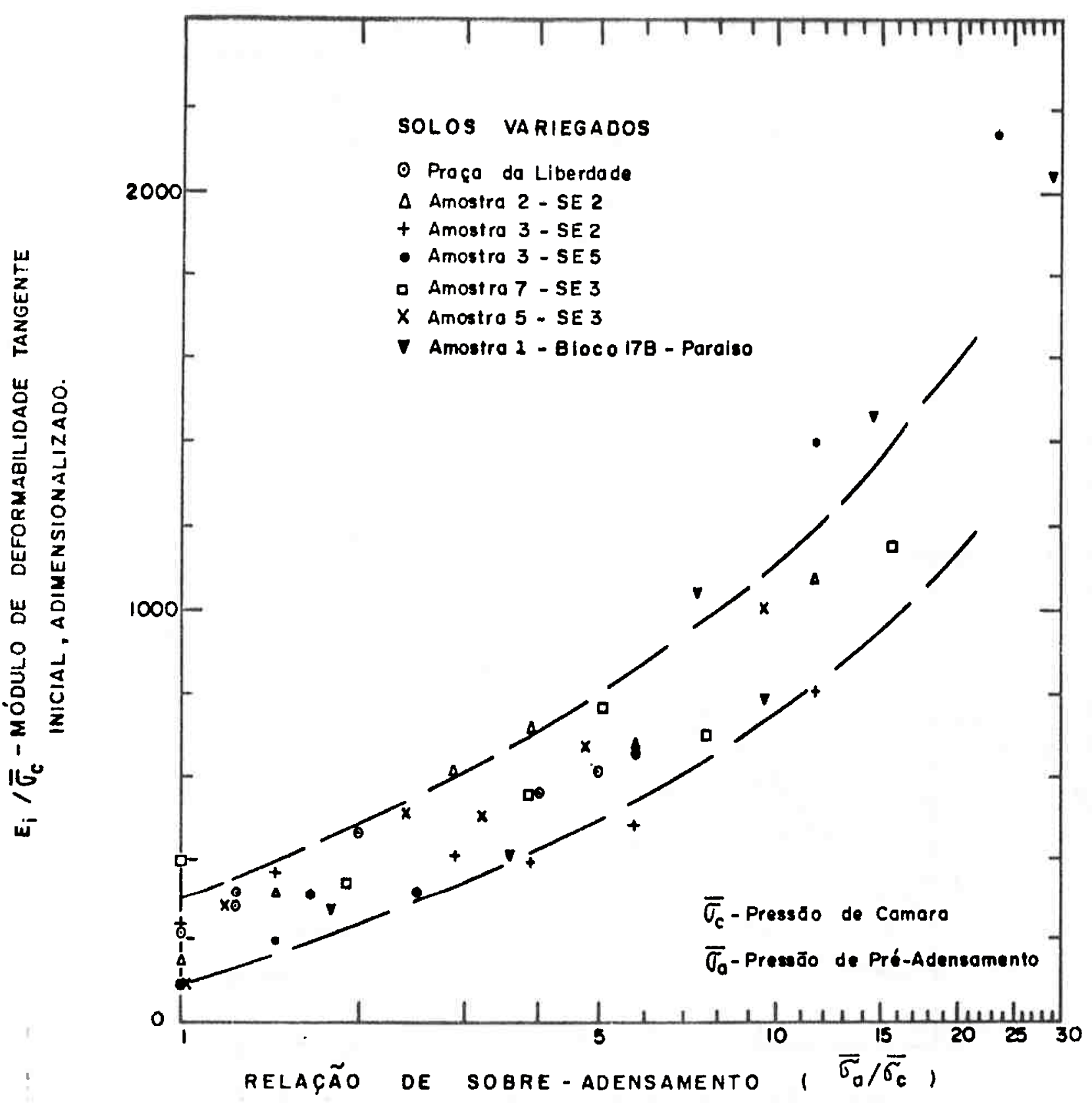

FIGURA I - 11 : FAIXA DE VALORES DO MÓOULO DE DEFORMABILIDADE - ENSAIOS TRIAXIAIS RÁPIDOS PRÉ-ADENSADOS ( $\bar{R})$ ISOTROPICAMENTE. 


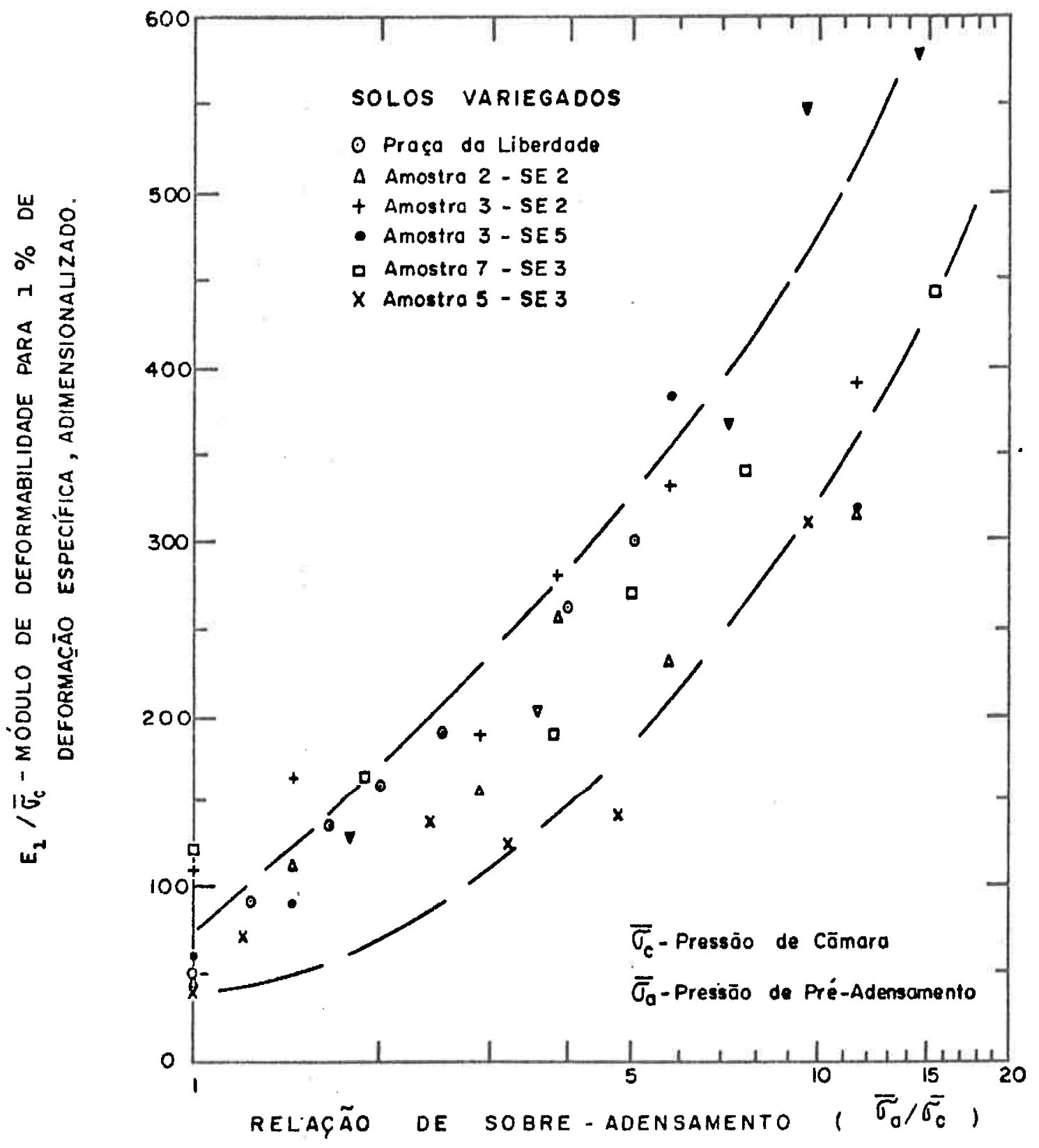

FIGURA Y - 12: FAIXA DE VALORES DO MÓdULO DE DEFORMABILIOADE - ENSAIOS TRIAXIAIS RÁPIDOS PRÉ-ADENSADOS $(\bar{R})$ ISOTROPICAMENTE. 


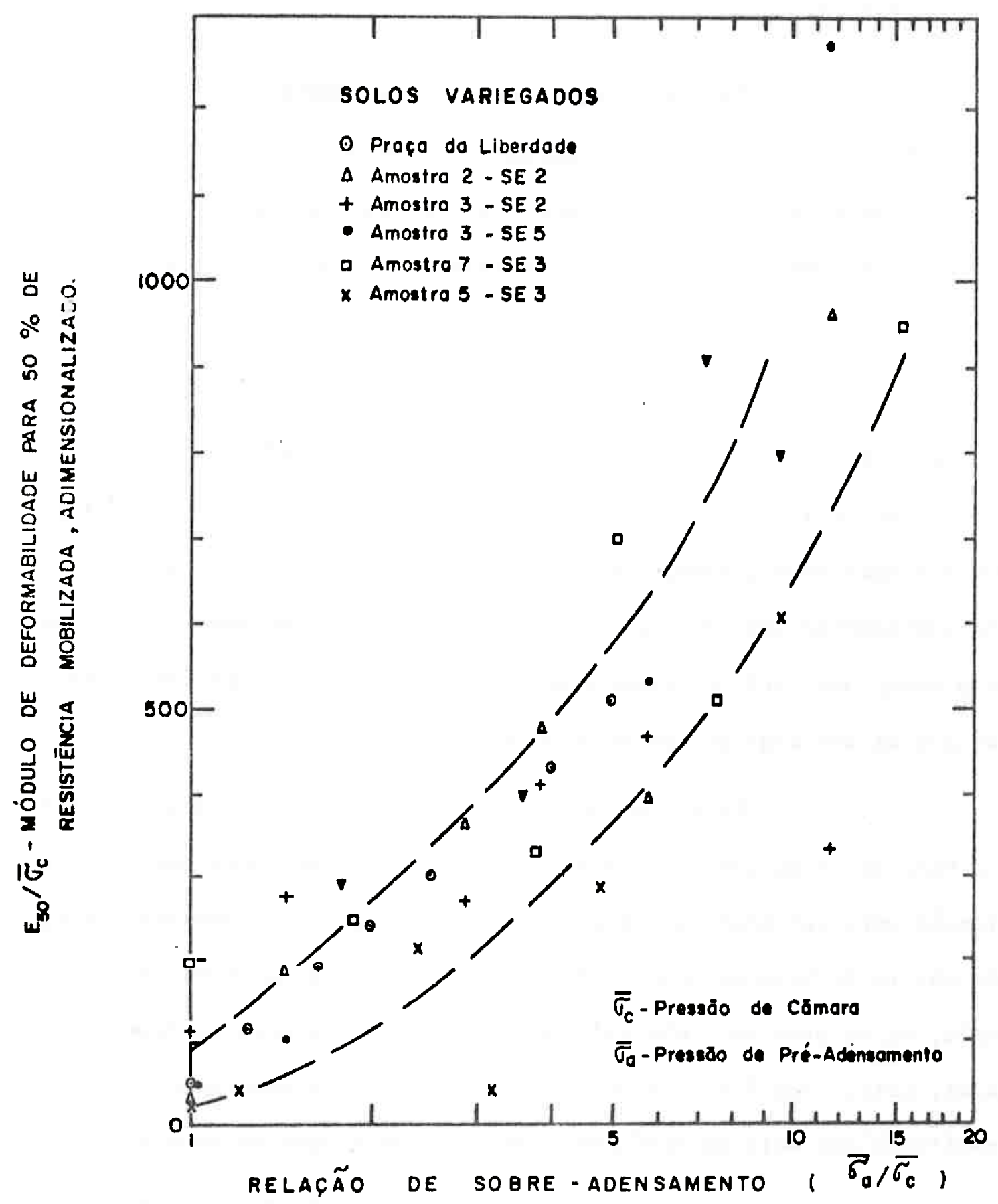

FIGURA $\bar{y}$ - 13: FAIXA DE VALORES DO MÓOULO DE DEFORMABILIOADE - ENSAIOS TRIAXIAIS

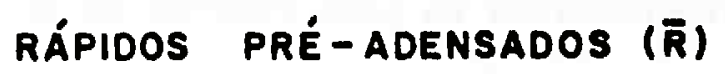
ISOTROPICAMENTE. 
cando a existência de uma cimentação entre partículas de solo (vide Apêndice $F$ ) quebrada à medida em que as deformações aumentam.

\subsection{Solos Variegados}

Para aplicar o mesmo procedimento aos Solos Variegados foram tomadas as amostras indicadas na tabela V-1, para as quais estavam disponívels ensaios triaxiais $\bar{R}$ em värias pressões confinantes, a fim de correlacionar os Módulos de Deformabilidade com a relação de sobre-adensamento.

A tabela $V-1$ mostra os valores obtidos para os $M 0^{-}$ dulos $E_{i}, E_{1}$ e $E_{50}$, que estão apresentados em forma gráfica em função da RSA, definida pela expressão $(V-8)$, nas figuras $V-11, V-12$ e $V-13$, Vêse que a dispersão é grande, quer porque é difícil de definir a pressāo de pré-adensamento com precisão, quer porque os solos de cada bloco inde formado eram, nāo raro, heterogêneos. Alēm disso não foi possível separar as areias das argilas, em dois universos distintos.

Para fins de ilustração, a tabela $V-5$ mostra valores da RSA, definida como a relação entre a pressão de pré-adensamento e a tensão vertical efetiva (peso efetivo de terra), para amostras de di versos perfis de Solo Variegado. Vê-se que alēm de variar numa faixa muí to ampla, os valores mais elevados da RSA estão associados às Argilas Va riegadas, pois, como é discutido no Apêndice $F$, o pré-adensamento pode ser explicado por meio de fenōmenos que envolvem o teor de argila.

Uma maneira de estimar-se os Mödulos de Deformabilidade Inicial seria valer-se da correlação da figura V-11. De fato, para cada RSA ter-se-ia um valor de $E_{i} / \sigma_{c}$, e como $\bar{\sigma}_{c}$ pode ser aproximada à tensão correspondente ao peso efetivo de terra, com as objeções explicitadas acima, seria entäo possível determinar-se os $E_{i}$. No entanto, além 
TABELA V-5

SOLOS VARIEGADOS DA CIDADE DE SAO PAULO

VALORES DA RSA EM FUNCYAO DA PROFUNDIOADE PARA VARIOS PERFIS DE SUBSOLO

\begin{tabular}{|c|c|c|c|c|c|c|}
\hline Local & Amostra & $\begin{array}{c}A \\
(\xi)\end{array}$ & $\begin{array}{l}\text { Prof undi dade } \\
(\mathrm{m})\end{array}$ & $\begin{array}{c}\sum_{Y z} z_{2} \\
(t / m\end{array}$ & $\begin{array}{c}\bar{\sigma}_{a_{2}} \\
\left(t / m^{2}\right)\end{array}$ & RSA \\
\hline \multirow{8}{*}{$\begin{array}{c}\text { SES } \\
\text { METRO }\end{array}$} & 1 & 58 & 5,8 & 9,2 & 85,0 & 9,2 \\
\hline & 2 & 49 & 6,8 & 11,1 & 65,0 & 5,9 \\
\hline & 3 & 56 & 9,3 & 15,3 & 58,0 & 3,8 \\
\hline & 4 & 25 & 11,2 & 18,8 & 42,0 & 2,2 \\
\hline & 5 & 20 & 16,2 & 28,2 & 19,0 & 1,0 \\
\hline & 6 & 75 & 18,2 & 32,0 & 90,0 & 2,8 \\
\hline & 7 & 68 & 18,3 & 32,0 & 72,0 & 2,3 \\
\hline & 8 & 15 & 19,3 & 33,8 & 36,0 & 1,0 \\
\hline \multirow{3}{*}{$\begin{array}{c}\text { SE } 3 \\
\text { METRO }\end{array}$} & 4 & 50 & 7,0 & 10,2 & 48,5 & 4,8 \\
\hline & 5 & 30 & 9.5 & 14,9 & 24,0 & 1,6 \\
\hline & 7 & 25 & 16,8 & 28,6 & 38,2 & 1,3 \\
\hline SE2 & 2 & 27 & 8,2 & 14,2 & 29,0 & 2,0 \\
\hline METRO & 3 & 27 & 14,9 & 26,4 & 29,0 & 1,1 \\
\hline SE6 & & 60 & 13,5 & 23,0 & 76,0 & 3,3 \\
\hline PROX. A & & 60 & 14,2 & 25,0 & 115,0 & 4,6 \\
\hline SE8 & & 60 & 16,4 & 28,0 & 115,0 & 4.1 \\
\hline $\begin{array}{l}\text { PCA. OA } \\
\text { LIBERDADE }\end{array}$ & & 47 & 7,0 & 13,5 & 50,0 & 3.7 \\
\hline
\end{tabular}

$$
\begin{aligned}
& \text { LEGENDA: } \bar{\sigma}_{a} \text { - Pressão de pré-adensamento } \\
& \Sigma \gamma z \text { - Peso de terra na profundidade } \underline{z} \text {. } \\
& \text { RSA - Relaçāo de sobre-adensamento, tomada } \\
& \text { como ö/ EYz. } \\
& \text { A - Teor de Argila }(\delta<5 \mu) \text {. }
\end{aligned}
$$


da dispersão implícita na figura $V-11$, jä comentada, esta determinação ficaria na dependência do resultado de um único ensaio de adensarento.

$$
\text { A alternativa que resta } \bar{e} \text { voltar aos resultados }
$$

apresentados na tabela $V-6$, que revelam um comportamento dos Solos Varlegados anălogo ao das Argilas Vermelhas, mas com dispersões bem menores, e de onde se pode extralr a expressão:

$$
\frac{E_{i}}{\left.\sigma_{1}-\sigma_{3}\right)_{\text {máx }}}=200
$$

para o cálculo aproximado dos $E_{\mathbf{i}}$ médios. Basta que se conheça as envoltómias de Mohr-Coulomb, em termos de pressões totais, isto é:

$$
\frac{\left(\sigma_{1}-\sigma_{3}\right) \operatorname{máx}}{2}=c \cos \theta+\frac{\left(\sigma_{1}+\sigma_{3}\right)}{2} \cdot \operatorname{sen} \theta
$$

onde $c$ e são os parâmetros de resistência. Notando-se que:

$$
\frac{\sigma_{1}+\sigma_{3}}{2}=\frac{\left(\sigma_{1}-\sigma_{3}\right)}{2}+\bar{\sigma}_{c}
$$

pois nos ensaios $\bar{R}$ a pressão confinante $\bar{e}$ mantida constante, tem-se, apös algumas transformações:

$$
\left(\sigma_{1}-\sigma_{3}\right)_{\max }=\frac{2 \cos \phi}{1-\operatorname{sen} \emptyset} \cdot c+\frac{2 \operatorname{sen} \phi}{1-\operatorname{sen} \emptyset} \cdot \bar{\sigma}_{c}
$$

que, substiturda na expressão $(V-13)$, resulta em:

$$
E_{i}=\frac{400 \cos \theta}{1-\operatorname{sen} \theta} \cdot c+\frac{400 \operatorname{sen} \phi}{1-\operatorname{sen} \phi} \cdot \bar{\sigma}_{c}
$$

Tal como foi feito para a expressão $(V-9), \bar{\sigma}_{c}$ será 


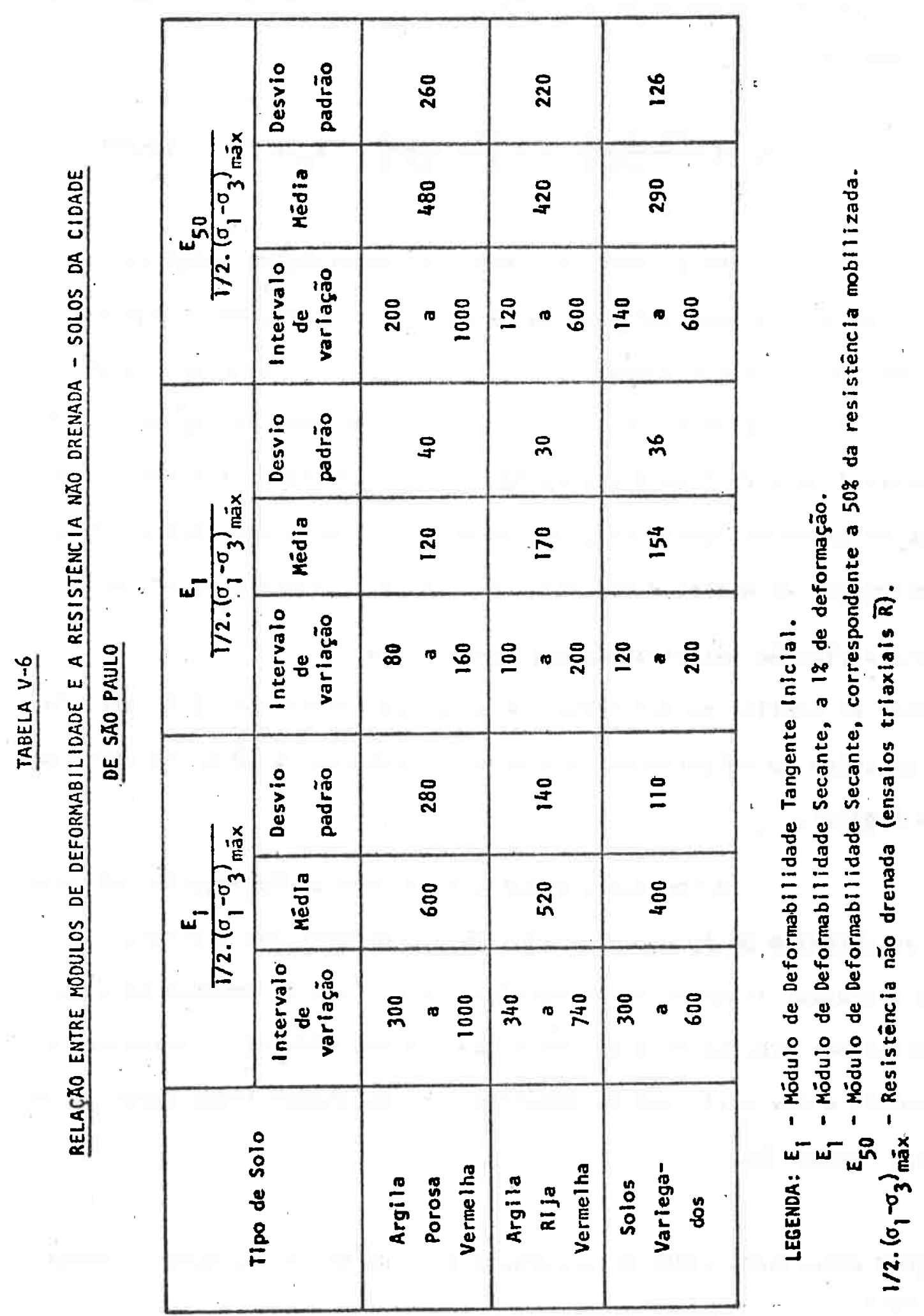


tomada como a tensão vertical associada ao peso de terra efetivo, mantidas as ressalvas quanto às simplificaçōes admitidas então. Assim, chegase finalmente a:

$$
E_{i}=\frac{400 \cos \theta}{1-\operatorname{sen} \theta} c+\frac{400 \operatorname{sen} \theta}{1-\operatorname{sen} \theta} \quad Y_{n} \cdot z
$$

Recorrendo-se a diversas amostras de Solos Variegados, não sō aquelas apresentadas na tabela V-5 como também outras analisadas por Sousa Pinto e Massad (1972), com disponibilidade de envoltórias de resistencia de ensaios triaxiais $R$, e com base na expressão $V-14$, foi possivel construir os gräficos da figura V-14. Como se anteviu por ocasião do exame da tabela V-5, foi necessärio e possível separar os Solos Variegados em Areias e Argilas. Para tanto, usou-se como critério:

a) a classificação tātil-visual das amostras; e

b) o teor de argila, de tal forma que se fosse inferior a $25 \%$ incluíase os solos no universo das Areias e, se superior a $40 \%$, no universo das Argilas.

A conclusão è que para as Areias Variegadas, em que a RSA se aproxima de 1 , e nas camadas mais profundas das Argilas, os $E_{i}$ tendem a crescer linearmente comaprofundidade. Para as camadas mais superficiais das Argilas nota-se uma tendēncia dos mödulos permanecerem constantes, o que allás vem de encontro aos resultados antecipados no item 4.1. deste CapituT.e.

5. ALGUNS RESULTAdOS SOBRE A INFLUENCIA DO TIPO DE SOLICITAÇÃO IMPOSTO AO SOLO

Os ensaios que melhor simulam o comportamento dos so los escorados, para o problema em foco, são os de extensão lateral em 


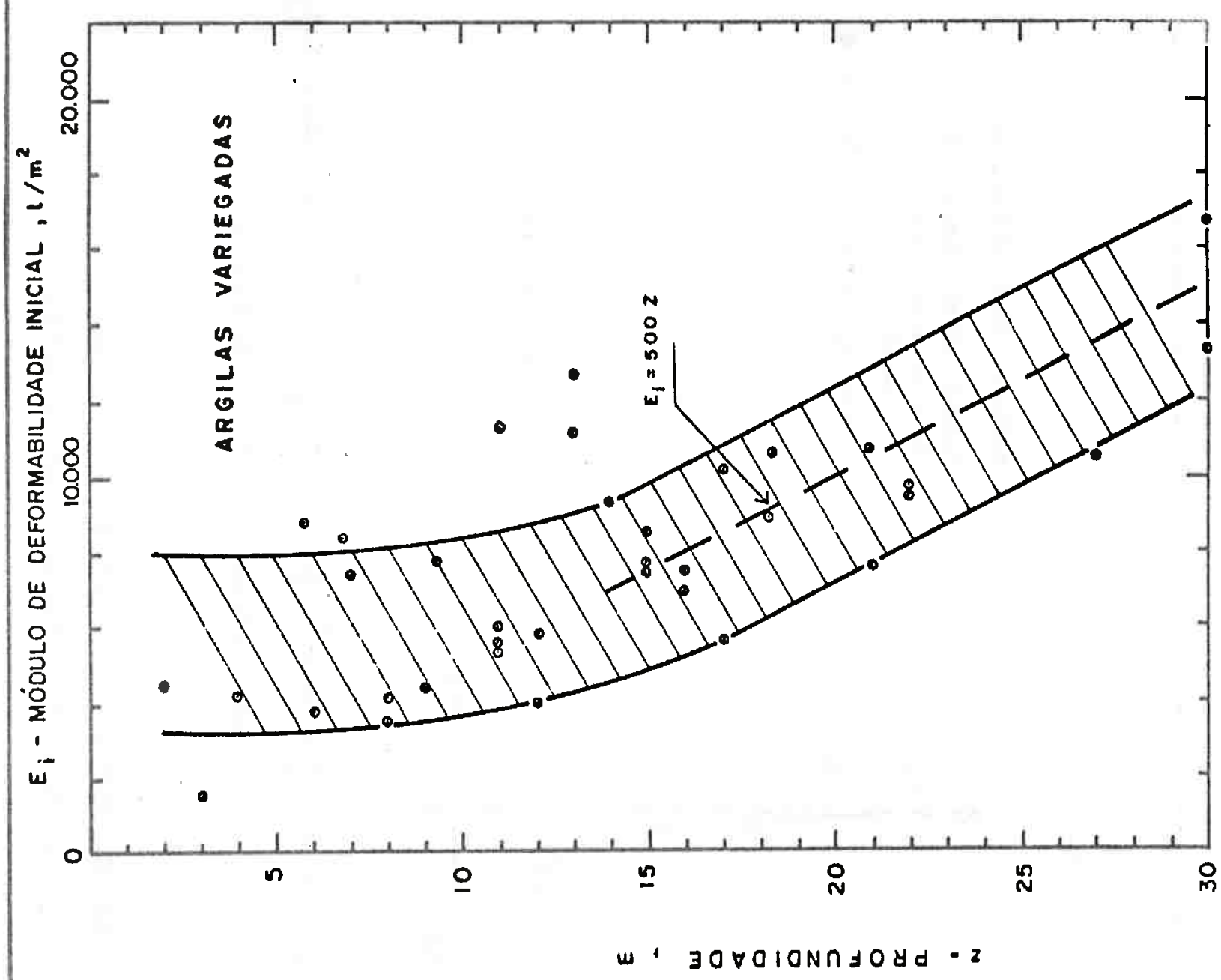

年

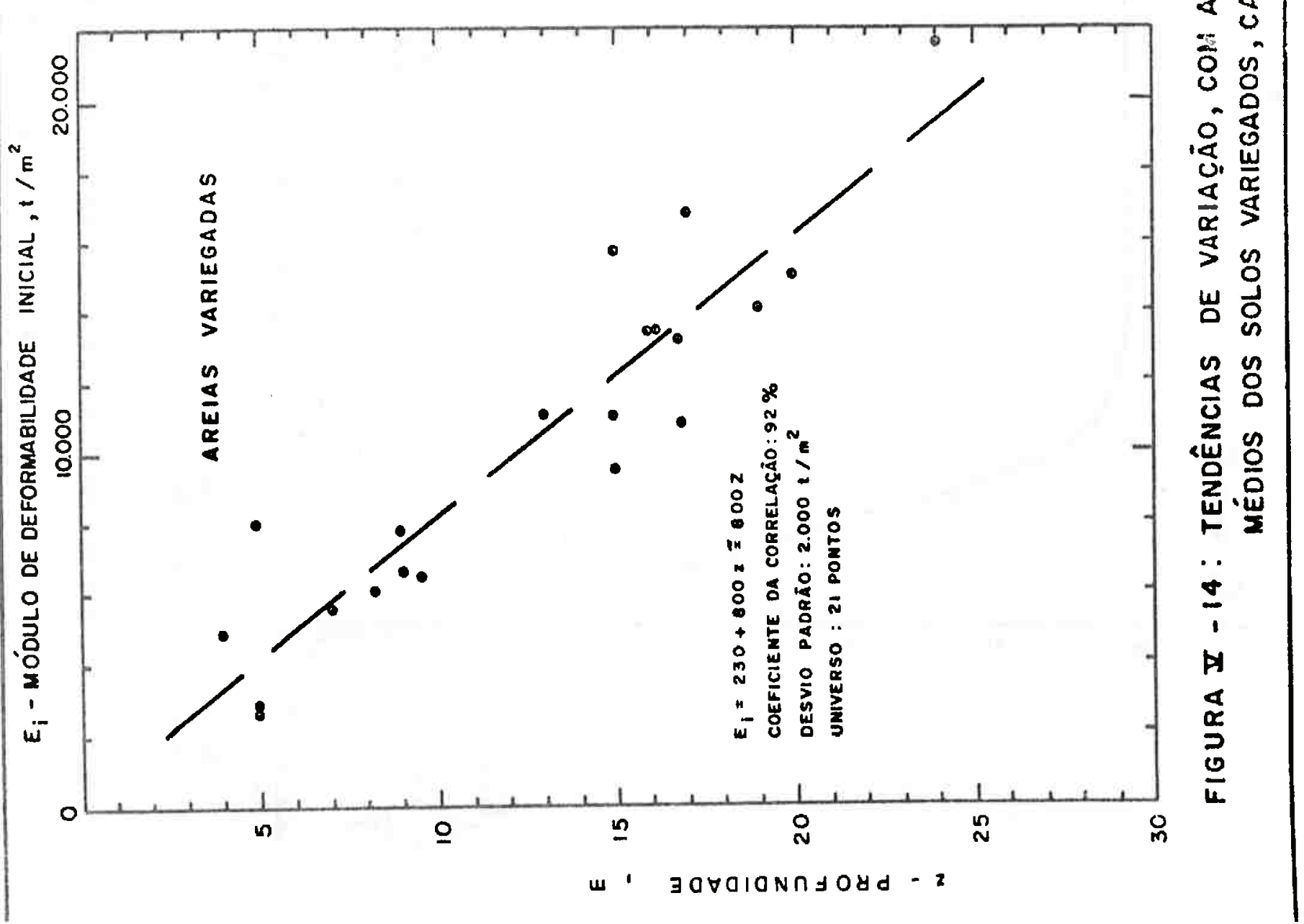




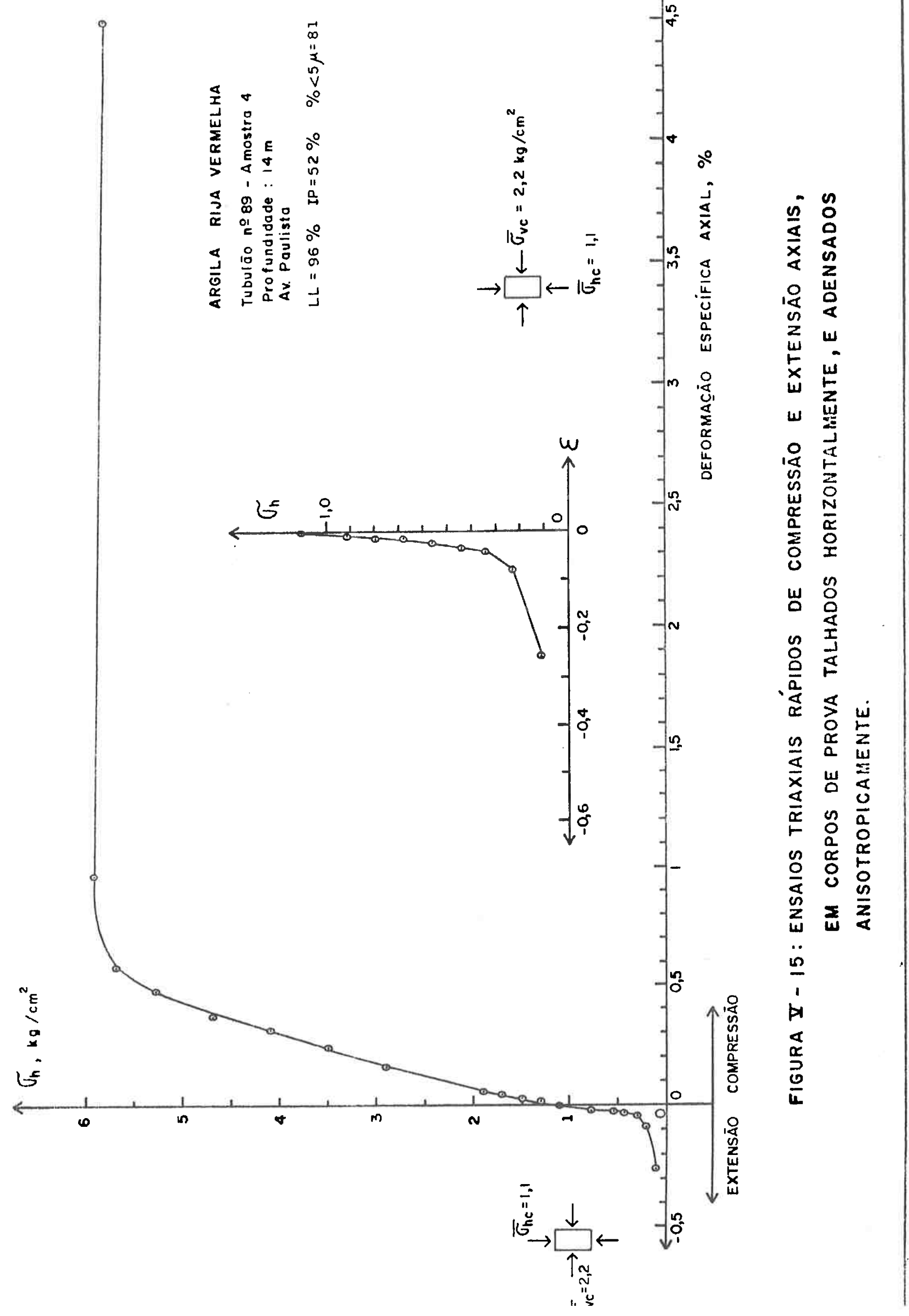


aparelhos de deformação plana, com o que è possivel levar em conta os efel tos da tensão principạ intermediāria; a tensão principal malor, que coincide com a tensão vertical (peso de terra) se o coeflclente de empuxo em repouso è inferior a 1 , è mantida constante.

Quando não se dispõe destes aparelhos costuma-se recorrer aos ensaios triaxiais de extensão axial, de preferêncla em corpos de prova talhados horizontalmente, isto $\dot{e}$, com seu eixo de simetrla na direção horizontal do bloco, perpendicularmente ao eixo da vala, para levar em conta eventuais efeitos anisotrópicos.

Tanto a tensão principal intermediäria quanto a mo dalidade de ensaio e a anisotropla dos solos têm influência acentuada nos seus parâmetros elásticos, como foi realçado no item 2 deste Capítuzo.

Um obstáculo anteposto a este tipo de empreitada refere-se ao desconhecimento do coeficiente de empuxo em repouso, necessärio para adensar prévia e anisotropicamente o corpo de prova. Para os solos da Cidade de São Paulo hä indicações de que o prē-adensamento função do teor de argila, não se correlacionando nem com a cota e nem com a profundidade de extração da amostra ensaiada. Como jā foi dito, o Apên dice $F$ apresenta discussão sobre o assunto e a conjectura de que o coeficiente de empuxo em repouso só poderā ser determinado atravēs de ensaios in situ.

A figura V-15 mostra, a título de ilustração, resultados de ensaios de compressão e extensão axiais, feitos em corpos de prova talhados horizontalmente e adensados anisotropicamente, em uma amostra de Argila Rija Vermelha. Adotou-se, arbitrariamente, o valor 0,5 para o coeficlente de empuxo em repouso. Em extensão axial obteve-se:

$$
\frac{E_{i}}{\bar{\sigma}_{V c}}=1000 \text { e } \frac{E_{0,1}}{\bar{\sigma}_{V c}}=410
$$


DEFORMAÇÃO ESPECÍFICA AXIAL，\%

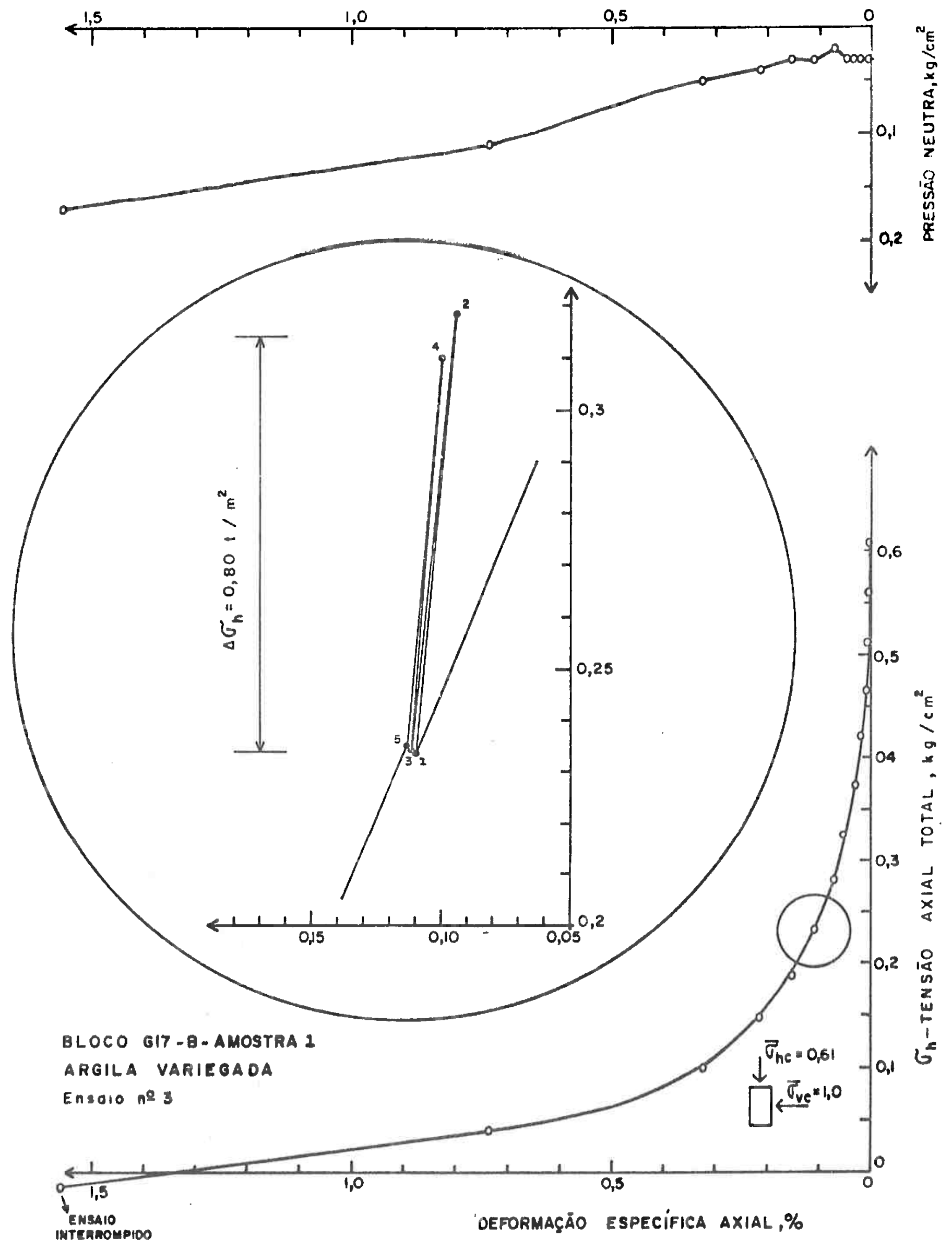

FIGURA I - 16: ILUSTRAGĀO DE ENSAIO TRIAXIAL RÁPIDO, DE EXTENSĀO AXIAL, COM REPETIÇĀO DE CARGACORPOS DE PROVA TALHADOS HORIZONTALMENTE 
onde $E_{0,1}$ corresponde ao Mödulo de Deformabilidade para 0,1 \% de defor mação especiffica, que, adimensionalizado, è da ordem de grandeza do valor indicado pela expressão $(V-11)$. Se esta ültima reflete o comportamen to de solos escorados por paredes flexíveis, a primeira das förmulas apresentadas em $(V-15)$ se aplica, grosso modo, a paredes rígidas. A rela çāo entre $E_{i}$ e $E_{0,1}$ é de cerca de 2,5.

Finalmente, executaram-se alguns ensaios de extensão axial, em corpos de prova talhados horizontalmente, como aqueles indicados na figura $V-16$, em que, ao atingir-se uma deformação de cerca de $0,1 \%$, retirava-se e reaplicava-se um incremento de tensão $\Delta \sigma_{h}$. Com isto tentou-se avaliar o efeito da repetição do carregamento, numa simulação simples do tipo de solicitação que ocorre numa vala escorada, em virtude da dilatação e contração tërmicas das estroncas. Foram realizados 6 ensaios, diferindo entre si no incremento $\Delta \sigma_{h}$ que, ao variar de 0,8 a $3 \mathrm{t} / \mathrm{m}^{2}$, fez com que a relação entre o Möduzo de Recarga (após dois ciclos) e o Módulo secante (no ponto em que houve aplicação de carga repetida) decrescesse de cerca de 2,0 a 1,2 , confirmando resultados obtidos por Baguelin e Jezequel (1973) em ensalos pressiomētricos, e tambëm estão. de um modo geral, em concordância com os experimentos de Ward, clados no item 2.2. deste Capítulo.

6. SOMULA: TENDENCIAS DE VARIAÇAO DOS MODULOS E COM A PROFUNDIDADE

Há uma gama enorme de fatores que tornam bastante complexa a fixaçāo, com base em resultados de ensaios de laboratórío,dos Mödulos $E$ de interesse para a continuação desta Investigação.

Entre eles destacam-se a heterogeneidade dos solos e o desconhecimento do estado de tensōes a que ele esteve submetido ante 
riormente,mercê do estāgio atual dos conhecimentos relativos à bacia sedimentar da Cidade de São Paulo.

Como consequência deste fato e da aleatoriedade do processo de escavação da vala e da construção de seu sistema de escoramento, ignora-se também a trajetöria de tensōes no maciço terroso escora do, em final de escavação.

$E$, pois, patente a dificuldade de reprodução em lạ boratoório da solicitação de campo. A rigor, deveria ser utilizado equipa mento de deformação plana, em corpos de prova talhados horizontalmente, para se levar em conta a anisotropia dos solos.

No entanto, apesar destes obstáculos, foi possivel estabelecer tendências de variação dos Módulos de Deformabilidade das Ar gilas Vermelhas e dos Solos Variegados da Cidade de Säo Paulo.

Para carregamentos estáticos, os mödulos $E_{i}$ tendem a assumir:

a) valores constantes para as Argilas Porosas Vermelhas e as Argijas Rijas Vermelhas; e

b) valores inearmente crescentes com a profundidade para os Solos Varie gados, exceto para as Argilas Variegadas que afloram na superfície, quando podem ser também constantes.

A aplicação de ciclos de carga e descarga provocam aumentos dos Módulos de Deformabilidade Secantes em cerca de 1,2 a 2 vezes, para incrementos de tensões variando na faixa de 1 a $3,0 \mathrm{t} / \mathrm{m}^{2}$; estes fatores de amplificação tendem a diminuir com o aumento da amplitude da tensão aplicada.

Assim, por exemplo, para as Areias Variegadas è de se esperar Mōdulos $E_{r}$ de Deformabilidade Inicial, com Repetição de Carga 
Horizontal, crescendo linearmente com a profundidade (z) segundo a expressão: $E_{r}=(960$ a 1600$)$ z. E isto sem levar em conta possiveis efeitos anisotrópicos dos solos e a influência da tensão principal intermediäría.

Para paredes rígidas, supondo indeformabilidade do solo escorado, pode-se, em primeira aproximação, usar mödulos duas ou três vezes maiores do que aqueles relativos às paredes flexíveis.

A fim de superar este estado de coisas procurouse, atravēs de retroanálise, ajustar os Módulos $E$ por tentativa, com a aplicação do modelo matemático exposto no Capitulo IV e comparação com os valores realmente observados dos gradientes de carga-temperatura, nas medições de campo levadas a cabo nas Secçöes Experimentais do Metropolitano de São Paulo. 


\section{CAPTTULO VI}

\section{FORMULAS PRÁTICAS PARA O CÁLCULO DOS GRADIENTES DE}

CARGA-TEMPERATURA

1. FIXAÇAO dOS MODULOS DE DEFORMABILIDADE DOS SOLOS ESCORADOS ATRAVES DE RETROANALISE

Em trabalho apresentado por Massad et al (1974-b) foram feitas comparações entre valores calculados e observados dos gradientes de carga-temperatura, para algumas das Seções Experimentais do Metrô de São Paulo. A análise feita naquela ocasião será retomada com aplicação do modelo matemātico à Secção Experimental 2.

\subsection{Módulos de Deformabilidade adotados}

Com base em algumas informações sobre os solos escorados, tinha-se adotado a seguinte expressão para a estimativa dos Mōdulos de Deformabilidade das Argilas Forosas Vermelhas:

$$
E_{S}=450 \bar{\sigma}_{c}
$$

Consequentemente, como $\bar{\sigma}_{c}=\gamma_{n} z$ e $\gamma_{n}=1,56 \mathrm{~g} / \mathrm{cm}^{3}$, pois o nivel de ägua estava rebaixado, resultava, para uma camada de espessura D', um Módulo médio constante igual a:

$$
E_{S}=350 D^{\prime}
$$

Exemplificando, para a Seç̧ão Experimental 1 , em que a espessura da camada de Argila Porosa Vermelha era de cerca de $12 \mathrm{~m}$, encontrou-se um Mö- 


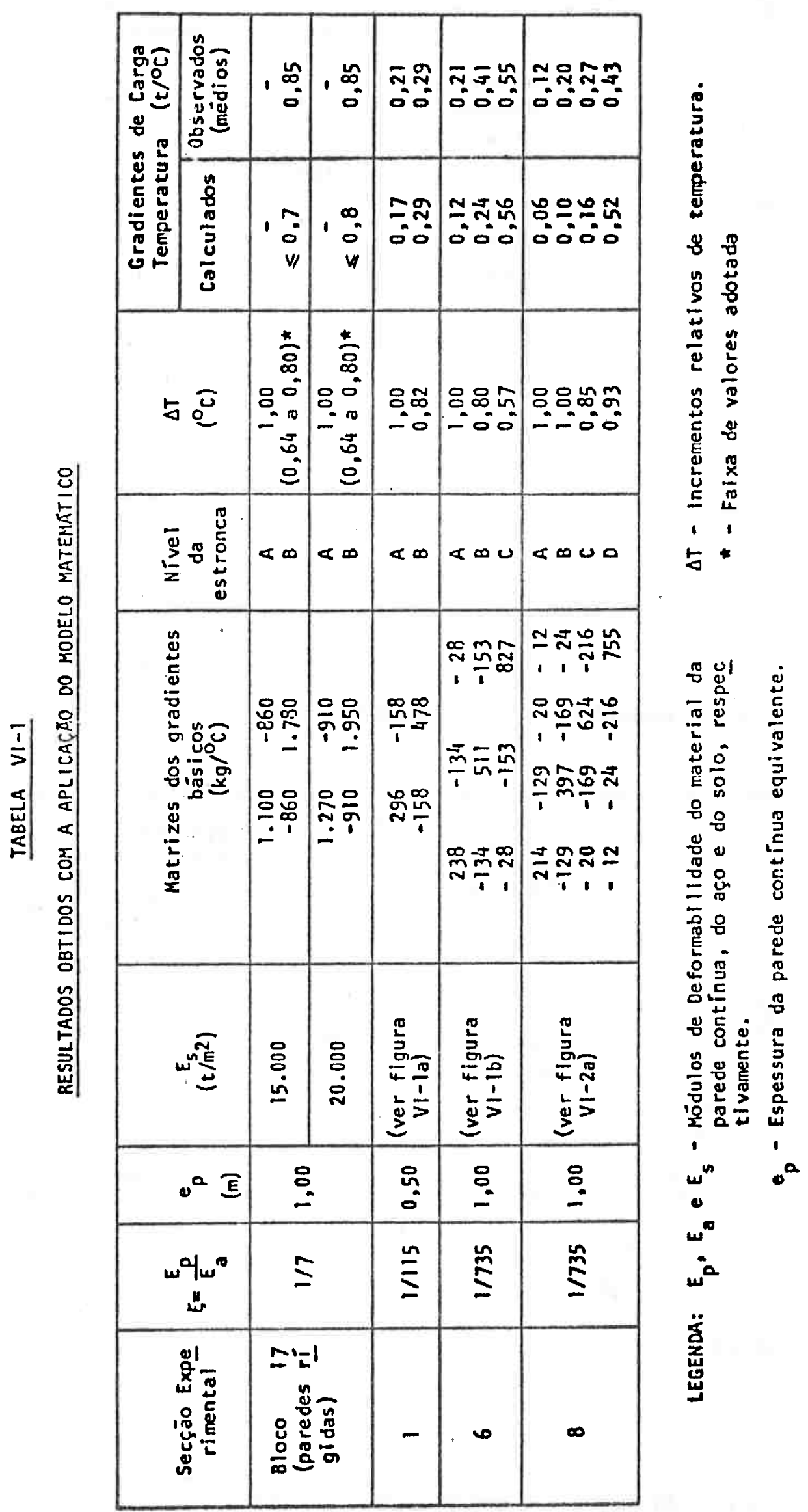




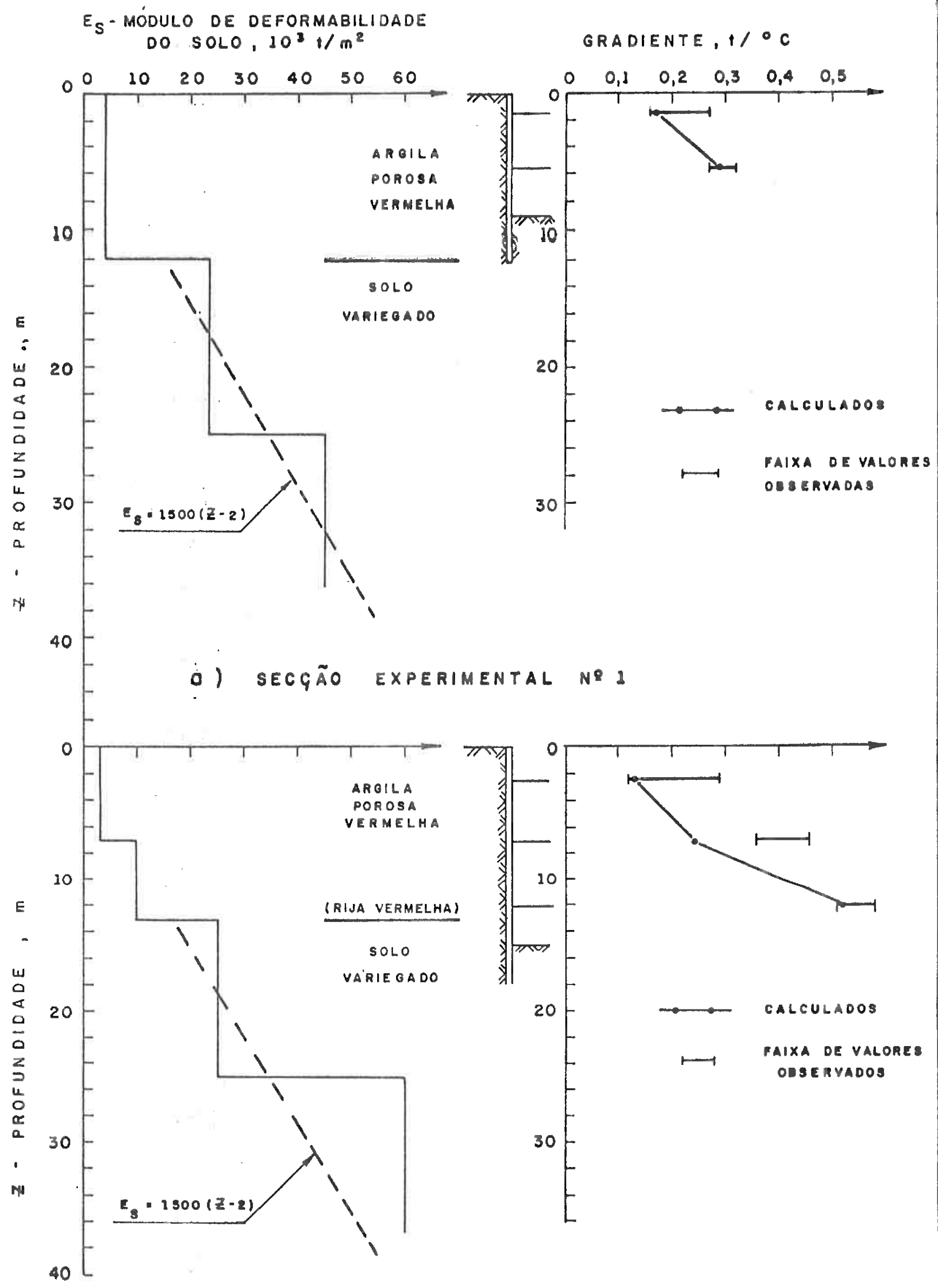

b) SECGÃo EXPERIMENTAL NeG

FIGURA ZI - 1:FIXAÇÃO DA RIGIDEZ DOS SOLOS ATRAVÉS DE RETROANÁLISE 


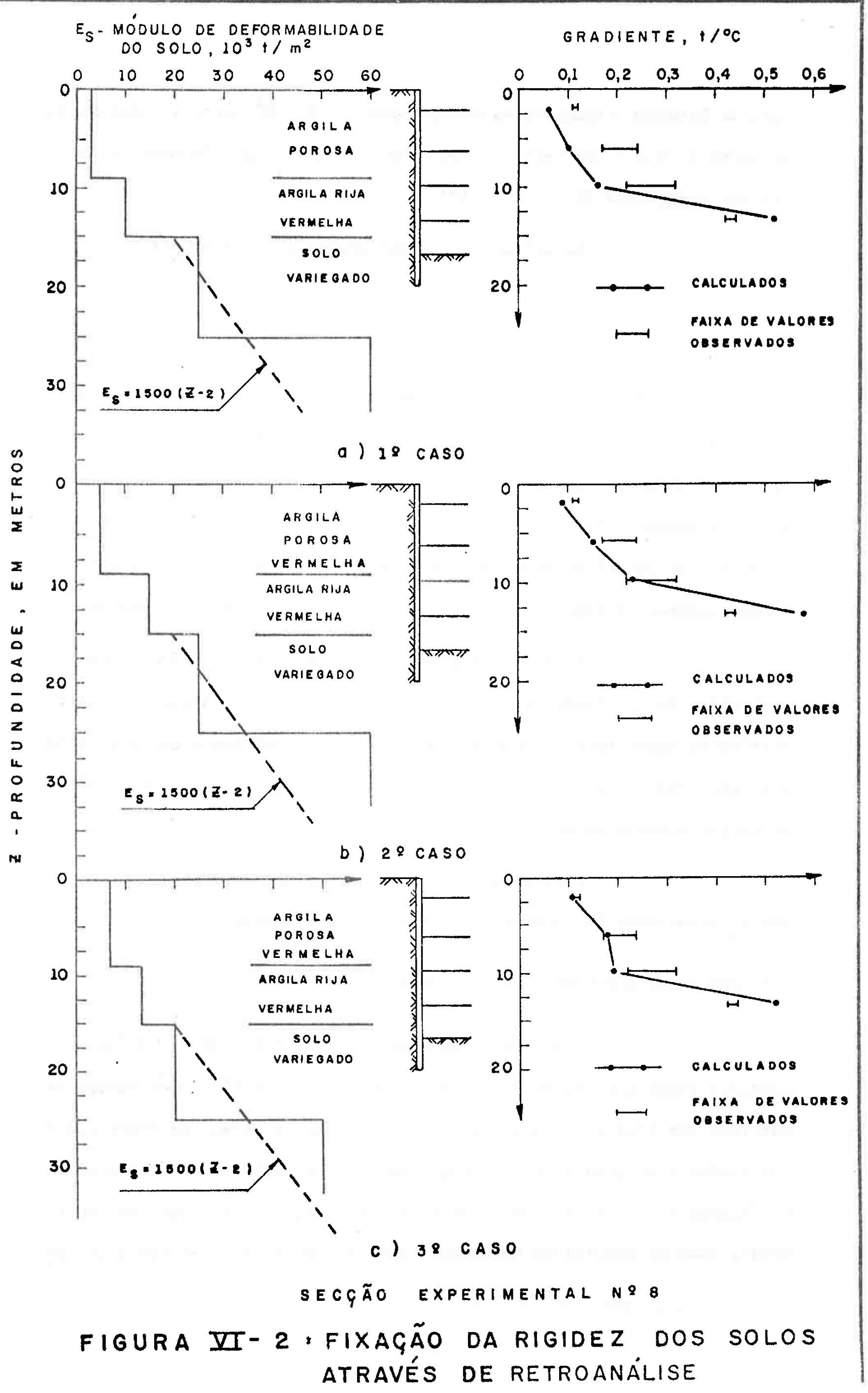


dulo de Deformabillidade de aproximadamente $4000 \mathrm{t} / \mathrm{m}^{2}$; para as Secções Ex perimentais 6 e 8 , de cerca de $3000 \mathrm{t} / \mathrm{m}^{2}$. Note-se a proximidade de valores das expressões $(V I-1)$ e $(V-10)$.

Quanto aos Solos Variegados partíra-se de:

$$
E_{S}=1500(z-2)
$$

em que $E_{s}$ é o Módulo de Deformabilidade do solo em $t / \mathrm{m}^{2}$ e z a profundida de em metros. Vê-se tambëm que, pelo menos para as Areias Variegadas, hā uma concordância com as conclusões do CapítuZo V. Camadas espessas de Solos Variegados eram divididas em subcamadas, em função da profundidade da vala e do perfil de sondagem. Para cada uma destas subcamadas o módulo era suposto constante e $z$ era igual à profundidade de seuplanomédio.

Estendeu-se a validade da expressão(VI-2)a grandes profundidades ignorando-se, em primeira aproximação, a redução no peso efetivo de terra face à submersão do solo. E isto porque a parte do solo escorado, dentro da zona de influência da escavação, è a que mais influi na resposta carga-temperatura.

Para as Argilas Rijas Vermelhas adotou-se a média dos $E_{s}$ associados às camadas sobrejacente e subjacente.

1.2. Avaliação dos Módulos $E_{s}$ por Retroanālise

A aplicação do modelo matemätico do Capitulo IV conduziu então aos resultados apresentados na tabela VI-1, que contém as matrizes dos gradientes bāsicos, os incrementos relativos de temperatura observados e os gradientes de carga-temperatura observados e calculados. As figuras VI-1 e VI-2a completam estas informações e mostram, em particular, como os Módulos de Deformabilidade adotados varlaram com a profun 
didade.

A anälise destes resultados revela, para as estron cas dos dols níveis da Seç̧ão Experimental l e as do ültimo nivel das Secções 6 e 8, uma boa concordância entre os valores dos gradientes calculados e observados.

A Secção do Bloco 17, com paredes rígidas, inerece alguns comentärios adicionais, em virtude dos incrementos relativos de temperatura $(\Delta T)$ terem sido adotados em função dos valores observados nas Secções Experimentais 6,8 e 7 a saber, 1 e 0,83 para as estroncas superiores e inferiores, respectivamente.

Com a emergência dos novos dados das outras Secções Experimentais constatou-se que a variação dos $\Delta T$ com a profundidạde ocorria em faixas mais ou menos amplas, conforme está ilustrado na figura IV-8; assim, ter-se-ia incrementos relativos de temperatura oscilando no intervalo de 0,64 a 1,00 . Por outro lado, as medidas de temperatura, feitas somente no interior das estroncas do segundo nivel (ver item 6 do Apêndice $B)$, acusaram valores no intervalo de 20 a $32^{\circ} \mathrm{C}$. Como as tempera turas mäximas nas estroncas dos níveis superiores das outras Secções Experimentais foram maiores do que cerca de $40^{\circ} \mathrm{C}$, resolveu-se fixar o intervalo dos $\Delta T$ em 0,64 a 0,80 .

Feitos os cálculos chegou-se aos limites superio" res dos gradientes assinalados na tabela VI-1. Constata-se que o Módulo $E_{5}$ do Solo Variegado, escorado com paredes rígidas, deve ser da ordem de $20.000 \mathrm{t} / \mathrm{m}^{2}$, o dobro do valor médio de $10.000 \mathrm{t} / \mathrm{m}^{2}$, obtido da expressão $V I-2$. Este resultado vem de encontro a uma das conclusões do Capitulo V.

0 caso da Secção Experimental 2, apresentado na ta bela VI-2, que jä tinha sido discutido no ïtem 5.2. do Capitulo IV, é 


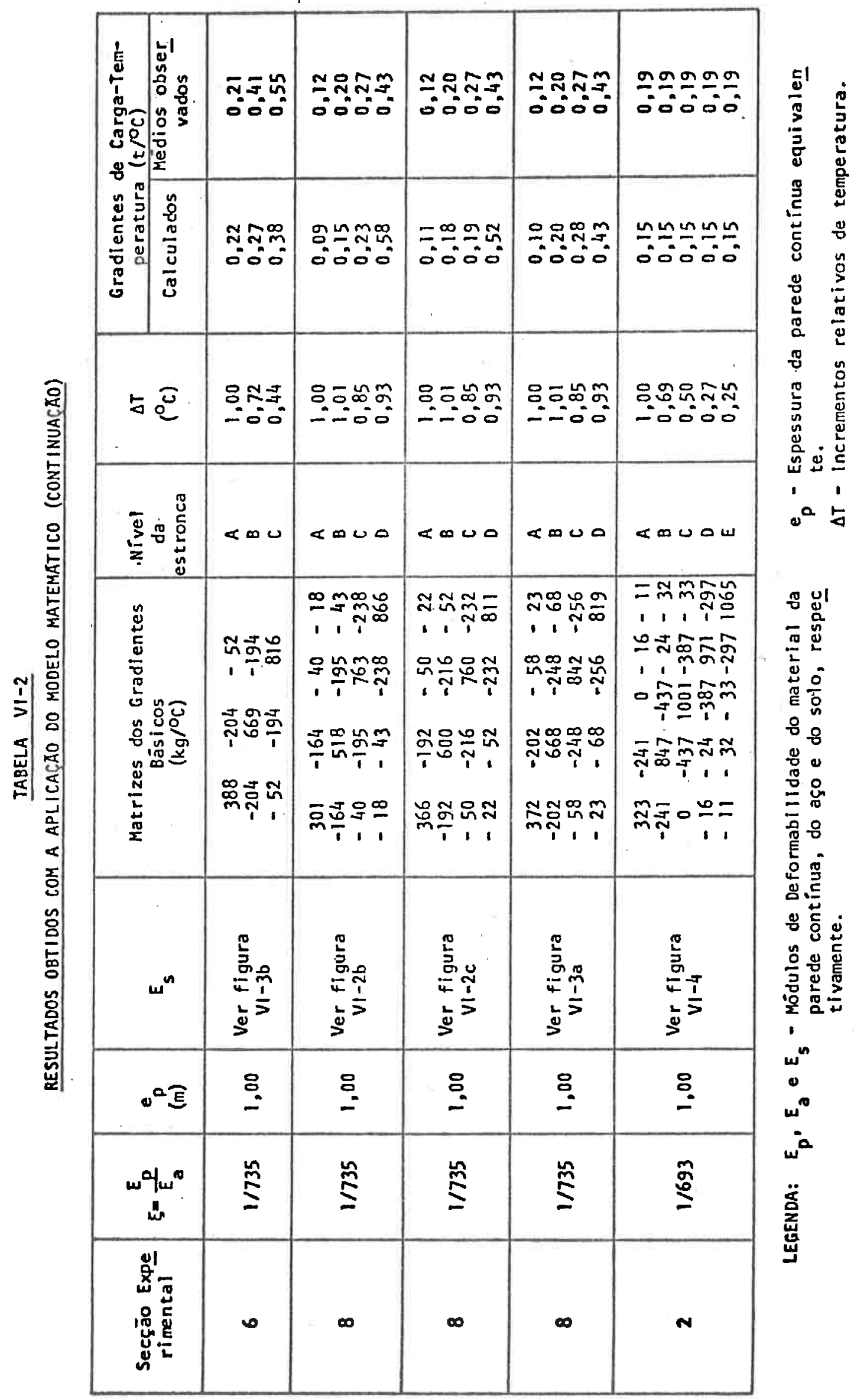




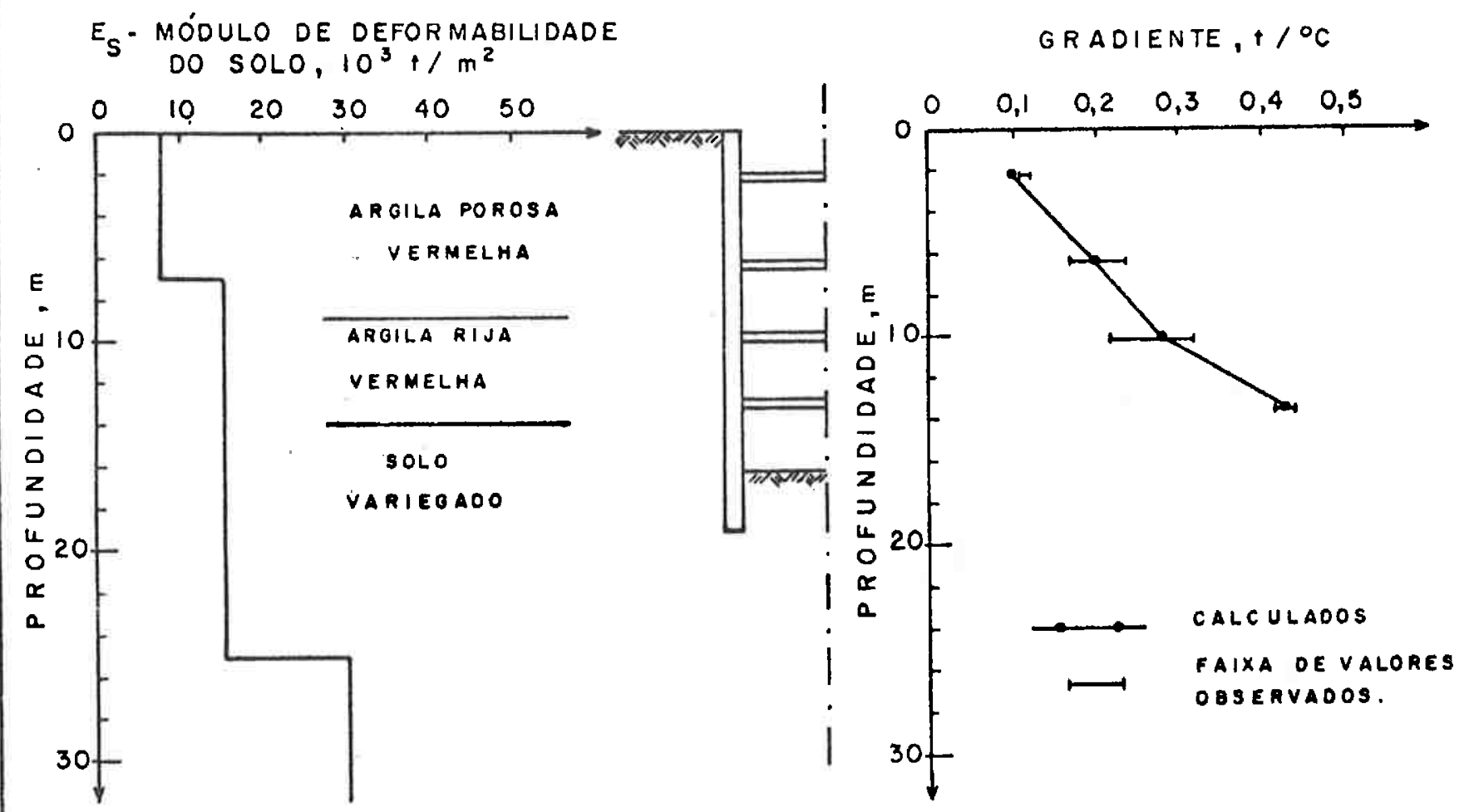

48 C A S O

-) SECGÄO EXPERIMENTAL NQ8

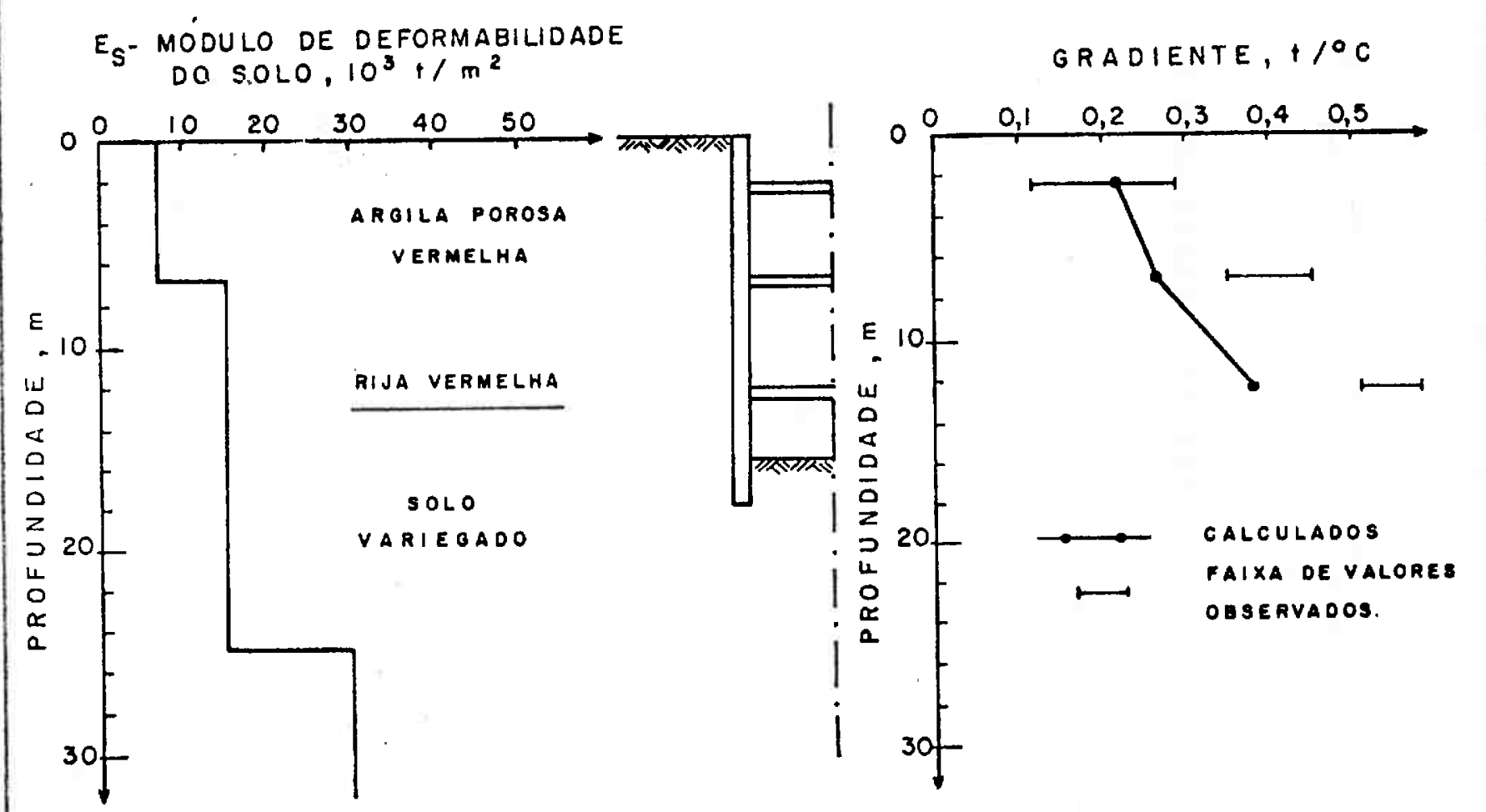

b) SECGÃO EXPERIMENTAL NQ6

FIGURA $\overline{Z I-3}$ : FIXAGÄO DA RIGIDEZ DOS SOLOS ATRAVÉS DE RETROANÁLISE 


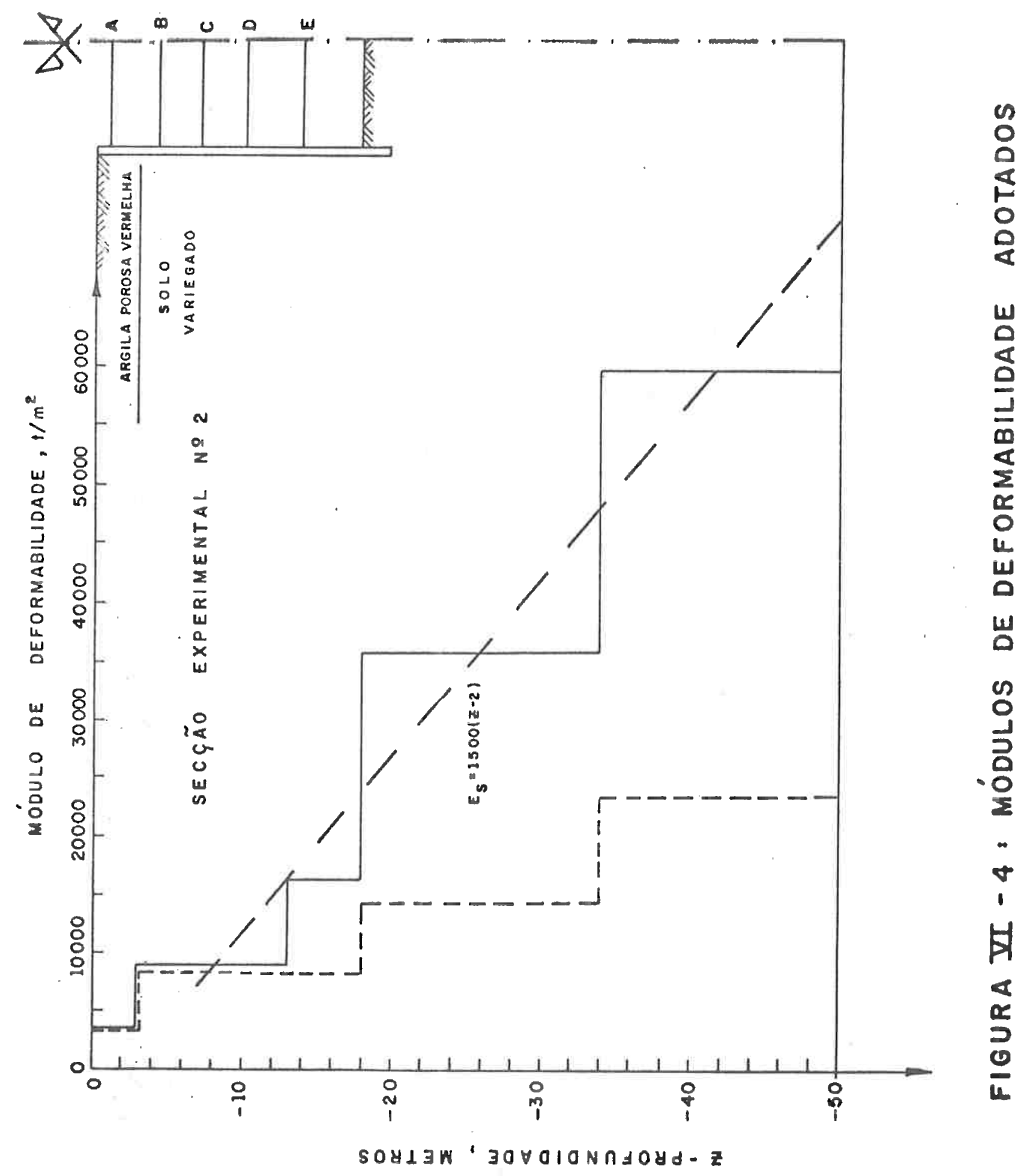


uma novidade. Note-se que o valor assinalado como gradiente calculado é - menor dos autovalores $\left(\lambda_{m}\right)$ da matriz dos gradientes básicos, uma vez que os incrementos de temperatura observados aproximam-se bem dos coeficientes do autovetor associado a $\lambda_{m}$ (ver figura $\left.I V-6\right)$. Os Mödulos $E_{s} u t i$ lizados estão desenhados com linhas cheias na figura VI-4. Os valores cor respondentes às linhas tracejadas conduziram a gradientes de $0,12 \mathrm{t} /{ }^{\circ} \mathrm{C}$ para todos os niveis de estroncas contra $0,19 \mathrm{t} /{ }^{\circ} \mathrm{C}$, observados experimen talmente. Ainda que a diferença entre gradientes seja de $0,07 \mathrm{t} /{ }^{\circ} \mathrm{C}$, ordem de grandeza da precisão do modelo matemático, a proximidade entre as curvas teörica e experimental, indicadas na figura IV-6, a testa a valida de da expressão VI-2 para o cálculo de $E_{s}$.

As Secções Experimentais 6 e 8 apresentaram resultados de cálculo diferentes dos medidos no campo, nas estroncas dos niveis mais elevados, fato este atribuido à heterogeneidade dos solos envolvidos que, por isso mesmo, dificilmente poderiam ser enquadrados em critērios gerais e simples para a determinação dos seus Módulos de Defor mabilidade. Alēm disso, desconhece-se os valores reais dos Coeficientes de Poisson, que podem introduzir desvios de atē $0,07 \mathrm{t} /{ }^{\circ} \mathrm{C}$ nos gradientes.

Foram feitas outras tentativas de ajustagem dos gra dientes calculados aos observados, para estas duas Secções Experimentals, consistindo principalmente no aumento da rigidez dos solos das camadas mais superiores. Os resultados obtidos estão apresentados na tabeIa VI-2 e nas figuras VI-2b,VI-2c,VI-3a eVI-3b. Verifica-se que houve uma melhor aproximação para as soluçōes indicadas nas figuras $V I-2 b \quad e$ $V I-3 a$, relativas à Secção Experimental 8 .

No entanto, preferiu-se deixar de lado este refinamento, em virtude dos gradientes calculados no ültimo nivel de estroncas praticamente coincidirem com os observados. E, como se verá adiante, 
eles são a base para a determinação dos gradientes atravēs de förmulas prāticas que, outrossim, somente poderão ser estabelecidas valendo-se de critérios simples para a estimativa dos Módulos de Deformabilidade.

2. REDEFINIÇAOO DO PARAMETRO I PARA SOLOS HETEROGENEOS

Para o estabelecimento destas förmulas präticas utilizar-se-à o conceito de envol tōrias dos gradientes māximos (Z̈tem 6 do Capïtuzo IV), estendendo a validade das expressões (IV-12) e(IV-13) a valas escoradas em solos heterogêneos.

Tal extensão terā que ser obrigatoriamente eivada de empirismo, não só na redefinição do adimensional n para solos heterogèneos, como tambëm, e principalmente, para se ter uma garantia quanto ao seu uso.

Nos casos em que o perfil de subsolo è constituído de värias camadas, no parâmetro dado por $\mathrm{E}_{\mathrm{a}} \mathrm{S}_{\mathrm{a}} / \mathrm{E}_{\mathrm{s}} \mathrm{t} l$, que mede a relação entre a rigidez à compressão das estroncas e a rigidez do solo, è ra zoável tomar para $E_{S}$ o valor mëdio dos Mödulos de Deformabilidade em toda a profundidade $D$, altura das paredes de escoramento. Tal parâmetro se rä designado, daqui por diante, por $\bar{\eta}$ e o Mödulo, $\bar{E}_{s}$.

Retomando-se a Seç̧ão Experimental 8, pode-se extrair das figuras VI-2 e VI-3a os seguintes valores de $\bar{E}_{\mathbf{s}} \mathbf{e}$, consequentemente, dos parâmetros $\bar{\eta}$ a eles associados:
a) $\bar{E}_{s}=10.600 \mathrm{t} / \mathrm{m}^{2}$ e $\bar{\eta}=1,24$ para o $1 \%$ caso; $e$
b) $\bar{E}_{s}=12.200 \mathrm{t} / \mathrm{m}^{2}$ e $\bar{n}=1,08$ para os $2 \%$, 3\% e $4 \%$ casos.

Admitindo-se que o Mödulo de Deformabilidade varie segundo as expressões (VI-1) e (VI-2), esta ültima simplificada a favor 
da segurança para:

$$
E_{s}=1.500 z
$$

o valor médio $\bar{E}_{s}$ serä dado por:

$$
\bar{E}_{s}=750 D\left[1-0,533\left(\frac{D_{1}}{D^{2}}\right)^{2}\right]
$$

onde $D_{1}$, espessura da camada de Argila Porosa, e $D$ valem, respectivamente, $9 \mathrm{~m}$ e 19,6 m, para a Secção Experimental 8. Feltos os cälculos, chega-se a $\bar{E}_{s}=13.400$ e $\bar{n}=1,0$.

Vê-se, pois, que è perfeitamente välido trabalhar com as expressões $(V I-1)$ e $(V I-2 a)$ para estimar $\bar{n}$. E o que se farā, através de förmulas simples.

3. FORMULAS SIMPLES PARA O CALCULO DE $\bar{n}$

Para as Argilas Porosas Vermelhas, partindo-se da expressão $(V I-1)$, com $D^{\prime}=D$, chega-se facilmente a:

$$
\bar{n}=6 \cdot \frac{S_{a}}{D t l}
$$

onde $S_{a}$ deve ser tomado em $\mathrm{cm}^{2}, D, t$ e $\ell$ em $m$. Relembra-se que $S_{a}$ e $\ell$ são, respectivamente, a ärea da secçāo transversal e o comprimento das estroncas; $t$ o espaçamento entre elas, em planta; $e \underline{D}$ a altura das paredes de escoramento.

$$
\begin{gathered}
\text { De }(V I-2 a) \text { pode-se deduzir: } \\
\bar{n}=3 \cdot \frac{\mathrm{s}_{a}}{\mathrm{Dtl}}
\end{gathered}
$$


a ser aplicada aos Solos Variegados.

Quanto às Argilas Rijas Vermelhas, sugere-se a ado

ção de:

$$
\bar{n}=4,5 \frac{s_{a}}{\overline{D t l}}
$$

ou, como a sua ocorrència è em camadas relativamente pouco espessas, pode-se incorporä-las às Argilas Porosas (posição otimista) ou aos Solos Variegados (posição conservadora).

Em geral e resumindo:

$$
\bar{n}=B \cdot \frac{s_{a}}{D t l}
$$

com $\mathrm{S}_{\mathrm{a}}$ em $\mathrm{cm}^{2} ; D, \mathrm{t}$ e $\ell$ em $\mathrm{m}, \mathrm{e} B=6$ para as Argilas Porosas Vermelhas e $\beta=3$ para os Solos Variegados.

No caso de subsolos compostos de camadas de Argilas Porosas Vermelhas e Solos Variegados, pode-se calcular $B$ através de:

$$
B=\frac{2,80}{1-0,533\left(\frac{D_{D}}{D}\right)^{2}}
$$

obtida da expressão (VI-3). Uma alternativa seria tomar para $\beta$ a média dos valores indicados acima, ponderada em função de suas espessuras em toda a altura $\underline{D}$ das paredes de escoramento. Assim procedendo, em detrimento da expressão (VI-5), chega-se a desvios, para menos, nos valores dos gradientes de carga-temperatura, inferiores a $20 \%$; e isto quando $0_{1} / D$ é da ordem de $50 \%$. Em virtude da sua simplicidade, optou-se pela mëdia ponderada na sequência desta Investigação. 
TABELA VI-3

METRO DE SÃO PAULO

VALORES DOS GRADIENTES (G) ADIMENSIONALIZADOS, OBSERVADOS E CALCULADOS PELA FORHULA DE CHAPMAN (V.CAPITULO I)

\begin{tabular}{|c|c|c|c|c|c|}
\hline \multirow{2}{*}{$\begin{array}{c}\text { Seç̧āo } \\
\text { Experimental }\end{array}$} & \multirow{2}{*}{$\begin{array}{l}\text { Nivel da } \\
\text { estronca }\end{array}$} & \multicolumn{4}{|c|}{$G /\left(E_{a} S_{a}{ }^{\alpha}\right), \%$} \\
\hline & & $\begin{array}{r}\text { Máximos } \\
\text { final }\end{array}$ & $\begin{array}{l}\text { observados em } \\
\text { de escavaçäo }\end{array}$ & $\begin{array}{c}\text { Calculados } \\
\text { de }\end{array}$ & $\begin{array}{l}5 \text { pela förmula } \\
\text { Chapman }\end{array}$ \\
\hline 1 & $\begin{array}{l}A \\
B \\
\end{array}$ & & $\begin{array}{l}7,6 \\
9,0 \\
\end{array}$ & & 6.3 \\
\hline 6 & $\begin{array}{l}A \\
B \\
C\end{array}$ & & $\begin{array}{r}8,2 \\
12,9 \\
16,3 \\
\end{array}$ & & 8,0 \\
\hline 8 & $\begin{array}{l}A \\
B \\
C \\
D \\
\end{array}$ & & $\begin{array}{r}3,4 \\
6,5 \\
9,0 \\
12,4 \\
\end{array}$ & & 5,6 \\
\hline 2 & $\begin{array}{l}A \\
B \\
C \\
D \\
E\end{array}$ & , & $\begin{array}{l}5,3 \\
6,5 \\
7,0 \\
8,2 \\
8,2 \\
\end{array}$ & 6 & 6,3 \\
\hline 5 & $\begin{array}{l}A \\
B \\
C \\
D \\
E \\
F\end{array}$ & & $\begin{array}{r}5,9 \\
5,3 \\
9,8 \\
10,1 \\
18,8 \\
12,4\end{array}$ & & 8.7 \\
\hline
\end{tabular}

LEGENDA: G - Gradiente de Carga-Temperatura.

E $S_{\text {a }}$ Carga que surgirla numa estronca bloqueada em suas ext
$10 \mathrm{C}$. 
4. FORMULAS PRATIICAS PARA O CALCULO DOS GRADIENTES EM FINAL DE ESCAVAÇÃO. COMPROVAÇÃO EMPIRICA.

4.1. Paredes Flesuveis

o cālculo dos gradientes mäximos atravës das expressões $(I V-12 a)$ e $(I V-13)$, is to é:

$$
G_{\operatorname{maxx}}=\frac{0,5 E_{a} S_{a} \alpha}{1+2 \bar{n}}
$$

e

$$
G_{i}^{\operatorname{mäx}}=G_{\operatorname{mäx}}-\frac{d_{i}}{140} E_{a} S_{a} \quad(V I-6 b)
$$

onde $\bar{\eta} \bar{e}$ dado pela expressão $(V I-4)$, conduziu aos valores indicados nas duas ültimas colunas da tabela III-1, para as Seç̧ões Experimentais com paredes flexiveis.

Vê-se que existe uma boa concordāncia com os mäximos observados em final de escavação, o que justifica o emprego destas förmulas prāticas para paredes flexíveis. Excetua-se a Secção Experimental 2, pelos motivis xpostos nos Capïtuzos III (ïtem 3.2) e IV (ítem 5.2).

Para fins de comparação, a tabela VI- 3 apresenta os gradientes adimensionalizados observados em final de escavação e calculados pelas expressões $(I-1)$ e $(I-2)$ de Chapman (vide Capitulo I). Ob serva-se que, alëm de não diferenciar a posição da estronca, em corte, os valores calculados chegam a ser atē a metade dos mäximos observados, em cada Seç̧ão Experimental.

4.2. Paredes Rïgidas

0 mesmo não sucede com a expressão $(I V-12 b)$, para 
paredes rigidas, como foi enfatizado no item 1 deste Capitulo. A explicação è relativamente simples; de fato, as paredes diafragmas são construidas para impedir ou restringir movimentos laterais do solo, is to $\bar{e}$, - maciço terroso deve continuar em estado pröximo ao de repouso, o que implica em Mödulos de Deformabilidade maiores. Ademais, a construção de paredes rígidas em trechos com prédios de porte è outro fator a considerar neste raciocínio, situação que implica num aumento do peso efetivo de terra ou de $\bar{\sigma}_{\mathrm{c}}$.

A duplicação do Mödulo de Deformabilidade pode ser levada em conta al terando-se a expressão $(I V-12 b)$ para:

$$
G_{\text {máx }}=\frac{0,5^{E_{a} S_{a}}}{1+0,5 \bar{n}}
$$

aplicável ao ültimo nível de estroncas. Este procedimento è preferível, à alternativa de propor separadamente expressões de $\bar{n}$, umas välidas para paredes flexíveis, outras para paredes rígidas.

$$
\text { Quanto aos outros niveis de estroncas recomenda- }
$$
se o uso da mesma förmula visando a consideração do efeito da dilatação tërmica das paredes de concreto que, como foi indicado no Copítulo IV e demonstrado no item 3 do Apêndice $E$, pode induzir acrëscimos nos valores dos gradientes de carga-temperatura das escoras.

A aplicação da expressão (VI-7) às Secções Experimentais com paredes rigidas, indicadas na tabela III-1, conduzlu aos valores das suas duas ūltimas colunas, que estão prōximos ou acima dos máximos observados em final de escavação.

5. INFLUENCIA DA RIGIDEZ DA PAREDE DE ESCORAMENTO, DA GEOMETRIA DA VALA E DO TIPO DE SOLO NOS GRADIENTES MAXIMOS DE CARGA-TEMPERATURA. 


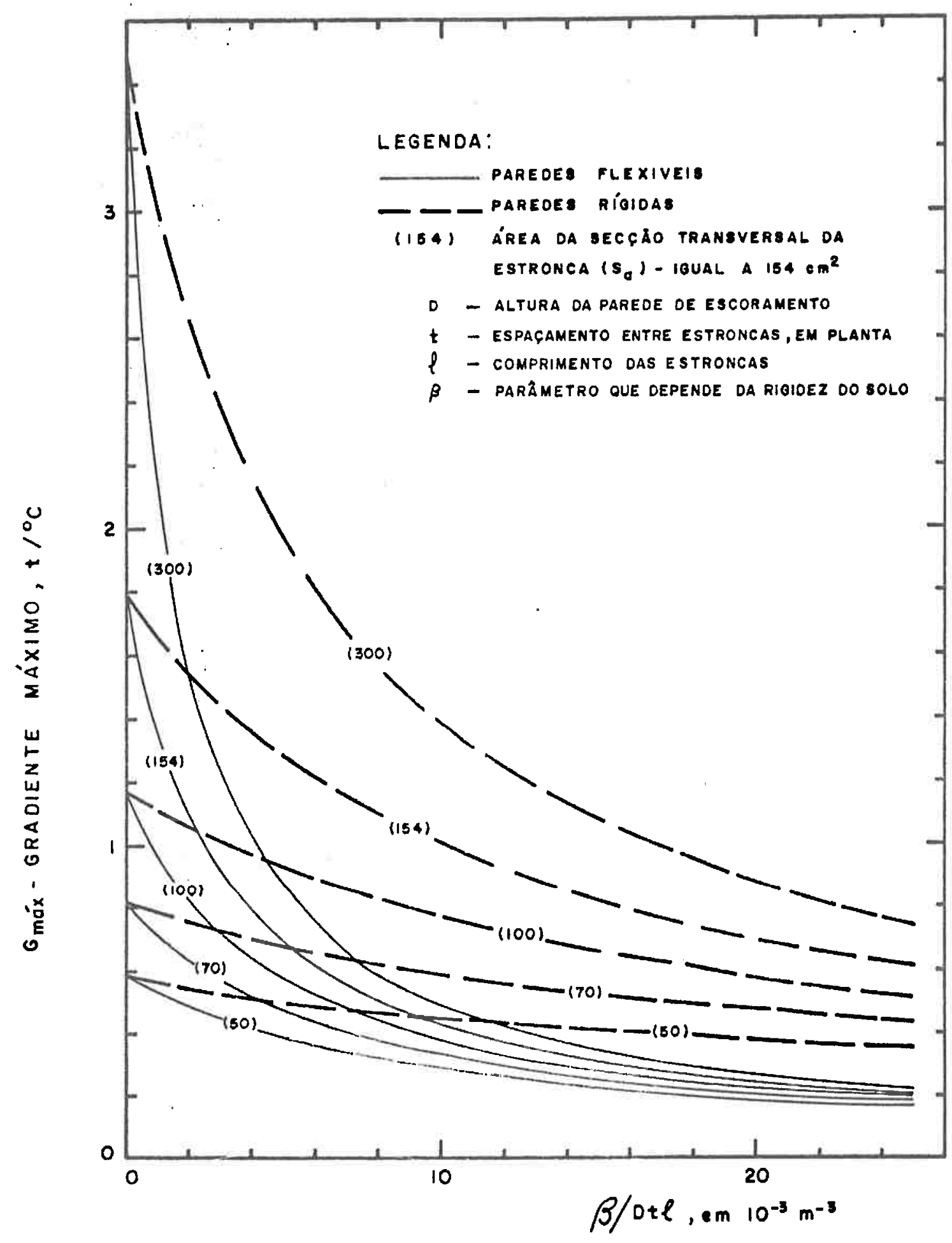

FIGURA II - 5: ÁBACOS PARA O CÁLCULO DO GRADIENTE MÁXIMO 
A figura VI-5 contêm um àbaco que permi te a obtençäo dos gradientes mäximos, tanto para paredes rigidas quanto flexivels, para diversos valores da Área da Seç̧āo Transversal de estroncas.

A fim de trazer à baila como os gradientes máximos são influenciados pelos parâmetros geométricos $\mathrm{D}, \mathrm{t}, \ell$ e $\mathrm{S}_{a}$, assim como pelo tipo de solo, através do parâmetro $B$ introduzido pela expressão $(V I-4)$, foram manipuladas as expresseões (VI-6a) ou (VI-7) de forma tal a permitir escrever:

$$
\frac{\Delta G_{\text {mäx }}}{G_{\operatorname{mäx}}}=\frac{2 \cdot \bar{G}_{\text {mäx }} \frac{\Delta S_{a}}{S_{a}}}{\left(1+\frac{\left.\Delta S_{a}\right)^{2}}{S_{a}}-\left[\left(1+\frac{\Delta S_{a}}{S_{a}}\right)+2 \cdot \bar{G}^{m a x}\right] \frac{\Delta S_{a}}{S_{a}}\right.} \quad(V 1-8 a)
$$

Esta equação fornece a varlação relativa do gradiente māximo em função de variaçōes relativas da ärea $S_{a}$, mantidos todos os outros parâmetros constantes. Supondo pequenos valores de $\Delta \mathrm{S}_{\mathrm{a}} / \mathrm{S}_{\mathrm{a}}$, ela se degenera em:

$$
\frac{\Delta G_{\max }}{G_{\operatorname{ma} x}}=2 \cdot \bar{G}_{\text {mäx }} \cdot\left(\frac{\Delta s_{a}}{S_{a}}\right)
$$

$$
\text { Para o comprimento das estroncas } \ell \text {, conservando }
$$
os outros parâmetros constantes, pode-se chegar a:

$$
\frac{\Delta G_{\text {mäx }}}{G_{\text {mäx }}}=\frac{\left(1-2 \bar{G}_{\text {mäx }}\right)\left(\frac{\Delta \ell}{l}\right)}{1+2 \bar{G}_{\text {máx }}\left(\frac{\Delta \ell}{\ell}\right)}
$$

ou, se as variaçōes relativas de $\ell$ forem pequenas:

$$
\frac{\Delta G_{\text {mäx }}}{G_{\text {mäx }}}=\left(1-2 \bar{G}_{\text {mäx }}\right)\left(\frac{\Delta \ell}{l}\right)
$$


Note-se que :

$$
\bar{G}_{\operatorname{máx}}=\frac{G_{\text {mäx }}}{E_{a} S_{a}^{\alpha}}
$$

é a forma adimensionalizada do gradiente mäximo e representa a fração de carga na ültima estronca em relação à carga que ocorreria estivessem suas extremidades impedidas de se movimentar,por efeito da temperatura.

As expressões (VI-8) e (VI-9) valem tanto para paredes rígidas quanto flexiveis, sendo a ültima aplicāvel ipsis litteris aos parämetros $D$ e $t$. Outrossim, para levar em conta o tipo de solo, deve-se substituir, ainda em $(V I-9 a), \Delta \ell / \ell$ por $-(\Delta \beta / \beta) /(1+\Delta \beta / \beta)$, sendo que somente para $\beta$ a relação é inversa, is to é, para seus acrēscimos $G_{\operatorname{māx}}$ decresce.

Serä mostrado a seguir que os gradientes mäximos, quando apresentam valores elevados, o que em geral ocorre em escoramentos com paredes rígidas, são bastante sensíveis a variações da área da secção transversal das estroncas $\left(S_{a}\right)$. Mutatis mutandi, para gradientes baixos, via de regra associados a paredes flexiveis, a dependência è muito maior com relação ao tipo de solo $(\beta)$, distāncia em planta entre estroncas $(t)$, seus comprimentos $(l)$ e altura das paredes de escoramento (D).

De fato, considere-se inicialmente pequenas variações destes parâmetros. Com gradientes baixos, nota-se pelas expressões $(V I-8 b)$ e $(V I-9 b)$ que as variações relativas do gradiente māximo praticomente independem das variaçōes relativas de $S_{a}$ e são quase iguais às variações relativas de $D, t$, lou $B$. 0 inverso è verdadeiro para gradientes elevados. Sousa Pinto et al (1974) jä tinham realçado este fato para paredes flexiveis com gradientes baixos, mostrando que a influência de 


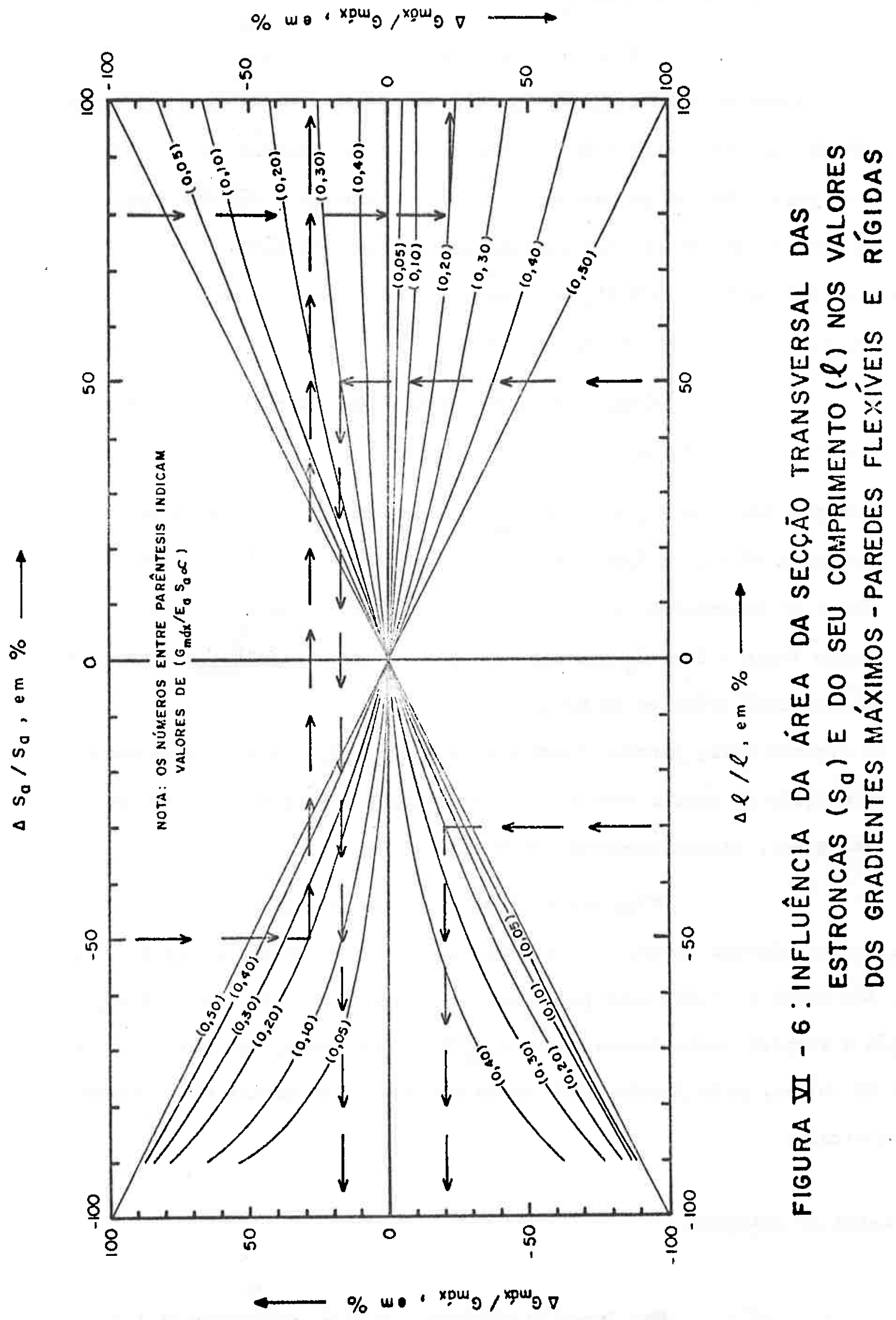


$\ell \dot{e}$ muito maior do que a de $\mathrm{S}_{\mathrm{a}}$.

De um modo mais geral, as expressões $(V I-8 a) \quad e$ $(V I-9 a)$ tambēm mostram estes mesmos tipos de dependência, como se pode depreender da anālise da figura $V I-6$, que è a sua representação gräfica. Tudo se passa como se as paredes rígidas mascarassem a rigidezproveniente do solo ou de menores espaçamento $(t)$ ou comprimento $(l)$ das estroncas; no limite $\left(G_{\text {mäx }}=0,5\right)$, os gradientes são função só de $S_{a}$, cujas variaçōes são linearmente dependentes entre si.

Como llustração, para fixar idēias, considere-se duas paredes, uma rigida e a outra flexível.

a) Para paredes rigidas, supondo $\bar{G}_{\text {máx }}=0,40$ e que o solo passe de Solo Variegado $(\beta=3)$ a Argila Porosa Vermelha $(\beta=6)$, tem-se $(\Delta \beta / \beta)=$ $100 \%$ e um decréscimo relativo no $\bar{G}_{\operatorname{māx}}$ de $17 \%$; se ao invēs desta variação fosse a ärea $S_{a}$ que duplicasse de valor, então $\bar{G}_{\operatorname{máx}}$ sofreria um acréscimo relativo de $67 \%$.

b) No segundo caso, paredes flexiveis, admitindo $\bar{G}_{\text {maxx }}=0,10$ e as mesmas alterações de solo e ärea $S_{a}$, os percentuais assinalados acima passariam a ser, respectivamente, $44 \%$ e $11 \%$

Finalmente, è de se notar na figura VI-5 que os gradientes mäximos, associados a paredes flexiveis com baixos valores de $S_{a}$, são pouco influenciados pelos outros parâmetros $B, D, t$ e $\ell$. A expli cação è simples, pois nestes casos $G_{\max } / E_{a} S_{a} \propto \bar{e}$ elevado, variando de 0,30 a 0,50 , o que, pela figura VI-6, torna pequena a influência dos parâmetros citados.

\section{FASES DE REATERRO}

Nas fases de reaterro, is to $\bar{e}$, nos estágios inter- 


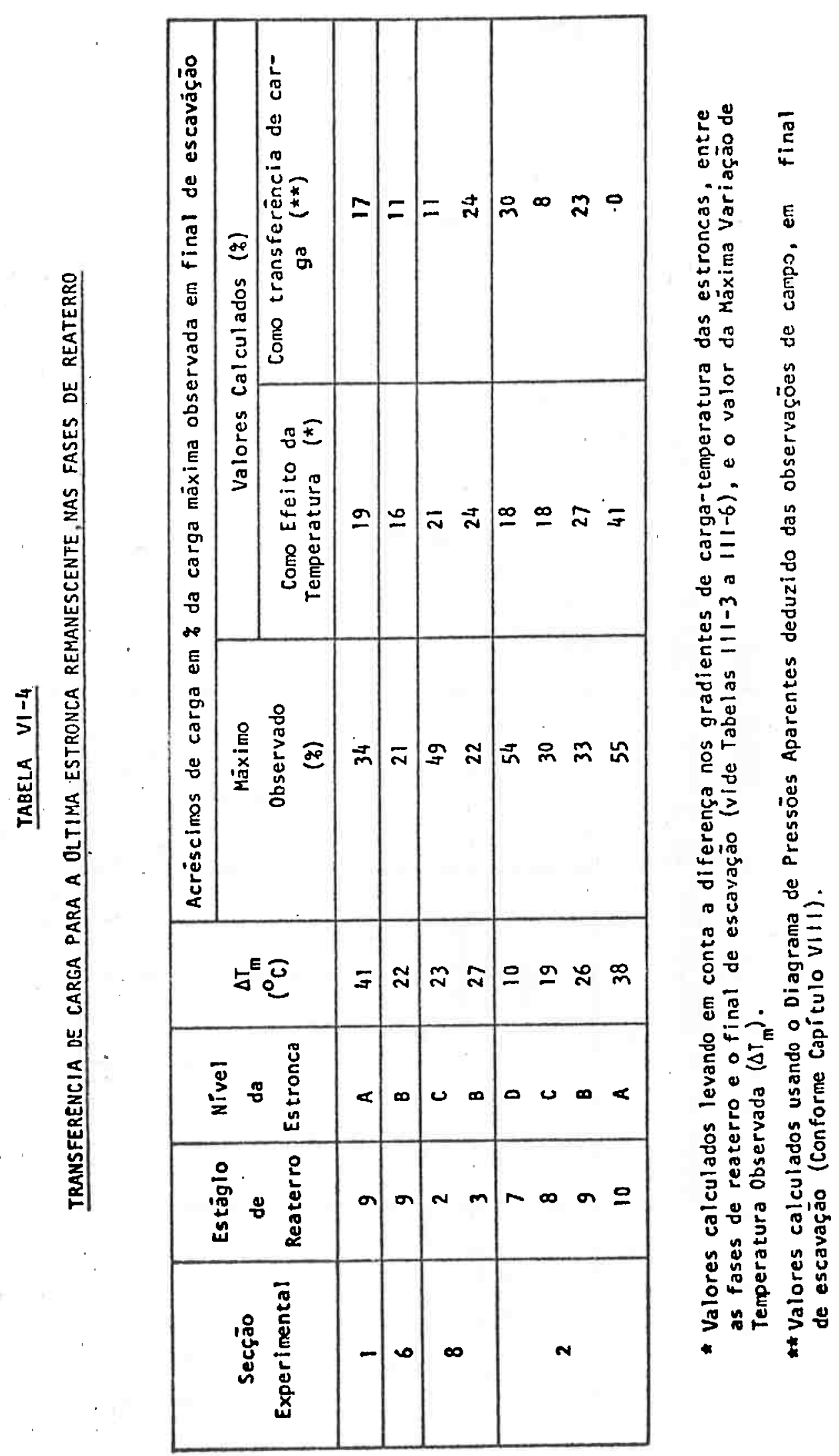




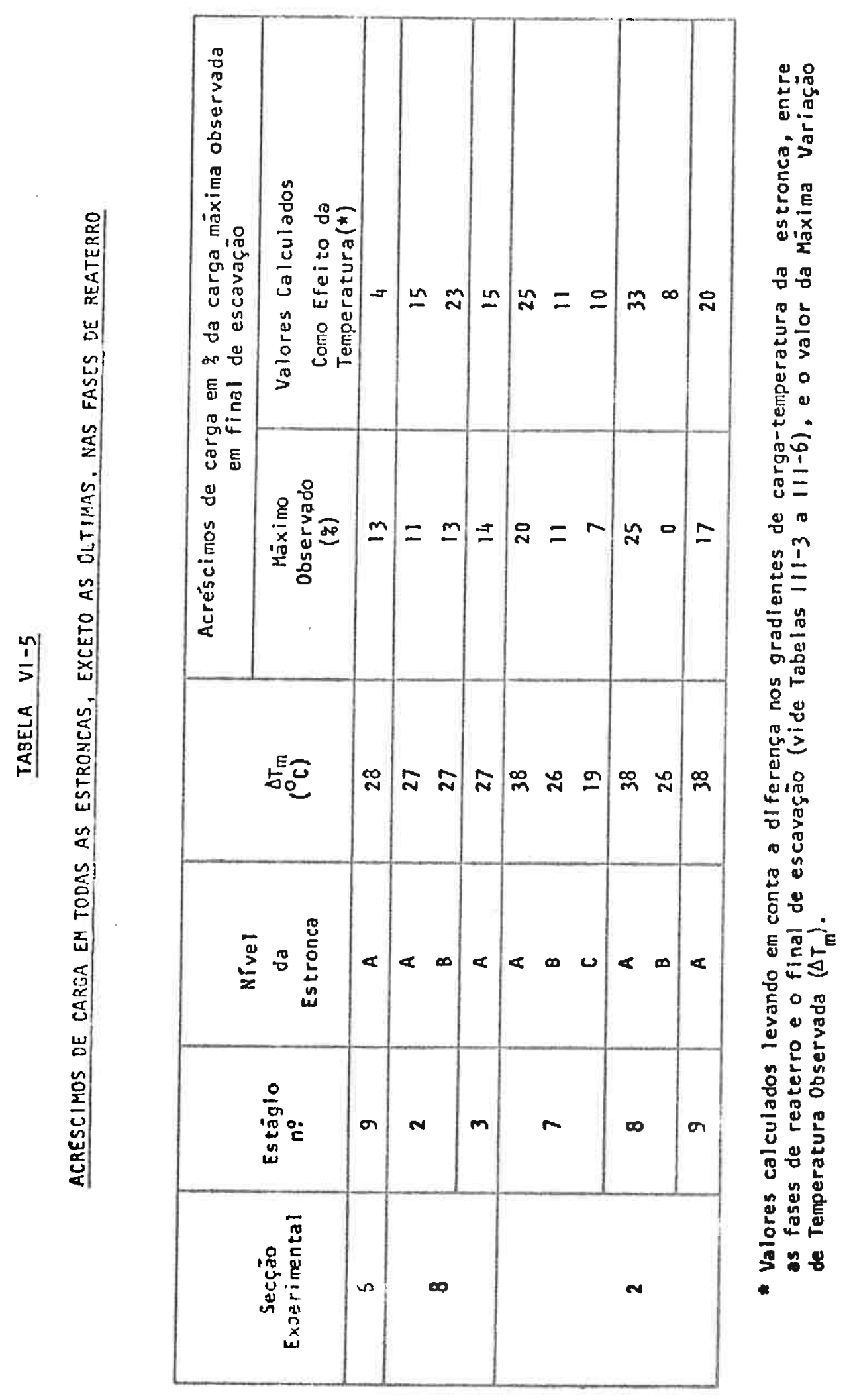


mediärios desde o final de escavação atē o término do reaterro ocorre um aumento dos gradientes de carga-temperatura nas estroncas remanescentes, mercê da maior rigídez do escoramento, conforme explicação apresentada no item 3.2. do Capitulo III.

As estroncas Imedlatamente acima do nivel removido serão denominadas de últimas estroncas remanescentes, em oposição às outras estroncas remanescentes dos niveis mais superiores. Alläs, as estroncas do primeiro nivel são designadas pela letra $A$; as do segundo, B; e assim por diante.

A título de ilustração, a figura $B-11$ do Apêndice $B$ mostra o estägio 6, final de escavação, e os estägios $7,8,9$ e 10 das fá ses de reaterro, relativos à Secção Experimental 2. Note-se que no estägio 7, em que se encunhou as estacas na base do tünel de concreto e remo veu-se as estroncas do nivel $E$, a $\vec{u}$ ttima estronca remanescente $\bar{e}$ a do $n \underline{I}$ vel D. Para o estägio 9, ē a do nível B.

Manipulando-se os dados contidos nas tabelas III-3 a III-6, relativos às Secções Experimentais 1, 6, 8 e 2, foi possível determinar os acrescimos de carga observados associados a cada nível de estroncas, quando se passa do final de escavação para os estägios de rea terro. Estes acréscimos devem ser entendidos como a maior diferença entre as cargas das estroncas de um mesmo nivel, medidas na temperatura mă xima. As tabelas VI-4 e VI-5 mostram os valores encontrados, em porcentagem da māxima carga observada no correspondente nivel de estroncas.

Na mesma tabela estāo Indicados os acréscimos de carga calculados, em função dos aumentos nos gradientes e dos valores da māxima variação de temperatura observada em cada nivel de estroncas. Em uma palavra, cada acréscimo de carga fol determinado como se fosse resul tante sö do efeito da temperatura. 
Da análise destes resultados pode-se concluir que - efeito da temperatura justifica os acréscimos de carga em todas as estroncas remanescentes, exceto as do ültimo nivel (tabela VI-5). Estes acrëscimos podem ser fixados em $30 \%$ da carga na temperatura máxima,atuan te em cada estronca em final de escavação.

0 mesmo não ocorre para as ültimas estroncas remanescentes (tabela VI-4), em virtude da transferência de carga por arqueamento do solo, resultante da remoção de escoras.

Atente-se, finalmente, ao fato dos gradientes māxi mos calculados pelas exprossõca $(V I-6 a)$ ou $(V I-7)$ serem, em geral, superiores aos gradientes máximo maximorım, medidos em qualquer nivel de estroncas, nas fases de reaterro (comparar os dados apresentados na tabeZa III-T).

7. OUTRAS APLICAÇOES DO MODELO MATEMATTICO ELABORADO ANTERIORMENTE

As fórmulas práticas para o cálculo dos gradientes terão aplicação direta no Copittuzo VIII; trata-se da tentativa de inclusão do efeito da temperatura nos processos de cálculo das cargas nas estroncas, em sistemas de escoramentos com paredes flexiveis.

Antes disso, valendo-se ainda dos resultados teóricos apresentados no item 1 deste Capitulo, as cargas observadas nas es troncas das Secçōes Experimentais seräo fracionadas em cargas de encunha mento, empuxos de terra e cargas devidas à dilatação térmica das estron cas. 


\section{CAPITULO VII}

REPARTIÇAOO DAS CARGAS MEDIDAS NAS SECÇOES EXPERIMENTAIS COM PARE

DES FLEXTVEIS EM TRES PARCELAS: A DE ENCUNHAMENTO; A DE EMPUXO DE TERRA E A DE DILATAÇAOO TERMICA DAS ESTRONCAS

\section{PREAMBULO}

A fim de realçar quantitativamente a importância rela tiva do efeito da temperatura em escoramentos com paredes flexíveis, serä desenvolvida uma concei tuação quanto à repartição das cargas nas estroncas, seguindo-se o pröprio processo construtivo, um tanto simplificado, de escavação e escoramento de valas a céu aberto.

O termo carga de encunhamento será usado para significar a carga instalada numa estronca por reação contra paredes flexiveis, durante a colocação das cunhas metálicas.

Para fixar idēias considere-se uma vala a ser escavada e escorada com 2 niveis de estroncamentos; as estacas metälicas jā estão cravadas em duas linhas paralelas.

Ao se atingir uma determinada cota de escavaçăo, a es tronca superior é colocada. e encunhada com carga $C_{E}^{S}$, que aumenta na medi da em que a escavação progride, sofrendo simultāneamente oscilações em função de variações de temperatura. Na temperatura mínima $\left(T_{0}^{s}\right)$ ocorre o mäximo de deslocamento e de deformação no solo escorado, que induz um empusco de terra $E_{s}$. Quando a temperatura atinge o valor máximo $\left(T_{m}^{\mathbf{s}}\right)$ a carga na estronca superior serā dada por:

$$
C_{s}=C_{E}^{s}+E_{s}+G_{s}^{\prime}\left(T_{m}^{s}-T_{0}^{s}\right)
$$


onde $G_{S}^{\prime}$ é o gradiente de carga-temperatura a ela associado. Concom'tante mente, pranchōes de madeira vão sendo colocados entre duas estacas consecutivas de uma mesma linha.

Chega o momento em que é instalada a estronca inferior com carga de encunhamento $C_{E}^{i}$, que provoca, de imediato, um alivio $\Delta C^{S}$ na carga da estronca superior, transformando-se a expressão acima em:

$$
C_{S}^{\prime}=\left(C_{E}^{S}-\Delta C_{E}^{S}\right)+E_{S}^{\prime}+G_{S}\left(T_{m}^{S}-T_{O}^{S}\right)
$$

onde $E_{5}^{\prime}$ e $G_{5}$ são os novos valores do empuxo de terra e do gradiente de carga-temperatura, respectivamente, na estronca superior.

$$
\text { Analogamente, para a estronca inferior pode-se escre- }
$$

ver:

$$
C_{i}=C_{E}^{i}+E_{i}^{i}+G_{i}\left(T_{m}^{i}-T_{0}^{i}\right)
$$

De um modo geral tem-se, numa vala escorada com n ni-

veis de estroncas:

$$
C_{j}=C_{E}^{j}+E_{j}+G_{j}\left(T_{m}^{j}-T_{0}^{j}\right)
$$

onde: $C_{j}$ è a carga atuante na $j$-ésima estronca $(j=1$ a $n)$ na temperatura mäxima;

$C_{E}^{j}$ e $E_{j}$ são as parcelas de carga devidas, respectivamente, ao encunhamento, já aliviado, e ao empuxo de terra propriamente di to;

G j $\bar{e}$ o gradiente de carga-temperatura relativo à j-ēsima estronca; e $\mathrm{T}_{\mathrm{m}}^{j}$ e $\mathrm{T}_{0}^{j}$ são as temperaturas mäxima e minima, respectivamente, relativas à j-èsima estronca. 
2. ESTIMATIVA dOS ALTVIOS DE CARGA DEVIDOS AO ENCUNHAMENTO

\subsection{Fundomentos Teóricos}

Suponha-se que värias estroncas jä tenham sido. encunhadas e que a escavação progrediu atè uma certa profundidade, sendo, pois, necessārio instalar a j-ēsima estronca, com a carga de encunhamento $C_{E}^{j}$

Tudo se passa como se somente a j-ésima estronca tivesse sofrido um incremento de temperatura $\Delta T_{e}$ fictício, que induz uma carga igual a $C_{E}^{j}$ e provoca alivios de carga $\Delta C_{E}^{i}(i=1$ a $j-1)$ nas estroncas situadas acima dela. Assim sendo, tem-se, pela expressão (III-1):

$$
\left\{\begin{array}{c}
\Delta C_{E}^{1} \\
\vdots \\
\Delta C_{E}^{j-1} \\
c_{E}^{j}
\end{array}\right\}=U\left\{\begin{array}{c}
0 \\
\vdots \\
0 \\
\Delta T_{e}
\end{array}\right\}
$$

onde $U$ é a matriz dos gradientes básicos para a vala no estägio em que se encontra escavada e escorada.

Efetuando-se a multiplicação matricial resultam jequa ções, a üitima das quais permite escrever:

$$
\Delta T_{e}=\frac{C_{E}^{j}}{u_{j j}}
$$

que, substituida nas outras, gera as seguintes relações:

$$
\frac{\Delta C_{E}^{i}}{c_{E}^{j}}=\frac{u_{i j}}{u_{j j}}, \text { com } i=1,2 \ldots(j-1)
$$


onde $u_{i j}$ e $u_{j j}$ säo termos da ültima coluna da matriz U. Elas possibilitam - cálculo dos percentuais de alívio de carga nas estroncas situadas acima da que foi encunhada e referenciadas à carga de encunhamento.

A aplicação da expressão (VII-2) aos resultados teóricos apresentados nas tabezas $V I-1$ e VI-2, relativos às Secções Experimentais com paredes flexiveis, conduz a alivios de carga de 19 a $33 \%$, na penūltima estronca, e de 3 a $8 \%$ para a antepenúltima, quando a ültima es tronca é encunhada com carga unitäria. Os valores mëdios destes alívios são, respectivamente, $27 \%$ e $4 \%$. Para as estroncas mais superiores os percentuais são desprezíveis, indicando que os alívios de carga se propagam a pequenas distâncias em escoramentos com paredes flexíveis.

\subsection{Comprovação experimental}

Infelizmente estas cifras carecem de comprovação experimental plena, pois, com algumas exceções, não se dispunha dos dados necessārios para tanto.

As exceções foram as Secções Experimentais 1, paredes flexíveis, e as Seç̧ões Experimentais 3 e 7, paredes rígidas, em que estes dados estavam à mão e permitem alguma comparação. A introdução das paredes rigidas neste ponto da anälise é acidental sob o ponto de vista das metas deste Capítulo, porēm ütil no sentido de uma melhor compreensão do assunto em pauta.

Na Seç̧ão Experimental 1 o encunhamento das estroncas do segundo nível foi feito em 09/03/1971, por volta das $16 \mathrm{~h}$, com a carga média de 5,1 t. As estroncas do nivel superior sofreram decréscimo médio de carga de $1,3 t$, valor este obtido por diferença com medidas feitas no dia anterior, estando as escoras aproximadamente na mesma temperatura. Is to dā, em média, um alívio de $1,3 / 5,1=25 \%$. 


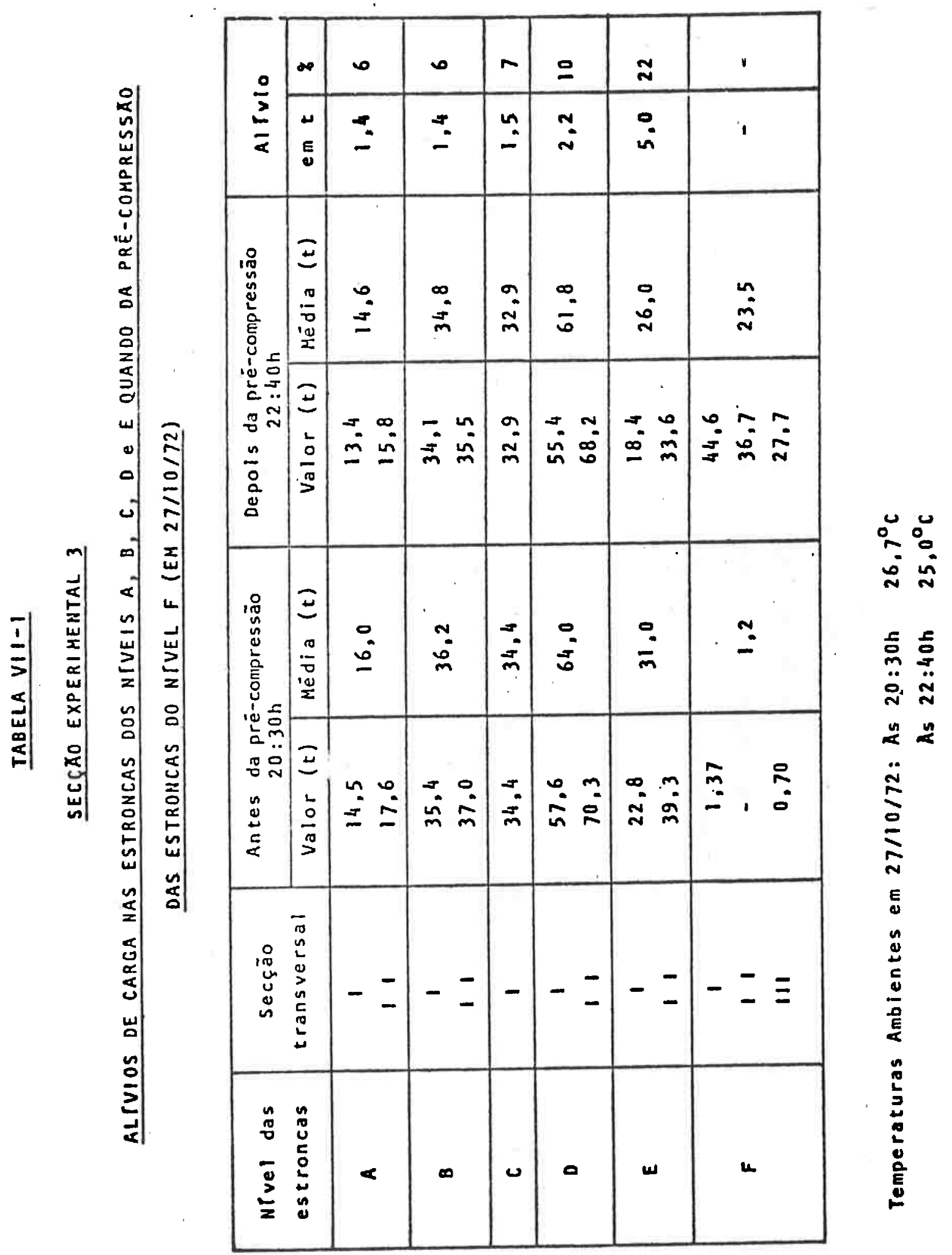




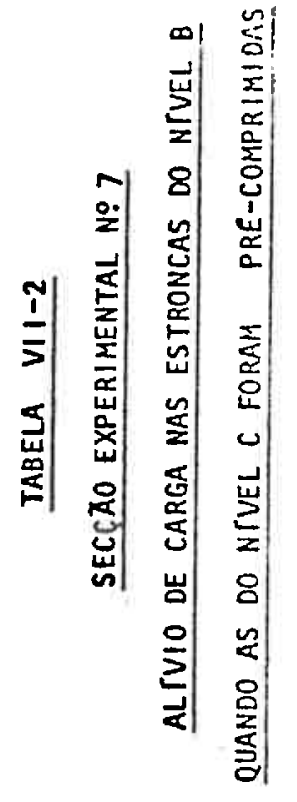

\begin{tabular}{|c|c|c|c|c|}
\hline$\stackrel{0}{2}$ & $\Phi$ & $\tilde{0}$ & $\vec{N}$ & \\
\hline $\bar{\alpha}$ & $\Xi$ & ־ & $\vec{\sigma}$ & ' \\
\hline 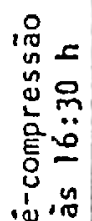 & $\begin{array}{l} \pm \\
\frac{\pi}{2} \\
\frac{\pi}{2}\end{array}$ & $\bar{N}$ & $\frac{n}{n}$ & $\begin{array}{l}n \\
=\end{array}$ \\
\hline 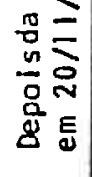 & $\begin{array}{l}\Xi \\
\frac{5}{5}\end{array}$ & $\sim$ & 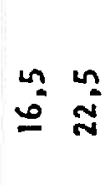 & $\stackrel{9}{m} \bar{q}$ \\
\hline 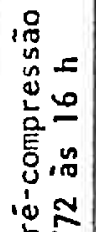 & $\begin{array}{l}\Xi \\
\frac{\pi}{5} \\
\frac{0}{2}\end{array}$ & $\stackrel{m}{\sim}$ & $\underset{\sim}{\sigma}$ & 1 \\
\hline 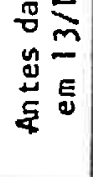 & $\begin{array}{l}3 \\
\frac{1}{5} \\
\frac{1}{3}\end{array}$ & $\tilde{\sim} \tilde{\sigma}$ & $\bar{m}$ & ' \\
\hline 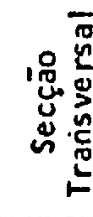 & & $-=$ & $-=$ & $-=$ \\
\hline$\frac{5}{x}$ & & * & 0 & $\omega$ \\
\hline
\end{tabular}


Quanto às Secções Experimentais 3 e 7, estavam em dis ponibilidade os dados de observação apresentados nas tabezas VII-I eVII-Z, obtidos na mesma hora e praticamente sob a mesma temperatura. As leituras concernentes à Secção 3 são mais fidedignas pois foram feitas num mesmo dia e à noite, o que é mais vantajoso sob o ponto de vista do equilíbrio térmico. Já as observaçōes relativas à Secção 7 foram realizadas à tarde e executou-se a prë-compressāo das estroncas IC e IIC após terem sido com primidas as estroncas vizinhas, do mesmo nivel.

\section{Verifica-se, quanto à Secção Experimental 3, que}

05

alívios de carga são de $22 \%$ e $10 \%$ para as estroncas situadas, respectivamente, a um e dois níveis acima da que foi prë-comprimida. Para a Secção Experimental 7 alívio na estronca imediatamente acima foi de $21 \%$; as estroncas situadas dois niveis acima tinham sido simplesmente encunhadas, razão pela qual foram ignoradas.

Os alivios de carga na estronca imediatamente acima da que foi prē-comprimida devem ser, na realidade, maiores do que os percentuais encontrados. E isto porque deve existir um pronunciado efeito tridimensional resultante da prë-compressão de estroncas vizinhas, situadas no mesmo nivel. Este efeito é maior no caso de paredes rígidas face à propagação dos alívios de carga a maiores distâncias.

Na falta de mais dados experimentais, tomou-se, em primeira aproximação, os seguintes valores para o aliviio de carga em pare des flexiveis: $27 \%$ e $4 \%$ para as estroncas situadas, respectivamente, um e dois niveis acima daquela que foi encunhada.

2.3. Limites superiores das parcelas de encunhamento

Com base nestes percentuais construiu-se a tabela VII-3. As Cargas Observadas referem-se ao momento do encunhamento que, em 
TABELA VII-3

SEC OES EXPERIMENTAIS COM PAREDES FLEXTVEIS - CARGAS OE ENCUNHAMENTO

\begin{tabular}{|c|c|c|c|c|c|c|}
\hline \multirow{2}{*}{$\begin{array}{c}\text { Secção } \\
\text { Experimental }\end{array}$} & \multicolumn{2}{|c|}{ Estroncas } & \multicolumn{4}{|c|}{ Cargas de Encunhamento $(t)$} \\
\hline & Nivel & $\begin{array}{c}\text { Secçäo } \\
\text { Transversal }\end{array}$ & Observada & Mēdia & Alivio & Real (*) \\
\hline \multirow{2}{*}{1} & A & $\begin{array}{c}1 \\
11 \\
111\end{array}$ & $\begin{array}{l}3,7 \\
3,5 \\
2,6\end{array}$ & 3,3 & $-1,4$ & 1,9 \\
\hline & B & $\begin{array}{c}1 \\
11 \\
111\end{array}$ & $\begin{array}{l}4,2 \\
7,9 \\
3,2\end{array}$ & 5,1 & - & 5,1 \\
\hline \multirow{3}{*}{6} & A & $\begin{array}{c}1 \\
11\end{array}$ & $\begin{array}{l}1,6 \\
4,1\end{array}$ & 2,9 & $-1,6$ & 1,3 \\
\hline & $B$ & $\begin{array}{c}1 \\
11\end{array}$ & $\begin{array}{l}4,8 \\
6,0 \\
\end{array}$ & 5.4 & $-0,7$ & 4,7 \\
\hline & c & $\begin{array}{c}1 \\
11\end{array}$ & $\begin{array}{l}1,4 \\
3,8\end{array}$ & 2,6 & - & 2,6 \\
\hline \multirow{4}{*}{8} & A & 1 & $\begin{array}{l}2,4 \\
2,7\end{array}$ & 2,6 & $-1,3$ & 1,3 \\
\hline & B & 1 & $\begin{array}{l}3,7 \\
4,5\end{array}$ & 4,1 & $-1,6$ & 2,5 \\
\hline & C & $\begin{array}{c}1 \\
11\end{array}$ & $\begin{array}{l}5,7 \\
4,6\end{array}$ & 5,2 & $-1,2$ & 4,0 \\
\hline & $D$ & $\begin{array}{c}1 \\
11\end{array}$ & $\begin{array}{l}5,4 \\
4,2\end{array}$ & 4,6 & - & 4,6 \\
\hline \multirow{5}{*}{2} & A & 11 & $\begin{array}{l}3.7 \\
3.7\end{array}$ & 3,7 & $-1,1$ & 2,6 \\
\hline & 8 & $\begin{array}{c}1 \\
11 \\
111\end{array}$ & $\begin{array}{l}3,9 \\
3,9 \\
1,8\end{array}$ & 3,2 & $-1,5$ & 1,7 \\
\hline & C & $\begin{array}{c}1 \\
11 \\
111\end{array}$ & $\begin{array}{l}4,0 \\
4,1 \\
6,0\end{array}$ & 4,7 & $-1,9$ & 2,8 \\
\hline & 0 & $\begin{array}{c}1 \\
11 \\
111\end{array}$ & $\begin{array}{l}7,6 \\
6,3 \\
4,7\end{array}$ & 6,2 & $-1,2$ & 5.0 \\
\hline & $\mathbf{E}$ & $\begin{array}{c}1 \\
11 \\
111\end{array}$ & $\begin{array}{l}3,8 \\
4,1 \\
5,9\end{array}$ & 4,6 & - & 4,6 \\
\hline
\end{tabular}

(*) Sem correção do efeito da temperatura. 
geral, era feito de dia, portanto com a estronca numa temperatura acima do seu valor mínimo. E aqui reside uma das dificuldades para se atingir o objetivo fixado no Preâmbulo deste Capítulo.

Para aclarar um pouco mais o problema, considere-se novamente o caso da Secção Experimental 1.

a) No dia 14/01/1971, às 17 horas, procedeu-se ao encunhamento das estron cas do nivel $\mathrm{A}$, que apresentavam uma temperatura média de $25^{\circ} \mathrm{C}$; a geometria da vala aproximava-se, então, daquela indicada na figura III-I, portanto com gradiente de carga-temperatura de $0,20 \mathrm{t} /{ }^{\circ} \mathrm{C}$. Como a carga mëdia das estroncas no momento do encunhamento era de 3,3 t (ver tabela VII-3), à noite, com a temperatura mínima de $T_{0}^{l}=11^{\circ} \mathrm{C}$ (tabela $I I I-1)$, esta mesma carga era de:

$$
c_{E}^{1}=3,3+0,20 \times(11-25)=0,5 \mathrm{t}
$$

que è compatível com a concei tuação implícita na expressão (VII-1).

b) As estroncas do nivel B foram instaladas no dia 09/03/1971, às 16:45, com a temperatura mëdia de $22^{\circ} \mathrm{C}$. Nesta situação estava-se pröximo do final de escavação, em que o gradiente era de $0,29 \mathrm{t} /{ }^{\circ} \mathrm{C}$ (Ver tabela $I I I-1)$, e à temperatura mínima de $11^{\circ} \mathrm{C}$, jă que à noi te ela é igual à da estronca superior. Assim, à noite, a carga de encunhamento nas estroncas inferiores era de:

$$
c_{E}^{2}=5,1+0,29 \times(11-22)=2,0 t
$$

que provocou um alívio de carga nas estroncas do nivel A de:

$$
\Delta C_{E}^{1}=2,0 \times 0,27=0,5 \mathrm{t}
$$


c) Em resumo as cargas de encunhamento nas estroncas $A$ e $B$ valiam, respec tivamente, 0 t e 2,0 t em final de escavação e não os nümeros indicados na ültima coluna da tabela VIT-3.

Es te procedimento não pōde ser aplicado às outras Sec ções Experimentais porque não se dispunham nem dos valores dos gradientes nos estägios de escavação da vala, nem de medidas das temperaturas nas es troncas, por ocasião do encunhamento.

Foi este fato que levou a trabalhar-se com cargas no momento do encunhamento que, pela expressão $(V I I-1)$ e como se verá adian te, inclui uma parcela do empuxo de terra propriamente dito. Assim, na repartição das cargas ter-se-ä limites superior e inferior das parcelas de encunhamento e do empuxo de terra propriamente dito, respectivamente. Ou, por outra, será possível apenas uma bipartição: dilatação térmica, de um lado, e encunhamento mais empuxo de terra, de outro lado.

\section{REPARTIÇÃO DAS CARGAS TOTAIS OBSERVADAS}

Isto posto, procurou-se repartir as cargas observadas nas estroncas apoiadas contra paredes flexíveis em três quinhões:

a) a parcela devida ao encunhamento;

b) aquela resultante da dilatação térmica das estroncas; e

c) finalmente, a parcela advinda do empuxo de terra propriamente dito.

o somatörio das cargas mäximas observadas nas estroncas, tomadas em cada nivel como a média dos valores das diferentes secções transversais, de agora em diante designado por Carga Total na Temperatura Măxima, vale, recorrendo-se à expressão (VII-1):

$$
\Sigma C_{j}=\Sigma C_{E}^{j}+\Sigma E_{j}+\Sigma\left(G_{j} \cdot \Delta T_{j}\right) \cdot\left(T_{m}^{s}-T_{0}^{s}\right)
$$




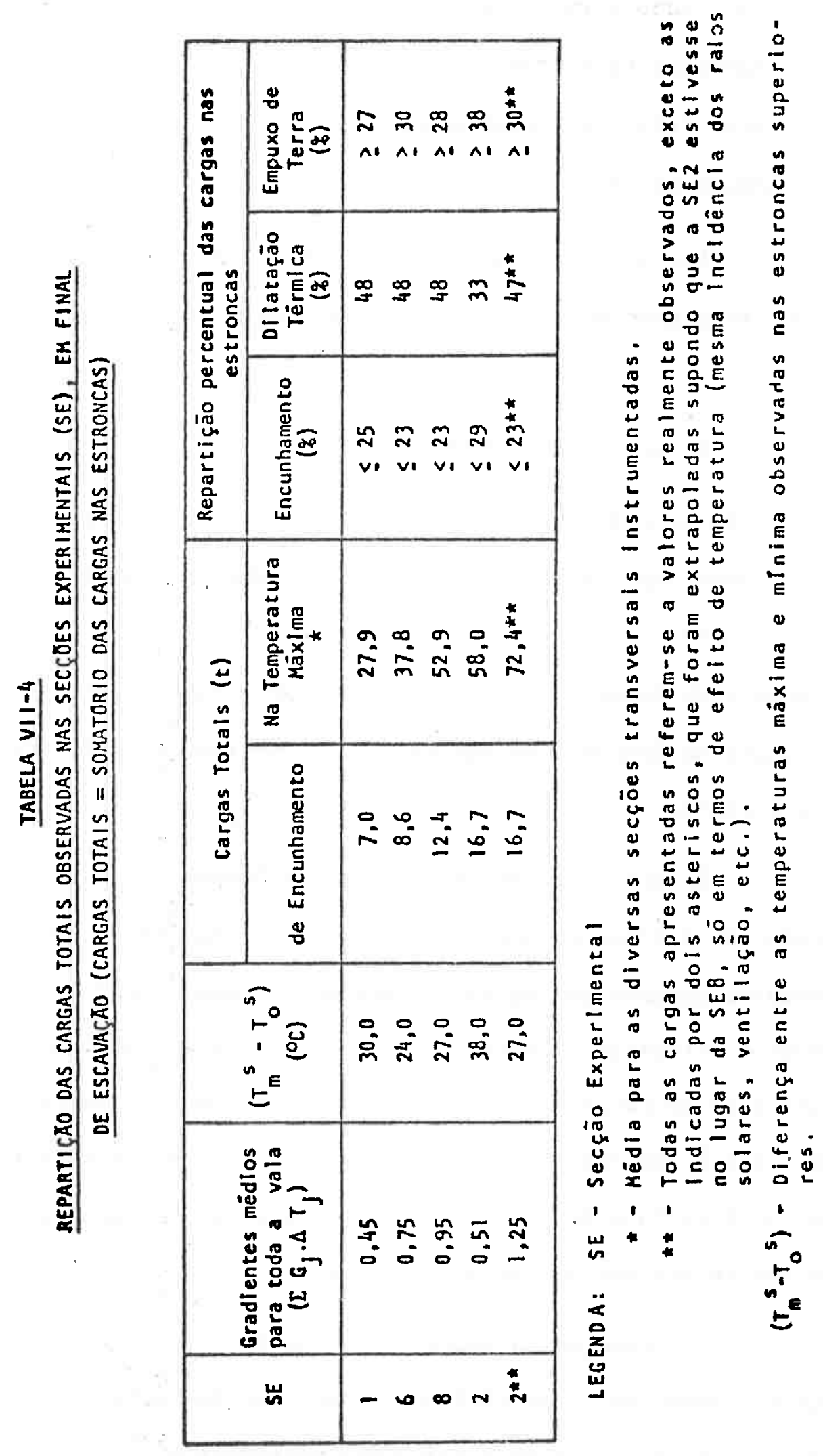


onde: $\Delta T_{j}$ è o incremento relativo de temperatura na j-ësima estronca;

$T_{m}^{S}$ e $T_{0}^{S}$ são, respectivamente, as temperaturas máxima e mínima observadas na estronca superior;

$\Sigma C_{E}^{j} \quad \vec{e}$ a Carga Total de Encunhamento; e

$\Sigma E_{j}$ è o Empuxo de Terra.

Por analogia, o somatörio $\mathcal{L}\left(G_{j} \cdot \Delta T_{j}\right)$ da expressäo (VII-3) serà definido como o gradiente médio de carga-temperatura para to $d a$ a vala.

\section{A tabela VII-I mostra:}

a) os gradientes mëdios e as diferenças entre as temperaturas mäxima e mí nima nas estroncas superiores $\left(T_{m}^{S}-T_{0}^{5}\right)$, calculados em função dos dados da tabela III-1;

b) as Cargas Totais de Encunhamento $\left(\Sigma C_{E}^{j}\right)$, conforme a tabela VII-3; e

c) as Cargas Totais na Temperatura Máxima $\left(\Sigma C_{j}\right)$, obtidas a partir das ta belas III-3 a III-6.

A repartição da Carga Total na Temperatura mäxima $\left(\Sigma C_{j}\right)$, indicada nas ültimas colunas da tabela VII-4, foi feita determinando-se a terceira parcela do segundo membro da expressão (VII-3), que è - quinhão devido à dilatação tērmica. Este, somado à Carga Total de Encunhamento e subtraído da Carga Total na Temperatura Mäxima, forneceu o Empuxo de Terra $\left(\Sigma E_{j}\right)$. Na realidade foram estimados os limites superiores da Carga Total de Encunhamento pelos motivos jā expostos, e consequentemente, os limites inferiores do Empuxo de Terra.

Com exceção da Secção Experimental 2, a tabela VII-4 mostra que, grosso modo, menos de $20 \%$ das cargas são devidas ao encunhamento; $50 \%$ ao efeito da dilatação térmica das estroncas e mais de $30 \%$ são oriundas do empuxo de terra. Ou então, que o efeito da temperatura 
TABELA VII-5

REPARTICAOO DAS CARGAS OBSERVADAS NAS ESTRONCAS DAS SECCOES

EXPERIMENTAIS

\begin{tabular}{|c|c|c|c|c|c|c|c|c|}
\hline \multirow[b]{2}{*}{ SE } & \multirow[b]{2}{*}{ Nivel } & \multirow{2}{*}{$\begin{array}{c}T_{m} \\
\left({ }^{\circ} \mathrm{c}\right)\end{array}$} & \multirow{2}{*}{$\begin{array}{l}T_{m}{ }^{-T_{0}} \\
\left({ }^{\circ} \mathrm{C}\right)\end{array}$} & \multirow{2}{*}{$\begin{array}{c}c_{\max } \\
(t)\end{array}$} & \multirow{2}{*}{$\stackrel{\mathrm{G}}{\mathrm{m}}_{\left.(\mathrm{t})^{\circ} \mathrm{C}\right)}$} & \multirow{2}{*}{$\begin{array}{l}C_{0} \\
(t)\end{array}$} & \multicolumn{2}{|c|}{ 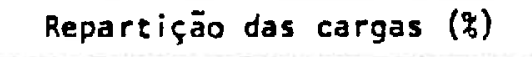 } \\
\hline & & & & & & & $\begin{array}{l}\text { Empuxo de terra + } \\
\text { encunhamento }\end{array}$ & $\begin{array}{c}\text { Di latação } \\
\text { Térmica }\end{array}$ \\
\hline 1 & $\begin{array}{l}A \\
B\end{array}$ & $\begin{array}{l}41 \\
41 \\
\end{array}$ & $\begin{array}{l}30 \\
25 \\
\end{array}$ & $\begin{array}{l}12,4 \\
15,5 \\
\end{array}$ & $\begin{array}{l}0,21 \\
0,29\end{array}$ & $\begin{array}{l}6,1 \\
8,3 \\
\end{array}$ & $\begin{array}{r}49 \\
53 \\
\end{array}$ & $\begin{array}{l}51 \\
47 \\
\end{array}$ \\
\hline 6 & $\begin{array}{l}A \\
B \\
C\end{array}$ & $\begin{array}{l}41 \\
32 \\
29\end{array}$ & $\begin{array}{l}24 \\
19 \\
14\end{array}$ & $\begin{array}{r}12,1 \\
17,2 \\
8,5\end{array}$ & $\begin{array}{l}0.21 \\
0.41 \\
0.55\end{array}$ & $\begin{array}{l}7,1 \\
9,4 \\
0,8\end{array}$ & $\begin{array}{r}58 \\
55 \\
9 \\
\end{array}$ & $\begin{array}{l}42 \\
45 \\
91\end{array}$ \\
\hline 8 & $\begin{array}{l}A \\
B \\
C \\
D\end{array}$ & $\begin{array}{l}45 \\
44 \\
39 \\
37\end{array}$ & $\begin{array}{l}27 \\
27 \\
23 \\
25\end{array}$ & $\begin{array}{l}14,2 \\
13,0 \\
10,8 \\
14,9\end{array}$ & $\begin{array}{l}0,12 \\
0,20 \\
0,27 \\
0,43 \\
\end{array}$ & $\begin{array}{r}11,0 \\
7,6 \\
4,6 \\
4,2\end{array}$ & $\begin{array}{l}77 \\
58 \\
43 \\
28 \\
\end{array}$ & $\begin{array}{l}23 \\
42 \\
57 \\
72 \\
\end{array}$ \\
\hline 2 & $\begin{array}{l}A \\
B \\
C \\
D \\
E\end{array}$ & $\begin{array}{l}49 \\
35 \\
29 \\
23 \\
21 \\
\end{array}$ & $\begin{array}{l}38 \\
26 \\
19 \\
10 \\
10 \\
\end{array}$ & $\begin{array}{r}8,5 \\
9,9 \\
13,9 \\
10,3 \\
15,4 \\
\end{array}$ & $\begin{array}{l}0,15 \\
0,18 \\
0,16 \\
0,19 \\
0,23\end{array}$ & $\begin{array}{r}2,8 \\
5,2 \\
10,8 \\
8,4 \\
13,1 \\
\end{array}$ & $\begin{array}{l}33 \\
53 \\
78 \\
82 \\
85 \\
\end{array}$ & $\begin{array}{l}67 \\
47 \\
22 \\
18 \\
15 \\
\end{array}$ \\
\hline 8* & $\begin{array}{l}A \\
B \\
C \\
D\end{array}$ & - & $\begin{array}{l}38 \\
28 \\
18 \\
11\end{array}$ & $\begin{array}{r}18,2^{\star} \\
12,9^{\star} \\
8,0^{\star} \\
6,3^{\star}\end{array}$ & $\begin{array}{l}0,19 \\
0,19 \\
0,19 \\
0,19\end{array}$ & $\begin{array}{r}11,0 \\
7,6 \\
4,6 \\
4,2 \\
\end{array}$ & $\begin{array}{l}60^{\star} \\
59^{\star} \\
58^{\star} \\
67^{\star} \\
\end{array}$ & $\begin{array}{l}40^{\star} \\
41^{\star} \\
42^{\star} \\
33^{\star} \\
\end{array}$ \\
\hline 2* & $\begin{array}{l}A \\
8 \\
C \\
D \\
E\end{array}$ & - & $\begin{array}{l}27 \\
27 \\
27 \\
27 \\
27\end{array}$ & $\begin{array}{r}4,4^{\star} \\
8,2^{\star} \\
14,6^{\star} \\
15,2^{\star} \\
31,7^{\star}\end{array}$ & $\begin{array}{l}0,06 \\
0,11 \\
0,14 \\
0,25 \\
0,69\end{array}$ & $\begin{array}{r}2,8 \\
5,2 \\
10,8 \\
8,4 \\
13,1\end{array}$ & $\begin{array}{l}64^{*} \\
63^{*} \\
74^{\star} \\
55^{*} \\
41^{*}\end{array}$ & $\begin{array}{l}36^{\star} \\
37^{\star} \\
26^{\star} \\
45^{\star} \\
59^{\star}\end{array}$ \\
\hline
\end{tabular}

LEGENDA: SE - Seç̧ão Experimental

$T_{m}$ e $T_{0}$ - Temperaturas mâximas e minimas observadas, respectiva mente.

$C_{\text {max }}$ - Carga observada na temperatura mäxima (mëdia relativa às secçōes transversais instrumentadas).

$G_{m}$ - Gradiente de Carga-Temperatura médio.

Co - Carga de encunhamento mals carga devida ao empuxo de terra.

- Todas as cargas referem-se a valores realmente observados, exceto as Indicadas por um asterisco, em que se supós uma permuta das caracteristicas acidentais de in cldēncia dos raios solares, ventilaçāo, etc., entre as Seçōes Experimentais 8 c 2 e vice-versa, mantidas inal teradas as respectivas idonildades (geometria, cargas de encunhamento, empuxo de terra. 
tende a dobrar a carga totai devida ae empuxo de terra mais encunhomento.

0 comportamento anormal da Secção Experimental 2 pẹ mitiu, en outros capítulos, exploração profunda dentro do contexto da pre sente Investigação: tal vala foi como que um corte no tecido do modelo matemático do Capítulo IV, ao comprovar sua validade e revelar a sua potencialidade.

Voltando ao mesmo argumento, visto sob novo prisma, isto $\vec{e}$, se fosse admitido que a Secção Experimental 2 tivesse as caracteristicas acidentais de incidência dos raios solares, ventilação, etc., al terados para os da Secção Experimental 8, mantendo no entanto a sua identidade quanto à geometria, ao solo escorado e mesmo às cargas de encunhamento, então os resultados seriam os indicados na ültima linha da tabela VII-4. Vê-se agora que a repartição das cargas segue a mesma tendência ma nifestada nas outras Secções Experimentais.

Note-se que o valor de 1,25 do gradiente mëdio para toda a vala, colocado na ültima linha da tabela VII-4, foi obtido supondo que os incrementos relativos de temperatura são unitários, isto $\bar{e}, \Delta T_{j}=1$ para qualquer $\mathrm{j}$ (Ver figura $I V-5)$ e que:

$$
\left\{G_{j}\right\}^{T}=(0,06 ; 0,11 ; 0,14 ; 0,25 ; 0,69)
$$

valores estes calculados atravēs da expressão (III-9) e dos dados da tabela $V l-2$, referentes à Secção Experimental 2 .

4. REPARTIÇAO DAS CARGAS DISTRIBUTDAS NAS ESTRONCAS DE UMA MESMA VALA

Manipulando-se de forma anäloga os dados experimentais foi possivel preparar a tabela VII-5. 


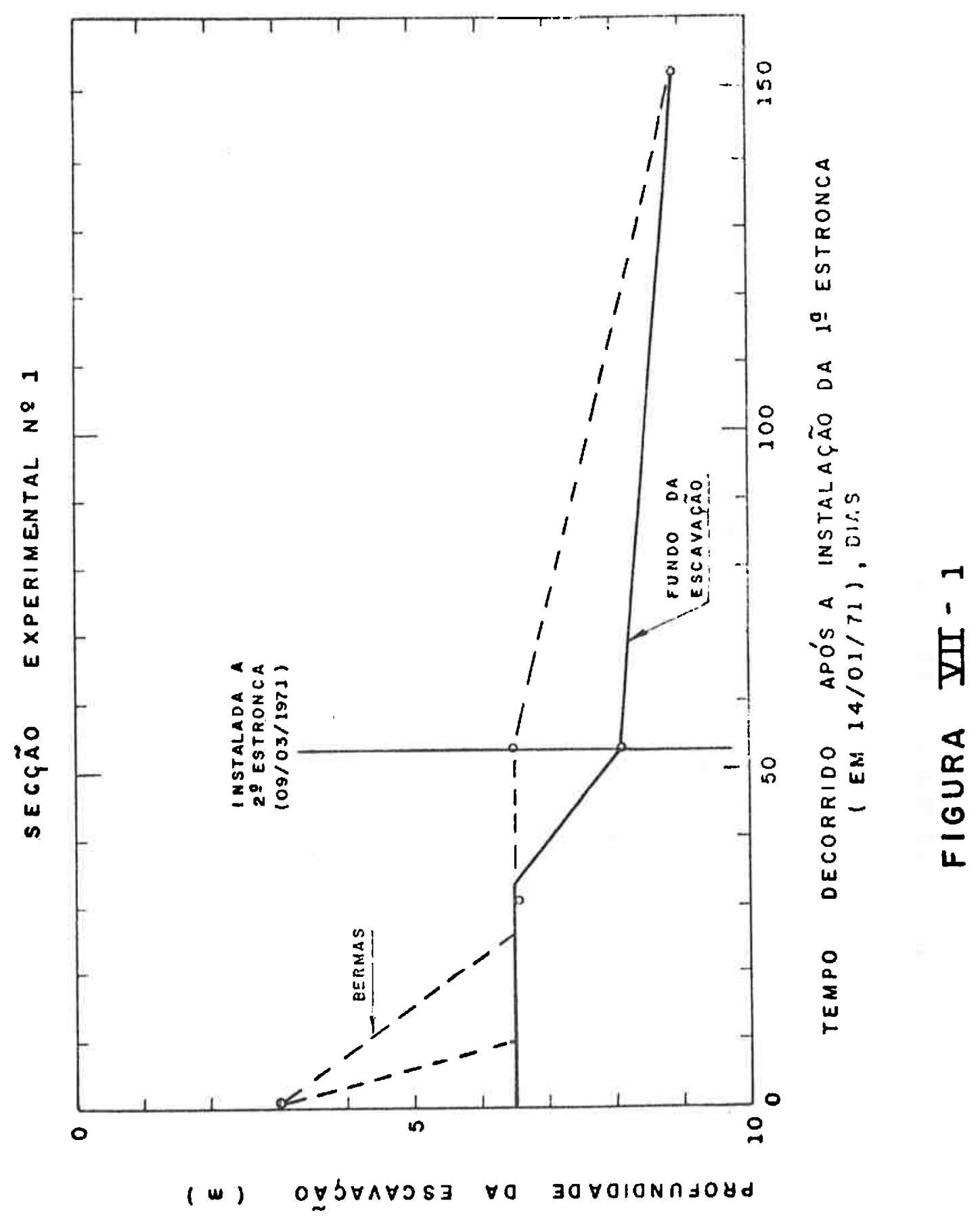




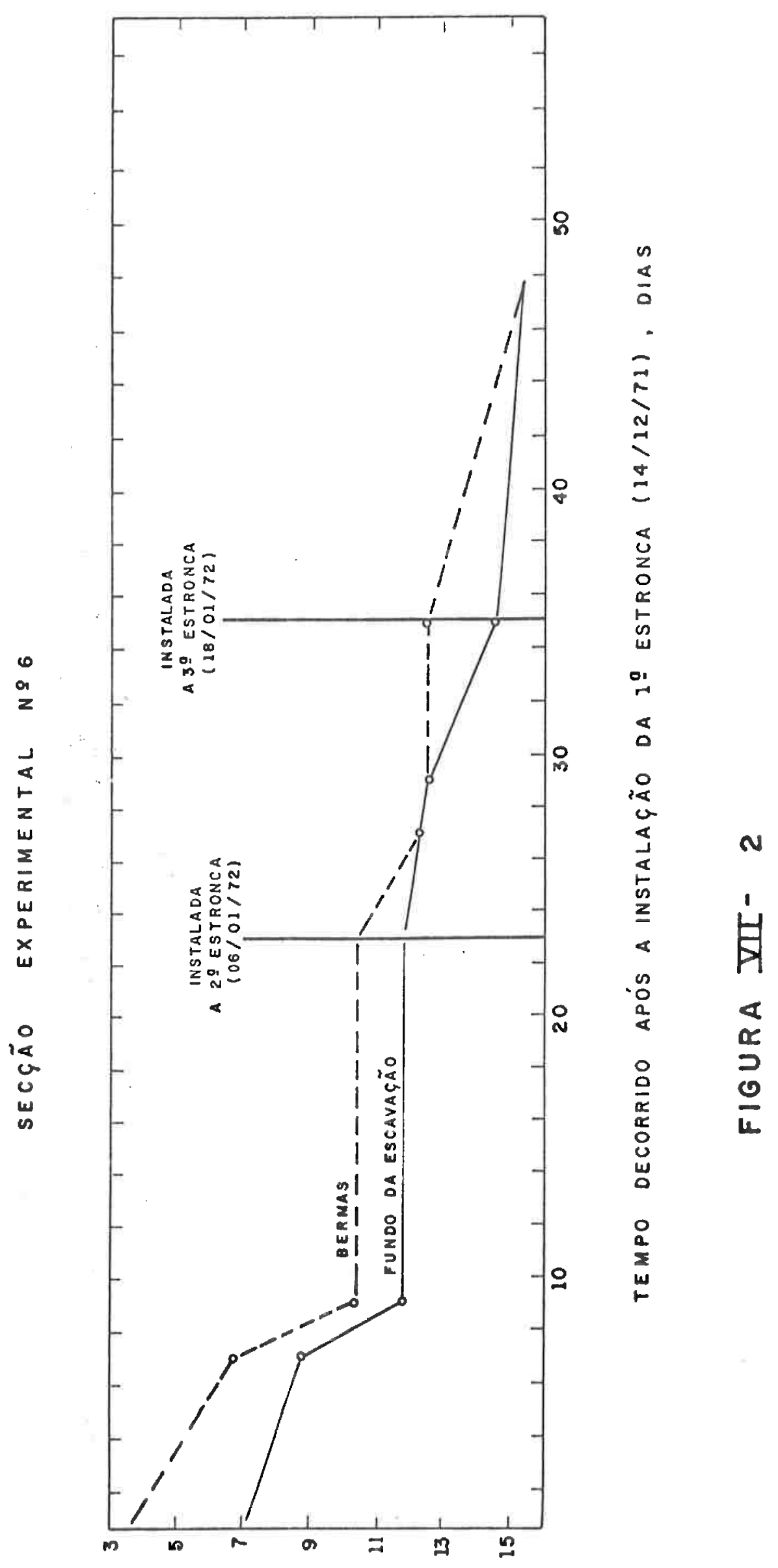

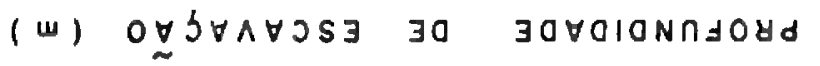




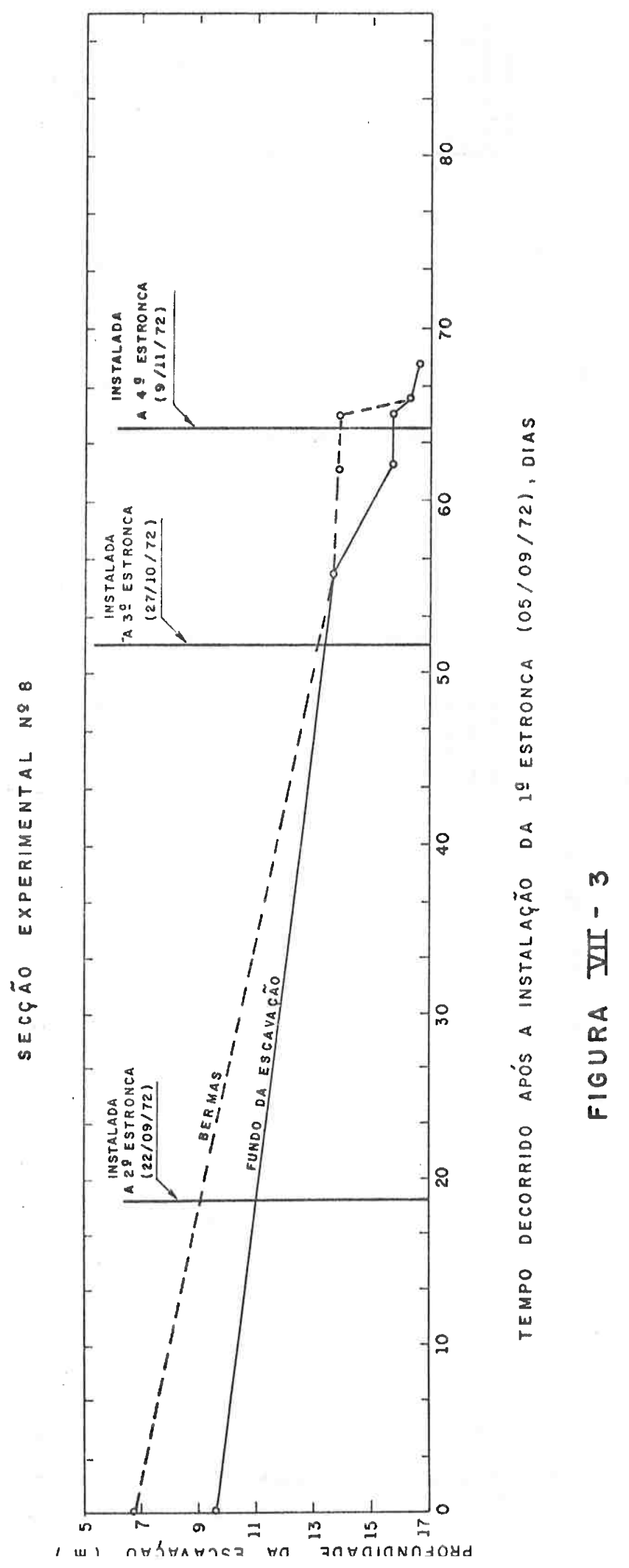




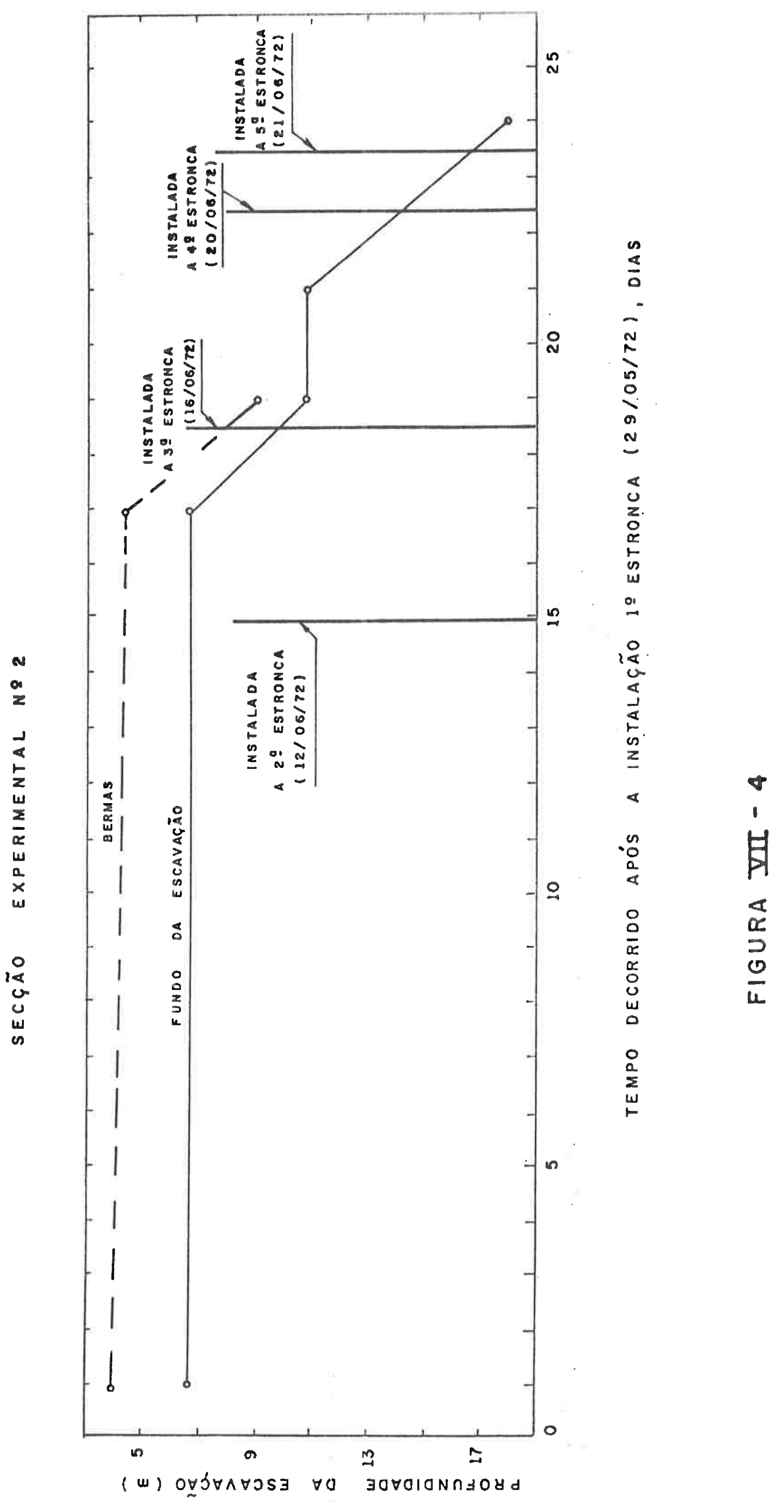




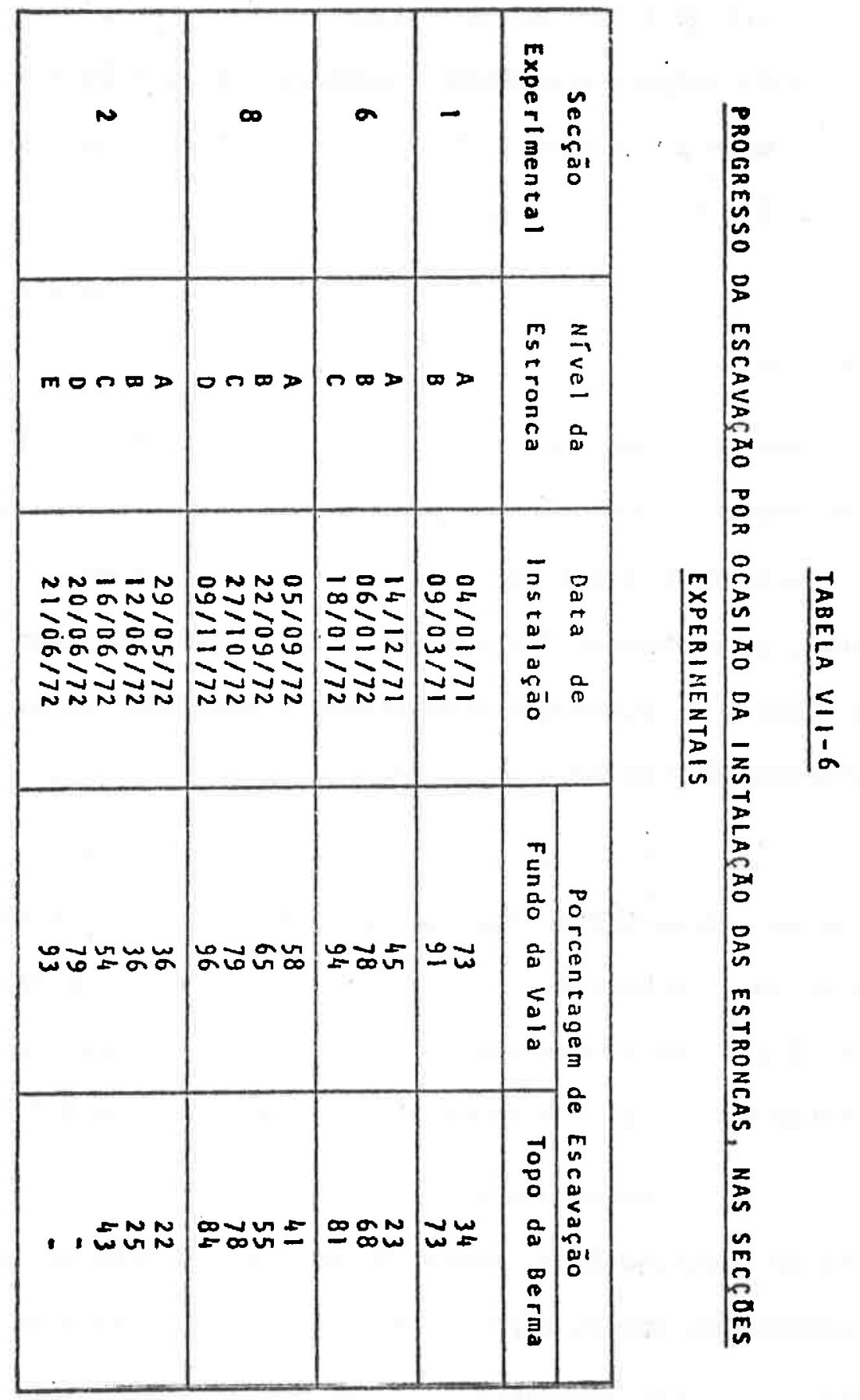


A separação foi feita em termos de quinhão de empuxo de terra mais encunhomento, de um lado, e quinhão resultante da dìatação térmica, de outro.

Com exceção da Seç̧ão Experimental 2 pode-se ver que nas estroncas superịores predomina a parcela de empuxo de terra mais encu nhamento, o reverso sendo verdadeiro para as estroncas inferiores. Naquelas o efeito da temperatura tende a aumentar de 30 a $50 \%$ o empuxo de ter ra; e nestas este percentual è de 100,257 e $1000 \%$, para as Secções Expe rimentais 1,8 e 6 , respectivamente.

As causas deste comportamento podem ser sintetizadas da seguinte forma:

a) para as Secções Experimentais 1, 6 e 8, os gradientes de carga-tempera tura observados crescem com a profundidade, aumentando nas estroncas mais inferiores o efeito da dilatação tërmica das estroncas; e

b) em geral, as estroncas dos ültimos níveis eram instaladas quando a vala jä tinha sido quase que completamente escavada, tornando pequenas as contribuições do empuxo de terra.

A ültima justificativa è verificāvel nas figuras VII-1 a VII-4, e na tabela VII-6, que mostram o progresso da escavação, tanto do fundo da vala, quanto do topo das bermas, para as Secções Experimẹntais 1, 6, 8 o 2. Vê-se que quando o ültimo nível de estroncas era instalado faltavam menos de $10 \%$ de escavação, às vezes atē $5 \%$.

Novamente sobressai o carāter excepcional de que se tem revestido a Seç̧ão Experimental 2, em que a dillatação tērmica das estroncas aumenta em apenas $15 / 85=18 \%$ o empuxo de terra mals a carga de encunhamento no nivel inferior.

E isto em virtude da anômala distribuição, em profun- 
didade, dos incrementos relativos de temperatura, diversas vezes enfatiza da nesta Investigação, que, tivesse ocorrido com a Secção Experimental 8, levaria ao mesmo resultado.

De fato, a Matriz U, indicada na tabela VI-2, correspondente ao $2 \%$ caso da Secção Experimental 8, (figura VI-2c), possui um au tovetor com os termos $1 ; 0,73 ; 0,48$ e 0,28 , para os niveis $A, B, C$ e $D$, respectivamente. A ele estā associado um autovalor de $0,19 \mathrm{t} /{ }^{\circ} \mathrm{C}$, que é $\mathrm{o}$ gradiente de carga-temperatura que surge em cada uma das estroncas. Admitindo ainda que a diferença entre as temperaturas máxima e minima $\left(T_{m}-T_{0}\right)$ na estronca superior seja de $38^{\circ} \mathrm{C}$, valor idêntico ao que se observou na Secção Experimental 2, tem-se, para a estronca do nivel $B, T_{m}-T_{0}=0,73 \times 38=$ $28^{\circ} \mathrm{C}$. Tanto este valor quanto os correspondentes aos outros níveis, calculados da mesma forma, estão apresentados na tabela VII-5, que contēm ainda as Cargas Mäximas, determinadas em conformidade com a expressão $V I I-1$; note-se que $c_{0}$, is to $\vec{e}$, o empuxo de terra mais a carga de encunhamento, foi mantido inalterado. Conclui-se, pois, que, para a estronca do nivel inferior, o efeito da temperatura tende a aumentar em apenas $33 / 67=$ $49 \%$ o empuxo de terra mais a carga de encunhamento, contra $72 / 28=257 \%$ realmente observado.

0 mesmo tipo de raciocínio foi aplicado à Secção Expe rimental 2 e os resultados obtidos estão indicados tambëm na tabela VII-5. Supôs-se que os incrementos relativos de temperatura $\left(\Delta \mathrm{T}_{\mathbf{i}}\right)$ eram unitärios, resultando os gradientes de carga-temperatura de 0,$06 ; 0,11 ; 0,14$; 0,25 e 0,69 para os niveis de estroncas de $A$ a $E$, respectivamente, valores estes computados com base na Matriz U indicada na tabela VI-2. Constata-se agora que a dilatação tērmica das estroncas do ültimo nível aumen ta em $59 / 41=144 \%$ o empuxo de terra mais a carga de encunhamento, contra $15 / 85=18 \%$, observado experimentalmente, de que jả se fêz menção. 


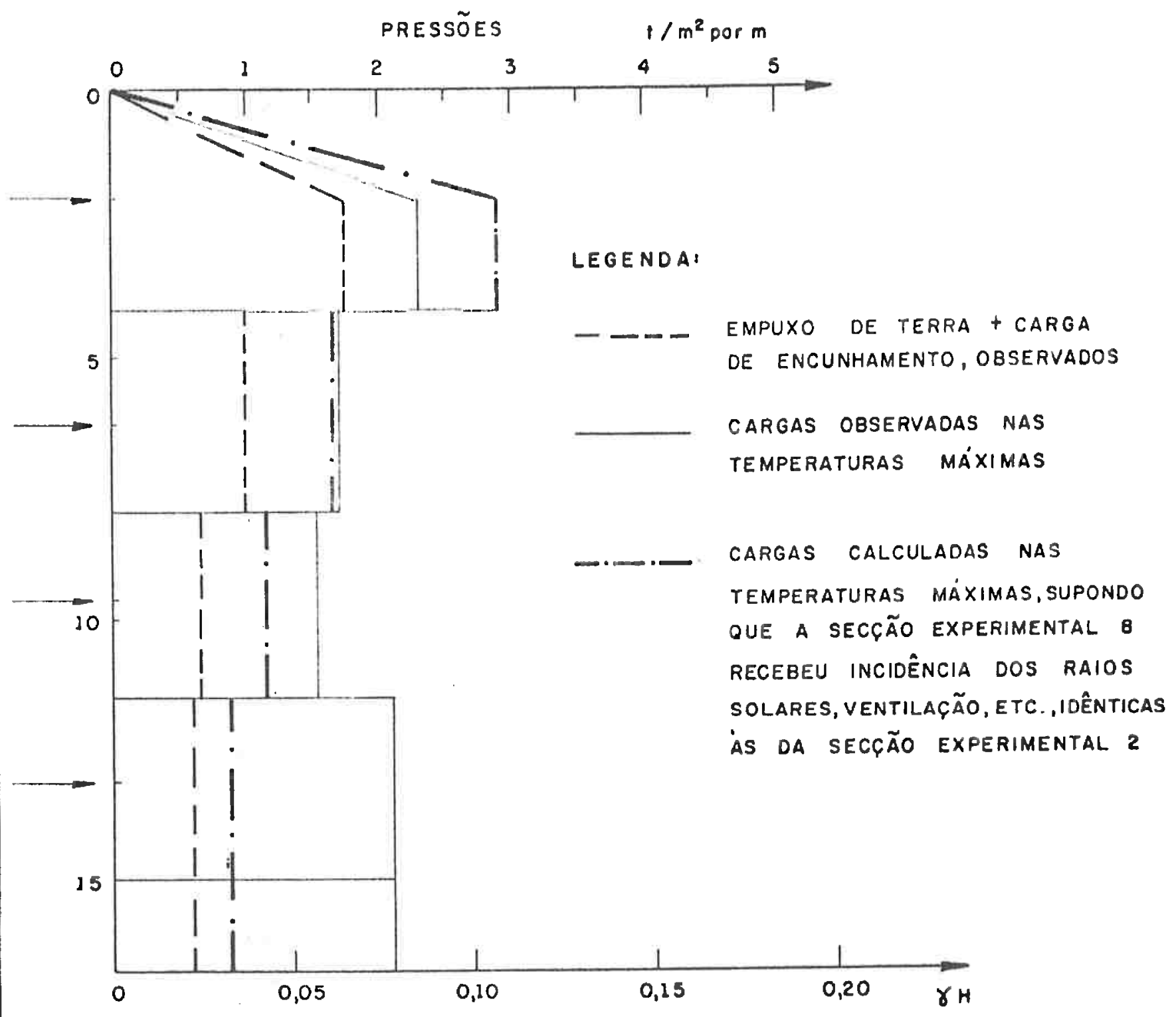

FIGURA ZII-5: DIAGRAMAS DE PRESSÕES APARENTES SECÇÃO EXPERIMENTAL 8 


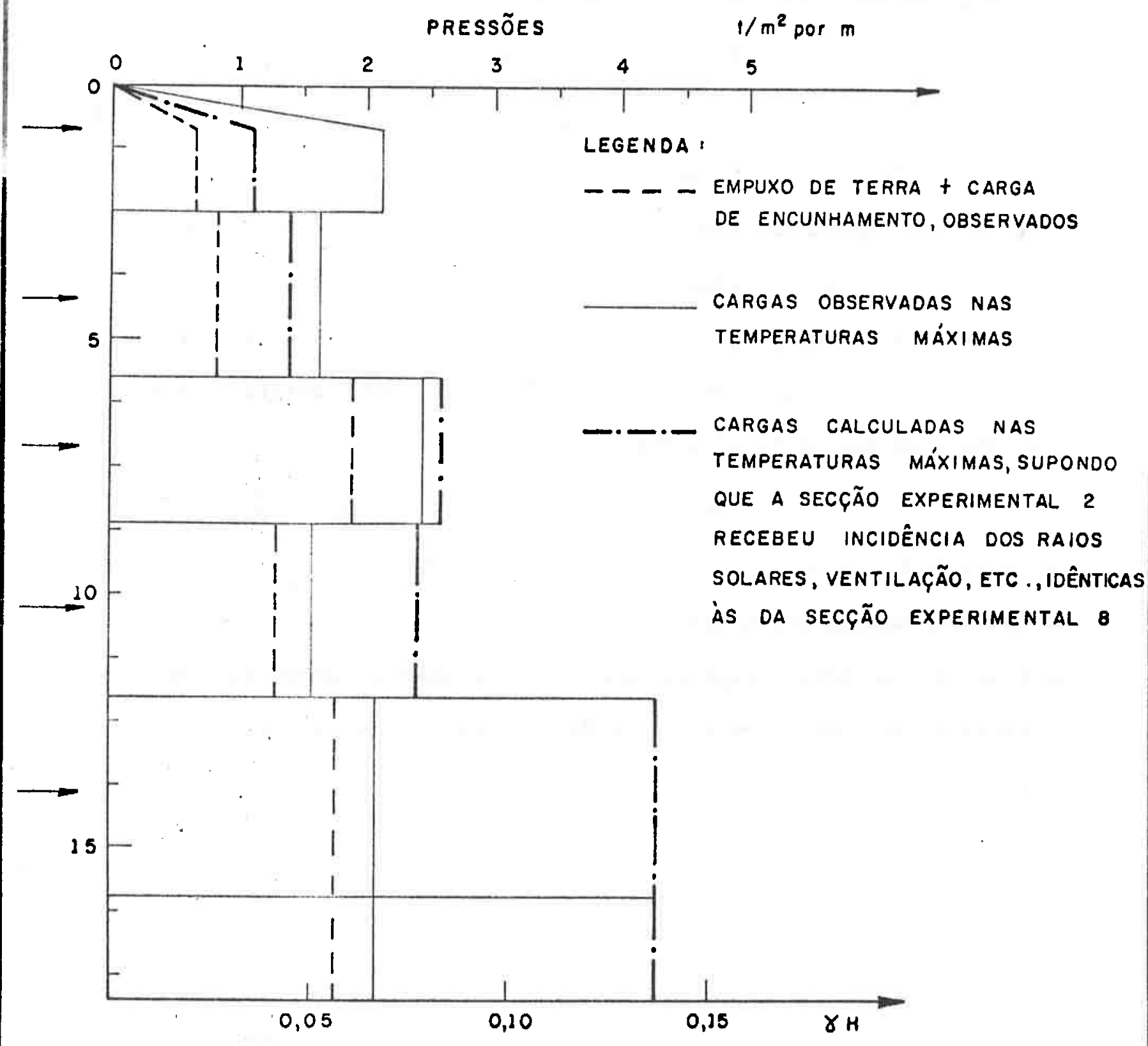

FIGURA III-6, DIAGRAMAS DE PRESSÕES APARENTES SECĢÃO EXPERIMENTAL 2 
5. DIAGRAMAS DE PRESSOES APARENTES

Associadas às cargas nas estroncas, depuradas do efeito da sua dilatação térmica ( $C_{0}$ na tabela VII-5), é possível traçar os diagramas de pressões aparentes seguindo roteiro delineado por Terzaghi $e$ Peck (1967), a ser apresentado com detalhes no Capitulo VIII.

Isto foi feito para as Seç̧ões Experimentais 2 e 8 , e os resultados obtidos estão apresentados graficamente nas figuras VII- 5 e VII-6, que tambēm mostram outros dois diagramas de pressões aparentes associados a cargas na temperatura mäxima. Um deles refere-se às cargas observadas. O outro, às cargas calculadas se tivesse havido a altemâneic das caracteristicas acidentais de incidência dos raios solares, ventilação, etc., de que se falou acima.

Alèm de corroborar as conclusöes do ítem anterior, es tes resultados levam à conclusão goral de que, trabalhando-se com envoltớrias de pressões aparentes, sem a consideração dos efeitos da dilatação tērmica das estroncas, sujeita-se a interpretações errōneas das medições de cargasem estroncas, em sistemas de escoramento com paredes flexiveis. 


\section{CAPITULO VIII}

\section{INCLUSAO DO EFEITO DA TEMPERATURA NO CALCULO DAS CARGAS NAS ESTRONCAS EM ESCORAMENTOS COM PAREDES FLEXTVEIS}

\section{PRELIMINARES}

\subsection{Colocação do problema e proposição}

No Capituzo anterior, a lém de mostrar quantitativamente a importāncia do efeito da temperatura nas forças suportadas pelas estroncas, evidenciou-se a invalidade da determinação das envoltörias das pressões aparentes, tal como foram conceituadas por Terzaghi e Peck (1967), associadas às cargas nas temperaturas mäximas. E isto porque, nu ma palavra, as envoltōrias estão na dependência de características intrínsecas dos solos e não das acidentais de insolação, ventilação, etc.

Assim, a questão que se coloca na sequência desta In vestigação refere-se ao modo de inclusão deste efeito no dimensionamento de estroncas em sistemas de escoramentos com paredes flexiveis.

o processo de cálculo proposto è simples e pode ser desmembrado em duas etapas:

a) determinação do empuxo de terra em cada estronca, atravēs de diagramas de pressões aparentes e de suas envol törias, obtidas experimental mente; ou por meio da distribuição simples e aproximada do empuxo total, também aferido empiricamente; e

b) incorporação do efeito da dilatą̧ão térmica das estroncas, calculadas multiplicando-se os gradientes de carga-temperatura pelas máximas diferenças de temperatura esperadas. 
Não serão consideradas sobrecargas de qualquer tipo, nem empuxos hidrostäticos em trincaṣ de tração, que eventualmente surgem na superfície de solos escorados.

1.2. Resenha sobre os métodos de cálculo do empuxo de terra

São antigas as evidências empíricas de que a distribuição das cargas nas' estroncas não é triangular, como se deduz da teoria de Rankine. A experiência vivida durante a construção de linhas do Metrô de Nova York, na primeira dëcada deste sëculo, levou os engenheiros à intuição de que a pressão de terra era maior na parte superior do escoramento. Assim, passou a imperar um sentimento de que a distribuição das cargas nas estroncas è, na melhor das hipóteses, uniforme e pode ser substituida por diagramas trapezoidais ou retangulares. A rigor, a distribuição real è aleatōria, tendendo a ser parabölica, pois, como mostraram Flaate (1966) e Terzaghi e Peck (1967), ao analisarem medições feitas em escavações nas areias de Munique, Berlim e Nova York, e nas argilas de Chicago, Oslo e Tókio, o centro de pressão dista $\mathrm{n}_{\mathrm{a}} \mathrm{H}$ do fundo da vala, com $n_{a}$ variando no intervalo de 0,46 a 0,55 (valor médio de 0,50 ) para as areias e 0,30 a 0,50 (média de 0,40 ) para as argilas.

As causas desta aleatoriedade prendem-se essencialmente a variaçōes locais do subsolo e detalhes construtivos, tais como a distâncla tolerada entre o fundo temporärio da vala e o ültimo nível de estroncas instaladas, ou o tempo de espera entre a escavação e o estroncamento, entre tantos outros.

Daí a prōpria razão da introdução dos conceitos de diagramas de pressões aparentes em fins da década de 1930, e de suas envoltoormias, que foram estabelecidas não para substituir a distribuição real das pressōes, mas para fornecer limites superiores das cargas nas 
estroncas, estando, pols, sujeitas a revisões periödicas, como o fêz Peck (1969) recentemente.

Uma alternativa às envoltörlas ë a fixaçāo de diagra mas de pressões aparentes na forma de trapēzios ou retângulos, com a imposição de que a sua resultante deva colncldir com o empuxo total calculado por um método de equllifbrlo plástlco, como por exemplo o de Rankine. Neste sentido, Terzaghi (1941) e Peck (1943), estudando dados experimentais dos Metrôs de Berlím e Chicago, respectivamente, concluiram que o solo escorado deve estar num estado de ruptura. Os cálculos de establildade feltos com IInhas de ruptura curvas apresentaram valores mul to pröximos daqueles obtitos com o uso da Teoria de Rankine, de uso mals fäcll e conveniente.

Historicamente, no entanto, foram Spilker e Klenner, citados por Bjerrm (1972) que, trabalhando em fins da década de $1930 \mathrm{com}$ medições em escavações nas arelas de Berlim e Munique, respectivamente, concluíram que o somatörio das cargas nas estroncas aproximava-se do Empuxo Ativo de Rankine. Klenner segundo Flaate (1966), propôs a primeira regra empírica, un diagrama retangular, para o cálculo das pressões atuan tes contra as paredes de escoramento.

Uma surpresa estava reservada para as escavaçōes fel tas nas cldades de Oslo (Norwegian Geotechnical Institute, Technical Reports, 1962) e Mëxico (Rodriguez et al, 1969), em que as camadas de so lo mole se estendlam bem abalxo do fundo da vala. o somatório das cargas nas estroncas chegou a atingir duas ou até três vezes o Empuxo Ativo de Rankine.

Foram, allās, estas medições que levaram Terzaghi $e$ Peck (1967) a reverem suas regras semi-empirlcas para argllas moles e mé dias, com a introdução do niomero de estabilidade $\mathrm{YH} / \mathrm{c}$ que, para camadas 
profundas de argila mole, pode ser maior do que 6 ou 7. Nestas condiçōes, as regras semi-empíricas continuam välidas desde que se reduza a resistência ao cisalhamento do solo em $40 \%(m=0,4)$. Note-se que o dia grama de pressões passa a depender não somente da resistência do solo co mo tambēm da profundidade da escavação. Um mesmo solo escorado Imprimi rä pressōes diferentes em função desta profundidade.

A explicação mais fecunda quanto aos fenômenos subjacentes à distribuição das cargas nas estroncas e ao seu somatōrio foi apresentada por Bjerrom (1972). Com a instalação de um nível de estroncas e a posterior remoção do solo, num dado estágio de escavação, ocorre uma movimentação das estacas entre estas estroncas e o fundo temporário da vala, o que gera um arqueamento do solo ou redistribuição de pressōes. Além disso a movimentação do solo abaixo do fundo da vala pode ser slgnificativa, dependendo da sua rigidez e das dimensões da escavação, conduzindo a uma outra forma de redistribulção de esforços nas estroncas.

Esta ültima forma de arqueamento levou Bjermum a Introduzir o concelto de profundidade de influênoia de uma vala $\left(D_{0}\right)$, defi nida como a distāncia, medida da superfície do terreno, abaixo da qual o solo não se movimenta, em consequência da escavação e do escoramento. Pạ ra as observaçōes de Oslo e México em que o solo mole era profundo, o va lor de $D_{0}$ era bem superior à profundidade da vala $(H)$, indicando uma mobilização da resistência ao longo de superfícies que lam abaixo do fundo da escavação. Parte do Empuxo Ativo de Rankine, que atuava em toda a pro fundidade $D_{0}$, era redistribuida entre as estroncas, cujas cargas somavam um valor bastante superior ao empuxo calculado atë a profundidade H; a outra parte era absorvida pelo solo situado entre as linhas de estacas, abaixo da cota de escavação. 
solo em profundidades rasas, $D_{0}$ coincide com $H$ e o arqueamento do solo só ocorre devido à movimentação entre a ültima estronca instalada e o fundo temporärio da vala. Nestas condições, o somatōrlo das cargas nas estroncas iguala o Empuxo Ativo de Rankine computado até a profundidade (H) da vala ou até a distância $\left(H^{\prime}\right)$ entre a superfície do terreno e o ponto que medeia a ültima estronca e o fundo da escavação.

Tal foi o caso observado por Skempton e Ward (1952) em Shellhaven (Londres), em que as estacas-pranchas penetravam em terreno firme, impedindo assim a movimentação do solo abaixo do fundo da va1a. E interessante frisar que estes autores concluíram, através de cälcuu los, que a deflexão das estacas-pranchas, antes da instalação das estron cas, é fator decisivo na distribuição das cargas nas estroncas.

Finalmente, lembra-se que para pequenas deformações não hā, necessariamente, uma mobilização total da resistência ao cisalha mento. Neste contexto Bjerrom (1972) afirma que valores do deslocamento horizontal da ordem de $0,1 \% D_{0}$, que ocorrem em valas escoradas em areia densa, jā são suficientes para mobilizā-la totalmente. A maior parte dos casos cai na faixa de $0,4-1 \%$ de $D_{0}$, podendo atingir ate $2 \% D_{0}$. No mesmo sentido, Peck (1969) adverte que para valas rasas em argilas moles, ou valas profundas em solos rijos, os métodos de equilíbrio limite não podem ser aplicados a materiais que não estão em estado plástico.

Nestas situaçōes pode-se, teoricamente, recorrer a métodos de cālculo maís abrangentes, que permitam a determinaçāo concomitante das tensões e deformações dos solos escorados. Tals potencialidades são Inerentes ao Método dos Elementos Finitos e ao Método dos Campos Associados. Para țanto é mister não só conhecer a fundo as caracteristicas de deformabilidade e coeficiente de empuxo em repouso dos solos, como também simular os processos construtivas de escavação e escora 
mento. Estas dificuldades tēm retardado a sua aplicação a problemas präticos.

\section{CÁLCULO DAS CARGAS PROVENIENTES DO EMPUXO DE TERRA}

A fim de por em prätica o processo de cálculo propos to no item 1.1., è necessärio:

a) determinar as envoltörias das pressões aparentes correspondentes às cargas observadas nas estroncas, depuradas do efel to da sua dil latação térmica; e

b) aferir a validade de uma aproximação entre o Empuxo Ativo de Rankine e o somatório destas mesmas cargas.

2.1. Envoltórias das Pressões Aparentes para as Argilas Vermelhas e os Solos Variegados

As cargas $C_{0}$, observadas nas estroncas das Secções Experimentais, descontados os efeitos da temperatura, podem ser calculadas a partir dos elementos contidos nas tabelas III-3 a III-6, mais os incrementos relativos de temperatura $\left(\Delta T_{i}\right)$, indicados na tabela III-1, e as variações de temperatura na estronca superior $\left(T_{m}^{S}-T_{0}^{S}\right)$ da tabela $V I I-4$. Elas são oriundas do empuxo de terra mais a carga de encunhamento.

E interessante observar, referindo-se sempre às cargas $C_{0}$, que o seu somatōrio numa mesma secção transversal apresenta um desvio de $\pm 20 \%$ em relação ao somatōrio das suas médias em cada nível de estroncas. Neste sentido, a Secção Experimental 2 constitui-se em exceção, pois iesta cifra atingiu cerca de $\pm 40 \%$. Este valor mäximo cai pa ra $\pm 15 \%$ se, ao Invés de $C_{0}$, forem tomadas as cargas observadas na temperatura máxima. Consideradas isoladamente, em cada nivel de estroncamen to, as cargas $C_{0}$ apresentam desvios mäximos em relação às cargas médias 
de $48 \%$, com um valor mëdio de $20 \%$. Para as cargas na temperatura mäxima tais cifras foram de $25 \%$ e $10 \%$, respectivamente. Vê-se que, em geral, estes valores situam-se abaixo dos desvios mäximos, encontrados por Flaate (1966) e apresentados tambēm por Terzaghi e Peck (1967), e que fo ram de $30 \%$ para valas profundas do Metrô de Chicago. Para a escavação de Shellhaven (Londres), Skempton e Ward (1952) constataram variações médias de $\pm 50 \%$ nas cargas individuals das estroncas.

Para as Secções Experimentais 1, 6, 8 e 2 tomaram-se os valores mäximos das cargas $C_{0}$ em cada nivel de estroncas, com o que foi possivel traçar os diagramas de pressões aparentes. Para tanto admitiu-se que:

a) a área de influência de cada estronca, exceto a superior e a inferior, estende-se horizontal e verticalmente atē a metade da distância que a separa das circunvizinhas; para a estronca superior a área prolonga-se verticalmente até a superficle do terreno; para a inferior , até a metade da distância que a separa do fundo da vala;

b) as pressões de terra distribuem-se uniformemente sobre as áreas de in fluência, exceto na parte superior, onde crescemlinearmente com a pro fundidade a té a cota de posicionamento da estronca do primeiro nível, passando depois a ser constante; e

c) a pressão de terra atuante do fundo da vala, tomado como uma estronca, atē a metade da distância da estronca inferior, è Igual à pressão reinante na região desta ültima.

Esta ültima hipótese é adotada quando não são medidas as reações do solo ao nível do fundo da vala. Algumas observaçōes de campo foram feltas Indiretamente por A. Casagrande e Peck, pela técnica de corte e bloquelo das estacas no plano da base do tūnel de concreto. Os dedos do primelro destes autores, apresentados por Terraghi (1941, pa्a 
PRESSĀO DE TERRA

PRESSÁO DE TERRA

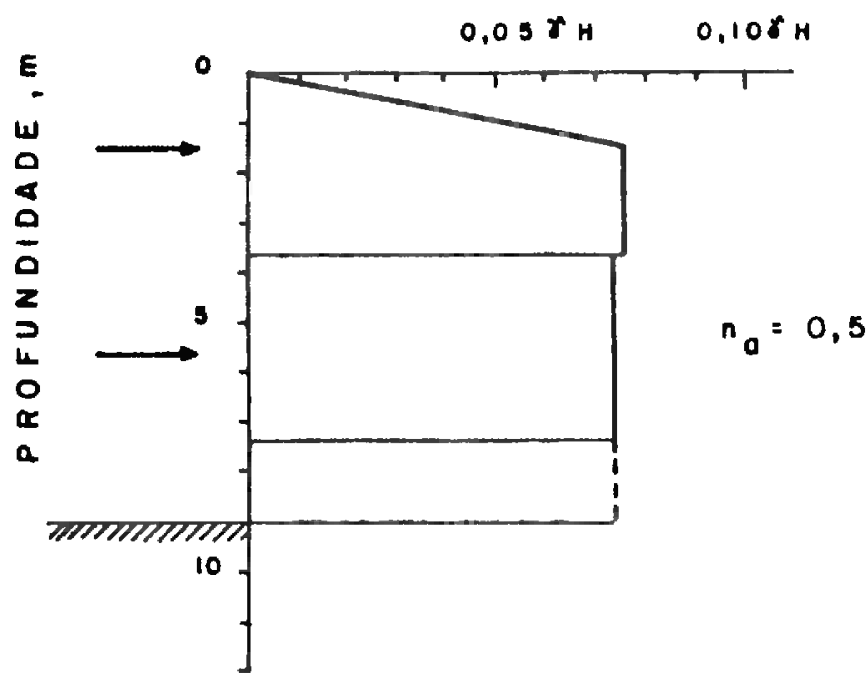

SECCĀO EXPERIMENTAL $\perp$

LEGENDA:

h - PROFundidade oa vala

\% - DENSIDAOE MÉdIA DO SOLO

n. H. DISTANCla até o Funoo da vala,

DA RESULTANTE DAS CARGAS DAS ESTRONCAB

SECCAĀO EXPERIMENTAL 6

PRESSÃO DE TERRA

PRESSĀO DE TERRA

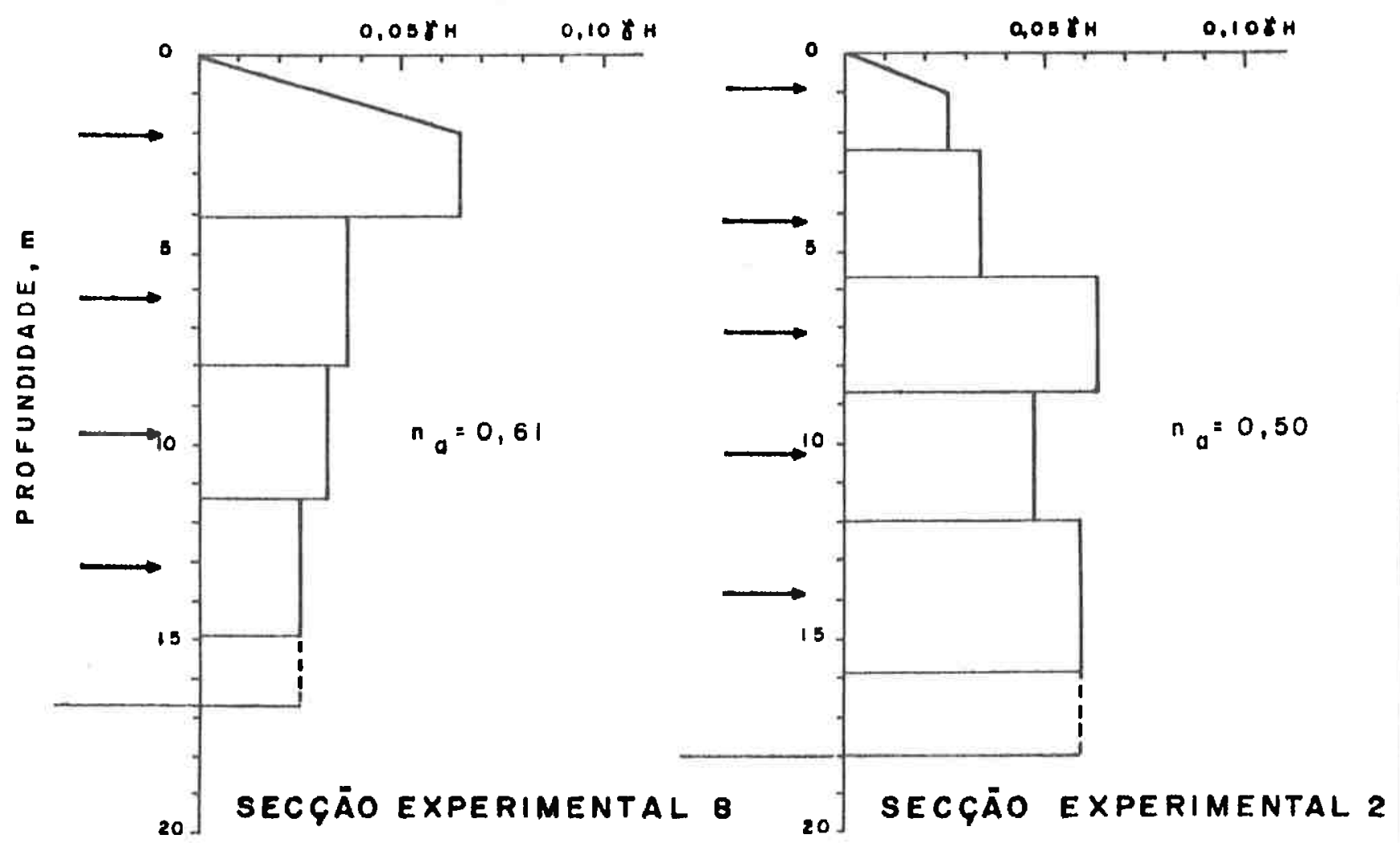

FIGURA ZIII-1: DIAGRAMAS DE PRESSŌES APARENTES MÁXIMAS, DESCONTADO O EFEITO DA DILATACÁOO TERMICA DAS ESTRONCAS 
TABELA VIII-I

PARAMETROS DOS SOLOS RELACIONADOS COM AS SECCDES EXPERIMENTAIS

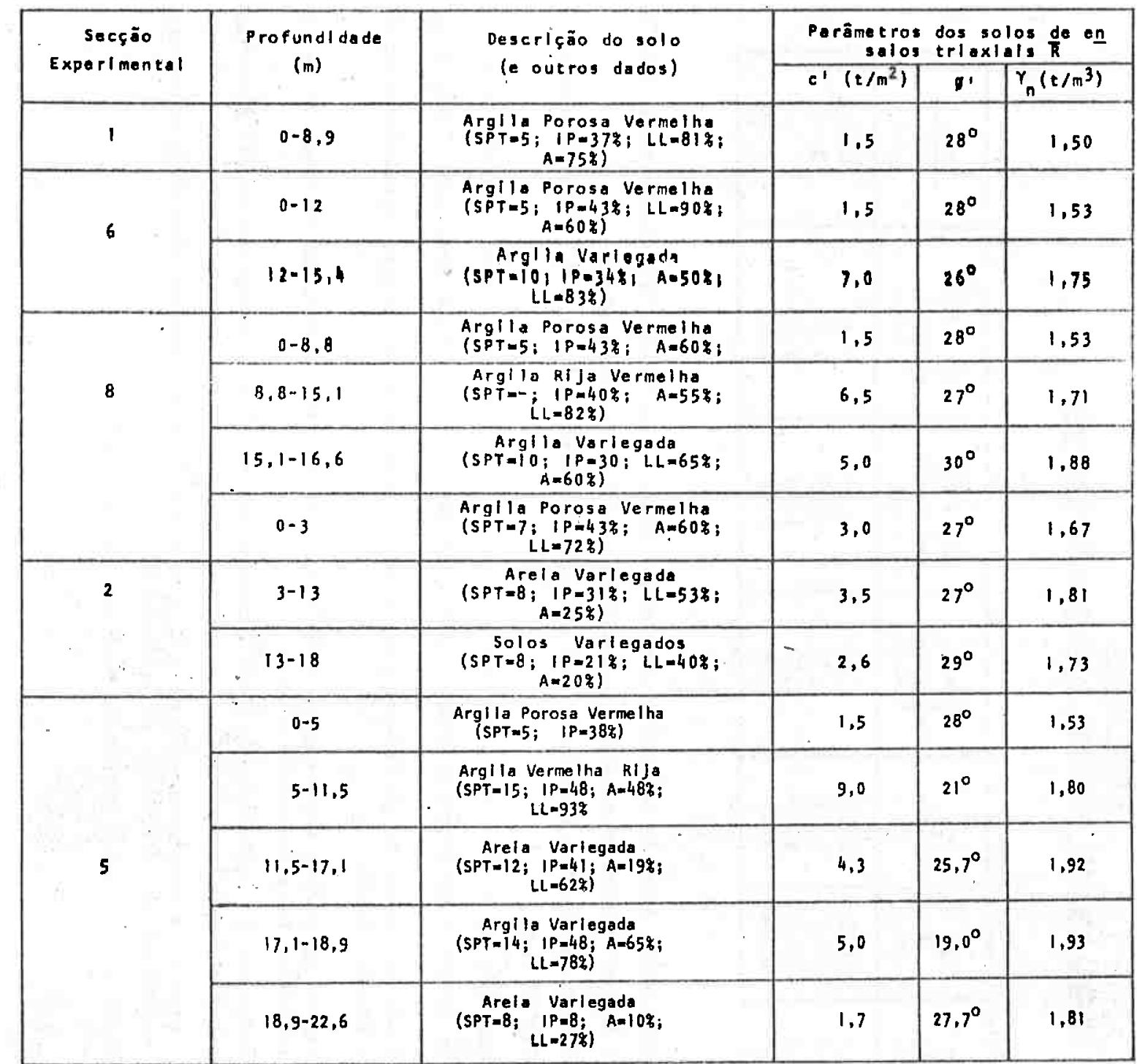

LEgENDA: IP - Indlice de Plasticldade

LL - Limite de Liquidez

A, - Fração de argila $(\%<5 \mu)$

SPT - Standard Penetration Test
$Y_{n}$ - Densidade natural

c' e g' - parâmetros de resisténcla en termos de pressões efetivas 

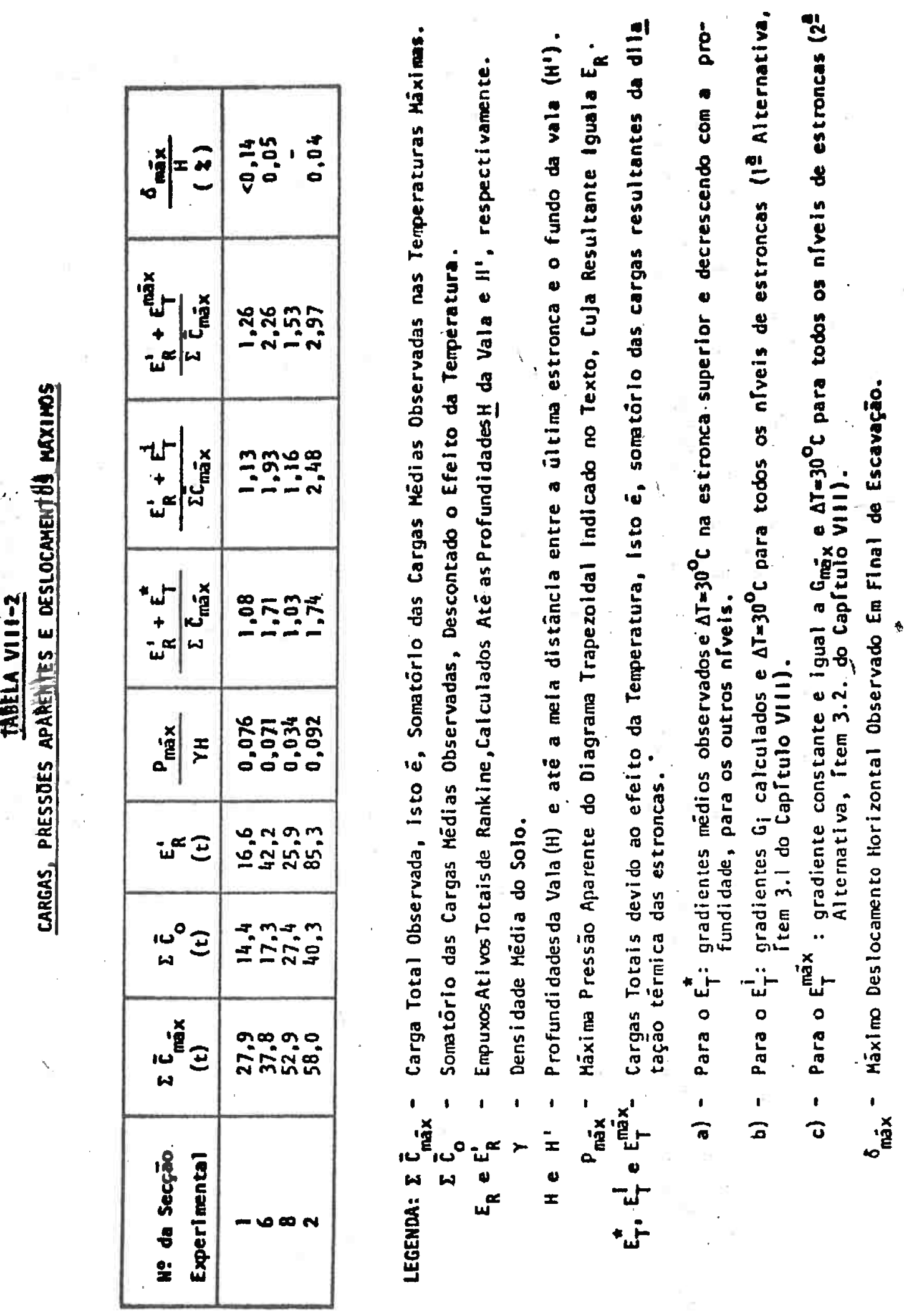
ginas 95 e $96 \%$, revelam que após o corte as cargas nas estroncas desviaram-se de no mãximo $8 \%$ em relação às cargas instaladas anteriormente. Flaate (1966), analisando estes resultados concluiu que há uma concordância razoável entre as pressões medidas e as calculadas pela hipótese em foco. 0 valor obtido por Casagrande fol $10 \%$ superior e o de Peck $20 \%$ inferior aos correspondentes valores computados.

A figura VIII-1 mostra os diagramas assim obtidos e indica os valores de $n_{a}$ definidos acima, que fornecem a posição da resultante das cargas nas estroncas. Nota-se que a distribuição está longe de ser triangular ou trapezoidal, tendendo a ser parabólica. A envoltöria geral destes diagramas pode ser tomada como trapezoidal, com a pressão crescendo linearmente com a profundidade atë o nível da estronca superior, a partir da qual torna-se constante e igual a $0,075 \mathrm{\gamma H}$. Para argilas rijas, Peck (1969) sugeriu valores de 0,2 a $0,4 \mathrm{\gamma H}$ para a pressão mäxima de um diagrama trapezoidal; no entanto entre os dados de que se valeu para a fixação deste intervalo existem aqueles relatados por Mansur e Alizadeh que fornecem um limite da ordem de 0,1 yH (Mansur eta, 1970 ).

2.2. Comparação entre o Empuxo Ativo de Rankine e o $\Sigma \bar{C}_{0^{\circ}}$

o cálculo do Empuxo Ativo de Rankine (E'R) levou em conta a heterogeneidade das camadas de solo das Secções Experimentais, cu从 jos parâmetros de resistêncla estão indicados na tabela VIII-1. A parte tracionada do diagrama de pressões foi desprezada.

Os valores de $E^{\prime}{ }_{R}$ assim obtidos, bem como os somatörlos $\left(\Sigma \bar{C}_{0}\right)$ das cargas mëdias observadas em cada nível de estroncas, apre sentados na tabela VIII-2, mantēm entre si relações pröximas de 1 para as Secções Experimentais 1 e 8, mas abaixo de 0,5 para as Secçōes 6 e 2 .

Para a compreensão destes resultados $\vec{e}$ necessärio re 


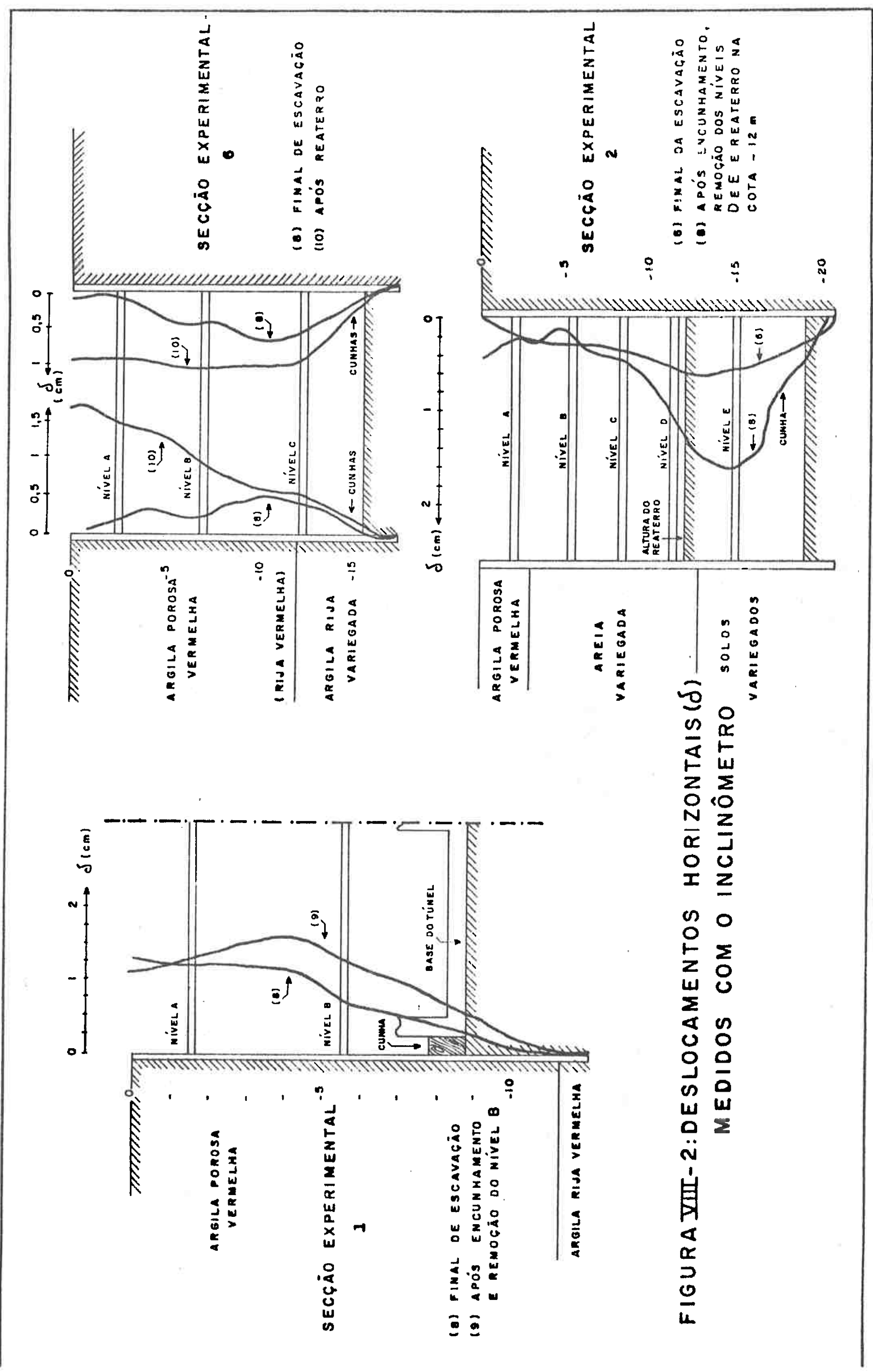


portar-se ao item 4 do Capítulo VII, em que se mostrou que para as estroncas dos niveis inferiores a contribulção do empuxo de terra foi pequena, face à demora na sua instalação.

$$
\text { E, pois, razoävel supor, estribado na resenha do }
$$

item 1.2., que nas valas em que os deslocamentos horizontais, medidos com inclinômetro (vide figura VIII-2), foram pequenos, a transferêncla de car ga para as estroncas mais superiores tenha se mantido em níveis muito baixos. Este caso deve ter ocorrido com as Secções 6 e 2, pois os mäximos deslocamentos horizontais (última coluna da tabela VIII-2) foram inferiores a $0,05 \%$ da profundidade das valas. Com base nesta cifra, podese afirmar que os solos escorados não entraram em estado de ruptura, isto $\vec{e}$, as suas resistências ao cisalhamento não foram totalmente mobiliza das.

Ao conträrio, nos casos da Secção Experimental 1, em que se verificou deslocamentos horizontais maiores, e da Secção 8 houve transferências substanciais de carga para as estroncas dos níveis superiores, como se constata por simples inspeção da figura VIII-1. Para a Secção 8 este fato é digno de nota.

Os dados da figura VIII-2, referenciados acima, mostram as linhas elásticas de estacas metälicas das Secções Experimentais 1, 6 e 2, em final de escavação, instrumentadas com tubos de alumínio de inclinômetros wilson, conforme fol relatado no Copítulo II e no Apêndice $B$ e apresentados nos trabalhos de Sousa Pinto et al (1972) e Massad(1978).

Os Empuxos Ativos de Rankine, distribuidos trapezoldalmente da forma Indicada no item 2.1., levaram aos valores mäximos de pressão $\left(p_{\text {mäx }}\right.$ ) apresentados na tabela VIII-2. Nota-se que para as Secções 1 e 6 eles se aproximam da envoltōrla de 0,075 YH dos diagramas de pressões aparentes. 
2.3. Resumo das Alternativas para o Cälculo das cargas resultantes do empuxo de terra

Fica-se assim com duas alternativas para a estimativa da parcela de carga correspondente ao empuxo de terra:

a) 1. Altemativa: calcular o Empuxo Ativo de Rankine pelas förmulas cläs sicas, tomando-se o cuidado de desprezar a parte tracionada do correspondente diagrama de pressões, e distribuílo de forma trapezoidal; ou

b) 2. Altemativa: adotar um diagrama de pressões aparentes trapezoidal, com a pressão mäxima igual a $0,075 \mathrm{\gamma H}$ ou $0,10 \mathrm{\gamma H}$.

Na sequência desta Investigação optou-se pela primei

ra delas.

3. ROTEIRO DE CALLCULO DAS CARGAS PROVENIENTES DA DILATAÇÃO TERMICA DAS ESTRONCAS

A segunda etapa do processo de cálculo delineado no ilem 1.1. deste Capituzo refere-se às forças que surgem nas estroncas por efeito da temperatura, cuja determinação é feita multiplicando-se, em ca da nível, os gradientes pelas máximas diferenças de temperatura que, supõe-se, ocorrerão durante a permanência do escoramento provisório.

Para as estroncas do nível superior das Secções Experimentais (ver tabela III-1) esta diferença assumiu valores no interva lo de 19 a $38^{\circ} \mathrm{C}$, com uma média em torno de $30^{\circ} \mathrm{C}$, que foi adotada para to dos os niveis de estroncas, na continuldade desta Investigação.

Is to posto, propõem-se tambēm duas alternativas de cálculo do efeito da temperatura, que se passa a descrever. 
3.1. 1. Altemativa

Os gradientes variam de nivel a nivel e serão estimados atravēs das förmulas präticas dadas pelas expreseões (VI-6a) e $\cdot(V I-6 b)$.

A título de ilustração, considere-se a Secção Experimental 6. 0 parāmetro $\bar{n}$ vale 1,34 , e foi calculado em funçäo dos per$f$ is de sondagem indicados na figura $B-5$, dos dados da tabela III-1 e com $\beta=4,2$ na expressão (VI-4); a camada de Argila Rija Vermelha foi incorpo rada ao Solo Variegado. Os valores dos gradientes assim calculados säo:

$$
G_{A}=0,21, G_{B}=0,33 \text { e } G_{C}=0,48 \mathrm{t} /{ }^{\circ} \mathrm{C}
$$

donde as cargas nas estroncas, oriundas do efeito da temperatura, valem:

$$
\begin{aligned}
& E_{T}^{A}=0,21 \mathrm{t} /{ }^{\circ} \mathrm{C} \times 30^{\circ} \mathrm{C}=6,3 \mathrm{t} \\
& E_{T}^{B}=0,33 \mathrm{t} /{ }^{\circ} \mathrm{C} \times 30^{\circ} \mathrm{C}=9,9 \mathrm{t} \\
& E_{T}^{\mathrm{C}}=0,48 \mathrm{t} /{ }^{\circ} \mathrm{C} \times 30^{\circ} \mathrm{C}=14,4 \mathrm{t}
\end{aligned}
$$

cujo somatōrio è:

$$
E_{T}^{i}=30,6 t
$$

3.2. 2. Alternativa

Os gradientes de carga-temperatura serão supostos constantes, qualquer que seja o nivel de estroncas, e dados pela expresва̃o $(V I-6 a)$.

Assim, vol tando-se ao exemplo da Secção Experimental

6 , tem-se: 
113

$$
\begin{aligned}
& G_{A}=G_{B}=G_{C}=0,48 \mathrm{t} /{ }^{\circ} \mathrm{C} \\
& E_{T}^{A}=E_{T}^{B}=E_{T}^{C}=14,4 t
\end{aligned}
$$

cujo somatōrio vale:

$$
E_{T}^{\operatorname{mäx}}=43,2 \mathrm{t}
$$

Finalmente, para fins comparativos, serão feitos cāl culos em que tanto os gradientes de carga-temperatura quanto os incrementos relativos de temperatura são os valores observados, dados na tabe Ia $(I I I-1)$.

Retomando a Seç̧ão Experimental 6, is to significa adotar para as estroncas dos niveis A, B e C os seguintes incrementos de temperatura:

$$
\begin{aligned}
& \Delta \mathrm{T}_{\mathrm{A}}=1 \times 30^{\circ} \mathrm{C}=30^{\circ} \mathrm{C} \\
& \Delta \mathrm{T}_{\mathrm{B}}=0,72 \times 30^{\circ} \mathrm{C}=22^{\circ} \mathrm{C} \\
& \Delta \mathrm{T}_{\mathrm{C}}=0,44 \times 30^{\circ} \mathrm{C}=13^{\circ} \mathrm{C}
\end{aligned}
$$

e, para os gradientes, os valores médios de final de escavação:

$$
G_{A}=0,21 \mathrm{t} /{ }^{\circ} \mathrm{C}, G_{B}=0,41 \mathrm{t} /{ }^{\circ} \mathrm{C} \text { e } G_{C}=0,55 \mathrm{t} /{ }^{\circ} \mathrm{C}
$$

do que resulta:

$$
\begin{aligned}
& E_{T}^{A}=0,21 \mathrm{t} /{ }^{\circ} \mathrm{C} \times 30^{\circ} \mathrm{C}=6,3 \mathrm{t} \\
& E_{T}^{B}=0,41 \mathrm{t} /{ }^{\circ} \mathrm{C} \times 22^{\circ} \mathrm{C}=9,0 \mathrm{t} \\
& E_{T}^{\mathrm{C}}=0,55 \mathrm{t} /{ }^{\circ} \mathrm{C} \times 13^{\circ} \mathrm{C}=7,2 \mathrm{t}
\end{aligned}
$$


e um somatörio de:

$$
E_{T}^{\star}=22,5 \mathrm{t}
$$

\section{COMPARAÇÕES ENTRE CARGAS CALCULADAS E OBSERVADAS}

\subsection{Cargas Totais}

A tabela VIII-2 contēm as cargas totals, is to $\overrightarrow{\mathrm{e}}$, os somatörlos das cargas nas estroncas, tanto as observadas $\left(\Sigma \bar{C}_{\text {mäx }}\right)$ quanto as calculadas. Os valores observados referem-se às cargas mëdias nas tem peraturas mäximas. As cargas calculadas correspondem aos Empuxos Ativos de Rankine $\left(E_{R}^{\prime}\right)$ somados à parcela devida ao efeito da temperatura, segun do o roteiro traçado no item 3 acima.

Da anālise destes resultados pode-se concluir que o $E_{R}^{\prime}$ somado à carga total devida à temperatura, calculada pela la alterna tiva $\left(E_{T}^{i}\right)$, conduz a valores de 13 e $16 \%$ acima da carga total observada para as Secções 1 e 8, respectivamente. Para a Secção 6 a diferença è mais acentuada em virtude da não mobilização total do Empuxo Ativo de Rankine, como foi discutido no item 2.2. deste CapituZo. Para a Secção 2, além deste fato, os gradientes de carga-temperatura observados estive ram bem abaixo dos calculados, face à anômala distribuição dos incrementos relativos de temperatura nas diversas estroncas, em profundidade, co mo jä foi enfatizado em outros Capitulos desta Investigação. Note-se que contornando esta anomalia com a adoção dos gradientes realmente observados, a diferença cai para $74 \%$ como mostra a 6 . coluna da tabela VIII-2.

Outra conclusão é que o $E^{\prime}{ }_{R}$ somado à carga total resultante da variação da temperatura, determinada pela 2a. Alternativa $\left(E_{T}^{m a ̄ x}\right)$, ultrapassa em excesso o valor da carga total observada. 
TABELA VIII-3

DISTRIBUIÇAOO DAS CARGAS NAS ESTRONCAS

SECÇOES EXPERIMENTAIS COM PAREDES FLEXIVEIS

\begin{tabular}{|c|c|c|c|c|c|}
\hline $\begin{array}{c}\text { Secçäo } \\
\text { Experimental }\end{array}$ & $\begin{array}{c}\text { Nível } \\
\text { da } \\
\text { Estronca }\end{array}$ & $\underset{(t)}{P}$ & $\begin{array}{c}C_{\max } \\
(t)\end{array}$ & $\begin{array}{l}c_{T}^{i} \\
(t)\end{array}$ & \\
\hline 1 & $\begin{array}{l}A \\
B\end{array}$ & \begin{tabular}{r|r}
6 & 91 \\
11 &
\end{tabular} & $\begin{array}{l}13(17) \\
17\end{array}$ & $\begin{array}{l}13 \\
19 \\
\end{array}$ & $|21|$ \\
\hline 6 & $\begin{array}{l}A \\
B \\
C\end{array}$ & \begin{tabular}{l|l}
20 \\
36 & $|49|$ \\
24 & \\
\end{tabular} & $\begin{array}{l}15 \\
18 \\
10\end{array}$ & $\begin{array}{l}18 \\
26 \\
29 \\
\end{array}$ & $|35|$ \\
\hline 8 & $\begin{array}{l}A \\
B \\
C \\
D\end{array}$ & $\begin{array}{l}30 \\
52 \\
42|59| \\
31\end{array}$ & $\begin{array}{l}14(16) \\
14(17) \\
13(18) \\
15\end{array}$ & $\begin{array}{l}10 \\
15 \\
17 \\
20\end{array}$ & $|23|$ \\
\hline 2 & $\begin{array}{l}A \\
B \\
C \\
D \\
E\end{array}$ & $\begin{array}{l}13 \\
32 \\
40 \\
44|68| \\
40\end{array}$ & $\begin{aligned} 9 & (13) \\
11 & (15) \\
15 & (19) \\
11 & (18) \\
16 & \end{aligned}$ & $\begin{array}{l}18 \\
26 \\
28 \\
33 \\
39\end{array}$ & $|48|$ \\
\hline 5 & $\begin{array}{c}A \\
B \\
C \\
D \\
E\left(E^{\prime}\right) \\
F\end{array}$ & $\begin{array}{l}28 \\
36 \\
56 \\
62 \\
69 \\
52\end{array}$ & $\begin{array}{rr}7 & (27) \\
20 & (26) \\
32 & (59) \\
19 & (21) \\
89 & (90) \\
53 & (60)\end{array}$ & $\begin{array}{l}28 \\
36 \\
44 \\
50 \\
57 \\
60\end{array}$ & $|76|$ \\
\hline
\end{tabular}

LEGENDA: P - Carga de Projeto,sem sobrecarga e sem a consideraçāo de trinca preenchida com ägua(Cälculo conforme a NCO3).

$C_{\text {máx }}$ - Carga Máxima Observada na Temperatura Mäxima em final de escavaçāo.

$C_{T}^{\prime}$ - Carga Mäxima; o efeito da Temperatura calculado de acordo com a la Alternativa, item 3.1. do

( ) - Nümeros entre parênteses indlcam a $C_{\operatorname{māx}}$ (observadas) Incluindo as fases de reaterro.

1 - Nümeros entre barras referem-se a cargas calculadas apös a remoção do ültimo nível de estroncas e encunhamento, com dispositivo de transferèncla colocado entre as estacas metälicas e a base do túnel. 
4. 2. Cargas distmibuidas nas estroncas

Uma prova mals severa da valldade do processo propos to consiste na comparação entre as cargas calculadas e observadas, distribuldas pelas estroncas. Para tanto as cargas nas estroncas foram computadas somando-se a parcela orlunda do empuxo de terra àquela resultante do efeito da temperatura, determinada pela la Alternativa.

Alëm destas cargas, são apresentadas na tabelaVIII-3 as cargas de projeto, obtidas de acordo com a NCO3 (Normas de Coordenação Técnica da Cia. do Metropolitano de São Paulo) e as cargas mäximas observadas nas temperaturas mäximas.

Os valores referem-se ao final de escavação, exceção feita às estroncas do penültimo nível, cujas cargas foram também determinadas para o estágio crítico que ocorre após a remoção do último nível de estroncas e encunhamento com dispositivo de transferência colocado en tre as estacas metālicas e a base do tünel. Nestas condições, os cälculos do efeit to da temperatura foram feltos tomando-se para os gradientes de carga-temperatura os valores associados à ültima estronca $\left(G_{\text {mäx }}\right.$ ), de conformidade com o item 6 do Capittulo VI.

A Secção Experimental. 5 foi também incluída na anäli se e, com base nos dados da tabela VIII-1, chegou-se a um $\mathrm{p}_{\max }$ (pressão máxima do diaǵrama trapezoidal que tem como resultante o Empuxo Ativo de Rankine) de $4,40 \mathrm{t} / \mathrm{m}^{2}$ ou $0,108 \mathrm{\gamma H}$, e às cargas, distriburdas pelas estroncas, indicadas na tabela VIII-3. Convëm ressaltar que esta Secção apresentou um. fenồmeno de redistribulção de cargas nas estroncas, cujas causas foram relatadas no item 5.3. do Apêndice B. Como resultado, surgi ram cargas elevadas no nivel E de estroncas. Enquanto a carga mäxima atingiu 89 t (tábela VIII-3), a média de leitura em três células de car- 
ga, instaladas em estroncas do mesmo nivel E, foi de $62 \mathrm{t}$; note-se também que a carga máxima no nível $D$ fol de apenas $18 \mathrm{t}$, sinal de um efel to de arqueamento do solo escorado.

0 exame da tabela VIII-3 revela que, com exceção da Seç̧ão Experimental 2, as cargas calculadas pelo processo descrito neste Copitulo cobrem razoavelmente bem as cargas mäximas observadas nas tempe raturas máximas. As cargas de projeto, apesar de não ter sido considerado o efeito da dilatação tērmica das estroncas, superestimam os valores observados, relativamente às Secçōes 8 e 2, e subestimam-nos quanto à Secção 1.

Como conclusão de carāter geral, o procedimento proposto, com o recurso do Empuxo Ativo de Rankine, distribuido trapezoidalmențe, e das fórmulas prāticas (1. Alternativa), para a inclusāo do efe i to da temperatura, $\vec{e}$ bastante satisfatörlo e estă do lado da segurança. 


\section{CAPITULO IX}

\section{A PRE-COMPRESSAO DE ESTRONCAS - SUA INFLUENCIA NOS RECALQUES DO TERRENO E SUA INTERRELAÇÃO COM O EFEITO DA DILATAÇÃO TER- MICA DAS ESTRONCAS}

\section{CONSIDERAÇOES INICIAIS}

A escolha de paredes rîgidas, isto $\dot{e}$, de paredes dia fragmas ou de estacas Justapostas, para escoramentos provisōrios, costuma ser feita em função de uma redução dos recalques na zona de influêncla da vala e da sua estanqueldade ao elliminar a possibilidade de carrea mento do solo atravēs de frestas entre os pranchões de madelra, de escoramentos com paredes flexivels.

Dai a razão da construção de paredes rigidas cóm escoras prē-comprimidas no caso de existirem edificações, canalizações ou outras utilidades sensiveis a recalques, nas vizinhanças das valas. As cargas de pré-compressão são calculadas em função do coeficiente de empu xo em repouso do solo.

E comum tambēm encontrar-se recomendações de uso de paredes flexiveis com escoras parcialmente comprimidas, para empuxo ativo aumentado, visando eliminar ou compensar deformações e para se obter uma melhor aderêncla entre a parede de escoramento e o solo.

Estes critërios levantam algumas questões vinculadas à presienté Investigação, que se passa a enunciar. Uma delas referese à eficácla de paredes flexiveis com escoras parclalmente pré-comprimidas na redução dos recalques nas imedlaçōes da vala; ainda para esta modal idade de arrimo, Indaga-se, quantitativamente, sobre a importâncla 
do efeito da temperatura. Uma outra diz respeito à hora do dia $\mathrm{m}$ que se deve proceder à pré-compressão de escoras apoladas em paredes rígidas,pa ra levar em conta os efeitos da sua dilatação têrmica.

Alēm de respondê-las será mostrado que a Incorporação das cargas em estroncas prë-comprlmidas, apoladas em paredes rigldas, è problema que merece cuidados especials.

\section{A PRE-COMPRESSÁO DE ESCORAS NO CASO DE PAREDES FLEXTVEIS}

\subsection{A sua função real}

E erröneo pensar que a prē-compressão das estroncas contra paredes flexiveis diminui os recalques do terreno circunvizinho. Um cälculo simples, feito com base na expressão (III-3), supondo tratarse de escoras $21^{\prime} 12^{\prime \prime}$, de $12 \mathrm{~m}$ de comprimento, com carga $P$ de prë-compressão de $30 \mathrm{t}$, mostra que o deslocamento imposto às estacas metálicas è de apenas:

$$
\left(\frac{E_{a_{a} S^{\alpha}}}{u_{i l}}-1\right) \cdot \frac{P l / 2}{E_{a} S_{a}}=\left(\frac{1}{0,2}-1\right) \times \frac{30 t \times \frac{12,0 \mathrm{~m}}{2}}{0,0150 \mathrm{~m}^{2} \times 2,1 \times 10^{7} \mathrm{t} / \mathrm{m}^{2}}=2,3 \mathrm{~mm}
$$

Subjacentemente, estabeleceu-se uma equivalência entre a prë-compressão e o efelto da temperatura, no mesmo sentido da simulação idealizada no ítem 2. 1. do Capitulo VII. Pelos dados da tabela VI-1 e VI-2, vê-se que $U_{1 i} / E_{a} S_{a} \alpha$ varla de 0,10 a 0,30 , em função do parâmetro $n$ e da posição da estronca, o que podería levar a deslocamentos de 1 a 5 vezes o seu encur tamento. Na expressão acima tomou-se o valor 0,20 para aquele adimensional.

A superficle do terreno recalcará multo mais do que 
isto, em função dos métodos construtivos (velocidade de escavação, tempo para a colocação das escoras, entre outros); da flexão dos pranchões de madeira e do processo de sua instalação; e do levantamento do solo no fundo da vala.

Estudos analiticos conduzidos por Palmer $e \quad$ Kenney (1972) com aplicação do Mẽtodo dos Elementos Finitos a uma das secções experimentais do Metrô de 0slo, mostraram que pré-carregamentos reduzem muito pouco os recalques, mas, como è öbvio, aumentam substancilalmente as cargas nas estroncas.

Então, qual seria a sua função? o'Rourke e Cording $(1974-a)$, ao analisarem os resultados de uma secção instrumentada do Metrô de Washington D.C., afirmam que the major function of preloading is to close the separations between the wale and braces, thereby effectively stiffening the bracing system. Movimentos laterais medidos no nivel de uma das escoras prē-comprimidas atinglram valores de até 3,0 $\mathrm{mm}$. E sugerem a limitação da carga de prē-compressão atē o valor suficiente para fechar espaços e vazios no sistema de escoramento; em outras palavras, bastaria encunhar as estroncas.

\subsection{O efeito da temperatura}

Quanto ao efeito da temperatura, recorrendo-se aos dados de O'Rourke e Cording (1974-a), relativos à escavação na Galery Station Place, as 4 estroncas do 39 nivel apresentaram, em médla, as seguintes parcelas de carga:

$$
\begin{array}{ll}
\text { - prē-compressão } & : 52 \text { t ou } 65 \% \\
\text { - temperatura }\left(\Delta T=30^{\circ} \mathrm{F}\right): 6 \mathrm{t} \text { ou } 8 \% \\
\text { - empuxo de terra } & : \frac{22 \text { t ou } 28 \%}{80 \mathrm{t} \text { ou } 100 \%}
\end{array}
$$


Vê-se que a dilatação térmica monta apenas $8 \%$ da carga total. E claro que se a variação de temperatura tivesse sido de $30^{\circ} \mathrm{C}$, este valor subiria para $13 \%$, e a carga total para 85 t. Inversamente, se a carga de prè-compressão tivesse sido da ordem de $10 \mathrm{t}$, então ter-se-la:

$$
\begin{array}{ll}
\text { - prë-compressão } & : 10 \text { t ou } 23 \% \\
\text { - temperatura }\left(\triangle T=30^{\circ} \mathrm{C}\right): 11 \mathrm{t} \text { ou } 26 \% \\
\text { - empuxo de terra } & : \frac{22 \mathrm{t} \text { ou } 51 \%}{43 \mathrm{t} 100 \%}
\end{array}
$$

isto é, a parcela de carga devida ao aumento da temperatura em $30^{\circ} \mathrm{C}$ seria de $26 \%$, praticamente o dobro da situação anterlor.

\subsection{Fontes de recalques nas imediações das valas}

De passagem, e retomando a questão dos recalques nas imediações das valas, è interessante analisar a sua maior fonte, no caso da Linha Norte-Sul do Metró de São Paulo.

Segundo autores alienígenas, diversos são os fatores a considerar neste contexto, sob o ponto de vista construtivo:

a) O espaçamento vertical e horizontal entre escoras;

b) a velocidade da escavação, ou a māxima distância permitida entre o úl timo nivel de estroncas já instaladas e o fundo temporärio da vala, durante a escavação; em particular, o tempo decorrido entre a escavação de fum trecho e a colocação das escoras é bastante significativo;e c) a remoção das estroncas e a recuperação das estacas metãlicas após a construção do túnel.

D'Appolonia (1971), comparando resultados de observaçōes nos Metrōs de 0slo, México, Chlcago e Boston, concluilu que 60 a $80 \%$ dos volumes de terra deslocados horizontalmente ocorreram abalxo 
do fundo temporärlo da vala, durante as escavações; as distânclas verticais entre estroncas varlaram de 2 a $3,5 \mathrm{~m}$. Para o Metrô de Washington D.C. O'Rourke e Cording confirmaram a importâncla deste movimento em profundidade, encontrando valores de $60 \%$ para aquela clfra. Esta fonte de deslocamentos jä tinha sido relatada por Peok (1869).

Nas fases de reaterro os casos cltados na literatura técnica têm mostrado que os incrementos de deslocamentos devidos à remoção das estroncas atingiram, no mäximo, $50 \%$ dos valores observados em final de escavação (Peck, 1969). Para o Metrô de Washington D.C., esta remoção teve pequena influência nos recalques e movimentos laterais do maciço escorado, em virtude do processo construtivo, em que as paredes de escoramento foram incorporadas ao prōprio tūnel.

No caso do Metrô de São Paulo, I inha Norte-Sul, havia necessidade de uma câmara de trabalho para impermeabilizar as paredes do tưnel apōs a sua construção, alēm do que as estacas metālicas das paredes de escoramento eram recuperadas depois do reaterro da vala. As operações construtivas estão descritas detalhadamente no item 2 do Capitulo II.

Com base nos resultados das observações das Seç̧ões Experimentais do Metrô de São,Paulo foi possivel mostrar (Massad, 1978) que cerca de $2 / 3$ dos movimentos laterais das estacas ocorreram após o seu encunhamento e o reaterro da vala. Para a Secção Experimental 2 é in teressante assinalar que a remoção das escoras do ül timo nível, concomitantemente ao encunhamento das estacas na base do túnel, acarretou um acrésclmo de $100 \%$ no volume de terra deslocado horizontalmente, em rela ção ao correspondente valor de final de escavação; a distância vertical entre o ūltimo nivel remanescente e as cunhas era de cerca de $8 \mathrm{~m}$. Após - reaterro completo da vala, este volume tinha sofrido um incremento de 
47 \%. Assim, verificou-se uma distribuição dos movimentos laterais de $34 \%$ ao final da escavação; $34 \%$ apōs a remoção do ültimo nivel de estroncas e encunhamento na base do tūnel e $32 \%$ após o reaterro fínal. Na altura do ūltimo nivel de estroncas os deslocamentos horizontais passaram de $6 \mathrm{~mm}$ par̉a $20 \mathrm{~mm}$, depois de sua remoção.

Em termos absolutos, os recalques após reaterro variaram, grosso modo, de $3 / 4$ a 1 polegada,o que vem de encontro aos poucos dados apresentados por Peck (1969) para argilas rijas.

Estes achados são de grande importâncla para a econo mia nos escoramentos, que è ditada em grande parte pelos recalques toleräveis nas imediações das valas(Bjerrum et al, 1965). No caso da tēcnica construtiva usada no Metrô de São Paulo, se se conseguir minimlzar os movimentos que ocorrem nos estäglos de reaterro, então será possivel aumentar os espaçamentos verticals entre estroncas.

3. A INCORPORAÇAO DAS CARGAS NAS ESTRONCAS PRE-COMPRIMIDAS - PAREDES DE ESCORAMENTO RTGIDAS

Serão abordados três aspectos ligados à incorporação das cargas nas estroncas, em sistemas de escoramento com paredes rigldas:

a) a técnica usada na prē-compressão;

b) o alívio de carga em estroncas jä prē-comprimidas, quanto da repetição do processo em estroncas vizinhas; e

c) o efelto da temperatura na carga instalada.

3.1. Técnica usada na pré-compressão

Por ocasião da pré-compressão das estroncas na Secção Experimental do Bloco 17 notou-se que parte da carga acusada pelo ma 
TABELA $\mid X-1$

CARGAS REALMENTE INSTALADAS EM ESTRONCAS PRE-COMPRIMIOAS

SECCOES EXPERIMENTAIS

\begin{tabular}{|c|c|c|c|c|c|}
\hline \multirow[b]{2}{*}{$\begin{array}{c}\text { Secção } \\
\text { Experimental }\end{array}$} & \multirow[b]{2}{*}{ Estronca } & \multicolumn{4}{|c|}{ Cargas (Toneladas) } \\
\hline & & Nominal & $\begin{array}{l}\text { Ll da na célula } \\
\text { de carga com o } \\
\text { macaco em pos l ção }\end{array}$ & $\begin{array}{l}\text { Apōs encunha- } \\
\text { mento e ret l- } \\
\text { rada do macaco }\end{array}$ & $\begin{array}{c}\text { Relaçāo entre } \\
\text { as cargas real } \\
\text { mente instala } \\
\text { da ea nominaT } \\
\text { (\%) }\end{array}$ \\
\hline \multirow{5}{*}{$\begin{array}{c}\text { Bloco } 17 \\
\text { (Trecho 43) }\end{array}$} & 1 & 30,0 & 15,1 & 7,5 & 25 \\
\hline & $1^{*}$ & 30,0 & 25,0 & 26,4 & 88 \\
\hline & 11 & 30,0 & 20,1 & 15,4 & 51 \\
\hline & 111 & 50,0 & - & 43,2 & 86 \\
\hline & iv & 50,0 & - & 31,0 & 62. \\
\hline \multirow{3}{*}{3} & I F & 100,0 & 74,6 & 50,3 & 50 \\
\hline & II $F$ & 100,0 & 71,8 & 37,0 & 37 \\
\hline & $\| 11 F$ & 100,0 & 75,1 & 33,1 & 33 \\
\hline \multirow{6}{*}{7} & I B & 40,0 & $\therefore 30,0$ & 29,6 & 74 \\
\hline & 11.8 & 40,0 & 27,6 & 37,0 & 93 \\
\hline & 16 & 48,0 & 41,9 & 50,0 & 104 \\
\hline & $11 c$ & 48,0 & 41,7 & 45.1 & 94 \\
\hline & 10 & 60,0 & 41,5 & 44,6 & 93 \\
\hline & 110 & 60,0 & 34,9 & 33,8 & 70 \\
\hline
\end{tabular}

- Apös aplicação de um outro processo de encunhamento. 
nômetro do macado (carga nominal) não lhe era transmitida. Ademais, con - simples ajuste das cunhas e a retirada do macaco, a carga nas estroncas, lida através de cēlulas de carga de cordas vibrantes caía às vezes substancialmente, como está indicado na tabela $I X-1$.

Para a estronca 1 do Bloco 17 (trecho 43), apōs a co locação das cunhas a ponto de só movimentar o ponteiro do manômetro do macaco, quando então ele era retirado, a carga instalada decrescia para cerca de $25 \%$ da carga nominal. Decidiu-se então repetir a operação de pré-compressão, nas forçando as cunhas atē que a carga lida no manômetro do macaco diminuisse consideravelmente; este procedimento fez com que a carga realmente instalada passasse a ser $88 \%$ da nominal.

Este exemplo ilustra a necessidade de se especificar mui to bem as operações de encunhamento e retirada do macaco e, inclusive, na medida do possivel, que se façam verificações das cargas realmente Instaladas, ell algumas estroncas, com o recurso de células de carga ou do próprio macaco. Os outros casos ilustrados na tabela IX-1 corroboram estas recomendaçōes.

O'Rourke e Cording (1974-a) fazem menção a uma perda de carga de $20 \%$ apōs encunhamento, nas escoras da vala da Galery Place Station, Metrô de Washington D.C.; e recomendam um prē-carregamento acima do nominal, para fins de compensação.

3.2. Alivio de cargas em estroncas vizinhas, durante a pré-compressão

Uma outra fonte de redução da carga realmente incorporada às estroncas é o alivio provocado pela pré-compressão de estroncas vizinhas.

De fato, um dos resultados do desenvolvimento teörico, confirmado por algumas informações de campo, fei to no item 2.1. do Ca 
pitulo VII, foi que para paredes rígidas os alivios de carga são de pelo menos $20 \%$ na estronca imediatamente acima da que fol comprimida.

Embora haja uma carêncla de dados experimentals, esta clfra è bastante significativa, principalmente se for levada em conta - possibilidade de se incorporar apenas uma fração de carga nominal durante a pré-compressão, discutida no item anterior.

\subsection{O efeito da temperatura na carga instailada}

A temperatura tem um efeito bastante significativo em paredes de escoramento rígidas, pols provocam variaçōes nas cargas das estroncas, mercè de sua dilatação térmica. Com base nos estudos apresentados no Copituzo VI, conclui-se que a carga que surge na estronca por unidade de temperatura è uma fração (G) da carga que nela se instalaria, se suas extremidades estivessem impedidas, sendo que:

$$
\bar{G}=\frac{0,5}{1+\frac{0,5 \beta S_{a}}{D t l}}
$$

fol obtida atravēs das expressões (VI-4) e (VI-7).

A título de ilustração, para a Seç̧ão Experimental 3 a expressão acima permite estimar em $21 \%$ a fração $\bar{G}$ para as estroncas do ül timo nível.

Suponha-se que a prē-compressão tenha sido feita à nolte; se és $13 \mathrm{~h}$ do día seguinte a temperatura tivesse aumentado de $30^{\circ} \mathrm{C}$, as cargas nas estroncas do ültimo nivel sofrerlam incrementos de atē ( $v i d e$ tabela III-1):

$$
\bar{G} \cdot E_{a} S_{a}^{\propto} \cdot \Delta T=0,22 \times\left(2,1 \times 10^{7}\right) \times 0,0300 \times\left(1,1 \times 10^{-5}\right) \times 30=44 t
$$


carga em função da temperatura, nos casos de valas escoradas com dois ou mais nivels de estroncas, mercê da assincronia dos seus picos de aque cimento.

2. RESULTADOS DA APLICAÇAOO DO MODELO MATEMATICO - ENVOLTORIAS DOS GRAOIENTES MAXIMOS

Os fatores que mais influem nos valores dos gradien tes de carga-temperatura, revelados pelo modelo matemātico, sāo, pela ordem de importância:

a) os incrementos relativos de temperatura nas estroncas dos diversos niveis, que são função do ângulo de incidência dos raios solares, da orientação do eixo da vala, época do ano em que é feita a escavação, presença de anteparos nas imediações das valas, entre outros;

b) o parāmetro $n$ que mede a relação entre a rigidez das estroncas e a do solo escorado;

c) a rigidez da parede de escoramento; e

d) a geometria da vala e do sistema de escoramento.

Tal è a relevância do primeiro fator que, imaginando-se uma permuta entre duas Secções Experimentais no que tange às contingências de incidêncla dos raios solares, ventillação, presença de ante paros, ou, numa palavra, entre os incrementos relativos de temperatura, mas mantidas as suas identidades quanto à geometria da vala, ao slstema de escoramento e também quanto ao tipo de solo, foi possível mostrar uma alteração significativa nos valores das cargas na temperatura máxima. E Isto graças a uma singularidade verificada na Secção Experimental 2, que apresentou incrementos relativos de temperatura medidos muito próximos daqueles que teoricamente conduzem a iguals valores dos gradientes de carga-temperatura, o que realmente se concretizou. 
A rigidez das paredes de escoramento pode ser levada en conta separando-as em dois universos: de um lado as paredes rigldas, isto è, paredes diafragmas ou estacas Justapostas; e de outro as paredes flexivels, constituidas de estacas e estroncas metälicas e pranchões de madeira. Dentro de cada uma destas categorlas a rigidez da pare de em si mesma tem pouca influêncla.

A geometria da vala e do sistema de escoramento afe tam enormemente os gradientes de carga-temperatura, mas sāo de difícil equacionamento. Por isso, e tendo em vista que em fase de projeto, e nes te tipo de problema, interessa a estimativa dos valores extremos, introduziu-se o conceito de envoltōria dos gradientes māximos de um slstema de escoramento, com base numa faixa de variação experimental dos incrementos relativos de temperatura.

Isto Implicou na eliminação de uma das variáveis, reduzindo-se toda a teoria a algumas fórmulas práticas para a determinação dos gradientes máximos tanto para paredes flexiveis quanto para as rigidas, funçōes apenas do parâmetro $n$.

\section{FORMULAS PRATICAS PARA O CALCULO DOS GRADIENTES}

A definição dos parāmetros elásticos dos solos, quando submetidos a carregamentos ciclicos, è por si só tarefa trabalhosa, a exigir equipamentos precisos tanto para a medição dos incrementos de tensōes, em niveis baixissimos, inferiores a $2,5 \mathrm{t} / \mathrm{m}^{2}$, quanto para medidas extensiométricas. Some-se a lsto o desconhecimento do estado de tensões iniclal a que o solo esteve submetido anteriormente e defrontase com um quadro complexo.

No entanto, fol possivel estabelecer tendências de 
variação dos Mödulos de Deformabilidade, obtidos de ensaios triaxiais, em função da profundidade, tendo-se constatado a sua constāncia em toda a camada, para as Argilas Porosas e Rijas Vermelhas, e, em geral, o seu crescimento linear com a mesma, para os Solos Variegados. Módulos de Deformabilidade apōs repetição cíclica de carga são de 1,2 a 2 vezes maiores do que os correspondentes valores estäticos, confirmando resultados de autores alienigenas.

A fixação dos Mōdulos de Deformabilidade, através de förmulas simples, fol possivel atravēs de retroanālise, em que se procurou ajustar os gradientes observados aos calculados, com a aplicação do modelo matemātico às Secçōes Experimentais.

Foram estabelecidas fórmulas prāticas para o cālculo de $\bar{n}$, que teve a sua definição estendida para a realidade concreta das camadas de solos heterogêneos, bem como para a determinação dos gradientes mäximos, atravēs das expressões (VI-6) para paredes flexíveis, e $(V I-7)$ para paredes rigidas, ambas ratificadas experimentalmente.

Uma conclusão Interessante a que se chegou è que gradientes elevados, da ordem de $0,40 \mathrm{E}_{a} \mathrm{~S}_{a}{ }^{\alpha}$, assoclados a paredes rígidas, são mals sensiveis a variações da ärea $S_{a}$ da secção transversal das estroncas do que de qualquer outro parâmetro; por exemplo, a dupllcação de $S_{a}$ provoca um aumento de $67 \%$ nos gradientes, enquanto que tal variação para o comprimento das estroncas redundarla em acrëscimos de apenas 11 \% nestes mesmos gradientes. 0 oposto ocorre com paredes flexiveis com gradientes balxos, da ordem de $0,10 \mathrm{E}_{\mathrm{a}_{\mathrm{a}}} \mathrm{a}$, em que as varlações de compr 1 mento das estroncas, seu espaçamento em planta e a altura da pröpria parede, são muito mais significativas; por exemplo, a duplicação destes pa râmetros implica em aumentos de 67 \% nos gradientes, cifra esta que seria somente de $11 \%$ se se dobrasse $S_{a}$. Tudo se passa como se as paredes 
diafragma mascarassem a rigidez do solo e das escoras.

4. RECOMENDAÇOES QUANTO A CONSIDERAÇAO DO EFEITO DA TEMPERATURA NAS MANIPULAÇOES DOS DADOS EXPERIMENTAIS E NO DIMENSIONAMENTO DE ESCORAMENTOS

\subsection{Paredes de Escoramento Flexiveis}

A Idealização da escavação como um processo simples, fazendo abstração de efeitos tridimensionais, aliada à estimativa do alívio de carga nas estroncas jä instaladas quando do encunhamento de novos niveis, feita com base em resultados de apllcação do modelo matemätico, permitiu repartir as cargas observadas em três parcelas:

a) carga total de encunhamento, que è inferior a $20 \%$;

b) carga total devida ao empuxo de terra, superior a $30 \%$; e

c) carga total resultante da dilatação térmica das estroncas, perfazendo cerca de $50 \%$.

Estes percentuais foram obtidos para as Seç̧öes Experimentais, 1,6 e 8 , do Metrô de São Paulo, e confirmados para a de nümero 2, se nela os incrementos relativos de temperatura tivessem sido os da Secção Experimental 8. Pode-se dizer que metade da carga total adveio do efeito da tempe ratura que, portanto, duplicou a carga total devida ao empuxo de terra mais encunhamento.

Consideradas isoladamente, as cargas nas estroncas chegaram a ser. värias vezes malores do que aquelas que surgiriam como consequêncla do empuxo de terra mais encunhamento. E como a parcela resultante da diliatação tērmica das estroncas depende dos incrementos rela tívos de temperatura, varlävel aleatórla, è descabido o uso das cargas observadas nas temperaturas mäximas para o traçado dos dlagramas de pres sōes aparentes. Um outro argumento a favor desta poslção refere-se à in- 
conveniência do dlagrama de pressões aparentes ser função do nümero de niveis de estroncas.

Para o dimensionamento do escoramento, em final de eacavagão, recomenda-se a estimatlva das parcelas de carga oriundas do empuxo de terra por melo de dlagramas de pressōes aparentes observadas em solos semelhantes, ou de outro processo semi-empirlco. A parcela de carga proveniente da dilatação térmica das estroncas poderä ser calculada multiplicando-se os gradientes māximos de carga-temperatura, obtidos atravēs das fōrmulas práticas, pelos máximos incrementos de temperatura esperados durante a permanência do escoramento. Nos estágios críticos do i'eaterro sugere-se utilizar o mesmo procedimento, tomando-se para todas as estroncas o māximo valor dos gradientes de carga-temperatura de final de escavação.

Para as Argilas Vermelhas e os Solos Variegados, pode-se adotar uma envoltória de pressões aparentes com forma trapezoidal, em que a pressão atinge o valor mäximo de 0,1 YH na altura do primei ro nivel de estroncas.

\section{2. Paredes de Escorcmento Rígidas}

Para as paredes rigidas, o efeito da temperatura è bastante significativo, primelro porque dificilmente a carga incorporada por pré-compressão è a nominal, Isto è,acalculada em função dos diagramas de pressões assoclados ao estado de repouso do solo. E segundo, face aos alfuios de carga devidos ao encunhamento de estroncas vizinhas. Estes alfvios podem atingir valores de 20 e $10 \%$, respectivamente, para as estroncas jä Instaladas a um e dols nivels aclma da que estava sendo prècomprimida.

Ipso facto, o problema levanta a questão do momen- 
to mais adequado para a prē-compressão, se de dia ou à noite, com baixas temperaturas. A resposta, a nosso ver, è que a operação deva ser felta à nolte, pols elimina a possibllidade da carga de pré-compressão ser perigosamente alivlada, propiciando ao solo escorado salr do estado de repouso, razão de ser da pröpría parede.

5. SUgESTOES PARA FUTURAS OBSERVAÇOES NO CONTEXTO DESTA INVESTIGAÇÃO

A manter-se ainda a tendência impulsionada

por

Terzaghl e Peck de uma busca de receitas regionais para o cälculo dos em puxos de terra, são feitas algumas sugestões para futuras observações de campo.

Alēm da medida concomitante da carga e da temperatú ra das estroncas ë recomendāvel medir-se a temperatura em diversos pontos das paredés rígldas, tanto em profundidade quanto ao longo de sua es pessura, até o contato concreto-solo. Isto permitirā aquilatar melhor, no futuro, a influência da dilatação térmica da prōpria parede nos gradientes de carga-temperatura.

De preferência, para a obtenção dos diagramas de pressōes aparentes, as leituras das cargas nas estroncas deveriam ser fel tas de madrugada, quando existe um equilifbrio térmico entre o ar ambiente e os materiais que constituem o sistema de escoramento.

Medidas cuidadosas das cargas e temperaturas deveräo ser feltas no decorrer de um ou mais dias, em cada estägio de escava ção. E importante que haja um sincronismo nas leituras das cargas e temperaturas em todas as estroncas dos diversos niveis, para minimizar as dispersōes das correlaçōes estatísticas que permltem determinar os gradientes de carga-temperatura e os Inerementos relativos de temperatura. 
Seria desejāvel que, pelo menos em final de escavação, o trecho da vala em observação fosse protegido da incidenncia dos raios solares, por um tempo que possibilitasse a definição, de uma forma consistente, dos gradientes de carga-temperatura para a nova configuração dos incrementos relativos de temperatura, criada artificialmente. Es tes dados serlam valiosos na repartição das cargas nas estroncas em cargas de encunhamento mais empuso de terra, de um lado, e cargas oriundas da sua dilatação tërmica, de outro. Alnda neste sentido è bom lembrar que a separação das cargas de encunhamento depende fundamentalmente do conhe cimento da temperatura da estronca no momento de sua instalação e da medida das cargas e das temperaturas nas estroncas vizinhas, antes e após o encunhamento.

Para a Cidade de São Paulo, em particular, sería in teressante programar-se Secções Experimentais em valas que rasguem outras formaçōes de solo, tais como as Arelas do Vale do Anhangabaü e os solos quaternārlos, completando assim o quadro de informações jā disponi veis.

Finalmente, de posse das cargas nas estroncas, depuradas dos efeitos da temperatura e do encunhamento, será possível comparar dados de observação de campo com os resultados da aplicação de pro cessos modernos de cálculo, seja com base no Método dos Elementos Finitos ou no Mētodo dos Campos Associados, ambos exigindo um conhecimento mais aprofundado das relações tensão-deformação dos solos escorados e dos seus coeficientes de empuxo em repouso. 
1 - BAguelin, F. Jezequel, J.F. Le Pressiomètre Autoforeur. Annales de L'Institute Technique des Bâtiment et des Travaux Publics Paris. Sêrie Sols et Fondations, (97): 135-160, Jui/aout. 1973.

2 - BISHOP, A.W. et al. Undisturbed Samples of London Clay from the Ashford Common Shaft: Strenght-effective Stress Relationships. Gëotechnique, 15 (1): 1-31, mar. 1965.

3 - BJERRUM, L. et al. The Effect of Time on the Shear Strenght of a Soft Marine Clay. In: CONFERENCE ON EARTH PRESSURE PROBLEMS, Brussels, 1958. Proceedings ... Brussels, 1958, vol. 1, p. 148-158.

4 - BJERRUM, L. et al. Mesuring Instruments for Strutted Excavations. Norwegian Geotechnical Institute Publication n: 64, 1965, p. 1-17.

5 - BJERRUM, L. Earth Pressures on Flexible Structures. In: EUROPEAN CONFERENCE ON SOIL MECHANICS AND FOUNDATION ENGINEERING, 5, Madrid, 1972. Proceedings ... Madrid, Sociedad Espanōla de Mecänica del Suelo y Cimentaciones, 1972. vol. 2, p. 169-196.

6 - BJERRUM, L. Problems of Soll Mechanics and Construction on Soft Clays and Structurally Unstable Soils (Collapsible, Expansive and others). In: INTERNATIONAL CONFERENCE ON SOIL MECHANICS AND FOUNDATION ENGINEERING, 8, Moscou, 1973: Proceedings ... Moscou, The USSR National Soclety for Soll Mechanics and Foundation Engineering, 1973. vol. 3, p. $111-159$.

7 - BOZOZUK, M. \& LEONARDS, G.A. The Gloucester Test FIII. In: SPECIALTY CONFERENCE ON PERFORMANCE OF EARTH AND EARTH SUPPORTED STRUCTURES, Lafayette, 1972. Proceedings ... Lafayette, American Society for Civil 
Engineers, 1972, vol. 1, p. 299-317.

8 - CASAGRANDE, A. \& SHANNON, W.L. Stress Deformation and Strength Characteristlcs of Solls Under Dynamic Loads. INTERNATIONAL CONFERENCE ON SOIL MECHANICS AND FOUNDATION ENGINEERING, 2, Rotterdam, 1948. Proceedings... Rotterdam, 1948, vol. 5, p. 29-34.

9 - CASAGRANDE, A $\&$ WILSON, S.D. Effect of Rate of Loading on the Strength of Clays and Shales at Constant Water Content. Gëotechnique, $\underline{2}$ (3): 251-263, Jun. 1951.

10 - CHAPMAN, K.R. et al. Performance of a Braced Excavation in Granular and Cohesive Soils. In: SPECIALTY CONFERENCE ON PERFORMANCE OF EARTH AND EARTH - SUPPORTED STRUCTURES, 1972. Proceedings ... American Society for Civil Engineers, 1972, vol. 3, p. 271-293.

11 - Cozzolino, v. Tipos de Sedimentos que Ocorrem na Bacia de São Paulo. São Paulo, 1972. Tese, Escola Politécnica da Universidade de S.Paulo.

12 - COZzolino, V. \& CHIOSSI, N. Condições Geotēcnicas da Bacia Sedimentar de S.Paulo. D.L.P., S.Paulo, 1969.

13 - D'APPOLONIA, D.J. Effects of Foundation Construction on Nearby Structures. In. PAN-AMERICAN CONFERENCE ON SOIL MECHANICS AND FOUNDATION engineering, 4, Porto RIco, 1971. Proceedings... Porto Rico . American Soclety Civil Engineers, N.York, 1971. vol. 1, p. 189-236.

14 - DIBIAGIO, E. E BJERRUM, L. Earth' Pressure Measurements in a Trench Excavated in Stiff Marine Clay. In: INTERNATIONAL CONFERENCE ON SOIL MECHANICS AND FOUNDATION ENGINEERING, 4, London, 1957.Proceedings... London, Butterworths, 1957. vol. 2, p. 196-202.

15 - DUNCAN, J.M. E SEED, H.B. Anlsotropy and Stress Reorlentation in Clay. Journal Soll Mechanics, 92 (5): 21-49 sept., 1966. 
16 - ENDO, M. Earth Pressure in The Excavation Work of Alluvial Clay Stratum. In: International Conference on Soll Mechanics and Foundation Engineering, Budapest, 1963. Proceedings ... Budapest, 1963, Hungarlan Academy of Sciences, p. $21-46$.

17 - FLAATE, K.S. Stresses and Movements in Connection With Braced Cuts in Sand and Clay. Illinois, 1966. Tese - University of lllinois, Michigan.

18 - FUJII, J. E.REMY, J.P. Anälise pelo Método dos Elementos finitos da Influêncla da Temperatura sobre Cargas nas Estroncas. In: SEMINÅRIO BRASILEIRO DO METODO DOS ELEMENTOS FINITOS APLICADO A MECANICA DOS SOLOS, 1, Rio de Janelro, 1974. Anais... Rio de Janelro, Coordena çắo dos Programas de Pōs-Graduação de Engenharia UFRJ, 1974, p. 247259.

19 - GOLDER, H.Q. Measurement of Pressure In Timbering of a Trench in Clay. In: INTERNATIONAL CONFERENCE ON SOIL MECHANICS AND FOUNDATION ENGINEERING, 2, Rotterdam, 1948. Proceedings ... Rotterdam, 1948, vol. 2, p. 76-81 (s.c.p.).

20 - HANNA, T.H. $\&$ ADAMS, J.I. Comparison of Field and Laboratory Measurements of Modulus of Deformation of a Clay. Highway Research Record (243): 12-22, 1968.

21 - HENKEL, D.J. The Relevance of Laboratory Measured Parameters in Field Studies. In: STRESS-STRAIN BEHAVIOR OF SOILS. ROSCOE MEMORIAL SYMPOSIUM, Cambridge, 1971. Proceedings ... London, G.T. FOULIS, 1972. p. 669-675.

22 - KARLSRUd, K. e F. MYRVOLL. Performance of a Strutted Excavation in Quick Clay. Norweglan Geotechnical Inst/tute Publication ni 111 , 1976, p. 9-16. 
23 - KEEN, B.A. The Physical Properties of the Soll. London, Longmans, Green and Co., 1931.

24 - KENNEY, T.C. Discussion. Journal Soll Mechanics and Foundation Division, 85 (3): 67-69, 1959.

25 - KONDER, R.L. ZELASKO, J.S. A Hyperbollc Stress-Strain Formulation for Sand. In: PAN-AMERICAN CONFERENCE SOIL MECHANICS AND FOUNDATION ENGINEERING, 2, Brasil, 1963. Proceedings ... Brasil, Associação Brạ sileira de Mecânica dos Solos, 1963, vol. 1, p. 289-324.

26 - LADD, C.C. Stress-Strain Behaviour of Saturated Clay and Basic Strength Principles. Massachusetts Institute of Technology. Research Report of Civil Engineering (R 64-17): 1-67, Apr. 1964a.

27 - LADD, C.C. Stress-Strain Modulus of Clay in Undrained Shear. Journal Soil Mechanics and Foundation Division, 90 (5): 103-132, $1964 \mathrm{~b}$.

28 - LAMbe, T.N. E WHITMAN, R.V. Soil Mechanics. New York, John Wiley, 1969.

29 - LANGendonCK, T.V. Cálculo de Concreto Armado, Rio de Janeiro, Cientifica, 1959.

30 - LEINZ, V. 8 AMARAL, S.E. Geologia Geral. 3 ed. São Paulo, Nacional, 1966.

31 - MANSUR, C.I. \& ALIZADEH M. Tie Backs in Clay to Support Sheeted Excavation. Journal Soll Mechanics and Foundation Division, 96 (2): 495-509, 1970.

32 - MASSAD, F, et al. Influêncla da Temperatura nas Cargas de Estroncas, en Valas Escoradas com Paredes Diafragma e Dois Niveis de Estroncas. In: SEMINARIO BRASILEIRO DO METODO DOS ELEMENTOS FINITOS APLICADO A MECANICA DOS SOLOS, 1, RIo de Janeiro, 1974. Anals ... Rio de Janeiro, Coordenação dos Programas de Pös-Graduação de Engenharía UFRJ, 1974-a, p. 209-228. 
33 - MASSAD, F. et al. Comparações entre Valores Medidos e Calculados dos Gradientes de Carga-Temperatura em Estroncas, em Valas Escoradas. In: CONGRESSO BRASILEIRO DE MECANICA DOS SOLOS, 5, São Paulo, 1974. Anais ... São Paulo, Assoclação Brasilel ra de Mecânica dos Solos, 1974-b, vol. 1, p. 73-86.

34 - MASSAD, F. et al. Influêncla da Temperatura nos Gradientes de CargaTemperatura para Escoramentos com Várlos Níveis de Estroncas. In: CONGRESSO BRASILEIRO DE MECANICA DOS SOLOS, 5, 1974. Anais ... São Paulo, Associação Brasileira de Mecânica dos Solos, 1974-c, vol. I, p. $87-103$.

35 - MASSAD, F. Características Geotēenicas das Argilas Porosas Vermelhas de São Paulo. In: CONGRESSO BRASILEIRO DE MECANICA DOS SOLOS, 5, São Paulo. Anais ... São Paulo - Associação Brasileira de Mecānica dos Solos, 1974, vol. 2, p. 131-144.

36 - MASSAD, F. A Influência do Método Construtivo no Desenvolvimento dos Recalques do Terreno, nas Valas Escavadas a Céu Aberto do Metrô de São Paulo, Escoradas com Paredes Flexíveis. In: CONGRESSO BRASILEIRO DE MECANICA dOS SOLOS, 6, 1978. Anais ... Rio de Janei ro - Associação Brasileira de Mecãnica dos Solos.

37 - MELlo, V.F.B. E TEIXEIRA, A.H. Mecãnica dos Solos. São Carlos Univer sidade de São Paulo, 1962.

38 - MORGENSTERN, N.R. \& EISENSTEIN, Z. Methods of Estimating Lateral Loads and Deformations. In: SPECIALTY CONFERENCE ON LATERAL STRESSES IN THE GROUND AND DESIGN OF EARTH-RETAINING STRUCTURE, I thaca, 1970. Proceedings ... I thaca, American Society Civil Engineers, 1970. p.51-102.

39 - NORWEGIAN GEOTECHNICAL INSTITUTE. Technical Reports 1 a 9, 0slo, 1962. 
40 - OLIVeira Pinto, M.C. E KUTNer, M. Estudo das Características Mecānicas de uma Argila da Colina de São Paulo. Revista Polltēenica, set., 1950.

41 - O'ROURKE, T.D. \& CORDING, E.J. Observed Loads And Displacements For A Deep Subway Excavation. In: R.E.T.C., 1974. Proceedings ... 1974-a, vol. 2, p. 1305-1325.

42 - O'ROURKE, T.D. \& CORDING,E.J. The History of Loads And Displacements For a Deep Excavation in a Mixed Soll Profile. Transportation Research Record (517): 1-15, 1974-b.

43 - ORTOLANI, A.A. \& PINTO, H.S. Temperatura do Solo. In: MONIZ, A.C. e outros. Elementos de Pedologia. Rio de Janeiro, Livros Técnicos e Cientificos, 1972, p. 59-76.

44 - PACHECO SILVA, F. Uma Nova Construção Gräfica para Determinação da Carga de Pré-Adensamento de Solos. In: CONGRESSO BRASILEIRO DE MECANICA DOS SOLOS, 4, Rio de Janeiro, 1970. Anais ... Rlo de Janeiro, Assoclação Braslleira de Mecânica dos Solos, 1970, v. 2, p. 219-223.

45 - PALMER, J.H.L. E KENNEY, T.C. Analytical Study of a Braced Excavation in Weak Clay. Canadian Geotechnical Journal, 9 (2): 145-164, May, 1972 .

46 - PECK, R.B. Earth - Pressure Measurements In Open Cuts, Chicago (ILL) Subway. Transactions American Society Civil Engineers. vol. 108, p. $1008-1036,1943$.

47 - PECK, R.B. Deep Excavations and Tunneling in Soft Ground. In: INTERNATIONAL CONFERENCE ON SOIL MECHANICS AND FOUNDATION ENGINEERING, 7, Mëxico, 1969. Proceedings ... México, Sociedad Mexicana de Mecänlca del Suelo, 1969. State of the Art Volume, p. 225-290. 
48 - PERLOFF, W.H. Pressure Distribution and Settlement. In: WINTERKORN, H.F. \& FANG, H.Y. ed. Foundatlon Engineering Handbook. New York, Van Nostrand Reinhold, 1975. Cap. 4, p. 148-196.

49 - PICHLER, E. Regional Study of the Solls from São Paulo, Brazil. In: INTERNATIONAL CONFERENCE ON SOIL MECHANICS AND FOUNDATION ENGINEERING, 2, Rotterdam, 1948. Proceedings ... Rotterdam, s.c.p. 1948. vol. 3, p. 222-226.

50 - PIECKERING, D.J. Anisotropic Elastic Parameters for Soll. Géotechnique $20(3): 271-276,1970$.

51 - PIPES, L.A. E HOVANESSIAN, S.A. Matrix Computer Methods In Engineering. New York, John WI ley, 1969.

52 - POULOS, S.J. Control of Leakage in the Triaxial Test. Harvard Soil Mechanics Series, (71) March, 1964.

53 - REMY, J.P. \& SZWARCBARG, M. Influência da Temperatura sobre as Cargas nas Estroncas duma Escavação do Metrô do Rio de Janeiro. In: CONGRES SO BRASILEIRO DE MECANICA DOS SOLOS, 5, São Paulo, 1974. Anais ... São Paulo, Associação Brasileira de Mecânica dos Solos, 1974. vol. 1, p. 309-322.

54 - RICHARDSON, J.R. A.M. \& WHITMAN, R.V. Effect of Strain-Rate Upon Undrained Shear Resistance of a Saturated Remoulded Fat Clay, Gēotechnique, 13 (4): 310-346, 1964.

55 - RICHART, F.E. et al. Vibrations of Soils and Foundations. New Jersey, Prentice Hall, 1970.

56 - RIOS, L. E PACHECo SILVA, F. Foundation In Dowtown São Paulo, Brazll. In: INTERNATIONAL CONFERENCE ON SOIL MECHANICS AND FOUNDATION ENGINEERING, 2, Rotterdam, 1948. Proceedings ... Rotterdam, s.c.p. 1948. v. 4, p. $67-92$. 
57 - RODRIgUEZ, J.M. \& Flammano, C.L. Strut Recorded In A Deep Excavation In Clay. In: INTERNATIONAL CONFERENCE ON SOIL MECHANICS AND FOUNDATION ENGINEERING, 7, México, 1969. Proceedings... México, 1969 , Sociedad Mexicana de Mecánica del Suelo. vol. 2, p. 459-467.

58 - RODRIGUEZ, J.M. \& PEREZ R.L. Deep Excavations And Tunneling in Soft Ground. In: INTERNATIONAL CONFERENCE ON SOIL MECHANICS AND FOUNDATION ENGINEERING, 7, México, 1969. Proceedings ... México, 1969, Sociedad Mexicana de Mecánica del Suelo. vol. 3, p. 370-373.

59 - ROSCOE, K.H. The Influence of Strains in Soil Mechanics: $10^{\text {th }}$ Rankine Lec ture. Géotechnique, 20 (2): 129-170, 1970.

60 - SHANNON, W.L. et al. Dynamic Triaxial Tests on Sand. In: PANAMERICAN CONFERENCE ON SOIL MECHANICS AND FOUNDATION ENGINEERING, 1, 1959. Proceedings ... 1959, vol. 1, p. 473-489, 1959.

61 - SIMONS, N.E. E SOM, N.N. The Influence of Lateral Stress on the Stress Deformation Characteristics of London Clay. In: INTERNATIONAL CONFERENCE ON SOIL MECHANICS AND fOUNdATION ENGineERING, 7, México, 1969. Proceedings ... México, Sociedad Mexicana del Suelo, $1969 . v$. 1. p. 369-377.

62 - SKEMPTON, A.W. \& WARD, W.H. Investigations Concerning Deep Cofferdam In the Thames Stuary Clay at Shellhaven. Géotechnique, 3 (3): 119139, sept., 1952.

63 - SODERMAN, L.G. \& KIM, Y.D. Fleld and Laboratory Studies of Modulus of Elasticlty of a Clay TIII. Highway Research Record, (243): 1-11, 1968.

64 - SOUSA PINTO, C. et al. Comportamento do Escoramento Numa Escavação do Metrô de São Paulo: Seç̧ão Experimental n: 1. Publicação do IPT n? $963,1972$. 
65 - SOUSA PINTÓ, C. et al. Aval lação das Cargas em Escoramentos, em Funçäo da Temperatura. In: CONGRESSO BRASILEIRO DE MECANICA DOS SOLOS, 5, Säo Paulo, 1974. Anals ... Säo Paulo, Associação Brasileira de Mecânica dos Solos, 1974, vol. 1, p. 151-164.

66 - SOUSA PINTO, C. E MASSAD, F. Características dos Solos Variegados da Cidade de São Paulo. Publicação do IPT n: 984, 1972.

67 - TEIXEIRA, A.H. Alguns Aspectos do Comportamento de Areias Argilosas de Baixa Compacidade como Apoio de Fundações. In: CONGRESSO BRASILEI RO DE MECANICA DOS SOLOS, 4, Rio de Janeiro, 1970. Anais... Rio de Janeiro, Associação Brasileira de Mecânica dos Solos, 1970, vol. 1, Tomo I, p. $v-29 / V-42$.

68 - TELLER, L.W. \& SUTHERLAND, E.C. The Structural Design of Concrete Pavements. Public Roads, 16 (9): 169-197, 1935.

69 - TERZAGHI, K. General Wedge Theory of Earth Pressure. Transactions American Society Civil Engineers. Vol. 106, p. 68-97, 1941.

70 - TERZAGHI, K. Evaluation of Coefficients of Subgrade Reaction. Géotechnique, 5 (4): 297-326, Dec. 1955.

71 - TERZAGHI, K. \& PECK, R.B. Soil Mechanics in Engineering Practice, New York, John Wiley, 1967.

72 - TIMONSHENKo, S.P. Resistência dos Materials. Rlo de Janeiro, Ao Livro Técnico, Tomo 1, 1958.

73 - VARgas, M. \& Bernardo, G. Nota Para o Estudo Regional do Solo do Cen tro da Cidade de São Paulo. Publicação do IPT n: 248, 1946.

74 - VARGAS, M. Bullding Settlement Observation in São Paulo. In: INTERNATIONAL CONFERENCE ON SOIL MECHANICS AND FOUNDATION ENGINEEAING, 2, Rotterdam, 1948. Proceedings ... Rot terdam, s.c.p. 1948, vol. 4, p. $15-21$. 
75 - VARGas, M. Problemas de Fundação de Edificios em São Paulo e Sua Re lação com a Formação Geolögica Local. Publicação do IPT n:514,1954.

76 - Vargas, M. Foundations of Tall Bulldings on Sand in São Paulo, Brazil. In: INTERNATIONAL CONFERENCE ON SOIL MECHANICS AND FOUNDATION ENG INEER ING, 5, Parls, 1961. Proceedings ... Paris, Dunod, 1961. v.1, p. 841-849.

77 - WARO, W.H. \& MARSLAND, A. Properties of London Clay as the Ashford Common Shaft: In-Situ and Undrained Strenght Tests. Géotechnique, 15 (4): $321-344,1965$

78 - WARD, W.H. et al. Further Studies of the Properties of London Clay. Géotechnique, 9 (2): 33-58, 1959.

79 - WeStergaARd, H.M. Analysis of Stresses in Concrete Pavements due to Variations of Temperature. In: Proceedings of Highway Research Board. p. 201-215, 1926.

80 - WESTLAKE, J.R. A Handbook of a Numerical Matrix Inversion and Solution of Linear Equations, New York, John Wiley, 1968.

-81 - WILKINSON, J.H. The Solution of 111 - Conditioned Linear Equations. In: Mathematical Methods for Digital Computers, New York, John Wiley, vol. 2, p. 65-93, 1968.

82 - WILKINSON, J.H. The Algebraic Elgenvalue Problem. London, Clarendon Press, 0xford, 1965.

83 - WILSON, E.L. Solld SAP: A Static Analysis Program for Three Dimensional Solid Structures. Denver Mining Research Center, U.S. Dept. of Interior. Bureau of Mines. Sept. 1971.

84 - WILSON, S.D. \& DIETRICH, R.J. Effect of Consolidation Pressure on Elastic and Strenght Properties of Clay. In: RESEARCH CONFERENCE ON 
SHEAR STRENGHT OF COHESIVE SOILS, BOULDER, COLORADO, 1960.

Proceedings ... Boulder, American Society Engineers, 1960. p. 419435.

85 - WROTH, C.P. \& BASSET, R.H. A Stress-Strain Relationship for the Shearing Behaviour of a Sand. Gëotechnique, 15 (1): 32-56, 1965.

86 - WROTH, C.P. General Theories of Earth Pressures and Deformations. In. EUROPEAN CONFERENCE ON SOIL MECHANICS AND FOUNDATION ENGINEERING, 5, Madrid, 1972-a. Proceedings ... Madrid, Sociedad Espanõla de Mecanica del Suelo y cimentaciones, 1972. vol. 2, p. 33-52.

87 - WROTH, C.P. Some Aspects of the Elastic Behaviour of OverConsolidated Clay. In: STRESS-STRAIN BEHAVIOUR OF SOILS: ROSCOE MEMORIAL SYMPOSIUM, Cambridge, 1971. Proceedings... London, G.T. Foulis, 1972-b. p. 347-361.

88 - ZIENKIEWICZ, 0.C. The Finite Element Method in Engineering Science. London, Mc Graw Hill, 1972. 


\section{CONSIDERAÇOESS QUANTO A PRECISAOO DAS CELULAS DE CARGA \\ E DOS PARES TERMOELETRICOS}

\section{INTRODUÇAOO}

A seguir serão discutidas algumas questões relativavas à precisão dos aparelhos de medida de maior relevância nesta Invest I gação, a saber, as células de Carga de Corda Vibrante e os Pares Termoelétricos.

Sempre que se julgar pertinente, serão feitas considerações quanto à influência das tëcnicas e dos erros de medida nos valores dos gradientes de carga-temperatura, tais como foram definidos no $\mathrm{Ca}$ pituro III.

2. PRECISÁO DE:MEDIDA DAS CELULAS DE CARGA DE CORDA VIBRANTE

\subsection{Precisão do aparelho em si}

O princípio de transdução da célula de carga (vide figura $A-1)$ consiste na transformação de variações de deformação de uma corda de aço especial, protendida com uma certa força inicial, em variações da sua frequência de ressonância. Em estado de repouso ou em vazio, a frequência de ressonância $\bar{e} L_{0}$; uma vez submetida a um esforço de compressão; a tensão na corda se reduz, o mesmo acontecendo com a frequência L. Sendo K o valor da constante do aparelho, è possivel determinarse a carga apllicada, atravēs da expressão: 

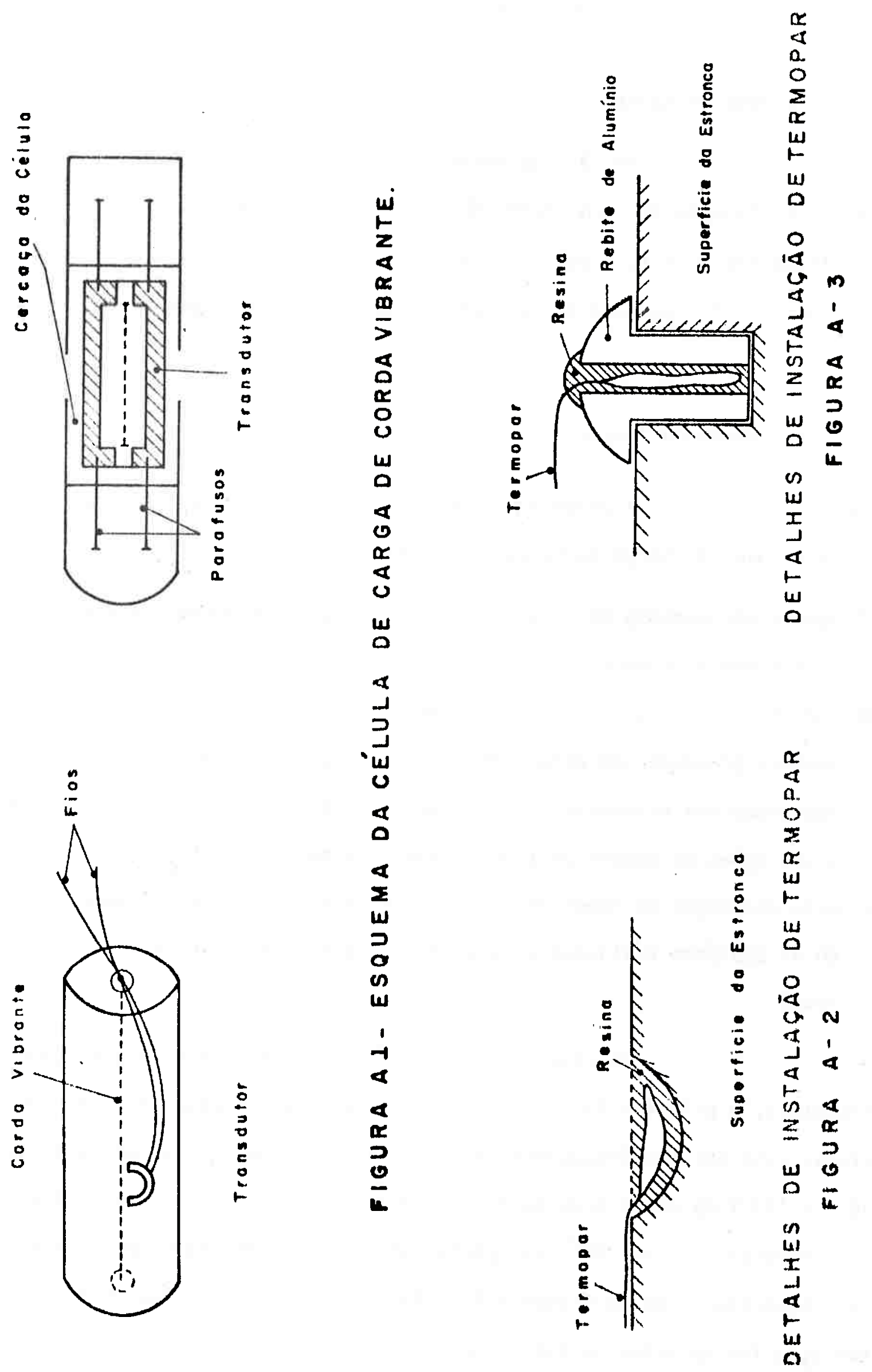


$$
C=K\left(L_{0}-L\right)
$$

onde $K$ è dada em $\mathrm{kg} / \mathrm{Hz}$.

As cêlulas usadas nas Secções Experimentais do Metrô de São Paulo eram do tipo Maihak MDS-636 com preclsão nominal de leltura da frequência de $1 \%$, o que faz com que o erro māximo de medida da carga seja de $2 \%$. Dispunha-se de células com capacidades mäximas de 25,50 e $100 \mathrm{t}$.

2.2. Influência da Temperatura no apare tho de medida

A temperatura pode interferir de trēs modos na leitu. ra de Células de Carga de Cordas Vibrantes:

a) iguais incrementos de temperatura na carcaça e na corda provocariam diferentes dilatações térmicas, se os materlais fossem diferentes;

b) a existência de gradientes de temperatura entre a carcaça e a corda podería provocar uma defasagem entre a carga lida e a carga. realmente instalada nas estroncas; ou, por outra, o tempo de resposta da célula a variações de temperatura do ar ambiente seria significativo; e

c) esta defasagem no tempo de resposta seria diferente se a temperatura do ar ambiente estivesse crescendo ou decrescendo (fenômeno de his terese).

No caso das células Maihak, usadas nas Seç̧ões Experimentais, a primeira fonte de erro inexiste, pois os materiais são i dên ticos. Is to fol confirmado atravēs de experimentação, em que células de 25 t e 100 t de capacidade mäxima foram observadas em vazio, em diversas temperaturas, até $60^{\circ} \mathrm{C}$ em estufa, tendo sido constatado um desvio na frequêncla $L_{0}$ de no mäximo $0,8 \%$. Em termos de cargas, nas de $100 \mathrm{t}$ a variação fol da ordem de $0,5 \mathrm{t}$; nas de $25 \mathrm{t}, 0,18 \mathrm{t}$. 


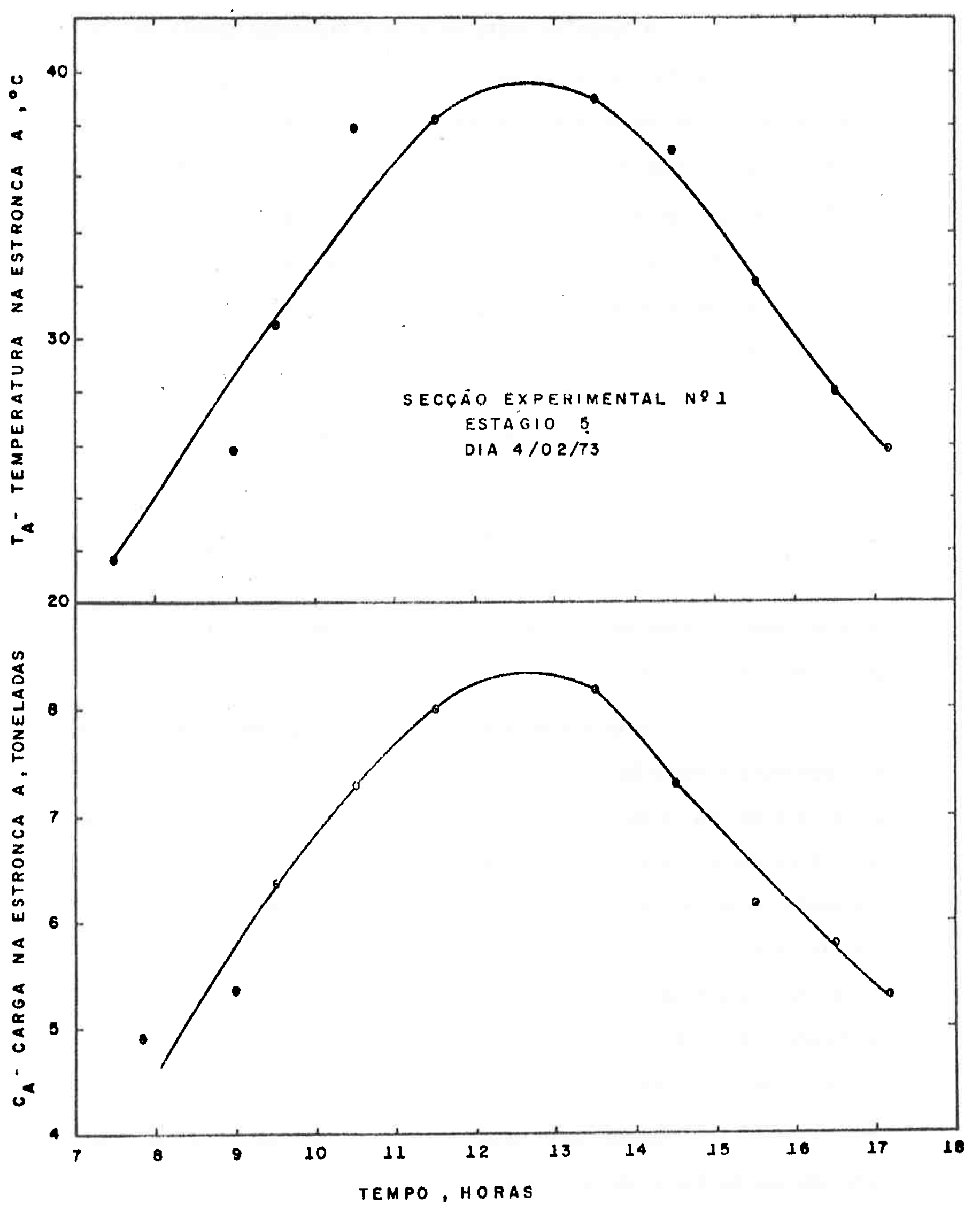

FIGURA A-4: INEXISTÉNCIA DE FENÔMENOS DE HISTERESE NA RESPOSTA DE CELULAS DE CARGA MAIHAK, DEVIDO A VARIAGŌES DE TEMPERATURA. 
A terceira fonte de erro (histerese) tambëm pode ser descartada, pela anällse da figura $A-4$, referente ao estägío 5 da Secção Experimental 1, em que só havia uma estronca instalada (ver figura B-3). A simetria das curvas de carga ou temperatura em funçāo do tempo são pro va disso. Ou, por outra, as correlaçöes carga-temperatura apresentam um desvio de $\pm 0,5 \mathrm{t}$, para $98 \%$ de grau de confiança, sem fazer distinção entre os ramos ascendente ou descendente das curvas em função do tempo. As correlações obtidas foram:

$$
c_{A}=1,1+0,172 T_{A}(r=98 \%)
$$

e

$$
C_{A}=0,9+0,170 T_{A}(r=99 \%)
$$

para os ramos ascendente e descendente, respectivamente; $r$ é o coeficiente de correlação da regressão.

Resta o problema do tempo de resposta da célula. Se a temperatura externa (da carcaça)estivesse aumentando e fosse maior do que a interna (da corda), a carga lida seria inferior à realmente instalada na estronca. Inversamente, se a temperatura externa estivesse decrescendo, a carga lida seria maior do que a real. Isto equivaleria a transladar a curva de carga lida-tempo para a esquerda, para se obter a curva real, o que não pode ser feito no caso dos resultados apresentados na figura $A-4$, pois a máxima temperatura e a máxima carga ocorreram praticamente ao mesmo tempo.

Assim, pelo menos para fins präticos, os erros envolvidos são bastante pequenos e despreziveis face a outros, a serem dís cutldos a seguilr, consequência do processo de medida das temperaturas. 
va carga real-tempo seria aproximadamente paraleza à lida, o que manteria os valores dos gradientes de carga-temperatura praticamente invarian tes.

A malor fonte de erro está realmente em variações bruscas da temperatura da carcaça da cēlula, tanto para mals (incidência direta de ralos solares, por exemplo), como para menos (chuvas de verão, rápidas e intensas ao mesmo tempo, ou passagem de uma nuvem, encobrindo repentinamente o sol). Tais eventos podem provocar grandes gradientes térmicos de uma forma não homogēnea na carcaça, gerando respostas das mais variadas possiveis. Para evitar estas mudanças bruscas de temperatu彑 ra, as células foram protegidas contra a incidência direta dos raios solares. Uma melhoria desta proteção poderia ser conseguida com o auxílio de placas de isopor, de $2 \mathrm{~cm}$ de espessura, revestindo internamente uma caixa metälica.

2.3. Influência da migidez das cétulas de carga

As células de carga utilizadas tinham comprimento mäximo de $27 \mathrm{~cm}$ e rigidez variando de 15 a 20 vezes a de uma estronca constituída de perfis $2112^{\prime \prime}$, com $12 \mathrm{~m}$ de comprimento, usualmente empre gadas nas valás escoradas do Metrô de são Paulo.

Nestas condições, pode-se provar que uma estronca apolada em cêlula de carga numa de suas extremidades possui rigidez de 5 a 7 \% inferior à de uma outra não instrumentada. Como consequência ocorrem fenômenos de arqueamento no solo com redistribuição das cargas transmitidas às estroncas, mas de pequena monta.

De fato, considere-se, para simplificar a anālise, um plano associado a um nivel de estroncamento. Imagine-se o quadro formado por diversas estroncas apoiadas em vigas de distribulção, ou vigas 
de rigidez, carregadas uniformemente com certa pressão. Suponha-se que apenas duas estroncas adjacentes sejam instrumentadas.

A aplicação do cālculo matricial de estruturas ao quadro assim idealizado conduziu a reduçōes māximas de $2,5 \%$ nas cargas das estroncas instrumentadas, referenciadas às cargas que ocorreriall se não existissem os instrumentos de medida. As estroncas vizinhas, não ins trumentadas, apresentaram acréscimos de carga da mesma ordem de grandeza. Os valores encontrados são os mäximos para espaçamentos entre estroncas variando de 2 a $3 \mathrm{~m}$, em planta. Este percentual subiria para $3,5 \%$ se a rigidez do conjunto estronca-cēlula de carga fosse $10 \%$ menor do que a de uma outra adjacente, não instrumentada.

\section{PRECISÃO NAS MEDIDAS DA TEMPERATURA}

\subsection{Erros inerentes à pröpria técnica de medida}

Os termo-pares usados eram constituídos de junções de cobre-constantan, tipo $T$, e as leituras eram feitas com uma ponte potenciométrica, balanceada em um galvanômetro. Uma vez atingido o ponto de equilíbrio do galvanōmetro, tinha-se uma mili-voltagem que, pela tabe la de conversão, indicava a temperatura.

A instalação, regra geral, era feita puncionando-se a superfície da estronca e colocando-se na cavidade a junção embebida e recoberta com resina. A seguir nivelava-se a superfície. Este processo, indicado esquematicamente na figura $A-2$, é räpido e de boa durabllidade; - termopar fica protegido pela camada superior da resina e eletricamente isolado, medindo-se a temperatura na superficie da estronca, com um erro de $\pm 0,5^{\circ} \mathrm{C}$. Um outro processo alternativo consistiu em introduzir na estronca um rebite de alumínio, vazado longitudinalmente, e onde se alo- 


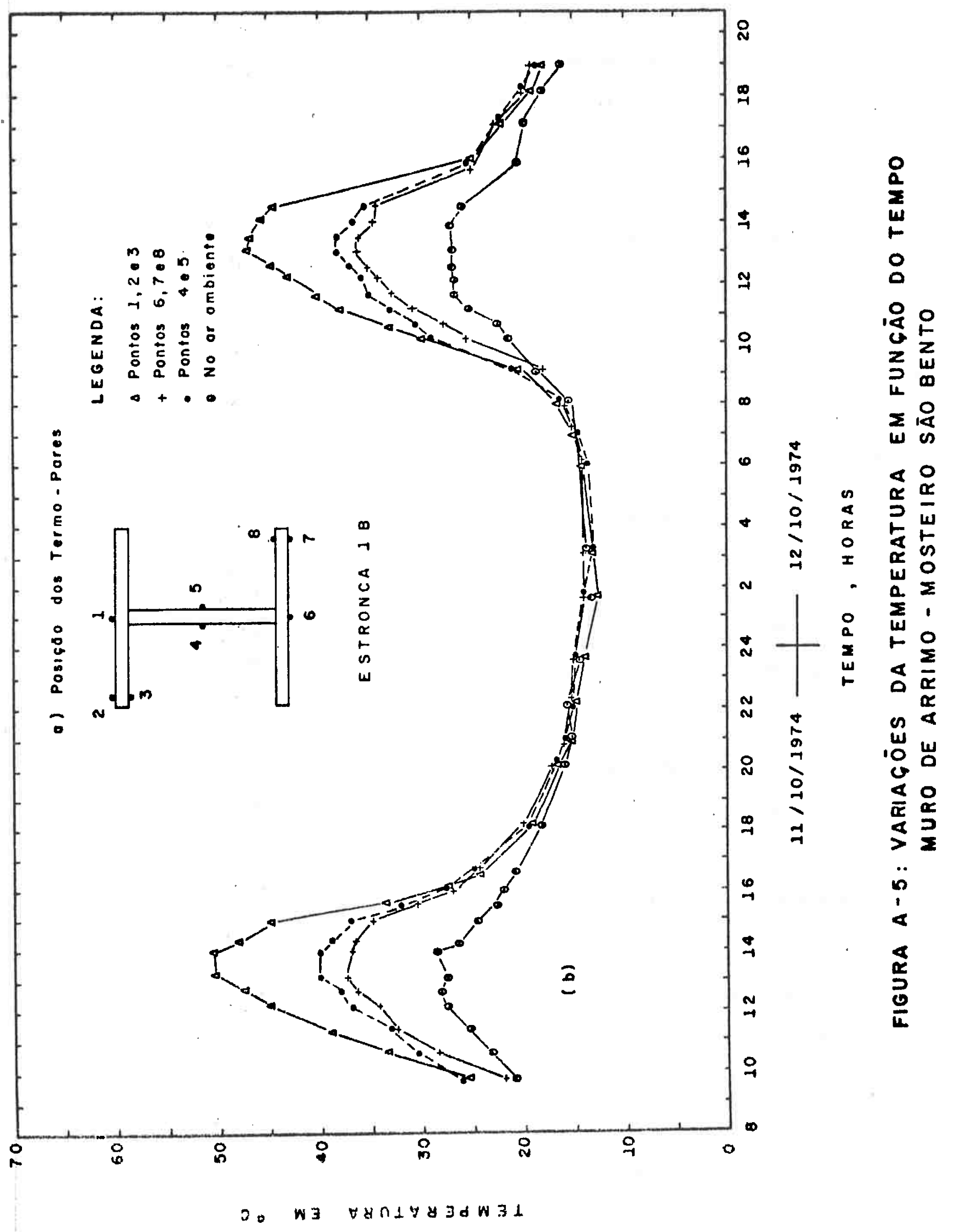


java a junção embebida e recoberta com resina, conforme llustrado na figura $A-3$.

0 uso de potenciômetro tornou a operação de leitura lenta e dispendiosa, mas teve-se a garantla de precisão. E isto porque ẽ mais fäcil de se detectar erros devidos a contatos elëtricos mal feitos, pelo balanceamento do galvanômetro, que se torna instävel quando o termo-par é tocado com as mãos. Finalmente, um outro cuidado refere-se ao uso de cabos, fios, ou conectores, em caixas seletoras (potenciómetros) apropriadas, pois, caso conträrio, os erros relativos podem ser elevados. Neste sentido, o ideal, econômica e tecnicamente, é utilizar fio de compensação (Cobre e Constantan) para levar o sinal elétrico do termopar ao apare lho de medida.

3.2. O que è a temperatura de uma estronca?

Considere-se os dados apresentados na figura A-5. Trata-se de medidas de temperatura em diversos pontos de uma secção de estronca, um perfil $\mathrm{H}$ com espessura de $25,4 \mathrm{~mm}$, largura da mesa de $347 \mathrm{~mm}$ e al tura de $344 \mathrm{~mm}$.

Vê-se que a temperatura na mesa superlor chega a ser $12,5^{\circ} \mathrm{C}$ malor do que na Inferior. Ademais, no centro da estronca (pontos 4 e 5 da figura $A-5 a$ ) a temperatura atinge valores até $4^{\circ} \mathrm{C}$ abaixo da média entre as temperaturas das mesas superior e inferlor.

Outro fato interessante que se depreende da anälise destes resultados é que durante a noite a estronca entra em equilíbrio tërmico com o meio amblente, confirmando o bom senso de eliminar-se o efeito da temperatura lendo-se as cargas de manhã, antes que o sol apare ça.

Finalmente, entre os pontos de medida 1,2 e 3 da me 


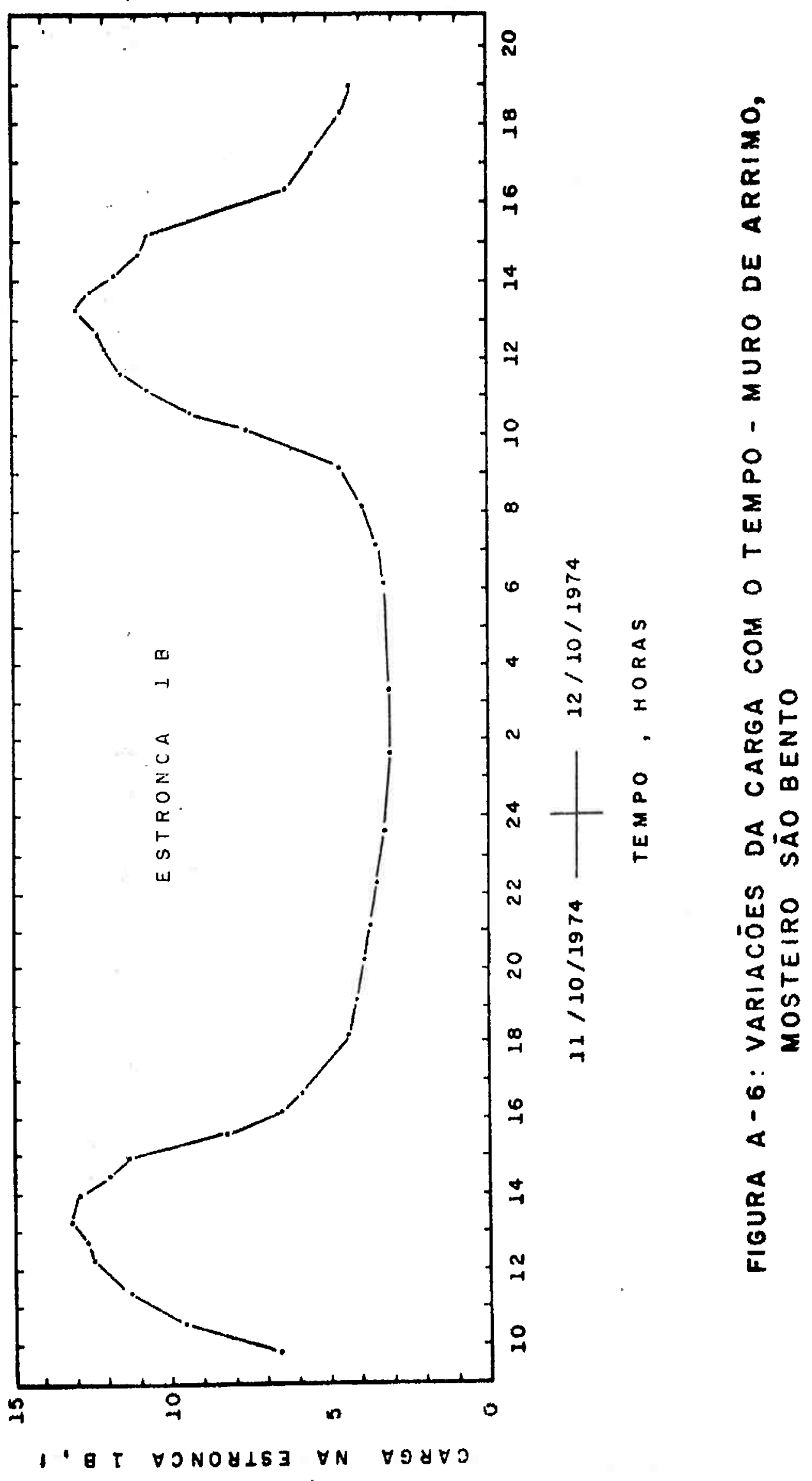


sa superlor (figura $A-5 a$ ) a mäxima diferença entre-as temperaturas foi de $1,5^{\circ} \mathrm{C}$; para os pontos 6,7 e 8 , fol de $2^{\circ} \mathrm{C}$; e para os pontos 4 e 5 , $1^{\circ} \mathrm{C}$

A figura A-6 mostra varlaçōes de carga na mesma estronca observadas nos dias 11 e 12/10/1974, em função do tempo. Supondo que a cēlula de carga se apolava no centro geomëtrico da sua secção trans versal, a temperatura a conslderar na determinação dos gradientes de car ga-temperatura é $T^{\prime}$, mëdla dos pontos 4 e 5 . A correlação estatística ob tida fol:

$$
\left.C=-4,90+0,45 T^{\prime} \quad \text { (coeficiente de correlação }=97 \%\right)
$$

para os 13 pontos compreendidos entre as 09:50h e 18:10h do dia $11 / 10 /$ 1974.

Se se tivesse tomado como temperatura da estronca a mëdia T" entre as temperaturas das mesas superior e inferior, ter-se-ia obtido:

$$
C=-2,60+0,36 \text { T' (coeficiente de correlação }-99 \% \text { ) }
$$

e o erro no valor do gradiente sería da ordem de $20 \%$, para menos.

No caso de perfis duplo 1, soldados, que foram os ut llizados nas Secções Experimentais do Metrô de São Paulo, a situação è diferente. Como existe uma chapa na extremidade da estronca em contacto com a célula de carga, tem sentido tomar-se a medila entre as temperaturas das abas superior e inferior como representativa de sua temperatura.

Diversas verlficaçōes de temperatura foram feitas pe los dois processos, tanto no campo como no laboratörio, tendo-se consta- 


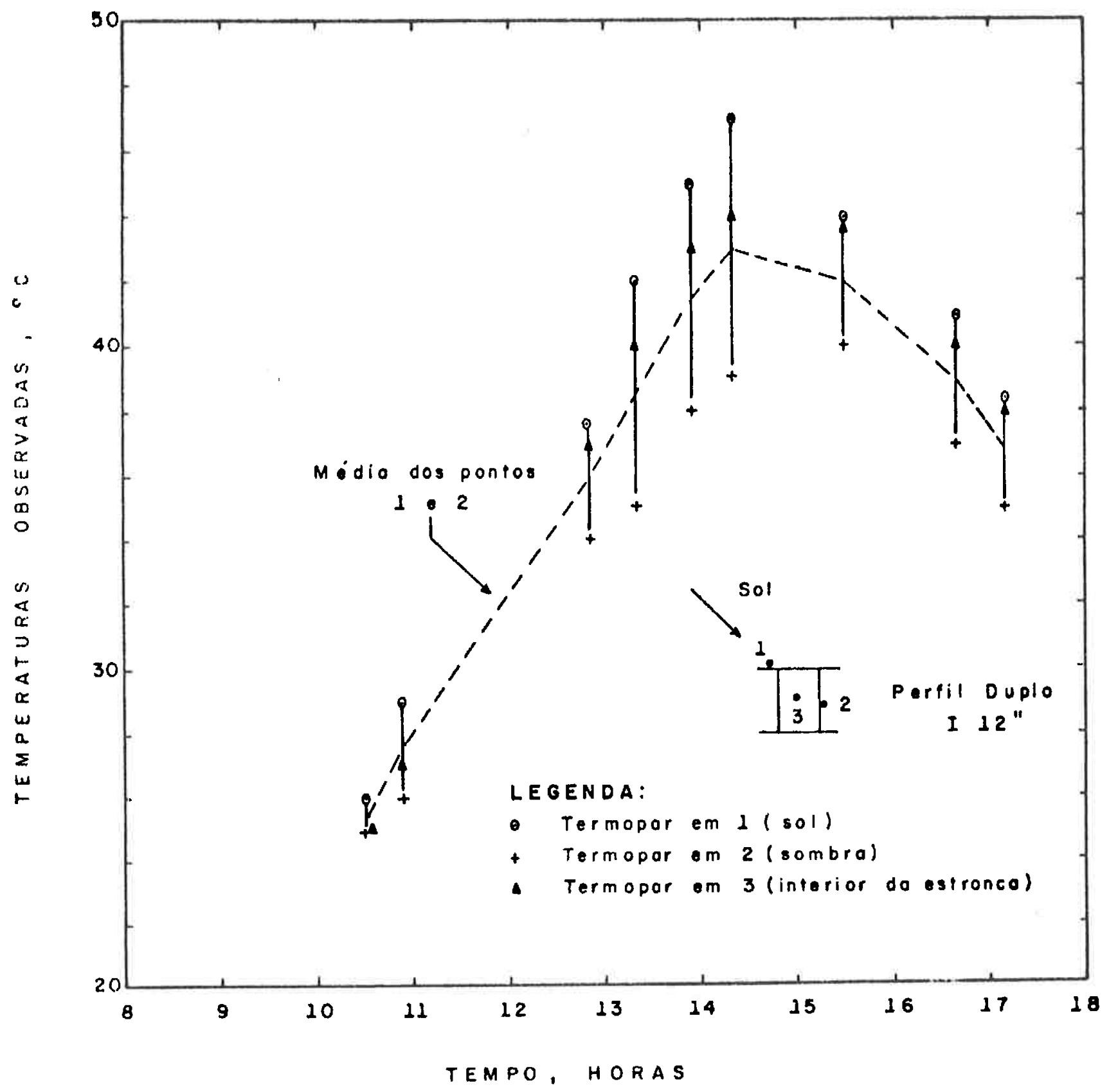

FIGURA A-7: MEDIDAS DE TEMPERATURAS FEITAS NUM PERFIL DUPLO I 12 " 


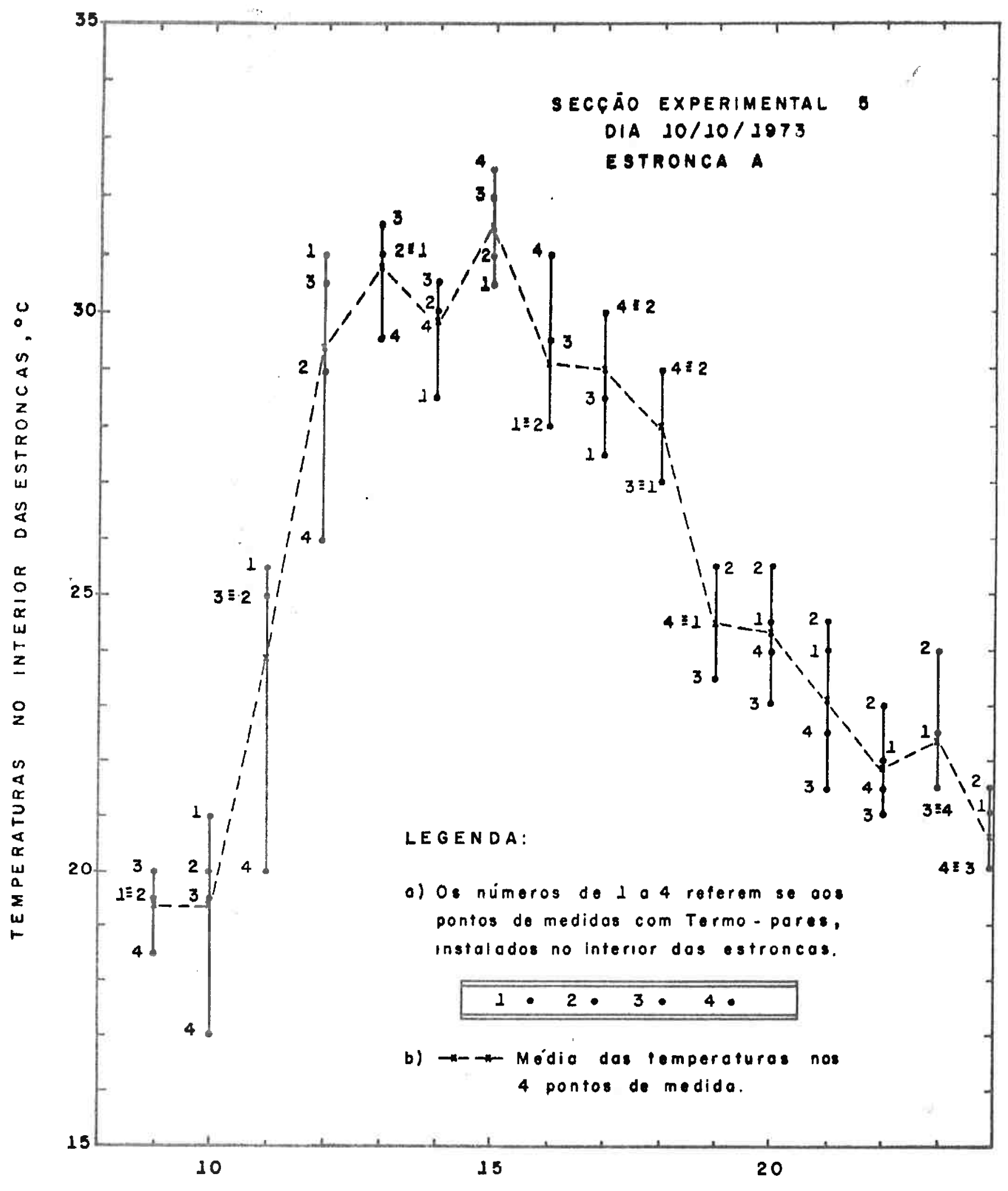

TEMPO, HORAS

FIGURA A-8: MEDIDAS DE TEMPERATURAS FEITAS NO INTERIOR DE UM PERFIL DUPLO I 12 ", AO LONGO DE SEU COMPRIMENTO. 


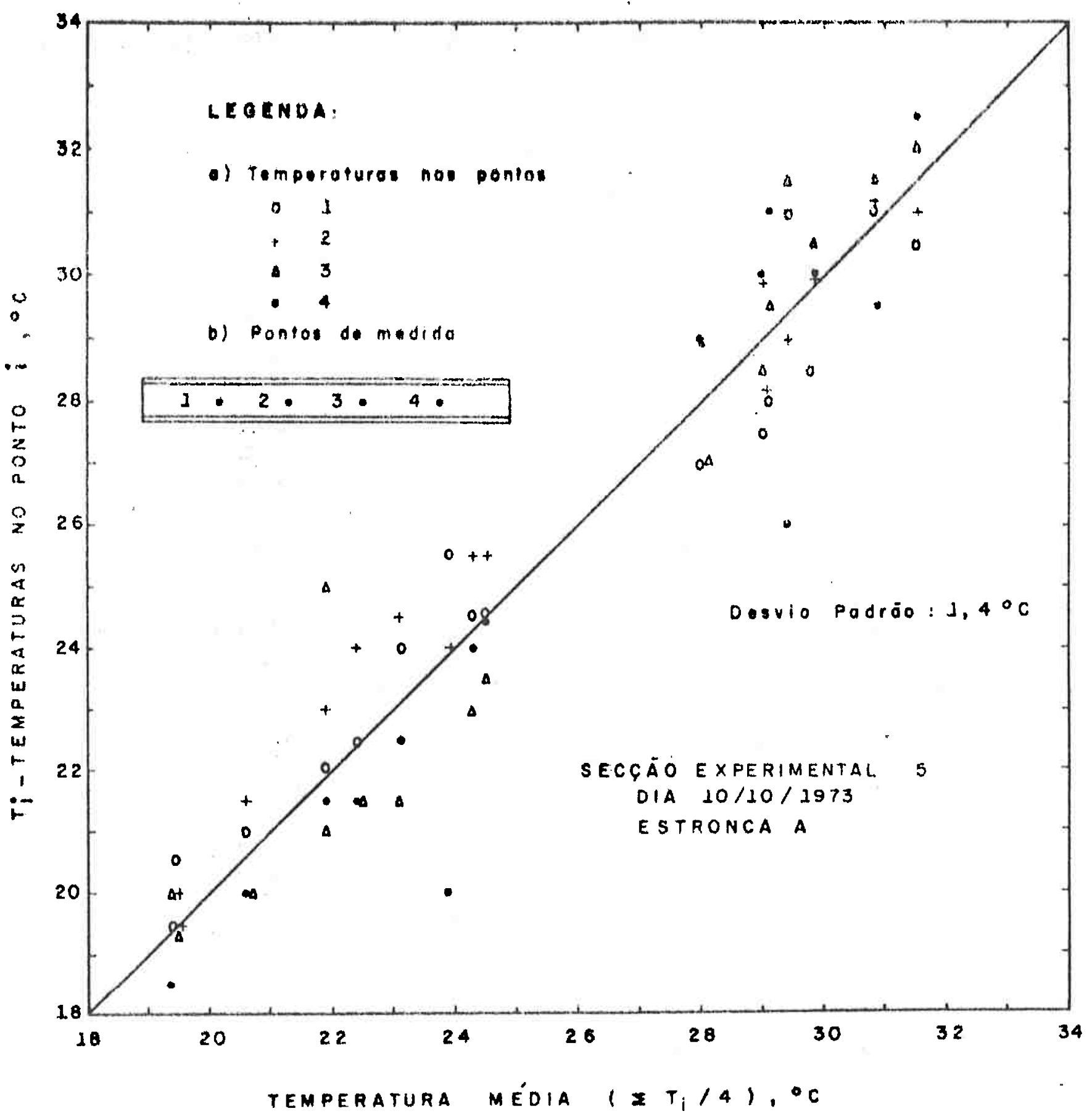

FIGURA A-9: CORRELACÁO ENTRE A MÉdia dAS TEMPERATURAS, MEDIDAS EM QUATRO PONTOS NO INTERIOR DE UMA ESTRONCA ( 2 I 12"), AO LONGO DE SEU COMPRIMENTO, E AS TEMPERATURAS EM CADA UM DESTES PONTOS. 
tado que a temperatura do ar no Interlor das estroncas era sempre pröxima à mëdia das temperaturas nas suas mesas superior (eventualmente expos ta aos raios solares) e inferior (à sombra). Por exemplo, a figura $A-7$ mostra resultados de medidas com pares termo-elétricos das partes sob in cidēncla direta dos raios solares (ponto 1); à sombra (ponto 2) e no interior (ponto 3) da estronca, um perfil duplo I 12". Depreende-se de sua anälise que a mëdia das temperaturas sombra-sol é, em mēdia, cerca de $1^{\circ} \mathrm{C}$ inferior à temperatura medida no interior da estronca.

Adotaram-se, portanto, as temperaturas do ar no inte rior da estronca como representativas da sua temperatura média. Por outro lado, foi decidido que a temperatura no interior da estronca seria medida em diversas posições ao longo de seu comprimento, pois, eventualmente, uma parte da estronca está exposta ao sol enquanto a outra se encontra à sombra. A média destes valores seria mais representativa da tem peratura média da estronca. De fato, experimentações feitas no campo na Secção Experimental 5, e apresentadas graficamente nas figuras $A-8$ e $A-9$ mostram que a partir das $10 \mathrm{~h}$, com os raios solares incidindo na região em que foi instalado o Termo-par n: 1, a temperatura era até $5^{\circ} \mathrm{C}$ superior à da extremidade oposta, que se encontrava à sombra; por volta das $15 \mathrm{~h}$, a situação se invertia com diferenças de atē $2^{\circ} \mathrm{C}$. A correlação apresentada na figura $A-9$ possui desvio padrão de $1,4^{\circ} \mathrm{C}$. 


\section{APENDICE B \\ DESCRIÇAO DETALHADA DAS CARACTERTSTICAS DAS SECÇOES \\ EXPERIMENTAIS DO METRO DE SAOO PAULO}

As caracteristicas das diversas Secções Experimentais são, a seguir, apresentadas detalhadamente nos seguintes aspectos: Zocalização; sub-solo; escavação e escoramento; e instrumentação instalada.

\section{SECÇÃO EXPERIMENTAL N: 1}

\section{1. Localização}

A Secção Experimental n? I se situava na Avenida Jaba quara, em frente ao edificio de nümero 2065, no trecho 6 da linha NorteSul do METRO. A locallzação da Secção estä indicada na figura B-1. Os tra balhos, nesta Secção, se desenvolveram de 1 de dezembro de 1970 a 4 de ou tubro de 1971.

\subsection{Sub-8olo}

O sub-solo no local da Seç̧ão Experimental era constituido de uma argila porosa vermetha, com cerca de $10 \mathrm{~m}$ de espessura, sobrejacente a uma argila rija variegada. Na figura B-2 estão reproduzidos os dados de uma sondagem executada nas proximidades.

\subsection{Escavação e escoramento}

A escavação no local atinglu uma profundidade de $8,9 \mathrm{~m}$, desenvolvendo-se, portanto, totalmente na camada de argila porosa. 0 escoramento empregado fol constituido de estacas metāllcas cravadas a cada 


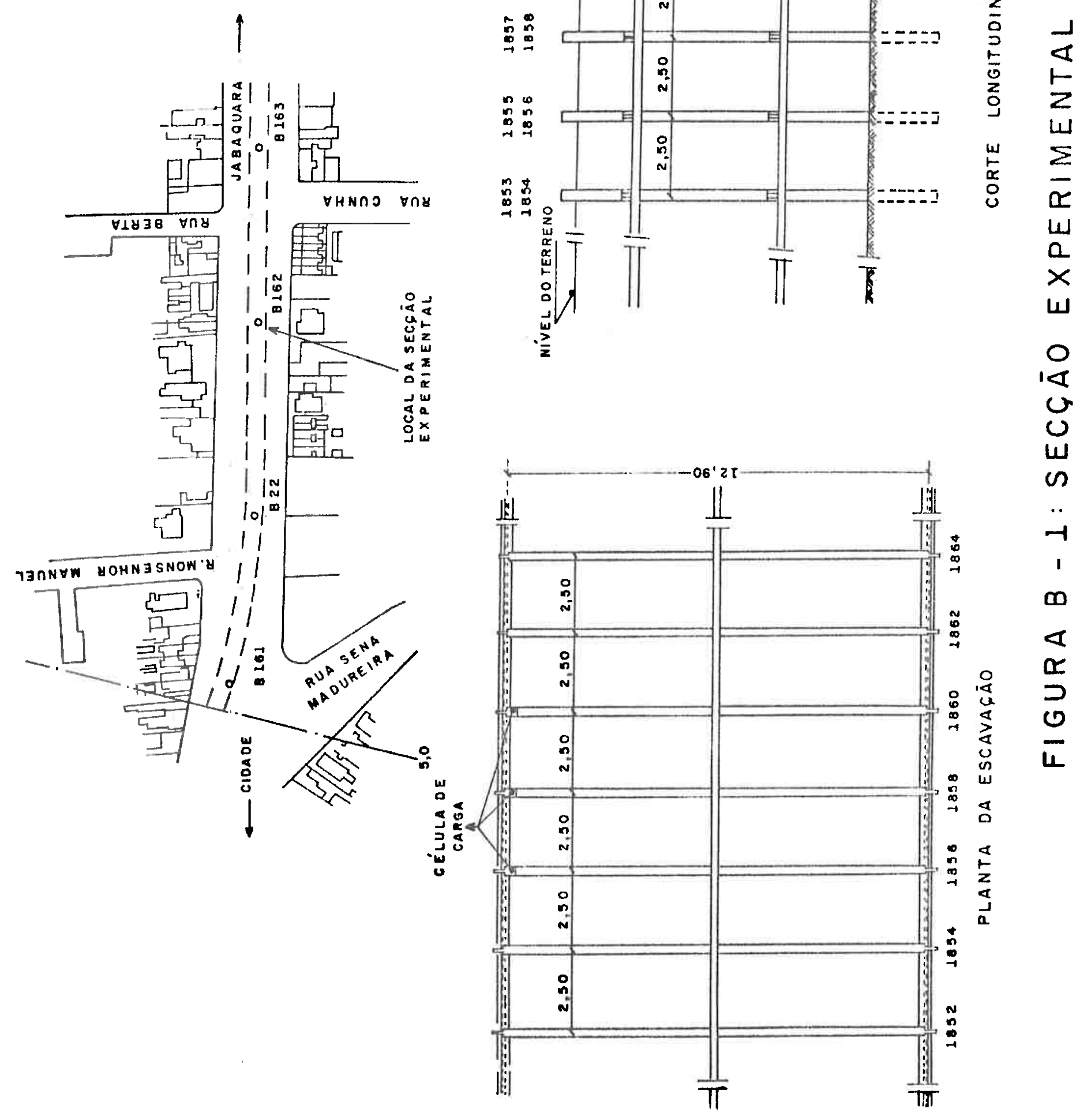




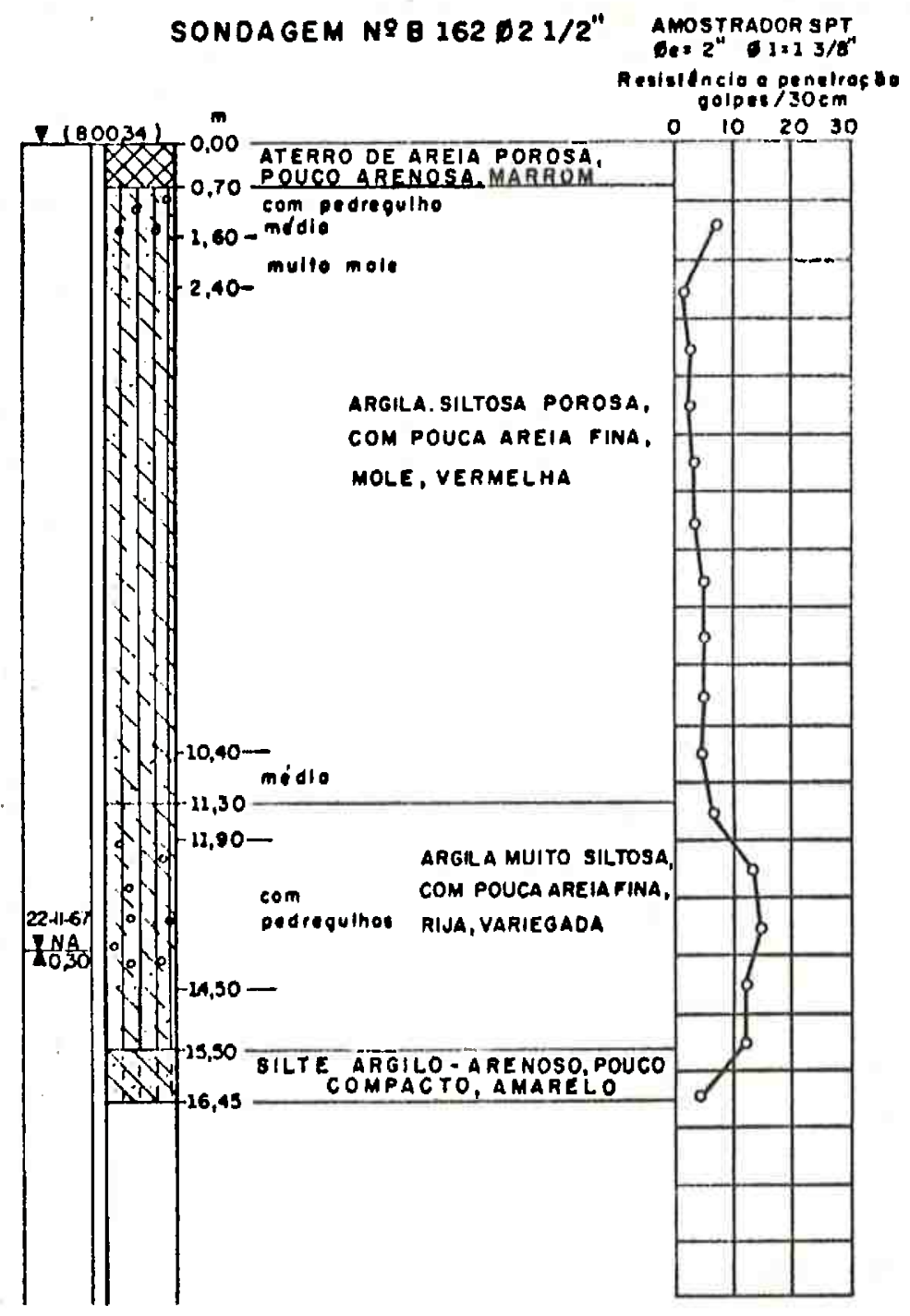

FIGURA B- 2 SECGĀO EXPERIMENTAL N 1 

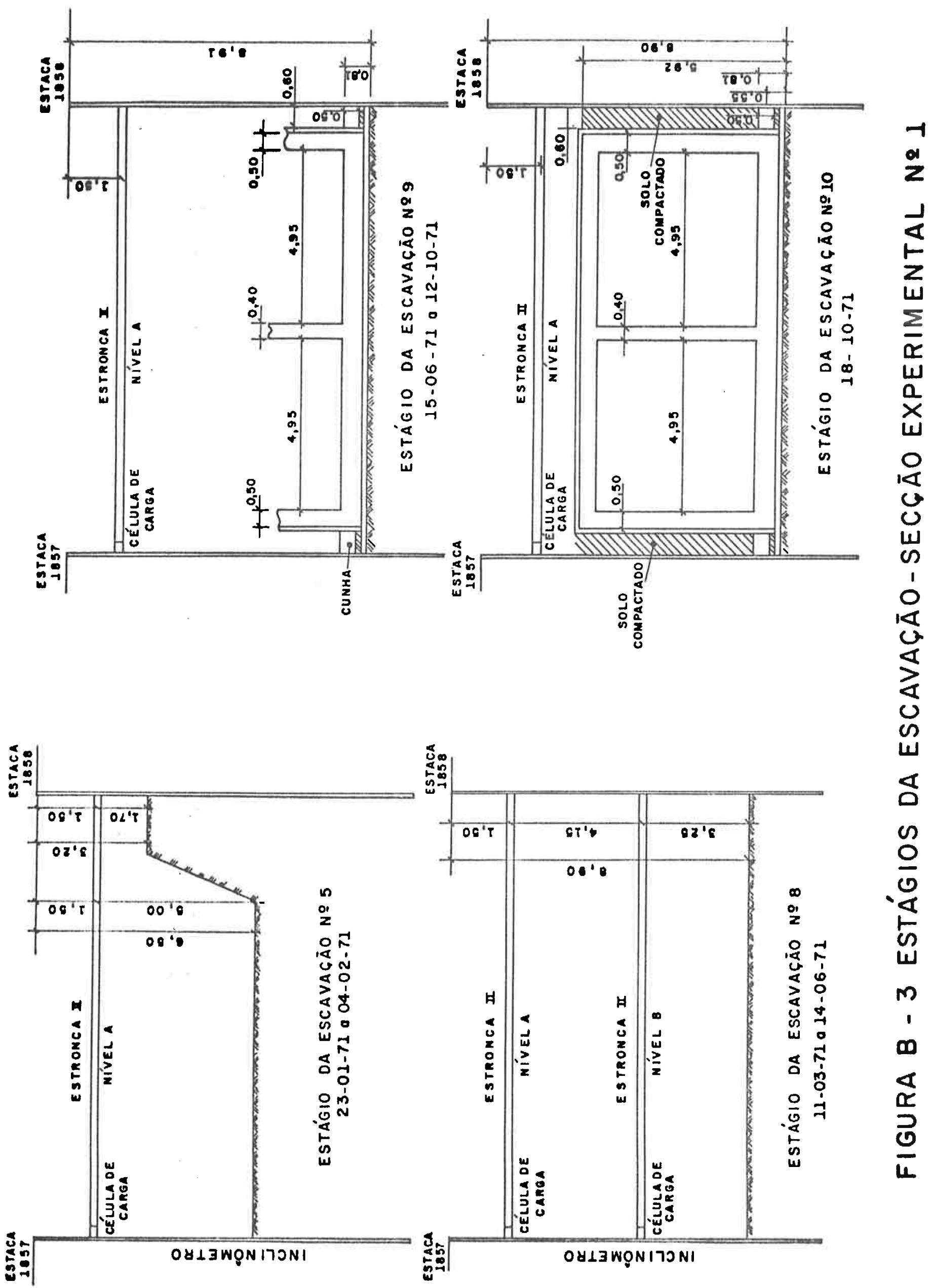
2,5m longitudinalmente, escoradas transversalmente por estroncas metálicas, em dois niveis distintos. Na figura $B-1$ estão representadas a planta e a seç̧ão longitudinal da escavação e do sistema de escoramento. Pranchōes de madeira, fixados em estacas contíguas, completavam o sistema de escoramento.

Para a análise dos resultados, no desenrolar deste tra balho, interessam os estägíos 5,8 e 9 da escavação, indicados graficamen te na figura $B-3$.

\subsection{Instrumentação}

a) Um tubo de inclinometro Wilson fol colocado no interior da estaca 1857, previamente limpa, e o espaço entre ele e a estaca fol preenchido com arela compactada.

b) Seis células de carga de corda vibrante, colocadas entre as estroncas e as estacas metālicas 1855, 1857, 1859, nos dois niveis de estroncas. Estas estacas foram designadas pelos nümeros 1,11 e 111 , referindose às estacas 1855,1857 e 1859, respectivamente, seguidas das letras A, para as do nivel superior, e da letra B, para as do nivel inferior.

c) Pares termo-elétricos, para medida das temperaturas, nas seis estroncas cujas cargas foram medidas. Estes pares foram colocados na parte superior e na parte inferior das estroncas, adotando-se a média dos va lores como representativa da temperatura das estroncas.

d) Referência na cabeça da estaca 1857 para medida de seus deslocamentos horizontais, que foram obtidos por levantamento topogräfico.

2. SECÇÃO EXPERIMENTAL N: 6

2.1. Localização

A Seç̧ão Experimental n: 6, situava-se na Rua Ver- 


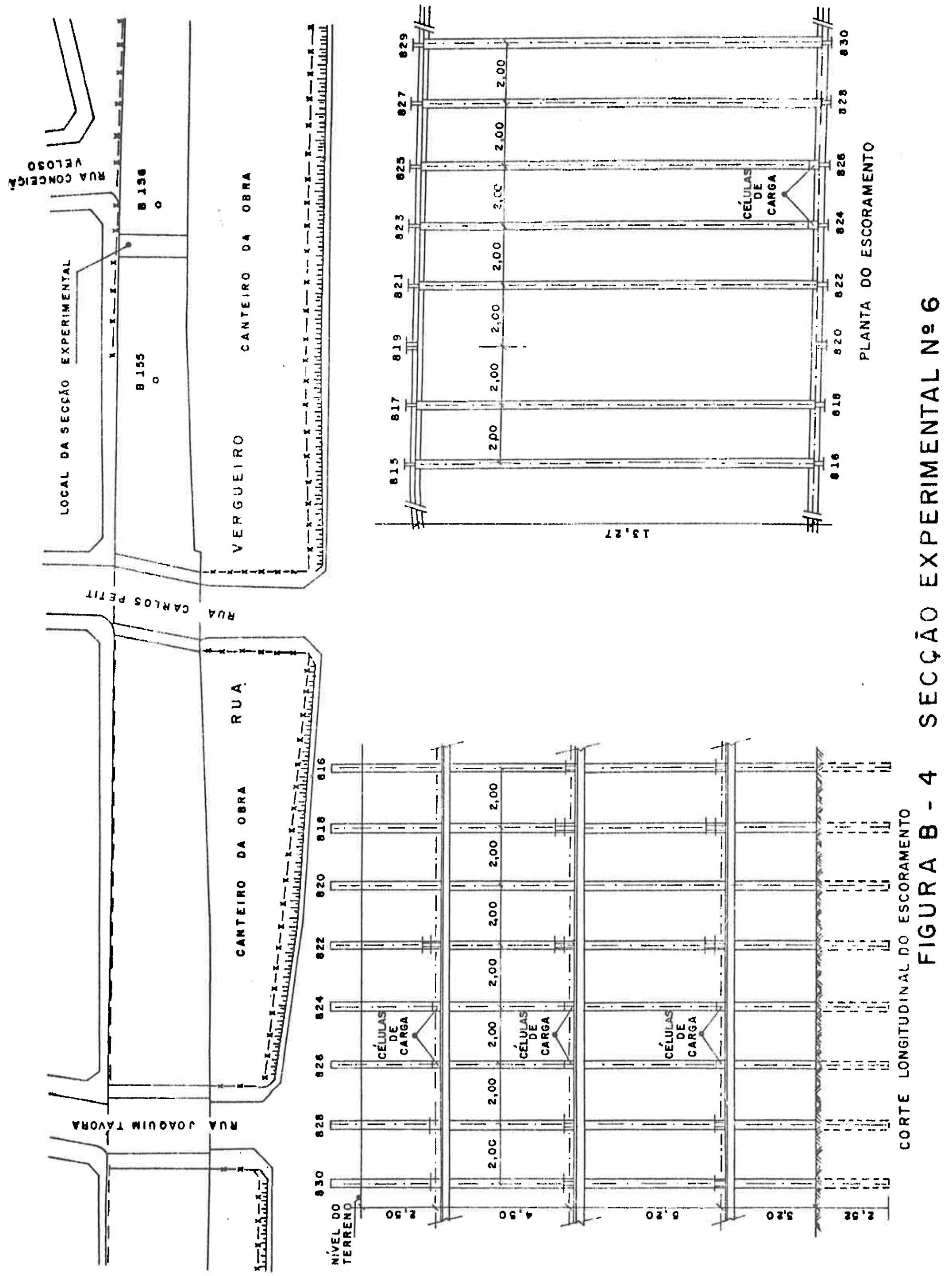



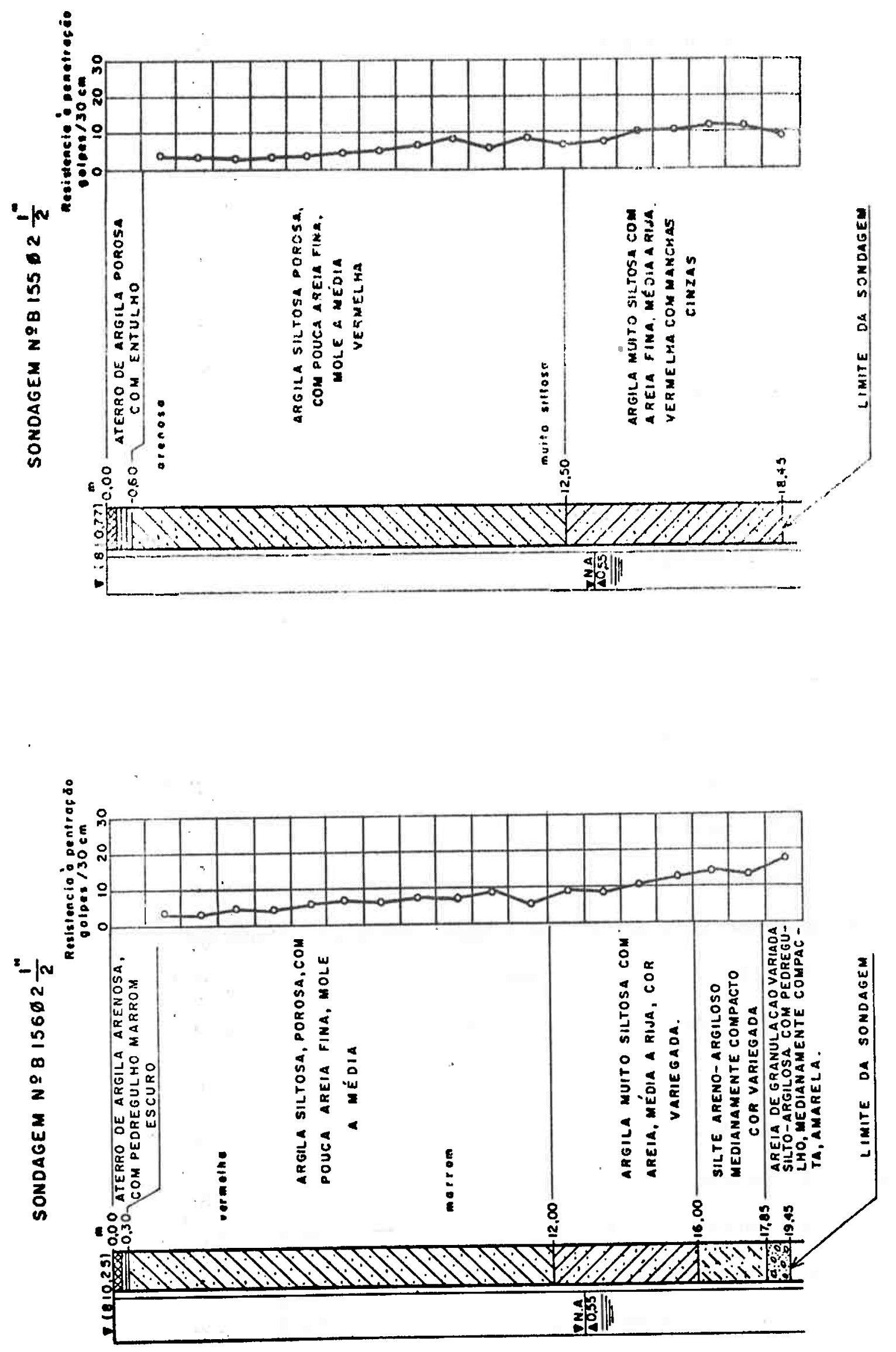

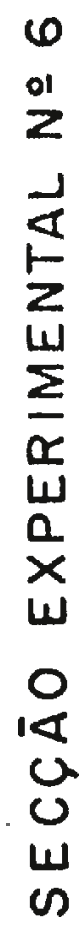

n

1
0
$\square$
$\frac{1}{2}$
$\frac{0}{4}$ 
gueiro, pröximo à Rua Conceição Veloso, no Trecho 6 da linha Norte-sul do METRO. A localização da Secção estã indicada na figura B-4. Os trabalhos, nesta Secção, se desenvolveram de 15 de novembro de 1971 a 11 de outubro de 1972.

2. 2. Sub-solo

O sub-solo no local da Secção Experimental era constituido de uma argila porosa vermetha, com cerca de $12,5 \mathrm{~m}$ de espessura, sobrejacente a uma argila rija variegada. Na figura B-5 estão reproduzidos os dados de duas sondagens realizadas nas proximidades, conforme loca ção indicada na figura $B-4$.

\subsection{Escavą̧ão e escoramento}

A escavação no local atingiu a profundidade de $15,4 \mathrm{~m}$, desenvolvendo-se, portanto, em cerca de $12,5 \mathrm{~m}$ de arglla porosa e $2,9 \mathrm{~m}$ na argila rija subjacente (pressão de prë-adensamento da ordem de $7,6 \mathrm{~kg} / \mathrm{cm}^{2}$ ). 0 escoramento empregado foi constituido de estacas metälicas, dois perfis 1 de $12^{\prime \prime}(60,6 \mathrm{~kg} / \mathrm{m})$ soldados, cravados a cada $2,0 \mathrm{~m}$ longl tudinalmente. As estacas eram escoradas transversalmente por estroncas metälicas constituídas de dols perfis 1 de $12^{\prime \prime}(60,6 \mathrm{~kg} / \mathrm{m})$ soldados, dispostos em três niveis, a $2,5 \mathrm{~m}, 7,0 \mathrm{~m}$ e $12,2 \mathrm{~m}$. Pranchões de madeira, com $10 \mathrm{~cm}$ de espessura, encunhados em estacas contíguas, completavam o sistema de escoramento.

Na figura $B-4$ estäo representadas a planta e um corte longitudinal do escoramento na região. As seç̧ões observadas foram as cor respondentes aos pares de estacas 823-824 e 825-826. Observa-se que numa secção pröxima, correspondente às estacas 819-820, não foram colocadas estroncas, para facilidade de remoção do material, ficando as secções a ela vizinhas com duas estroncas em cada nivel. 


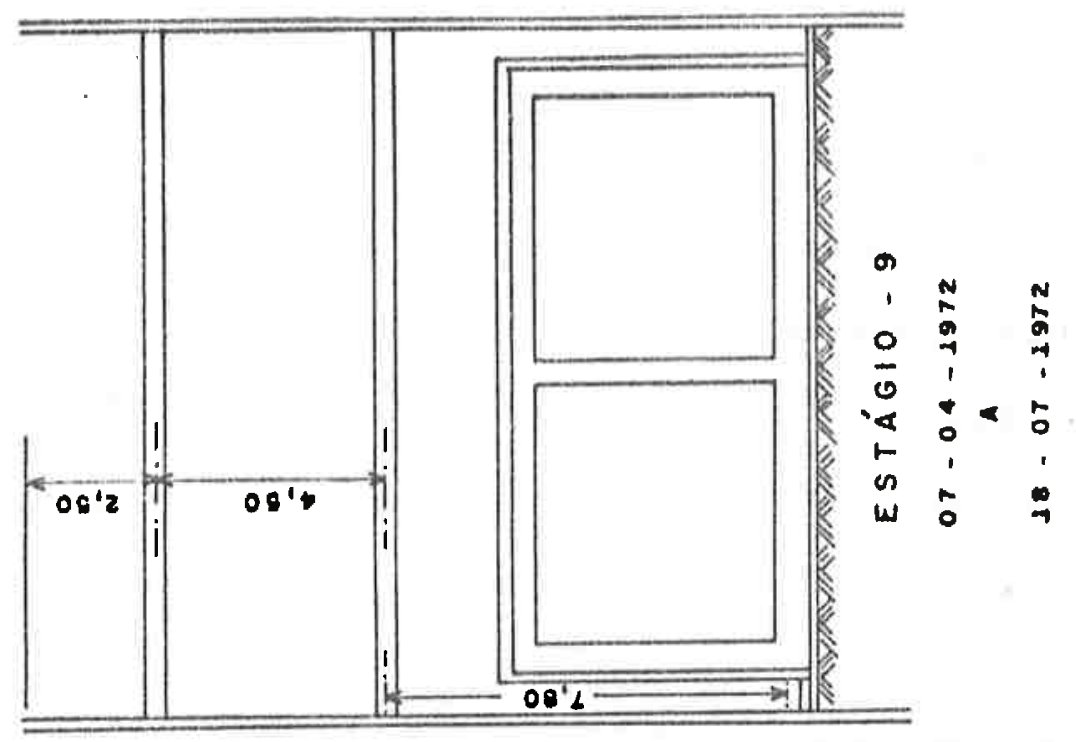

0
에

$\frac{1}{4}$
$\frac{2}{w}$
$\frac{1}{\alpha}$
$w$
$\frac{1}{x}$
$w$

0

U.

w

0

3

$z$

0

N

w

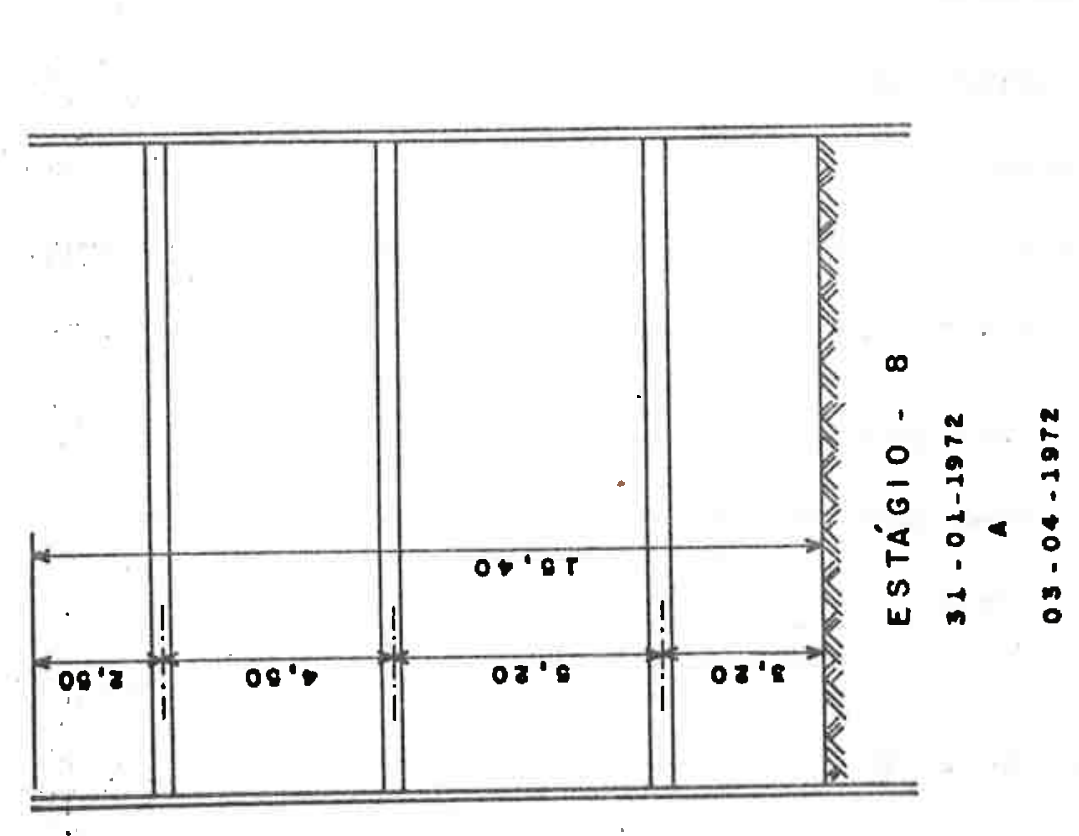

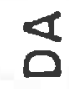

o

$\frac{0}{6}$

$-2$

穴

山

6

1

$\infty$

$\frac{a}{0}$ 
Os trabalhos de escavação desenvolveram-se em diversos estägios, sendo que os de n? 8 e 9 estão graficamente indicasos na figrma $B-6$.

\subsection{Instrumentação}

a) Nas estacas 825 e 826 de uma mesma secção foram colocados tubos de inclinometro Wilson. Os tubos foram colocados no interior das estacas, previamente limpas, e o espaço entre o tubo e a estaca foi preenchido com areía compactada.

b) Entre as estroncas das duas secções de observação e as estacas 824 e 826 foram colocadas as céluzas de carga de corda vibrante. Estas estroncas foram designadas pelos nümeros I e II referindo-se aos pares de estaca 823-824 e 825-826, respectivamente, seguidas das letras A, $B$, e C, indicando o nível correspondente, sendo $A$ indicativo do nível superior.

c) Nas estroncas IIA, IB e IIC foram feitas leituras de temperatura por dois processos:

i) por meio de termômetro colocado no interior da estronca a cerca de $2,5 \mathrm{~m}$ da extremidade oeste, medindo-se, portanto, a temperatura do ar no interior da estronca;

ii) por meio de pares termo-elétricos colocados quer nas abas superiores e inferiores das estroncas, quer no seu interior.

$$
\text { Nas demais estroncas näo foram feitas leituras das }
$$

temperaturas, que foram consideradas como iguais às das estroncas instrumentadas do mesmo nivel.

\section{SECÇÃO EXPERIMENTAL N: 8}

\subsection{Localizacão}




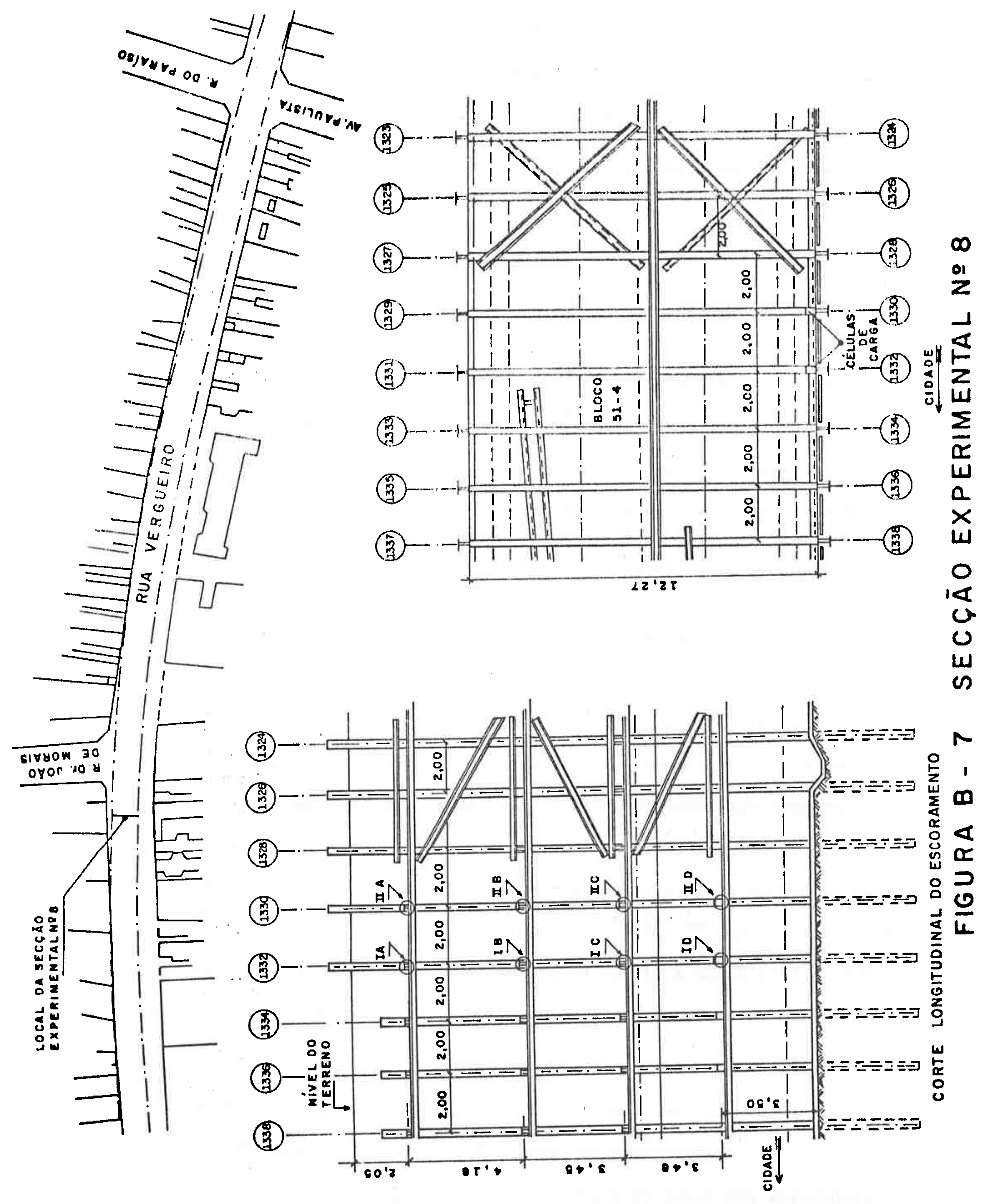


A Secção Experimental n? 8 situava-se à Rua Vergueiro, em frente ào prédio de nümero 1018, pröximo à Rua Dr. João de Moraes, no trecho 5 da linha Norte-Sul do Metrô. A sua locallzação estä Indicada na figura B-7. Os trabalhos se desenvolveram de 5 de setembro de 1972 a 6 de abril de 1973.

\subsection{Sub-solo}

O sub-solo na região da Secção Experimental, segundo sondagens prōximas, era constituído de uma argiza porosa vermetha, com cer ca de $8,80 \mathrm{~m}$ de espessura, sobrejacente a uma camada de argila silto-areno $6 a$, de consistência média a rija, marrom, com aproximadamente $6,30 \mathrm{~m}$ de es pessura e, sob estas, camadas de argilas e areias de cor variegada.

\subsection{Escavação e escoramento}

A escavação no local atingiu a profundidade de $16,66 \mathrm{~m}$, desenvolvendo-se em cerca de $8,80 \mathrm{~m}$ de argila porosa, e nas camadas subjacentes a esta, 6,30m de argila silto-arenosa, de consistência média a rija, marrom e $1,56 \mathrm{~m}$ de argi la de consistência rija, varlegada. 0 escoramen to empregado foi constituido de estacas metālicas (dois perfis 1 de $12^{\prime \prime}$ $(60,6 \mathrm{~kg} / \mathrm{m})$ soldados, cravados a cada $2,0 \mathrm{~m}$ longltudinalmente. As estacas eram escoradas transversalmente por estroncas metälicas constituidas de dois perfis 1 de $12^{\prime \prime}(60,6 \mathrm{~kg} / \mathrm{m})$ soldados, dispostos em quatro niveis, a 2,05m; 6,23m; 9,68m e 13,16m de profundidade. Pranchões de madelra, com $10 \mathrm{~cm}$ de espessura, encunhados em estacas contiguas, completavam o sistema de escoramento.

Na figura $B-7$ estão representadas a planta e um corte longltudinal do escoramento na reglão. As seç̧ões observadas foram as cor respondentes aos pares de estacas 1329-1330 e 1331-1332, locallzadas no 81 oco $51-4$. 

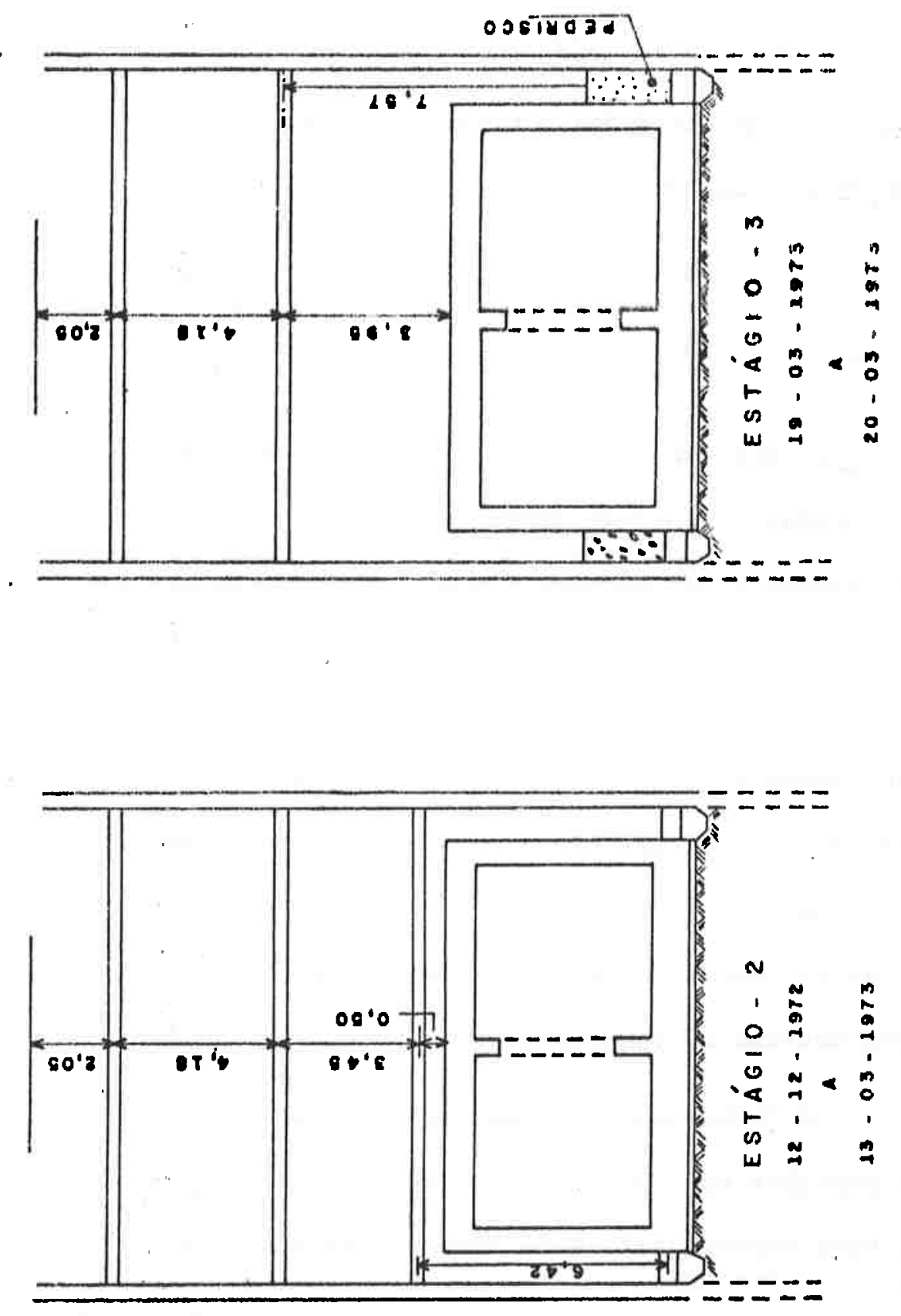

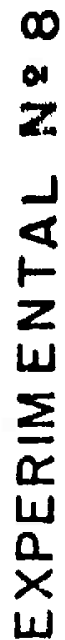

0 14 4 U os

1 14 u $\frac{4}{2}$ 0 in w 吉 o O $-\frac{1}{4}$

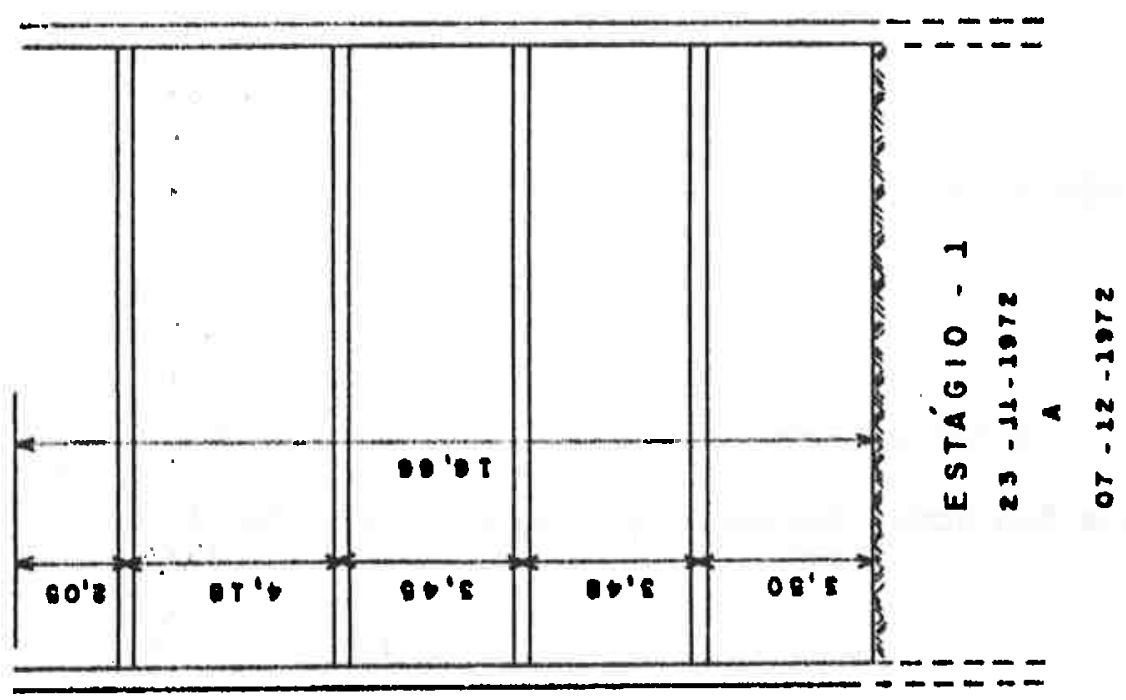

$\infty$

1 m $\varangle$ 똑 $\frac{0}{4}$ 
Foram estudados 3 estāgios, durante o desenvolvimento dos trabalhos de escavação, conforme indicado graficamente na figura $B-8$, anexa.

\subsection{Instrumentação}

a) Entre as estroncas das duas secçōes de observação e as estacas 1332 e 1330 foram colocadas células de carga de corda vibrante. Estas estroncas foram designadas pelos nümeros 1 e 11 referindo-se aos pares de es tacas 1331 e 1332, 1329 e 1330, respectivamente, seguidos das letras $A, B, C$ e D indicando as camadas de estroncas correspondentes, sendo $A$ indicativo da camada superior. Colocou-se na camada A cëlulas de carga com capacidade de 25 e, nas estroncas das demais camadas, cèlulas de carga com capacidade de $50 \mathrm{t}$.

b) Instalou-se nas estroncas da Secção I (estacas 1331-1332) pares termoelétricos para medidas de temperaturas.

A temperatura foi medida no interior das estroncas, em três diferentes posiçōes ao longo do seu comprimento e tomando-se a mëdia destes valores, como representativa da temperatura média da estronca.

Nas estroncas da Secção II (estacas 1329-1330) não fọ ram feitas leituras de temperatura. As temperaturas destas estroncas foram consideradas como iguais às das estroncas instrumentadas do mesmo nível (Secção 1).

\section{SECÇAO EXPERIMENTAL N: 2}

4. 1. Localização

A Secçāo Experimental no 2 se situava na Avenida Liberdade, pröximo à Rua Tomaz Gonzaga, no trecho 4 da Linha Norte-Sul do 

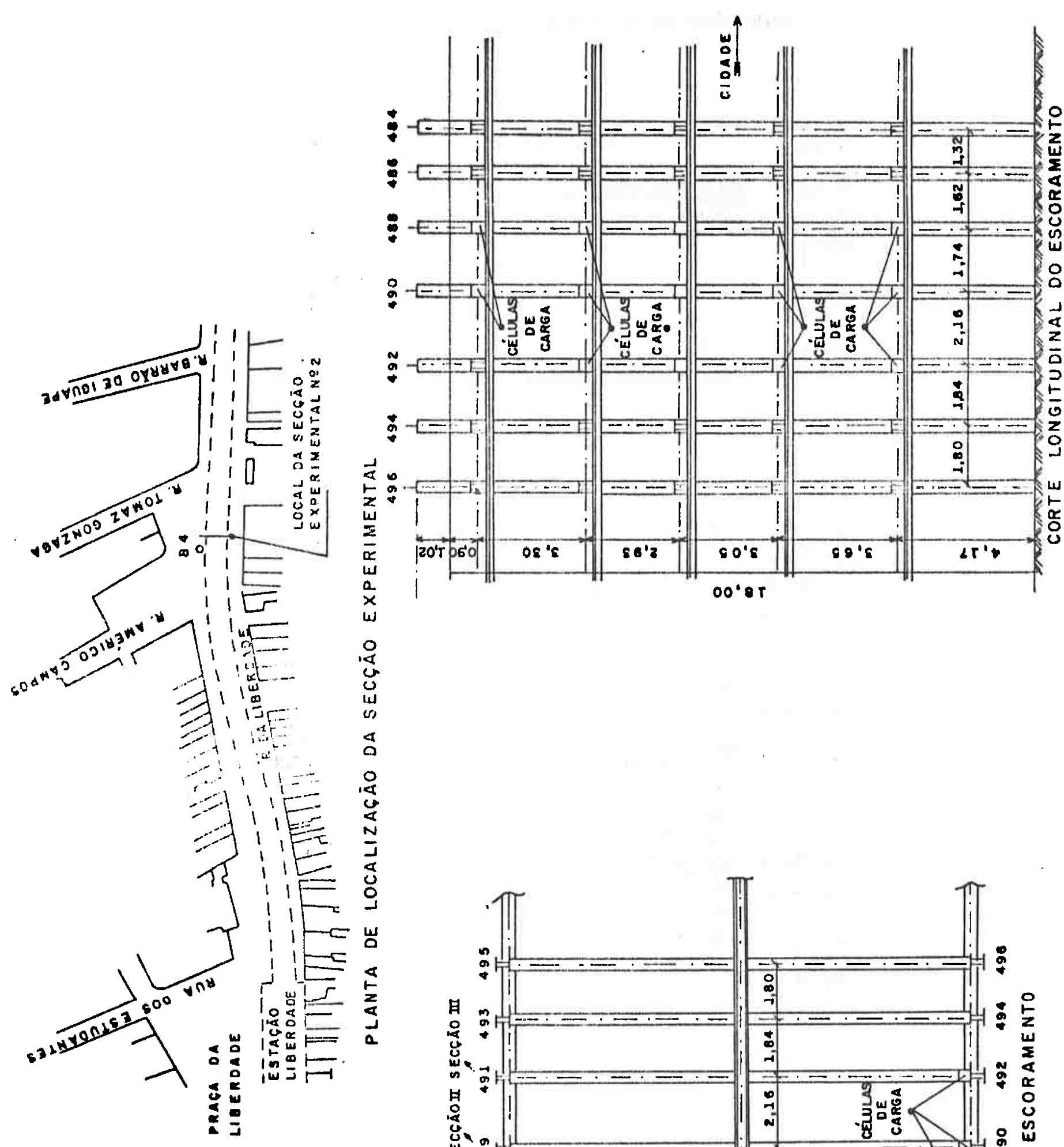

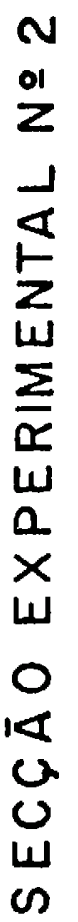

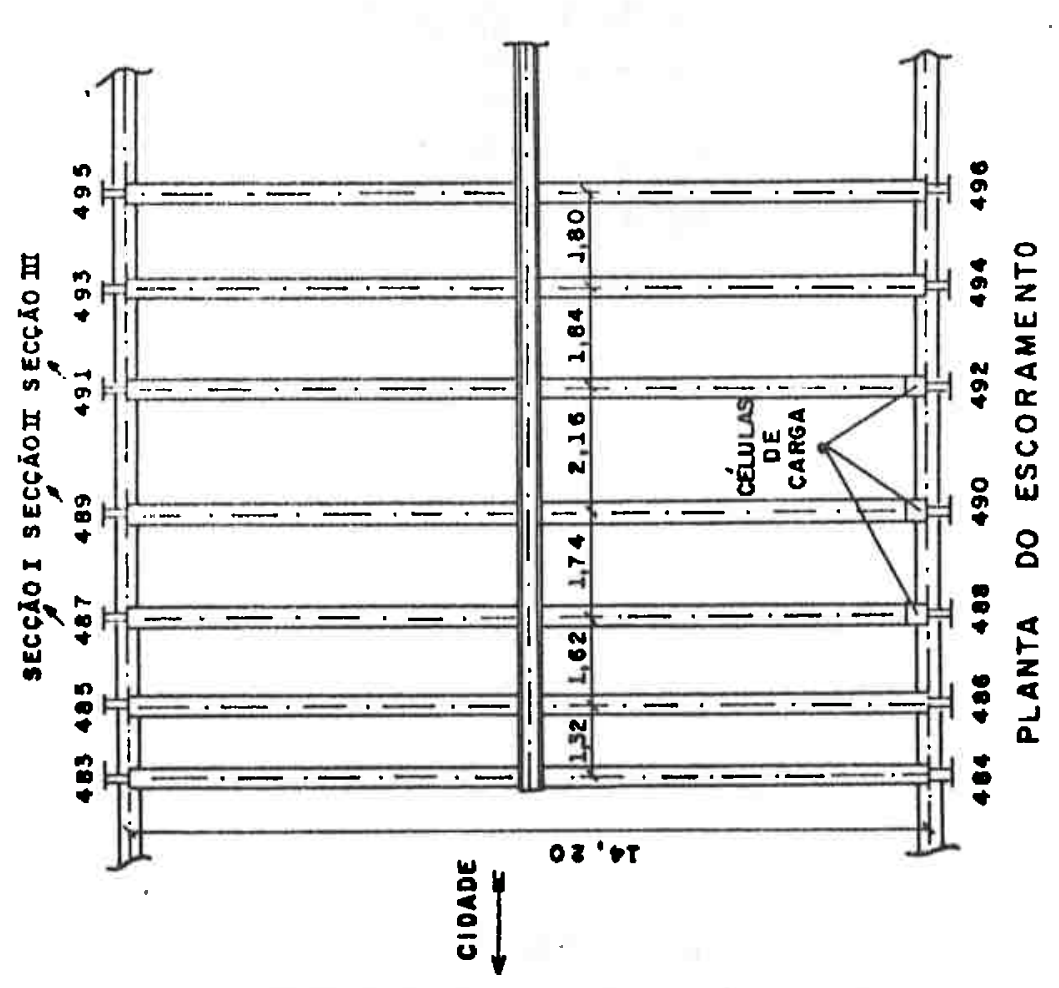

$\sigma$

(

$\alpha$
$\frac{\alpha}{0}$
$\frac{0}{u}$ 
SONDAGEM NQ B $21 / 2$ "

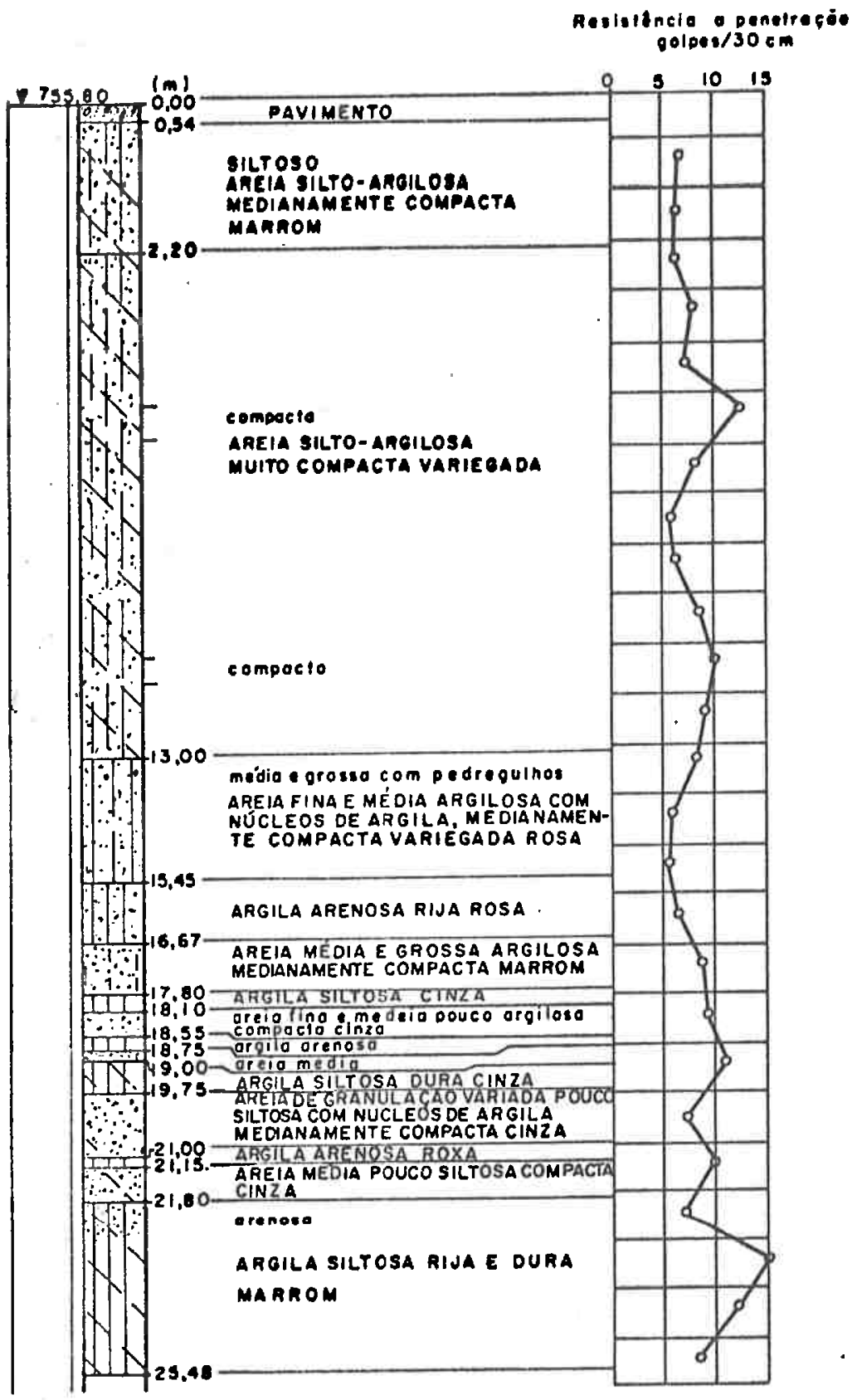

FIGURA B-10 SECCÃO EXPERIMENTAL N 22 
Metrō. A localização da Secção estä indicada na figura $B-9$. Os trabalhos nesta Secção desenvolṿeram-se de 06 de março de 1972 a 18 de maio de 1973.

\subsection{Sub-8olo}

Segundo amostras retiradas no local e sondagenspröxlmas, o sub-solo è constituido de uma argita vermelha com pouca areia fina, com cerca de $3 m$ de espessura, seguida de uma areia silto-argilosa, com cerca de 10,0m de espessura, sobrejacente a camadas intercaladas de argila arenosa, areia e argiza siztosa. Na figura $B-10$ estão reproduzidos os dados de uma sondagem realizada nas proximidades, cónforme locação indicada na figura $B-9$.

4.3. Escavação e escoramento

A escavação no local atingiu a profundidade de $18,00 \mathrm{~m}$. O escoromento empregado foi constituído de estacas metálicas (dois perfis I de $15^{\prime \prime}$ soldados), cravados longitudinalmente à vala, espaçadas entre si de $1,50 \mathrm{~m}$ no bloco 8 e de $2,00 \mathrm{~m}$ no bloco 9 . Nestes blocos as estacas eram escoradas transversalmente por estroncas metälicas constituidas de dois perfis 1 de $12^{\prime \prime}(60,6 \mathrm{~kg} / \mathrm{m})$ soldados, dispostos em cinco níveis: a $0,90 \mathrm{~m}, 4,20 \mathrm{~m}, 7,13 \mathrm{~m}, 10,18 \mathrm{~m}$ e $13,83 \mathrm{~m}$ do nível do terreno. No bloco 8 as estacas 487 e 488 eram escoradas por dois perfis 1 de $12^{\prime \prime}$ nos niveis a $0,90 \mathrm{~m}, 7,13 \mathrm{~m}$ e $13,83 \mathrm{~m}$ e por dois perfis 1 de $15^{\prime \prime}$ nos níveis a $4,20 \mathrm{~m}$ e $10,18 \mathrm{~m}$. Pranchōes de madeira com $10 \mathrm{~cm}$ de espessura, encunhados em estacas contiguas, completavam o sis tema de escoramento.

Na figura $B-9$ estão representadas a planta e um corte longltudinal do escoramento no local das observações. As secções observadas foram as correspondentes aos pares de estacas 487-488, 489-490 e 491492, que foram designadas, respectivamente, de secções 1 , II e 111 . 


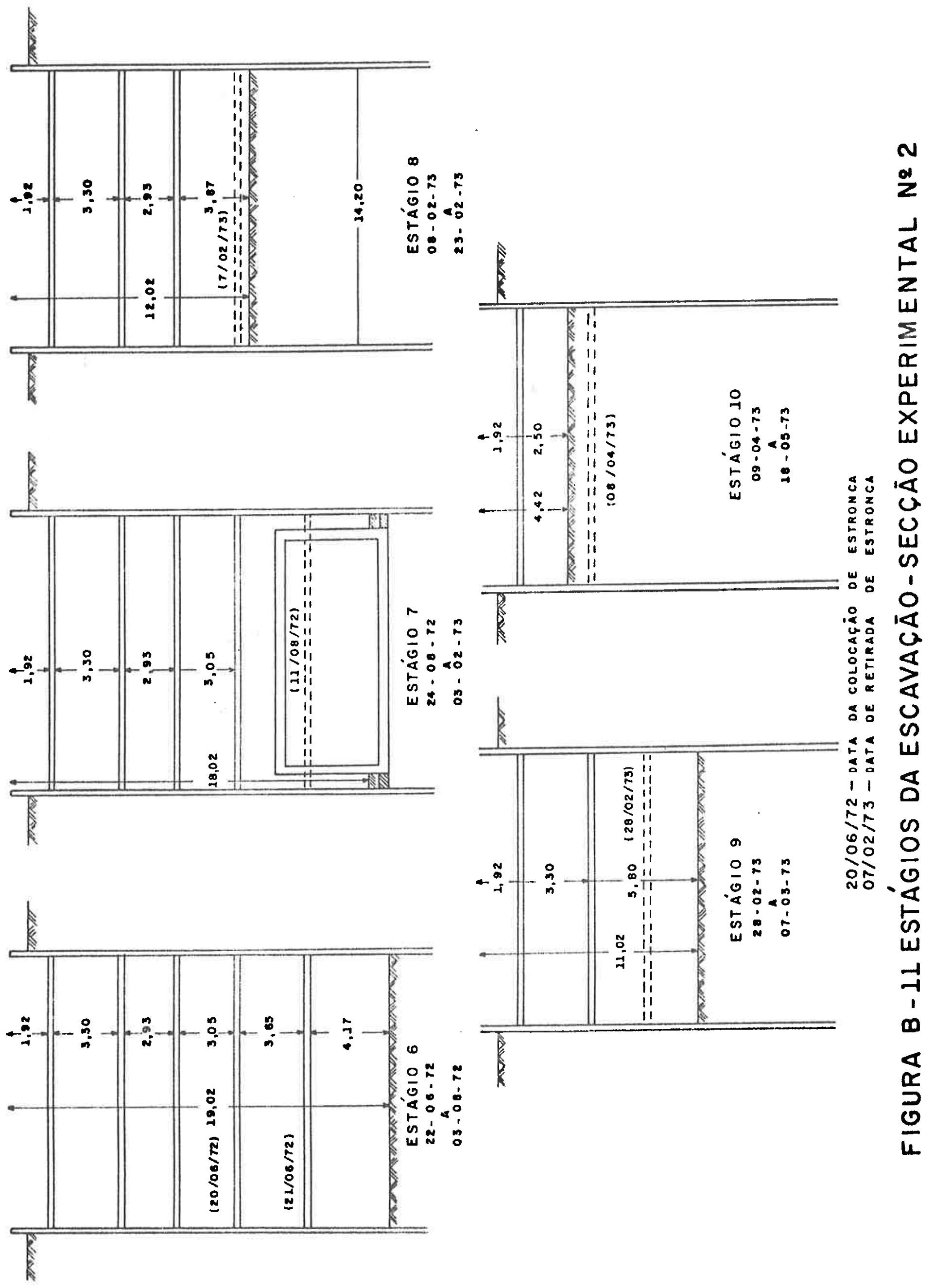


Os trabalhos de escavação e reaterro se desenvolveram em 10 estägios; aqueles de interesse a este estudo estão indicados graficamente na figura $B-11$.

\subsection{Ins trumentação}

a) Nas estacas 488 (parede Oeste) e 489 (parede Leste) foram colocados tu bos de inazinömatro Wilzon. Os tubos foram colocados no interior das estacas, previamente limpas e o espaço entre o tubo e a estaca fol preenchido com areia compactada.

b) Em cada Seç̧ão, entre as estroncas e as estacas, foram colocadas células de carga de corda vibrante. Estas estroncas foram designadas por um algarismo romario, 1,11 ou 111 , conforme a Seç̧ão à que pertenciam, seguidas das letras A, B, C, D e E para indicar o nível correspondente, sendo A indicativo da camada superior, B, C, D e E dos niveis subsequentes. Não foi colocada cêlula de carga na estronca III-A.

c) Nas estroncas IIA, IIB, IIC, $1 / 0$ e IIE foram feitas leituras de temperatura por meio de pares termo-elëtricos, colocados nas abas superiores e inferiores das estroncas, e do ar no seu interior. Nas demals es troncas não foram feitas lelturas de temperaturas. As temperaturas dessas estroncas foram consideradas como iguais às das estroncas instrumentadas de mesmo nivel.

\section{SECÇAO EXPERIMENTAL No 5}

\section{1. Locatização}

A Secção Experimental n: 5 situava-se no Largo Sete de Setembro no trecho 4 da Linha Norte-Sul do Metrô. A sua localização es tá Indicada na figura $B-12$, anexa. Os trabalhos nesta Secção se desenvolveram de 22 de março de 1973 e 02 de janeiro de 1975. 

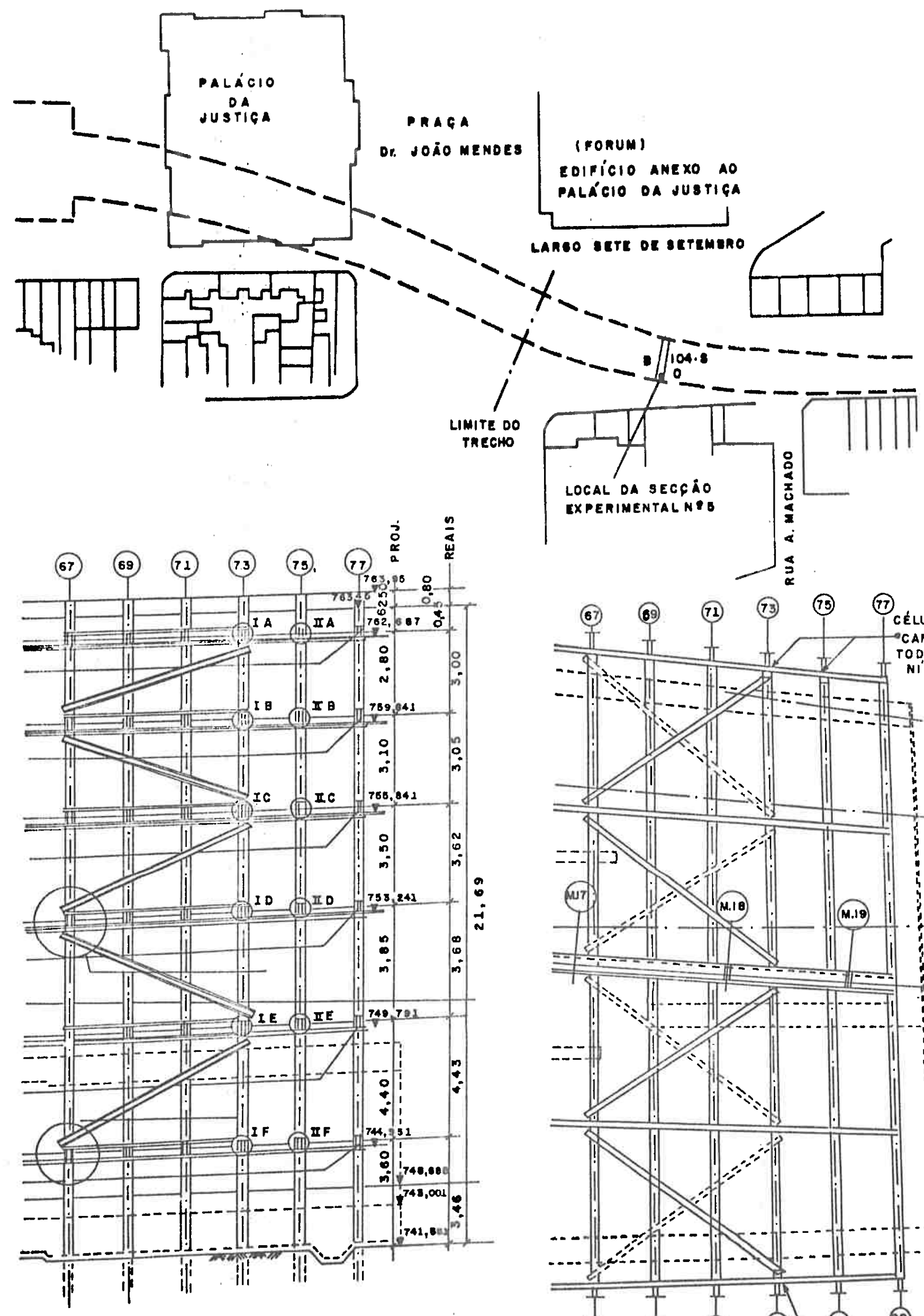

CORTE LONGITUDINAL DO ESCORAMENTO

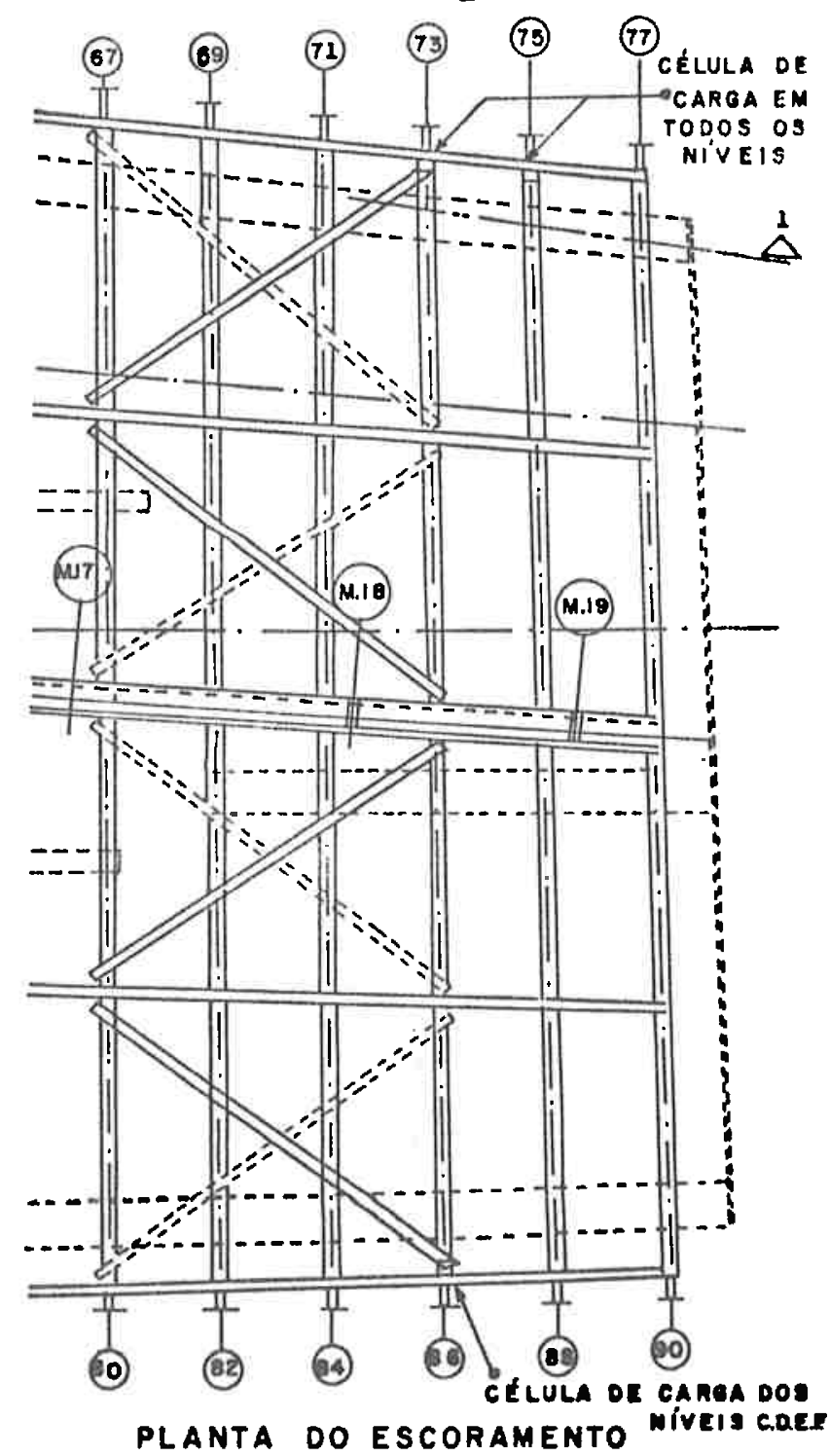

FIGURA B - 12 SECCĀO EXPERIMENTAL N25 


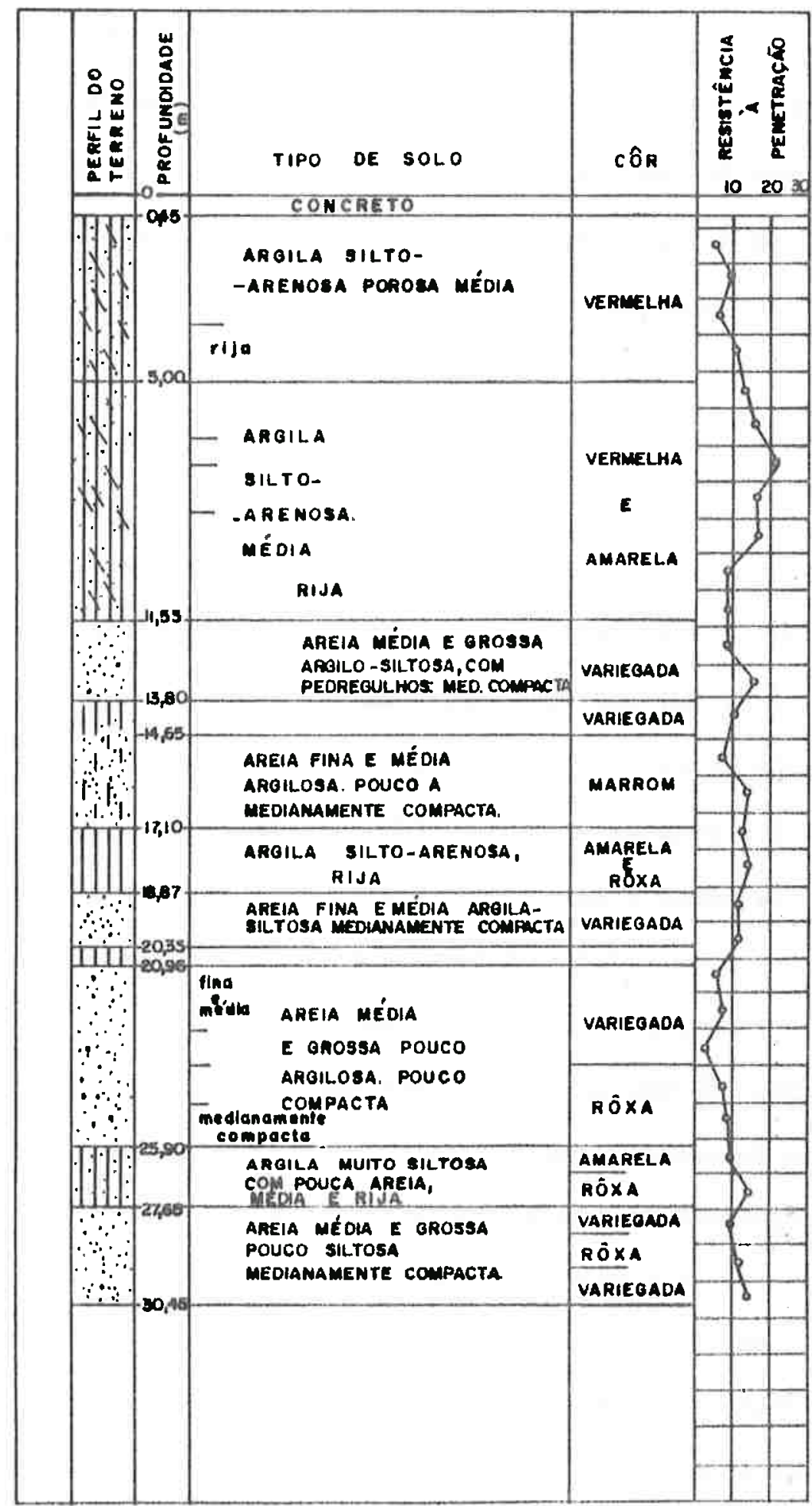

FIGURA B- 13 SONDAGEM DE RECONHECIMENTO DO SUB -SOLO NA ÁREA DA SECÇĀO EXPERIMENTAL N $\cong 5$ 
5.2. $5 u b-8070$

O sub-solo na região da Secção Experimental, segundo sondagens pröximas, è constltuido de uma argila porosa verme tha sobrejacénte a camadas de areia e argila com cor variegada. Os dados de uma sondagen realizada nas proximidades, conforme locação indlcada na figura $B-12$, estão reproduzidos na figura $B-13$.

\subsection{Escavação e escoramento}

A escavação no local atingiu a profundidade de $21,69 \mathrm{~m}$ do lado leste e $22,59 \mathrm{~m}$ do lado oeste da vala. 0 escoramento empregado foi constituído de estacas metālicas cravadas longitudinalmente à vala, espaçadas entre si de $2 \mathrm{~m}$, dos dois lados da vala, (dois perfis I de 18" solda dos constituiam as estacas do lado oeste e um perfil I de $18^{\prime \prime}$ as estacas do lado leste) e estacas metálicas (dois perfis I de 15" soldados) cravadas longitudinalmente à vala, em seu eixo central, com espaçamentos variäveis entre si. As estacas eram escoradas transversalmente por estroncas metālicas dispostas inicialmente em seis niveis: $0,45 \mathrm{~m}, 3,45 \mathrm{~m}, 6,50 \mathrm{~m}$, $10,12 \mathrm{~m}, 13,80 \mathrm{~m}, 18,23 \mathrm{~m}$, distâncias medidas a partir do nível do terreno no lado leste da vala. Estas estroncas eram formadas por dois segmentos justapostos apoiados em vigas centrais que, por sua vez, apoiavam-se nas estacas centrais. Na camada superior, as estroncas eram constituídas por dois perfis 1 de $12^{\prime \prime}$ soldados e, nas demais camadas, dois perfis 1 de $15^{\prime \prime}$ soldados. Pranchões de madeira encunhados em estacas contíguas, dos dois lados da vala, completavam o sistema de escoramento.

Durante a escavação ocorreram recalques nas estacas centrais, motivo pelo qual o nivel superior de estronca teve que ser rebaixado, nos apoios extremos pröximos às paredes da vala, para a sua horizontalização, ficando a $0,80 \mathrm{~m}$ do nível do terreno (contada esta profun- 


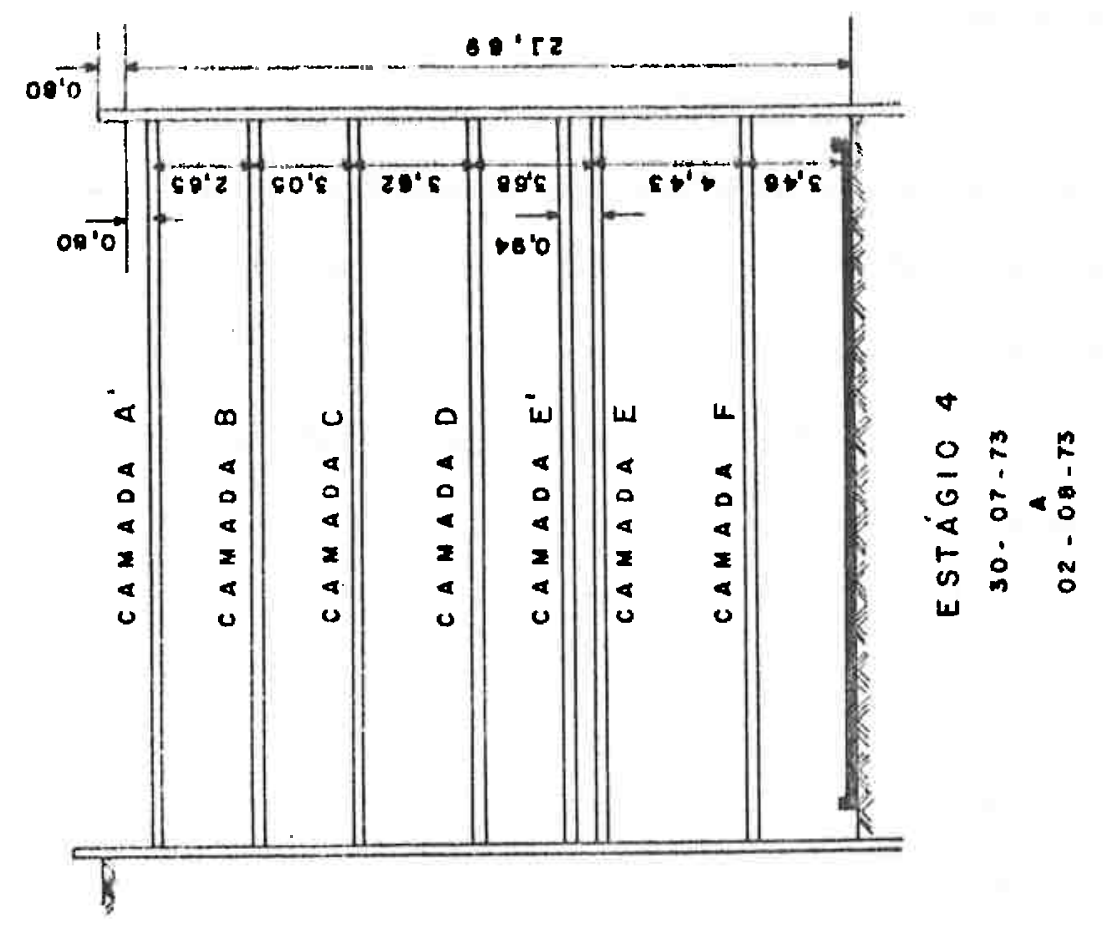

$n$

ol

2

$\frac{1}{\frac{1}{2}}$

LI

$\frac{2}{x}$

U.

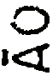

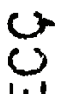

os

'

10

$\frac{1}{5}$

4

0

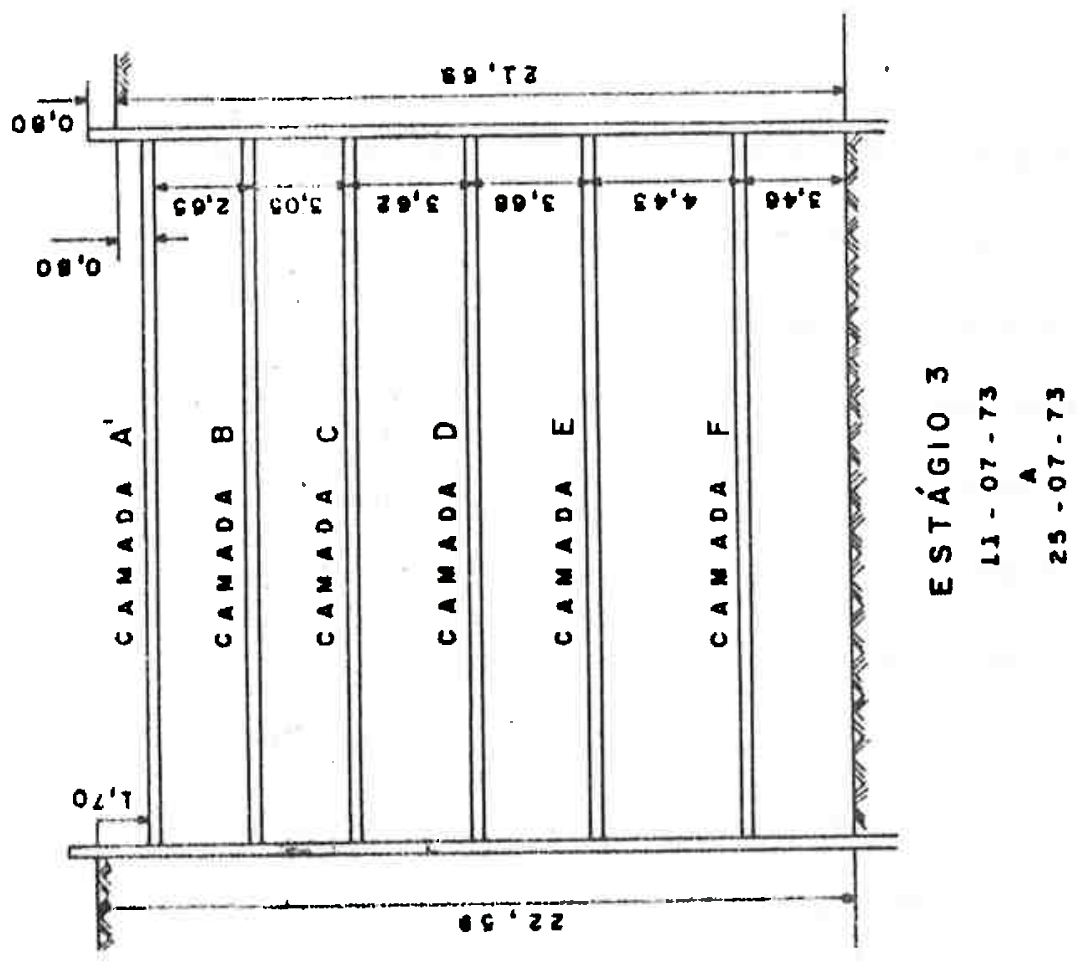

Ш

$\checkmark$

$\omega$

0

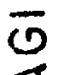

$\leftarrow$

(s)

w

$\frac{7}{1}$

m

$\frac{a}{0}$ 
didade do lado leste da vala). Alèm disso, uma das estroncas do 5 : nível $(13,80 \mathrm{~m}$ de profundidade) acusou cargas muito altas durante a escavação, tendo que ser feito um reforço no escoramento, colocando-se para is to mais um nivel de estrancas, a 12,86m de profundidade. Tanto a estronca vizinha do mesmo nivel, quanto as do nível imediatamente superior apresentaram cargas mais baixas, revelando um efelto de arqueamento que deve ter sido consequência do carreamento de areía, junto à estaca 73 (figura B-12), em final de escavação.

Na figura $B-12$ estão representadas a planta e um corte longitudinal do escoramento na região. As secções observadas foram as correspondentes aos pares de estacas 73-86 e 75-88.

Os trabalhos de escavação e reaterro se desenvolveram em 16 estägios. Na figura $B-14$ estão definidos graflcamente os estäglos 3 e 4, de maior interesse para este estudo.

\subsection{Instmontação}

a) Nas estacas 73 (parede leste) e 86 (parede oeste) foram colocados tubos de inclinömetro Wilson. Os tubos foram instalados no terreno, ao lado das estacas, e o espaço entre o tubo e a estaca fol preenchido com areia compactada. Note-se que as estacas centrais e as do lado les te foram colocadas em prë-furos, devido à dificuldade de atravessar uma camada de limonita existente, o que dificultou sobremaneira a interpretação das leituras de inclinômetro na estaca 73.

b) Dos dois lados da vala, pröximos das estacas 73 e 86 , foram instalados marcos superficiais, 4 de cada lado da vala. Também foram instalados 2 referenclais de nivel RN, um do lado leste e outro do lado oeste da vala.

c) Foram Instalados 4 piezômetros tipo Casagrande, 2 de cada lado da va- 
la: um piezômetro a $16 \mathrm{~m}$ e outro a $22 \mathrm{~m}$ de profundidade.

d) Entre as estroncas e as estacas 73 e 86 de uma das seç̧öes observadas e 75 da outra foram colocadas células de carga de corda vibrante. Estas estroncas foram designadas pelos algarismos romanos 1 e 11 , referindo-se aos pares de estacas 73-86 e 75-88, respectivamente, seguidas das letras A, B, C, D,EeF para Indicar o nivel de estroncas correspondente, sendo $A$ indicativo do nivel superior, $B, C, D, E$ e $F$ dos niveis subsequentes. Quando as estroncas do nivel A foram rebaixadas, seu nivel passou a ser designado por $A^{\prime}$. A célula de carga colocada na estronca IA teve que ser substituida, por ter sido danificada por ocasião do rebaixamento da estronca. 0 ültimo nivel de estroncas a ser co locado, e que ficou a $12,86 \mathrm{~m}$ da superfície do terreno, foi designado pela letra $E^{\prime}$. Nas estroncas IA e IB, Secção $I$, só foram colocadas cēlulas de carga no lado leste da vala. Nas estroncas das camadas C, D, E', E e foram colocadas células de carga dos dois lados da vala, ten do-se então chamado IL à Secção I do lado leste e 10 à Secção 1 do lado oeste. Na estronca IIE' foram colocadas células de carga dos dois lados da vala, chamando-se IIE'O e IIE'L à estronca E'da Seç̧ão II nos lados oeste e leste, respectivamente.

e) Nas estroncas da Seção 1 foram instalados pares termo-elëtricos, colo cados nas abas superior e inferior das estroncas e no seu interior. As temperaturas das estroncas da outra secçāo foram consideradas iguals às das estroncas de mesmo nível, instrumentadas.

6. SECÇAO EXPERIMENTAL DO BLOCO 17

A secção experimental do Bloco 17 localizava-se no trecho 43 da linha Norte-Sul, na Liberdade. As observaçöes foram feitas entre os dias $03 / 02 / 1972$ e 24/03/1972. 


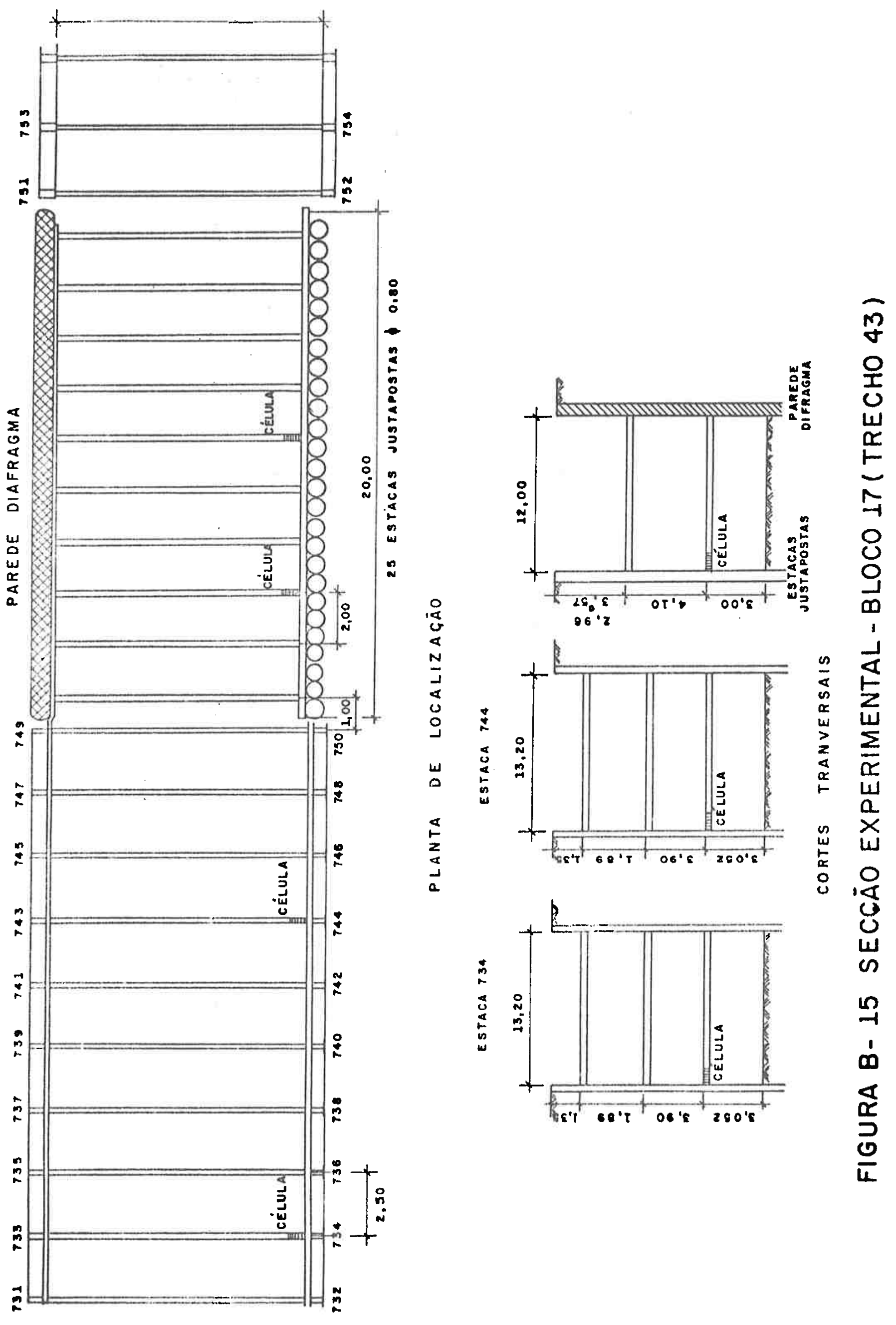

0
0
$\vdots$
0 
A vala, com $10 \mathrm{~m}$ de profundidade, estava escorada por meio de estroncas apoiadas, quer em paredes diafragmas e estacas juctapos tas; quer em estacas metällcas, pranchöes de madeira e vigas de rigidez.

No primeiro caso, aqui designado por paredes rigidas, havia 2 nivels de estroncas, constituidas por perfis 21 de $12^{\prime \prime}$, com $12 m$ de comprimento, nas cotas $-3,0 \mathrm{~m}$ e $-7,0 \mathrm{~m}$; o espaçamento entre elas, emplan ta, era de $2 \mathrm{~m}$.

No caso das paredes flexiveis, havia três niveis de estroncas do mesmo tipo, Instaladas nas cotas $-1,3 \mathrm{~m} ;-3,0 \mathrm{~m}$ e $-7,00 \mathrm{~m}$; o e paçamento entre elas, em.planta, era de $2,5 \mathrm{~m}$ e o seu comprimento de $13,2 \mathrm{~m}$.

A figura $B-15$ mostra cortes transversais e disposições em planta, bem como a localização das células de carga para a medida das cargas das estroncas, que foram instaladas apenas no ültimo nível de estroncamento. Neste mesmo nível foram medidas as temperaturas no interior das estroncas.

o sub-solo do local era constituído de solos variegados.

7. SECÇÃO EXPERIMENTAL NO 7

\subsection{Localização}

A Secção Experimental n: 7 situava-se à Rua Vergueiro, em frente ao prédio de nümero 1108, no trecho 5 da linha Norte-Sul do Metrō. A sua localização está indicada na figura B-16, anexa. Os trabaIhos nesta secção se desenvolveram de $17 / 08 / 72$ a 11/04/73.

\subsection{Sub-8olo}

O sub-solo na região, segundo observações levadas a 

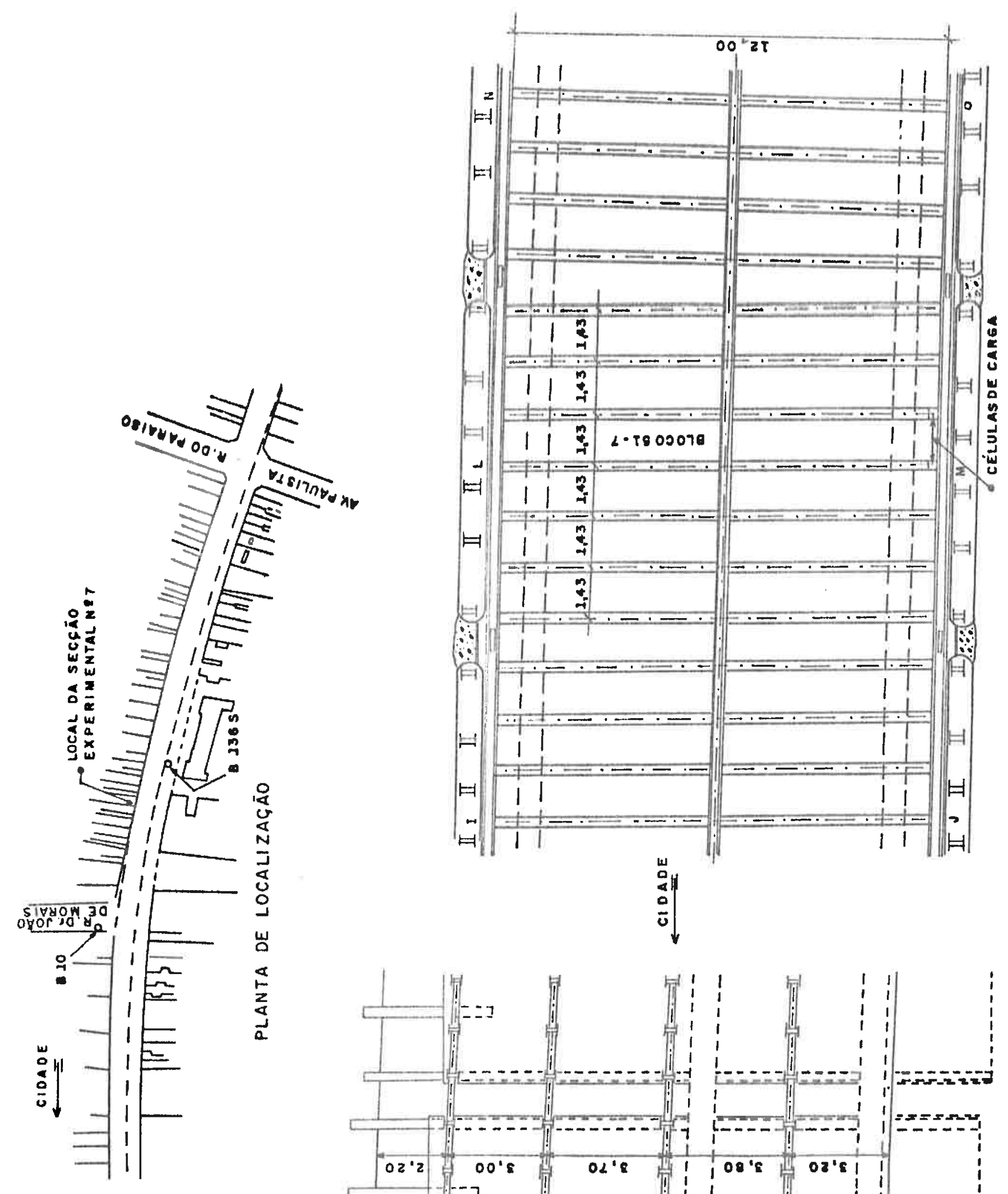

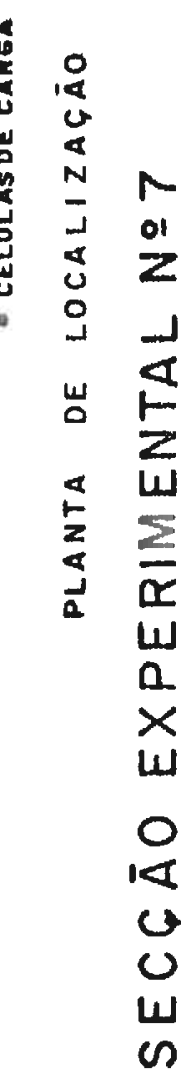

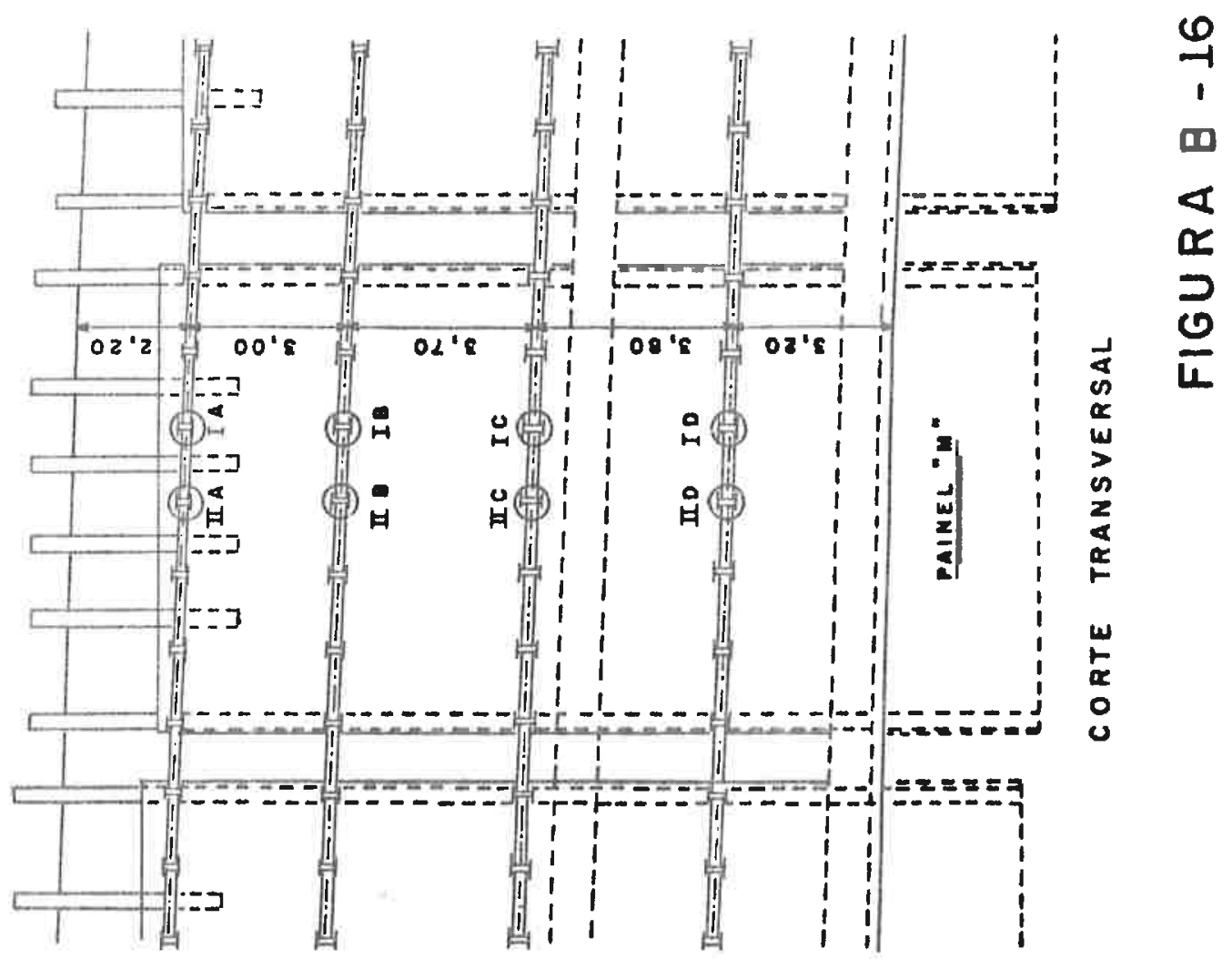



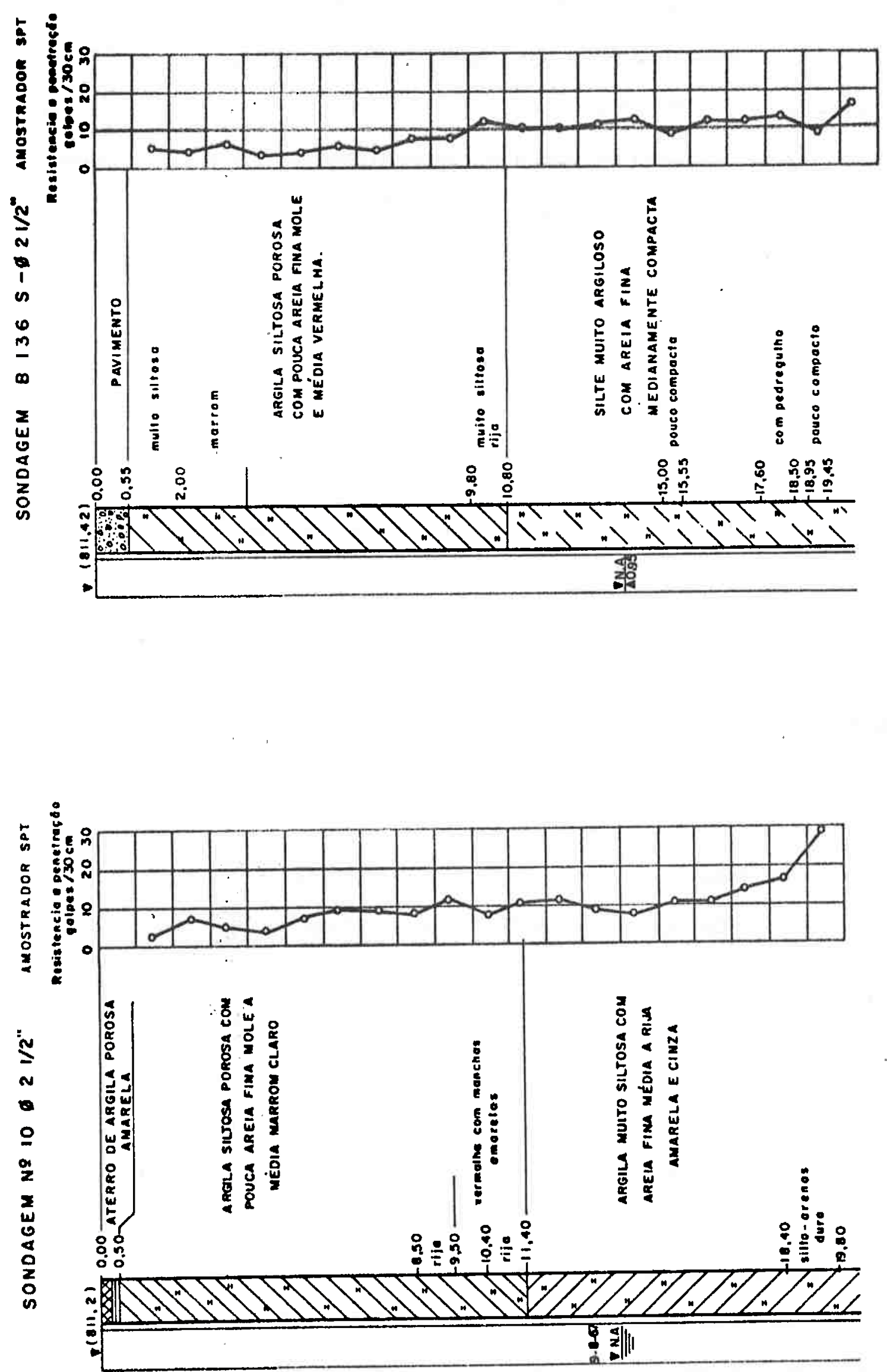

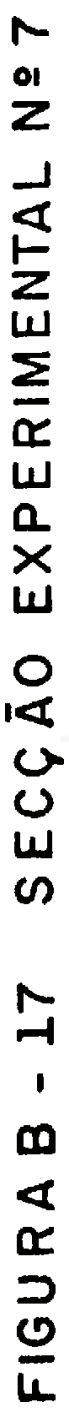


efeito durante os trabalhos de escavação e a Interpretação de duas sondagens próximas, è constituido de uma argila porosa vermetha, com cerca de $9,00 \mathrm{~m}$ de espessura, sobrejacente a uma camada de argila silto-arenosa de consistência mëdia a rija, marrom, com aproximadamente $3,40 \mathrm{~m}$ de espessura e, sob estas, camadas de argizas e areias de cor variegada.

A locallização dessas sondagens encontra-se na figura $B-16$ e os respectivos perfis do sub-solo na figura $B-17$.

\subsection{Escavação e escoramento}

A escavasão no local atingiu a profundidade de $15,90 \mathrm{~m}$, desenvolvendo-se em cerca de $9,80 \mathrm{~m}$ de argila porosa e nas camadas subjacentes a esta, $3,40 \mathrm{~m}$ de argila silto-arenosa, de consistência média a rija, marrom, e $2,70 \mathrm{~m}$ de argila de consistência rija, variegada. 0 escoramento empregado foi constituído de paredes diafragmas, construídas em pa nëis de $9 \mathrm{~m}$ de comprimento e $0,80 \mathrm{~m}$ de largura. Entre os painēis havia um espaçamento para facilitar a drenagem. As estroncas eram apoiadas em longarinas constituídas de dois perfis metälicos, 1 de $15^{\prime \prime}(63,3 \mathrm{~kg} / \mathrm{m})$, soldados. Estas estroncas metālicas eram dispostas em quatro niveis a $2,20 \mathrm{~m}$; $5,20 \mathrm{~m} ; 8,90 \mathrm{~m}$ e $12,70 \mathrm{~m}$ de profundidade, e constituídas de dois perfis metā licos 1, soldados, de $12^{\prime \prime}(60,6 \mathrm{~kg} / \mathrm{m})$ para os dois primeiros niveis e de $15^{\prime \prime}(63,3 \mathrm{~kg} / \mathrm{m})$ para. o ültimo nível. O terceiro nível, segundo o projeto, seria constituído de dois perfís metälicos 1 , soldados, de $15^{\prime \prime}(63,3 \mathrm{~kg} / \mathrm{m})$, porém, constatou-se no local que foram utilizados perfis $H$, equivalentes. Entre a extremidade superior dos painéis e a superfície do terreno, o escoramento consistia de estacas metālicas, 2 perfis 1 de $15^{\prime \prime}(63,3 \mathrm{~kg} / \mathrm{m})$ soldados, engastados nos painēis e pranchões de peroba de $8 \mathrm{~cm}$ de espessura encunhados entre estacas contíguas. Entre dois painēis vizinhos o esco ramento era constitulido por estacas metālicas, 2 perfis 1 de $12^{\prime \prime}(60,6 \mathrm{~kg} / \mathrm{m})$ soldados, engastados lateralmente no concreto e pranchões de peroba de 


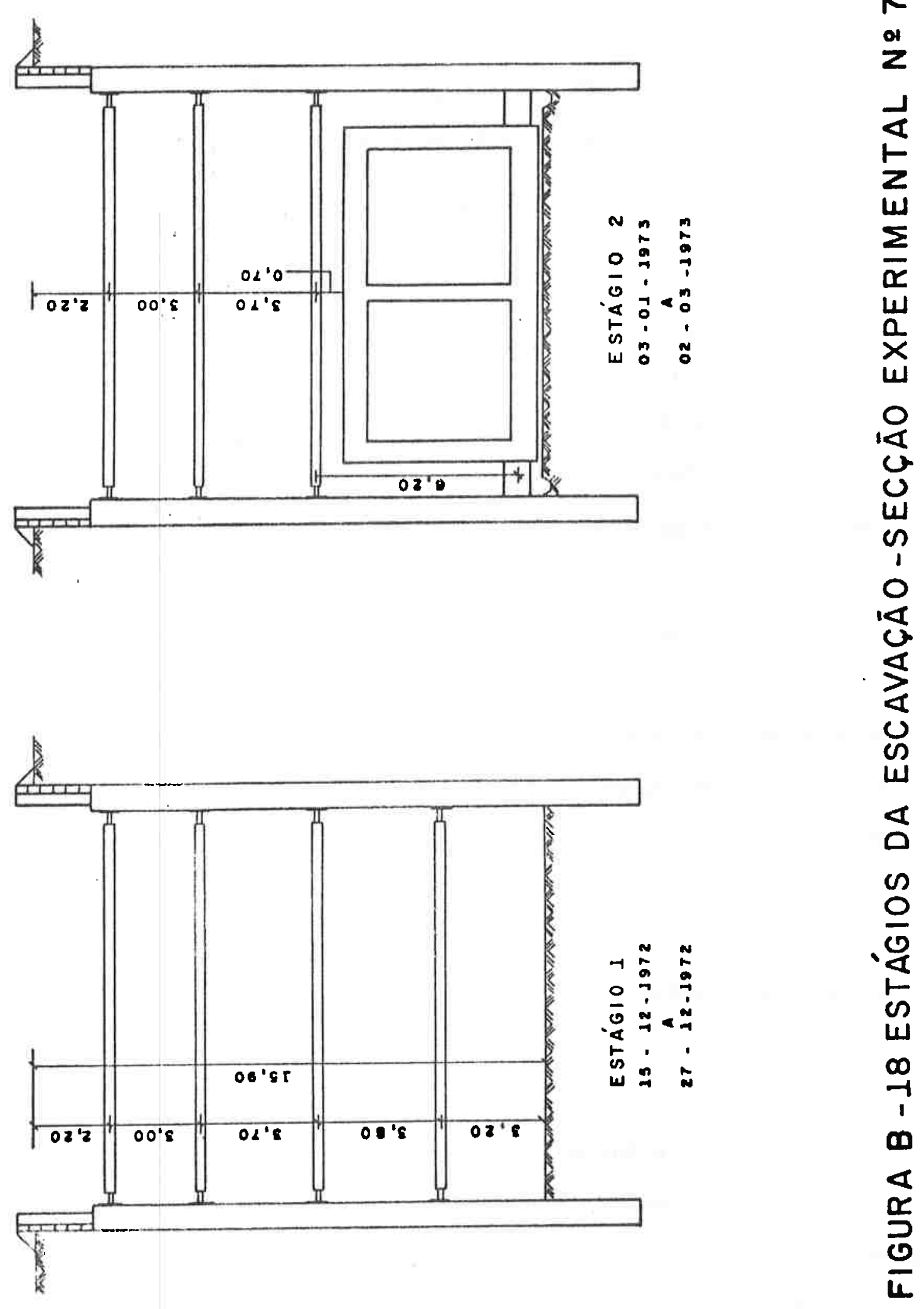


$8 \mathrm{~cm}$ de espessura encunhados entre elas.

Na figura $B-16$ estão representadas a planta e um corte longitudinal do escoramento na região. As secções observadas estavam localizadas entre os painëis $L$ e $M$, no Bloco 51-7.

A figura $B-18$ mostra os dois estäglos de escavação, de interesse a este estudo.

\subsection{Instrumentação}

a) Entre as estroncas das duas secções de observações e a parede diafragma (painel M) foram colocadas as cēlulas de carga. Estas estroncas foram designadas pelos números 1 e 11 (sentido Norte-Sul), seguidos das letras A, B, C e D, sendo A indicativo da camada superior. Foram utill zadas cēlulas com capacidade de 25 t na camada A e de 100 t nas demais.

b) A temperatura foi medida atravēs de pares termo-elētricos Instalados no interior das estroncas da Secção I, em tres posições ao longo de seu comprimento; tomou-se a mëdia destes valores como a temperatura më dia da estronca. Nas estroncas da Secção II não foram feitas leituras de temperatura.

8. SECÇAOO EXPERIMENTAL N: 3

8. 1. Localização

A Seç̧ão Experimental n? 3 situava-se à $A v$. Liberdade, prōxima à Rua Américo Campos, no Trecho 4 da linha Norte-Sul do Metrō de São Paulo conforme estā indicado na figura B-19. Os trabalhos se desen volveram de 24 de junho de 1972 a 14 de junho de 1973.

8. 2. Sub-solo

o sub-solo no local da Secção Experimental è consti- 


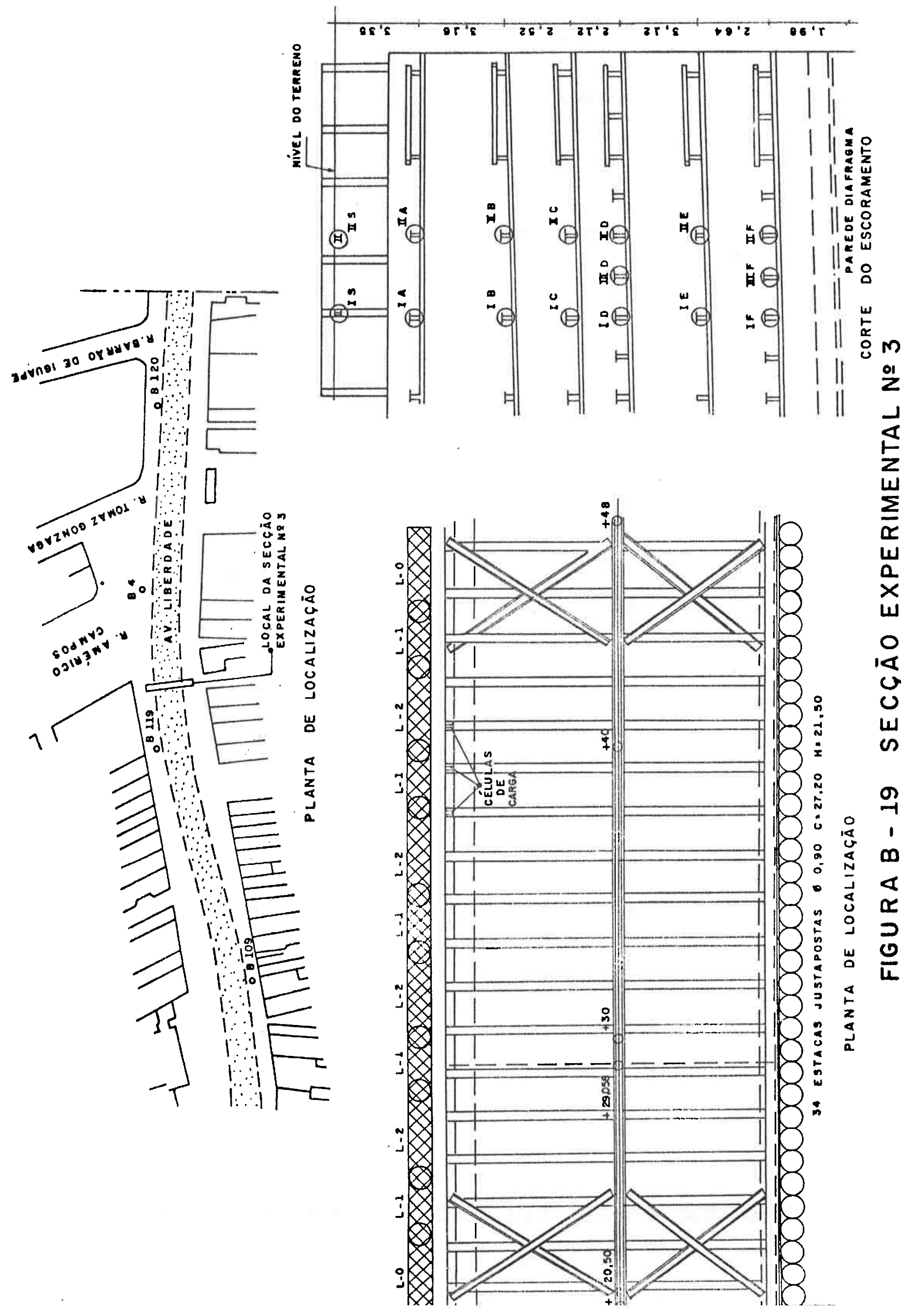


SONDAGEM BIIS (RUO dOL LBberdade)

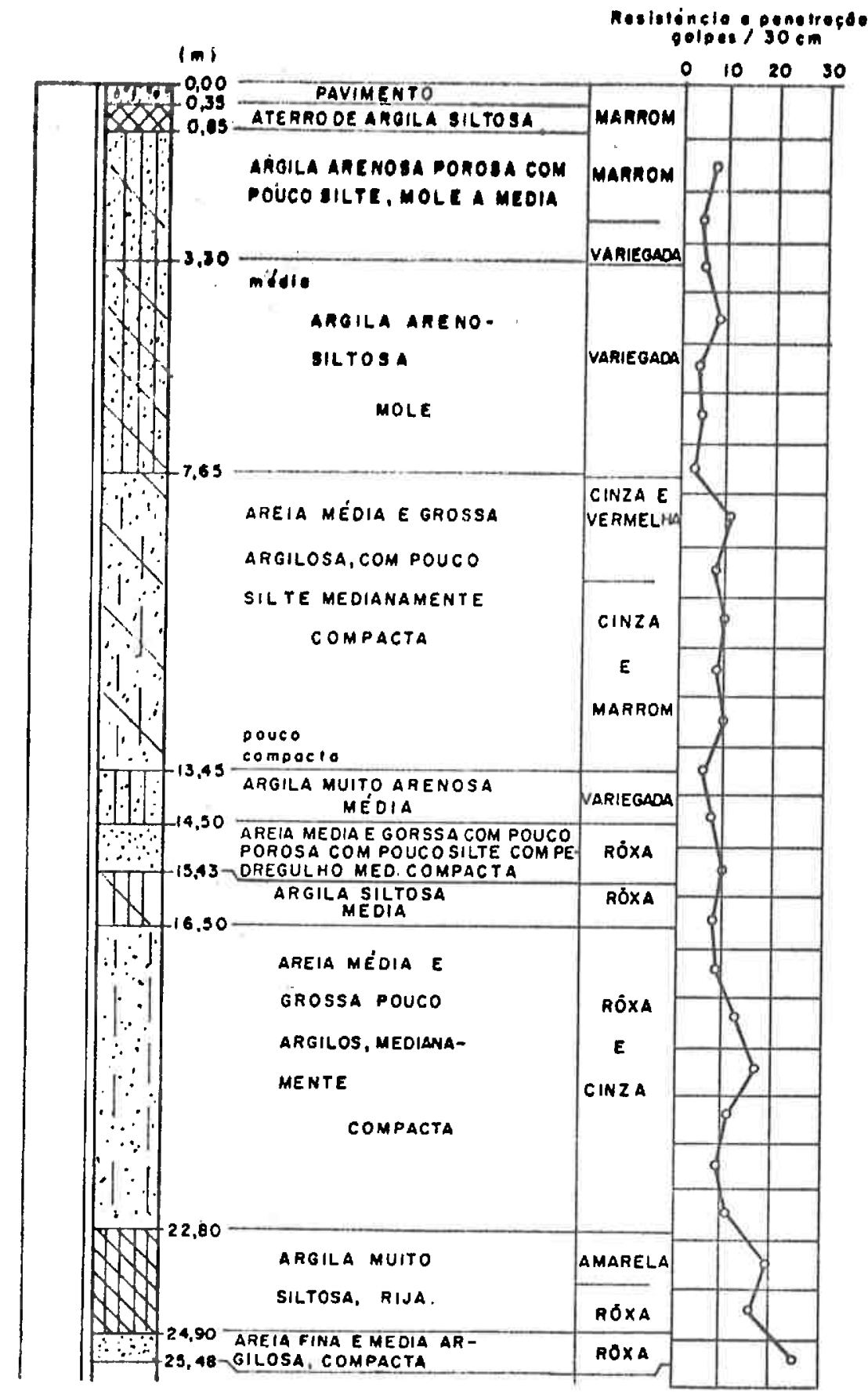

FIGURA B- 20 SECGĀO EXPERIMENTAL N 23 
tuílo de camadas intercaladas de areia e argita, como pode ser visto na figura $B-20$, onde estão reproduzidos os dados de uma sondagem realizada nas proximidades, conforme locação indicada na figura $B-19$.

\subsection{Escavą̧ão e escoramento}

A escavação atingiu a profundidade de $18,89 \mathrm{~m}$. 0 escoramento empregado era consti tuído por 34 estacas justapos tas com diâmetro de $0,80 \mathrm{~m}$ e altura de $21,50 \mathrm{~m}$ de um lado da vala e parede diafragma do outro, numa extensão de $27,06 \mathrm{~m}$.

0 escoramento transversal fol constituído de estroncas (perfis metālicos), dispostas em 6 niveis, do seguinte modo: $2112^{\prime \prime}$ a $3,35 \mathrm{~m} ; 2118^{\prime \prime}$ a $6,51 \mathrm{~m} ; \mathrm{H} 350$ a $9,03 \mathrm{~m}$ e $11,15 \mathrm{~m} ; 2120$ " a $14,27 \mathrm{~m}$ e H 500 a $16,91 \mathrm{~m}$ de profundidade, sendo estas distâncias contadas a partir do nivel do terreno. Antes da retirada do ültimo nível de estroncas, foi colocada uma sëtima camada de estroncas na altura do nível do terreno. As estroncas estavam apoiadas em longarinas, constituidas de dols perfis metálicos $\cup 8^{\prime \prime} \times 21 / 4^{\prime \prime}$.

Na figura $B-19$ estão reproduzidas a planta e um corte longitudinal do escoramento na região, Indicando-se as posições das secçōes observadas. Os trabalhos de escavação e reaterro se desenvolveram em 9 estāglos, delimitados pelas datas de instalação e retirada das estroncas, conforme indicação da figura B-21.

\subsection{Instrumentação}

a) Entre as estroncas das duas seç̧ões de observações (Seç̧ões 1 e 11) e a parede diafragma foram colocadas células de carga de corda vibrante, em 6 niveis diferentes ( $A, B, C, D, E$ e $F$ ). Nos niveis $D$ e $F$ havia estroncas intermediárias entre as duas secçōes observadas e foram denomi 


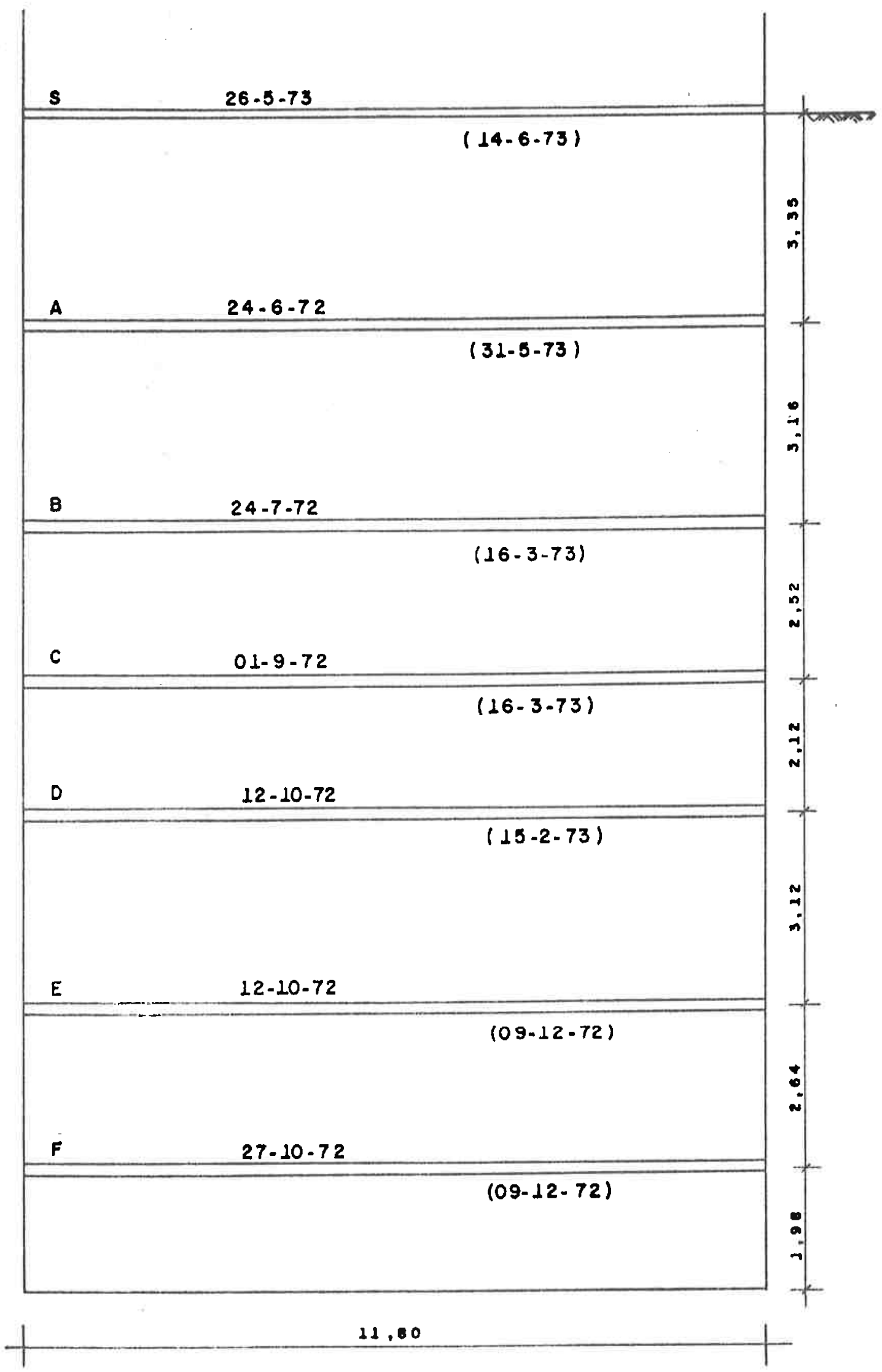

DATAS DE INSTALAGÃO E RETIRADA DAS ESTRONCAS

24-06-72. COLOCACÃO DA ESTRONCA

(32-0B.73). RETIRADA DA ESTRONCA

FIGURA B-2L SECÇĀO EXPERIMENTALN 23 
nadas IIID e IIIF; destas duas, somente a ültima foi apoiada contra uma cēlula de carga.

b) Instalaram-se nas estroncas da Secçăo I pares termo-elétricos para medidas das temperaturas. Nas camadas A, B e E, a instalação fol no interior das estroncas; nas camadas $C, D$ e $F$, nas abas superior e inferior dos perfis metālicos $H$. 


\section{APENDICE C}

FUNDAMENTOS MATEMATICOS DAS REGRESSOES DE QUE TRATA

O CAPITULO III

\section{BASES TEORICAS}

Considere-se o caso de uma vala escorada com dois ní veis de estroncas. 0 problema, tal como foi colocado no Capituzo III, con siste no estabelecimento de uma förmula do tipo

$$
\left\{\begin{array}{l}
c_{1} \\
c_{2}
\end{array}\right\}=\left\{\begin{array}{l}
c_{1}^{0} \\
c_{2}^{0}
\end{array}\right\}+\left[\begin{array}{ll}
u_{11} & u_{12} \\
u_{12} & u_{22}
\end{array}\right] \cdot\left\{\begin{array}{l}
T_{1} \\
T_{2}
\end{array}\right\}
$$

onde os $u_{i j}$ e os $c_{1}^{0}$ e $c_{2}^{0}$ são as incögnitas procuradas, de tal forma que $c_{1}$ e $C_{2}$ se aproximem ao mäximo das cargas observadas $\bar{c}_{1}$ e $\bar{c}_{2}$ nos 19 e 2\% niveis de estroncas, onde as temperaturas medidas foram $T_{1}$ e $T_{2}$, respectivamente.

$$
\begin{aligned}
& \text { Para tanto será imposto que: } \\
& \Sigma\left(c_{1}-\bar{c}_{1}\right)^{2}+\left(c_{2}-\bar{c}_{2}\right)^{2}
\end{aligned}
$$

seja um mínimo. A expressão entre colchetes é igual a:

$$
\left(c^{\prime}-\bar{c}^{\prime}\right) \cdot(c-\bar{c})
$$

onde, por exemplo, $C^{\prime}$ é o vetor transposto de $C$, cujos termos valem $c_{1}$ e $\mathrm{C}_{2}$. 
Apōs derivar a expressão $(C-2)$ em relação às incōgnitas $u_{i j}$ e $c_{1}^{0}$ e $C_{2}^{0}$, vem, tendo-se em conta as expressões $(C-3)$ e $(C-1)$ :

$$
\left[\begin{array}{ccccc}
\Sigma T_{1}^{2} & \Sigma T_{1} T_{2} & 0 & \Sigma T_{1} & 0 \\
\Sigma\left(T_{1}^{2}+T_{2}^{2}\right) & \Sigma T_{1} T_{2} & \Sigma T_{2} & \Sigma T_{1} \\
\Sigma T_{2}^{2} & 0 & \Sigma T_{2} \\
(S) & & m & 0 \\
u_{12} \\
u_{22} \\
c_{1}^{0} \\
c_{2}^{0}
\end{array}\right]=-\left[\begin{array}{c}
u_{11} \\
\Sigma \bar{C}_{1} T_{1} \\
\Sigma\left(\bar{C}_{1} T_{2}+\bar{C}_{2} T_{1}\right) \\
\Sigma \bar{C}_{2} T_{2} \\
\Sigma \bar{C}_{1} \\
\Sigma \bar{C}_{2}
\end{array}\right]
$$

Note-se que os somatörios se estendem a todo o universo de m pares de valores de cargas e temperaturas, observadas no campo.

No caso de trés niveis de estroncas, as expressões $(C-1)$ e $(C-4)$ passam a ser, respectivamente:

$$
-\left[\begin{array}{l}
c_{1} \\
c_{2} \\
c_{3}
\end{array}\right]=-\left[\begin{array}{l}
c_{1}^{0} \\
c_{2}^{0} \\
c_{3}^{0}
\end{array}\right]+\left[\begin{array}{lll}
u_{11} & u_{12} & u_{13} \\
u_{12} & u_{22} & u_{23} \\
u_{13} & u_{23} & u_{33}
\end{array}\right] \cdot\left[\begin{array}{c}
T_{1} \\
T_{2} \\
T_{3}
\end{array}\right]
$$

e:

$$
M \cdot V=R
$$

onde: 


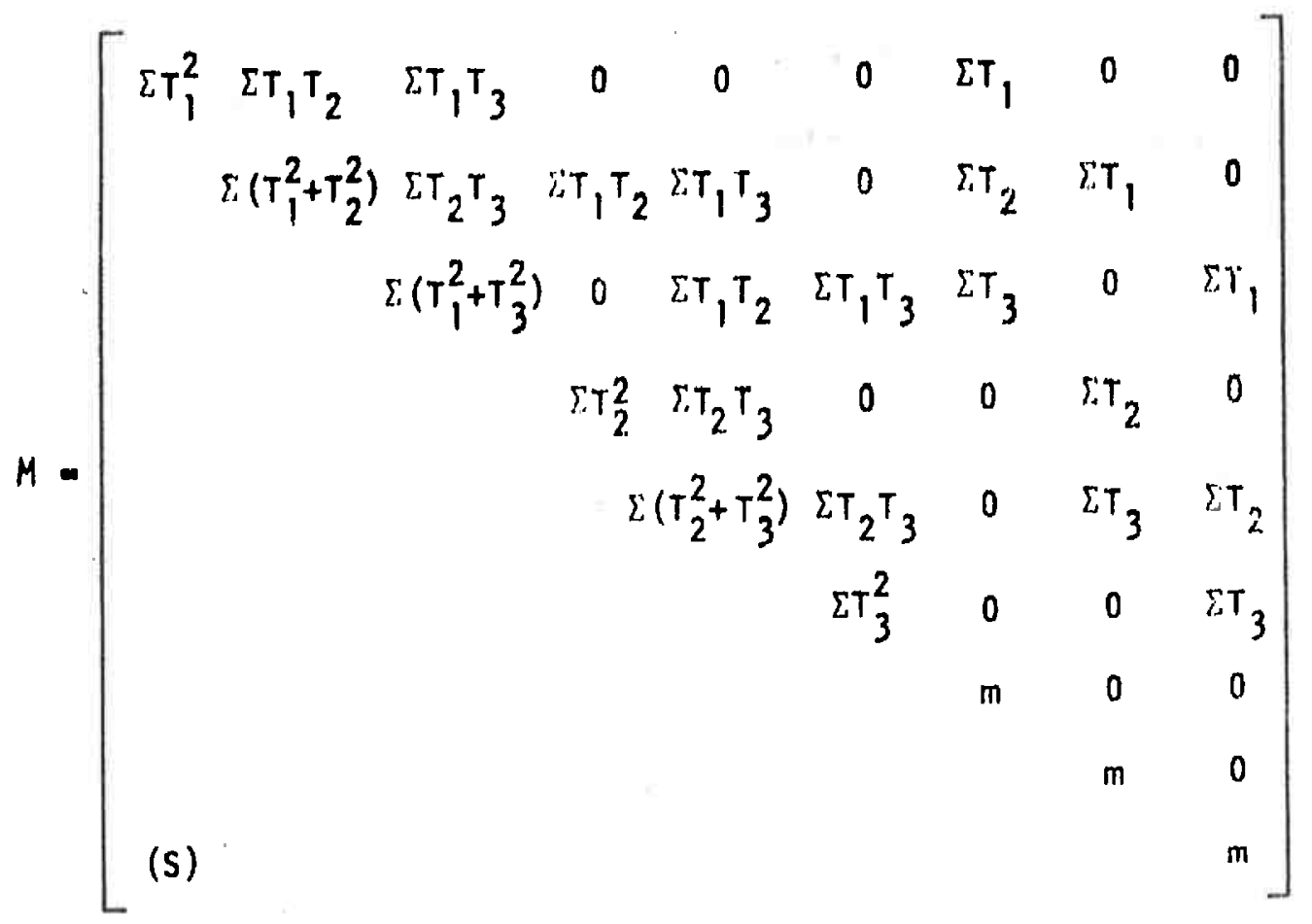

e:

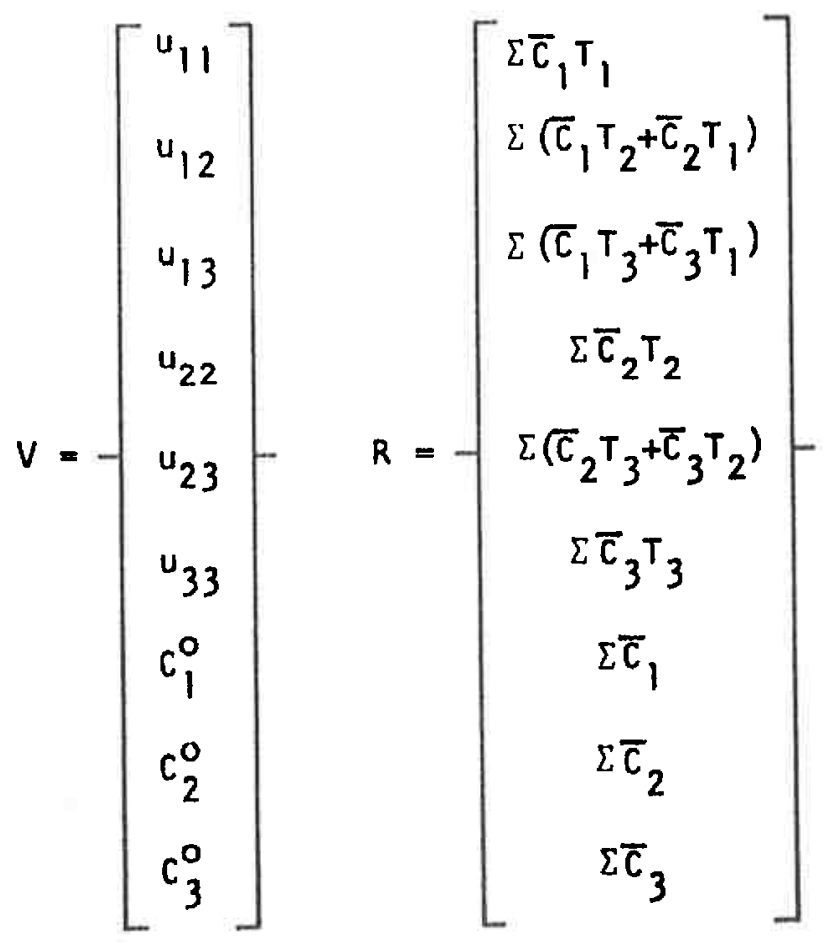

Para $n$ niveis de estroncas, a ordem da matrlz quadrada e simétrica, que aparece nas expressões $(C-4)$ e $(C-6)$, é l gual a

$$
\frac{n(n+3)}{2}
$$


Uma vez obtidos os valores das cargas calculadas, pode-se determinar, facilmente, os valores do desvio padrão e do coeficiente de correlação de cada variävel dependente.

\section{SENSIBILIDADE INERENTE DO SISTEMA DE EQUAÇÖES OBTIDO}

Os sistemas de equações dados por $(C-4)$ ou $(C-6)$ são indeterminados quando as variäveis $T_{1}, T_{2}, \ldots T_{n}$ forem linearmente depen dentes entre si.

De fato, suponha-se que, para o caso de 2 niveis de estroncas exista uma relação linear entre $T_{1}$ e $T_{2}$. Como se pode fazer uma transformação simples de variäveis de tal forma que:

$$
\Sigma T_{1}=\Sigma T_{2}=0
$$

e admitindo-se que $T_{2}=K T_{1}$, o sistema de equações $(C-4)$ se transforma em:

$$
\Sigma T_{1}^{2}\left[\begin{array}{ccc}
1 & k & 0 \\
k & 1+k^{2} & k \\
0 & k & k^{2}
\end{array}\right]\left\{\begin{array}{l}
u_{11} \\
u_{12} \\
u_{13}
\end{array}\right\}=\left\{\begin{array}{c}
\Sigma \bar{c}_{1} T_{1} \\
k \Sigma \bar{c}_{1} T_{1}+\Sigma \bar{c}_{2} T_{1} \\
k \Sigma \bar{c}_{2} T_{1}
\end{array}\right\}
$$

No entanto, o determinante desta matriz è nulo,pois, como pode ser constatado facilmente, a terceira linha é uma combinação linear entre a primeira e segunda linhas, com fatores multiplicativos de $\left(-k^{2}\right)$ e $(K)$, respectivamente; como este mesmo tipo de combinaçāo existe entre os termos do vetor do sistema de equaçōes acima, fica provada a sua indeterminação. 
173

No caso de 3 niveis de estroncas, o sistema de equações que se obtēm, supondo que

$$
\begin{aligned}
& T_{2}=K \cdot T_{1} \\
& T_{3}=L \cdot T_{1}
\end{aligned}
$$

è :

$$
\Sigma T_{1}^{2} . \quad\left[\begin{array}{cccccc}
1 & K & L & 0 & 0 & 0 \\
& 1+K^{2} & L K & K & L & 0 \\
& & 1+L^{2} & 0 & K & L \\
(S) & & L^{2} & K L & 0 \\
u_{12} & & & L^{2}+K^{2} & L K \\
u_{12} \\
u_{13} \\
u_{22} \\
u_{23} \\
u_{33}
\end{array}\right]-\left[\begin{array}{c}
u_{11} \\
K \Sigma \bar{C}_{1} T_{1}+\Sigma \bar{C}_{2} T_{1} \\
L \Sigma \bar{C}_{1} T_{1}+\Sigma \bar{C}_{3} T_{1} \\
K \Sigma \bar{C}_{2} T_{1} \\
L \Sigma \bar{C}_{2} T_{1}+K \Sigma \bar{C}_{3} T_{1} \\
L \Sigma \bar{C}_{3} T_{1}
\end{array}\right]-
$$

que tambëm ë indeterminado, pois a quinta linha è uma combinação linear das primeira, segunda e terceira linhas, com fatores multiplicativos iguais a $\left(1+K^{2}\right)(L / K),(-L)$ e $(-1 / K)$, respectivamente, $e$ isto inclui os termos do vetor do segundo membro.

Se, ao invés de uma relação matemática perfeita entre $T_{1}, T_{2}, \ldots T_{n}$ existissem correlaçōes estatisticas, com coeficientes de correlação pröximos de $100 \%$ (dependência total), os sistemas de equa ções $(C-4)$ ou $(C-6)$ passariam a ter uma sensibilidade inerente no sentido indicado por Wilkinson (1968). Em outras palavras, pequenos desvios (perturbações) nos valores dos coeficientes das matrizes e do vetor dos termos independentes poderiam provocar mudanças sensiveis nos valores das incōgnitas. 


\title{
APENDICE D
}

\section{PROPRIEDADES DA MATRIZ DOS GRADIENTES BASICOS}

\begin{abstract}
A Matriz U dos Gradientes Bäsicos, introduzida pela expressão (III-1) do Copĩtuzo III, possui quatro propriedades de interes se a esta Investigação. As demonstraçōes relativas às duas primeiras e à ültima delas podem ser encontradas em Pipes e Hovanessian (1969). A tercei ra delas será provada mais adiante.
\end{abstract}

\section{PROPRIEDADES DA MATRIZ U}

a) Propriedade 1: Sendo a matriz U simëtrica e real, os seus autovalores são reais.

b) Propriedade 2: Os autovetores associados a diferentes autovalores da matriz U são ortogonais entre si. Como corolário, se um dos seus auto vetores tiver todos os termos positivos, qualquer outro terä pelo menos um termo negativo, mas não todos ao mesmo tempo.

c) Propriedade 3: Admitindo-se, por hipōtese, que: 19) os termos da diagonal principal de $U$ são todos positivos; e 2\%) existe um autovetor $T_{m}$ com todos os termos positivos, então o autovalor $\lambda_{m}$ a ele associado è o minimo dos autovalores de U.

d) Propriedade 4: Se a matriz U tem um autovalor $\lambda$ associado ao autovetor $T$, então a matriz $P(U)$, em que $P \vec{e}$ uma função racional, tem um au tovalor $P(\lambda)$ e o mesmo autovetor $T$. 
2. DEMONSTRAÇAOO DA PROPRIEDADE 3

Para demonstrar a Propriedade 3, note-se iniclalmen-

te que:

$$
\lambda_{m}<u_{11}, 1=1,2, \ldots \ldots n
$$

ou seja, $\lambda_{m}$ è menor que qualquer elemento da diagonal principal de $U$, condição para que a expressão (III-10) possa ser verificada. De fato, da exprescão $(I I I-10)$ deduz-se que:

$$
\sum_{j \neq i} u_{i j} \cdot t_{i}+\left(u_{i i}-\lambda_{m}\right)=0, i=1,2, \ldots n(0-2)
$$

e como

$$
u_{i j}=u_{j i}<0 \text { para } i \neq j
$$

e

$$
t_{i}>0, i=1,2, \ldots n,
$$

resulta necessariamente a desigualdade $(D-1)$.

2.1. Natriz $U$ de ordem 2

$$
\begin{aligned}
& \text { Para } n=2 \text { a expressão }(D-2) \text { reduz-se a: } \\
& \left\{\begin{array}{l}
\left(u_{11}-\lambda\right) \cdot t_{1}+u_{12} \cdot t_{2}=0 \\
u_{21} \cdot t_{1}+\left(u_{22}-\lambda\right) \cdot t_{2}=0
\end{array}\right.
\end{aligned}
$$

onde $t_{1}$ e $t_{2}$ são termos do vetor T. Logo: 


$$
\frac{t_{1}}{t_{2}}=\frac{-u_{12}}{u_{11}-\lambda}=\frac{u_{22}-\lambda}{-u_{21}}
$$

Se existisse um $\lambda_{p}<\lambda_{m}$, a ele corresponderiam valores de $t_{1} / t_{2}$ positivos, pois $u_{21}<0$ e vale a expressão $(D-1)$; isto $\dot{\mathrm{e}}$, o autovetor $\mathrm{T}_{\mathrm{p}}$ teria todos os termos positivos ou negativos, o que contrariaria o corolärioda Propriedade 2. Logo, $\lambda_{\mathrm{m}}$ é o mínimo dos autovalores de U.

2.2. Matriz $U$ de ordem 3

Para $n=3$, a demonstração é fei ta tambën por redução ao absurdo. Suponha-se que exista um $\lambda_{s}<\lambda_{m} e$, associado a ele, um autovetor $T_{5}$ com os termos $t_{1}^{s}, t_{2}^{s}$ e $t_{3}^{s}$. Do corotärio da Propriedade 2 segue que todos os $t_{i}^{s}$ não podem ser positivos ou negativos ao mesmo tempo. Donde resultam seis possibilidades de combinações de seus sinais, mas nenhuma delas satisfaz todas as equações implicitas na expressão $(D-2)$, o que $\dot{e}$ absurdo. Por exemplo, se:

$$
\mathrm{t}_{1}^{\mathrm{s}}>0, \mathrm{t}_{2}^{\mathrm{s}}<0 \text { e } \mathrm{t}_{3}^{\mathrm{s}}<0
$$

a igualdade:

$$
u_{21} \cdot t_{1}^{s}+\left(u_{22}-\lambda_{s}\right) \cdot t_{2}^{s}+u_{23} \cdot t_{3}^{s}=0
$$

não se verifica, pois todos os seus termos são negativos. A redução ao absurdo ainda se mantēm, mesmo que alguns dos $t_{i}^{s}$ sejam nulos.

\section{‥3. Matriz U qualquer}

A extensão da Propriedade 3 para qualquer valor de $\underline{\mathrm{n}}$ pode ser feita recorrendo-se ao quociente de Rayleigh dado por: 


$$
\lambda_{R}=\frac{T^{\prime} \cdot U \cdot T}{T^{\prime} \cdot T}
$$

Nesta expressão $T^{\prime} \dot{e}$ o transposto de $T$, que $\dot{e}$ um vetor de coeficlentes $t^{*}$

$$
\begin{aligned}
& \text { Logo, pode-se escrever: } \\
& \lambda_{R}=\frac{\Sigma u_{i i} \cdot t_{i}^{2}+2 \sum_{j j}^{i \neq u_{i j} \cdot t_{i} \cdot t_{j}}}{\Sigma t_{i}^{2}}
\end{aligned}
$$

Seja $\lambda_{S}$ o mínimo dos $\lambda_{R}$ para qualquer T. Sabe-se que $\lambda_{5}$ ë o menor dos autovalores de U (veja-se, por exemplo, Wilkinson, 1965); - autovetor asścciado a ele serä designado por $T_{s}$.

Se $\lambda_{s}<\lambda_{m}$, então, pelo corolärio da Propriedade 2 , pelo menos um dos.coeficientes de $T_{s} \bar{e}$ negativo, isto $\bar{e}$, existe um

$$
t_{k}^{s}<0
$$

Ao vetor $T_{p}$, definido da seguinte forma:

$$
\begin{aligned}
& t_{i}^{p}=t_{i}^{s} \quad \text { para } i \neq k \\
& t_{k}^{p}=-t_{k}^{s}
\end{aligned}
$$

estā associado um Quociente de Rayleigh menor do que $\lambda_{s}$, o que $\dot{e}$ absurdo. 


\section{APENDICE E \\ DISCUSSAOO DE ALGUMAS HIPOTESES INCORPORADAS AO MO- DELO MATEMATICO DO CAPTTULO IV}

\section{VIGAS DE DISTRIBUIÇÃO COM RIGIDEZ INFINITA}

Admitiu-se que as vigas de distribuição, colocadas horizontalmente entre as estroncas e as paredes de escoramento, possuiam rigidez infinita. Isto implica na suposição,implicita na expressão IV-2 do Capĩtulo IV, de as reações das cargas pontuais, transmitidas pelas estroncas, serem linear e uniformemente distribuidas.

A fim de avaliar a validade desta hipótese simplifi cadora valeu-se da solução teōrica de uma viga solicitada por carregamen to estático e apoiada sobre base elästica, ocupando um espaço semi-infinito, utilizada por Timoshenko (1958, päginas 17 e seguintes do Tomo II) no estudo da flexão de trilhos ferroviärios.

A força reativa $F$, linearmente distribuida no conta to viga-base elästica, è dada por:

$$
F=\frac{P B}{2} \cdot e^{-B x}(\cos B x+\operatorname{sen} B x)
$$

onde $P$ è a única força vertical atuando sobre a viga $e$

$$
B=\sqrt[4]{\frac{K}{4 E J}}
$$

mede a rigidez relativa entre o solo, tomado como meio elástico, e o material da viga, com mödulo de elasticldade $E$ e momento de inércia J. 0 
parâmetro $K$ è a força, linearmente distribuída, de reação do solo, para um recalque unitärio. Quando a tuam värias forças, a soluçäo è obtida aplicando-se o princípio de superposiçào.

Para uma estimativa de $K$ considerou-se a dilatação tërmica das estroncas como verdadeiras provas de carga, pois imprimem uma força $C$ e um deslocamento $\delta$ à parede, do que resulta, em primeira aproximaçāo:

$$
K=\frac{C}{\delta t}
$$

sendo $t$ o espaçamento entre elas, em planta.

Para as Secçōes Experimentais com paredes flexiveis os valores de $\mathrm{K}$ crescem com a profundidade, de 100 a $550 \mathrm{~kg} / \mathrm{cm}^{2}$, valores estes calculados com base numa expressão anăloga à III-3 do Capítulo III. Se as vigas de distribuição forem perfis $112^{\prime \prime}, \beta$ assume valores de 0,55 a $0,85 \mathrm{~m}^{-1}$; com perfis $118^{11}$, estes nümeros passam a ser 0,4 a $0,6 \mathrm{~m}^{-1}$.

Vê-se assim que as situações de maior flexibilidade relativa correspondem a valores de $\beta$ da ordem de 0,85 . Por isso foi cons truído o gráfico da figura E-1, que mostra como a força $F$ se distribul no contato da viga com a parede de escoramento. Para espaçamentos em planta (t) entre estroncas de até $2,5 \mathrm{~m}$ a sua distribuição è praticamente uniforme, o que torna vālida a hipōtese de rigidez infinita para as Secções Experimentais do Metrō de São Paulo (ver valores do espaçamento t na tabela III-1). No caso de $\mathrm{t}=2 \mathrm{~m}$, a força distribuída varia de +5 a $-5 \%$ do seu valor mëdio, no ponto de aplicação da carga $P$ e a meia distância entre duas cargas, respectivamente. Se $t=2,5 \mathrm{~m}$, estes percentuais assumem valores de cerca de $\pm 10 \%$. 


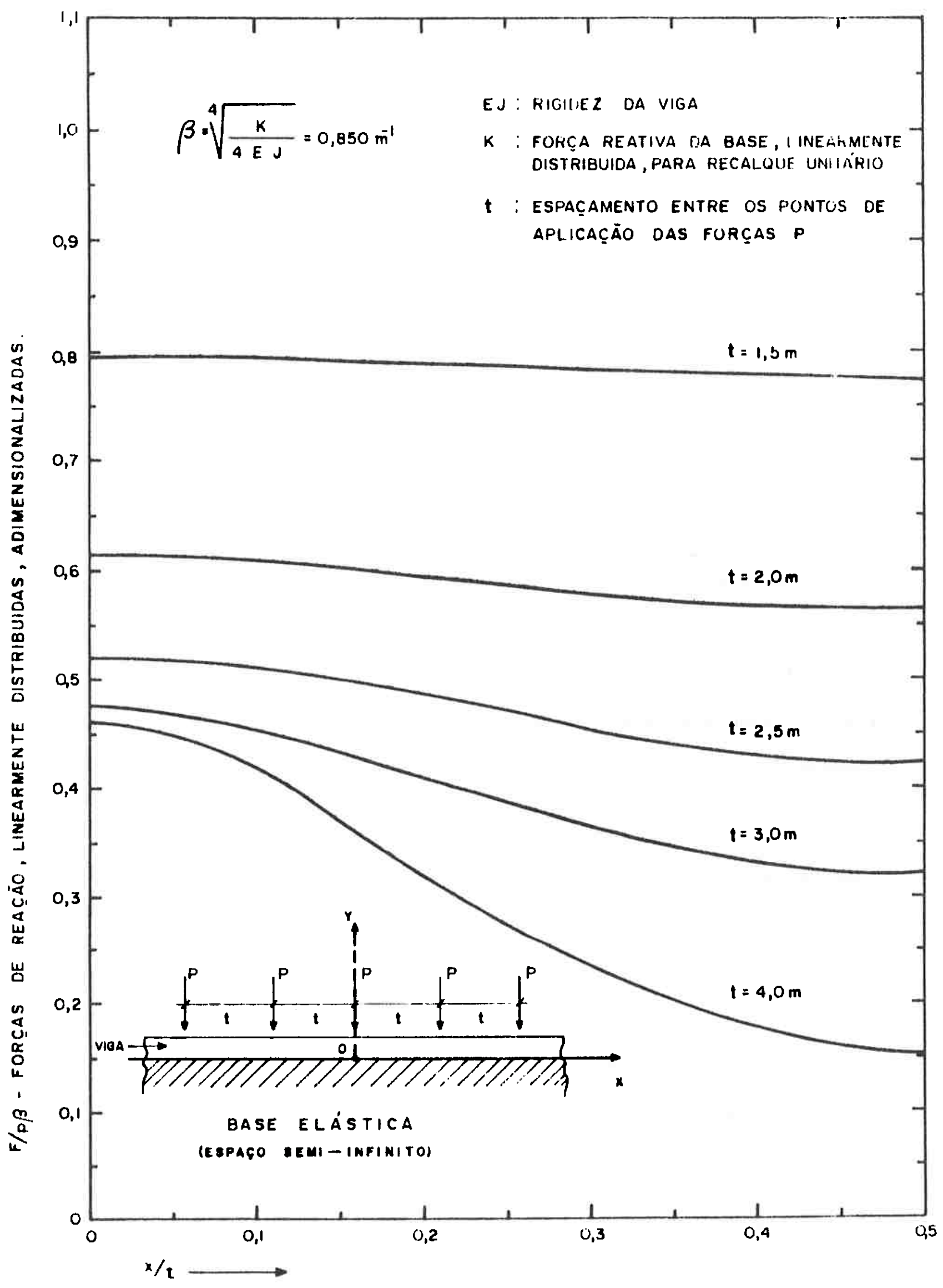

figura E-I :Forças de REAçĀo, No contato VIGA-BASE ELÁSTICA 
distribuição são longas, is to è, quando

$$
B \ell^{\prime}>5
$$

sendo $\ell '$ o seu comprimento. Nas Secções Experimentais, via de regra, havia pelo menos 4 estroncas apolando-se numa mesma viga, o que implicou em comprimentos minimos de $6 \mathrm{~m}$ ou mals, que verifica a desigualdade acima, pelo menos para $\beta=0,85$.

\section{EFEITO DA TEMPERATURA EM PAREDES DE SISTEMAS DE ESCORAMENTOS}

Em trabalho ci tado na revisão bibliogrāfica do Cap $\underline{i}$ tulo I, Rémy et al (1974) fazem menção ao efelto da temperatura nas pare des diafragmas de sistemas de escoramento, que introduziria acrëscimos de cargas nas estroncas dos niveis intermediärios. Estes acréscimos deve riam ser superpostos ãqueles provenientes da dilatação tërmica das estroncas.

Como o modelo matemático elaborado no Capítulo IV ignorou este efeito, procurou-se fazer uma avaliação quantitativa do mes mo, recorrendo-se novamente ao Método dos Elementos Fini tos e a estudos analiticos desenvolvidos por Westergaard para pavimentos de concreto sujeitos a variações tērmicas.

Antes, contudo, foi necessārio valer-se de alguns relatos de medições de temperatura em pavimentos de concreto e em solos, para que se tivessem os subsidios que tornaram viävel esta empreitada.

2.1. Medições de Temperatura em Lajes de Concreto e em Solos

Teller (1935) apresentou resultados interessantes de medidas de temperatura em pavimentos de concreto, com 15 e $22,5 \mathrm{~cm}$ de 
espessura, através de pares termo-elètricos colocados no seu interlor, a cada $2,54 \mathrm{~cm}$, nas superfícies do topo e da base e, inclusive, no solo subjacente, atēi cerca de $5 \mathrm{~cm}$ de profundidade.

Eis algumas de suas conclusões:

a) a temperatura do concreto é controlada pela temperatura do ar; pelo ângulo de incidência dos raios solares; pela temperatura do solo, que flutua com a temperatura média do ar dos dias anteriores; pela umidade relativa do ar e pelas condiçōes de umidade do solo;

b) bem cedo e à tarde, quando ocorrem as malores diferenças entre as tem peraturas do topo e da base, os gradientes de temperatura, ao longo da espessura da laje, são constantes;

c) em algumas estaçōes do ano a temperatura no topo da laje chegou a superar de cerca de 5 a $11^{\circ} \mathrm{C}$ a temperatura do ar; a diferença $\vec{e}$ tanto maior quanto maior for o ângulo de incldencla dos ralos solares; e d) a diferença entre as temperaturas máximas e mínimas, no topo da laje, foi de cerca de $20^{\circ} \mathrm{C}$, no dia mais quente, em que as temperaturas do ar e da superficie do concreto atingiram $32^{\circ} \mathrm{C}$ e $43^{\circ} \mathrm{C}$, respectivamente.

E Importante frisar que enquanto a superfície da la je se aquece por radiação térmica, o solo esquenta-se por condução, e se comporta como um reservatório de grande capacidade atuando como um estabillizador tërmico. Assim, o ciclo diärio de variação de temperatura não chega a influir significativamente na temperatura do solo, mas o ciclo anual o faz, atè profundidades de $10 \mathrm{~m}$ ou mais (veja-se Keen, 1931).

Experiências feltas em latossolo roxo de Ribeiräo Preto, citados por Ortolani e Pinto (1972), em que foram medidas a varia ção geotērmica horária a profundidadesde atē $1 \mathrm{~m}$, mostraram que:

a) para o solo nu e profundidadessuperiores a $0,5 \mathrm{~m}$, a temperatura ë pra 
ticamente constante e cerca de $12{ }^{\circ} \mathrm{C}$ inferior à da superficie; existindo alguma cobertura, gramado, por exemplo, esta diferença è bem me nor;

b) na superficie do terreno, num mesmo dia, a diferença entre as tempera turas mäxima e minima não atlnge $20^{\circ} \mathrm{C}$ para o solo nu, e $10^{\circ} \mathrm{C}$ para o so lo recoberto; para profundidades superiores a $0,50 \mathrm{~m}$ a diferença entre as temperaturas do solo nue osolo recoberto è da ordem de $2^{\circ} \mathrm{C}$; e

c) durante o ano, os valores médios mensais de temperatura variaram de 20 a $24^{\circ} \mathrm{C}$ a $1 \mathrm{~m}$ de profundidade, onde a temperatura mëdia anual foi de $22,3^{\circ} \mathrm{C}$ para una temperatura média anual do ar de $21,8^{\circ} \mathrm{C}$.

Este ültimo fato foi também realçado por Leinz $e$ Amaral (1966), para quem, de um modo geral, a temperatura média anual do ar controla a temperatura do solo atē 10 a $20 \mathrm{~m}$ de profundidade. Dai para baixo a temperatura cresce continuamente de cerca de $1^{\circ} \mathrm{C}$ a cada $30 \mathrm{~m}$, em mēdia.

2.2. Hipöteses Concernentes à Variação da Temperatura nas Paredes Diafragma

Com base nestas informações, serä admitido que a temperatura do solo em contato com o concreto permanece constante, com um valor de $20^{\circ} \mathrm{C}$. Na face externa da parede, em contato com o ar ambiente, tomar-se-ā a temperatura com um valor de $40^{\circ} \mathrm{C}$ no plano da superfície do terreno, diminuindo linearmente atē $30^{\circ} \mathrm{C}$ ( 1 a hipótese) ou $20^{\circ} \mathrm{C}$ ( 2 a hipōtese) na posição do fundo da vala.

A forma de variação de $40^{\circ} \mathrm{C}$ a $20^{\circ} \mathrm{C}$ (1. h hipötese) coincide aproximadamente com aquela observada nas estroncas dos diversos niveis da Secção Experimental 7, com paredes rígidas, conforme dados da tabela III-1. Como os raios solares incldem sobre as estroncas com um 
ângulo muito maior do que nas paredes diafragmas, ela é bastante severa. As hipöteses adotadas quanto aos incrementos de temperatura foram as seguintes:

a) gradientes de temperatura constantes ao longo da espessura da parede;

b) Incrementos de temperatura nulos na interface concretomsolo; e

c) incrementos de temperatura decrescendo llnearmente com a profundidade na face da parede exposta ao ar.

2.3. Aplicação do Método dos Elementos Finitos

Considere-se novamente uma vala escorada com paredes continuas e admita-se que somente ela sofra os efeitos da temperatura. Pode-se escrever, no lugar da expressão (IV-7):

$$
\left(\bar{K}_{s}+\rho \bar{K}_{c}+n \bar{K}_{b}\right) \delta=\frac{E_{c} \cdot \alpha}{\left(1-2 \nu_{c}\right) E_{s} t} \Sigma B^{\top} \cdot\left(\begin{array}{c}
\Delta T \\
\Delta T \\
0
\end{array}\right)
$$

onde $\bar{K}_{c}$ è a matriz de rigidez da parede contínua, a menos de um escalar; B é a matriz definida pela expressão $(I V-3)$ e $\Delta T$ o incremento de tempera tura, variável de ponto a ponto no interior da parede de escoramento. № te-se que o 29 membro desta expressāo fol obtido impondo-se uma deformação inicial ao elemento, dada por

$$
\varepsilon_{0}=\left\{\begin{array}{c}
\infty \Delta T \\
\alpha \Delta T \\
0
\end{array}\right\}
$$

- que equivale a aplicar as seguintes forças nodais (veja-se Zienkiewicz, 1972):

$$
B^{T} \cdot D \cdot \varepsilon_{0}=\frac{E_{c} \cdot \alpha}{1-2 \nu_{c}} B^{\top} \cdot\left(\begin{array}{c}
\Delta T \\
\Delta T \\
0
\end{array}\right\}
$$


D ë a matriz de elasticidade, introduzida pela expressão (IV-4).

Seguindo orientação anāloga àquela imprimida por Westergaard (1926), quando analisou o comportamento de pavimentos de con creto sujeitos a variaçōes de temperatura, introduziu-se o Fator de Rigi dez Relativa Parede-Solo, como sendo:

$$
M=\sqrt[4]{\frac{E_{c} \cdot h^{3}}{12\left(1-v_{c}^{2}\right) E_{s} t}}
$$

onde $E_{c}$, $\nu_{c}$ e h säo, respectivamente, o Módulo de Elasticidade, o Coeficiente de Poisson e a espessura da parede contínua de concreto; $E_{5}$, O Mödulo de Deformabilidade do solo e t,o espaçamento entre estroneas, em planta. Tem-se, assim, a expressão:

$$
\left(\bar{K}_{s}+\rho \bar{K}_{c}+n \bar{K}_{b}\right) \cdot \delta=M^{4} \cdot \frac{\alpha \cdot\left(1-\nu_{c}^{2}\right)}{\left(1-2 \nu_{c}\right) h^{3}} \Sigma B T \cdot\left\{\begin{array}{c}
\Delta T \\
\Delta T \\
0
\end{array}\right\}
$$

Uma vez formulado matematicamente o problema passou-se a uma aplicação prātica, relacionada com a vala indicada na figura IV-1. Fixou-se o parâmetro $\eta=1,0$ e a espessura da parede de escoramento em $h=1,0 \mathrm{~m}$, e permitiu-se que $M$ variasse de 0,5 , que corresponde a paredes mais flexiveis, a 2,0, paredes mais rígidas.

Foram utilizados elementos finitos isoparamétricos retangulares para a parede de escoramento. Num dos casos estudados, que serão apresentados a seguir, utilizou-se ora os elementos con modos compativeis, ora com modos incompativeis, estes ültimos introduzidos por Wilzon (1971), pols os primeiros não conseguem reproduzir certas varlações de tensões, quando solicitados à flexão, como ocorre no problema em pauta. As diferenças encontradas num e noutro caso foram da ordem de $10 \%$ no deslocamento horizontal do topo da parede e de cerca de $3 \%$ no valor 


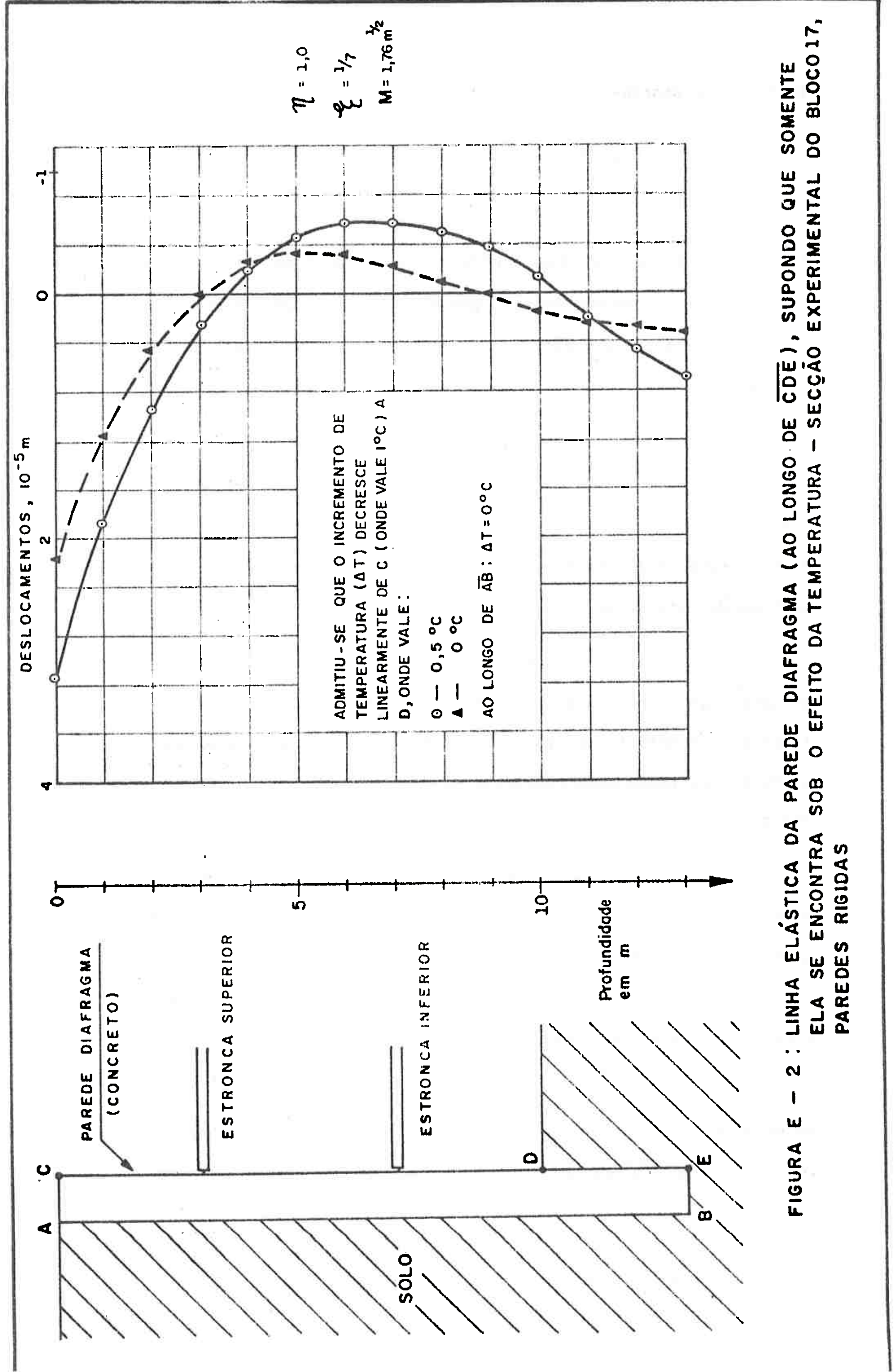


da força de compressão na estronca do nível inferior.

\subsection{Resultados obtidos}

A figura E-2 mostra, a titulo de llustração, as linhas elästicas para as duas hipōteses de varlação da temperatura, enuncia das no item 2.2. acima. Note-se que è um caso em que a rigidez da parede é bastante elevada e a estronca superior é aliviada de uma parcela de sua carga iniclal.

Convēm realçar novamente a suposição de que somente a parede de escoramento sofre os efeitos da dilatação térmica. Os aumentos ou alivios de carga devem ser superpostos às forças prē-existentes de compressão e aos incrementos de carga devidos ao efeito da di latação térmica das estroncas.

A figura E-3 apresenta os valores dos incrementos de carga nas estroncas do nível inferior, em função do Fator de Rigidez Relativa Parede-Solo. A linearidade constatada na correlação não è de to do fortuita, tendo sido inspirada no jà cltado trabalho de Westergaard (1926).

A primazia da espessura h da parede sobre os outros parâmetros é patente. Por exemplo, aumentando-a de 80 para $100 \mathrm{~cm}, a$ força na estronca é multiplicada por 1,6, mantidos os outros parâmetros constantes. Isto é equivalente a reduzir a rigidez do solo $\left(E_{s} t\right)$ de $(1,25)^{3}=2$ vezes, aproximadamente, ou ainda a duplicar o $E_{c}$.

E curioso notar que o deslocamento horizontal do to po da parede, ponto $C$ da figura $E-2$, correlacionou-se da seguinte forma com o Fator de Rigidez Relativa Parede-Solo:

$$
\delta_{c}=0,685(1+0,918) \cdot \propto \cdot M^{2}
$$




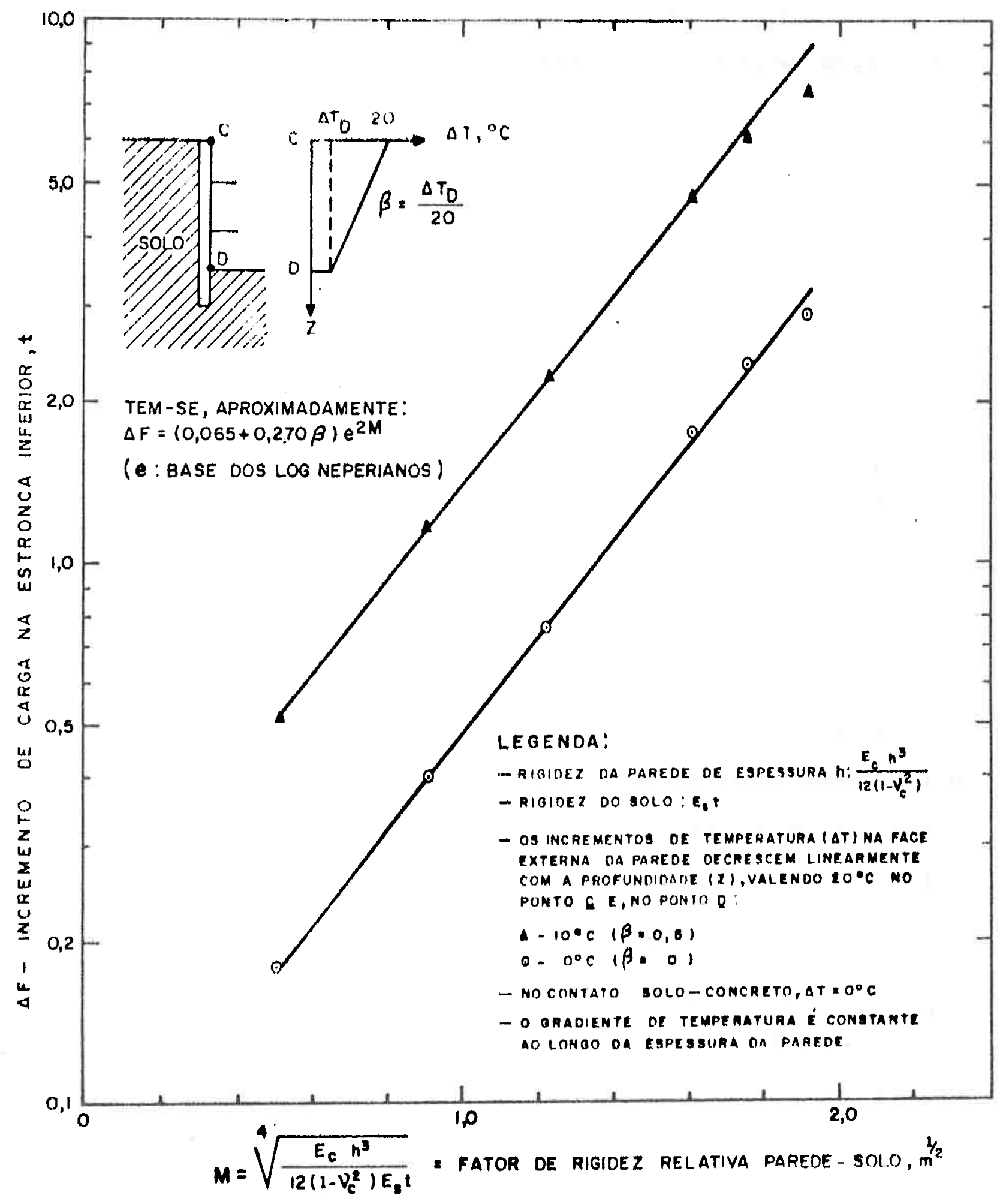

FIGURA E - 3: INCREMENTO DE CARGA NA ESTRONCA INFERIOR EM FUNÇÃO DO FATOR DE RIGIDEZ RELATIVA, PAREDE - SOLO, QUANDO SÓ A PAREDE CONTINUUA DE ESCORAMENTO ESTÁ SOB O EFEITO DA TEMPERATURA 
com coeficiente de correlaçāo de $100 \%$. Para $B=1$, isto é, supondo incrementos de temperatura uniformes em toda a face externa da parede (ver figura $E-3)$, tem-se:

$$
\delta_{c}=1,31 \propto \cdot M^{2}
$$

que se compara multo bem com o valor:

$$
\delta_{c}=\frac{1+\nu_{c}}{h} \cdot \propto \cdot M^{2}
$$

deduzido por Westergaard, para os bordos de lajes de concreto apoiadas em solos.

Voltando-se à tabela III-1, à Secção Experimental do Bloco 17, paredes rígidas, correspondem os seguintes valores:

a) $\xi=1 / 5$ a $1 / 10$ ou $M=1,47$ a 1,24 ;

b) incrementos relativos de temperatura iguais a 1 e 0,80 (valores adota dos) para as estroncas do nivel superior e inferior, respectivamente; e

c) gradiente na estronca inferior, em final de escavação, de $0,85 \mathrm{t} /{ }^{\circ} \mathrm{C}$.

Para um incremento de temperatura de $40^{\circ} \mathrm{C}$ na estron ca superior, tem-se, na estronca inferior, um incremento de carga de:

$$
40 \times 0,80 \times 0,85=27 t
$$

Os incrementos de carga advindos só do efeito da temperatura na parede de escoramento (ver figura $E-3$ ) variam de 2,4 a 4,0 t, na hipótese mais severa de incrementos de temperatura, o que significa desvios de $9 \%$ a 16 \% quando comparados com os incrementos de carga resultantes só do efe to da dillatação tērmica das estroncas. 
Na prätica as coisas não ocorrem como se supōs no modelo matemático, não somente no que se refere à forma de variação dos incrementos de temperatura com a profundidade, na face exposta do concre to, como também pela assimetría e não simultaneidade do aquecimento das paredes, ora de um lado, ora de outro lado da vala.

Diante destas considerações e tendo em vista que:

a) o efeito da temperatura nas paredes flexiveis pode ser desprezado, co mo mostra a figura $E-3$ para baixos valores de $M$; e

b) para valas mais profundas do que a estudada no modelo matemātico è de se esperar um efeito maior nas estroncas dos nivels intermediärios, af irmação esta que encontra respaldo no trabalho de Westergaard para pavimentos, guardadas as distāncias entre um problema e outro, resolveu-se ignorar, em primeira aproximação, o efei to em foco, tomandose algumas precauções quanto a paredes rigidas, como estä exposto no $\mathrm{Ca}$ pitulo VI, item 4.2.

\section{SIMULAÇÃO DAS PAREDES FLEXIVEIS POR PAREDES CONTINUAS}

Para facilitar a aplicação do Método dos Elementos Finitos, as paredes de escoramentos flexiveis foram simuladas por meio de paredes continuas equivalentes, de espessura constante.

Abstração feita aos pranchöes de madeira, admitiuse, em primeira apróximação que:

$$
E_{a} J_{a}=E_{p} J_{p}
$$

onde $E_{a}$ e $J_{a}$ são, respectivamente, os mödulos de elasticidade e o momento de inërcla, das estacas metälicas; e $E_{p}$ e $J_{p}$ os correspondentes valo- 
res para as paredes contínuas. Os pranchões de madeira não acrescentam nenhuma parcela de rigidez às estacas metälicas, pois o seu flexionamento, quando è excessivo, provoca um arqueamento do solo com a consequente redistribuição de esforços, que passam a sollicitar diretamente as estacas metällcas.

A validade da hipōtese implícita em $(E '-9)$ é patente se forem observadas detidamente as expressões $(E-2)$ e $(E-6)$, relacionadas com vigas e lajes, respectivamente, e onde intervēm o produto EJ que, sendo invariante, resulta na univocidade de seus comportamentos.

A outra hipōtese refere-se ao estado plano de defor mação; is to é, as paredes equivalentes foram consideradas continuas. A alternativa seria a simulação atravēs de paredes discretas, com compria mento constante, uma para cada estaca metālica. Neste caso, o problema se ria de estado plano de tensão e a equivaléncia estabelecida ainda pela expressão $(E-9)$.

A aplicação do procedimento de cālculo, delineado no CapítuZo IV, à Seç̧ão Experimental 6, admitindo-se estado plano de ten são, conduziu ao seguinte resultado:

$$
U=\left[\begin{array}{rrr}
233 & -129 & -27 \\
-129 & 497 & -144 \\
-27 & -144 & 799
\end{array}\right]
$$

e, supondo estado plano de deformação:

$$
U=\left[\begin{array}{rrr}
238 & -134 & -28 \\
-134 & 511 & -153 \\
-28 & -153 & 827
\end{array}\right]
$$

Vê-se que para os termos da diagonal principal o māximo desvio è de 
$3,5 \%$. Para incrementos relativos de temperatura de $1,00,0,72$ e 0,44 , os gradientes de carga-temperatura diferem somente no $3:$ nivel de estron cas, de un valor de apenas $0,011 \mathrm{t} /{ }^{\circ} \mathrm{C}$. 


\section{APANHADO GERAL SOBRE AS PROPRIEDADES GEOTECNICAS DE SO- LOS DA CIDADE DE SÃO PAULO DE INTERESSE A ESTE ESTUDO}

\section{PRELIMINARES}

- A Cidade de São Paulo estã construída numa bacia sedimentar terciäria, sobreposta a rochas pré-cambrianas constituídas de granitos, gnaisses, micaxistos, quartzitos e calcáreos. Esta bacia possui uma forma elítica, com o seu eixo maior, de 60 a $70 \mathrm{~km}$ de comprimento, estendendo-se de Este a Oeste; e o seu eixo menor, de $40 \mathrm{~km}$, na dire ção Norte-Sul.

0 relevo topogräfico è relativamente suave, com montes arredondados ou tabulares, em contraste marcante com as montanhas circundantes, que atingem 100 a $300 \mathrm{~m}$ acima do ponto mais elevado da cidade, cota $831 \mathrm{~m}$; a cota mais baixa è encontrada no Rio Tietê, $718 \mathrm{~m}$. Acompanhando a Rua Cerro Corá, Av. Heitor Penteado, Av. Paulista e Av. Ja baquara, encontra-se um alongamento do divisor de ăguas que domina esse espigão central de cotas medeando entre 810 e $830 \mathrm{~m}$.

A espessura de sedimentos é muito variävel, sendo de 100 a 120 m no Vale do Anhangabaū, Rua Nestor Pestana e Parque D. Pedro II, $10 \mathrm{~m}$ na Av. Angëllca, $180 \mathrm{~m}$ ao longo da Av. Paullsta e no bairro da Moōca.

Em sua tese de doutoramento, Cozzolino (1972) apresenta perfis geológicos mostrando as diversas ocorrênclas de sedimentos, a té o embasamento rochoso, bem como os conhecimentos atuais sobre a gêne 
se destas formaçōes.

A origem tectônica da bacia, confirmada por estudos conduzidos por $E$. de Almeida, bem como a alternâncla de regimes torrencial e lacustre que predominaram durante a época de sua formação, explicam a extrema heterogeneidade dos solos da Cidade de São Paulo. Inicialmente, teriam se formado lagos com o represamento das äguas do Rio Tletê, graças ao escorregamento de solos residuais, resultantes da decomposição das rochas cristalinas. Em seguida, solos argilosos e siltosos das encos tas foram carreados pelas äguas da chuva para dentro dos lagos, iniciando um ciclo de sedimentação. Posteriormente, o Rio Tietê teria rompido a barreira que interrompera seu curso e iniciado o processo de erosão do material depositado, dando forma ao atual relevo. Mais tarde, pröximo ao canal do rio, foram se acumulando os aluviões quaternārios.

$$
\text { Os solos superficiais que recobrem os morros, }
$$

nas partes mais altas da cidade, são extremamente ricos em ferro e exibem uma coloração vermelha intensa. Foram encontrados valores de 4 a $5 \%$ de óxido de ferro; nos primeiros metros da camada deste solo; à profundidade de 4 a $6 \mathrm{~m}$, estes valores subiram para $16 \%$.

$$
\text { Uma outra característica dos solos da bacia de São }
$$

Paulo é a sua grande heterogeneidade tambëm no que se refere ao pré-aden samento que, para a sua maior parte, não guarda nenhuma relação com o pe so de terra erodida. Atribui-se este fato a processos de ressecamento, cimentação e lixiviação, entre outros. Constituem-se, no entanto, em exceção, as argilas duras cinzas esverdeadas, que ocorrem sempre abaixo do presente nível de drenagem, cota $715 \mathrm{~m}$, mantendo a sua pressão de préadensamento original.

Os solos de São Paulo, principalmente no centro da cidade, têm sido de há muito tempo objeto de estudos de quem se dedica 
aos problemas de fundações e de escavaçōes. Pichler (1948), Vargas (1948 e 1954), Rios e Pacheco Silva (1948), Oliveira Pinto e Kutner (1950), De Mello e Teixeira (1962) e Teixeira (1970) apresentaram dados sobre as ca racteristicas geotëcnicas de algumas ocorrências das Argllas Porosas e dos Solos Varlegados.

Por ocaslão dos estudos para o projeto e para as Sec ções Experimentals do Metropolitano, o Instituto de Pesquisas Tecnológicas teve a oportunidade de realizar um nümero razoavelmente grande de en saios sobre amostras do subsolo de São Paulo, das quais a maior parte provinha de camada de Solos Variegados e das Argilas Porosas Vermelhas. As caracteristicas apresentadas a seguir, sobre estas duas formações, são um resumo dos trabalhos de Sousa Pinto e Massad (1972), sobre os Solos Variegados e Massad (1974), sobre Argilas Porosas Vermelhas.

\section{CARACTERTSTICAS GERAIS DE ALGUNS SOLOS DA BACIA DE SAO PAULO}

\subsection{Argilas Porosas Vermelhas}

Estas argilas, que cobrem as partes mais altas da ba cia, acima da cota $750 \mathrm{~m}$, com uma espessura que varia em mëdia de 4 a $8 \mathrm{~m}$, são solos não saturados, vermelhos e possuem uma macro-estrutura po rosa. São encontradas ao longo do espigão central, desde a Rua Cerro Corā, Av. Dr. Arnaldo, Av. Paulista, Rua Domingos de Moraes atē a Av. Jaba quara, e nas suas encostas, tais como Av. Angēlica, Av. Rebouças, Av. Con solação, Rua Augusta, Av. Brigadeiro Luiz Antonio e outras. A sua presen ça tambēm foi constatada na Aclimação, no Ipiranga e na Moöca (vide Cozoltino, 1972).

Pichler (1948) reconheceu que a alta porosidade 


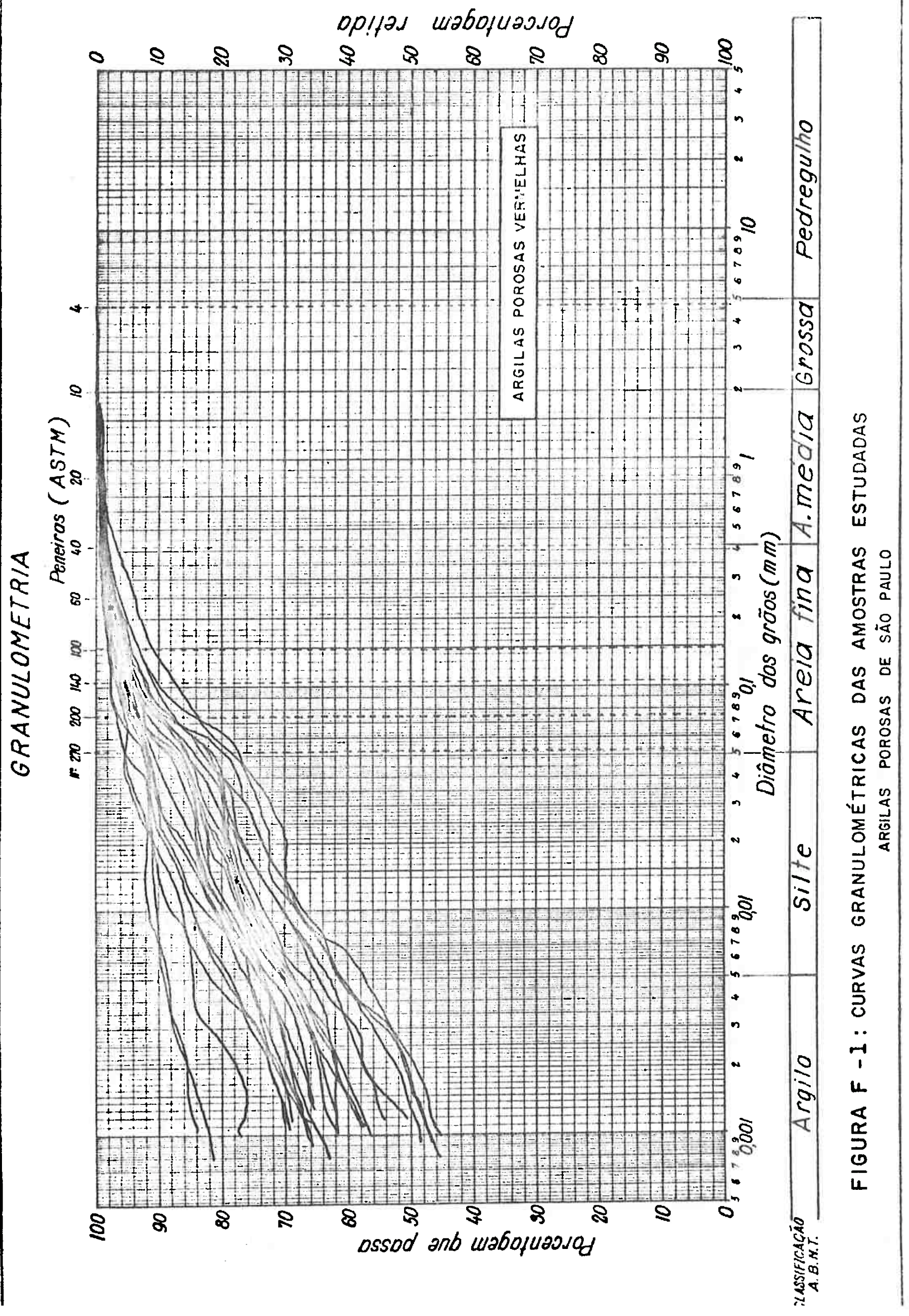




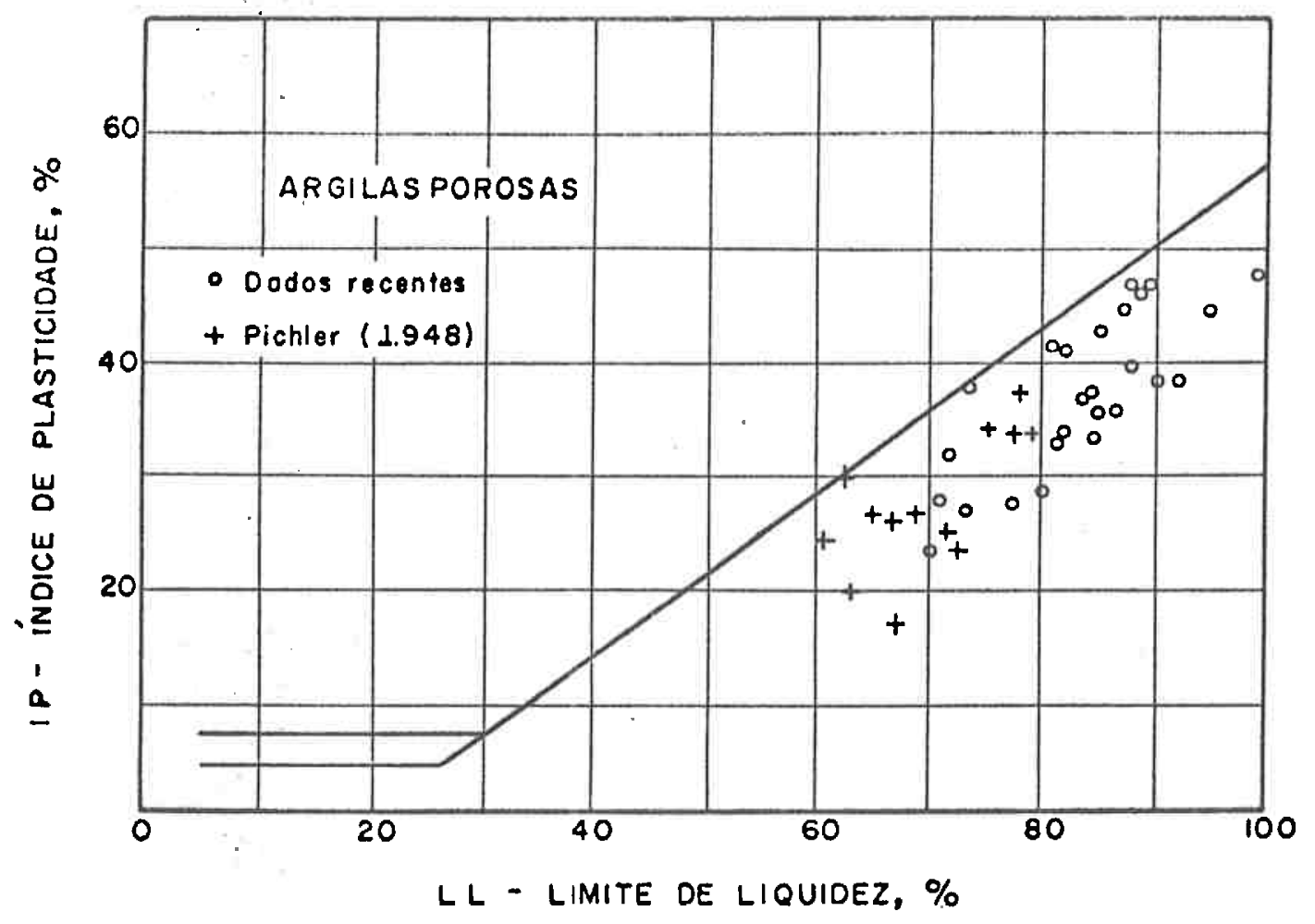

FIGURA F - 2: POSIÇĀO DAS AMOSTRAS ESTUDADAS NA CARTA DE PLASTICIDADE - ARGILAS POROSAS VERMELHAS. 


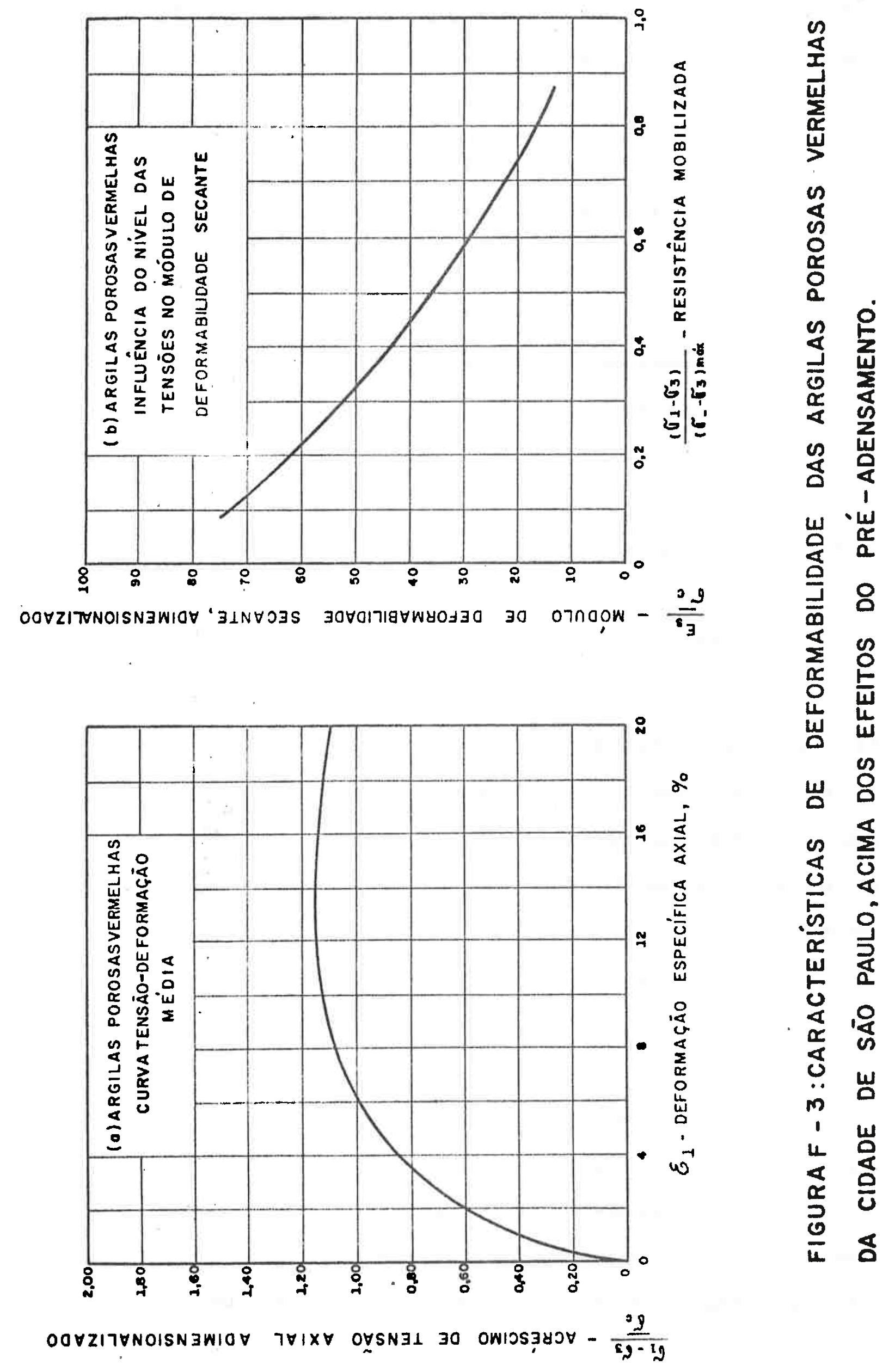


allada ao fato da consistência aumentar com a profundidade, e o tipo de transição para a camada inferior, indicarlam serem as Argllas rorosas Vermelhas solos lateriticos.

As Argilas Porosas Vermelhas são solos bastante compressiveis, o que restringe o interesse do seu estudo a problemas de escavação.

A Julgar pelas suas caracteristicas de identifica\&ão, são solos homogêneos, predominando a fração de finos, em geral maior do que $80 \%$; a fração argila $(\%<2 \mu)$ è superior a $50 \%$. A sua composição granulomētrica (ver figura $F-1$ ) apresenta-se com pequena dispersão quando comparada com a dos solos variegados. Os limites de Atterberg (figura F-2) situam-se abaixo da linha A de Casagrande, com 0 LL variando de 70 a $100 \%$ e o IP de 20 a $50 \%$. O Indice de Atividade de Skempton assume um valor mëdio de 0,63 .

No entanto, o seu comportomento mecânico reflete uma heterogeneidade, consequência do processo de laterização a que estes solos estiveram submetidos. Estas transformações afetaram as pressões de prē-adensamento, que não se correlacionam nem com a cota de retírada das amostras, nem com as pressões efetivas atuantes sobre elas; valores desta pressão se situam no intervalo de 0,5 a $4 \mathrm{~kg} / \mathrm{cm}^{2}$.

Este fenōmeno de laterização tería provocado uma errätica cimentação das particulas do solo, somente destruída quando as pressões aplicadas sāo elevadas, acima dos efeitos do pré-adenscamento. Nestas condiçōes, obteve-se um àngulo de atrito interno médlo de $28^{\circ}, \mathrm{com}$ dispersão não malor do que a apresentada pela literatura técnica (Kenney, 1959). O índlce de compressão médlo è de 0,46, com desvio padrão de 0,07. Alèm disso, foi possivel obter uma única curva tensāo-deformação mēdla (ver figura $F-3 a$ ) adimensionalizada em relação à pressão de câmara $\left(\sigma_{c}\right)$; 


\section{TABELA F-I}

VALORES MEOIOS E INTERVALOS DE VARIACAOO DE ALGUMAS

CARACTERTSTICAS DAS ARGILAS POROSAS

(RETIRADAS ENTRE AS COTAS $800^{\circ}$ e 820)

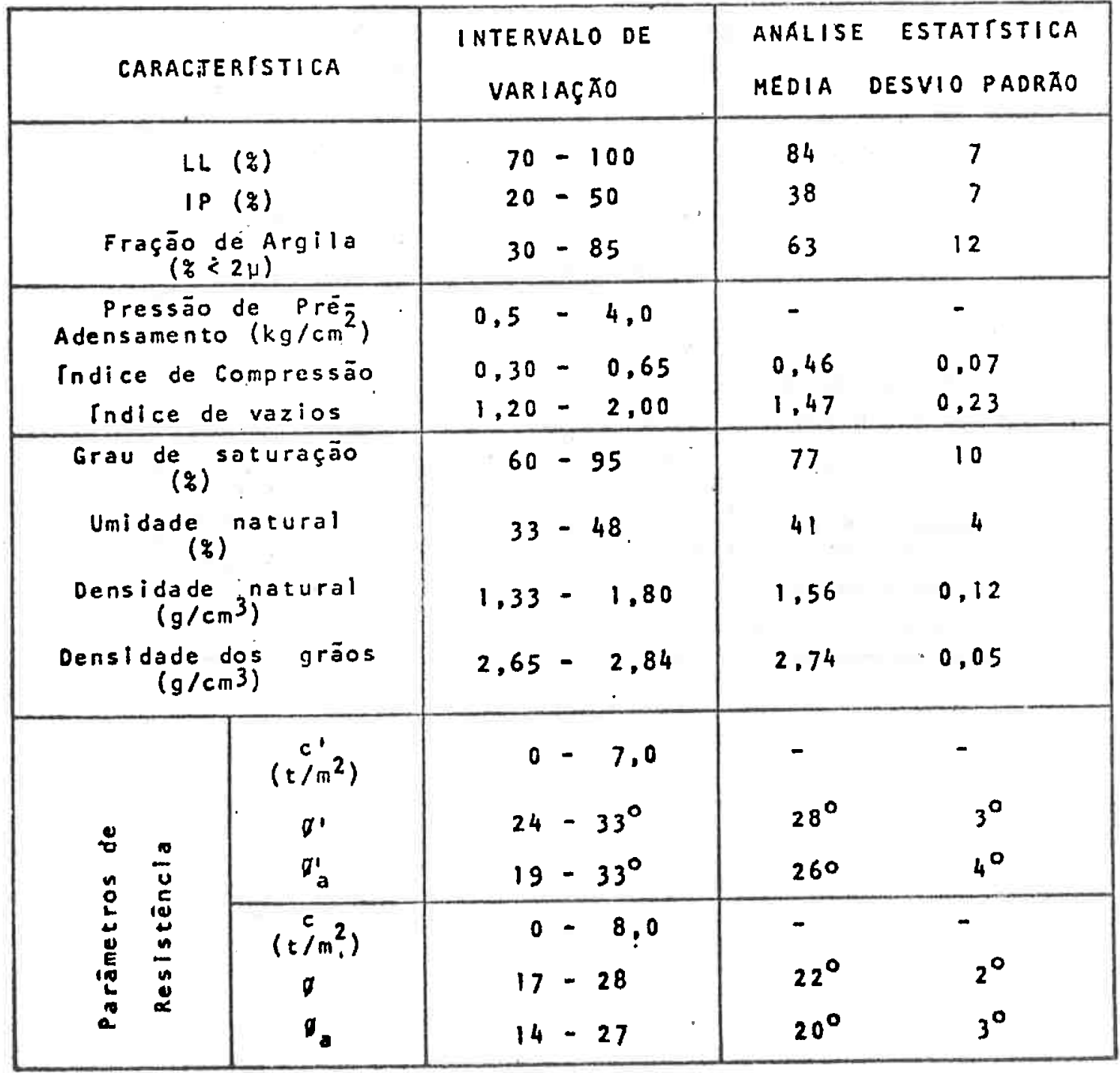




\section{TABELA F-2}

VALORES MEOIOS E INTERVALOS DE VARIACAO OE ALGUMAS CARACTERISTICAS DAS ARGILAS POROSAS (DADOS PUBLICADOS POR P(CHLER, 1948)

(COTASDE RETIRADA DAS AMOSTRAS: 750 a $800 \mathrm{~m}$ )

\begin{tabular}{|c|c|c|}
\hline CARACTERISTICA & $\begin{array}{l}\text { INTERVALO DE } \\
\text { VARI AÇAOO }\end{array}$ & VALOR NEDIO \\
\hline $\begin{array}{c}\text { LL }(\xi) \\
\text { IP }(\xi) \\
\text { Fração de Argila }(\xi)\end{array}$ & $\begin{array}{l}61-79 \\
17-37 \\
24-74\end{array}$ & $\begin{array}{l}70 \\
28 \\
45\end{array}$ \\
\hline $\begin{array}{c}\text { Pressäo de Pré-Adensamento } \\
\text { Indice de Compressäo } \\
\text { Indice de Vazios }\end{array}$ & $\begin{array}{l}0.5-7,00 \\
0.25-0.57 \\
1.00-1,70\end{array}$ & $\begin{array}{l}- \\
0,37 \\
1,30 \\
\end{array}$ \\
\hline $\begin{array}{c}\text { Grau de Saturaçāo } \\
\text { Umldade Natural }(\xi) \\
\text { Densidade dos Grãos }\left(\mathrm{g} / \mathrm{cm}^{3}\right)\end{array}$ & $\begin{aligned} 60 & -98 \\
33 & -41 \\
2,66 & -2,86\end{aligned}$ & $\begin{array}{l}78 \\
36 \\
2,75\end{array}$ \\
\hline
\end{tabular}


os mödulos de deformabilidade para $1 \%$ de deformação especifica (ver figura $F-3 a$ ) e para $50 \%$ de resistência mobilizada (ver figura $F-3 b$ ) valem $40\left(\bar{\sigma}_{c}\right)$ e $37\left(\bar{\sigma}_{c}\right)$, respectivamente.

Abaixo dos efeitos do pré-adensamento as dispersões em torno dos valores médios dos parâmetros de resistêncla foram maiores, pelo motivo referido acima; o ângulo de atrito mëdio è de $26^{\circ}$, com um desvio padrão de $4^{\circ}$; a coesão efetiva fol da ordem de $17 \%$ da pressão de prë-adensamento, com uma dispersão maior do que a encontrada para os Solos Variegados.

As tabelas F-1 e Fi-2 apresentam valores médios e intervalos de variação de algumas caracteristicas das Argilas Porosas Vermelhas.

\subsection{Argilas Rijas Vermethas}

Imediatamente abaixo da camada de Argila Porosa Vermelha, coincidindo geralmente com a posição do nível de ägua, existe uma argila também vermelha, de consistência rija, com um alto teor de öxido de ferro, que algumas vezes se encontra concentrado formando nōdulos ou lajes de concreçöes de limonita, com espessuras variando de alguns centí metros a até 1 metro. Estas concreçōes têm sido encontradas entre as cotas 800 e $710 \mathrm{~m}$.

As Argilas Rijas Vermelhas apresentam as mesmas características de identificação que as Argllas Porosas (ver figuras $F-4$ e F-5) diferindo destas apenas pela consistência rija. E o que se constata comparando-se as tabelas F-1 e F-3; vê-se que as Argllas Rijas Vermelhas possuem menores indices de vazios, malores densidades naturais e graus de saturação, e elevados valores das pressōes de pré-adensamento.

Pode-se atē dizer que existe uma passagem gradual de 


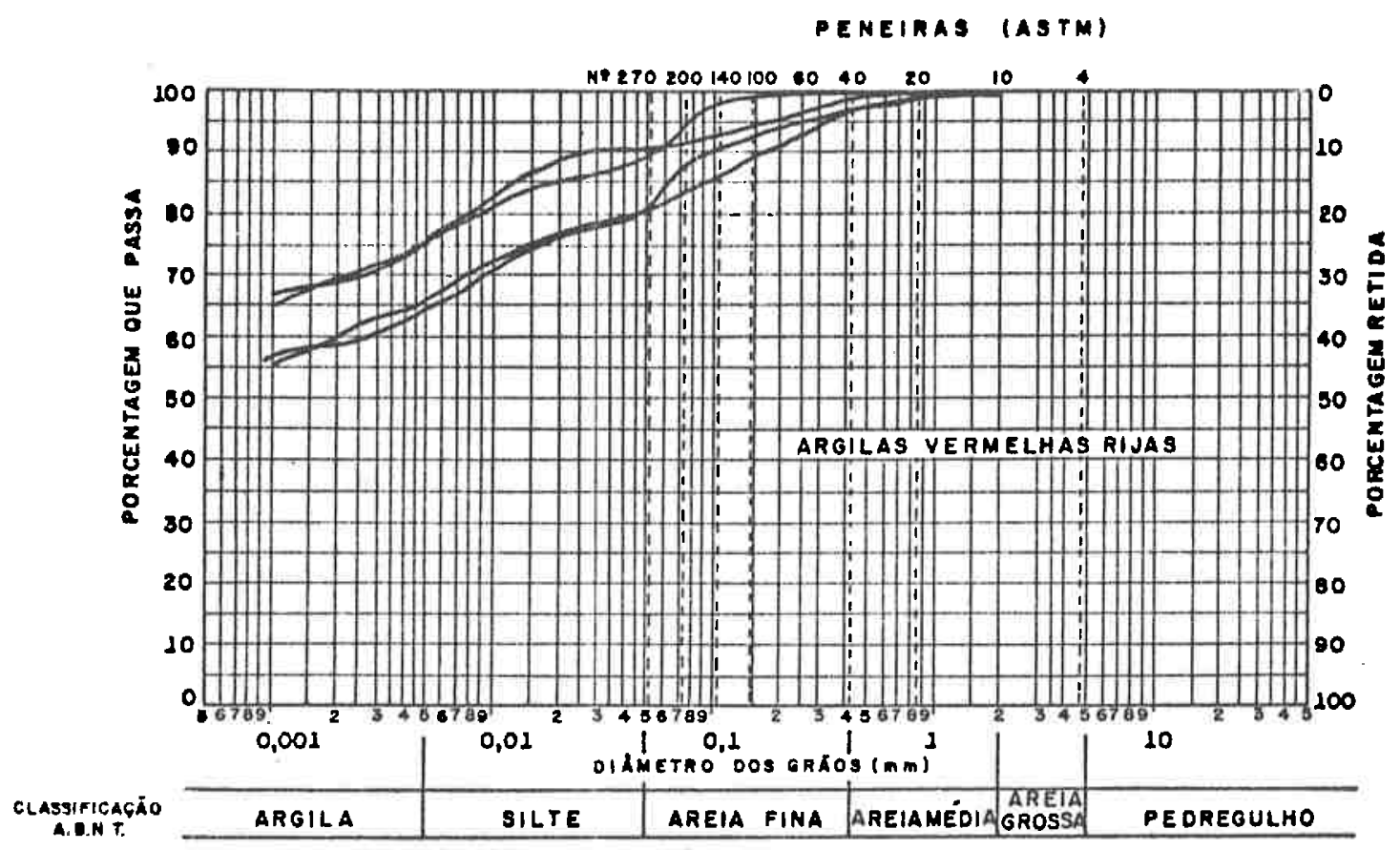

FIGURAF-4: CURVAS GRANULOMÉTRICAS.

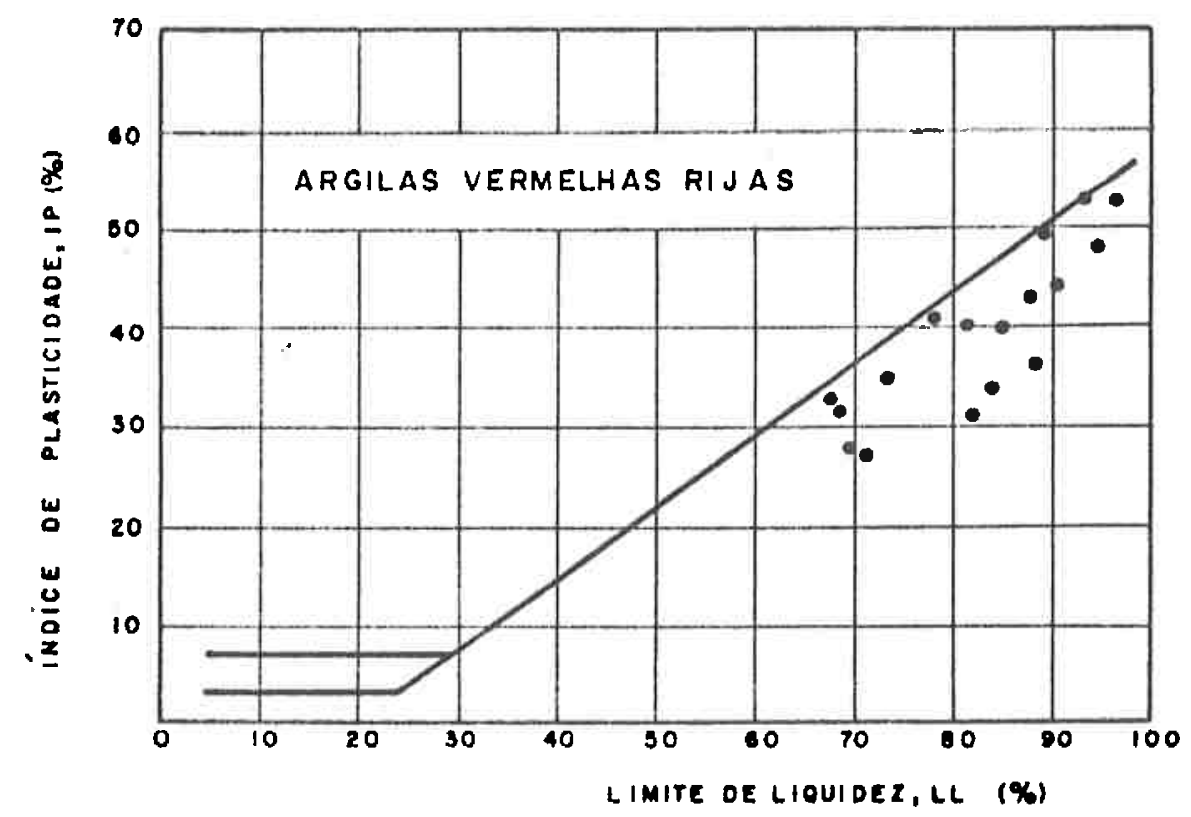

FIGURAF - 5: POSICAĀO DAS AMOSTRAS NA

CARTA DE PLASTICIDADE. 
TABELA $F-3$

CARACTERTSTICAS MEDIAS DAS ARGILAS

RIJAS VERMELHAS

TOTAL DE AMOSTRAS : 15

PROCEDENCIA: AV. PAULISTA E RUA VERGUEIRO

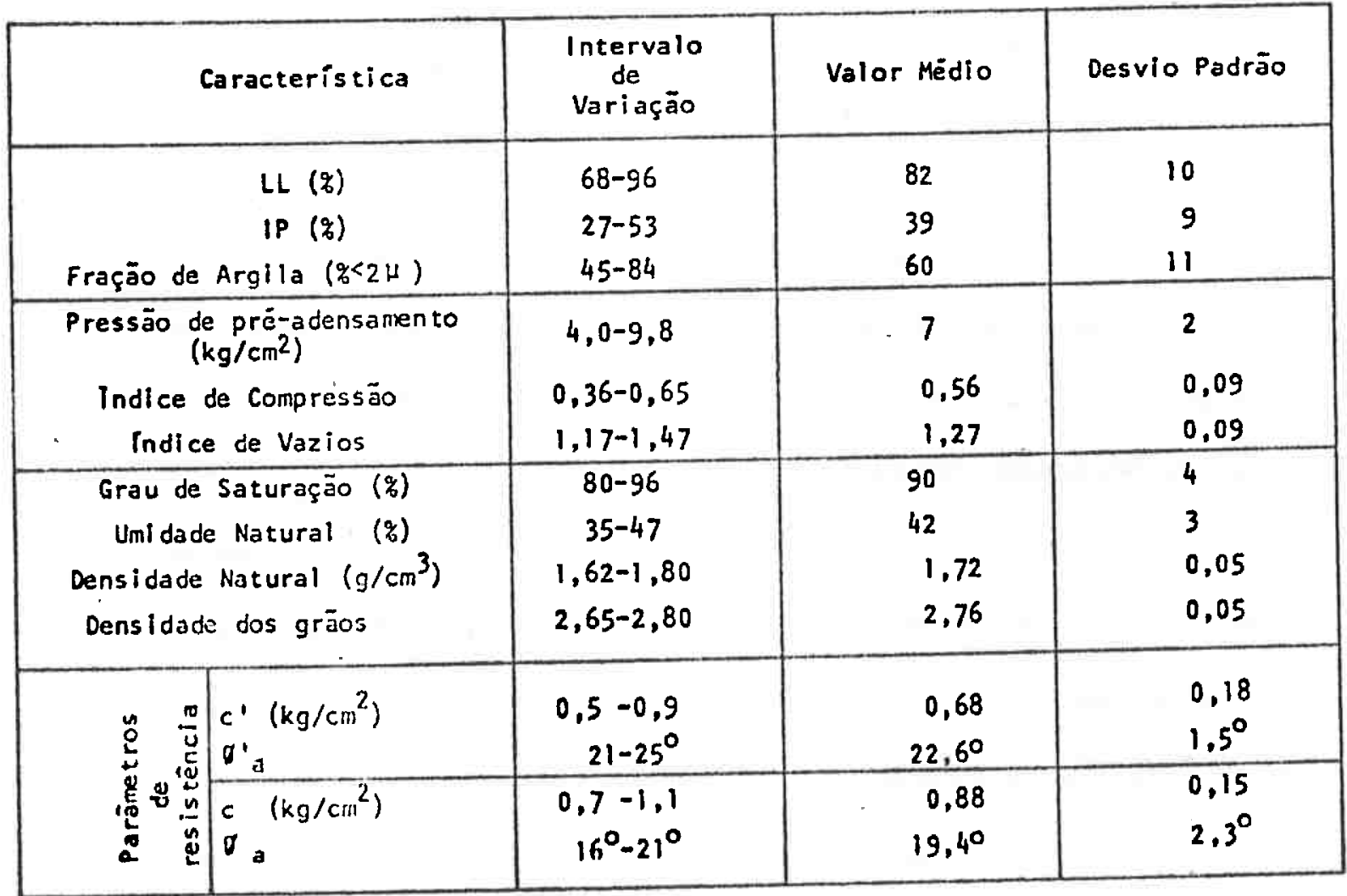


uma à outra, em que os macro-poros das Argilas Porosas Vermelhas apresen tam dimensões cada vez menores, até desaparecerem por completo nas Argilas Rijas Vermelhas.

Sob certos aspectos, è, pols, perfeltamente välldo supor que estes dols tlpos de solos se constltuem num sö unlverso, que serä deslgnado, de ora em dlante, por Argilas Vermelhas. E Interessante lembrar que em um de seus trabalhos Pichler (1948) tratou-os como sendo solos de um mesmo grupo.

\subsection{Solos Variegados}

Estes solos ocorrem numa vasta ärea da bacia sedimen tar, entre as cotas 790 e $715 \mathrm{~m}$. A sua coloraçāo varia muito, sendo encontrado nas tonalidades amarelo, vermelho-azul, vermeliho e branco; daí a sua denominação variegado.

Pelo fato de se situarem sobre outras camadas nitidamente distintas e, em algumas regiōes da Cidade, sob as Argilas Porosas Vermelhas, esta formação tambëm fol denominada por Cozollino e Chiossi (1969) de camada intermediäria.

Sua característica principal è a heterogeneidade, quer quanto à composição granulomētrica, quer quanto à consistência ou compacidade. São encontradas argilas pouco arenosas alternadas com areías finas argilosas, com espessuras variando de alguns centímetros até cerca de $10 \mathrm{~m}$.

Os Solos Variegados são bastante heterogêneos, como se observa na figura $F-6$, existindo uma grande variedade de distribuiçöes granulométricas, com a porcentagem de argilla oscilando de 10 a $80 \%$.

Alguns aspectos Interessantes a conslderar são:

a) a fração slite é sempre relativamente pequena nestes solos; 


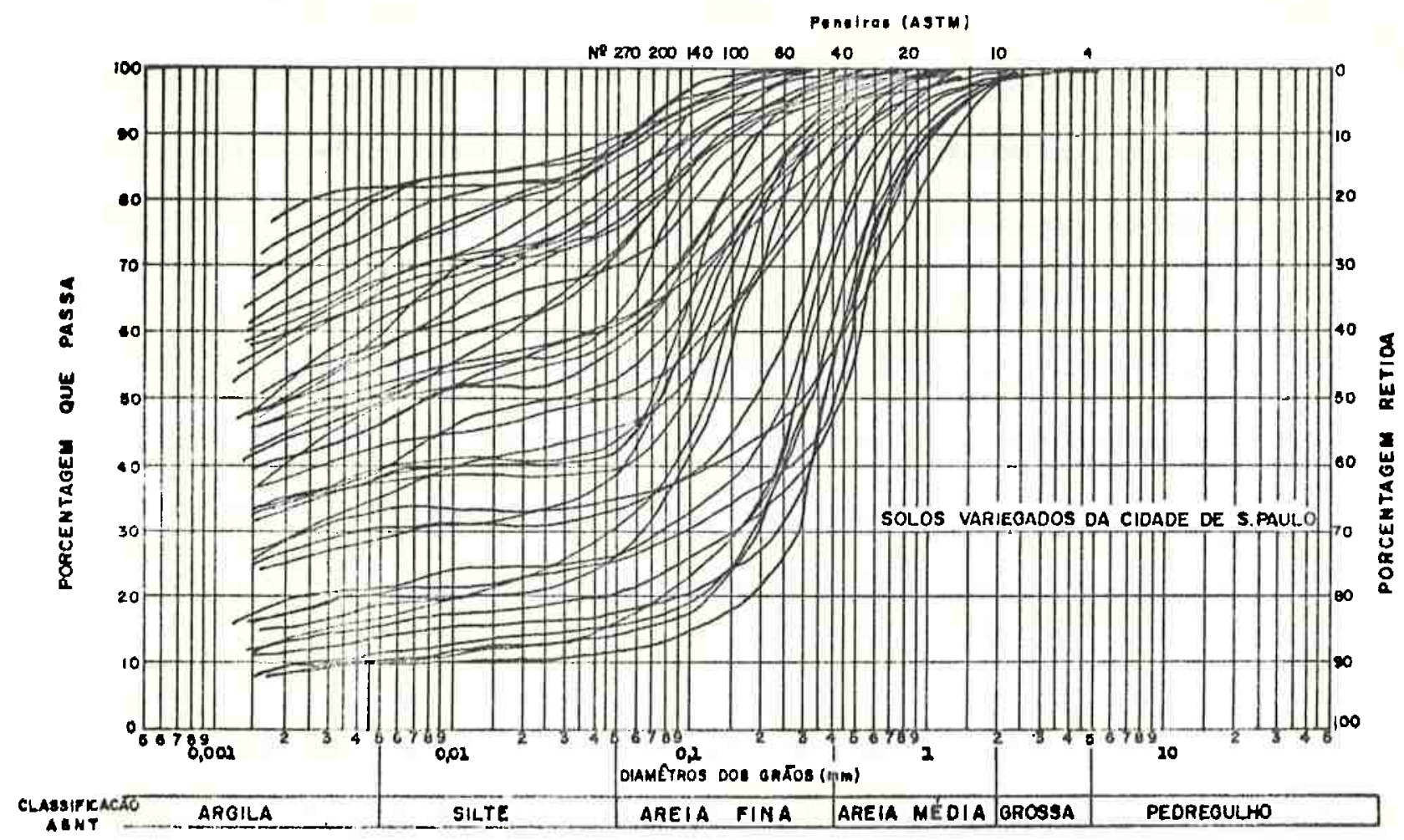

FIGURA F - 6: CURVAS GRANULOMÉTRICAS DAS AMOSTRAS ESTUDADAS.

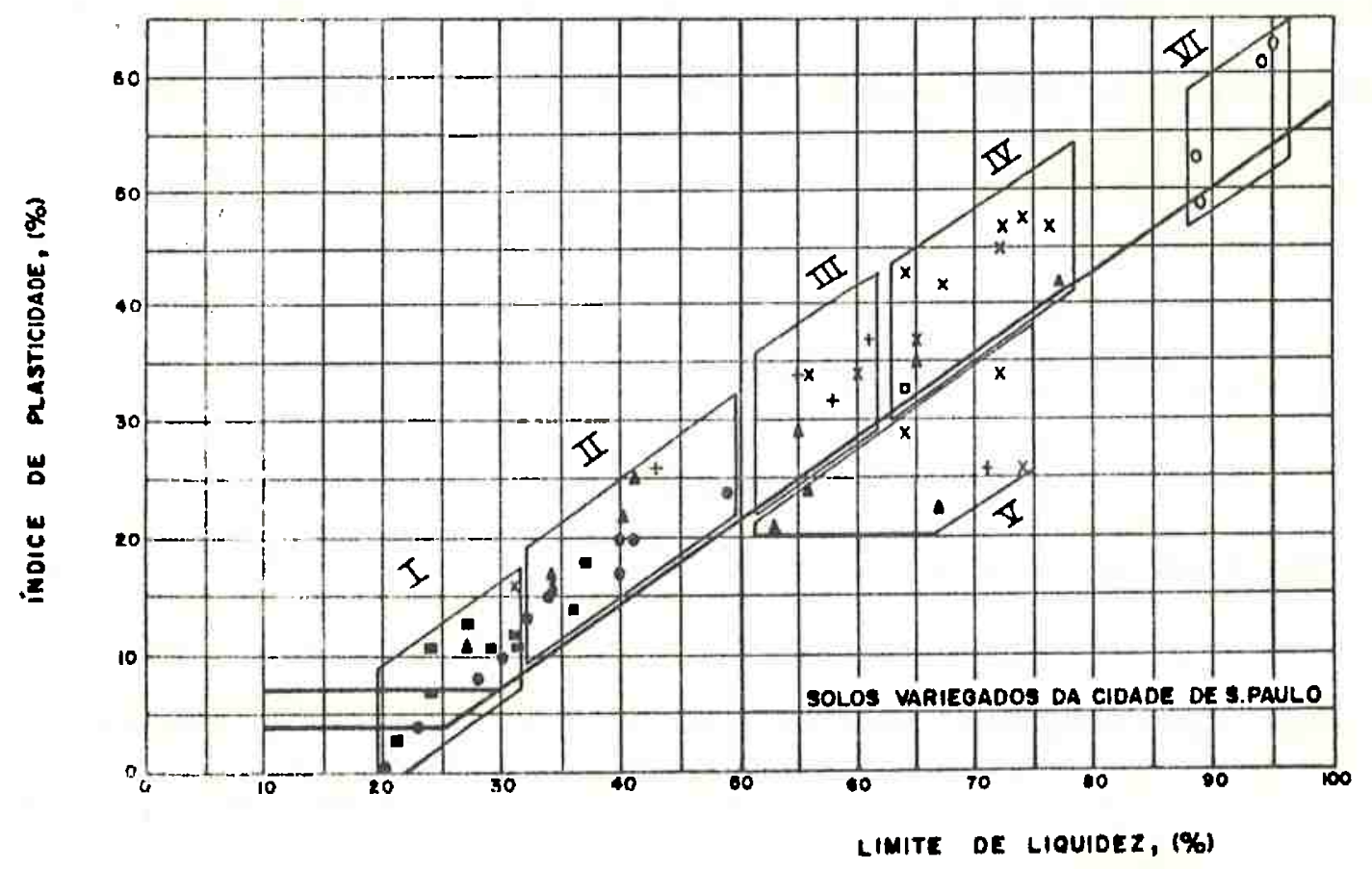

FIGURA F -7: DISTRIBUICAAO DOS SOLOS NA CARTA DE PLASTICIDADE. 
b) considerando-se sö a fração arela, suas disțribuições granulomētricas não são muito diferentes entre as diversas amostras, havendo predomināncla de areias médias, seguidas das finas, com pouca contribulção das areias grossas; e

c) a variação de granulometria das amostras mals arenosas para as mais argllosas é gradativa, não se podendo distinguir dois universos distintos, um de areias e outro de argllas. Aparentemente, existe um só universo de solos variegados no qual a fração areia è bastante varlävel.

No Gräfico de Plasticidade de Casagrande (figura $F-7$ ) estes solos se situam acima da linha $A$, com exceção de poucas amostras na faixa de limites de liquidez de 50 a $75 \%$. Novamente constata-se uma variação contínua de resultados, indicando a existência de um ünico universo. O Indice de Atividade destes solos è da ordem de 0,65.

As pressões de prē-adensamento $\left(\sigma_{a}\right)$ não são função nem da cota, nem da profundidade de coleta da amostra, mas, em geral, crescem com A, a fração argila $(\%<5 \mu)$, de acordo com a correlação:

$$
\bar{\sigma}_{a}=0,045 A+1,82
$$

com desvio padrão de $1,4 \mathrm{~kg} / \mathrm{cm}^{2}$.

Este fato sugere que o pré-adensamento dos Solos Variegados é um fenômeno menos ligado ao peso de terra sobre ele atuante do que a um processo de outra ordem, relacionado com a sua porcentagem de finos. Como hipötese, pode-se imaginar que tal processo podería ser a tensão capizar devida a ressecamento, que $\overrightarrow{\mathrm{e}}$ tanto maior quanto mais finas forem as particulas do solo; ou a uma cimentação quïmica das partículas de argila, consequêncla da evolugãa pedolögica do solo. 
0 ângulo de atrito interno efetivo, acima dos efeitos do prē-adensamento, correlacionou-se com värias características fís cas dos Solos Variegados, sendo que as melhores foram:

$$
\begin{aligned}
& g^{\prime}=34,4-0,20 \mathrm{~A}(3,25) \\
& g^{\prime}=34,4-0,30 \text { IP }(3,07) \\
& g^{\prime}=34,9-0,19 \text { IP }-0,085 \mathrm{~A}(2,98)
\end{aligned}
$$

Os nümeros entre parênteses indicam os correspondentes valores do desvio padrão. E interessante observar que a primeira destas correlações aproxi ma-se muito de outra apresentada anteriormente por Vargas e Bernardo (1946).

Conforme se depreende dos conhecimentos gerais sobre a Resistência ao Cisalhamento dos Solos, a coesão efetiva (c') è resultante do seu prē-adensamento. Daí a razão de ter-se pesquisado e encontrado, estatisticamente, a seguinte expressão:

$$
c^{\prime}=0,10 \bar{\sigma}_{a}
$$

para a coesāo efetiva, com desvio padrão de $0,9 \mathrm{t} / \mathrm{m}^{2}$.

Uma vez obtidos $0^{\prime}$ e $c^{\prime}$, fica determinado 0 ângulo de atrito interno do trecho inicial da envoltöria $\left(g_{a}\right)$, desde que se aceite a hipótese de que a concordāncia entre os seus dois trechos retilíneos ocorra para a tensão normal igual a $75 \%$ da pressão de prē-adensa mento.

Geometricamente, pode-se estabelecer a seguinte correl ação:

$$
\operatorname{tg} \theta !=\operatorname{tg} \theta^{\prime}-\frac{c^{\prime}}{0,75 \vec{\sigma}_{a}}
$$



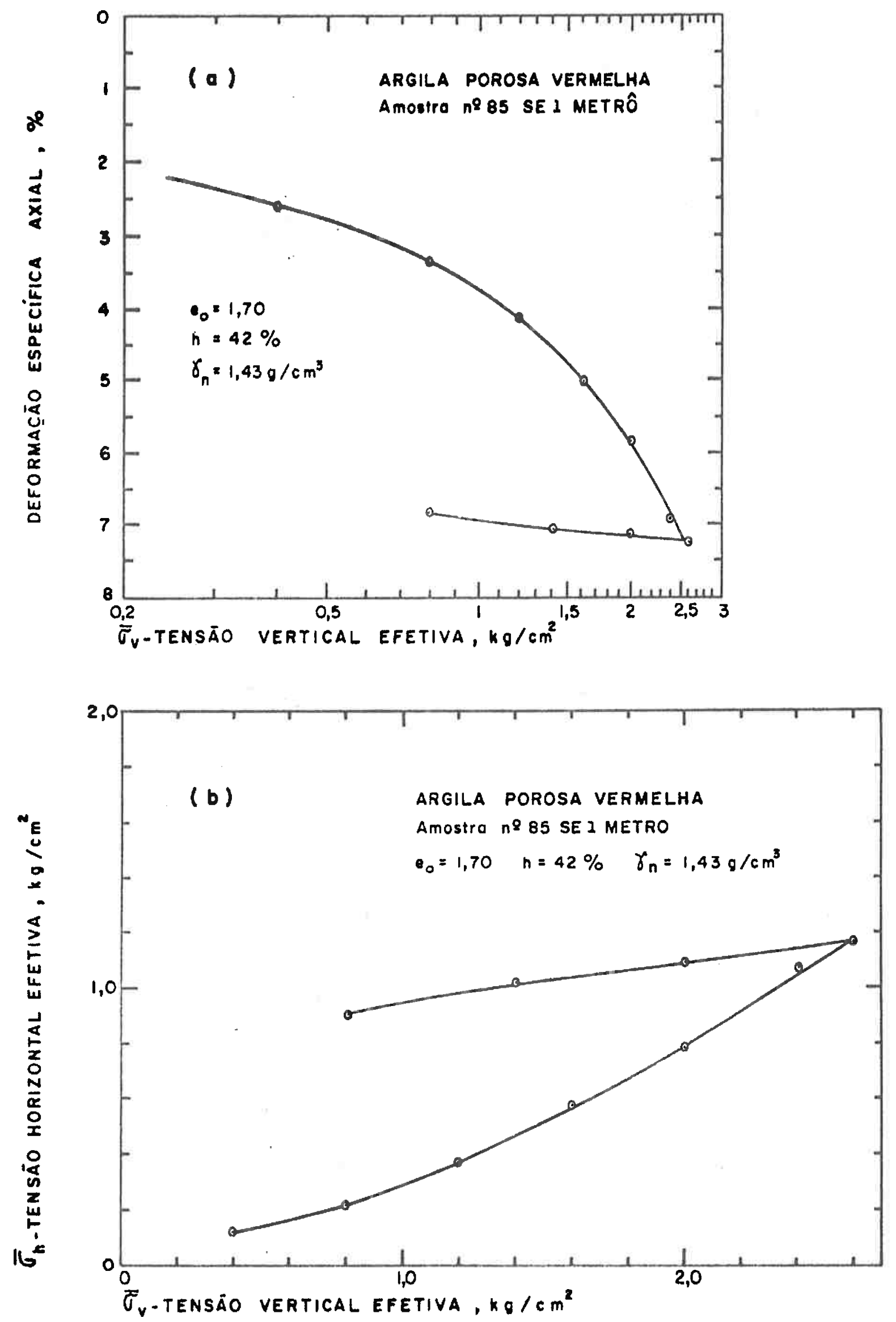

FIGURA F-8: ENSAIO OEDOMÉTRICO EM ANEL CINTADO, DO APARELHO "DIRECT SIMPLE SHEAR TEST" (CORPO DE PROVA CILINDRICO COM $32 \mathrm{~cm}^{2} \times 1,7 \mathrm{~cm}$ ) 

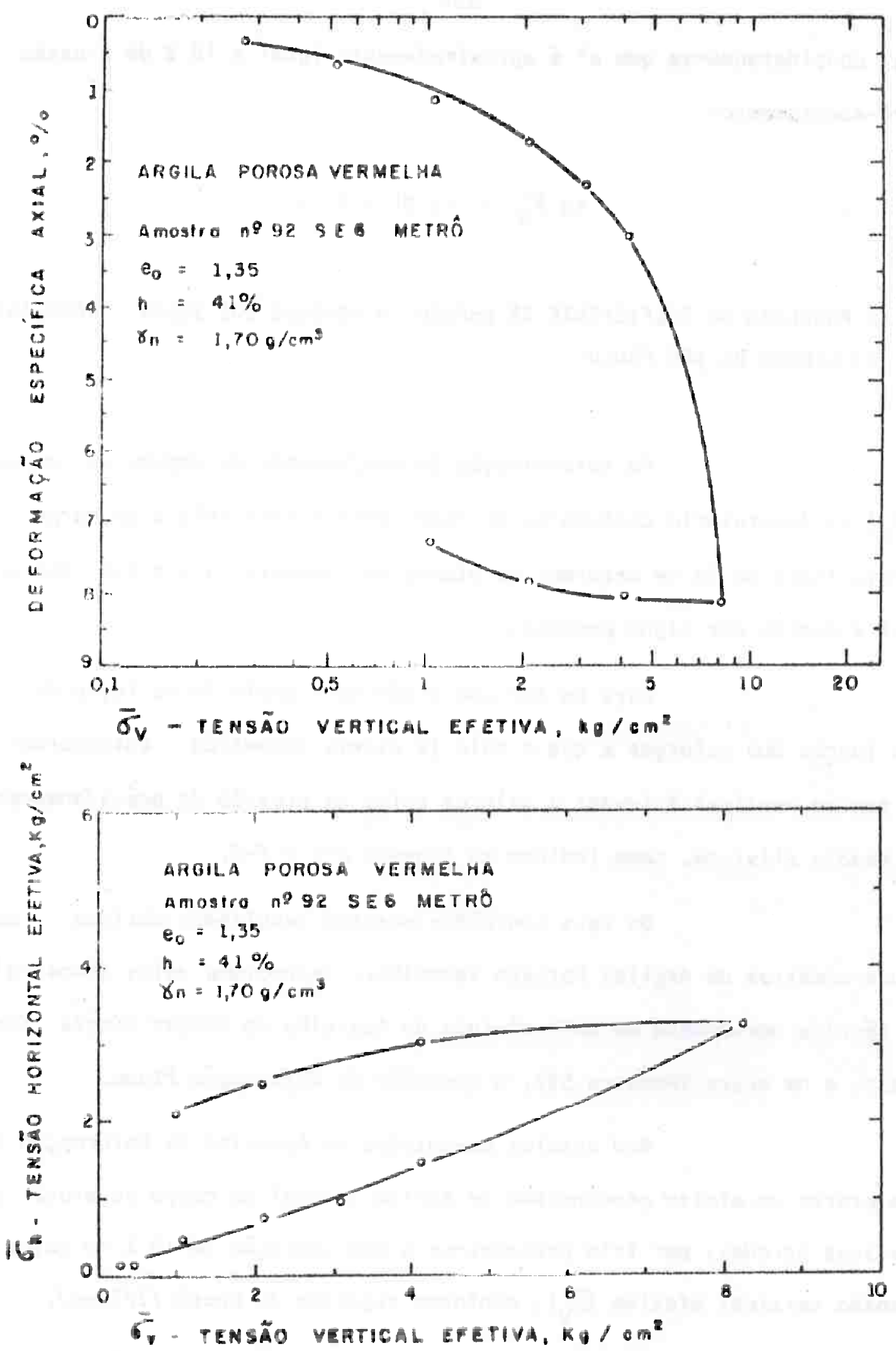

hota V Valokes de $\bar{\sigma}_{*}$ näo conaigioos do Efeito do htrito lateaal

FiguRA F-9: ENSAIO NO APARELHO dE DEFORMAGä́ PLANA. COM CONFINAMENTO LATERAL NO PLANO HORIZONTAL (ADENSAMENTO) - ( CORPO DE PROVA PRISMÁTICO COM DIMENSÖES DE 8,89 (ALTURA) $8.89 \times 3.56 \mathrm{~cm}^{3}$ । 
ou, considerando-se que $c^{\prime}$ é aproximadamente igual a $10 \%$ da pressão de prē-adens amento:

$$
\operatorname{tg} \theta=\operatorname{tg} 1=0,133
$$

\section{O PROBLEMA DO COEFICIENTE DE EMPUXO EM REPOUSO DOS SOLOS TERCIARIOS} DA CIDADE DE SAO PAULO

Na determinação do coeficiente de empuxo em repouso $\left(k_{0}\right)$ em laboratörio costuma-se aplicar tensões verticais a um corpo de prova impedido de se deformar em planos horizontais; a pressão horizontal è medida por algum processo.

Para se ter uma visão mais ampla da variação de $K_{0}$ em função dos esforços a que o solo jā esteve submetido anteriormente, a tensão vertical é levada a valores acima da pressão de prē-adensamento, e depois aliviada, como indicam as figuras $F-8$ e $F-9$.

Os seus conteüdos mostram resultados obtidos para duas amostras de Argilas Porosas Vermelhas, usandonuma delas (Amostra 85) a tēcnica norueguesa do anel cintado do Aparelho do Direct Simple Shear Test, e na outra (Amostra 92), o Apare tho de Deformação Plana.

Nos ensaios executados no Aparelho de Deformação Plą na ocorre um efeito pronunciado de atrito lateral do corpo de prova com as suas paredes; por isto procedeu-se a uma correção de $10 \%$ no valor da tensão vertical efetiva $\left(\bar{\sigma}_{v}\right)$, conforme sugestão de Wroth (1972-a).

Os dados assim corrigidos, bem como aqueles referentes à amostra 85, foram lançados no desenho da figura $F-10$, seguindo ainda orientação de Whoth, do que resultou, como se vè, uma excelente corre lação entre $K_{0}$ e' a relação de sobre-adensamento (RSA): 


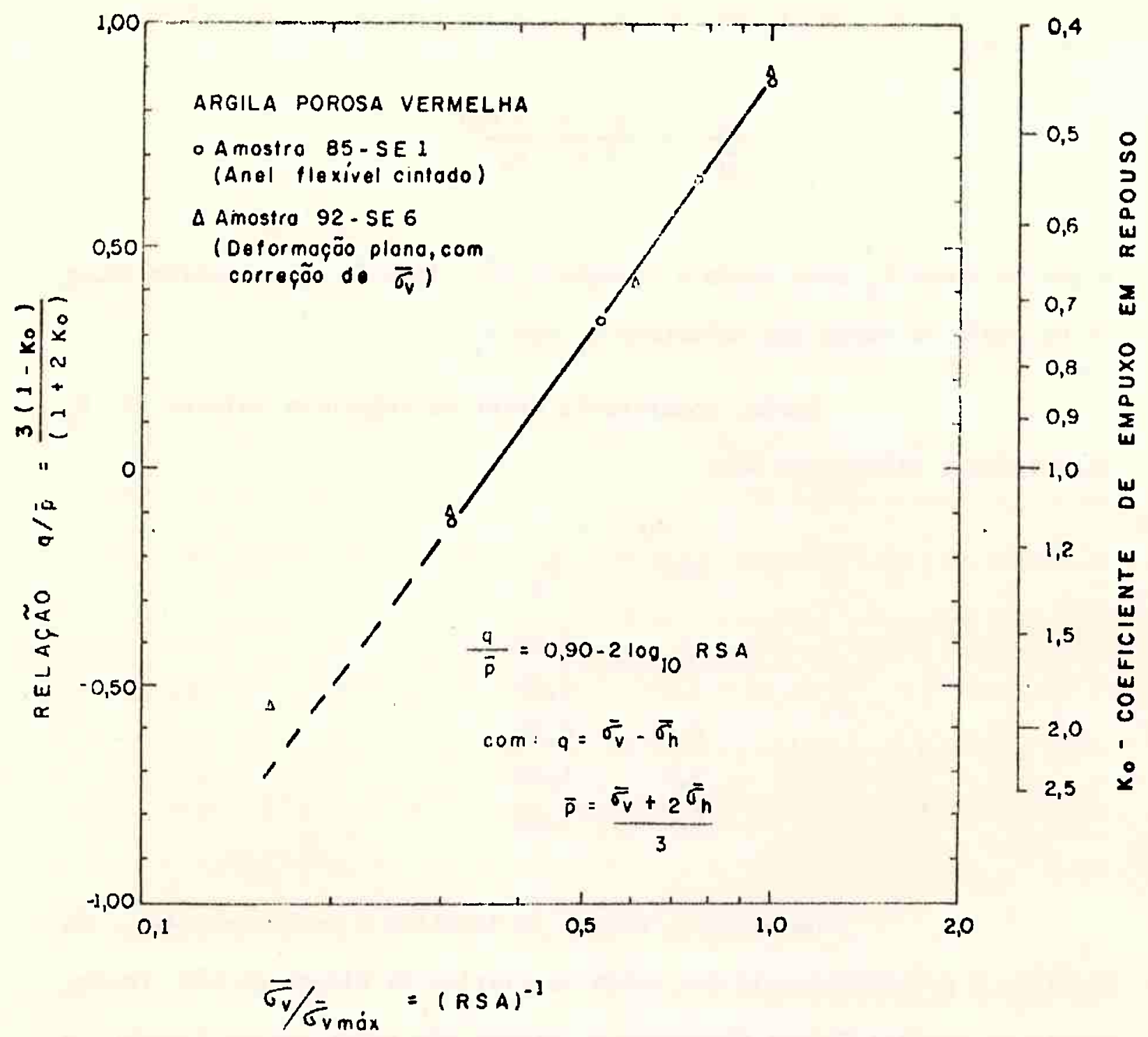

FIGURA F-10: VALORES DO COEFICIENTE DE EMPUXO EM REPOUSO (Ko) EM FUNÇ̃̃o DA RELAÇÃO DE SOBRE ADENSAMENTO (R SA), EM PRE CARREGAMENTOS INDUZIDOS EM LABORATÓRIO 


$$
\frac{q}{\bar{p}}=0,90-2 \log _{10} \text { RSA }
$$

com:

$$
q=\bar{\sigma}_{v}-\bar{\sigma}_{h} ; \bar{p}=1 / 3\left(\bar{\sigma}_{v}+2 \bar{\sigma}_{h}\right) \text { e RSA }=\frac{\bar{\sigma}_{v \text { mäx }}}{\bar{\sigma}_{v}}
$$

Note-se que:

$$
\frac{q}{\bar{p}}=\frac{3 \cdot\left(1-k_{0}\right)}{1+2 k_{0}}
$$

e que se tomou $k_{0}$ como sendo a relação $\bar{\sigma}_{h} / \sigma_{v}$, is to é, como o valor secan te no ponto da curva que relaciona $\bar{\sigma}_{h}$ com $\bar{\sigma}_{v}$.

$$
\text { Assim, poder-se-ia obter os seguintes valores de } K_{0}
$$

associados a diferentes RSA:

$\begin{array}{cc}\text { RSA } & K_{0} \\ 1 & 0,45 \\ 1,5 & 0,59 \\ 2,0 & 0,73 \\ 3,0 & 1,00 \\ 5,0 & 1,54\end{array}$

No entanto, e aqui se localiza o ponto central da questão, o pré-adensamento dos solos terciáríos da Cidade de São Paulo, exceto as Argilas Cinzas Esverdeadas, parece não estar apenas ligado a um processo de alivio de peso de terra érodido, mas ser de origem mais complexa, consequência de fenômeno relacionado à porcentagem de argila e à evolução pedológica dos solos, como jã foi enfatizado neste Apẹndice.

A rigor, seră necessärio esperar pelo desenvolvimento de instrumentos de medida in situ do coeficiente $K_{0}$, tal como o pres- 
siōmetro de autofuração, para se ter uma correlação mais segura do que a apresentada acima. 
